\title{
Foreign direct investment, spillovers and innovation : the case of Kenyan manufacturing industry
}

Citation for published version (APA):

Gachino, G. (2006). Foreign direct investment, spillovers and innovation : the case of Kenyan manufacturing industry. [Doctoral Thesis, Maastricht University]. Datawyse / Universitaire Pers Maastricht. https://doi.org/10.26481/dis.20060519gg

Document status and date:

Published: 01/01/2006

DOI:

10.26481/dis.20060519gg

Document Version:

Publisher's PDF, also known as Version of record

\section{Please check the document version of this publication:}

- A submitted manuscript is the version of the article upon submission and before peer-review. There can be important differences between the submitted version and the official published version of record.

People interested in the research are advised to contact the author for the final version of the publication, or visit the DOI to the publisher's website.

- The final author version and the galley proof are versions of the publication after peer review.

- The final published version features the final layout of the paper including the volume, issue and page numbers.

Link to publication

\footnotetext{
General rights rights.

- You may freely distribute the URL identifying the publication in the public portal. please follow below link for the End User Agreement:

www.umlib.nl/taverne-license

Take down policy

If you believe that this document breaches copyright please contact us at:

repository@maastrichtuniversity.nl

providing details and we will investigate your claim.
}

Copyright and moral rights for the publications made accessible in the public portal are retained by the authors and/or other copyright owners and it is a condition of accessing publications that users recognise and abide by the legal requirements associated with these

- Users may download and print one copy of any publication from the public portal for the purpose of private study or research.

- You may not further distribute the material or use it for any profit-making activity or commercial gain

If the publication is distributed under the terms of Article $25 \mathrm{fa}$ of the Dutch Copyright Act, indicated by the "Taverne" license above, 
FOREIGN DIRECT INVESTMENT, SPILLOVERS AND INNOVATION:

THE CASE OF KENYAN MANUFACTURING INDUSTRY 
ISBN 10: 90-5278-535-X

ISBN-13:978-90-5278-535-6

Unversitaire Pers Mastricht

Printing: Datawyse / Universitaire Pers Maastricht 
FOREIGN DIRECT INVESTMENT, SPILLOVERS AND INNOVATION:

THE CASE OF KENYAN MANUFACTURING INDUSTRY

\section{PROEFSCHRIFT}

ter verkrijging van de graad wan doctor alan de Universiteit Maastricht, op gezag van de Rector magnificus Prof. Mr. G.P.M.F. Mols, volgens het besluit van het College van Decanen

in het openbaar te verdedigen op viljdag 19 mei 2006 om 12.00 un

door

GEOFFREY G. GACHINO

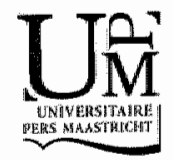


Fessor. Dr. Lynn K. Mytelka

fessor Dr. Rajah Rasiah, University of Malaya, Malaysia

ifessor Dx. Robin Cowan, voorzitter

ifessor Dr. Pierre Mohnen

fessor Dr. Carlo Pietwobelli, University of Rome III, Italy

iponsored this Ph.D. thesis research:

ty, Institute for New Technologies (UNU-INTECH), ands

trch Consortium (AERC), 
This thesis is dedicated to

\section{The God Almighty}

for his protection, kindness and mexcy;

Grace Akosua Acheampomaah Bandoh

for het patience, persistent prayers, encouragement and support. 


\section{ACKNOWLEDGEMENT}

I am graterul to Professor Lynn $K$. Mytellsa my thesis promoter and formar director of UNU-MERTT for the immense intellectual support she accorded the at every stage of my thesis minting. Lyon introduced me into the scholarly writing skills and articulation of critiques and arguments to existing scholarly works. Thank you Lynn for all the difficult moments you had while introducing writing skills into a mind deeply rooted in statistical methods and number wotks. Similarly, I am exceedingly grateful to my co-promoter, Professor Rajah Rasiah for his intellectual guidance and support in my work. In addition to being my academic mentor, he encouraged me a lot to participate and learn from projects, conferences and publishing. I feel particularly beholden to him for his proficient supervision at all stages especially with the conceptual framework and at the construction phase of my questionnatre not to mention the numerous supporting materials he offered me in making this study a success. Most of all, I am extremely appreciative for the patience excercised by my promoter and co-promoter, comments, guidance and their kind advice which spurred me on especially in moments of despair. I would also like to thank the members of the reading committee (Professor Robin Cowan, Professor Carlo Pietrobelli and Professor Pierte Mohnen) for their willingness to read and examine the thesis draft. Your the and effort was greatly appreciated.

I would like to acknowlodge with thanks financial and institutional support from UNUMERIT. UNU-MERT offered financial support for four years including partial financial support for fieldwork in Kenya. I am also grateful to African Fconomic Research Consortium (AERC) for generous financial support in the form of Ph.D. research grant to meet my fieldwork expenses as well as liwing expenses white in the Netherlands. Without the sponsorship of both UNU-MERIT and AERC the completion of this thesis would not have come into fruition. On the same note, I would like to thank most sincerely the Ministry of Planning and National Development for granting me studyleave to pursue my doctoral studies. I must also acknowledge the unlimited Ministerial support and facilitation through my department Central Bureau of Statistics (CBS).

I would like to thank all the UNU-MERIT research members who at various levels engaged me in fruitful discussions while writing my thesis. Among those who engaged me in early and incisive discussions included Luc Soete, Rajneesh Narula, Louan Barclay, Marjolein Camal, Robin Cowan, Shulin Gut, Anthony Bartzokas and Yoonghae Suh. Support and encouragement was also obtained from Banji Oyeyinka, Cartherine Nyaki, Saushelesh. Lall and Padmastree Gehl Sampath. I can not also forget to acknowledge the continuous encouragement and support from UNU-MERIT support staff; Marc Vetgels, Ad Notten, Wangu Mwangi, Yvonne de Groot, Wilma Coenegrachts, Exeline in de Braek, Jacqueline van Kesteten, Silvana de Sanctis, Ann Kelledy, Raeleen Wasdotp, Monique Racdts, Mourik Young, Herman Pijpers and Martin Reed. Assistance by Jacqueline in designing the thesis cover was very much appreciated. The support offered by Cotien Gijsbers and her continued encouragement over the years are deeply achnowledged.

Special gratitude also goes to all CBS staff in Nairobi who continuously encouraged me and in one way or another made my freldwork a success. In particular, I am greatly indebted to Mr. Stephen Wainana, now the director of planning, for his advice and continued encourigement. I am equally indebted to the director of statistics Mr. Anthony Kilele whose cordial relation offered me the support I needed to make this study a success. I also would like to acknowledge immeasurable support and assistance received 
from Mr. Mwando, Mr. Muhu, Mr. Too (now lecturer at Moi Universityl and Mi. Ndegwa all from industry section. Encouragement by Mi Mboni and Mir. Opiyo is also acknowledged. I can not forget ro recognise and acknowledge the extended CBS network of District Statistical Officers (DSOs) who in no little measure made significant contribution to the data collection process. In this respect, I would particalarly like ro single out the support I obtained from the following DSOS: DSO Eldoret (Mr. Samoei), DSO Mombasa (Mr. Konde), DSO Malindi (Ms. Masila), DSO Nakuru (Mr. Ibwaga and his deputy Mr. Nzivo), DSO Kericho (Mr. Odrwa) and DSO Kisumu (Mr. Odhiambo Orieno). Special mention also goes to all the other CBS staff members who in diverse ways assisted in the data collection process. Special mention must therefore be made to Mr. Mayende, Mr. Kamau, Mr. Oburu, Ms. Kariuk, Mr. Nganga and Ms, Frida Katua. Their deep knowledge of the manufacturing industry coupled with their rich newwork of extremely useful ftriends proved to be a real social capital at its best. Other special mention must be made to Ndobi, Wanjema, Kinyanjui and Esther for belping me with compilation and entry of official secondary data. Itonya, Choge, Eva, Milka, Judy, Gatungu, Mulwa, Phyllis, Muthoni, Peter, Florence and Vivian were always there as good friends. Thanks to you all for your encouragement and prayers of many years.

I am also greatly indebted to all the company chief executives, plant managers and production engineers, professional staff and other officers in all firms that were included in this study. I take this opportunity to specially thank all of them. Their time was greatly appreciated. It would have been extremely difficult to count success without their cooperation and willingness to participate in this study. I would also want to thank all the officers from the business and institutions interviewed both private and public. In particular, the following people engaged me in extremely useful discussions: Benjamin $\mathrm{C}$. Chesang (EPZA), Francis K. Rotich (EPZA), Robert S. Bwire (IPC), Ms. Kamau (KIRDD), Tomothy K. Tiampati (IDB), Robert G. Kiboti (IDB), Moses K. Kambuthi (KAM), Stephen Odua (MTT), Moses Ikiara (KIPPRA), L. Ikonya (KFBS), Humphrey Njonoge Muhu (CBS), Geziron Nyangito (KIPPRA), Ptofessor Terry Ryan (Nairobi university, ACEG and economic consultant) and Professor Dorothy McCormick (IDS).

This thesis drew tremendous insight from participation in CERES Ph.D. summer school programme on "Structutal Transformation and Development" held at the Institute of Social Studies (ISS) in "The Hague. The European Doctoral Training programme on the Economics of Technological and Institutional Change (ETTC) programmes organised by MERIT was also extremely beneficial. It also benefited from participation in summet school programme organised by Central European University (CEU) in Budapest Hungary on "Competition Policy in the Transition: Theory, Implementation and Challenges." Other conferences and workshops benefited from included: "Cambridge Advanced Programme on Rethinking Development Economics (CARPODE)" based on heterodox perspective in economic development and organised by Cambridge School of Development Economics at Kings College, University of Cambridge, Britain; "Understanding FDI-Assisted Economic Development" organised by Centre for Studies of Technology, Innovation and Culture (TIK), University of Oslo, Norway; "Transnational Corporations, Technological Capabilities and Competitiveness: Evidence from Africa, Asia and Latin America" held at UNU-MERTT, Maastricht-Netherlands; "Multinationals and Developing Countries: A Matching Couple" held at The Tiburg Unversity, Tilburg-Nethetlands and finally "Post Liberalisation Constraints on Macroeconomic Policies", IDEAS conference held in Muttukadu, Chennai, India. Many other conferences, seminars and workshops held at UNU-MERIT wete equally useful. Among the respected scholars attending these conferences and programmes and whose 
presentations of incisive comments and critics inspired this study included: John Dunning, the late Sanjaya Lall, Rajneesh Narula, Ha-Joon Chang, Carlota Perez, Nathan Rosenberg, Erik Reinhart, Finn Tarp, Pierre Mohnen, Bent Dalum, Jochen Lorentzen, Jan Fagerberg, Bart Verspagen, Jorge Katz, Kiichiro Fukasaku, B. A. Lundvall, Prasada Reddy, Frederich Sachwald, S. K. Jomo, Peter Nolan, Daniele Archibugi, Gabtiel Palma, Giovanni Dosi, Lance Taylor, John Toye, Richard Nelson, Franco Malerba, Nagesh Kumar, Deepak Nayyat, Jayati Gosh, Constantine Vaitsos, Joseph Stiglitz, C. P. Chandrasekhar, Howard Stein and Jose Antonio Ocampo.

Finally, I am most thankfull to all my friends and especially my colleagues in UNUMERT' for the many occasions we engaged in intellectual exchanges; Elad (Israel), Minh (Vietnam), Preet (India), Rose (Uganda), Pedro (Mexico), Samia (Sudan), Marnata (India), Muge (Turkey), Bulat (Russia), Oxana (Ukraine), Paola (Italy), Tom Pogue (South Africa), Habiyatemye (Rwanda) and Motari (Kenya). Habiyaremye's generous help in translating the thesis summary into Dutch was very much appreciated. Lastly, since it is impossible to acknowledge everyone involved individually, I would like to take this opportunity to thank all those who in one way or another might have helped either directly or indirectly in this study. None of the contribution was least.

The usual disclaimer applies. 


\section{TABLE OF CONTENTS}

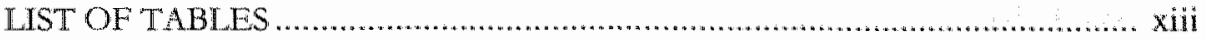

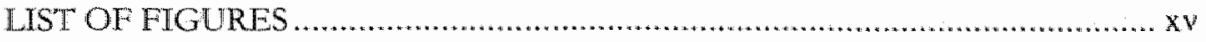

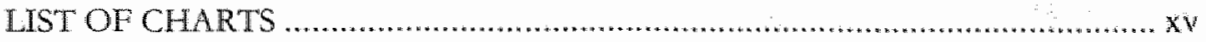

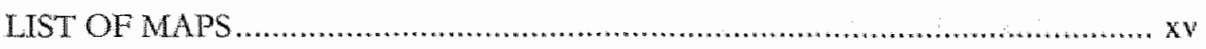

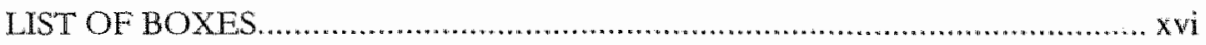

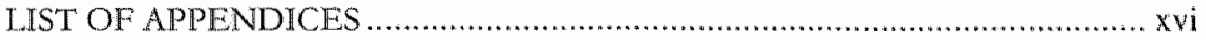

LIST OF ABBREVIATTONS ................................................................. $x$ vii

\section{PART ONE: INTRODUCTION AND THEORETICAL CONSIDERATIONS}

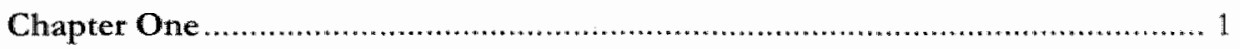

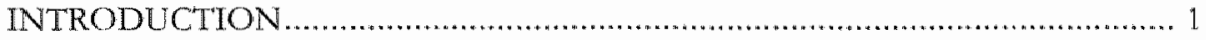

1.1 Background: Technollogical Capabilities and Foreign Direct Investment ...... 1

1.2 Research Problem and Questions ...............................................................................3

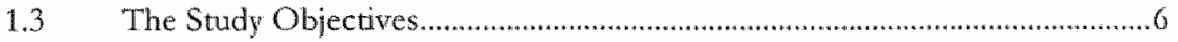

1.4 A Brief Summary of the Thesis Approach ........................................................... 7

1.5 Justification and Limitations of the Study .....................................................

1.6 Data Collection and Scope of Study ............................................................110

1.7 Thesis Outline ............................................................................................ 10

Chapter Two

FOREIGN DIRECT INVESTMENT AND TECHNOLOGICAL SPILLOVERS

CRTTICAL REVIEW AND CONCEPTUAL FRAMEWORK ......................... 14

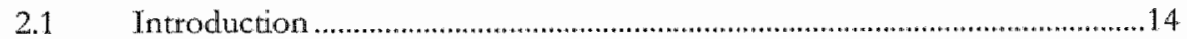

2.2 International Technology Transfer............................................................... 14

2.3 Foreign Direct Investment and Technological Spillovers ...............................18

2.3.1 Types of Technological Spillovers ................................................... 20

2.3.2 Technological Spillovers and Foreign Presence: A Critical Analysis of Issues ................................................................................... 23

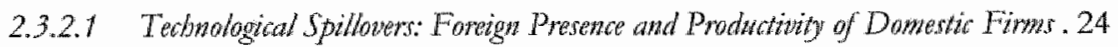

2.3.2.2 Technological Spillowers and Technology Gap.......................................... 28

2.3.2.3 Technological Spillovers axd Foreigy Equity Partitipation ........................... 32

2.3.2.4 Tecbnological Spillovers atrd Absorption Gapatity ...................................... 34

2.3.2.5 Endogenow Spillowers: Competinom, Demonstration and Interations .............. 36

2.3.2.6 Tecbnologiach" Spillowers and Gonermment Policies: Does the Lewot of Protedion Mather?...............................................................................4 45

2.4 Emerging Issues and Alternative Theortical Framework............................46

2.4.1 A Brief Summary of Emerging Issues........................................... 46

2.4.2 Spillover Occurrence: Towards an Altemative Theoretical Framework ... 49

2.5 Analytical Framework for Measuring Spillovers Based on Technological Changes, Learning and Capability Building......................................................57

2.6 Formulation of Study Propositions ....................................................................60

2.6.1 Presence of Multinationals and Spillover Stimulation ...........................60

2.6.2 The Determinants of Spillover Occutrence ......................................60 60

2.7 Research Design and Methodologicall Setting .............................................73

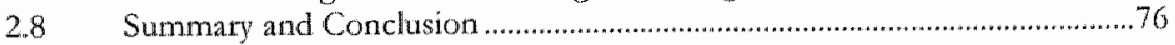


Chaptet Three

MANUEACTURING INDUSTRY AND FOREIGN DIRECT NNVESTMENT

IN KENYA: ORIGIN AND INSTITUTIONAL SETTING $\ldots \ldots \ldots \ldots \ldots \ldots \ldots \ldots \ldots \ldots . \ldots 77$

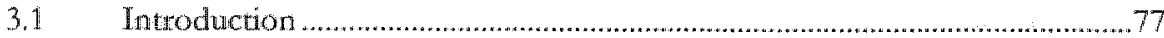

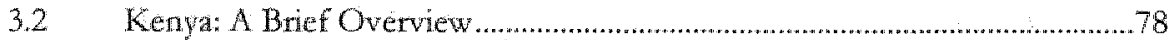

3.3. Industrial Policy and FDI: Otigin and Tnstiturional Setting ...........................82

3.3.1 Pre-Independence: The Colonial Period ............................................ 83

3.3.2 Post-Independence: The Early Decades of Import Substitution ............. 89

3.3.2. FDr and Industrial Capability Dextopmeta: The Role of Intstutions Daning the Import Swlstitution Period ...................................................93

3.3.2.2 Brief Sumwary of Enterging Issues Based on the Role of Institutions Examinted

3.3.3 Structural Adjustments: The Era of Liberation and Expont-Promotion. 104

3.3.3. FDI and Tudustrial Capability Development: The Role of Instinutions Duning the Export Onentation Period. 108

3.3.3.2 Brief Sumnary of Exyerging Issues Based an the Role of Institutions Examined

3.3.4 Recent Performance and Effott towards Industrialisation ................... 118

3.4 Summary and Conclusion .............................................................................. $\$ 19$

Chapter Four.

FOREIGN DIRECT INVESTMENT AND FIRM LEVEL PRODUCTIVITY

A PANEL DATA ANALYSIS

4.1 Introduction ............................................................................................... 121

4.2 Theoretical Framework, Data and Estimation Technique........................... 122

4.2.1 Theoretical Framework: The Productivity Approach Revisited ............. 122

4.2 .2 Data Description.................................................................. 124

4.2.3 Empirical Analysis: A Panel Data Estimation Technique.................... 125

4.3 Comparative Behaviour of Foreign and Locally Owned Firms: Analysis

based on Panel Data Trends in the Manufacturing Industry ....................... 127

4.3.1 Important Firm Trends in the Panel Data Sample: Comparing Foreign and Locally Owned Firms based on the Entire Manufacturing Industry ...... 128

4.3.2 Important Trends in the panel Data Sample: Comparing Foreign and Locally Owned Firms based on the Manufacturing Industrial Sectors ... 130

4.3.3 A Brief Summary of Emerging Thends in Kenyan Manufacturing Industry Based on Pand Data Examined ..................................................... 140

4.4 Effect of Foreign Presence on Firm Level Productivity .............................. 141

4.5 Effect of Foreign Presence on Firm Productivity: Analysis by Scale ......... 148

4.6 Effect of Foreign Presence on Firm Productivity: Analysis by Technology Gap.

4.7 Summary and Conclusion 153 
FOREIGN PRESENCE AND TECHNOLOGICAX SPILLOVER

EXTENT; DETERMINANTS AND MODE OF OCCURRENCE ,............... 156

5.1 Introduction .............................................................................................. 150

5.2 Sample Chatacteristics .............................................................................. 150

5.2.1 Labour Mobility in Food and Beverages and Machine and Fngineering Industrites......................................................................... 158

5.22 Linkages in Food and Beverages and Machine and Engineering Industries 161

5.2.3 Competition in Food and Beverages and Machine and Engineering Industries....................................................................... 162

5.2.4 Demonstration Fffects in Food and Beverages and Machine and Engineering Industries $\quad \ldots \ldots \ldots \ldots \ldots \ldots \ldots \ldots . .163$

5.3 Occurtence of Technological Spillovers: Technological Spillover Index.. 164

5.3.1 Occurrence of Technological Spillovers in the Manufacturing Industry. 166

5.3.2 Comparison of Technological Spillover Oconrence by the two Industries.

5.4 Determinants of Technological Spillover Occurrence in the Kenyan

Manufacturing Industry ............................................................................... 182

5.4.1 Descriptive Statistics of the Sampled Firms ........................................ 182

5.4.2 Econometric Setting: Binomial Logit Estimation for the Determinants of Spillover Occutrence................................................................... 188

5.4.3 Econometric Setting: Multinomial Ordeted Logit Estrmation for the Determinants of Spillover Occurrence

5.4.4 Binomial and Ordered Logit Model Estimation: Results and Discussion 195 5.5 Summaty and Conclusion.

Chapter Six

TECHNOLOGICAL CHANGE FROM FOREJGN FIRMS IN IKENYA ......... 210

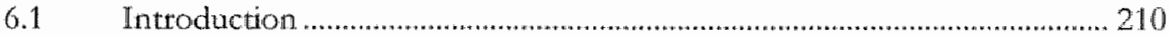

6.2 Framework of Analysis...........................................................................210

6.3 Brief Analysis of the Firms: Background and General Infomation .......... 213

6.3 .1 Food and Beverages Industry .................................................... 213

6.3 .2 Machine and Engineering Industry .................................................. 218

6.4 The Case Studies of Foreign Firms in the Food and Beverage Industry... 219

6.4.1 Firm Selection and Justification: Emphasis on Production Technology, Leatning and Ifnovation ....................................................... 219

6.4.2 Human Resources Development and Labour Mobility ....................... 224

6.4 .3 Linkage Effects ............................................................ 232

6.4.4 Competition Effects....................................................... 237

6.4 .5 Demonstration Eiffects ................................................. 246

6.5 The Case Studies of Foreign Firms in the Machine and Engineeting

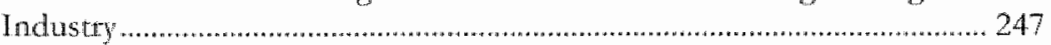

6.5.1 Firm Selection and Justification: Emphasis on Production 'Technology, Learning and Innovation ...................................................... 247

6.5.2 Human Resoutce Development and Labout Mobility ......................... 252

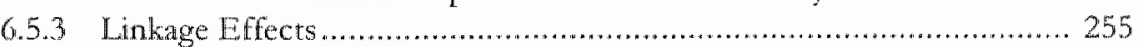

6.5.4 Competition Fffects...................................................... 260

6.5 .5 Demonstration Effects................................................... 262

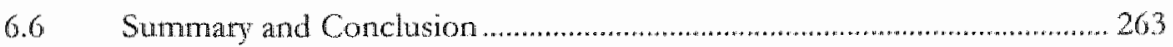


TECHNOLOGICAL LEARNING AND INNOVATION IN THE LOCAL FIRMS

\begin{tabular}{|c|c|}
\hline 7.1 & Introduction .......................... \\
\hline 7.2 & 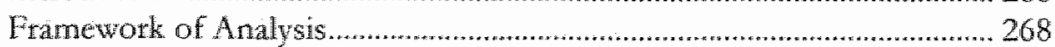 \\
\hline 7.3 & Brief Analysis of the Firms: Background and General Information .......... 271 \\
\hline 7.3 .1 & Food and Beverages Industry Briefly ........................... \\
\hline $7,3.2$ & 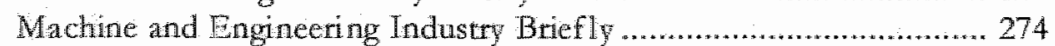 \\
\hline 7.4 & 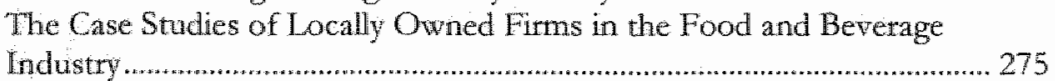 \\
\hline 7.4 .1 & $\begin{array}{l}\text { Fin Selection and Justification: Emphasis on Production Technology, } \\
\text { Learning and Innovation ............................................................. }\end{array}$ \\
\hline 7.4 .2 & Fuman Res outces Development and Tabour Mobility ....................... \\
\hline 7.4 .3 & Linkage Effects ................... \\
\hline 7.4 .4 & Competiti on Effects ......... \\
\hline 7.4 .5 & Demonstration Effects..... \\
\hline 7.5 & $\begin{array}{l}\text { The Case Studies of Locally Owned Firms in the Machine and Engineeris } \\
\text { Industry }\end{array}$ \\
\hline
\end{tabular}

7.5.1 Firm Selection and Justification: Emphasis on Production Technology, Learning and Innovation .......................................................... 301

7.5.2 Human Resources Development and Labour Mobility ..................... 308

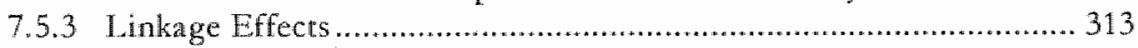

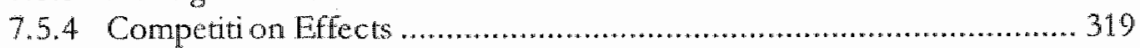

7.5 .5 Demonstration Effects ......................................................... 321

7.6 Perceived Government Role in the Spillover Process .................................... 323

7.7 Summary and Conclusion ......................................................................... 324

Chapter Eight ................................................................................................. 328

SUMMARY, CONCLUSIONS AND POLICY IMPLICATIONS ................... 328

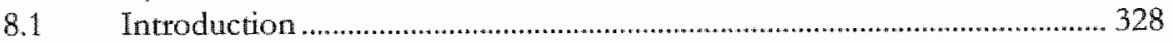

8.2 Research Problem and Objectives ............................................................. 328

8.3 "Theoretical Considerations and Conceptual Framework Design ................ 328

8.4 Summary of the Study's Findings .....................................................................329

8.5 Policy Implications of the Study ................................................................ 339

8.6 Recommendation for Further Research Works........................................... 342

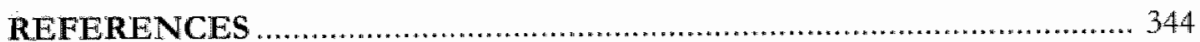




\section{LIST OF TABLES}

\section{Chapter 2}

Table 2.1

Table 2.2

Table 2.3

\section{Chapter 3}

Table 3.1

Table 3.2

Table 3.3

Table 3.4

Table 3.5

Table 3.6

Table 3.7

Table 3.8

Table 3.9

Table 3.10

Table 3.11

Chapter 4

Table 4.1

Table 4.2

Table 4.3

Table 4.4

Table 4.5

'Table 4.6

Table 4.7

Table 4.8

Table 4.9

\section{Chapter 5}

Table 5.1

Table 5.2

Table 5.3

Table 5.4
Reaction to Competition Pressure Ranked by Order of Importance (58)

Computation of Spillower Index, SPO MDEX (59)

List of Institutions and Number of Interwews Conducted, Kenya (75)

Selected Population and Social Indicators for Kenya, 1970-2002 (79)

Selected Economic and Technology Indicators for Kenya, 1970-2002 (82)

Principal Foreign-Based Firms in Kenya Before 1945 (86)

Major Foreign Investments 1945-63 (88)

Sectotal and GDP Annual Average Growth Rates, Kenya, $1972-2002(105)$

Average Sectoral Share of GDP, Kenya, 1972-2002 (105)

FDI Inflow and Stock, Kenya, 1977-2001 (108)

Performance of Export Processing Zones, Kenya, 1994-2002 (111)

Capital and Employment of DPC Processed Project, Kenya, $1990-2000(112)$

IPC Projects Approved, Kenya, 1990-2000 (113)

Foreign Investment Capital, KShs. Million, Kenya, 1990-2000 (1\%4)

Important Firm Trends in the panel data sample: Percentage based Shares, Kenya, 1994 2001 (129)

Important Trends in the Panel data sample: Percentages Based on Annual Averages, Kenya, 1994 2001 (135)

Growth and Shares of Manufacturing Industries, Kenya, 1964-2000 (136)

Two-Tail T-Test Results Comparing productivity Performance Behaviour of Foreign and Local Firms, Kenya Sample, 2004 (139)

Impact of Foreign Presence on Total Factor Productivity: Panel

Regression Estimates for All the Firms, Kenya, 1994-2001 (146)

Impact of Foreign Presence on Total Factor Productivity: Panel

Regression Estimates for Domestic Firms, Kenyn, 1994-2005 (147)

Key Indicators: Percentage Shares by Scale Dummy and Firm

Ownership (148)

Impact of Foreign Presence on Total Factor Productivity by Scale: Panel Regression Estimates for All the Firms by Scalle (150)

Impact of Foreign Presence on Total Factot Productivity by Technology Gap: Panel Regression Estimates for All the Firms by Technology Gap (152)

Distribution of Sample Fitms by Ownership, Kenyan Firms, 2004 (158)

Labour Mobility: Food Processing and Beverages, and Machine and Engineering Industries, Kenya, 2004 (160)

Linkage Effects: Food Processing and Beverages, and Machine and Engineering Industries, Kenyo, 2004 (162)

Competition Effects: Food Processing and Beverages, and Machine and Engineering Industries, Kenya, 2004 (163) 
Table 5.5 Demonstration Effects: Food Processing and Bewerages, and Machine and Engineering Industries, Kenya, 2004 (164)

Table 5.6 Compuration of Technological Spillover Index, SPO INDEX (165)

"Table 5.7 Occurrence of Technological Spillover in Local and Foreign Firms, Food and Machine and Engineering Industries Combined, Kenya, 2004 (167)

Table 5.8 Occurrence of Technological Spillover in Local Firms Only, Food and Machine and Engineering Industries Combined, Kenya, $2004(170)$

Table 5.9 Two-Tall T-Test Results Comparing Technological Spillover occurrence from Foreign and local Firms, Kenya sample, 2004 (17)

Table 5.10 Occurrence of Technological Spillover in Local and Foreign Fims in Food Processing Industries, Kenya, $2004(173)$

Table 5.11 Occurrence of Technological Spillover in Local Firms Only in Food Processing Industry, Kenya, $2004(175)$

"Table 5.12 Occurrence of Technological Spillover in Local and Foreign Firms in Machine and Engineering Industry, Kenya, 2004 (177)

Table 5.13 Occurrence of Technological Spillover in Local Firms Only in Machine and Engineering Industry, Kenya, 2004 (179)

Table 5.14. Two-Tail T-Test Results Comparing Spillover Occurrence from Foreign and Local firms, Kenya Sample, 2004 (180)

Table 5.15 One-way Results Comparing Spillover Occurrence in Food and Machine and Engineering Industries, Kenya Sample, 2004 (181)

Table 5.16 Descriptive Statistics, by Industry and Firm Ownership, Kenya, $2004(188)$

"Table 5.17 Variables Included in the Empirical Models and their Hypothesised Influence on Spillover Occurrence in Kenya's manufacturing Industry (194)

Table 5.18 Marginal Effects: Deteminants of Spillover Occurrence, Binomial Logit Estimation, Food Ptocessing and Machine and Engineering Industries Pooled (197)

Table 5.19 Determinants of Spillover Occurrence, Ordered Logit Analysis, Food Processing and Machine and Engineering Industries Pooled (200)

\section{Chapter 6}

Table 6.1

Basic Data and Information on Foreign Firms Interviewed, Kenya, 2002-2004 (217)

Table 6.2 FBF3 Comparative Yearly Accounts (Figures Prowided in Millions) (218)

\section{Chapter 7}

Table 7.1

Basic Data and Information on Locally Owned Firms Interviewed, Kenya, 2002-2004 (273) 


\section{LIST OF FIGURES}

\section{Chapter 1}

Figure 1.1

\section{Chapter 2}

Figure 2.1.

Figure 2.2

\section{Chapter 3}

Figure 3.1

Figure 3.2

\section{Chapter 5}

Figure 5.1

\section{Chapter 7}

Figure 7.1

Figure 7.2

Figure 7.3
Organisation of the Stody (13)

Framexork Model for Spillover Analysis: Determinants, Mechanisms and Effect on Technological Leaming and Capability Building (56)

Industrial Organisation Framework (61)

Inflation, Real Interest Rates and Exchange Rates, Keny̧, $1980-2000(107)$

Ownership of EPZ Enterprises: 2002 (109)

An Ordered Structure of Technological Spillower Occurrence (189)

Simplified Soft Drink Production Process in FBL2 (278)

The Metal Pipe Making Process in MCTL2 (303)

Production of Aluminum Cookware in MCTL3 (305)

\section{LIST OF CHARTS}

\section{Chapter 4}

Chart 4.1

Comparisons between Foreign and Locally owned Firms, Kenya, 1994-2001 (130)

Chart 4.2 Foreign Presence Determined by Capital, Employment and Output Sales (137)

Chart 4.3 Average Firm Age by Manufacturing Sector, Kenya, 1994-2001 (132)

\section{LIST OF MAPS}

\section{Chapter 3}

Map 3.1

Kenya, Provinces, Principal Cities and Neighbours (81) 


\section{LIST OF BOXES}

\section{Chapter 4}

Box 4.1

\section{Chapter 6}

Bok 6.4.1

Bor 6.4 .2

Box 6.4.3

Box 6.4.4

Bo\% 6.4 .5

$\operatorname{Box} 6.4 .6$

Box 6.4.7

Bor 6.4 .8

Box 6.5.1
Synopsis Based on Aggregate data from Secondary Sources (135)

Human Resource Development: The Case of FBF2 (226)

Labour Mobility: The Case of FBF2 (230)

Labour Mobility: The Case of FBF6 (231)

Iinkage Effects: The Case of FBF2 (234)

Linkage Effects: The Case of FBF3 (236)

Competition Effects: The Case of FBF3 (240)

Competition Effects: The Case of FBF5 (242)

Competition Effects: The Case of FBF6 (244)

Linkage Effects: The Case of MCTF3 (258)

\section{Chapter 7}

Box 7.5.1 Technological Spillovers through International Labour Mobility: The Case of MCTL2 (311)

Box 7.5.2 Technological Spillovers through International Labour Mobility: The Case of MCTL4 (312)

\section{LIST OF APPENDICES}

\section{Chapter 4}

Appendix 4.1 Annual Growth Rates for All Firms and Some Selected Manufacturing

\section{Chapter 5}

Sectors, Kenya (155)

Appendix 5.1 a Labour Mobility: Analysis of Workers Lost by Owners and Industry (204) Appendix 5.1b Labour Mobility: Analysis of Workers Employed by Ownership and Industry (205)

Appendix 5.2 Linkage Effects: Analysis by Ownership and Industry (206)

Appendix 5.3 Competition Effects: Analysis by Ownership and Industry (206)

Appendix 5.4 Demonstration Effects: Analysis by Ownership and Industry (207)

Appendix 5.5. Correlation Matrix of All the Independent Variables used in the Analysis (208)

Appendix 5.6 Determinants of Spillower Occurrence, Ordered Logit Analysis, Food Processing and Machine and Engineering Industries Pooled (209) 


\section{LIST OF ABBREVIATIONS}

$A C E G$

$\mathrm{ADB}$

AGOA

ARIPO

ASK

ATIA

ATPS

CBS

CBIK

$\mathrm{CIC}$

CMA

COMESA

COYA

DBK

DCs

DEG

DFCK

DSO

$\mathrm{E}-\mathrm{O}$

EAC

EIB

EMS

EPC

$\mathrm{EPZ}$

EPZA

FDI

FIPA

FPEAK

$\mathrm{FKE}$

GDP

GFCF

GMK

Grok

HIV

IBRD

ICDC

ICDCIC

ICSD

IDB

IDC

IDS

IMF

IPAR

IPC

I-S

ISO

KAM

KANU
African Centre for Economic Growth

African Development Bank

African Growth Opportunity Act

African Regionall Industrial Property Office

Agricultural Society of Kenya

African Trade Insurance Agency

African Technology Policy Studies

Central Bureau of Statistics

Centre for Business in Kenya

Capital Issues Commitree

Capital Market Authority

Common Market for Eastem and Southern Africa

Company Of the Year Award

Development Bank of Kenya

Developing Countries

Germany Investment Corporation

Development Finance Company of Kenya

District Statistical Officer

Export Orientation

East African Community

European Investment Bank

Environmental Management System

Export Promotion Center

Export Processing Zone

Export Processing Zone Authority

Foreign Direct Investment

Foreign Investment Protection Act

Fresh Produce Exporters Association of Kenya

Federation of Kenya Employees

Gross National Product

Gross Fixed Capital Formation

General Motors Kenya

Govemment of Keny

Human Immunity Virus

International Bank for Reconstruction and Development

Industrial and Commercial Development Corporation

Industrial and Commercial Development Corjporation, Investment

Corporation

International Center for the Settlement of Investment Disputes

Industrial Development Bank

Industrial Development Corpotation

Institute of Development Studies

International Monetary Fund

Institute of Public Affairs Research

Invesment promotion Council

Import Substitution

International Organisation for Standardisation

Kenya Association of Manufacturers

Kenya African National Union 


\begin{tabular}{|c|c|}
\hline $\mathrm{KBS}$ & Kenya Bus Service \\
\hline KEBS & Kenya Bureau of Standards \\
\hline $\mathrm{KIE}$ & Kenya Industrial Estates \\
\hline KIM & Kenya Instimte of Management \\
\hline KIPI & Kenyal Industrial Property Institute \\
\hline KIPPRA & Kenya Institute for Public Policy Research and Analysis \\
\hline KIRDI & Kenya Industrial Research and Development Institute \\
\hline KITI & Kenyon Industrial Training Institute \\
\hline KNCCI & Kenya National Chamber of Commerce and Industry \\
\hline $\mathrm{KPB}$ & Kenyanisation of Personnel Bureau \\
\hline $\mathrm{KQA}$ & Kenya Quality Award \\
\hline KShs & Kenya Shillings \\
\hline MDGs & Millenium Development Goals \\
\hline MEST & Ministry of Education, Science and Technology \\
\hline MIGA & Multilateral Investor Guarantee Agency \\
\hline MNC & Multinational Corporation \\
\hline MoF & Ministry of Finance \\
\hline $\mathrm{NPC}$ & New Projects Committee \\
\hline MPND & Ministry of Planning and National Development \\
\hline MTT & Ministiry of Trade and Industry \\
\hline MUB & Manufacturing Under Board \\
\hline NCST & National Council for Science and Technology \\
\hline $\mathrm{NPC}$ & New Projects Committee \\
\hline OHSAS & Occupational Health and Safety Assessment Series \\
\hline $\mathrm{PCT}$ & Patent Cooperation Treaty \\
\hline QMS & Quality Management Systems \\
\hline $\mathrm{R} \& \mathrm{D}$ & Research and Development \\
\hline RPED & Regional Programme on Enterptise Development \\
\hline SGS & Société Générale de Surveillance \\
\hline $\mathrm{SAB}$ & South African Brewery \\
\hline$S A B C O$ & South African Beverages Company \\
\hline SEFCO & Small Enterprises Finance Company Limited \\
\hline $\mathrm{SIC}$ & Swiss Investment Corporation \\
\hline SMLs & Small and Medrum Enterptises \\
\hline $\mathrm{TPM}$ & Total Productive Maintenance: \\
\hline UK & United Kingdom \\
\hline UNCIAD & United Nations Conference on Trade and Development \\
\hline UNDP & United Nations Development Programme \\
\hline UNIDO & United Nations Industrial Development Organisation \\
\hline UNESCO & United Nations Educational, Scientific and Cultural Organisation \\
\hline US $\$$ & United States dollars \\
\hline USA & United States of America \\
\hline VSAT & Very Small Apertute "Terminal \\
\hline WCP & World Class Performance \\
\hline WIPO & World Intellectual property Organisation \\
\hline WTO & World Trade Organisation \\
\hline
\end{tabular}




\section{Chapter One}

\section{INTRODUCTION}

\subsection{Background: Technological Capabilities and Foreign Direct Investment}

The importance of technology in industrial production came to the fore in the immediate years after World War II. It was believed that in order to achieve high and sustained levels of economic development, technological progress was hecessary and this had to take place through a steady process of technological accumulation. This process enabled a continuous and increasing introduction of entirely new processes and new products into an economy (Landes, 1969; Maddison, 1991; Freeman and Soete, 1997). The debate on economic development was of particular importance to the underdeveloped countries, which were trying to devise ways to overcome levels of poverty and low productivity. Although altemative sources of technology transfer such as licensing, turnkey projects and consultancy existed, it was largely thought that the successful accumulation of technology mainly depended on foreign investment into a host country. Such investment was believed to result in the transfer of technology and other capital goods. 'The technology transferred was however dominated by a focus on 'embodied' capital - machinery and equipment (including at times human capital) and included less of the 'dis-embodied' capital.

During the 1950 s and 1960 s little effort was therefore made to analyse technological change in underdeveloped country industries. Technological change was either presumed to be absent or was assumed to result from technological innovations that had been made elsewhere in industrialised countries and could simply be selected and applied in underdeveloped countries. Accordingly much of the technology and development literature was located within neo-classical framework where the choice of rechnology became the main point of concern to the underdeveloped countries: hence the coining of the concept of "appropriate technology" in the 1970s. "The prime objectives of appropriate technology were to maximise social welfare and to optimise the use of available resources in a given environment [Stewart, (1972: 1979); Willoughby, 1990]. Mote attention was therefore given to how to access and tmasfer foreign technology at low and affordable prices. Technology mastery was assumed to automatically result from learning by doing in the course of production in the firms using the ransferred technology.

Nevertheless, by the mid 1970 s the debate over whether imported technology was appropriate or inappropriate took a new turn. Transfer of machinery, equipment and other capital goods to underdeveloped countries failed to contribute to economic development in a number of countries. The perceived automatic mastery of foreign technology by locally owned firms often failed to materialise and the whole notion and relevance of technology transfer was beginning to be queried. The need for change was advocated and the debate revolved around a highly significant issue at the time: "why some countries were more successful in acquiring, learning and diffusing technological knowledge from imported technology or from foreign investment than others". Evidence from research conducted in some of the newly industrialised comntries (NICs) supported the need for local effort to develop technologies - whether indigenous technologies or of the imitative kind developed through reverse engineering (Enst, Mytelka and Ganiatsos, 1998: p. 6). The notion of technological capability came 
to the fore and ostensibly became a central focus of further research and discussion [Fransman, 1984); Lall, (1982: 1987: 1992); Katz, 1985; Bell, 1984; Bell and Pavitt, (1992: 1993)]. Further studies were conducted widely for instance in Asia by Dahlman and Westphal (1982); Westphal, Kim and Dahman (1985); Westphal, (1990); Hobday, (1995); Kim (1997: 1999); Ernst, Mytelka and Ganiatsos, (1998). In Latin America by Katz, (1987) and Dahlman, (1987). Finally, in the Andean Group by Mytelka (1978) and in Africa by Mytelka (1985: 1989); Langdon (1981: 1984) among others.

On the basis of lessons from the NICs and Latin America the consensus that emerged out of this phase was that developing countries needed some degree of technological capability. This was more so if they were to be successful in choosing, adapting, and making incremental improvements in imported technology or better still if they were to be alble to imitate foreign products and processes. Researchers therefore introduced the phrase tedynological capability and since then it has been embraced in the developing colntries especially with regard to firms, as they try to identify and formulate their strategies to meet the ever increasing challenges of intensified innovative competition resulting from liberalisation and globalisation measures among others. Despite the adoption of this phrase, it is nonetheless difficult to interpret it partly because the resources firms accumulate are diverse and difficult to categorise. Fxamples of such resources comprise human capabilities: skills, experience and knowledge vested in people along with institutional resources: the internal procedures, routines and organisational structures of the firm, and the external linkages cemented with other firms and institutions.

Just as it is difficult to interpret technological capability it has also proved difficult to understand how it can be acquired and/or batlt in firms, industries or economies particularly in the underdereloped conomies. Acquisition of technological capability is a complex learning process that comes from many sources for instance international, domestic and in-house sources (Kim, 1997: p. 90). The point we are trying to emphasise here is that technological capability building is a difficult process that takes time, results from contimous effort and involves diverse resources. As a result of this, many developing countries such as those in sub Saharan Africa (SSA) have not been successful in acquiring and/or building these capabilities and are therefore chatacterised by low capability levels in choosing, adapting and making incremental improvements in imported technology or imitating techniques employed by foreign investors. In this study we shall try to understand how such countries whose technological capabilities are nelatively low stand to benefit from foreign direct investment (FDI). This study shatl not limit its analysis to the fitm level as has commonly been done in the past. It will be emphasised tather that the firm is situated in a broader context, which some theorists have described as a national system of innovation (NSI). These theorists emphasise that learning and innovation at the firm level are stimulated by interactions with othet firms e.g. clients or competitors and the process is supported by other actors in the system, notably research institutes and production centers. This thesis will conceptualise the firm in this systemic context and within the evolutionary framework that has resulted from theoretical developments in the economics of technical change extended widely since 1980 s with the pioneering work by Rosenberg (1982), Nelson and Winter (1982) and Freeman (1982) among others. 
FDI is regarded as one of the driving forces integrating underdeveloped countries into the globalisation process that has characterised the world economy over the past several decades. It is presumed to be an important chantel through which international diffusion of knowledge and technology takes place. Since the underdeveloped countries lag behind in the wotld technology frontier, they rely considerably on inflows of foreign technology from the technically advanced countries (Lall 1987: p. 193; Pack and Saggi 1997: p. 81). This however, should not be interpreted to mean that underdeveloped countries do not generate indigenous technology. Technicians \& artisans, weavers and metal workers in underdeveloped countries possess considerable technological know-how and the material technology needed for production. Some underdeveloped countries have significant packages of technical knowledge (even in more advanced technologies) and there is no reason to suppose that many technologies cannot be developed indigenously:

However, absorption of new and adwanced technologies in underdeveloped countries may be problematic for firms in the short run especially when the technology gap is wide. It would require much time to nurture research and to develop human capaciry - for instance training scientists and engineers. This would call for sustained expenditure on education and reseatch and development (R\&D). All this notwithstanding, it would also take a long time to ensure that findings from research were transferred to locally owned firms for exploitation. This long process does, howewer, represent an alternative to FDI as does the import of machinery and equipment and the hiring of technical and engineering personnel with a mandate to train local personnel in its use and maintenance. Unfortunately, the scarce resources in the underdeveloped countries and the amount of time this process would take before it can be accomplished leads many to stress the need to import technology and the role of FDI in facilitating this process. In this respect, we will argue that FDI is not only important in the international transfer of technology and skills to the underdeveloped countries but could also act as a srimulant to the technological development process which in turn enhances industrial development and eventualiy long run economic growth. Based on this proposition, a relevant task would therefore be to investigate whether imported technology is absorbed locally not only into a single firm, but through spillovers, into a wider system of innovation that could be created as a means to develop a dynamic process of innowation in an industry.

Technology transfer irrespective of the channel through which it occurs is not easy. It requires much effort and investment in various resources on the side of the recipient to facilitate the adaptation of the technology before it is implemented (Teece, 1.977: p. 245; Nelson and Pack, 1997: p. 18). Contrary to the over-simplified assumptions accorded to technology in the neo-classical framework, the chatacteristics of rechnology ave quite complex making it different from other normal market products. The tacit nature of technology makes it ill defined to the extent that, it becomes difficult to transact in a notmal commodity market. The seller has mote information than the buyer, has grealer bargaining power and can exercise imperfect competition hence malking the buyet operate under a situation of information asymmetry (Arrow, 1962: $\mathrm{p} .615$ ). It is difficult to judge the value of any specific technology and agree about prices and licensing costs

\footnotetext{
1 The term tacir is taken hete to imply that tochrobgy cannot be codified and that tacit linowhedge is unique and specific to individual firms. It cannot be chchanged arrong firms as it is dered afrer a long period of learring experiences of indiwdual fitms through accumalation of technological capability. It is embodied in the "organisational routines and collective expertise or shills of specific production, procurement, R\&D and marketing teams" (Ernst, Mytelka and Ganiatsos, 1998: p. 6).
} 
that are acceptable to both partes. The benefits of technology transfer are also difficult to deremine. In the short-run technology transfer benefits the recipient by increasing productivity, contributing to the dewelopment of new products and by raising profits. In the long run the benefits depend on how much recipients learn from the technology and are able to deepen and develop their own capabilities (UNCTAD, 1999: p. 203).

To the contrary, there are those who hold a different wiew on the importance of FDI in a host country. Ftom the old dependency theory in development, MNCs ate viewed as major finstuments of capitalism underdeveloping deweloping economies to expand accumulation in the developed world [Frank, (1973: 1978)]. Increased MNC penettation was considered to de-skill wotkers. This was so given that MNCs considered minimum and/or low wage employment to be the basis of incorporation in developing economies. Taking as an example, when a small market size exits it restricts the number of fims to only a few at a given time. This has untold repercussions in that it can present monopsony powers to firms making them pay skilled workers wages at par with unskilled workers which in turn discourages Labour from acquiring skilled workers. In support of the same arguments advanced above, Amin (1973: 1976: 1977) further reiterated that MNCs transfer inappropriate capital-intensive technology to the developing countries. He argued that such technologies once transferred increases their cost of adoption and diffusion thus making the process of technological development difficult in the host developing countries. These arguments are founded in Marx earlier arguments that increased capitalism by MNCs in a given industry would deny the underdeveloped countries the chance and potential to learn and develop their own technological capabilities. The same sentiments were expressed by $\mathbb{L}$ all and Streeten (1978) who observed that while MNCs enjoyed the potential to generate strong efficiency spillovers to locally owned firms it was also possible for them to create bias towards capital intensive technology. This would have adverse effects on employment, income distribution and consumption pattern. Most importantly competition created by the MNCs may crowd out domestic investment. This would again result in an industry without strong indigenous technological capabilities. ${ }^{2}$ The same dependent relationship long run results would be an industry deprived of the opportunity to generate own knowledge and innovations that are necessary for se]f propelled economic growth and development.

This thesis will investigate whether technology, knowledge and other skills transferred to the undendeveloped countries from developed countries contributes to the development of technological capabilities in the former, which would in turn enable them to learn and innovate. This aspect has not been accorded due recognition in the spillover literature whose work, mainly placed in the neo-classical litetature, tends to navely reduce technological change to production. Production function was consideted to be the dominant framework to measure and determine the impact of technological spillovers lsee among others studies by Caves, 1974; Globerman, 1979; Blomstrom and Persson, 1983 using data for Canada, Australia and Mexico respectively]. The effort by the locally owned firms, for instance to leam, imitate or copy production, processing, marketing, managerial or organisational techniques demonstrated to them by the foreign firms was neglected as was done to the understanding of dynamics and mechanisms through which

2 This is supported by Lall (1292, p. 179) argument when he remaked that "an strong foreign presence with adwanced technologies can prewent loca competrots from investing in deepening their own capabilities". 
specific spillovers occurred ${ }^{3}$. As will be shown at a later chapter, the production function approach, which conceptualises spillowers in terms of labour of total factor productivity rather than learning, capability building or innovation, does not actually measure spillovers or capture their economic impact. "There has been little work if any which directly investigates spillovers taking learning, capability building or innovation as their point of departure in line with Schumpeterian tradition, which emphasises the importance of learning and innovation in development.

This thesis aims to fill in this gap in the spillover literature taking an evolutionary perspective. The analysis will be done by examining the effect of spillover "externalities" from subsidiaries of MNCs to locally owned firms in the context of a technologically underdeveloped country namely Kenya in sub Saharan Africa. Despite the existence of voluminous literature on FDI spillovers in both developed and advanced developing countries, little if anything is known about spillovers and their effect particularly in SSA where economies differ substantially from other developing countries. Most of these are characterised by very fragile economies where markets are small, firms are weak, capital poor and still 'locked into' low levels of traditional skills and non-competitive techniques and where institutions and infrastructure are weaker than in many other developing countries (DCs). All these factors demonstrate why the case of third world countries in $S S A^{*}$ is therefore unique and one that tronically failed to receive any significant atrencion in the spillover literature in the 1.970s, $1980 \mathrm{~s}$ and into the 1990s. In this respect, the current study will address five broad questions that focus on analysing the benefits of FDI in the context of technically underdeveloped countries with particular reference to Kenyan manufacturing enterprises. The specific questions can be stated as follows:

(1) Does the presence of MNCs stimulate spillovers to local manufacturing enterprises in Kenga?

(2) If so, what kind of spillowers occur and to what extent?

(3) What are the main mechanisms and/or channels through which these spillovers occur?

(4) Under what conditions do spillovers occur in the Kenyan enterprises?

(5) How do spillovers influence technological innovations at the enterprise level in the Kenyan manufacturing industry?

The thesis will argue that oxer time as subsidiaties of MNCs located in an underdeveloped conntry use technologies new to that connry, leakage of knowledge and skills in the form of spillovers may take place. These spillovers include new knowledge, skills and other resources that would enable locally owned firms to generate and manage technological change, and may lead to sustained technological capability development and technology self-sufficiency in the long run. Such spillovers, we shall atgue, take place as firms compete and interact through the formation of industrial network linkages or co-operative activities |Richardson, 1972; Brusco and Sabel, 1981; Brusco, 1982; Piore and Sabel, 1984; Best, 1990; Rasialh, (1994: 1995); Saxenian, 1991]. These arguments are as well raised in the new endogenous growth and trade theories, which emphasise the importance of positive externalities in technological development and subsequent economic growth. In addition, endogenous growth theory stresses that for technological development to take place, positive spillovers must be accompanied by accumulation of

\footnotetext{
By rniling to examine the mechanisms through which spillovers take place, the production function approach treas them as a "black box', denying ws full understanding of the spillower process.

"For an elaborate discussion see Freman and Lindauer (1999)" "Why not A frica" NBIR wotking Paper

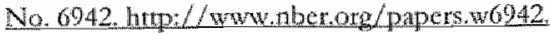


Capital and accumulation of knowledge through R\&D, human capital formation and technolugical learning IArrow, 1962; Nelson and Phelps, 1966; Lucas, 1988; Romer, (1986: 1990), Griliches, (1984: 1992); Benhabib and Jovanovic, 1991; Grossman and Helpman: 1991]. On the basis of this theory, technological change therefore results from conscious effort to investments and from different decisions undertaken by economic agents. The theory emphasises that without spillovers, externalities, or other sources of increasing teturns, economic growth cannot proceed at a constant, undiminished rate into the furure.

\subsection{The Study Objectives}

The broad objective of this study is therefore to examine the role of FDI in the industrial development in Kenya. Investment in the form of FDI is likely to spur development in a host country by playing a supportive role or by acting as a complement to local investment and innovation. Under certain conditions, FDI could serve to improve host countries industrial development effort and their competitiveness by bringing into them some desirable attributes such as best practices in production, new skills and trainings, leading-edge or new technology, new managerial and marketing know-how, facilitate supply and knowledge linkage formation. Such linkage formation facilitates spread of skills and information to the economy and might catalyse the existing entrepreneurial efforts through demonstration effect. Further, FDI might help strengthen local systems of innovation within underdeveloped countries when the subsidiaries of MNC encourage local R\&D institutes to enthance commercialisation of their accumulated capability. This study therefore arises out of concerns to understand how FDI affects industrialisation process in Kenya with particular emphasis on MNCs' influence in promoting a dynamic manufacturing industry. The specific study objectives formulated to guide this study can be outlined as follows:

(1) To investigate the extent to which the presence of MNCs stimulates spillowers to local manufacturimg enterprises in Kenya.

(2) To determine the conditions under which spillovers occur in Kenyan manufacturing enterprises.

(3) To investigate how spillowers from MNCs impact on technological innovations at the enterprise level in the Kenyan manufacturing industry ${ }^{5}$.

(4) To draw some lessons and policy implications for a spillower driven industrial development in Kenya.

\footnotetext{
5 This is based on iwo selected manufacturing industries: Food processing and beverages, and machine engineering industry.
} 
This Thesis will take an empirical approach using a fum lewel survey mehod, which will be backed up by sexeral case studies with a strong interview questioninaire instrument aimed at providing deeper insights into the underlying issues observed in the survey findings. To achieve this goal, this thesis adopts three strands of literture. The first one is the litetature on technological spillover. This was pioneered by Caves (1974; 1982) applying the production function framework and latter led to a plethora of other works employing a similat framework fGlobeman, 1979; Blomstrom and Persson, 1983; Blomstrom, 1986; Kokko, (1992: 1994); Blomstrom and Wolffe, 1994; Blomstrom and Sjoholm, 1997, Djankov and Hoekman, 1998]. This has been adwanced by recent studies which have introduced new methodologies which have taken into consideration new dimensions, instruments and dynamics such as time rariations, industry type, locational and other spatial variables (Hadda and Harrison, 1993 and Aitken, Hansen and Harrison 1999). The spillover literature has also been advanced by the proponents of new growth theory who emphasise endogenous technological change, accumulation of human capital and openness to international trade and investment [Lucas, 1988; Romer, (1986: 1990); Aghion and Howitt, 1990; Coe and Helpman, 1995; Grossman and Helpman, 1995|. The literature emphasises the importance of technological spillovers in long run economic growth and development.

Second, the study adopts the literature on clusteting and network dymamics. This is founded in industrial organisation and begins with the pioneering work by Coase (1937), Chandler (1961: 1977), Richardson (1972) and Williamson (1975: 1979: 1985). The literature extracts elements of transaction costs and institution economics. Additionally, several works exist that support examples of effecrive industrial networks, where cooperation, market forces and social capital such as trust have been cited as important elements in the formation of production relationships (see Brusco and Sabel, 1981; Brusco, 1982; Piote and Sabel, 1984; Best, 1990; Saxenian, 1991) among others. In the proposed framework, we shall rely on industrial networks of individual enterprises to reveal various kinds of technological spillovers that occur (pecuniary or non-pecuniary) and investigate their impact on technological learning, capability building and innovation.

The third literature strand adopred relates to economics of technological innovation, which emphasises the importance of firm technological leatring and capability in incurring technological change and innovation. This literature is founcled undet the broad framework of evolutionary economics recently adwanced by Nelson and Winter, 1982; Rosenberg, 1982; Freeman, 1982; Stoneman, 1983: 1995; Dosi, Freeman, Soete and Silversberg, 1988; Metcalte, 1989; Freeman and Soete, 1997 among others, This has in addition motivated the development of national system of imovation framework [Freeman, (1987: 1995); Lundvall, (1988: 1992: 2000); Nelson and Rosenberg, 1993; Nelson, 1993; Edquist, 1997; Mytelka, (2000: 2004)|.

\subsection{Justification and Limitations of the Study}

The existing litetature on FDI and technological spillover is mainly based on the traditional neo-classical approach, production function framework, which is employed as

\footnotetext{
"Howewer network dynamics in our context could also be refented to as sociat netwoths.
} 
the dominant approach to capture technological spillowers and their economic impact. This is problematic in that the spillover literature has failed to maintain pace with the growing importance of technological learning, capability building and innovation in technology development for economic growth. This problem is further compounded by another shortcoming in that spillovers are conceprualised in terms of productivity, which is inherendy static and does not actually capture potential spillowers from the perspective of leaming, technological change and innovation. The direct implication of this is that there is yet a lot of investigation that ought to be done to fill this void in the spillover literature. This thesis is therefore justified as it intends to analyse technological spillovers in the perspective of learning, capability building and innowation contrary to productivity technique, which takes production function framework as its point of departure.

With regard to distribution of studies examining technological spillovers from foreign investment and their effects on a host country, it is notable that such studies are skewed to the deweloped countries. The existing theory and empiricall studies have to a large extent been based on scenarios and case studies illustrated by experiences in developed countries or advanced developing countries. Systematic studies rooted in least developed countries, especially sub Saharan Africa have been limited. Such a study would take the structural specificities and other characteristics of sucla countries into consideration. This study is therefore relevant and justified in its attempt to contribute towards bridging this knowledge gap. We provide some examples to explicitly demonstrate why relying on developed country studies to draw general conclusions on spillovers would be misleading. First, studies done in the developed countries focus on instruments that are of little relevance in developing countries. A voluminous litetature exists where spillovers are measured taking $R \& D$ as the starting point [Gtiliches, (1979: 1992)]. Wheteas R\&D based knowledge spillovers may exist in developed countries, this may not be the case in developing countries since firms there undertake little R\&D and even MNCs hardly conduct R\&D there [Mansfield, Teece and Romeo, 1979; Lall, (1979: 1980): Dunning, (1993: 1994); Rasiah, 1995]. The technology and scientific infrastructure or the broad national system of innovation in developing countries offers minimum support for $R \& D$ activities as it does to other technology development initatives. Business and financing institutions are in their weakest form to offer credible financing opportumities capable of supporting innovation - there is a general lack of credible information and knowledge flow in the existing knowledge systems.

Second, a plethora of studies exist in dexeloped countries that use patent citation to measure knowledge spillovers Jaffe, 1986; Jaffe, "Trajtenberg and Henderson, 1993; Jafte and Trajtenberg, 1999; Maurseth and Verspagen, 2000; Criscuolo, 20041]. The logic behind patent citation is that a patent document often makes reference to an earlier existing patent document. The proponents of this approach then argue that citations of earlier patent documents could be interpreted as spillovers from the knowledge described in the cired patent to the knowledge in the citing patent. This is exactly where the problem lies in a developing country context in that only a few patents are granted in developing countries and even then only a few of them are translated into actual production. Patents are therefore not relevant in a developing country setting. This is more so given that their capacities in terms of resources to innovate are weak even when an idea around a patent may appear plausible. As indicated above, a strong financing mechanism to sustain an innovation process is not in place as well as a solid bnowledge base to support innovation e.g. developed R\&D and national system of innovation.

\footnotetext{
Although the empirical models estrmating the production function may have been extended and refined the basic approach is still, by and large, the same.
} 
In this light one of the countries with a relatively mature mantacturing base in the Sub Saluaran Africa was opted for in this study and Kenya was chosen based on several factors. Fint, Kenya is a unique country in Sub Saharan Africa in that it is not richly endowed with natural resources but because of the scale of its local production in her industry, it tends to be resource-intensive. This does not depend on domestic naw matertals only but also on imports and on the trading linkages established by local or foreign Grms. Serond, the eaflest inward foreign direct investment in Kenya tended to be local market-oriented or trade-related. MNCs started coming into Kenya long before her independence in 1963. It is believed that the early entry of MNCs enabled Kenya to develop a comparative advantage in manufacturing compared to other countries in the region. Finaly, although there was a slight decline in FDI inflow in the early 1990s, foteign entrepreneurs and expatriate firms have already developed a major presence, and constitute an impottant linkage between MNCs and localities. These arguments tend to support a widely held belief that Kenya's success in the manafacturing industry could be attributed to the existence of FDl, a fact that needs to be ascertained empirically.

This study is also relevant for policy making particullarly in view of the current initiative for structural transformation in Kenya. As documented in a major strategy paper entided "industrial transfomation to the year 2020 " the country will undergo a process of structural change aimed at fully industrialising the country by the year 2020 (Kenya Govemment, 1997 (a)). This thesis is therefore televant and significant as might offer several insights towatds understanding the role (both dynamic and complementary) that FDI in Kenya could play in such an important industrial development process. Further this thesis is timely in that its findings will contribute to the on going international debate on the best interventions and policy measures that are necessary in order to achieve the United Nations Millennium Development Goals (MDGs). The United Nations millennium development project is spearheaded by the United Nations to identify "practical strategies to emdicate poverty by scaling up investment in infrastructure and human capital promotion while promoting gender equality and environmental sustainability" (UN Millennium Project - UNIDO, 2005). The study is equally relevant for policy particularly at this point in time when neo-liberal prescriptions seem to be increasing pressure on the developing countries. Policy prescriptions of multilateral agencies and international organisations such as World Bank, IMF, WTO are critical of discrimunatory policies towards FDI, exports, globalisation, privitisation.

In terms of innovative aspect, the study is highly justified in that its scope of analysis is not limited to the firm level as has commonily been done in the past. In this study the firm will be conceptualised as situated in a broader context, which some theorists have described as national system of innovation (NSI). These theotists emphasise that learning and innovation at the firm level are stimulated by interactions with other firms e.g. clients or competitors and the process is supported by other actors in the system, notably research insritutes and production centres.

One of the limitations to the study is that of data inadequacy. Until recently most underdeveloped countries lacked strong technology policies on technology issues e.g. technology generation, acquisition, transfer and diffusion. Data on technology was therefore scarcely collected or not collected at all. Issues of technical change and innowation still appear somehow new to most underdeveloped countries. Kenya is not unique in this respect, as very little data if any on technological change is collected and/or documented. However to justify the feasibility of this study, we will conduct the 
study in two phases first by utilising the data at aggregate level and secondly by going behind the aggregate and conduct firm level interviews, which will be followed by specific case stadies to complement the survey data/information. However, data and information collected through the firm level interviews was limited to only food processing and beverages and machine and engineering industries. The two industries were selected on the basis of their dynamism compared to the other industries. $A$ s will be shown extensively in Chapter 3 and 4 the two industries were the most productive with the fastest growth rates, high FDI levels, value added, employment generation and contribution to the GDP.

\subsection{Data Collection and Scope of Study}

Data collection for this study was done in two phases and then supplemented with a few case studies. "The first phase included collection of data from secondary sources and was only concentrated in Nairobi while in the second phase interviews wete carried out basically in six regions in Kenya believed to have the most industries - Nairobi, Mombasa, Nakuru, Kericho, Eldoret and Kisumu (See Map 3.1).

In the second phase, interviews were conducted using a pre-tested structured questionnaire. Purposive, and proportionate and probability sampling techniques were employed in the selection of the firms to be included in the survey. To begin with, two sectors were purposively selected on the basis of high levels of FDI and their activicies; food processing and beverages and machine and engineering industries. Similarly the sub sectors were also selected in the same manner. Firms in the sub sectors were then divided into local, joint ventures and fully foreign. Then on the basis of this classification, proportionate and probability-sampling technique was used to select the firms to be incorporated in the survey. The firms were then interviewed using a questionnaire guided technique.

The case studies were selected on the basis of the survey done in the second phase. This was done by interviews coupled with organised firm visits to acquaint with production technology, learning mechanisms and innovation. The objective of the interview was to collect qualitative information, which would shed further insight into our understanding the impact of FDI in Kenya's industrial development. By so doing we were able to clarify more concretely what happened in the domestic firms as a result of MNC's presence, and answer the questions of how and why. A few institutions selected from business associarions, government departments and institutions such as R\&D, academic and financial instinutions were also interviewed in order to understand the role of institutions and systemic influences in the spillover occurrence process. The information sought was obtained from government officials, professionals and academic scholars knowledgeable in investment, indusury, innovation, privitisation and FDT.

\subsection{Thesis Outline}

This thesis is organised into nine chapters which comprise an introductory chapter, a theoretical and conceptual setting chapter, a chapter on FDT overview in Kenya, two

8 Nore that "food processing and beverages" and "food processing" will sometimes be used interchangeably. Similarly, "machine and engineering" and "machine engineering" will be used interchangeably. 
empirical chapters, two derailed case studies and a concluding chapter which presents the summary of the findings and policy tecommendations. In Figure 1.1 a schenatic overview of this thesis is presented.

Chapter 1 presents the thesis background, outlines the study objectives and states the main study questions. The chapter presents justification and limitations of the sindy and provides a summary of the data collection methods. The research methods to be employed and the theoretical approach are highlighted.

Chapter 2 presents an analysis of the literature on technological spillovers from FDI. The chapter commences with a brief discussion on international technology transfer. This is followed by a detailed analysis of FDI and technological spillowers. A discussion on the emerging issues from the technological spillover analysis is presented from which an attemative analytical framework to goven the study is offered.

Chapter 3 presents an analysis of industrial policies pursued by the Kenya government for the purpose of industrialisation and to attract foreign investment. This chapter attempts to put FDI and manufacturing industry evolution into context by tracing FDI from the origin and institutional setting in Kenya's manufacturing industry. The chapter discusses the importance of institutions in spillover occurtence, learning and capability building in firms.

Chapter 4 presents an empirical analysis. It begins with an analysis of technological characteristics of Kenyan manufacturing industry based on an in-depth analysis of panel sample characteristics. We also undertake to discuss comparisons of technological characteristics between local and foreign firms. Finally, we determine empirically the effect of foreign presence on total factor productivity using panel data estimation technique.

Chapter 5 uses the analytical framework designed in Chapter 2 to examine the extent of spillover occurrence in the Kenyan manufacturing inclustry. The chapter begins by presenting detailed descriptive characteristics of the survey data collected in food processing and beverages, and machine and engineering - two most dynamic industries. The kinds of spillowers occurting as well as the modes through which they occur are examined. We compute a technological spillower index, which offers tremendous insight on the extent to which technological spillovers conceptualised in terms of technological learning and capability building do occur in the manufacturing industry. The chapter uses limited dependent variable estimation technique to investigate the determinants of spillover occurrence.

Chapter 6 presents ten detailed firm level case studies of foreign firms operating in the Kenyan manufacturing industry. The case studies included wholly owned forcign firms and joint ventures (IVs) drawn from food processing and beverages, and machine and engineering industries. Using the selected case study firms, this chapter illustrates the extent to which foreign firms stimulated spillower occurrence to the locally owned firms. For this purpose, a framework based on the approach utilised in Chapter 2 and 5 was adopted taking into consideration four critical spillover mechanisms idlentified -w firm level training and labour mobility, competition, linkages and demonstration effects. The suidy argues that foreign furms played an important role in stimulating technological learning, capability building and innovation in the locally owned firms as well as in the domestic institutions and business associations. "This seemed to suggest a possible role 
FDI plays in accumulation of technological capability in manufacturing industry and intum industrial development.

Chapter 7 uses a similar approach to that employed in Chapter 6 to examine spillover occurrence from the perspective of locally owned firms. Subsequently, eight detailed case studies are drawn from the same industries as in the prewious chapter. Conceptualising technological spillovers in the form of skills and knowledge, this chapter presented an extensiwe anallysis on how such knowledge spillovers engendered technological changes and learning processes with subsequent accumulation of technological capability in. locally owned firms. We also discuss the government's role in spillover occurrence process.

The summary and conclusions of the study are presented in Chapter 8 . The chapter also offers policy implications based on our findings with respect to the role of FDI in industrial development in Kenya. Limitations of the study and possible future directions for further research are also illuminated in this section. 


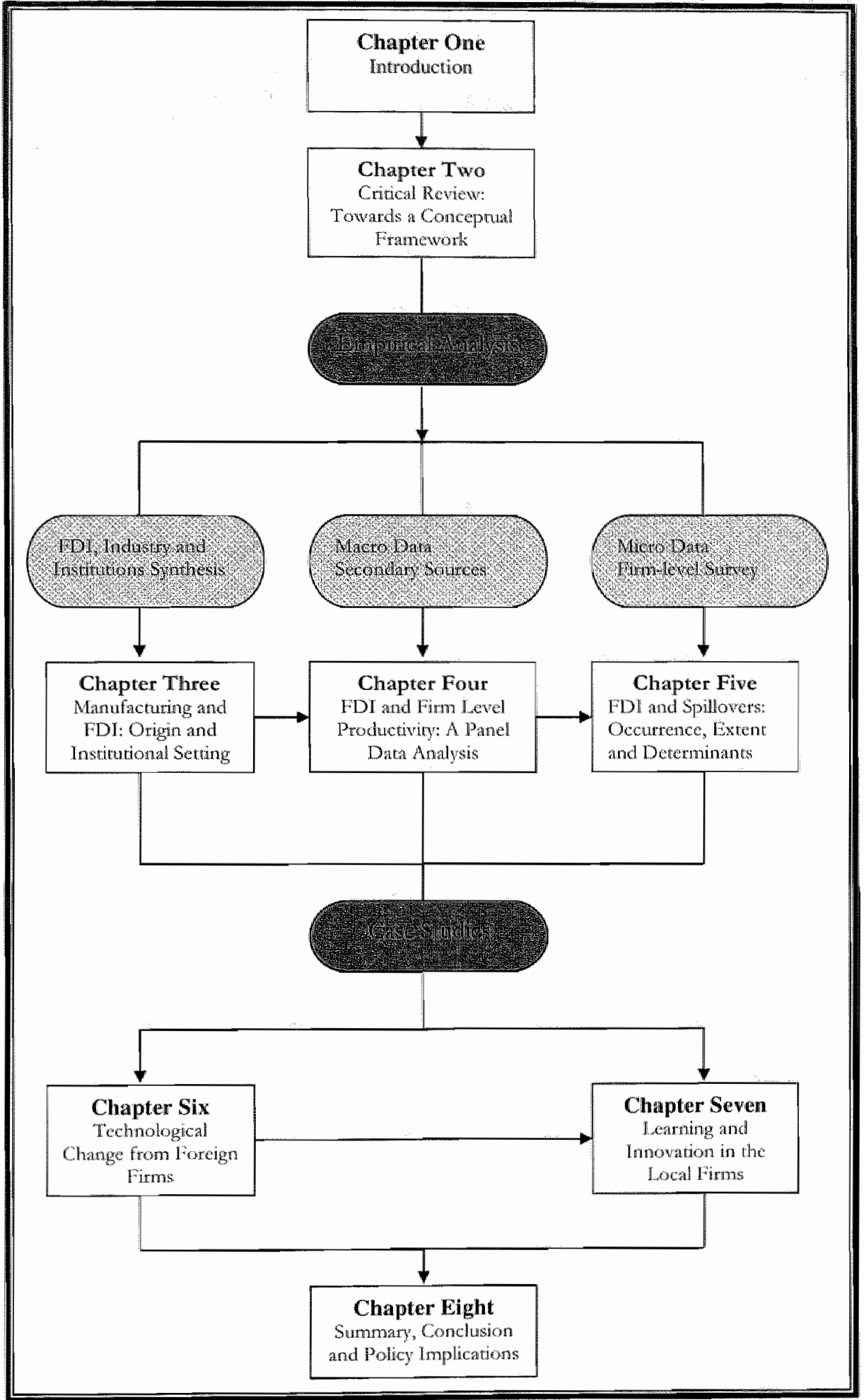




\section{Chapter Two}

\section{FOREIGN DIRECT INVESTMENT AND TECHNOLOGICAL SPILLOVERS CRITICAL REVIEW AND CONCEPTUAL FRAMEWORK}

\subsection{Introduction}

Chapter 1 presented a brief introduction for the entire study by outlining the research questions and objectives, relevance and justification, theoretical approach in brief and the study's structure. This chapter presents a critical analysis of FDI and technological spillovers literature and integrates it with two alternative theoretical literature strands to develop an analytical framework for examining spillovers in Kenya's manufacturing industry. The two alternative literature strands included technological innovations, and clustering and network dynamics. The chapter begins with a brief discussion on international technology transfer in section 2.2 followed by a detailed analysis of EDI and technological spillovers in section 2.3. In section 2.4, we discuss the emerging issues from the literature review and present an alternative theoretical framework. In section 2.5 , we develop the analytical framework to be used in analysing technological spillovers. The propositions to be tested in our study are formulated in section 2.6. Section 2.7 presents the research design and methodological setting employed. Summary and conclusion are presented in section 2.8 .

\subsection{International Technology Transfer}

This section begins by trying to conceptualise industrial technology in a bid to provide a basis for the analysis of technology transfer and how technological spillovers take place. This is deemed important since analysing the two requires a well-grounded understanding of technology's nature and its characteristics. Over time two distinct conceptualisations of technology have evolved. The first one is the traditional neoclassical perspective, which treats technology nartowly and in a very simplified manner. Technology was regarded as a public good that was freely available, costless and existing in a form that could be easily codified in designs, blue prints or operating manuals making it transferable with little effort. The second one and the more current is the endogenous perspective which views technology as something that is possessed by individuals, firms or institutions and includes a strong tacit element in that, it cannot be expressed in a completely explicit form. This is the kind of knowledge that is usually accumulated through experience as firms undertake their operations like design, production, and investment activities over time |Kaldor, 1957 Pentose, 1959; Polanyi, (1966: 1973); Ernst, Mytelka and Ganiatsos, 1998; Rasiah, 2002]. During various problem solving and trouble-shooting activities in firms, knowledge is generated and experience accumulated. Such knowledge acquired over time remains in the firms and in a substantially tacit form even during times of rechnology transfer, implying that other firms would have difficulties accessing it (Rosenberg and Frischak, 1985). A more rigorous way of putting it is that a considerable portion of technology is individual and firm specific with less of it explicitly expressed making it unavailable in a more complete form. Understanding of a particular firm's technology by other firms thus becomes difficult, as does its copying and imitation. 
The two perspectives demonstrate how the concept of technology has been wewed differenty by different participants in the technology debate. The cuntent discussion starts from the second perspective, which regards technology as something that is complex, diffcult to define precisely and is far more than a mere collection of patents, blue prints, machinery and equipment. By the same token technology tansfer would therefore be anticipated to be a much more complex affair than the ransfer of objects from firm to firm or shipment of capital equipment from country to country. Technology is transferred from multiple sources and in multiple ways. These differ from one country to another: sometimes due to a particulat country"s technological capability. The entite process involves many participants demonstrating a kind of integrated systemic tramework involving a process that is non-linear, continuous, dyonamic and interactive.

The main channels of international technology transfer include FDI, market transactions such as international trade in capital goods and selling directly through technology licensing artangements [Dunning, (1973; 1993); Lall, (1979: 1980); Romer, 1990; Coe and Helpman, 1995; Grossman and Helpman, 1995]. Others include joint ventures and strategic alliances (for an elaborated analysis of international channels of technology transfer see: Mowery and Oxlley, 1997: pp. 140-9). Technology transfer also arises due to patent disclosures, publications or technical meetings, conversations with employees of innovating firms, possibly in the context of informal networks, hiring of employees of the innovator (international consulcing services) and reverse engineering (Caves: 1974, $p$ 185; Mansfield: 1985, p 269). Despite the existence of these mechanisms of technology transfer, empirical evidence indicates that the dominant channel is MNCs. As an example, intra firm transactions in royalties and license fees between parent MNCs and subsidiaries have been reported to account for seventy percent of total global flows of royalties and license fees (UNCTAD, 1997: p. xvi). Transfer of technology by parent MNCs to their subsidiaties should howewer not be taken to reflect technology absorption and its diffusion to locally owned firms in the receiving countries where subsidiaries locate their operations. Unless otherwise specified for example when talking about the strategy of parent firms, the rerm MNCs in this study will be used interchangeably with subsidiaries.

Since it is outside the focus of this thesis, a detailed comprarison of the various technology transfer channels will not be provided. However, it is important to indicate brielly that FDI differs distinctly from matket transaction mechanisms in that, despite being a dominant technology transfer channel it deals with the transfer of relatively newer technologies. It is believed that imnovative firms in the developed countries are hesitant to transfer their new and recent technologies even through market transaction for a number of reasons including the fear of losing their ownership advantages. $A$ study involving the transfer of technology by U.S. based multinational firms to their overseas subsidiaries found that the mean age of the technologies transferred to overseas subsidiaries in developed countries was about 6 years (Mansfield and Romeo, 1980: pp. 738-9). This was significanty less than the mean age of the technologies transferred to overseas subsidiaries in developing countries whose average age was about 10 years"

\footnotetext{
"Nonetheless, the difference is not surprising. "Becanse many newer technologies are imappropriate tor: developing countries, or are difficult and expensine to transfer there, we would expect the rechnolog mansferted to developing countwes to be older than that transferred to developed countries (Manstald and Romeo: $1980:$ p. 738,." It is well known that not all technologies developed in adwanced countries cat readily be exploited in developing countries, where society needs an different and infrasmucure under which such technology would be exploited. Abramovitz (1994) tefers to this process as "lack of rechological congruence".
} 
whereas the corresponding figure for outside licensing was 13 years. Although the validity of this argument may be questionable today amid the current speed of technical change and great degree of internationalized production, the mainstream literature increasingly supports the view that FDI is a better means of enswring rapid technology transfer from abtoad than it can be brought in the market.

Traditional approaches to growth and development have emphasised the need for technology transfer. From their perspective, intemational technology transfer and acquisition was a linear process involving technology from one point or region to another mainly in the form of capital goods from suppliers in the industrialised world. One early representation of this approach comes from tracle theory and consists of product cycle models based on Posner (1961) and Vernon's (1966) theories' of economic development. According to the product cycle model, innovations were assumed to take place in the advanced industrialised countries located in the North, which were technically efficient and at the technology frontier. The model assumed that as developing countries (DCs) in the South had comparatively lower abilities to innovate than the advanced countries, the latter would enjoy preferential monopoly powers at the initial stage of the cycle in both production and export of new commodities. The higher wages in the adwanced countries reflected the monopolistic rents associated with the monopolistic powers of the advanced countries, which eroded gradually as the imitation process in the low wage underdeveloped countries picked up. A remarkable feature of this model was that imitation in the DCs is gradual and takes some time, this time lag places the advanced countries at a comparative advantage in the production of new commodities and DCs in the production of old commodities (Krugman: 1979). This model infers that the continuous process of innovation by the advanced countries and imitation by the DCs helps to explain the continuity of international trade. One policy implication from the product cycle model was that a country needed to open up its domestic economy and to participate more in the international trade, allowing the inflow of capital goods and other commodities, which would bring in new techniques, skills and knowledge.

Although traditional trade theory improves our understanding of the dynamic gains from international trade, its emphasis on a quasi-permanent role for developing countries as recipients of technology tansfer and as technological mitators is static and a historical. This notwithstanding, traditional international trade theory fails to treat technology as a Iradable commodiry in its own respect (Pack and Saggi, 1997: p. 92). This has recently been noted by several authors who contrast traditional trade theories and the internationalization of production as represented by FDI. Saggi (1999) though drawing a comparison to FDI, seemed to buttress the same point when he emphasised that:

"... what makes FDI especially important is that unlike trade in goods, where developing countries try to glean whatewer information they can from the products and services imported or import capial goods that embody modem technology, PDI involves explicit trade in technology" (Saggi: 1999: p. 16 ).

Technology was therefore treated implicity and viewed as something that could be easily copied, transferred or imitated using information and knowledge obtained from the embodied tradable commodities. As pointed above, this flowed from the traditional neoclassical perspective that reduced to the equivalent of capital goods: machinery and equipment that could be selected and chosen effortlessly, bought, transferred and imitated easily irrespective of the softness and tacit nature component embodied in the 
technology. An additional problem with traditional trade approaches is that they never, examined the nature of technology, the specific conditons under which various components of technology are transterted or the basic factors characterising the receiving frrms, institutions, industries or economies at large. International trade in goods camnot therefore be taken to explain the process of intemational technology transfer.

The dewelopment of both endogenous growth theory and evolutionary economics thas put the notion of a linear technology transfer process further into question Nelson and Winter, 1982). External sources of technology need not be limited ro machine suppliers from uniquely specified localities. Other firms vertically linked to a specific firm even in underdereloped countries, could for instance be important sources of rechnology so, too, do suppliers and customers provide not just knowledge about product specifications but also a wide range of other technological elements. In such a case the countries wider national system of innovation becomes important.

Taking the case of late industrialisers as an example, specifically Japan, Korea and Taivan, interactions among firms and between firms and their customers helped to diffuse knowledge and technology in most industries. Entrepreneutral effort by firms in these countries in the form of duplicative or innovative imitation, replicating and reverse engineeting of products from the industrialised countries, enhanced technology transfer, its exploitation and diffusion. Morement of skilled personnel between firms and countries helped to strengthen technological know-how, technological learning as well as technology transfer. The relationship between government and business was also instrumental as was participation in the export matket forcing firms to learn and increase their technological effort in order to compete effectively in the world market ${ }^{k}$. A wide review on these issues is available [Amsden, (1989: 1994); Fransman, 1985; Wade, 1990; Chang, 1994; Rasiah, 1994; Lall, 1996; Hobday, 1995; Kim, (1988: 1997); Ernst, Mytelka and Ganiatsos, 1998]

The issue here is that just as the nature of technology is muli-faceted, the same holds for its soutce, multiple sources exist and the process of creating and transferring technology should be viewed as dynamic involving the interaction of various actors and the effort of entrepreneurs. Given the nature of technology; tacit, incomplete availability, imperfect understanding and uncertainty, interactions become very important if technology is to be acquired, absorbed and diffused to other firms in a wider organisational and industrist set-up. Effective absorption and diffusion of rechnology requires that the receiving end must have built the necessary capability but would still require conscions ef fort that can be quite rigorous sometimes even for undertaking simple imitations or duplicative innovation.

However, given that there is always some amount of technological capability in underdeveloped countries, technological generation does exist. This would imply the existence of still other technology sources. Such technology and knowledge could of

\footnotetext{
10 As Dathlman and Westphal (1982: p. 106) pur it "techoology ranster is misleading, to the exterat that it snggests technologies can in tact be transferred wholesale and in working order. Capital goods alone do not constature a technology; they represent only that part of the technology which is cmbodicd in whe hardwate."."

"1) Participation in export markess sumvlated and supported strong and dyomic learning in two ways: Fist by introducing pressure to compete in international markets the entreprencurs were made to pay attention to the worle standards. Seasulb, the exports involved mainly the contracis with advanced firms in the TRIAD who demanded thigh performance and provided assistance to achieve it (Westplial, Kintr and Dahiman, 1985: pp. 137-50).
} 
course be transfered among frms as they interact through formal and informal linkage networks ethet directly or indirecty. As would be expected these countries also have a measure of absorption capacity that would facilitate absorption of such knowledge and skills. Nonetheless it would be naive to expect that ary country for instance the underdeveloped ones in SSA could transfer and absorb complex technologies and innowations detreloped elsewhere in the advanced countries automatically and instantaneously irrespective of whether they are embodied or dis-embodied in capital goods. A number of factors including the extent of linkages, of technological gap, of absorption capacity and of interactive learning create differences between technologically advanced courtries and rest of the world. Generally therefore, a combination of many factors both to the transferting end and the receiving and, influence transfer of technology both at domestic and international level. These factors combined within an integrated system make the entire process of technology transfer non-linear.

As the above demonstrates, the conceptualisation of technology transfer has changed from a unique, linear and automatic process that is costless to one that is non-linear, and requites considerable conscious effort, investment in technological learning and apprenticeship. Given tacit nature of technology, its cumulativeness, uncertainty and firm specific chanacteristics, its acquisition, transfer, diffusion and assimilation by firms will not be easy. Cost requirements and effort do indeed reflect the difficulties of taking up technology across different firms or national economies. As iliustrated by other late industriallisers, recipients of foreign technology must have to devote effort and substantial resources in otcer to absorb imported technology [Katz, (1985: 1987); Mytelka, (1978: 1985); Dahlman, 1982; Kaplinksy, 1984; Pietrobelli, (2000); Lall (1999:2001)]. Appropriate human resources have to be put in place that facillitates interactions with suppliers to provide technical support. Such effort leads to opportunities for the generation and greater exploitation of technology [Rosenberg and [Ftischtak, 1985].

A number of factors were observed to be responsible for the non-linear process of technology transfer for instance age of technology, warious sources of technology, levels of technological capability, interactions and technological learning. Increasing levels of international integration of innovation at the frontier through internationalisation of R\&D activities pressured by globalisation effects and changes on international trade. It can be anticipated that the presence or absence of these factors will influence the rechnollogy transfer benefits, spillovers or external effects that occur. In the next section we will look in detail at the technology spillover litetature.

\subsection{Foreign Direct Investment and Technological Spillovers}

This section focuses on foreign investment and the benefits that may accrue from it into a host country. Patticular attention has centered on the role of foreign investment as a channel of technology transfer and on the spillovers of knowledge to other firms in the economy. Foreign investment in a host country has both direct and indirect effects. Direct effects take place when a multinational company sets up a subsidiary in a foreign councry whereby it transfers some or part of its technology. Until recently, trade theorists have mainly been interested in the direct effects of foreign investment on factor rewards, employment, and capital flows, while those following industrial organisation approaches have put more emphasis on indirect effects of externalities. 
Indrect effects comprise all those aspects resulting from the presence of subsidianes of MNCs on the national economy that may inctease the productive efticiency of donestic fums. Such benefits occur since it is not possible for subsidaries to fully appioprate them ... "the MNC cannot capture all quasi-rents due to its productive actuvites of to the removal of distortions by the subsidiary"s comperitive pressure" (Caves, 1974: p. 176). Caves referred to them as productivity spillovers and classified them into allocative efficiency, technical efficiency and technology transfers. Alowath offiemg occurred when MNCs introduce competition in the host country market by breaking existing monopolies while terbnacal efficieng that come about when competitive pressure and demonstration effects by subsidiaries induce technical efficiency to domestic firms. Finally tholnology tranger due to the fact that MNCs may speed up their technology transfer and innovation processes, causing them to disseminate faster, than would have been the case, to locally owned firms in the host countryn this points will be revisited in a later section.

According to Blomstrom and Kokko (1998: p. 248), spillovers can be classified into two broad categories - productive spillovers and market spillovers. Produt spilloners come about when domestic firms are able to improve their productivity as a result of forward or backward linkages with subsidiaries, they may imitate subsidiaries' technologies, on hire workers trained by subsicliaries. The increase in competition that occurs as a result of foreign entry may also be considered a benefit, in particular if it forces locally owned firms to introduce new rechnology and work harder. Market spillowers come about when as a result of MNCs export operarions, they pave the way for locally owned firms to enter the same export makkets, either because they create transport infiastructure or because they disseminate information about foreign markets that can be used by domestic firms. MNCs often possess strong competitive advantages in entering world markets, such as experience and knowledge of international marketing, established international distribution networks, and lobbying power in their home countries.

According to Griliches (1979), spillovers can be classified into two distinct categories rent spillowers and puw spillowers. Rent spillowers could be associated to the exchange of goods. The work by Coe and Helpman (1995) provides a good evidence for the existence of rent spillowers. From their anallysis they found existence of such spillovers linked to (bilaternl) international trade flows among countries. According to Griliches, putw spillowrs could be thought of arising purely from the process of knowledge generation - such as through R\&D. Stated differently, prre spillowers occur when the innovator fails to scope full benefits from his innovation. Some of the innovator"s benefits spills over to other firms; sometimes including rival and competing firms, with a possibility of raising their existing stock of knowledge upon which new innovations could be based. The mechanism through which por spithower occur are diverse and include imitation and reverse engineering, labour mobility (such as $\mathbb{R} \& D$ staff). Other mechanisms include exchange of information, skills, ideas and information in meetings as well as conferences, industrial espionage, etc. Romer (1990) is a typical example of an existing analysis that attempted to model pure spillaver of knowledge.

As various researchers and analysts in the spillover literature seem to suggest, activities of subsidiaries in a host country tesult in positive spillovers of different kinds affecting locally owned firms that may be vertically integrated with subsidiaries ot in direct competition with them. Spillovers from foreign investment improwe the allocation of resources among productive sectors in host countries. However, as noted in the spillover literature most of the spillower benefits have been observed in the context of developed 
or advanced developing countries. Litde about such benefits is actually known about FDI in context of underdeveloped countries. This does not mear that subsidiaries of MNCs do not exist in the underdeveloped countries. Actually thete are many subsidiaries already existing in such countries either because of existing markets (windows of opportunities), raw materials, cheap labour and sometimes to tap on existing skill. As an example in Sub-Saharan Africa - Kenya in the Eastern Africa region has had many subsidiaries of various MNCs, which came into Kenya in the early years of her independence. Kenya served as an excellent regional manufacturing base to serve an existing regional matket in the whole of Eastern Africa, part of Central and Great Lakes region in Africa and ewen countries included in the southern Africa. Availability of raw materials mainly agricultural and readily available cheap labour served as addition factors towatds attrateting subsidiaries to Kenya. Despite the fact that these subsidiaties are more technically efficient and thus more competitive, it would be expected that locally owned firms in Kenya drop out following existence of efficient subsidianes. Howewer though this does happen, many locally owned firms still survive the pressure of these subsidiaries and in fact continue their operation alongside these subsidiaties and in the same industries. This perhaps makes it an interesting case considering the competitive pressure usually presented by the subsidiaties, yet most domestic firms survive. It is fascinating therefore to look at the cases where they have survived to ry and understand the changes, technological, that take place in the locally owned firms and how they undergo the process of undertaking these changes and the like. Of importance would be to find out whether spillovers from FDI have any impact in any of these processes.

Although subsidiaries therefore exist in the underdeveloped part of the world we have no idea as to how their spillovers conrribute to the development of domestic technical efficiency. It would be ironical to argue strongly, as is done in the spillover literature that since the presence of FDI in the industrialised wotd results in positive benefits, the same would happen with certainty in the underdeveloped countries. Thus expecting that FDI would introduce competition, transfer complex technology that enhances productivity and marketing performance in locally owned firms automatically without paying attention to the cost incurred or even the tacit wature of technology involved is problematic given the wide variation of issues, conditions, instruments and institutional structures characterising the underdeveloped countries. Studies on FDI in underdeveloped economies might not always lead to findings similat to those in developed and advanced developing economies, moreover, studies condated in the advanced countries depict: wide variations in definition and conceptualisation of spillovers, as well as differences in methodological approaches employed to analyse the existence of spillovers and their effect. The result is that the literature often presents conflicting findings of spillover occutrence and spillover effects even among advanced countries.

\subsubsection{Types of Technological Spillovers - Modes of Occurence}

Several case studies have shown that technological spillovers from the activities of MNCs to locally owned firms may occur through various modes/channels ${ }^{12}$. Four main channels are identified in the literature. These include competition, human capital labour turnover, linkages and demonstration effects.

is Rewiews of such studies are Lall and Streeren (1977); Lall (1980); Blomstrom and Kolko (1997); Blomstrom, Kokko and Zejan (2000); Saggi (1999); Pack and Saggi (1997); Kokko (1994); Rasiah (1995); Rasiah and Gachino (2005); Tommaso (1998) and Lan (1996). Also various papers presented in Cantwell (1999) and in Moran, Gratran and Blomstrom (2005). 
MNCs possess specific proprietary assets, which enable them to compensate for the problems associated with operating in afferent country's enwironment [Hymer, 1960 ; Caves, (1974: 1982); Dunning, (1973: 1993), Buckley and Casson, 1976; Cantwell, 1989; Lall, (1978: 1980); Rasiah, 1995; Narula, 1996]. These Ownership advantages are in the form of superior process and product technology, organisational skitl, managertal practices and knowledge, global exposure to dynamics of intentional markets, superior network structures that accord MNCs an edge over the locally owned firms. Due to these artributes of MNCs, they exhibit oligopolistic characteristics, characterised by increased product differentiation, high R\&D and advertising expenditure (UNCTAD, 1997: p. 140). Quite often, these MNCs will have come from oligopolies already operating in their home countries and would hence enter the domestic markets of host underdeveloped countries as very strong competitors to the indigenous firms. Their entry puts automatically competitive pressure on the domestic firms inducing them to enhance their capabilities through increased technological learning - competition spillovers. If the domestic enterprises are relatively small, weak, and technologically lagging far behind the MNCs, the MNCs might force these firms out of market attaining oligopolistic market power [Blomstrom: 1986; Wang and Blomstrom, 1992). The importance of a country's sustained competitiveness is that it may force the MNCs to import or bring newer technologies from their parent companies in otder to compete and keep their market shates and profit. Hence, spillovers due to competition are only substantial when the locally owned firms in a host country pose competition to the foreign firms. Blomstrom, Kokko and Zejan (1992) have shown that local competition was positively related to the technology import of foreign owned affiliates and thus the higher the competition, the higher the spillovers will be.

Since MNCs exploit state-of-the-art technologies requiring skill levels that are higher than those used by locally owned frms, they are mote likely to offer training to their staff more than the locally owned firms. This amounts to human capital development whose results could be human capital spillovers in future. As opposed to the privately-locally owned firms, human capital investment is a priority for the MNCs (Patibandla and Petersen, 2002). At the same time employees of MNCs may acquire skills, tacit knowledgre, attitudes and ideas just by doing routine work in a firm that conforms to international production standards - this however does not always follow. Human capital spillowes occur due to the mobility of workers or labour turn-over from MNC affiliates to domestic firms hence diffusing knowledge and skills. This channel of technology transfer is quite unique from the others in that it involves technology embodied in the workers as they move between firms, in this case from foreign firms to the locally owned firms or when employees of MNCs leave their jobs to form their own firms (Donnithome and Allen, 1957; Rasiah (1994: 1995)]. "This kind of spillover is infuenced to a great extent by the level of absorption capacity in the firms ${ }^{13}$. It should be noted however, that if $\mathrm{MNCs}$ decide to raise their wages and pay 'efficiency wages' to productive employees in their foreign affiliates, this can serve to some degree as a disincentive to worker mobility. This argument is supported in the literature by studies that found MNCs to offer higher salaries - efficiency wages - than locally owned firms do [Mazumdar, 1995; Aitken, Harrison and Lipsey, 1996; Velde and Morrissey, 2001; Lipsey and Sjoholm, 2001;

\footnotetext{
1.9 While labour curnover is likely to be an effective mode of technology transfer in NCs, it may not be the same in other developing regions including Africa. The NICs are characterised by a relatively high degree of absomption capacicy, competitiveness, entrepreneurship, supportive policies and an enabling scientific infrastructure. When workers in NICs leave MNCs, they prefer to establish their own firms contraty to wotkers in other developing tregions who would perhaps opt to join already cstablished finms, The rapidit with which aach mechanism impacts spillover diffusion is still unclear.
} 
Patibandla and Petersen, 2002:. Since MNCs have resources and superior technology that erable them to compete successfully with domestic firms, sometimes through market distortion, MNCs would then have an incentive to limit technology diffusion to their local competitors through such mechanisms. Actually labour turn over spillovers, are difficult to determine empirically since as we would expect, data on mobility of the labour force is hardly kept - speciffcally on mowement of workers between firms in an industry or country.

However, we do have evidence of labour turnover in some negions, Gerschenberg (1987) examined MNCs and the training and spread of managerial skills in Kenya. His survey included 72 Kenyan managers, where 28 were employed in subsidiaries of multinational firms, 19 were from joint ventures, 16 from locally owned firms and the remaining from publicly owned firms. He observed that MNCs offered more training of various sorts to their managers than private locally owned firms do (Gerschenberg, 1987: p. 934). About $16 \%$ of managers in about 91 jobs considered covered in the study had moved from MNCs to locally owned firms thus contributing to the diffusion of know-how. An example provided in IIn and Rasiah (2003) elaborated how the development of the information hardware industry in Taiwan relied extensively on the technology transferred from MNCs. From the onset, these MNCs were characterised by heavy technology transfer that was widely supported by a strong domestic institutional development. There was also increased employment of the locals in the MNCs. As a result, there was tremendous accumulation of human capital in the 1970 s to the locals working in MNCs who acquired tacit and experiential knowledge. Over time, relocation of human embodied capital from MNCs to the locally owned firms helped stimulate the growth and development of domestic firms in the same industry. Examples cited in (Saggi: 1999, pp. 23.4) provided additional evidence of labour turnover spillovers. He cited an example where Korea's Daewoo supplied Desh Bangladeshi firm to manufacture and export garments) with technology and credit. Eventually, 115 of the 130 initial workers left Desh. to set up their own firms, or to joirn other newly established garment companies. The speed with which the former Desh workers transmitted their know-how to other factories demonstrated the role labout turnover could play in technology diffusion. A similar example is cited where in the mid 1980s, about fifty percent of all engineers and approximately sixty three percent of all skilled workers that left $\mathrm{MNCs}$, left to join locally owned Taiwanese firms.

We now tum to linkages. Linkage spillovers occur through either upstream linkage or downstream linkage. The former takes place when MNCs establish linkages with local suppliers [Hirschman, 1958; Lall, 1980; Rasiah, 1995; Rodriguez-Claire, 1996; UNCTAD, 2001; Belderbos, Capannelli and Fukao, 2001; Smarzynska, 2003). MNCs may help prospective suppliers to set up production facilities, provide technical assistance, ptovide information to raise the quality of suppliers' products or to facilitate innovations, provide training and help in management and organisation. Spillovers of this kind usually contribute to raise the productivity and efficiency of the local supplying firms. The downward stream is when MNCs establish links with customers. The benefits of such linkages arise for instance when a MNC producing machinery and equipment offers after sales services beyond the usual advice on how to use and maintain the purchased equipment. A third kind of linkage is between MNCs and their technology partners. These allow for the shating of information and exchange of knowledge and ideas.

Demonstration effects occur when locally owned firms may adopt technologies introduced by foreign firms through imitation or reverse engineering. Due to the 
ownetship adwantages of the MNCs, they are likely to bring new knowledge, management and marketing skills as well as new marketing chamels to a host comtry where locally owned firms observe these innovations and imitate then adapting them to their needs - dexnowrtation spillowers. It is correct to atgue that, by exposing supenot technologies to the locally owned firms, FDI increases the set of arailable technologtes to the locally owned firms as far as they are geographically located in a common location - close proximiry. When an export oniented MNCs commences operations in a host country the locally owned firms may be prompted to enter the exporting business. This is partly due to reduced uncertainty and cost of searching for new export markets and netwotks that the locally owned firm might enjoy as a result of the ptesence of MNCs. We can therefore argue that without FDI, it may be costly for domestic firms to acquire the information needed to adopt new technologies if they are not first introduced into the local economy by MNCs. While MNCs possess state of -the-att skills in the management and organisation - and other forms of corporate governance - the level of such skills in LDCs furms is low and in dire need of upgrading. So, following the entry of MNCs into a host country, locally owned firm may copy their management and organisation skills. It has been noted that MNCs prefer to mansfer management techniques rather than production techniques to locally owned firms since the former are not specific to a given business and thus are not critical core capabilities. One major characteristic of the spillovers through demonstration effects is that they take place unconsciously without active involvement of the MNCs. This factor coupled with the fact that demonstration effects ate never reconded makes it rather difficult to analyse their effects empirically. It would be very difficult to control for other effects of FDI on market structure in such an investigation. The number of demonstration effect studies therefore, is limited to only a few case studies and in a few regions of the world. This limits our understanding of the importance of demonstration effect in stimulating the technical efficiency.

\subsubsection{Technological Spillovers and Foreign Presence: A Critical Analysis of Issues}

In this section we undertake a critical review of the spillover literature. Rather than review all the papers, we focus our attention to only important studies with a focus on developing countries. Analysis of these papers will allow us to critically examine and highlight the main arguments articulated in the spillover literature and subsequently offer our own cuticism. A notable observation in the spillover literature is that the distribution of studies examining technological spillovers from MNCs and their effects on a host country are skewed to the developed economies and the NICs. Part of the reason fot this could be lack of adequate statistical data in underdeveloped countries that hinders empirical verification of theoretical hypothesis on technological spillovers. Nevertheless, studies on technological spillovers in general hawe been inconclusive in terms of overall direction and magnitude of the spillovers. Some of these srudies have found either positive or weakly positive spillover impacts of foreign presence on the productivity of locally owned firms. Several cases also exist that found no positive spillover impacts. lack of conclusion in the spillover studies could be attributed to diverse methodologies used including measurement problems as well as firm, industry and country specificities.

Technological spillover occurrence can be determined by the interaction of economicsocial and policy conditions, which include among others technological and market conditions as the main factors. The analysis undertaken below will focus mainly on technological and market conditions beginning with level of foreign presence in a host 
country, techmology gap between foreign and locally owned firms, trade orientation, equity participation with locally owned firms and absorption capacity in a host country. An avalysis of endogenity phenomena will also be undertaken in this section followed by emerging issues and conceprual tramework to the study. In the context of technological capability development in indigenous firns, the teview undertaken points to an existing caveat: evidence that the literature does not look critically at the impact of spillovers on innovation thus neglecting learning, capability building and innovation. Even then, only a handful of spillover literature exists that focus on the underdeveloped countries. In addition to the spillover literature, the conceptual framewrotk defined will be based on the literature on technological innowations, NSI, which emphasises the importance of interactions, in knowledge generation, utilisation and diffusion. This will be overlapped with the literatute on cluster and networl dynamics both considered critical elements in interactive-knowledge flow, accumulation of tacit knowledge, leaming and innovation.

\subsubsection{Technological Spillowers: Foreign Presence and Productivity of Domestic Firns}

A study of intra-industry spillovers by Caves (1974) is one of the earliest known on technological spillovers that attempted to test for certain potential benefits of FDI to a host country. According to Caves, investment by foreign firms resulted in various gains to host countties. For instance, host country governments, obtained tangible benefit in the form of corporate income tax collected from foreign firms. Host countries also benefits due to the effects of FDI on the value productivity of resources owned by the host economy. Gains to domestic firms in a host country depend on spillover gains that lead to productivity, such occurs in the course of subsidiaries' operations in the country.

Caves attempted to measure directly the impact of foreign presence on labour productivity in the Australian manufacturing sectors using the production function framework. His hypothesis was that a large presence of subsidiaries in an industry would in the long run induce a higher technical efficiency and speed up the transfer of technology to competing domestic firms. He therefore attempted to test the effect of multinational competitors on the technical efficiency of host country furms and the transfer of technology to them. A set back in his analysis was that of little statistical data avallable, limited to only 23 manufacturing industries covered. The main finding was that foreign presence in Australian manufacturing industry was characterised by positive technological spillovers that enllanced technical efficiency in the domestic firms raising their productivity.

Although this study had the expected results that spillovers existed due to the presence of foreign investment it can can however be argued that the general conclusion of technical efficiency from such spillowers in a country may not always be justified. This can be clatlenged in a sense in that spillover benefits might have resulted following the disappeatance of weaker firms leaving only the efficient domestic firms. Also in addition to data limitation that included a very short time span, the study uses data in a very aggregated format hence trearing the industries, sectors and firms uniformly, which may not be the case. Industries, sectors and firms ate characterised by high levels of heterogeneity with significant differences in technological capabilities and capacities to undertake technological learning and absorption. "The technologies used by foreign firms in various industries also differ widely in terms of complexity, which imply that rechnology grap between foreign firms and locally owned fitms ought to have been considered. The study failed as well to take into consideration the selectivity bias 
problem, it could be true that foreign fums chose sectors which are dymamic, innowative and presumably operating in such sectors would be wewed profitable. Lastly but wery important problem was that the study did not explicitly analyse the mechanisin of spillower occurrence and diffusion to the locally owmed firms. Learning and technological changes were treated as 'black box'. Thus the conclusion of technical efficicney is rather too general to warrant our making any deductions of how locally owned firms in a host country benefit in their technological development effort from the foreign firms.

Despite the shortcomings in Caves' (1974) study, several other studies have reported similar findings. We will only examine a few of such studies. A model by Koizumi and Kopecky (1977) found that when foreign investment is made in a host country, technical knowledge is transmitted in the form of externalities or 'spillovers'. Their model builds upon the standard model of long-tem international capital movement, which investigates patterns of economic development in a country in the presence of free capital mobility. Their major critique of the standard model was that it failed to distinguish the role played by FDI in a country's development. Koizumi and Kopecky argued that direct investment possessed superior know how and managenal expertise, which enabled the MNCs to reap profits upon investment in host countries. This is similar to the arguments by among others Hymer 1960; Caves (1974); Dunning (1973: 1993); Buckley and Casson (1976) and Lall (1980). Further, direct investment was likely to transfer intangible assets such as technical skills to the host country and that these new ideas could occur through discussions, observation and training and tend to diffuse throughout the country's economy. "They argued that transmission of foreign technical knowledge could be viewed as spillowers or externaliries (public goods) since MNCs could not fully apptopriate retums from them.

One of the assumptions in their model was that capital owned by $\operatorname{MNCs}\left(K_{f}\right)$ could be taken as a proxy for the technical know-how transferred by the foreign firms to a host country - this was a questionable assumption. The total capital stock for the borrowing conntry becomes $K=K_{f}+K_{n}$ where $\left(K_{n}\right)$ is the pottion of capital owned by the domestic country residents. They introduced the foreign capital into a host country's aggregate production function of the form:

$$
Q=\Psi\left(\frac{K_{j}}{L}\right), G\left(K_{j}+K_{n}, L\right)
$$

Where $Q$ represents output by all firms in the country; while 1 represents labour. The technological transfer function in this model is defined by $\Psi\left(\frac{K}{L}\right)$.

They further assumed that technological spillovers were directly proportional to the extent of foreign ownership of a country's capital stock, thus:

$$
\frac{\partial \Psi}{\partial K_{f}}>0
$$

Viewing spillowers as public goods meant that matginal social return (MSR) for both foreign capital and domestic capital would be different. This is easily observed by 
differentating the specification of the techrological transfer function (2.1) above, to obtain the marginal products as follows:

$$
\begin{aligned}
& \operatorname{MSR}_{\mathrm{n}}=\frac{\partial X}{\partial K_{n}}=\Psi G_{K} \\
& \mathrm{MSR}_{i}=\frac{\partial X}{\partial K f}=\frac{\partial \Psi}{\partial K_{f}} G+\Psi G_{K}
\end{aligned}
$$

Where $\mathrm{MSR}_{\mathrm{n}}$ and MSR, are the marginal social returns on national and foreign capital respectively.

The term $\frac{\partial \Psi}{\partial K} G$ represents effects produced by the transmission and dissemination of foreign technical know-how in the host coumtry. It is this component that makes foregn capital have a higher marginal social return than the capital owned by the residents, hence $\mathrm{MSR}_{\mathrm{f}}>\mathrm{MSR}_{\mathrm{r}}$. Because of the nature of technology (public good), it was difficult for foteigners to capture this component. The conclusion from this model was that when a foreign investment is made in a host country technical knowledge is transmitted in the form of externalities or "spillovers". A major shortcoming of this model begins with the assumption that the technological spillovets were proportional to the extent of foreign capital in a host country. This reduces technological spillovers to a mere transfer of capital. This would not be the case to the LDCs especially when the technology gap between the two countries is wide. The model did not take LDCs absorption capacity into considention. This is important since technological spillovers do not occur costlessly, much effort is needed and consciousness.

Globerman (1979) investigated the spillover benefit to Canadian mamufacturing industries employing the same methodology as in Caves (1974). His results indicated a positive relationship between labour productivity of domestic firms and the presence of foreign firms implying positive spillovers which were responsible for the increase in technical efficiency and productivity in locally owned firms. Similarly, Blomstrom and Pearson (1983) used industry level data to investigate whether technical efficiency of Mexican plants derived from spillover efficiency associated with FDI. Assuming that MNCs represented adwanced technologies they questioned whether such technical knowledge in one way or another gets transferred to domestic plants owing to the mere presence of MNCs. Blomstrom and Pearson observed that spillover efficiency benefits occurred in a host country through vatious channels. Such channels include competition, training of labour and management, or investment in human capital, which may then become available to the economy in general. Another possible source of spillover efficiency benefits is that MNCs may speed up the transfer of technology to firms in backward countries. As a contrast to locally owned firms, a central activity of MNCs is technology transfer. This may stimulate domestic firms to hasten their access to a specific technology, either because they would not have been aware of the technology's existence, or because they would not have felt it profitable to try to obtain the technology in this manner (Blonstrom and Pearson, 1983: p. 494).

Contrary to the studies analysed some less optimistic, empirical firm level studies exist and based on total factor productivity which suggest that the effects of foreign presence 
are not akways beneficial to the locally owned firms. We will analyse some of these studies (tecent developments) beginning with Haddad and Hartison (1993) whose study differed from others in two main aspects. First, the study amployed s comprehensive empirical data set at the level of individual firm over several years. The data set came from an anmual survey of all the mamuacturing firms in Morocco. Secondly the study used detailed information on the level of quota and tariff protection to investigate wherher lack of spillovers stemmed from a tendency of foreign fims to move towards protected sectors. Following the same line of thought as in Caves (1974) Globerman (1979) and Blomstrom and Pearson (1983), their hypothesis was that when knowledge or new technology embodied in foreign firms is transmitted to domestic firms it would tresult in higher productivity levels and growth rates for domestically-owned firms in sectors with latge foreign presence. They first examined the influence of foretgn presence on the dispersion of productivity levels, then the influence of foreign presence on the growth of productivity for domestically owned firms and finally the effect of foreign presence on the technology gap and the level of protection.

The tesults of dispersion showed that the share of each firm's assets that are foreign owned had positive and statistically significant coefficient. "This supported the idea that joint ventures would exhibit less deviation from best-practice productivity relative to domestic firms. The sector level analysis showed that smaller deviation from maximum productivity levels existed in sectors with large foreign presence evidence that productivity dispersion was smaller in sectors with many foreign firms. This could be explained to be due to greater competition induced by the foreign firms, causing firms that cannot approach the best-practice frontier to exit the industry. The effect of foreign presence on the rate of productivity growth showed that foreign investment in the sector level was negative and statistically significant. The hypothesis that foreign presence accelerated productivity growth in domestic firms was thus rejected. This would perhaps be due to distortions in the trade policy regime or due to the short time period analysed. A similar study using plant level data to investigate the effects of foreign investment in Utuguayan manufacturing industry had a similar conclusion. Kokko, Tansini and Zejan (1996) noted in their statistical estimations that the effects of foreign presence was not significantly different from zeto, which implied that foreign presence did not have any substantial impact on local productivity, there were no signs of spillovers.

Despite the fact that this study utilizes a different technique from others "dispersion on productivity", the basic principals of total factor productivity are still maintained and thus the study shares the same shortcomings as in the other studies discussed above: the difficulty in determining how the foreign furms contribute to the increase in locally owned firms' technical efficiency in an underdeveloped country. Though the study was quite innovative in the wide coverage of isstes, the assumption of large foreign presence in a firm or sector and the coincidental large productivity do not reveal fo us the mechanism in which technical efficiency come about. Large productivity could be due to specific sectors characteristic of heary capital investment with large imports of capiral or it could be that the foreign firms select such sectors due to some existing aclvantages (e.g. conducive business climate) that would allow high profit. A case study would perhaps have been an appropriate addition to the study to investigate whether imitation, interaction, labour turn over and technological learning do take place in the locally owned firms.

As a conclusion to this section we note that most of the studies adopted the production function technique whereby total factor productivity proxied by value added per 
cmployee in the locally owned firms, was the dependent variable. The value added per employee is taken as a function of the corresponding shate of foreign presence amongst other varables. As noted elsewhere productivity technique has a major draw back in that it assumes that adoption of technologies would "automatically" lead to an improvement in rechnical efficiency followed by productivity in a firm or sector. The linear regression techniques employed in all these analyses provide correlation between variables, which should not be taken as causality. In depth analyses ate necessary to understand mechanisms in which the indigenous furms learn and buld their capabilities with reference to Foreign firms. For instance does the technology gap (technology complexity) deter locally owned firms from absorbing, learning and copying foreign technigues? Given the tacit, imperfect understanding and uncertainty of technology we need also to understand how existing networks and linkages, local capacity building effort, interactions and co-operations among firms and institutions facilitate the technological spillover occurrence and their assimilation, to support innovation. Existence of foreign firms alone, single factor exponentiation, is not enough and neither magnitude of their presence nor capital should be taken to reflect the occurrence of spillover efficiency. This is one major caveat with the above approaches. It could be possible to demonstrate that technology imports of foreign furms may be larger in countries and industries with high level of human capacity, tongh domestic competition, and where the host country imposes minimum formal requirements on foreign firms' operations. We add that though such transfers ate necessary for spillovers to occur they should not be taken as sufficient in their own right.

As a general conclusion to this section, the "single factor" exponentiation' or paying. attention to foreign presence alone can be challenged when considered alone in the analysis of spillover effect. This is a rather too natrow approach as it disregards all other factors and is thus likely to be problematic, as does the assumption of automaticity particularly when trying to understand the mechanism and process of spillover.

\subsubsection{Technological Spillovers and Technology Gap}

An examination of the literature on the impact of MNCs activities on the technological development of domestic firms reveals two divergent wiews on the relationship between technological spillovers and technology gap. One of the views argues strongly in support of a wide technology gap as a necessary condition for indigenous firms to achieve higher levels of technical efficiency by leaming and imitating from foreign firms. On the contrary, the other view asserts that a widle technology gap constitutes a major obstacle to technological spillovers, by deterring the ability of the domestic firms to catch up with foreign lirms. In this section, we will discuss the two views including their implications for the technological development of locally owned firms.

Among the proponents of a wide technology gap, as a necessary condition for domestic firms to catching up was Findlay (1978) who constructed a simple dynamic model of technology transfer through FDI from developed to the developing countries based on the Veblen and Gerschenkron ${ }^{14}$ catching-up hypothesis. His hypothesis was that:

\footnotetext{
Werschentwon (1962) and Kuznets (1971) were particularly poptalar in the 1960 sund 1970 for endorsing the so-calliod "advaratages of backwardness". Their argument was that a technologically laggard country had a major advange in that it would only be reguired to borrow' new technology from the leading edge comarnes at the technology frontice. This is thowever quescionable from technological innovations school of thought in that much cfot is required to fully master toreign bechngues given the tacit and imperfect understanding nafure of technology. Mone so, huge resources ane required to train human capital, dewelop
} 


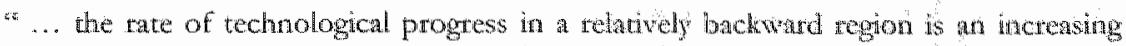
function of the gap berween its own level of technology and that of the advanced region which improves at a constant rate, and the degree to which it is open to ditec foreign investment, measured by the proportion of foreign capital operating in the backwird region to domestic capital in that region" (Findlay" 1978: P. 2).

For Findlay, the wider the technology gap between the developed and developing country, the greater the pressure for change within the developing country. Hence, the growth rate will be faster as long as the disparity is not too wide to deter the learning process. Findlay assumed that spillovers could occur through personal contacts accomplished through MNCs and similar to the spread of a contagious disease.

The model categorized the world into two distinct regions, 'advanced' and 'backward', by assigning a technological efficiency index to each region. Taking $A(t)$ as an index of technology efficiency - such as the aggregate production function, in the developed country, he postulated that technological efficiency in the advanced countries increased at a constant rate $(n)$ and according to the function"

$$
A(t)=A_{0} e^{n t}
$$

Supposing $B(t)$ was the analogous level for the developing countries, the VeblenGerschenkton catching-up hypothesis can be put as:

$$
\dot{B}=\frac{d B}{d t}=\lambda\left\{A_{\theta} e^{n i}-B(t)\right\}
$$

In this case, $\lambda$ is a positive constant whose size depends on exogenous factors such as level of human capital, technological capability and other productivity determinants. We can interpret this to mean that at a given point in time, if MNCs from the advanced countries transfer and use their technology in the developing countries, then the bigger the technology gap between MNCs and the domestic furms, the higher the spillovers will be. These are the spillowers that will be responsible for the convergence between the two countries.

Findlay further based his argument on past work by Mansfield (1961) whose postulate compared well to the contagion theory. Mansfield showed that in a given industry an innovation was adapted at a rate, which was an increasing function of the proportion of furms within the industry that had already adopted the innovation. Similatly, Findlay hypothesized that, holding other things constant, the rate of change of technical effuciency in the developing country was an increasing function of the relative extent to which the activities of foreign firms with their superior technology pervade the local economy.

Considering $K_{f}(t)$ and $K_{d}(t)$ to represent the capital stocks and $A(t)$ and $B(t)$ the technical efficiency levels in the adwanced and developing countries respectively it can be defined:

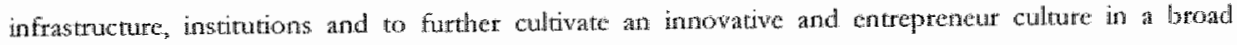
national innowation system. 


$$
\chi \equiv \frac{B(t)}{A(t)}
$$

and

$$
\gamma=\frac{K_{f}(t)}{K_{i}(t)}
$$

Combining the relative backwardness and contagion hypotheses, it can be postulated that:

$$
\frac{\dot{B}}{B}=f(\chi, \gamma)
$$

With $\frac{d f}{d \chi}<0$ and $\frac{d f}{d \gamma}>0$

The model shows that catching-up by locally owned firms is a function of technological gap and foreign presence i.e. for a given amount of foreign ptesence, the amount of spillover is larger the bigger the technology gap between the foreign and domestic firms. Simillarly for a given technology gap, spillovers increase with the degree of foreign presence. Findiay's model compares to Abramovitz (1986) catching up model in some aspects. According to Abramovitz

"... Countries which are technologically backward have potentiality for generating growth more rapid than that of more advanced countries, provided their social capabilities ate. sufficiently developed to permit successful exploitation of technologies already employed by the rechnological leaders" (Abramovitz, 1986: p. 390 ).

While the two models focus mainly on technology gap, Findlay's model does not consider the social capability (absorptive capability) of the backward country. He emphasises that the degree of technological progress is dependent on the openness of the economy as measured by the level of foreign presence. Abramovitz on the other hand does not focus on foreign investment; his model is more concerned with "technology borrowing by followers". Abramovitz' model however, underscores the importance of interactions via trade and rivalries, population movement, capital flow and flow of knowledge.

Findlay's postulate though interesting in its argument that a wide technology gap would create high pressure for catching-up process to take place, can however, be challenged on two grounds. First, is that a number of studies have indicated the importance of a certain threshold lewel of technological capability in a country in order to transfer and assimilate the spillovers (Lapan and Bardhan, 1973: p. 585). Lapan and Bardhan's simple model of technology choice by a developing country showed that an advanced technique would only be employed in a developing country if its efficiency was high and had a small capital intensity difference from a technique altready in use in the developing country. Second, some of the technologies exploited by MNCs in LDCs may not be appropriate (less suitable) and hence spillovers may not arise. This argument compares to what 
Abramovicz (1994) refers to as "lack of technological congruence. An example is when a complex technique from an advanced country is complicated hence creating obstades that reduce the possibility of spillovers, imitation and technological leaming in the domestic firms. Lapan and Bardhan (1973: p. 585) nored that technical advances and technologies applicable to the factor-proportions of capital-rich developed countries ate hardly of any use in improwing techniques of low capital intensity in less dexeloped countries ${ }^{13}$. This is due to the large difference in technology gap.

Contrary to the above, a study by Cantwell (1989) found that technological spillovers were most important in industries where the technology gap was small and that a wide technology gap deterted the ability of the domestic fims to cath up with the foreign firms. Cannwell (1989) examined the responses of locally owned firms to the entry and presence of U.S. MNCs in the European markets in the period 1955-1975. He used shate of trade manufacture and performed simple regression using observations on local exports and U.S. inward direct investments - capital in the manufacturing. He observed that the impact of these MNCs on the locally owned firms was not beneficial unifomly in all industries. Technological spillovers occurred mainly where locally owned firms wete initially relatively strong enabling them to challenge the invading U.S. affiliates. Weaker locally owned firms had either been forced out of business, or confined to limited segments of the market that were neglected by the foreign MNCs. Haddad and Harrison (1993) had comparable results in the case of Morocco. An extension to their study, discussed above, categorized the sectors into high and low technology. The elfect of FDI at the sectoral level was found to be more positive in low-tech sectors. The authors interpreted these results as indicative of the lack of absorptive capacity on the part of locally owned firms in the high-tech sector, where they may be further behind multinationals and unable to absorb foreign technology. Other studies that supported a relatively small technology gap for technological spillovers to take place include $\mid \mathrm{Kok} k \mathrm{k}$ 1994; Kokko, Tansinil and Zejan, 1996; Sjoholm, 1997].

The studies investigating the empirical relationship between technology gap and technological spillovers suggest that wide technology gap diminishes technological spillower. A long run implication for these results would be greater divergence and inequalities between economies. While a technology gap is necessary if the follower is to learn from a technological leader, it can be argued based on the findings from the studies discussed that a country lagging behind can only absotb knowledge from a technological leader if the initial gap is not too wide. The technological gap must not be below a certain threshold level. According to evolutionary economics, growth of knowledge is highty cumulative and path-dependent. Incremental stock of knowledge to a firm or industry depends on prior accumulated knowledge and technological learning is facilitated only if the stock of knowledge grows Romer, (1986: 1990); Cohen and Levinthal, 1990; Benhabib and Spiegel, 1994J. This point emphasises the need for a technologically backward country to accumulate some knowledge at least above a certain threshold level. This point is extended briefly in the next section.

A small technology gap however, should not be riewed as sufficient for spillover to occur. As was discussed in the preceding section, a host of other heterogeneous factors

\footnotetext{
15 L apan and Benhabib were snggesting that the wechology gap in terms of capital inensity neoded not be: too wide. They cited ransport technology as an example where improvements modern jev aircraft technolog do not particulaty help raising the productivity of rick-shaw-pullers in the strets of Calcutra or Hong Kong.
} 
intluence the effects of foreign investment on domestic economy. They include otganisation of knowledge communication between various research organisations or the linkages within the domestic systems of innovation, level and organisation of a councry's homan capital, technology imports, market conditions and government intervention. Beforc concluding this section we would like to mention that analysing the relationship between technology gap and technological splllovers in the context of underdeveloped countries would shed some light into the foreign investments contribution to technological leaming and capability development of the domestic firms in a host country. For instance, if we assume that domestic firms in a given sector or industry are able to leatn by imitation or copying techniques demonstrated to them by foreign firms, then we can assert that the exusting technology gap permits technological spillovers and thus technological innovation occurrence.

\subsubsection{Technological Spillovers and Foreign Equity Participation}

With the increased perception that FDI. transfers technology into a host country, most governments in the underdeveloped countries have in the last few decades tried to work out policies articulating modalities and frameworks within which MNCs can operate so as to integrate their activities with those of domestic firms. Some of the measures introduced encourage MNCs to ransfer technology and/or to engage in equity partnership with locally owned firms, mostly in the form of joint ventures (JVs) ${ }^{16}$. It is anticipated that JVs may offer advantages to firms on both sides of the relationship. Usually, it is argued that doing business in underdeveloped countries is risky and at the same time developing country markets are becoming much more open to intermational competition. To meet these challenges, it is important to position the firms in such a way as to become more competitive. One way of cloing so is to complement a firm's strength through strategic alliances such as JVs (Miller, Glen, Jaspersen and Karmokolias, 1996: pp. 4-6). Besides minimising costs, sharing management and financial risk, a host of several other aspects prompt firms to form JVs. They include lack of country familiarity, lack of relevant contacts within the government and elsewhere, existing facilities and more effective technology use (Gomes-Casseres, 1989; Blomstrom and Zejan, 1991).

This notwithstanding, empirical studies have demonstrated a mixed scenario while some find much evidence of positive spillovers from equity participation others report little or no evidence at all based on level of analysis, industry and country. We shall analyse only a fow studies in this section. Aitken and Harrison (1999) used annual census data on over 4000 Venezuelan firms to measure the productiviry effects of foreign ownership. The study found a positive relationship between foreign equity participation and plant performance. This implied that there were productivity gains, which could be attributed to foreign equity participation. Surprisingly, the results however, were the inverse of what was normally expected. Domestic firms in sectors with more foreign ownership were found to be significantly less productive than those in sectors with a smaller foreign presence. In orher words, they found evidence of negative spillovers from FDI and suggested that such negative spillovers could tesult from a market stealing effect: foreign competition may have forced domestic firms to lower output and theteby forego economies of scale. Nevertheless, adding up the positive own-plant effect and the negative spillovers, on balance, the study found that the overall effect of FDI on productivity of the entite industry was positive though quite small.

\footnotetext{
16 Defined as " ... a common project between legally and commercially independent companies in which the parties jointly bear the responsibility tor management and the financial risk (Miller, Glen, Jaspersen and Karmokolins, 1996: p. 2)"
} 
Similar results were obtained for Indonesa where Blomstrom and Sjoholm (1999) conducted an empirical analysis based on Indonesian establishment dati to determine whether the type of foreign ownership had any effect on productwity and the degree of spillowers. Thex: study primarily sought to answer the following questions: first whethet establishments with minority (OVs) and majority ownership (wholly owned subsidiaries) differ in terms of their productivity levels? Second, whether the degree of technology spillovers varied with the extent of foreign ownership? Their analysis was based on the assumption that MNCs would prefer to have joint ventures with locally owned fims especially when local partners possessed better knowledge of local conditions. Local participation with foreign firms may reveal some of their proprietary knowledge, which would occur through various trainings in foreign firms or by gathering experience at work. These aspects are likely to influence technology diffusion thus facilitating. spillovers. The results showed that foreign establishments had a comparatively high level of labour productivity and that intra-industry spillovers from foreign investment existed in the Indonesian manufacturing sector. Labour productivity in domestically owned establishments varied with the degree of foreign presence. However, the degree of ownership neither affected the labour productivity in foreign establishments not the degree of spillovers.

In the Czech Republic, Djankov and Hoekman (1998) investigated the inpact of foreign investment on the productivity performance of firms using information on Czech enterprises compiled from a survey and from a data base containing financial and ownershp information in the Czech Republic. They estimated a production funcrion using total factor productivity as a proxy for technology transfer. Their assumption was that adoption of new technologies would, with some lag in time, lead to an improvement in productiviry. They found a negative spillover effect. Greater foreign participation in an industry had a statistically significant negative effect on the performance of firms without foreign linkage (pure firms). When they excluded JVs from the sample, testricting their attention to the impacr of majority owned affiliates on all other firms in an industry, the negative effect lost statistical significance.

An explanation could be that JV firms invested significantly more in technology capacity than purely domestic firms did. Purely domestic firms might have lacked the ability therefore to absorb the rechnologies introduced by foreign firms. In support of this point their survey data showed that $18 \%$ of the firms without foreign partners, answered in the affirmative to a question on whether workers had undergont awy training in the past two years. JVs and majority foreign equity firms had 47 and $60 \%$ respectively that answered positive. Another question investigating whether furms had obtained any new teclowology ${ }^{17}$ in the previous two years found that $70 \%$ of the majority foreign equity and 50 percent of the JVs had acquired some kind of technology. Only 35\% of the locally owned firms without any foreign ownership linkages had acquired some new techniques.

Ftom the above analysis we note that foreign establishments uswally have a generally high level of labour productivity. Labour productivity in domestirc firms varies with degree of foreign presence i.e. existence of a positive relationship between foreign equity participation and plant performance. Intra-industry spillovers from foreign investment exist - productivity gains, which could be attributed to foreign equity participation. It was also noted that greater participation in an industry had no effect on locally owned firms with no foreign linkages. In the context of the developed countries, as was

\footnotetext{
17 New technology was detned here as Machinery, equipment or telated lifnowledge.
} 
observed in the case study discussed above, equity partnetship thus appears to be beneficial for locally owned firms. Nonetheless, a few questions sill remain unanswered. The questions stem from the fact that the stuclics focus on productivity and use variables which measure captall intensity as much as they do productivity gains failing to indicate for instance any learning or innovation in a dynamic and continous way. Investigating some of the questions through case studies may be very help full. Such questions include; to what extent and under what conditions does equity participation lead to positive spillovers? Can these spillovers stimulate firms to lannch a spirited technological effort, which would enthance their technical efficiency? To what extent can the same spillovers benefit a wider social and economic netwotk? We appreciate the fact that benefits of equity particijoation may be negative and transitory in the short run in the case of underdeveloped countries, but a throbbing question remains as to wherher positive effects are likely to be permanent to counter the short-run transitory negative effects in the long run.

We would argue that equity participation by MNCs may reveal some of the MNCs proprietary knowledge and expose various skills, which may in the long-run spillover to other firns and sectors. As noted, foreign firms exhibit a high level of productivity, this productivity advantage of foreign ownership might increase the stock of human capital if domestic wortkers absorb this advantage through training, learning-by-doing, learning-byusing and learning by performing. Over time, this advantage might eventually spillover through labour mobility, firm interactions, demonstation and so on to other firms and sectors of the economy. In this aspect, further work is needed to improve our understanding of the role and possible effects of equity partnership on technological spillovers. Such studies are badly needed in the context of underdeveloped countries where both empirical analyses and case studies are scarce. Results of studies conducted in other developed ot advanced developing countries may not hold for underdeveloped countries and thus such studies cannot be generalised. While hypotheses and arguments may be justified, the methodologies and variables used in developed countries might bring a distorted image of how things are likely to be in underdeweloped countries.

\subsubsection{Technological Spillowers and Absorption Capacity}

d.ow levels of absorption capacity in the developing countries have been heavily cited in rechnological spillower literature as one of the main obstacles to the effective spillover occurrence from foreign firms to domestic firms in host countties. A sufficient level of absorption capacity is necessary to enable a firm to recognise the value of new external information and knowledge and to be able to assimilate and exploit it for various means including commercial purposes (Lapan and Bardhan 1973; Cohen and Levinthal: 1990, $\mathrm{P}$ 128; Benlabib and Spiegel, 1994) . Many innovations exist outside the firm, which could be a source of knowledge splllovers that might bring new changes to fimms existing products, processes and organisational structures. These changes in turn conild lead to improvements in allocative efficiency to a firm and sometimes the entire industry. While it is necessary fot the firm to be able to adopt and assimilate these spillovers, a firm has to be able to utilise this knowledge, improve and adapt it to the prevailing conditions. The dynamic models that investigate effects of limited absorptive capacity in LDCs

whe study by findlay (1978) suggesting that the rate of technological externalioy from FDI is an increasing function of the technology gap between the 'backward" region and the 'adwanced" region secms to contradict the importance of absorptive capacity. Similarly, Wang and Blomstrom (1992) wodel, which predicts a posivive relationship between the degree of spillovets from FDI and the size of the technology gap between MNCs and domestic firms. 
emphasise the significance of access to knowledge and human capacity to absonb this knowledge. Keller (1996) argues that before a regine change, for instance structural adjustments and liberalisation of trade, it is necessary to have accumulated adequate killi and at much a higher rate than before. With trade liberalisation in an economy, new technologies and goods are likely to flow in and the accumulated skill enables firms to absorb some of these knowledge and technologies (Keller, 1996: p. 202-3).

The main determinants of absotption capability are human capital, R\&D activities, organisation of the $\mathbb{R} \& D$ staff and organisation of knowledge communication betweet various research institutions and other supporting organisations ${ }^{19}$. Absorptive capacity is generated in several ways: Fint, firms that conduct in-house R\&D are in a better position to exaluate and utilise external knowledge as opposed to the firms that do no R\&D. Inhouse R\&D makes a firm acquire and accumulate basic knowledge and skills. $A$ positive relationship between imported technology and in-house $R \& D$ has been found to exist and both of them play a complementary tole (Siddharthan, 1992: p. 267). However a recent study gives a confirmation of a substiturion view (Basant and Fikkert, 1996: p. 195). Logically a firm that has been conducting in-house R\&D is better placed to detect new external knowledge and its value than a firm which does not undertake any R\&D. Thus when a firm invests in $R \& D$ we can assume that in the process it creates absorption capacity. Second, absorption capacity is gradually developed in a firm as it engages in its manufacturing activities and finally by taking the personnel for further technical taining.

Borensztein, Gregorio and Lee (1995) examined empirically the role of FDI in the process of technology diffusion and economic growth in developing countries. "Their empitical work stemmed from a model of endogenous growth, in which technological progress was a major determinant of long term growth rate in income. Technological progress took place through a process of capital deepening that involved introduction of new varieties of capital goods and advanced technology. According to the model, introduction of such technologies depended highly on the absorptive capability in a host country. The logic of the model was that foreign firms possess advanced knowledge and a higher productive efficiency, which allows them to introduce new capital goods into a developing country at lower cost. Application of these technologies would require a sufficient level of human capital in a host economy, in which case, below such levels the absorptive capability of host developing countries would be too limited to warmant any technology transfer and diffusion to take place. The study used data on FDIf from International Financial Statistics and Balance of Payment Statistics ${ }^{2}$.

The main results indicated that FDI had a positive overall effect on economic gtowth and that the magnitude of this effect depended on the stock of human capital available in the host country. High productivity of FDI held onlly when the host country had a minimum threshold stock of human capital. Interacting FDI with human capital showed that countries with low levels of human capital had a negative effect from PDI. "The conclusion was that: Since MNCs possess advanced techniques, knowledge and skills, which enables them to introduce new capital goods, accumulation of absorptive capacity

\footnotetext{
19 See Rewew in Cohen and Leviruthal (1990) and Lankhuzen (1996).

${ }^{20}$ Data on national accouncs, such as growth rate of incombe, intial income and government came from Summers and Heston. (1991). The data on human capital stock variable was obtained from Barro and Les (1993) while data on other explanatory warables like domestic investment rate, foreign exchange, pollitical instability and financial development were also taken from Barto and 1.ee (1994). Estimatons were done using ragressions.
} 
is necessary before $\mathrm{FDI}$ can contribute to economic growth. Flow of advanced technology brought along by FDI can increase the growth tate of the host economy only by interacting with the countries absorptive capability - presence of a sufficient level of humar capital in the host country. Jack of these limits the absorptive capability of a dereloping country.

\subsubsection{Endogenous Spillowers: Competition, Demonstration and Interactions}

In this section the focus is upon the endogenisation principle which takes into consideration the subsidiaries'effect and effort by locally owned firms together as equally important in the process of spillover accurrence. This would take place as both kinds of firms learn from each another in the cause of their interactions within an economy or as they engage in the process of dynamic competition. According to the spillover literature, the traditional approach seemed narrowly defined in focus: attention was only accorded to one side concentrating on subsidiary as the sole determinants of spillover occurrence. This grossly neglected the effort by the locally owned firms at any moment, while in actual fact; locally owned firms at least make an attempt to learn, imitate or copy some of the production or processing techniques demonstrated to them by the foreign firms. In a bid to understand the difference between the traditional approach to spillovers and the current endogenous approach, we shall present one of the carly studies done by Caves (1974): where entry of foreign firms into a host country helped break existing monopolies leading to improvement in allocative efficiency. This will be followed by the discussion on endogenous process.

Caves (1974) study is tegarded as one of the earliest empirical studies on spillovers that attempted to do an in-depth analysis on the effect of foreign investment on allocatiwe efficiency in an industry. He argued that if foreign investment did occur, a horizontal kind of FDI was expected where subsidiaries of MNCs would take place in industries producing the same goods as the parent companies and that these parent companies were usually oligopolies that were chatacterised by high product differentiation and large scalle. As a consequence of this, Caves argument was that the subsidiary, an established firm in "the same industry in a foreign market, enjoys adwantages that render the barricrs to entry, and potential monopoly rents, lower in such inclustries than they would be in its absence". Caves view was that allocative efficiency occurted when subsidiaries helped break existing monopolies and introduced competition in the local industries - this would be presumably expressed by the profit rates of locally owned firms being inversely welated to the comperitive pressure supplied by foreign firms. He therefore hypothesised that the compatinive pressum would be propottional to the share of an industry's sales controlled by subsidiaries.

The results of Caves hypothesis that subsidiaries help break existing monopolies by introducing competition leading to imptovement in allocative efficiency in domestic firms made fundamental contributions to the spillover literature and most other studies conducted afterwards on spillovers have either emulated his approach or attempted to werify his postulate. More recent studies done on FDI have attempted to endogenise spillovers by introducing leaming, comperition and interaction in their analysis. Among the early studies done on endogenous spillovers was that by Das (1987) and Wang and Blomstrom (1992). Das (1987) constructed a model where firms in a host country learn from the subsidiaries of the MNCs who transfer new technologies to their countries. The MNC is taken as the dominant firm (price leader) facing competition from the locally owned firms, viewed as a competitive fringe. She postulated that technological leaning 
by the locally owned firms increases theit technical etficiency and that at any given point in time the cate of productivity growth in the locally owned firms was directly tared to the output of the MNCs. In other words, the increase in technical efficiency by the locally owned firms was positively related to the scale of operation by the MNCs. This inctease in technical efficiency reduces the average production cost for the locally owned fims. Given that locally owned firms are likely to leatn from the MNCs, it reduces levels of MNC profits as well as market shares. To mantain their share of the market and atio of profits, the MNCs bring in new technologies to counteract increased competition by the locally owned firms. The conclusions drawn from this model is that although a technology leakage may exist; MNCs may still find it profitable to transfer new technology and the more the technology is transferted the mote the spillover increases. Similar to Findlay (1978) model, Das" model reflects the contagion kind of spillovers where relative activities of subsidiaries and their interactions with locally owned firms are key factors in determining the amount of spillovers to the latter.

The assumption that locally owned firms learns from the subsidiaries of MNCs and secondly that increase in technical efficiency by the locally owned firms would be positively related to the scale of operation by the MNCs makes Das model an interesting one in the perspective of underdeveloped countries. The model shows the limit to which one can count on spillovers from MNCs. Das model differs slightly from Wang and Blomstrom's (1992) model discussed below in that it is more pracrical in case of underdeveloped countries where small-scale industries are characterised by low capacities $^{21}$ that do not facilitate immediate or automatic learning from the MNCs. Given that these firms" level of accumulated technological capability is low, it requires much effort before any effective learning can take place. If the complexities of a technique exploited ate high, this would imply a wide technology gap that would affect interactions and learning process in the small scale industries.

Wang and Blomstrom (1992) used a similar argument as in Das (1987) but employed a deeper mechanism by endogenising technology transfer and investment in learning activities by both foreign and domestic firms. They constructed a model of interaction between MNCs and locally owned firms in a host country where techwology: transfer tbrough multinational firms emerged as an endogenised equilibritu phenomenon, resulting from the strategio

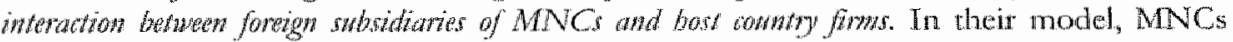
increased their transfer of high technology and new knowledge the more the locally owned firms invested and improved on their technological learning function. Wang and Blomstrom's model was based on a duopoly with differentiated goods wherc competition among firms was structured as a Cournot game in which each firm solves its individual dynamic optimization problems subject to the other firms' actions. The objective of the MNC would be to choose how much to invest in imports of new technology while locally owned firm's objective would be to decide how much to invest in learning to imitate MNC rechnology, given that both know the other party's decisions and/or intentions. The model will be discussed briefly beginning with definitions to the main variables considered:

$I_{f}$ : The resources devoted to the transfer activities (imports) by the MNC firm.

$C_{f}$ : The cost of transferring technology (impotting) by the MNC firm.

$I_{d}$ : The domestic firm's investment in learning.

21 Capacity of various forms: Absorptive, technological, financial, human, institutional and so on. 
$C_{d}:$ The actual cost of leaming (imitang) incurred by the domestic fims.

The main assumption of their model is that, there is no free copying of technolagy in the world. Seafching for information, imitation and personnel training et cetera make Learning costly and time consuming and thus determination of how much resource to devote to learning is an essential investment decision. Another assumption was that a wider technology gap gives MNC"s products quality advantage that translates into higher profits because it can take out a higher price or captuie a larget matket share, whereas the profit of the locally owned firm is negatively related to the size of the technology gap. Aso technology gap between the firms grows as new technology is imported, but diminishes as a result of the locally owned firm's learning efforts and finally that some spillovers proportional to the size of technology gap always take place irrespective of the locally owned firm's active learning efforts.

The utility function was specified as follows:

$$
U(Y)=U\left(\sum_{i} G_{i} Y_{i}\right), \text { where } G_{i}(r)=G_{i}\left(K_{i}\right), G^{\prime}\left(K_{i}\right)>0, i=f, d
$$

Whete $Y$ is the industry output index, $Y_{i}$ is an observable firm $i^{\prime \prime}$ s output. $G_{i}$ is the attractiveness of the $i^{\text {th }}$ firm's product, which depends on qualities embodied in the product. It is assumed to be an increasing function of the furm's technology level, $K_{i}$.

Taking $G_{i}\left(K_{i}\right)$ to be represented by a power function $K_{i}^{\alpha}, \alpha>0$. They assumed a utility function of the following logatithmic form:

$$
U(Y)=\alpha \ln K_{d}+\ln \left(Y_{d}+k^{\alpha} Y_{f}\right)
$$

Where $k=\left(\frac{K_{f}}{K_{a}}\right)$ is the technology gap between the foreign and the domestic firms. Demand for the goods is obtained by setting price equal to the partial derivative of the consumer's utility function as follows:

$$
\begin{aligned}
& P_{d}\left(k, Y_{d}, Y_{f}\right)=\left(Y_{d}+k^{\alpha} Y_{f}\right)^{-1} \\
& P_{f}\left(k, Y_{f}, Y_{d d}\right)=k^{d x}\left(Y_{d}+k^{\alpha} Y_{f}\right)^{-1}
\end{aligned}
$$

This implies that the prices faced by each firm depend on the quantities of both fims and the relative artractiveness of the product is detemined by the technology differences between the two firms. This attractiveness is determined by the technology difference (gap) between the two firms and hence by the logic of their model, the bigger the technology gap the higher the price and quantity sold by the technically leading firm MNC. According to their model, technological capability, $K_{f}$, is augmented by devoting resontces to transfer activities.

$$
\dot{K}_{f}=l_{f} K_{f}
$$

Speed of technology transter is proportional to the foreign firm's commitment to the transfering activity. The locally owned firm's technology level is assumed to be an 
increasing function of its learning invesment and dximishing tetums occurs as the lewning effort increases with time. They incorporated Findly (1978) hypothesis, that the tate of technological progress in a relatively backward country is an increasing function of the technology gap between the two.

$$
\dot{K}_{d}=\phi\left(I_{d}\right) k K_{d} \quad \phi^{\prime}>0, \phi^{*}<0, \phi(0)=v>0
$$

Combining equation (2.15) and (2.16), we obtain an equation that depicts the changes in the technological gap over time.

$$
\dot{k}=\left[I_{f}-\phi\left(I_{d}\right) k\right] k
$$

Equation (2.17) or the "Irangfer-absomption prowss", demonstmates an interesting point, where the two firms play an equally active role in determining the size of the technology gap and thus the convergence spillovers. Given that the strategies of one firm influence the decision of the other, competition related spillovers are also genetated.

(a) The objective of the foreign frm is to make a choice of $l_{f}$ that maximises the discounted value of its profit stream $V^{t}$ subject to the transfer-absorption process, considering the learning effect by the locally owned firms.

$$
V^{f}=\int_{j}^{\infty} e^{-r y}\left[R_{f}(k)-C_{f}\left(I_{f}\right)\right] d,
$$

Whete $R_{f}$ represents profit and $r$ is the discount rate, used by the foreign firms.

(b) The objective of the locally owned firms is to decide the amount of $I_{d}$ which will also maximise their objective function.

$$
V^{d}=\int \ell^{-\rho t}\left[R_{d}(k)-\theta C_{d}\left(I_{d}\right)\right] d,
$$

Where $R_{i l}$ represents profit and $\rho$ is the discount rate used by the firms and $\theta(>0)$ represents efficiency of the domestic firm's learning investment. Finally, the two sets of problems are solved by intertemporal optimisation techniques, which employ the Hamiltonians procedure. One major difference between this model and those by Koizumi and Kopecky (1977) and Findlay (1978) is that, while their models were based on the convergence and contagion hypotheses, Wang and Blomstrom's model was based on endogenous competition between MNCs and the locally owned firms. Regarding contagion effect the model did not show any relationship that ties technological spillovers to penetration by the foreign firm on the host country. Nevertheless, the model had an interesting observation in that amount of spillovers were not determined by the degree of foreign presence alone as; the firms" own investment were also impottant.

Among the interesting findings of this model was its recognition of Teece's (1977) Findings, that intemational technology transfer is costly, tequires extra resources and effort, for instance learning in the firms. If learning by doing existed in the firms, the 
technology transfer costs tended to diminish with the frequency of transfers. According to this model both fortign firms and locally owned firms devote tesources to undertake technology transfer and to learn new technologies respectively. The more the resources are utilised by the locally owned firms, the more they improve their absorption capacity for the foreign technologies and the more they increase their potential for capturing the spillovers. As locally owned firms rise in their technology learning function, they gradually reduce the technology gap existing between them and MNCs. This induces competition in the industry prompting the subsidiaries of MNCs to inport new and efficient technologies from their parent MNCs so that they can protect their market shares and profits. Assuming that locally owned firms will have developed adequate capabilities, when MNCs import new technology, locally owned firms would leam or imitate it once it leaks or gets demonstrated to them. This poses further increase in comperition pressure to the MNCs and the cycle continues. Compared to the Das (1987) model, Wang and Blomstrom model is more limited to the firms whose technical level is already high. In underdeveloped countries it would be applicable to industries where firms have developed technological capability over time; then they can compete with subsidiaries in the cournot game being proposed in the model.

The endogenous principle based on Wang and Blomstrom (1992) has been applied in several empirical studies [Blomstrom, Kokko and Zejan, (1992: 1994); Kokko 1996]. Blomstrom, Kokko and Zejan (1992) used unpublished data from Mexican manufacturing industry to examine how rivalry in host country markets affects $\mathrm{MNC}$ technology transfer to their foreign affiliates. The results obtained supported the existence of positive correlation between local competition and the technology imports of foreign owned affiliates. According to their result it would then seem obvious to expect that when the foreign firms are faced with continuous competirion they are more likely to continuously import their technology. In other words, the decision to transfer technology to their foreign affiliates is influenced by the performance of competing firms in the host economy. Contrasting results were obtained in a policy study by Kolkio and Blomstrom (1995) who investigated the determinants of technology imports of USA majority owned foreign affiliates in 33 host countries using data from the USA department of commerce. The study examined whether policies increasing the level of competition in the host country were likely to erode the MNC affiliate's technological advantages and force them to import new technologies from their parent companies. Similar to the above study, technology imports of MNCs affliates increased with the comperitive pressure in the host countries. A recommendation from the study was that host country govemments need to support local inwestment, competition, and education mather than embarking on measures to control and secure FDI inflows of technology to the affiliates of foreign MNCs.

Blomstrom, Kokko and Zejan (1994) extended their 1992 study by including labour skills in their investigation. They investigated whether market rivalry and availability of skilled labour could force MNCs to transfer more technology to their foreign operations. Similar to their previous study, the results obtained indicated a statistically significant relationship between technology importation by foreign affiliates and local competitor investment and output growth. The level of technology imports was positively correlated with the proxy for labour skills in the affiliates' industries. However, when the industries were classified into consumer goods, intermediate goods, and durables and capital goods, the effects of the competition proxies were particularly strong for consumer goods and intermediates. This seemed to suggest that MNCs are sensitive to the local environment when barriers to entry in the form of advanced technology or high capital requirements 
are relatively low. Sjoholm (1997) arrived at similar conchsion after investigating how domestic competition affects spillowers from foreign investment in the Indonesiat manufacturing industry. His results showed that spillovers from $\mathrm{FDI}$ had positwe effects an prodnctivity growth, which differed between different industries i.e. spillovers existed in industries with a high degree of competition.

While the hypothesis, arguments and findings of all these studies look plausible, they should however not be generalised to all categories of developing countries. Developing countries ate not homogenous and differ in diverse ways. Besides social and cultural differences developing countries have wide disparities in income and development capabilities. The Asian - NICs which were until recently classified as developing countries like Korea, Singapore or Tawwan cannot be compared to countries in subSahata Africa like say Zambia, Malawi, Tanzania or Kenya. While these countries are still highly poor, underdeweloped and lie at the bottom in the technological capability line up, the NICs have accumulated a sizeable amount of technological capability which enables them to acquire and master new rechnologies they adopt from advanced nations fast enough to challenge MNCs. The firms in these countries went through tigorous process of many trials and errors coupled with lots of uncertaintes, factors that required high entrepreneurship spirit, innovation and willingness to learn.

Most of the NICs, from the outset relied on various mechanisms of international technology transfer for instance import of capital goods, licensing, FDI and so on to deepen their technology base. Some of these countries removed import bartiets in certain industries and sectors for strategic purposes, mainly the import of capital goods and specific technologies that could bring in new knowledge or could serve as soutces of new learning to the domestic firms. [For a detailed insight Asian experience see Fransman, 1985; Amsden, (1989: 1994); Chang, 1994; Lall, 1996; Kim, (1988: 1997)]. This enabled the firms to acquire capabilities to imitate, replicate and teverse engineer products from other inclustrialised countries. Participation in the export market forced these firms to learn and increase their technological effort in order to compete effectively? in the world market ${ }^{22}$. As an example, these countries participation in the global commodity chain framework as exporters made them master the dynamics of the buyerdriven commodity chains. While some of the these countries were able to shift from a mere assembly of intermediate goods assembled elsewhere to a high value added exports that involved original equipment manufacture (OEM), still others like Japan went ahcad to manufacture original brand names (OBM) and to design and market them intemationally. This is attributed to the ability to establish linkages with the lead firms in the buyer driven chains, which serve as a source of technology and knowledge spillovers. [Gereffi, (1994: 1999: pp. 38-40)].

Over the past four decades, NTCs have transfomed themselwes from technologically backward and poor to relatively modern economies. In these countries many firms ate now able to produce technologically complex products competing effectively with $\mathrm{MNC}$ rivals both in their countries and outside - Europe and US. The successful technological and industrial development in these countries can be attributed to the policy dynamics that were created and the policy instruments used with the right timing and sequencing; facilitating the technologicai leatning process (Kim, 1997: pp, 1-60; Kim, 1988: p. 19-29;

22 Participation in export matkets stimulated and supposted strong and dynamic learning in wo ways: First by introducing pressure to compete in international matkes the entreprencurs were made to pay atmention

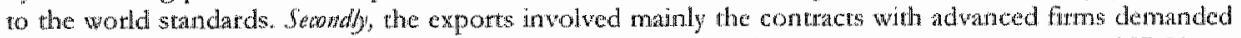
High performance and provided assistance to achicve it (Westphal, Kum and Dahlman, 1985: pp. 137..50) 
Amsden, 1989; Chang, 1994; Wade; 1990, Mytelka, 1998: pp. 2-6). Some of the key elements in the policies that helped to shape the incentive systems in successful NICs by promoting leatning and technological capability building wete: Fint, policies that promoted prior improvement of the humam resources before launching the process of industrial development. Technological capability is embodied in people and hence it is essential to have a pool of wel-trained personnel, such as managers, scientists and engineers. Stowd, given the low technological capability at the outset, these countries relied heavily on foretgn imports of technology - capital goods and turnkey plants. A few of them restricted FDI and foreign licensing at the inital stages. This policy of restricting FDI and fortein licensing coupled with the improved level of human capacity and the entreprencurial spirit of the people encouraged the learning process at the firm level. Third, policies that brought about appropriate sequencing of events in the technological development, for instance production capability was developed first before investment and innowation capabilities (Kim and Lee, 1987). Fowrth, although these countries protected their infant industries, they strategically allowed competition so that pressure could be exerted on the firms to learn and acquite capabilities steadily in competition among firms. Fyally, policies that supported investment in the necessary technology infrastructure mainly indigenous $R \& D$.

This marks an important difference in terms of technology policies, although underdeveloped comntries did have technology policies in place, they were however not very effective in promoting technology effort to develop capabilities domestically. Examples of such circumstances can be traced, where although technology was transferred by vartious means; technological effort to develop capabilities domestically failed to exist, a factor that limited the ability of locally owned firms to remain competitive over time. A study by Mytelka based on technology licensing in the Andean group found that technology licensing resulted in continued reliance on foreign technology, which she referred to as a "tedonology dependency syzdrome" (Mytelka, 1978: p. 449). This resulted from the loss of opportunities for various forms of technological learning to take place in the locally owned firms. This supported the arguments made by the proponents of "new-marxists dependency theories of economic development" [Baran, (1957: 1975); Amin, (1973: 1976: 1977); Frank, (1973: 1978)]. This phenomenon reduced domestic technological capacity building and weakened the competitiveness of these firms. Technology dependience came about due to the preference accorded to the foreign technology and skills by the entrepreneurs in those countries. In addition to being capital intensive and sometimes inappropriate, these technologies lacked social optimality despite the fact that they may have been rational in the view of private enterprises (Cooper, 1973: pp. 6-13). In the case of textile industry in Cote d'Iroire and Kenya, firms were protected, relied on a capital-intensive mode of production in an atmosphere of minimum domestic competition and technological apprenticeship this led to dapendence on expatriate technical personnel, and to some extent, on imported inputs (Mtytellka, 1985: p. 117).

Turning to our point, and in light of the examples cited, it is possible to conclude that in NICs domestic competition would force MNCs to import newer vintage of technologies in order to contain the competition pressure while in weak underdeveloped countries, this did not occur. "That is why we argue that this study would be applicable only in advanced deweloped countries. This should not be construed to mean that underdeveloped countries lack sectors and industries with similar characteristics to those in advanced developed countries. Though examples of capabilities exist in some countries (furmiture, textile and clothing industries in Kenya and Biotechnology in Cuba) 
their competence may not be at par with NICs and the suppottre environment-other firms, policies and so on is not strong. We would argue that competition posed by such firms is minimal. It is thus more relevant to inquire into the competition affects of MNCs and the interactions and technological effort of locally owned firms in the underdeveloped countries. That is, to what extent do locally owned fims embark on use of existing technological knowledge together with other resources to assimilate or adapt existing technology or to create new technology?

A better example of an empirical study based on the endogenous principle is that by Kokko (1996) who determined the effect of comperition in Mexican manufacturing industry by endogenising both the activities of foreign and locally owned firms. Contrary to the earlier hypothesis that productivity spillovers are strictly proportional to foreign presence, Kokko's argument was that spillovers from competition were not determined by foreign presence alone; the interactions between foreign and locally owned firms played an important role. He argued that markets in which foreign firms stimulated competition and interactions were high, promoted spillovers as opposed to situations where foreign firms dominate and with little or no competition with the locally owned firms. His two proposirions were that productivities of foreign and locally owned firms were whylaweowh - jointly determined because of competition and that competition had an independent effect on the productivity of locally owned firms, even after accounting for the demonstration and contagion spillovers that are related to foreign presence.

Given the argument for joint determination due to interactions, Kolko used simultaneous system of equations to capture contagion-type spillowers related to foreign presence as well as spillovers that are caused by competition. "The endogenous test showed positive results only when the industries characterised by enclaves were excluded. This finding compared to Kokko (1994) results where industries characterised by large foreign shares and large differences in labour productivity between foreign affiliates and locally owned firms formed enclaves that crowded out locally owned fitms. Interestingly, the results of the study supported both the hypotheses only when the subsample considered excluded enclaves - believed to be isolated preserves of foreign fims operations only. This study had a rather unique conclusion in that while past studies concluded that externalities were proportional to foreign presence this study concludes that spillovers from competition ate not determined by foreign presence alone, but raduer by simultaneous interactions berween foreign and locally owned furms.

One policy conclusion from this study was the support it gives to the need for local technological capability development in host developing countrics. Such countries should support measures that stimulate competition between foreign and locally owned fitms. While the findings and the policies from this study may be valid and interesting, we find them rather ambitious for many of the poor underdeveloped countries with fragile economies, weakly performing sectors with weakly enforced policies ${ }^{23}$ that failed to affect decisions to invest in capacity building. Most industries in these countries are technologically backward still locked into outdated traditional processing techniques in comparison to techniques used by MNCs. The firms in these industries are naturally

\footnotetext{
23 Such policies include; fiscal policies, policics related to payments for land, electricity and water (e.g. creation of industrial zones). Others include banking policies that affect lending policies and interest rates, educarional policies that support vocational schools and training programs for workers in factories, research policies that provide scientific and engineering support to local industry, business support service development etc.
} 
static chatacterised by unskilled labour, lack of strong entrepreneurship culture, matketing and maragerial skills. Following structural adjustments and globalisation pressure many underdeveloped countries embarked on privatisation and liberalisation measures some of them as early as 1980s. This led to the influx of many MNCs into most of these countries and surprisingly many countries like in sub-Sahara Africa and Latin America, two decades down the load, their domestic firms still cannot compete with MNCs.

As in the immediate studies above, it would be owerly ambitious to expect that firms in underdeveloped countries would pose competition in the short-run into foreign firms endowed with high skill in international production and marketing. Even in the case of

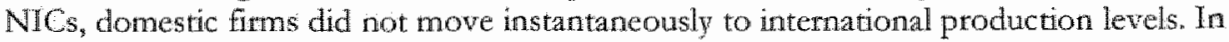
order to arrive at sound policy prescriptions for underdeveloped countries, we propose that studies on spillovers should first seek to address the following questions: What kind and/or nature of spillovers exist in the industries and what determines their occurrence? Whether interactions between firms exist, if so which industries and what is the nature of these interactions? Are the interactions induced and/or enhanced by MNCs? Do spillowers and interactions stimulate leaming in the locally owned firms? What about adaptations and minor changes (innovation) to imported technologies got from foreign Firms? Kokko's productivity approncly takes a high aggregate level of analysis and it is not quite clear how interactions take place, their contents and how they induce learning and innovation in locally owned firms. Koklso's mechanism as in other productivity studies clearly depicts a missing link in the development of technical efficiency in the underdeveloped countries. An in-depth study, in the form of a case study, wrould be ideal for underdeveloped countries if we ate to understand how spillovers lead to increase in technical efficiency and thus productivity in hosit country firms.

Our final study on endogenous effects analyses briefly a demonstration study by Aitken, Hanson and Harrison (1997) who used logit specification to investigate the role of foreign investment in enhancing export behaviour of the locally owned firms in a host country - whether MNCs act as export catalysts. The main thesis was that MNCs might produce spillowers that enhance export prospects of domestic firms. When some of the firms are already exporters they tend to reduce the entry barriers and costs for other firms willing to penetrate the foreign market. This could occur through demonstration, learning by doing and buyer-supply linkages both domestically and internationally MNCs link domestic firms to foreign buyers.

"... While MNCs may internatize some of the benefits of their activities through subcontracting or licensing arrangements, other effects, such as those related to demonstration or expanded cross-border trade, are more difficult to internalize, and may spill over onto neighbouring firms (Aitken, Hanson and Harrison, 1997: p. 4)."

The study utilised annual data on Mexican manufacturing plants for the period 19861990 supplemented with data from the 1986 and 1990 Mexico Industrial Census. The study was motivated by a model in which case the probability of expotting was a function of domestic and foreign output prices, factor prices and geographic concentration measures. They found that locating near MNCs exporters raises the chance of expotting for an individual Mexican manufacturing firm. They concluded that foreign owned firms acted as conduts through which domestic furms could distribute their goods. To this end foreign investors could directly or indirectly provide information and distribution services, their activities enhancing export prospects of locally owned 
firms. Case studies in other regions support the combined effects of demonstration and competion from MNCs on locally owned furms. In a study investigating the effect of FDI in the Kenyan soap industry, it was reported that entry of MNCs introduced mechamised production and packaging techniques, that made it difficult for the locally owned firms unable sell their handmade soap in the urban markets. In order to netain theit niche narket, they were forced to introduce mechanised techniques to stay in business. Simflarly, entry by MNCs in the Kenyan footwear industry led to increased competition and changes in the production technique (Langdon, 1981).

Benefits accruing from demonstrarion effects may not be enjoyed only by the locally owned firms in a country but could be extended to a wider social and economic domain. Unfortunately, on the social side when locally owned firms are adjusting to the demonstrated practices, they result in massive cuts in employment and reduction of unproductive deparments. This amounts to teduced income to the many employees who are rellieved as a result of the ensuing otganisational changes and rationalisation process. Given that firms in the underdeveloped countries rarely have the experience, financial resources, and human capaciries needed to develop new industrial technologies the number of small scale firms also reduces leaving only those which are capable of meeting the demands necessitated by the demonstration effects.

Assuming that certain technologies brought into a country by MNCs are targeted to engender growth, employment, local linkages or to engage in further innovation in developing countries attempts to copy and imitate such technologies are important. Since small scale firms in underdeveloped countries do not perform $\mathbb{R} \& D$ their learning by watching from demonstrated techniques, learning by doing and by using rather than producing ate often more relevant and important than basic research. This enables them to improve on their assimilation capability, to adapt technology to local conditions and to interact with other firms - vertical linkages. We conclude this section by arguing that demonstration effects may act as a trigger for the warious types of learning processes in the firms such as reverse engineering and imitative researcl and development. This we note will enable firms to improve on theit in house technological capability and subsequently their absorptive capacity, which will keep them abreast of the latest external technological developments and facilitate their further ability to learn and innovate.

\subsubsection{Technological Spillovers and Government Policies: Does the Level of Protection Matter?}

A few studies have been undertaken that attempt to detemine the impact of protective trade policies on the productive spillovers from the presence of MNCs in a host country. The trade policies involve protective instruments like quotas, tariffs and effective protective rates. The study by Blomstrom and Pearson (1983) found out that there existed some correlation between effective tate of protection (ERP) and foreign presence, however, ERP did not have a direct influence on the productivity of domestic firms proxied by value-added per employee in domestic plants. Haddad and Harrison (1993) used tariffs and quotas to classify industry into low and high protection levels. This did not support any technology spillovers. They found negative and insignificant relationship between the presence of trade barriers and the productivity of firms in Morocco. Similarly Sjoholm (1997) found no effect from the ERP on the degree of spillovers in Indonesia. 
In this section we endeavour to develop an altemative framework, which will guide the remaining part of the study. We will extract elements of technological innovations with a focus on learning and capability building. A systemic approach taking network cohesion as an impotant factor for knowledge gencration, exploitation and diffusion to a wider national system of innovation is considered to be extremely useful. Before the proposed alternative framework is presented, a brief discussion of the emerging issues from the spillover literature analysed is presented.

\subsubsection{A Brief Summary of Emerging Issues}

The foregoing litetature review on technological spillovers has demonstrated wide differences among authors regarding the conceptualisation of spillovers, methodologies for determining the effect of spillovers and in the findings of their studies ${ }^{24}$. Since the main focus in this thesis is on the occurrence of spillovers in locally owned firms, this section will concentrate on a number of weaknesses that characterised the spillover literature with regard to spillover effect on technological learning, capability building and innovation in locally owned firms. Three of these are of particular importance. First is a tendency towards single factor expontintion where a single factor was considered to be the only major factor in determining occurrence and effect of spillowers in a host country. Here we are referring to some of the early studies that focussed primarily on one factor such as foreign presence or equity participation.

Let us look at this point in more detall. Much of the early literature on spillowers held that foreign presence in a host country would in a way; automatically generate productivity spillovers, which would enhance the efficiency of locally owned firms [Caves, 1974; Koizumi and Kopecky, 1977; Findlay, 1978; Globerman, 1979; Blomstrom and Persson, 1983; Blomstrom, Kokko and Zejan, 20001. Total factor productivity was examined as a linear function of foreign participation and most of the empirical analyses were therefore based on such a framework. Regardless of this simplistic treatment in the traditional hypothesis however, spillover studies demonstrated mixed results, some of which supported the existence of efficiency spillovers but primarily in the developed countries. All such studies, moreover failed to provide a rigorous study of the mechanisms through which spillovers brought about inevitable technological changes, in terms of skills, knowledge and technological learning.

As was noted in the literature, most studies thus limited their scope of analysis to a high aggregate level that concentrated narrowly on productivity performance only. Nevertheless, the existence of such benefits in developed countries can be challenged since in most cases spillover benefits accrued simply because they were using data from developed countries where technology gaps were relatively small and were likely to result in spillovers unlike in cases where large technology gaps existed like in the underdeveloped countries. Another reason could be that local firms and the local system of innovation in such countries are relatively strong and thus have accumulated the necessary innovative and absorptive capacity needed to assimilate spillovers from foreign investment. At the same time, seemingly faulty methodologies, followed in most studies conducted in such countries resulted in spillover benefits because of their failure to measure the distribution of productivity and social gains within the entire industries or

24 Methodological (Gorge and Strobl, 2002:2003) and country characteristics (Lipsey and Sjoholm, 2004) 
economy-wide networks. In most cases when a foreign investment is undertaken thete are chances that the less capable domestic firms drop out or get replaced by foint ventures. Logically then if technological spillover is neasured by aggregate gains in productivity that include both locally owned firms and foreign firms, it does not make much sense to talk of spillovers to locally owned frms as the litetature implicity does. These points to another debate that is still very much open for further research mainly in the underdeveloped countries.

The second weakness observed in the spillower literature is that of awhomaticity or arogmety where spillowers and their effect were narrowly thought to occur automatically, making the mechanism and process of spillovers quasi-inevitable. The assumption of automaticity ignored the entire process of endogenous technological change placing technological learning, mechanism and process of spillover occurrence to the background. This weakness is implied in almost all the early and recent studies conducted based on spillover.

The thind problem trelates to the narow conceptualsation of spillowers. Foreign firms were the only one taken into consideration while analysing spillorers in these studies distegarding the role and effort of locally owned firms and other supportive factors in the local systems of innowation in a host country. No attention seemed to have been paid to the supportive and systemic infrastructure in which firms are embedded. Firms at times could be situated in localities with varying or no infrastructural or institutional support systems. The spillover literature thus lacks a rigorous articulation of the mechanism of how spillover effects occur particularly in so tar as their role in enhancing technological leatning and innovation that essentially leads to productivity increase in locally owned firms is concerned.

Regarding the last two weaknesses, we observed in the spillover literature that a narrow, linear and automatic conceptualisation of spillovers was not only restricted to cases. where the approach focussed primarilly on foreign presence. A similar problem was. evident in most other approaches, which concentrated on other factors like technollogy gap, equity participation and so on. These approaches, which also envisaged linear relationship between foreign investment and technological development of locally owned. firms in host countries, failed to recognise that technological spillover occurrence and their effect resulted from a combination of several factors, especially when tacit knowledge is involved. Contrary to the proponents of a linear relationship, those working from an endogenous and exolutionary principle argue that restricting the concept of spillovers to mean that a specific or individual unit originally produces all knowledge misses factors critical to what has come to be referred to as a leaming economy. These are networking, co-operation and learning-by-interacting - important elements that chatacterise successful technology capability building and innovation strategies (Lundvall and Botras, 1997). The learning process is socially embedded and organisational form and institutional set-ups are crucial to the outcome of interactions as emphasised in the national system of innovation.

In the spillover literature rexiewed, very few studies acknowledged that spillovers, do not: result automatically from foreign presence but rather from dynamic interactions among domestic firms, foreign firms and government policies [see some of the studies whider endogenans spillowers; Das, 1987; Wang and Blomstrom, 1992; Kokko, (1992: 1994)]. However, in cases where endogenous growth principles were employed, the approach proceeded more or less in an aggregate manner, using simultaneous equations solved 
empirically at an aggregate level, to depict firm interactions [see Kokko, (1992: 1994)]. As we have argued earlier, solving quantitatively a set of selected simultaneous equations can effectively caprure the mechanism and dyramics involved in the spillover process or its effects. The chatacteristics of spillowers are often unnoticeable, uncertain and sometimes complex, meaning that their effect can only be traced through a more complex and integrated system. Hence much effort must be put in place to understand the technological changes as a result of spillower occurrence as well as learning and capability building that might arise.

In technically underdeveloped countries, spillover estimation using quantitative data is not usually available and even if it does exist, limiting oneself to an aggregate level study would be misleading due to its inaccuracy and the wide gap between locall and foreign firms. One would have to get behind the aggregates to unearth the reality of spillovers by conducting systematic case studies at an enterprise level taking into consideration multiple issues from multivariate dimensions. For instance, this would have to involve among other things the size and age of domestic fums in the sector, their capacity to absorb new technology and to undertake dynamic changes. It would also have to consider the gap between their technology level (and the supporting structures in the economy) and the technological complexity of the technology brought about by a MNC subsidiary. It would have to consider the spatial distribution of firms, their production activities, whether they are located in an export-processing zone or in an industrial district and if so how the nature of their linkages influences spillover occurrence. An understanding of firm's prevailing trade orientation and labour market conditions would also be useful in the analysis. Testing for a specific set of conditions as was done in most studies does not allow us to see how these conditions interact to make learning and innowation possible in smaller domestic firms that sometimes do not even have access to the finance or the basic technology and management skills needed to change.

Based on the above, more empirical and theoretical work needs to be done taking into consideration an altemative approach. An approach that would enable us to assess what the influence of interactions, technological learning and capability development is in the accurrence of technological spillovers in the context of countries whose absorption capacity is particularly low. 'This will require a deeper knowledge of the role and importance of the local support system in the spillover process. It would also require a deeper understanding of the network dynamics and cortoborative linkages that exist in the industry and/or economy wide systems. The role of supportive infrastructure and institutions would hawe to be examined. The role of social capital, which entails social trust, norms and newworks of civic engagement would also have to be taken into considetation. We can regard social capital here as a set of horizontal associations between people, consisting of social networks and associated norms that have an effect on community productivity and well being. They facilitate co-ordination and cooperation and thus increase productivity by reducing the transactions costs of doing business.

In conclusion therefore, we believe that in the context of vast development in the endogenous, technological change and evolutionary literature, traditional linear argument is definitely flawed if taken to explain the occurrence of technological spillover from foreign firms to the domestic firms. This simplistic hypothesis tends to reduce technological spillovers to the presence of foreign firms or even foreign capital, making us fail to understand the actual effect of spillovers and real mechanism of how they occur. The process can be better anderstood from the lenses of evolutionary and 
instintionalist wew, which views firms not as isolated, static and pure economic agents, but rather as members of changing economic and sochalinstitutional henworks. In the next section we suggest an altemative framework, which will guide the cument study.

\subsubsection{Spillover Occurrence: Towards an Altemative Theoretical Framework}

Giwen the problems and weaknesses identified above with most studies conducted earlier, in this section we shall formulate an alternative theoretical framework, which we propose to use in examining the occurrence and influence of MNCs spillowers on locally owned enterprises. It is now clear that the occurrence and infuence of MNCs spillovers on locally owned enterprises cannot be properly explained using simple linear aggregate level analysis particularly in the case of non-pecuniary technological spillovers. Unike pecuniary spillovers, non-pecuniary technological spillowers ate exceptionally difficult to deduce from aggregate macro economic data [see Hirschman 1958; Rusiah, 1994] $]^{25}$. Such spillovers include knowledge flows that are invisible, imperfectly understood, determined by multiple factors, and difficult to tack and as such difficult to investigate. This is the more reason why a high aggregate analytical level fails to capture and explain effects of many other factors such as influence of the government policies and a variety of socialinstitutional factors such as cooperation, coordination and trust among entreprenetrs. Many other aspects are neglected including importance of networks and linkages to support structures such as productive centres, funancial institutions, research and academic institutions; all of which are important factors to consider when investigating spillovers. Transaction costs also become impotant for the promotion and furthert development of networks and linkages through contractual enforcement. It is garmane to argue here that only firm level analysis is capable of offering a well-grounded understanding of relationship among firms, including MNC influences on locally owned firms. This thesis shall therefore adopt a firm-level study procedure to examine the mechanism of spillover occurrence and their influence on local enterprises in the Kenyan industry. In this perspective, we present the critical concepts that will be used to guide this study.

\subsubsection{Clluster and Network Dynamics}

The theoretical framework we propose here is founded under a broad analytical framework, which we will refer to as cluster and nerwork dynamics. This framework emanates to a large extent from the industrial district concept, which was pionected in the nineteenth centuty by Mfred Marshall 1890. Marshall posited that an economy stood to gain, when enterprises within a particular industry clustered in close proximity to each other. As a consequence of this, individual firms rended to specialise in certain specific levels of production processes that led to greater division of labour and collectine ffriteng. Existence of a pool of specialised knowledge in the cluster, reinforced through a common set of culture and social walues created an industrial atmosphere for driving differentiation and division of labout (Young, 1928: 1994).

The framework on cluster and network dynamics has benefited from a multidisciplinary niche of approaches in social sciences. The framework combines a wide range of elements ranging from industrial organisation to social capital. Here we only discuss a few of these starting with transactions costs and institutional economics founded in the

\footnotetext{
25. For extra details on pecuniary and technological external cconomies emerging from manufacturing growth see Scitowsty (1964) and Rosenein Rodan (1964).
} 
industrial organisation theory with pioneering wotks by Coase (1937), Chandler (1961: 1977) and Williamson (1975: 1979:1985) among others. According to Chandlex (1961: $1977)$ the evolution and development of modern corporations depends on what he refers to as the visible hand of the hierarchy, which differs substantially from the invisible hand of the market in terms of tesource allocation. His argument is that the visible hand of hierarchical coordination and control catried out internally through direcrion outcompetes the invisible hand of market coordination. Chandler argues in favour of being big and mainly vertically integrated as one condition for al successful performance; by making it possible to stimulate efficient throughput, imnovation and development capabilities. However this notion of vertical integration has been criticised for its failure to explain some observed phenomena $4 . g$. growth or decline of most industries ${ }^{20}$. In the face of cutrent international competition, there is increased pressure of rapidly changing product designs and technologies, companies including big corpotations (including: MNCs) have resulted heavily on outsourcing/selling various components to other firms including (smali and medium enterprises). Such companies are left performing only key aspects of the production like initial design, funal assembly and final testing. This implies that in an envitonment that demands rapid new product introductions and continual technological change, no single furm can complete the design and production of most products on their own. That way, firms then gain flexibility to introduce increasingly sophisticated products faster by relying on nerworks of suppliers.

The tansaction cost theory by Coase"s (1937) and later by William"s (1979: 1985) emphasises that; matkets and hierarchies play important roles in coordinating: production. According to the rransaction theory, the choice between long-term contracts and a standard maxket transaction for the axchange of goods will depend on the costs and benefits of the former trelative to the latter. Put simply, a firm decides to contract when it gets to a point where the costs of organising an extra transaction within the firm are equal to the costs involved in carrying out the transaction in the open market, or, to the costs of organising by another entrepreneur. If the market for intermediate goods is prone to failure, because of small number problems, asymmetric information, asset specificity, uncertainty and irreversible commitment, then incentives for opportunistic behaviour can be reduced by intemalising or partially intemalising the transaction. Thus transaction cost theory becomes important in explaining inter-firm relationships. However, when such contraciual relationships emerge among firms, cooperation and market forces are necessary to facilitate production coordination (see Richardson, 1972 . 883-96). Richardson viewed an industry as a system of dense and integrated activities. Such activities included discovery and estimation of future wants, research and development, execution and co-ordination of processes of physical transformation and marketing of goods. These activities had to be carried out by fitms with appropriate capabilities (capabilities here refer to several things like knowledge, experience and skills) ${ }^{27}$. This seemed to extend Smith's specialisation principle where enterprises specialise in activities that use a particular capability and collaborate with other enterprises that specialise in complementary activities and thus stimulating networking activities as a means of production co-otdination that can stimulate resource creation of firms.

\footnotetext{
23 As noted in Best, 1990 Chandler"s analysis, as applied to Britain by Elbaum and Lazonick, does provide a compelling aecount of the decline of British industry, but it does not explain the decline of American industry, the rise of Japanese industry, or the international success of groups of small firms in Germant; Italy, and elsewhere that have been dominared by hierarchical organisation.

27 Richardson (1972) secmed to be extending an earlier idea by Edith Penrose (1995). According to Penrose the growth of the firm depended on resources and productive services, which Richardson refers to as activities and capabilities.
} 
The above process of stimulated networks of interdependent producers increases the opportunity to innovate in the firms by encouraging specialisation based on a combination of existing intemal technological capabilities and external knowledge, experience and skills in the form of extemalities. These extenalities are from the existing institutions and other firms e.g. competitors ot subcontmctors in the existing network of linkages and collaborations. However, being innowative can increase the probability of spillover occurrence ünto a firm as this depends on the absorptive capaciry of a firm, which tends to increase with the degree of innowativeness in the firm. This is the reason why we combine industrial technological innovation with the cluster and networti framework in our spillover analysis. Industrial technological innovation do not take place as a result of individual firms lone technological effort, if this happens it's only to a limited extent. Mary innowations ${ }^{23}$ and their causes exist outside individual firms and it is justifed to argue that a very tiny fraction of innovations at a given point in time do take place in firms compared to external imnovations. As will be discussed in the next section, technological innowations can therefore be visualised in an embedded systemic perspective where networls in the form of technology linkages and other collaborations could often influence their accurrence.

The frumework on clusters and network dynamics attempts to go beyond transaction cost framework, which placed markets and hieratchies as the prime coordinators of production. The literature on clusters and network dynamic posits that while transaction cost framework is useful in explaining inter firm collaborations the importance of "social

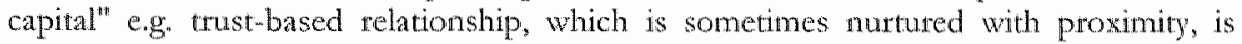
hardly given attention. The main criticue here is that, though the contractual relationships bind suppliers/purchaser and trainers to firms, firms have to build trust relationships to obtain commitment and loyalty [Brusco, 1982; Brusco and Sabel, 1981; Piore and Sabel, 1984; Rasiah, (1995: 2001); Nadvi, 1999; Wolfe, 2000]. This is to say that trust arises to overcome problems of reliability, information access and uncertainty hence helping to strengthen long-term efficiency. Trust therefore plays an important complementary role, in shaping the inter-fim networks that atise in the process of overcoming coordination problems that emanate from imperfect market. This is to mean that given this role played by trust in angmenting outsourcing relationships, it should then be included as part of transaction costs framework. Several works exist which show the influence of cooperation and market forces in the growth of collaboratrve relationships. Such telationships between agents within clusters and networks, through the sharing of vital information, resources, skill, knowledge and technical expertise, and other forms of joint action reduce transaction costs and further enhance competirveness as well as accelerate learning and technical innovation [See Brusco and Sabel, 1981; Brusco, 1982; Plore and Sabel, 1984; Best, (1990: 2001); Saxenian, 1991; Rasiah, 1995]. In the curtent study, the cluster and network dynamics framework will be further expanded by combining it with the literature on technological innovation which has led to the development of national systems of innovation. The national system of innovation is imporrant and particularly relevant to this study because of its classic development, which recognises technological learning and innovation as a non-linear, dynamic and

\footnotetext{
28 Schnmpeter acknowhedged this point when he wrote: "capitalist economy is not and cannot be stanonary. Wor is it merely axpanding in a steady manne. It is incessintly being rexolutionalised from whin by new conterptises, $i_{\text {. }}$. by the intuston of new commodites or new methods of producton ar acw commercial oppontumies into the industrial stuctume as it exists at any moment. Any existing structures and all the conditions of doing business are alwags in a process of change (Schumpeter, 1943: pp. 31-2)**
} 
interactive process. This illuminates a central theme in this thesis that dymamic interactions berween MNCS and local enterprises are necessary as mechanisms through which technological innowations and spillovers can take place.

\subsubsection{Technological Innovation: National System of Innovation and Evolutionary Perspectives}

The national system of innovation emphasises whe ways in which technology, socialcconomic agents, organisations, institutions and policies interact with each other for the sole purpose of fostering knowledge, learning, capability building and innovation. It is thus characterised by agents engaged in formal government and education institutions, metwork of physical, scientific, economic and technology infrastructure. The flow of technological information, knowledge and skills within the NSI is reganded as the most important thing for the purpose of technological leatning and capability building in the local, national and global context. The literature on technological capability accumulation has offered substantial insight on various learning aspects as well as stylised facts on a national systemic learning economy where changes, internal transformations and restructuring are important for the success of firms and industries. NSI emphasises that flow of knowledge and information is dynamic and non-linear. As a result, national system of innovation framework reiterates the significance of interactions among agents to facilitate flow of skills, information and knowledge to stimulate or enhance learning, capability building and innovation. The national systems of innovation views technological learning as a product of multiple iterations of trial and errot: learning by doing learning by using and learning by interacting in knowledge accumulation. As will be discussed below these attributes of involving all actors dynamically and interactively for social-economic benefit, led to the formulation of the national systems of innowation Freeman, (1987: 1995); Lundwall, (1988: 1992: 2000); Nelson and Rosenberg, 1993; Edquist, 1997; Nelson, 1993; Mytelka, (2000: 2004)]. The NSI has largely been motivated by evolutionary economics theory expounded by Nelson and Winter (1982), Rosenberg (1982) and Freeman (1982) among others. According to Lundvall (1992):

"A system of innowation is constituted by elements and relationships which interact in the production, diffusion and use of new, and economically useful, knowledge and ... a national system encompasses elements and relationships, either located within or rooted inside the bordlers of a naton state." "The broad definition includes all parts and aspects of the economic structure and the institutional set-up affecting leatring as well as searching and exploting ... the production system, the marketing system and system of finance (fundvall, 1992 : p. $2 \& 12$ ).

Another definition views economy's NSI as:

"The nerwork of agents and set of policies that affect the introduction of technology that is new to the coconomy. Since in the vast majority of developing countries technology is imported, the innowation system is defined very broadly to include policies towards $\mathrm{FDl}$, arm's-length technology wansfer, intellectual property trights, and impottation of capital goods (Dahiman and Nelson, 1.995: p. 90).

It can therefore be noted that specific features exist which differentiate an innovation system from earlier general equilibrium models of economic systems. In a local production system, it is easy to conceptualise the systemic nature of innovation simply by imagining a scenario portrayed by various actors in a complex, dimensionless system that comprises numerous uncertain events, which depict an evolutionary process. Just think 
of many continuous changes due to fims' competion emanating from drverse and contmuously changing customers" preferences alld tastes. "The changes due to new fundings emanating from research and technical institutes. The marketing and other contractual changes due to the rapid and erratic changes in the global market coupled with intensive process and product changes. The changes due to social, economie and political factors. Recognition of complex systemic perspecrive of innovation suggests that sources of learning and innovations to the firms are multiple, anpredictable and uncertain, involving many users and producers of innovation to the extent that mapping them out at a particular point would be extremely strenuous ${ }^{2 y}$.

Models that depict innowation as a smooth, well-behaved linear process badly misspecify the narure and ditection of the causal factors at wok. Innovation is complex, uncertian, somewhat disorderly, and subject to changes of many sorts. lnnovation is also difficult to measure and demands close coordination of adequate rechnical knowledge and excellent market judgement in order ro satisfy economic, technological, and other types of constraints all simultancously. The process of innovation must be viewed as a series of changes in a complete system not only of hardware, but also of market environment, production facilites and knowledge, and the social contexts of the innoxation organisation (Kline and Rosenberg, 1989: p. 275).

It is important to emphasise that from the foregoing definitions as does the vast literature on NSI places interaction among agents at the heart of national system of innovation approach. Interactions among agents are important for the purpose of production, diffusion and use of new and economically useful knowledge, which is extremely essential in bringing new products, new processes and new forms of organisation into economic use $\mathrm{s}^{30}$. As indicated above, agents in support of this process include institutions and organisations such as industry and business associations, R\&D, innovation and productiviry centres and technological and financing infrastructure support Care should be taken since institutions need to be distinguished from organisations. Organisations comprise universities, public sector research bodies, science councils and firms, that are the traditional focus of science and technology studies while institutions can be viewed as "sets of common habits, routines, established practices, rules or laws that regulate the relations and interactions between individuals and groups" (Edquist, 1997). According to Johnson (1992) instututions are seen as informal and formal norms and rules regulating how people interact.

The concept of NSI fits most analysis dealing with technological changes, leaning and innovation in developing countries, where technological change and learning does not have to emanate from formal R\&D institutions. Contrary to this argument, the sciencepush school of thought, tended to reduce inmovation into a well-defined sequence of activities that suggests a unidirectional flow of causation, from fundamental discoveries in science leading eventually to technological inventions, innovations, and the diffusion of new ptoducts and production techniques. This model, traditional linear model, referred elsewhere by David as "Simplest Linear Model - SIIM" influenced economic thinking and policy analysis to a wide extent for a long time (David, 1992) " The science push model and its attributes were however misleading. Its postulate was that

\footnotetext{
2" Kline and Rosenberg (1989) offer a very illuminating discussion on this.

Wh should however be emplasised that the having potential agents co-located within a geographical location does not necessarily mean they interact.

32 Stated more explicitly, "fit linear process was presumed to begin in a secientific laboratory, possibly in a basic scientific discovery, and then go through stages: applied tescarch, experimental development, initall commercial application, improvement, and so on" (Cooper, 1960 .
} 
innovations required spectallsed scientific and technological skill. This tended to teduce innovation to a preserve of sertous scientific research whose source could only be RdD laboratories. This was wrong as many innovations do not necessanily require basic tesearch not even applied research, but just occur in the process ot as end results of many trials and ertrors. In addition, innowations needed not only occur in any extraordinary laboratories, this was a narrow scope of visualisation accorded to innovation as innovations took place everywhere and at all times even on the shop floors. One need not limit himself to the scientific R\&D laboratories looking for innovations, local artisans and craftsmen in the least of the developing countries do have their own innovations as does the support and maintenance engineers in production processes or even local traders and merchants. These arguments were well articulated by Freeman (1987) in his view of NSI as "...the network of institutions in the public and private sectors, whose activities and interactions initiate, import, modify and diffuse new technologies ${ }^{32 "}$. The foregoing discussion provides a candid illustration that in trying to understand industrial technological dynamism in underdeveloped countries like those in sub Saharan Africa, there is much out there to observe in addition to the acquisition of externally sourced knowledge and innovations.

\subsubsection{Spillover Occurtence and Host Country's Technological Innovation Development: Stimulating Technological Learning and Capability Building}

Contrary to the traditional technique, production function, where spillovers were conceptualised in terms of productivity gains, we propose to conceptualise spillovers in terms of leaming and technological capability building. Looking at spillovers through productivity techaiques latgely neglects capability building process treating it as a black box'. We will argue strongly that firm's productivity and performance largely depends on the accumulated technological capabilities over time where constant technological leatning leads to a dynamic process of technological accumulation and eventually technological capability building. This would then support technological innovations as articulated in the NSI framework. We shall therefore assume that foreign presence through knowledge spillovers and other factors are likely to lead to technological learning and capability building in domestic firms either by providing rav materials, resources or specified stimuli which tesults in various technological changes in the firms. This process is likely to trigger learning and stimulate technological capability building at the firm level. As we argued elsewhere, this should be treated with a caution and should not be taken to imply that spillowers are the only deteminants of capability building in firms. $A$ whote variety of other factors are involved ranging from incentive framework (determines the demand side of capability building); supply factors (access to skills, finance and information) to institutional factors (this serves as the rules of the game). Rather, the task in this study is to investigate what capabilities are likely to be built in the locally owned firms due to foreign presence and spillover occurrence. By talking into considerations technological changes and various form of technological leaming taking place as a result. of foreign presence and spillovers we shall develop a measure for spillovers technological spillover index (SPI). Construction of this index is discussed in the next section.

Before concluding this section, we look albeit briefly at various technological capabilities in a firm. Fitm level technological capabilities can be categorised in many ways. Due to

${ }^{32}$ Acconding to Meralle (1995), the NST denotes a system of interconnected institurions involved in the creation, stotrge and transfer of skills and knowledge. 
the magniude and scope of this study, we shall only focus on production capability and then identify the associated leaming and technological changes. Our classification on technological capability will be drawn from Lall (1987: 1990: 1992), Bell and Pavitt, (1992: 1993); Wangwe (1995), Emst, Mytelka and Ganiatsos (1998), Dahlman, RossLarson and Westphal (1987). Useful categorsation of technological capibilities considers the functions they perform and the degree of complexity as the nwo classificatory principles. Thus it is possible to single out inwestment, production, major innowation, minor innowation, linkage, organisation and marketing capabilities. Developing countries at the eaty stages of their development spend much effort on the development of basic pre-investment, production and basic innovation involving minor changes, adaptation and incremental innovation. Linkage capability has also become increasingly important particularly due to the learning aspects involved when firms ate involved in forward and backward linkages with other firms through subcontracting and others. 


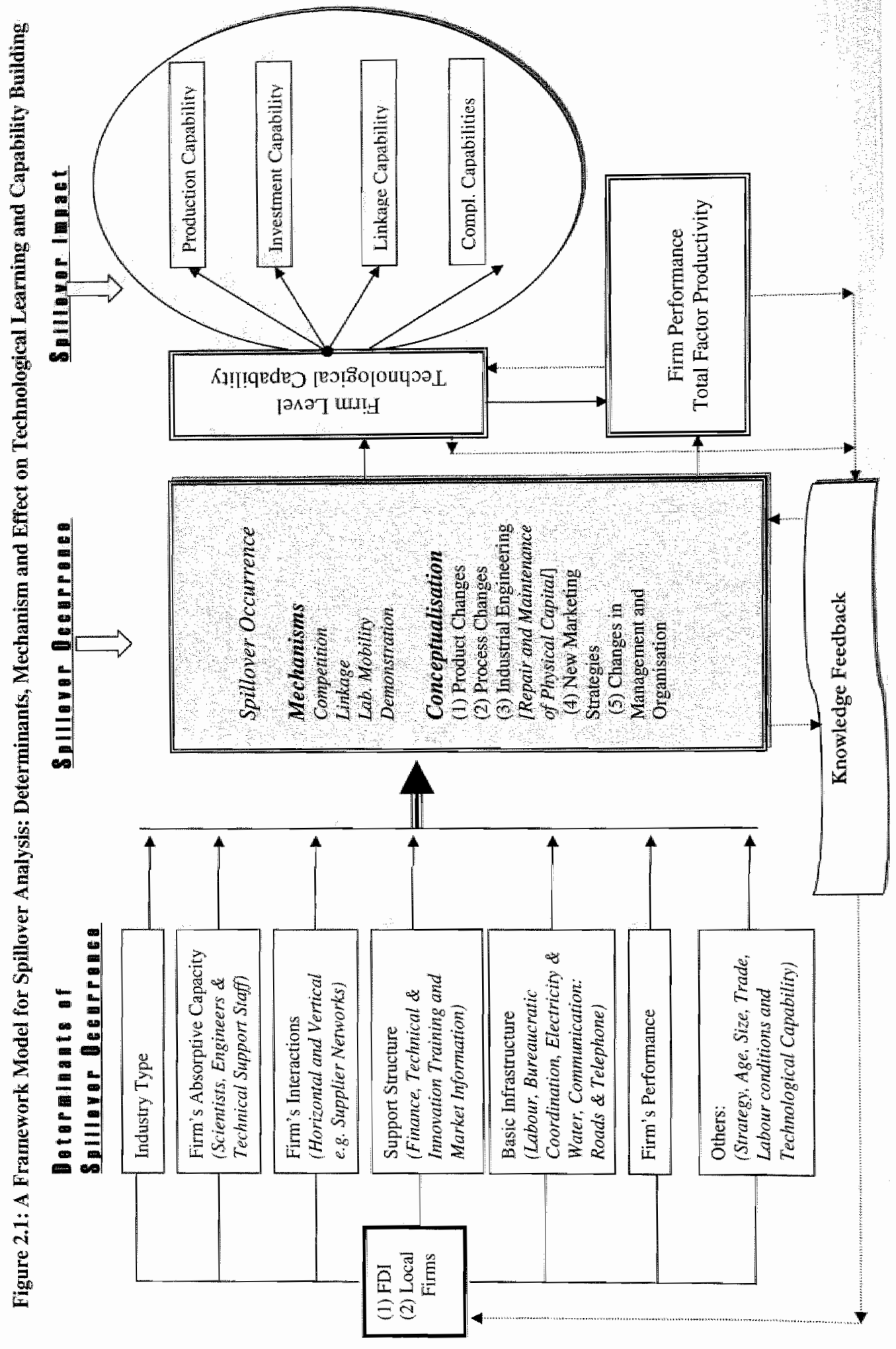


In a developing conntry like Kenya, occumence of technological spillovers from fortign investment is likely to place domestic enterprises on a leaming function thus increasing their likelihood to leam and accumulate experiential tacit lknowledge and thus build certain technological capabilities that would in tum enable then innovate. For these reasons and contrary to earlier spillovers studies, spillovers are conceptualised broady in the fom of learning and technological capability building. Using conceptual Figute 2.1 , we outline the procedure of how spillower occurrence might induce firms to learn and accumulate technological capability. The chart is elaborate; it includes deteminants of spillover occurrence traced within the structure-conduct-framework of industrial organisation. This is discussed in more details in as section below.

The analytical framework includes four channels of spillover occurrence identified from the spillover literature examined - they include competition, linkage, labour mobility and demonstration effects. Technological spillovers taking place through each of these channels ate further conceptualised in tems of learning and dymamic technological changes taking place in a firm. This thesis argues that firms are likely to respond to external stimuli, skills, knowledge or technology transferted by implementing dynamic technological changes. Such technological changes include modifications, improvements and extensions meant to improve efficiency and increase firm productivity. According to the literature on technological innovations (which emphasises interactive learning; capability building and innovation), the process of undertaking technological change is fully embraced as an important procedure in the process of technological capability accumulation. This arguments have been postulated by the proponents of technological change and innovation [Stoneman, (1983: 1995); Metcalfe, 1989; Rosenberg, 1982; Nelson and Winter, 1982; Freeman and Soete, 1997]. This process of undertaking technological changes provides learning in firms, learning by doing, by watching or by experimenting; results in explicit, experience and experiential knowledge accumulation. This helps increase firms" endowment of technical and tacit knowledge, skill base and capability and subsequently their ability to imnowate [For more details see Bell, ScottKenmis and Satyarakwit, 1982; Fransman, 1984; Kim, (1997: 1999) . In suppott of the same argument, a study by Mytelka (1985; p. 82-3) presented an illuminating discussion on how changes in consumption, production, organisationall and matketing conld promote technological capability within the firm. The direct implication of the curtent discussion is that occurrence of technological spillovers could indeed stimulate allocative, technical and technology transfer into the firms.

For each of the spillover occurrence channel considered, we identified fiwe linds of technological changes associated with production capability building. Before we proceed, it is imperarive to indicale at this point that this study focuses on only one form of technological capability - production capability, since it is not possible to consider exhaustively all kinds of technological capabilities here due to time and resource constraints. Under production capability the following technological changes are considered to proxy spillover occurrence; production changes, process changes, industrial engineeting, new marketing strategies, management and organisation changes. The degree to which each technological change takes place would be determined subjectively in the firms, by the respondents (production manager/engineer), on a continuous gradual ondinal scale ranging from a minimum scote of 0 to a maximum score of 5 . In this scale, score 0 represents "hothing bappening" while score 5 represents "very much". On the basis of this scale a spillover index is computed. This index is then 
used in the quantitative deremination of spillover occurrence and the subsequent hypotheses. It should however be acknowledged that the index inevitably suffers from drawbacks especially due to the fact it was largely based on firms own subjective assessment which could distort the index. As an atrempt to minimise excessive distortions, we had to rely mainly on the production managers as they were more acquanted with technological issues at the firm level.

We provide one example based on competition mode of spillover occurvence just for demonstration purposes. Due to competition pressure from competing firms, an enterprise is bound to react by implementing multiple technological changes ranging from production to organisational (see Table 2.1). These changes can be broadly classified under five components of technologicall changes inwolving production capability mentioned in a paraguaph above. Two other important technical changes that could result in accumulation of complementary capabilities have also been included they include changes in marketing, organisation and management. For each of these technological changes, a firm would have to choose subjectively what they perceived the degree of technological change was due to competition on the basis of the scale ptovided. For instance, consider the first case depicted in the second row of Table 2.1 , a score between 0 and 5 would be chosen for changes in products due to competition pressure.

As an example, technological changes in products would include development of completely new products or imptovement of old products. Assuming a particular firm introduced new products in response to intense competition pressure and that this particular firm rates this change as "a score of 4 " on the score range provided. "The awarded score, "a score of 4 ", becomes our $\mathbf{P d}_{\mathrm{c}}$ as shown in Table 2.1. It is noteworthy to mention that the most important thing for the respondents was their ability to identify who their competitors were and to classify them in to locally owned or foreign firms. Without this bit of information it would be very hard to differentiate the effect of foreign firms from that of the locally owned firms. To control for this problem, the respondents were asked during the survey to write the names of their competing firms, firms they were linked to, firms they copied or imitated certain products from and finally firms they got technical or non-technical workers from. The names provided were then counterchecked with the investment promotion council and the registrat of companies in the Ministry of Trade and Industry to detemine their actual ownership status.

Table 2.1: $\quad$ Reaction to Competition Pressure Ranked by Order of Importance

\begin{tabular}{|c|c|}
\hline Reaction to Competitive Pressure & $\begin{array}{l}\text { Ranking by } \\
\text { Importance }\end{array}$ \\
\hline Improving our products, develop new ones or copy/imitate their products & 0123.5 \\
\hline $\begin{array}{l}\text { Improve processing techniques, raw material and quality control, upgrade our } \\
\text { technology \& equipment to save energy or maise productivity etc. }\end{array}$ & 012345 \\
\hline Repair and Maintenance of physical capital, inventong control etc. & 012345 \\
\hline $\begin{array}{l}\text { Improve and strengthen our marketing department by new ideas skills and } \\
\text { knowledge in domestic or forcign matkers (exporting) etc. }\end{array}$ & 012345 \\
\hline $\begin{array}{l}\text { Undertake organisational changes for better management and implementation of } \\
\text { production \& other routine activities that enhance the firm's efficiency. }\end{array}$ & 012345 \\
\hline Others (please specifi) & 0123.45 \\
\hline
\end{tabular}

Sonrec: Author $2003 / 2004$ 
Similary, using the scores for all other four cases, technological changes, a technological spillover index (SPO INDEX) was developed. "The idea of employing an inder to evaluate fim level processes and activities is now widely embraced particularly when dealing with technological capabilities in developing countres. This can be traced to the works of Westphal, Kritayakirana, Petchsuwan, Sutabutr and Yuthavong (1990), Lall 1992: 1994: 1996: 1999); Bell and Pavitt (1992: 1993); Call, Barba-Nawarett, Tetel and Wignaraja (1994); Emst, Ganiatsos and Myrelka (1998); Wighajajand Ihiara, (1999); Wignaraja (2001) and Rasiah (2002: 2003). Howexer the present spillower index, is different and attempts to quantify firm level technological behaviour with patticular emphasis on qualitative information from survey interviews and then uses limited dependent econometric techniques for spillover analysis. On the basis of the five scores awarded; $\mathbf{P d}_{0,} \mathbf{P r}_{c_{x}} \mathbf{R m u}_{\mathrm{c},}, \mathbf{M} \mathrm{s}_{\mathrm{c}}$ and $\mathbf{M o}$ an average, $\mathbf{C}$, is then computed as shown at the bortom of the competition column, see Table 2.2. This process is repeated for the other spillover channels, for linkage the average is $\mathbf{L}$, mobility is $\mathbf{M}$ and demonstration is D. Eventually, our complex spillovet index, SPO $\mathbb{N D E X}$, is computed as an average of all the four spillower channels, as shown by the following expression:

$$
\text { SPO INDEX }=\text { Composite Average }(C, L, M, D)
$$

Table 2.2: $\quad$ Computation of Spillover Index, SPO INDEX

\begin{tabular}{|c|c|c|c|c|c|}
\hline $\begin{array}{c}\text { Soillover } \\
\text { Conceptualisation }\end{array}$ & $\begin{array}{l}\text { Compecition } \\
\text { (c) }\end{array}$ & $\begin{array}{c}\text { Lind age } \\
\text { (1) }\end{array}$ & $\begin{array}{l}\text { Isbour } \\
\text { Mobility } \\
\text { (m) }\end{array}$ & $\begin{array}{l}\text { Demonstration } \\
\text { (d) }\end{array}$ & $\begin{array}{l}\text { Average } \\
\text { Score }\end{array}$ \\
\hline $\begin{array}{l}\text { Product Changes } \\
\text { (Pd) }\end{array}$ & $\mathrm{Pd}_{\mathrm{c}}$ & Pdo & $\mathrm{Pd}_{\mathrm{d} 1}$ & $\mathbb{P}^{2}$ & $\mathrm{PD}$ \\
\hline $\begin{array}{l}\text { Process Changes } \\
(\mathbf{P t})\end{array}$ & $\mathrm{Pr}_{\mathrm{r}}$ & $P_{n}$ & $\mathrm{Pt}_{\mathrm{ra}}$ & $\mathrm{P}_{\mathrm{r}_{i}{ }^{8}}$ & $\mathbf{P R}$ \\
\hline $\begin{array}{l}\text { Repair \& } \\
\text { Mantenance } \\
\text { (Rm) }\end{array}$ & $\operatorname{Rm}_{e}$ & $\mathrm{Rm}_{\mathrm{H}}$ & $\operatorname{Rm}_{\mathfrak{k}}$ & $\operatorname{Rn} n n_{\mathrm{d}}$ & $\mathbf{R M}$ \\
\hline $\begin{array}{l}\text { Marketing Strategy } \\
\text { (Ms) }\end{array}$ & $\mathrm{Ms}_{\mathrm{c}}$ & $\mathrm{Msl}_{\mathrm{l}}$ & $\mathrm{Ms}_{\text {b }}$ & $\mathrm{Mss}_{\mathrm{d}}$ & MS \\
\hline $\begin{array}{l}\text { Maragenent \& } \\
\text { Organisation } \\
\text { (Mo) }\end{array}$ & $\mathrm{Moc}_{\mathrm{c}}$ & Mor & $\mathrm{Mo}_{n}$ & $\mathrm{Mo}_{\mathrm{d}}$ & MO \\
\hline $\begin{array}{l}\text { Average } \\
\text { Score }\end{array}$ & C & L. & $\mathbf{M}$ & $\bar{D}$ & $\begin{array}{c}\text { SPO } \\
\text { INDEX }\end{array}$ \\
\hline
\end{tabular}

Souree A Larhor 2003/2004

Similarly, the SPO INDEX can be computed by column average $A$ score for product change under each mode of spillover occurrence would be taken and averaged to give PD; the row average in Table 2.2. This is done for the four other rows - Pr, Rm, Ms and Mo. In the end, the average for the last column is computed as follows:

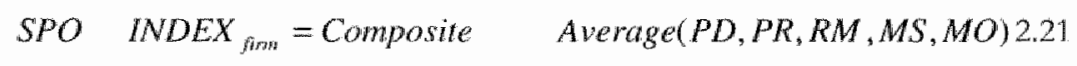

The two procedures; average by column or average by row yield the same results, a complex spillover index, SPO INDEX, which would serve as a proxy for spillover occurrence in the Kenyan manufacturing industry. The average spillover occurrence for the industry would be obtained by computing the average for all the firms. The SPO 
MDEX will range on Liken scale in the interval 0 to 5 . This would be in an ordered framework as follows:

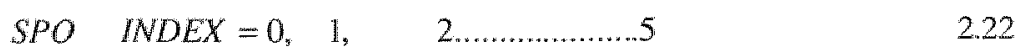

Where SPO INDEX $=0$ represents "None ${ }^{\prime \prime}$ occurrence of spillowers

SPO INDEX $=1$ represents "Least" spillover occurrence

SPO INDEX $=2$ represents "Loy" spillower occurrence

SPO INDEX = 3 represents "Awerage" spillover occurrence

SPO MNDEX $=4$ represents "Higls" spillover occurtence

SPO INDEX $=5$ represents "Highest" spillover occutrence

This index will be used in spilover occurrence determination using multinomial ordered logit analysis discussed extensively in Chapter 5.

\subsection{Formulation of Study Propositions}

Following from the above discussions, alternative framework offered, and guided by the analytical framework established we fomulated the following propositions to help us examine technological spillovers in the context of Kenyan manufacturing industry. Note that specific objectives remained as stated in Chapter 1 .

\subsubsection{Presence of Multinationals and Spillover Stimulation}

This section begins by revisiting one weakness notable in the earlier literature. It was noted that spillover process remained largely a nartondy conceived concept; the definition of technological spillovers in the literature also remained virtually static. Spillovers were largely associated with increases in the productivity efficiency of domestic firms. Contrarily, this thesis conceptualises spillovers in terms of learning and technological capability building in firms. This thesis will therefore regard technological spillowers as skills, knowledge and technology that serve to stimulate dynamic technological changes in firms triggering the learning process and accumulation of technological capability. A process that later spurs technological innovations. This has a strong implication in that based on the vast knowledge, capital and technology resources possessed by MNCs; they can play an active role in restructuring industrites in a developing country. From the perspective of the above discussion, the first main proposition in this study is set as follows:

Proposition 1: The presente of MNCs stimulates redbulogical spillowers to locally onmed matwlaturing entomprises in Kewla.

\subsubsection{The Determinants of Spillover Occurrence}

So far one thing about technological spillovers is clear that due to their complexity, it is not possible to disentangle pecuniary spillowers from non-pecuniary technological spillowers for a proper quantitative analysis. It is also cleat that non-pecuniary spillovers mainly occur to firms in form of skills, knowledge or in form of stimuli (e.g. competition pressure) which induces firms to continuously introduce dynamic technological changes in their production processes, products, their routine work and to their organisational procedures. All these dynamic changes have extensive implications for technological learning and capability building in fitms. 
Since the process and impact of technological spillovers can be largely visualised as a function of individual firm's resource endowment and interactions with socio-economic agents, in this study it is assumed that spillover occurtence is determined by number of factors encapsulated in the structure-conduct-perfomance framework, Figure 2.2. This framework is founded in the theory of industral orgatisation $13 \mathrm{ain}, 1968$; Scherer, (1973: 1980)]. According to this framework various elements of market structure detremine fim conduct, and that structure and conduct together interacted determine market performance. The major elements of structure include organisational structute of firms; whether they ane vertically or horizontally integrated. Firm orientation; whether they operate to serve domestic market or external market (export oriented). Others include buyer and seller sizes, product differentiation, and entry and exit conditions, The major elements of conduct were human capital development strategy, product dexrelopment strategy, co-ordination with other furms and existing supporting institutions. Although R\&D is also identified in this category, very few firms in Kenya undertake it. Lastly, performance includes firm revenue in terms of output sales and wallue added, market share, unit cost of production, total factor productivity or partial productivity levels as in case of labour and capital productivity.

Figure 2.2: Industrial Organisation Framework

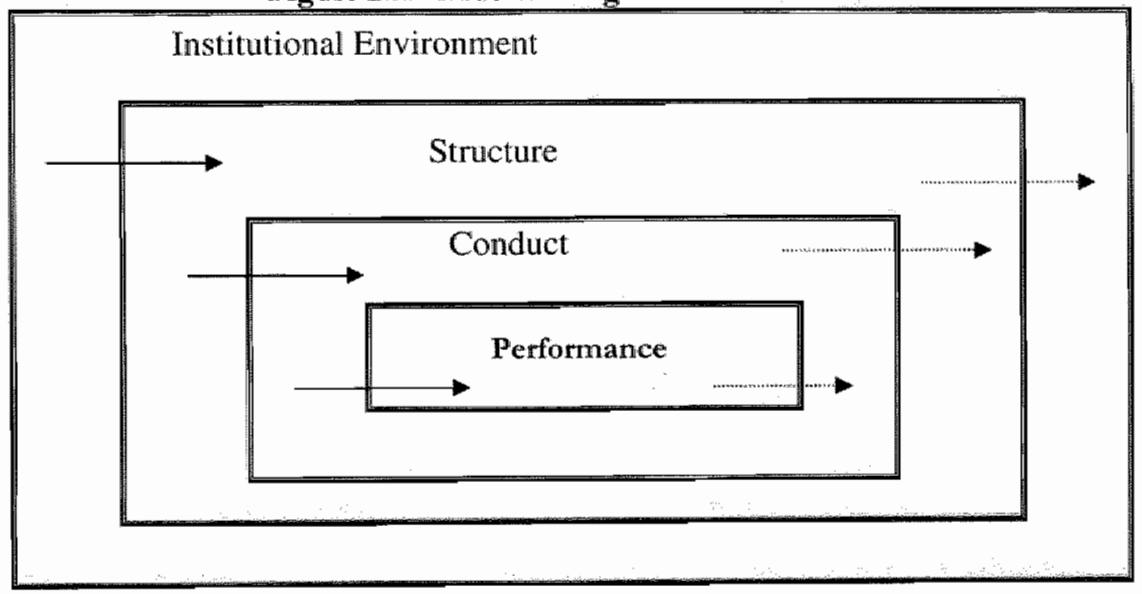

An institutional environment is incorporated into this framework since its influence on firms' stmucture and conduct might in turn have an influence on firm performance, all of which again affect each other interactively and dynamically. "This is inspired by the works of institutional economists [Williamson, 1985; Richardson, (1960: 1972); North, 1992]. In the words of Douglas North (1992), "... institutions and the way they evolve shape economic performance." Under the institutional envitonment several factors ate identifiable which might directy or indirectly impinge on firms" performance. "They include basic infrastructure, labour force characteristics, prevalling government policies and political climate, degree of accountability and transparency level, ethniciry background and cultural practices, existing market structure of competing firms, firm ownership structure, trade orientation, inter-firm and institutional links etc.

Similarly, from the debate alluded to above on technological innovations, many factors sociomeconomic, technological including multiple agents and their interactions are 
involved in the spllower occurrence. This called for a systemic approach while designing the analytical tranework. Ir was assumed that; determinants of spillover occurrence, their mode of occurrence and impact on firms" activities leading to technological leatring and capability building could also be traced and identifed within the national system of innowation. However, this does not mean mapping the entre Kenyan NSI, the main assumption is that knowledge fow, frms and their interactions are embedded within the Keryan NSI. In this context, the analysis to be undertaken in this study views the NSI from the lenses of a firm and partly of support institutions - e.g. Kerya's industrial stpport institutions:

On the basis of the above, and following from the insight garnered from the spillover literature analysed, altemative theoretical framework offered and based on analytical framework designed above, the determinants of spillover occurrence in Kenya can be outlined in a broad proposition as follows:

Proposition 2:In a tectbrically underdeveloped cownty like Kowy, the occurrence of spillowers into the Intigentous enterprises will not only depend on the presence of MNCS, but also an absorptive capacity (vechyological gap), presence of support stmotures and institutions (e.g. institutions offering finance for leaving and inwowation), presence of interactions and trade orientation. Otbers will iadude form size, age, ownership structure, performance and competitiveness, labour market conditions, strategy of a firm and industy strycture).

From this broad proposition we subsequently formulate testable propositions as follows:

\subsubsection{Absorptive Capacity}

In the literature analysed, one of the recurring arguments was that; for spillovers to occur to the locally owned firms, there must be high absorptive capacity [Cohen and Levinthal, 1990; Grossman and Helpman, 1991; Benhabib and Spiegel, 1994; Keller, 1996; Botensztein, Gregorio and Lee, 1995]. Knowledge spillovers depend on the ability and effort of the recipient parts to exploit new knowledge and technology as knowledge does not diffuse effortlessly. R\&D although hardly conducted by domestic firms become important in keeping pace with and absotbing the knowledge spillovers. A firm with a strong R\&D base would therefore be efficient in the diffusion of spillovers. Some of the spillover literature also argue that the technological gap should be small |Cantwell, 1989; Kokko, (1994: 1996). A different version of the literature also argues that a large technological gap axts as a stimulus to innovation and spillover [Findlay, 1978; Abramovitz, 1986]. However, this is unlikely in underdeveloped countries since the absorption capacity is too low to permit such leaps. The supporting national system of innovation in which firms are embedded is rather weak.

In a technically underdeveloped country like Kenya, it is assumed that absorption capacity is important if spillovers are to occur. A firm's internal absotption capacity can be viewed as accumulated technological knowledge over time sometimes reflected by age of a firm. However, most firms in developing countries, like Kenya, might not be in a position to accumulate knowledge due to lack of resources and knowledge cannot

\footnotetext{
${ }^{33}$ Kolko (1994), Kokko, Tansini and Zejan (1996) and Sioholm, (1997) define teclanology gap in the following ways: First, in terns of different industries capital intensities. Second, in ternas of the difference in labour producrivity and finally, in terms of the amount of patent fees in different industries. The later is obviously out of guestion in the context of underdeveloped countries since patents are hardly considered important there.
} 
therefore be taken as a simple function of frm age In the same rein, R\&D measures might not be very applicable as most fims hatdly do it for lack of either human or technical resources. We shall therefore resont to other indicarors like share of technical personnel and the existing level of capital investmert. It will be assumed that the absorptive capacity depends on the lewel of technological knowledge in human resources and physical capital investment. Both are important for the complementaty role in which they play to each other. Technical personnel can be measured in terms of share of engineers, scientists and support technicians in the total employment of the firm while physical capital can be taken as the capital investment by the firm. Using capital investment a technology gap variable between domestic and foreign firms will be derived.

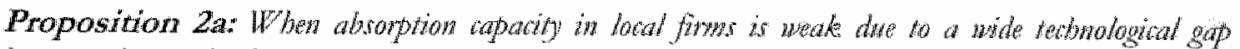
between their tedonological base and that of the MNC subsidaries in theit industy or sector then

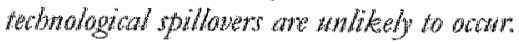

\subsubsection{2}

\section{Systemic Infrastructural and Institutional Support Structure}

One of the arguments that emerged was that it was important to reconceptualise spillower process in a broader context. Following from our synthesis, critiques and discussions above, accurrence and impact of technological spillovers is not an automatic process and cannot therefore be examined just using a handful of a few selected factors employing a narrowly conceived framework. This is especially so given the, dynamic, uncettain and tacit nature of technology and knowledge. This thesis views the spillover occurrence process as an extremely dynamic process influenced to a very large extent by a multivariate of instruments amid other determining factors. Such factors could be internal or exogenous to the firm and sometimes to the country - implication that they are beyond the control of the firm as well as the country. "This aspect prompted this thesis to adopt a complex and systemic approach guided by the literature on technological innovations - in particular the NSI, which largely overlaps with the literature on cluster and network dynamics in the industrial organisation. The two litetature strands stresses the importance of knowledge generation, its exploitation in firm's production, its utilisation for learning to lean and to innovate, and further its diffusion through a dynamic and interactive process. As the literature emphasises, systemic interactions among agents arise from networks and linkages created in the form of sub-contracting relationships or: supplier-client linkages that serve to demonstrate techuological innovations ot serve as stimuli for learning and innovation ${ }^{34}$.

Also emplasised in the same literature is the importance of infrastructural and institutional support structures. Examples include institutions like productivity centres, technology transfer bodies, training programmes and investment pronotion councils. Similarly, institutions such as those providing financing play a very active role towards facilitation of innovation based on knowledge acquired in the spillover process. The role of these institutions as intermediary organisations that coordinate demand-supply relations between firms, government, and institutions has been atticulated (Rasiah, 2001; Doner, 2001; Aoki, 2001). They play an important role in strengthening network cohesion. Exen those that enforce contractual arrangements play an impottant role since as Williamson (1985) demonstrated lack of commitment through long-term contracts leads to under-invesment in relationship-specific assets. Viewed in the

\footnotetext{
34 These auributes of imolving all actors tynamically and interactively for the sole purpose of social beneht to at wide comomic standpoint, led to the formation of NSI builc upon thotks of lreeman (1987: 1995), Lundval! (1988: 1992: 2000) and Nelson and Rosenberg (1993).
} 
Systemic lenses, both infrastnctural and institutional capacity to function effectively depends on systemic relationships established ower time. To a large extent, systemic and network cohesion is often facilitated by infrastructural and institutional structure created to coordinate between government policy-making organ, implementation body and fims. If infrastructural and institutional structures play an effective role, then the risk of government failute is minimised.

We will therefore argue by analogy that where support structure is present, it would be more likely that local firms would be able to absorb spillovers from MNC firms. However, testing a proposition based on existence of strong support structure such as financing for innovation at an aggregate level is a difficult thing to do, since data on which firms urilise what kind of support structures is hardly documented in poor developing conntries. Such a proposition can only be tested using firm level data collected by a survey methodology. Infrastructural and institutional structures will be taken as present if a firm claims to have received support of some kind (such as technical, financial etc) from the existing technical and financial institutions in the Kenyan industry.

Proposition 2b: The presence of strong suppow structure (eg. basic infrastructure and supportine institwtions) in an industo induding fivancing for leawizg and innowation increases the probability of redonalogitat spillowers.

\subsubsection{Systemic Embeddedness: Importance of Firm Interactions}

The conceptual framework developed in this thesis regarded the spillover process as an extremely interactive and dynamic, one that is influenced by a multitude of socioeconomic agents as well as existing policies that operated in a systemic manner. A strong netwotk cohesion that supported generation and diffusion of knowledge was emphasised. This is articulated in the network dynamics and NSI literature, which singles out dynamic and interactive involvement of agents as important [Freeman, (1987: 1995); Lundvall, (1988: 1992: 2000); Nelson and Rosenberg, 1993; Mytelka (2000)]. The literature regards interactions as important means through which interactive learning, information and technology can be exchanged or exploited jointly for the purpose of productive activities. This implies that interactions among firms, institutions, and government and business associations are likely to stimulate the process of spillover occurrence. Fitms embedded in such systems would thus benefit exploitation of spillovers of knowledge, accumulation of capability through learning from demonstration effects. In light of this discussion, we hypothesise that firm systemic interactions in Kenyan manufacturing industry are important for spillover to occur. As the literature emplnasises, systemic interactions among agents arise from networks and linkages created - with common ones being vertical and honzontal linkages. Other forms of networks and linkages include informal contracts, membership in formal and informal associations and collaborations. Mytelka and Fulvia (2000), Saxeniaan (1991), Best (2001) and Rasiah (2003) offered detailed discussions on the importance of clustering and networking in promoting new product development, spurring diffusion of new technologies by facilitating information exchange and joint probletm solving between firms in an industry and sometimes in different industries.

Proposition 2c: The presence of interations between localb onned ferws and MNCs increares the probability of tecturobigial spillowers. 
There exists a long debate in industrial organisation on importance of size on firms' competitiveness and now on spillover occurrence. Studies conducted angue that firms achieve competitiveness once they attain a certain minimum efficiency scale (MES). MES is the lowest level of output where the minimum average cost (MA) is required to exhaust scale economies in manufacturing [Scherer, (1973: 1980: 1991); Pratten, 1971]. MES tends to wary with industries. Large and heavy industries, such as steel and metal industry, manufacturing things like trains and locomotion, aeroplanes, automobiles or ship building are characterised by high scale economies. In such cases a high MSE unit production is required if low unit costs are to be achieved.

To a large extent, big frrms may be at an advantageous posicion in terms of spillover occurrence primarily on account of their ability to mobilise productive resources and other services $^{35}$ that are either external or internal to a firm. As an example, there might exist some kind of market segmentation that favours large firms in that only firms above a certain size are able to have access to certain skills, information and credit facilities needed to be competent. Due to their large size, large firms can have more specialised manpower obtained from sustained training while on-the-job or externally including abroad. Large fims often have formal information gathering systems, spend much time and resources to identify and use important external sources of scientific and technological expertise. Large firms usually bave more networks with individuals and institutions that provide training, technical information and technical services, which are important inputs in the technological capability acquisition process. The networks enable exchange and diffusion of useful information, skill and technologies. When it comes to financing for capability development, capital market imperfections confer an advantage on large firms in secuting finance for technological activities. Availability of capital means more resources to engage in systemic research, labour training and a greater need for structured information gathering. It could also be due to sectoral distribution of activities that due to economies of specialisation only large fimms could reach efficient levels of technological capability. In a study of enterprise development in Kenya's manufacturing industry based on probit analysis it was observed that the probability of an enterprise to attain a searching level in acquisition of foreign technology was influenced by fitms' specific characteristics which included firm size (Department of Economics 1994).

To the contraty, not all industries require high MSE unit production. In many castes scope rather thar scale is impotant. For instance, in industries dealing with plastic components or stmall-batch machine tools, it is scope that is important but not the scale (Piore and Sabel, 1984; Rasiah, 1995). It should also be emphasised that information technology has continued to play a contributory role in making small size very efficient following the increased decomposition and dispersal of production. Several empirical studies now exist which dispel arguments supporting the significance of large size in efficiency and innovative activities [Audretsch and Zoltan, 1991; Audrersh, (1995:2002)]. Nonetheless, when small furms make no effort to improve their technological capabilivies due to over reliance on labour intensive technologies, the tesult is weak absorptive capacity, low spiliover occurrence, reduced leatning and innovation. This point is futther supported by the fact that smali firms are somerimes characterised by low levels of output sales, which might be inadequate to spread over the costs of learning and capability building eg. research and development. Small firms often lack time or

35 The is a result of economies of scale that atr nost often associnted with the scatc or out of establishment or whth the size of fims. 
resources to identify and use important extemal sources of scientific and technological expertise. In light of the above controversy over the influence of firm size in economic performance and the arguments purported br the proponents of industrial organisation over differences in MSE in different industries, we propiose size will have a neutral impact in determining spillover occurrence. The influence of size can be detemined by considering employment level in the firm. The value of output can be taken as an alternative measure of size, however, information about employment is more preferred as it is readily available and is often considered by firm officials (managers) to be less confidential.

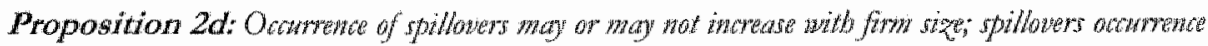
shay be whore in shall firms as well.

\subsubsection{Firm Ownership Structure: Ethnic Origin of Owners and Foreign Equity Participation}

\section{(a) Ethnic Origin of Owners}

Firms in the Kenyan manufacturing industry can be broadly classified into three categories on the basis of ethnic originality of the firms" owners. The first category of firms belongs to firms of Africans of Kenyan origin, the second one is that of fims owned by Kenyan Asians and finally fims owned by people from all other nationalities. Finms owned by the Kenyans of African origin are the majority and easily distinguishable, as they have greatly remained SMEs in nature. The Asian furms are large and involve heavy manufacturing particularly in engineering works and textile. Firms owned by people from other mationalities are equally large and more dynamic than perhaps all other categones; such include Furopeans, USA, and Middle East. This category of firms has also made heavy capital investment suppassing that of Kenyan Asians and is a large employer.

We note that compared to the other two categories, the local African firms have been disadvantaged. They have invested in less physical capital, employ less skilled people, hardly perform $\mathbb{R} \& D$ and thus their technological capability and absorption capacity has largely remained tather weak. This is surprising since these kinds of firms received. enormous support and protection at the carly days of Kenya's industrialisation after her independence in 1963. As will be shown in Chapter 3 , in the initial days of Kenyn's industrialisation most of the industries were protected and foreigners were not allowed to make investment in certain industries. The government launched a strong campaign to support and promote entrepreneurship owned and managed by indigenous Africans through provision of finances and advisory serwices, necessary for expansion, modernization or rehabilitations of existing enterprises. "This famous campaign was

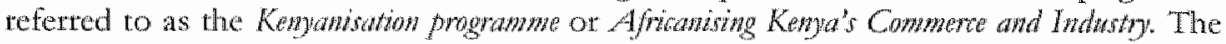
scarciry of private domestic saving's, management talent and entrepreneurial experience, especially among Africans, mesnt that if Kenyanisation was left to natural forces in the private sector, it would proceed slowly incleed (Leys, 1975; Coughlin, 1988; Himbara, 1994). The Kenya government thus introduced a wide range of business support instimations to provide financial assistance, technical and managetial services for faster: industrialization, technology acquisition and development. Other examples of essential services included training on planning and implementation of projects, provision of extension services to solve technical problems and to offer training on management and marketing skills. Operational premises wete also offered to the indigenous Africans at reduced rents. 
Despite all these institutional and structural support, most indigenous African firms still remained small, medium and sometimes micro in size. It is argued that since the other categories of firms could not qualify for financial and credit suppot from the existing finamcial and credit support institurions, they wotked wery hard and urilsed other sources of financial as well as technological resources. This was thought to be more so especially with the Kenyan Asians who began with minor investments and in light industries but have been able to accumulate technological capabitices over time in comparison to Africans of Kenyan origin. This classification therefore points to an interesting and an existing case that is likely to influence spillover occurtence into the Kenyan firms. We therefore formulate the proposition that occurrence of spillovers is likely to be dependent on ethnic origin of owners: Kenyan African, Kenyan Asian or others if owned by individuals from other nationalities such Europeans and Americans.

\section{(b) Foreign Equity Participation}

One of the most important contributions by MNCs to the local firms is the formation of JVs. Aldhough not all JVS are beneficial to the local firms, local enterprises in underdeveloped countries ate motrvated to form $\mathrm{JV} / \mathrm{s}$ in the hope that spillover benefics might follow such partnerships, for example access to efficient product and process techniques, access to management know-how, international marketing slills and so on Aitken and Harrison (1999) used annual census data on over 4000 Venezuelan firms to masure the productivity effects of foteign ownership. The study found a positive relationship berween foreign equity participation and plant performance. This implied that there were productivity gains, which could be attributed to foreign equity participation. In Kenya, JV's would be expected to behave in a similar manner to MNCs in that they invest in technology capacity, undertake more training and acquire technologies regularly compared to the domestic firms. In the Czech Republic, Djankor and Hoekman (1998) investigated the impact of foreign investment on the productivity performance of firms using information on Czech enterprises. He found out that $\mathrm{JV}$ frrms invested significantly more in technology capacity than purely domestic firms did. A high proportion of workers in the JVs compared to that of purely domestic firms reported that they had undergone trainings of vatious kinds in the past two years. JVs also obtained new technologies mote often than purely domestic fims. Purely domestic firms might have lacked the ability therefore to absorb the technollogies introduced by foreign firms. Since this notion is likely to hold in the case of Kenyan firms, we shall therefore test the sub-proposition that occurrence of spillovers is dependent on foreign equity participation in the Kenyan firms. "The foreign equity in Kenya will be determined by the share of foreign capital in the total capital outlay of a firm (0Vs).

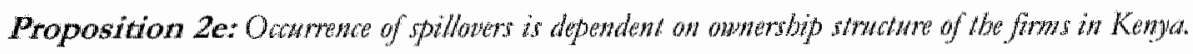

(a) Sub-proposition 2e: Octurrence of spillowers is dependen an etbric origin of onners of dut fanms in Kenyan.

(b) Sub-proposition 2e: Ocumence of spillowers is dependent on foragne equily particitation in the Konyon joms.

\subsubsection{Age of the Firm}

To a large extent, the influence of age on the spillover occurrence is similar to that of size from the perspective of those who associate spillower occurrence with firm size as discussed above. We therefore hypothesise that firms with longer experience are consictered to enjoy greater experiential and tacit knowledge and thus the older a firm is, the more the spillowers are likely to occut. In a period of time, large firms are expected to 
improve their technical capability and thus efficiency than the small ones. This is supported by the fact that latge frms enjoy economies of scale and thus have the tesources to spread over leaming, capability building and innovation initiatives. In a recent study on Kenyan manufacturing industry, Lundvall and Battese (2000) investigated whether technical efficiency is systematically related to the size and age of firms. They estimated a translog stochastic fronter production function using an unbalanced panel of 235 Kenyan firms in the four sectors - food, wood, textile and metal sectors. Firn size had a positive and significant effect in the wood and textile sectors while the ange effect was less systematic, but was significant in all sectors, except textiles.

Linking the size and age of a firm, Jowanowic (1982) argued that firms increase in size as a result of a selection process, in which efficient firms grow and survive, while inefficient furms stagnate or exit the industry. He noted that since the process takes time, larger firms are therefore expected to be older. This would then mean that there exists a positive age spillover relationship. This would be expected based on a firm's accumulated stock of knowledge and experience over time, emanating from various kinds of leaning processes undertaken in the firms as they imitate their competitors and MNCs, as they do R\&D and search for information or simply as they conduct basic adoptions and incremental innovations. The accumblated stock of knowledge and experience over time amounts to absorptive capacity that is necessary if a firm is expected to recognise external knowledge in form of spillowers, absorb ir and utilise it for productive purposes. To most fitms in the Kenyan industry, the process of knowledge accumulation is slow; hence time becomes a crucial factor leading us to formulate the proposition that occurrence of spillovers increases with the age of a firm. The age of a firm will be determined in terms of absolute numbers - based on the year a firm was establishment in Kenya.

Proposition 2f: Occumence of spillowers increases mith firm age; spillower accurvence tend to be wore in ald fints or in other words spillowers ocurrence is function of years of expentence.

\subsubsection{Industrial Specificity}

Industrial specificiry has a strong beating on spillover occurrence, learning and technological copabiliny building. To a large extent industries are as different as firms are. A high level of heterogeneity with signifficant differences in technological capabilities and capacities to undertake technological learning and absorption exist. This is more so to the extent that exen technologies used by MNCs in various industrial sectors often differ widely in complexity. There is a wide array of literature in support of this fact. Take for instance the garments and automobile industries. According to Gerrefi (1999: 2002) framework of ptoducer-buyer driven value chains, garments ate categorised in terms of buyer-driven chains, while automobiles are characterised by producer-driven chains. However, in both industries there is incteased use of technology and tacit knowledge. While garments have become high technology users, the auto parts have equally become more knowledge intensive. The auto parts industry is closely telated to machinery and engineering industries and electronics assembly. "This is a tremendous transformation from being labour intensive to knowledge intensive since 1980s (Rasiah, 1988; Ennst, 2000; Kraemer and Diedrick, 2003). Another notable characteristic is that changes in national and international policies over time have significant influences in different industries. In auto parts industry the nature of liberalisation measures pursued seem to erode technological capabilities developed through the import-substitution period. As a result, specialised suppliets of auto parts in some host countries have reduced significandy. Countries lite South Africa, Mexico, Brazil, Philippines and Tawan are 
typical examples [Bames and Lorenzen, 2003; Quadros, 2003; Orreneo, 2003]. With regard to other industries like food processing and beverages, differences anse deponding on the nature and characteristics of ptoducts processed: Products can wary from smallscale confectionery manufacture to high volume resource-dependent such as frut and juice packing by MNC firms such as Del Monte and Chiquita. In these industries too, thefe is increased use of knowledge and technology. Detailed case studies by Mytclka (1999) and Mytelka and Farinelli (2000) have demonstrated that even tuaditional industries such as wine producing have become knowledge-intensive. From this debate, this thesis will examine the role industry specificity in spillover occurrence by using industry dummies as control variables in statistical analysis as well as elabotate case studies.

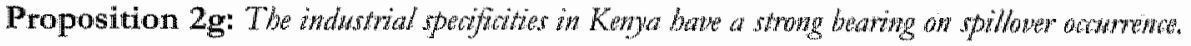

\subsubsection{Firm Performance}

Another determinant of spillover occurrence into the Kenyan manufacturing industry is the level of firm's performance. By all standards, a firm in Kenya like in most other developing countries is able to performance well if it has developed a substantial amount of technological capability. Such a firm is characterised by high capacity urilisation, high output in terms of annual sales and thus profits. Such a firm in Kenya would be in a position to undertake dynamic strategies; perform basic $R \& D$, recruit well-trained professionals like scientists and engineers, undertake human resources development and other enrichment programmes. "This arguments are articulated in industria organisation, which postulates that a firm's performance is a function of its own endowments, conduct and the systemic enviromment characterised by interactions among economic agents [Bain, 1968; Scherer, $(1973,1980)]$. The direct implication of this is that a firm with high performance offers more room for learning, acquisition of tacit and experiential knowledge through performing. All these factors enhance the firm's absotptive capacity necessary for assimilation and exploitation of spillowers. Quite often, a high performing firm is also be deemed as competitive. As noted in the spillover literature, competition is one of the important elements that influences spillover occurrence. When locally owned firms have the capacity to offer strong competition to MNCs, this prompts the MNCs to constantly change their techniques by transferting more of their recent technologies, which are in tum imitated by the domestic fims demonstrating some kind of vicions cycle. We would therefore hypothesise that spillover accurrence in Kenya rends to increase with a firm's performance the performance can be proxied by firm's output; capacity urilisation; annual sales and annual ptofits..

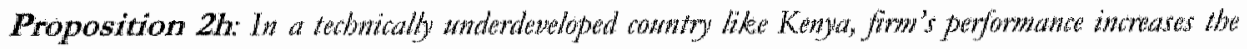
probability of spillower acarrence.

\subsubsection{Firm Strategy}

Another factor that is likely to influence spillover occurrence is firm strategy. Some examples of firm strategies include process modernisation to enhance efficiency and flexibility of the firm, diversification into new products, capturing new markers including exports. Others include lowering of overhead costs, scale expansion and qualing improvement - i.e. through achievement of $\mathbb{H A C C P}$, ISO 9000 or ISO 14000 certifications. A firm may also have a strong strategy to broaden its knowledge base. This may take place through conducting $R \& D$ or human resources development by adopting a training strategy in vocational, technical or professional education aimed at improving 
skills to the technicians; equipment maintenance and other skilled workers. The direct implication of this is that a fim with a demonstrated strong path dependence leading. towards absorption capacity accumulation would result in spillover occurrence to the locally owned fims. To the contrary, a frm locked into old habits and technicues with limited or no leatning, is not likely to assimilate any spllovers. Other strategy adopted by firms included contruned importation or teliance of foreign knowledge and technology depicting foreign technology dependency discussed earlier. Consequently, we hypothesise that in Kenya, the strategy adopted by a firm influences spillower occurrence.

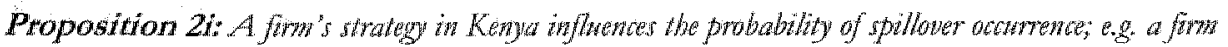

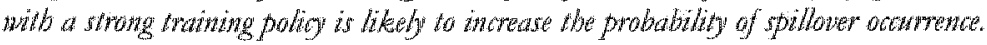

\subsubsection{Trade Orientation}

Trade orientation is another factor widely believed to influence the technological spillover process. In this thesis, trade orientation at the level of a firm will be considered in terms of export and import participation. Exports are likelly to result in spillovers in two ways. Hirst, when MNCs in a host country export, and second, when locally owned fims begin to participate in export. "To a locally owned firm producing for the domestic market, participation in export matket would imply adding sunk costs looking for new global markets, establishing international distribution linkages and networks as well as establishing overseas tramsport infrastructure. More time and incteased effort would be required to understand the global regulatory framework and contimuously learn the constantly changing consumers' tastes and preferences internationally. We hypothesise that locally owned fitms are likely to benefit from MNCs existing stock of knowledge on international market and hence enable them to become exporters. This shottens their process, which would hawe inadvertently been longer for the locally owned firms. This would take place if the MNCs in the host country produce for export market - this is often the case in developing countries. In such cases, MNCs will already have an existing export networlss abroad supported by established transport infrastructure internationally. Locally owned firms can benefit from the "export information externalities" through collaboration or more likely demonstration and penetrate the export markets. The MNCs" knowledge of intemational market could spill over to the locally owned firms through the MNCs' export activity. Through demonstration effects, the domestic firms can leatn or imitate the techniques (processing, production, marketing, networks, managerial or organisational) from $\mathrm{MNC}$, which would in turn enable them participate in the international export mathet.

The arguments are supported by the assimilation literature based on the East Asian miracle. That exports contributed tremendously to development of technology capability building as a result of internationall spillowers occurring from interactions with $\mathrm{MWN}$ (s well as sophisticated foreign clients abroad [Dahlman and Westphal, 1982; Westphal, Kim and Dahlman, (1985: pp. 137.50); Westphal, 1990; Lall, 1990; Rasiah, (1995: 2004)]. Aitken, Hanson and Harrison (1997) used Mexico to estimate the effect of export activity by MNCs in the industry and region. Export activities of MNCs in a sector had positive effects on the probability of whether a firm in the same sector, either foreign or domestic was an exporter. Similar results were observed for Uruguay using cross-sectional firm level data (Kokko, Zejan and Tansini, 2001). The same phenomenon was observed from studies conducted in cleveloped countries, where locally owned firms were allso shown to have benefired from 'export information externality' or demonstration effect from MNCs - examples include Greenaway, Sousa and Wakelin (2004) for UK and Barrios, Gorg and Strobl (2003) for Spain. 
In the second case, participation in the export marker is anticipated to stimalate a dynamic learning process in several ways. First, by incroducing pressure to compete in international markets the locally owned firms are made to pay attention to the global tastes and preferences and thus by doing so maintain wotld standards. We can tefer to this as learning by exporting. Secondly, participation in the export market forces locally owned firms to increase their technological effott in order to continuously learn and master techniques required in maintaining international comperitiveness at the world matket. As a result of the two factors, the locally owned firm learns and accumulates technological capability. It's innovative as well as absorptive capaciry are enhanced and thus its assimilation of knowledge spillovers. Exen at the local level the competition for foreign market based on the host country's available resources by the MNCs and locally owned firms stimulates domestic firms to lean and improve on their export performance. Export orientation is believed to relax the market size constraint, which means more MNCs and new locally owned firms can enter. The larger the number of firms the larger will be the spillover effects be as argued by the postulates of agglomeration economies.

Importation by a firm is also believed to have a positive relationship with spillover occurrence to the firm. This means that high spillover occurrence would be expected in locally owned firms that import than in those that do not import. The argument in support of this is that through imports, a firm is likely to increase its level of knowledge and technology particularly when imports are sourced from countries with fromrier R\&D and innovative capabilities. This would tresult in accumulation of absorption capacity necessary to assimilate spillovers. Imports of new capital and intermediate goods are viewed as some of the main channels for intemational transfer of knowledge, technology and innovation. In this tegard countries that participate in imports benefit the foreign technologies (Coe, Helpman and Hoffmaister, 1995). The proponents of international trade have elaborated this in detall (see Posner, 1961; Vernon, 1966; Romer, 1990; Grossman and Helpman, 1995). By importing, the firm learns through imitation, becomes innovative and at the same time builds absorptive capacity necessary to absorb spillovers from the MNCs. The argument is founded on the view that knowledge is embodied in international trade. Following the discussion above, we therefore set the following hypothesis for our testing:

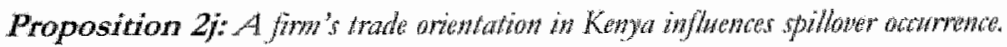

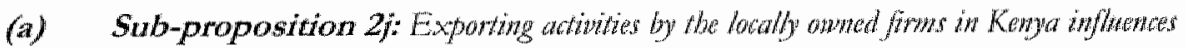
spillowers accurreste pasitively.

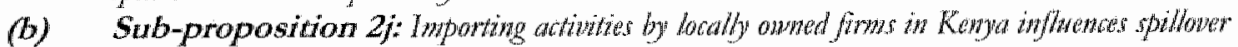
aicumence positivedy.

\subsubsection{Labour Market Conditions}

Labour matket conditions often influence spillowers occurrence and thus learning, capability building and innoxation. When analysing labour market conditions the most common factors examined include wages and affliation to trade unions. Related studies examining the role of labour market conditions indicate that good labour conditions can positively contribute towards industrialisation by stimulating competitveness [Sabel, 1989; Sabel and Piore, 1984; Zeitlin, 1989; Sengenberger and Zeitlin, 1991; Wilkinson and You, 1995/. The same studies have shown the converse to be also true involving low road to industrialisation when good labour market conditions are not observed. In the 
curtent context, we argue that when a firm observes good labour market conditions it is bound to pay high salaries and wages, offers fridge benefits, provides staff with haman resources training opportunities including enrichment programmes etc. In such cases, however, the workers morale is motivated reducing their willingness to leave their jobs. Hence the premium paid involving professionalls, skilled and technical workers translates into reduced spillover occurtence, which would inadvertently occur through mobility of such workers ${ }^{36}$. Contrary to the above, if the labour market conditions are just fait, uncertain or even bad, then the mobility of workers is bound to be high and so would be the accompanying technology spillovers. Given that the two industries considered are believed to observe good labour market conditions, it is predicted that good labour market conditions will affect the spillover occurrence negatively following the reasons advanced above. Wages will be used to represent labour market conditions.

\section{Proposition 2k: Good labowr market conditions inflwences spillover ocurrence negatinely in Kenya.}

\subsubsection{Influence of Spillover on Technological Innovations at the Enterprise Level}

We begin this section by looking at innovation from the perspective of a technically underdeveloped country. Quite often when talking about innovation there is a tendency to identify and define technological innovation with major, radical innovations or "Schumpetetian breakthroughs" associated with activities undertaken by firms at the technology frontier. Almost all the radical innovations take place in technologically advanced countries and are characterised by major contributions to the existing stock of knowledge, organisational changes and behavioural patterns.

Although much of what we therefore know in the innovation litetature seems to have been derived principally from technologically advanced countries, this should not be construed to reflect absence of innovation in the underdeveloped country industries. This has only to do with how innovation was initally conceptualised, in actual fact, even the most technologically backward countries within the underdeveloped countries have their own kinds of innovations only that their nature may differ substantially from innovations taking place in the advanced countries. Technological innovations taking place in underdeveloped countries do not constiute any landmark changes, which may be deemed as revolutionary in the world. 'The reason is simple, that they do not result in vast increment to the existing stock of knowledge or productivity in the industries. This is however expected given that firms in underdeveloped country industries have not yet accumulated enough and adequate, and perhaps necessary resources to facilitate occurrence of such breakthrough innovations. In the same vein, this argument helps explain the wide difference between the nature of innovation trajectories followed by the advanced countries and those followed by the rest of the countries.

As emphasised elsewhere in this study, innovation is now recognised in a systemic perspective with many users and producers of innovations. It's a dynamic and interactive process chamacterised by many interactions among firms and with many feedbacks involved at all levels of the production chain. Going by this notion, we would expect that

\footnotetext{
3 Note that good labour conditions could also imply positive impact of spillowers on firms' capabilinics.

37 Early worle by Schumpeter inspired a whole generation of economists. It should be pointed out that while this early work emphasised the importance of the individual entepreneur as in nowator, Schumpeter points to the big firms and their R\&D laboratories as the soutce of unnovation in his later contributions [Schumperer, (1934: 1952)]. "The tem "Schumpeterian brealithroughs" is therefore used to reflect major innovation that comes from R\&D laboratories of large firms in advanced councries.
} 
MNCs located in the industries of technically underdeveloped countries are participants in the innovation process and with a possible influence on innowation at the enterprises. In line with our study, we believe that in a country like Kenya; where domestic firms are not technically advanced, presence of MNCs is likely to influence innovation in the domestic firms through, competitive pressure compelling them to change, linkages, labour mobility and others.

In at study done by Rasiah (1995) on Malaysian Machine tool industry using a framework based on linkages, from the angle of local firms, revealed significant infuence of MNCs on the local firms innoxation and learning. The process took phace systematically in defined stages; first MNCs subcontracted parts fabrication with particular specifications. This gave local firms the opportunity to have their fabrication technology improved through constant monitoring by MNCs. In the second stage, MNCs monitored vendor's workshops in the early stages of production sometimes by stationing its engineers in rendor firms. Third, MNCs introduced a significant amount of innovation into adaptive engineering techniques employed to modify and restructure machines. Such modifications and innovations were pertinent as the MNCs tailor them to respective flexible production requirements. Local firms began to depict significant signs of flexible specialisation. Fourth, the local firms were able to establish export contacts abtoad with sister plants of the MNCs and finally, the local firms were able to take orders from independent firms (for an elaborate discussion on this see Rasiah, 1995; pp 167-74).

We shall therefore propose that occurrence of spillovers in the Kenyan industry is likely to increase the probability of technological innovation and learning. Here we regard innovation as changes firms have made in their own capacity or in response to competition from competing firms. They include new products they have introduced; more attention to feedback from clients; new processes that are more efficient, better quality control; reduced costs through energy or material usage; training of workers; linkage to local research institutions or production centers. The nature of innovation undertaken in developing countries, as we have discussed before, differs greatly from that of advanced countries as it mainly involves technological improvement on products or processes that lead to a fall in manufacturing time, reduction production and operation costs and increase in production and quality. Assessment of spillover influence will be assessed qualitatively from the case studies in Chapter 6 and 7 .

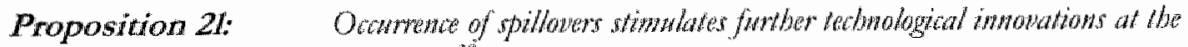

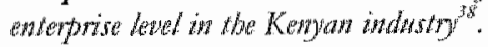

\subsection{Research Design and Methodologicall Setting}

To test the above set hypotheses, this study was designed in fout stages. In the first stage available aggregate and firm-level data was collected from official secondary sources for empirical analysis. The purpose of the first stage was to provide first hand information on spillover analysis in the Kenyan manufactuting industry. With this data, it was possible to understand certain dynamics and industry characteristics in the manufacturing industry. Similatly, it was also possible to identify sectors with high levels of MNCs and their activities. It was possible to determine whether the MNCs outperformed domestic firms in Kenya and if so in which sectors and on what fronts. The role played by MNCs

\footnotetext{
3A This hypothesis might appear true by the definition of spillover indes; howeweremphasis is paid to futher innowations undertaken by Kenyan enterprises as a result of inital spillover occurrence.
} 
in domentic firms' performance could as well be estimated at the level of the entire industry. Finally, it was also possible to empirically determine whether MNCs had any infuence of broad capability formation in the farms in Kenya. This was done by use of panel data to investigate the impact of foreign presence on local firms productivity. However, as discussed widely, use of empirical data and linear models in spillover analysis has its own limitations. It was therefore necessary to get behind the empirical antysis and attempt to investigate what happens in the firms by a way of conducting interviews. Thas formed the basis of the second stage.

In the second stage we therefore conducted a firm levell surwey. Since, secondary data was insufficient for the objectives set and hypotheses outlined, we resulted to firm level data collection mainly through face-to-face interviews. A pilot study was conducted before the actual survey, to pre-test the questionaire design. "This involved a practical field-test on the questionnire by conducting face-to-face interviex's with respondents in about five cases within the target sectors. This helped to detect and remedy in advance problems and other shortcomings that were likely to troubleshoot in the course of doing the actual survey. Qualitative approach was used to analyse mainly clata and information gathered from finm interviews. These data was mainly in form of words as opposed to statistical numbers. The qualitative data was coded putting it into conceptuall categories and create specific themes or concepts which enabled the analysis to be undertaken. Given the difficulties involved in qualitative data coding, the process was begun once data collection commenced.

'The thind shage involved case sudy approach. Based on the survey, several enterprises were selected for a deeper investigation in the form of case studies. The criterion for choosing firms for case studies was biased towards positive information obtained in the survey regarding technological spillovers and other important issues within the framework of this study's focus. These are discussed in detail in the case study chapters. The case study involved face-to-face interviews with production managers, scientists \& engineers using semi-structured questionnaires comprising both closed and open questions. The production managers and engineers provided information on rechnology while general managers provided information on how current government policies in Kenya influence company's decisions and strategies. Whete possible, open discussions. were held with other staff and a tour of the firms' plants was undertaken to acquaint with techniques in use. Methods used in case study analysis included comparative analysis as well as case and synthesis analysis.

The role of institutions and systemic influences was equally assessed in the spillover occurrence process. Thus in the ford $3 /$ tge, a few instimutions were selected from business associations, government deparments and instimtions - R\&D, academic as well as financial institutions. The information was obtained through interviews and discussions held with personalities deemed knowledgeable mainly in inwestment, industry, innovation, privitisation and FDI. These personalities included government officials, professionals and academic scholars. Institutions included investment promotion council $(\mathrm{CPC}$ ); Kenya Industrial Training Institute (KITI); Kenya Industrial Estates (KIE); Industrial and Commercial Development Corpotation (ICDC); Kenya Bureau of Standards (KEBS); Kenya Industral Property Office (KIPO); National Council for Science and "Technology (NCST) etc. See Table 2.3 for the whole list of institutions and numbet of interviews conducted. 
Table 2.3 List of Institutions and Number of Interviews Conducted, Kenya

\begin{tabular}{|c|c|}
\hline Institutions and Business Associations & No of Interviews Conducted \\
\hline \multicolumn{2}{|l|}{ Economic Policy } \\
\hline Ministry of Finance (MoF) & Several \\
\hline Ministry of Planning and National Development (MPND) & Several \\
\hline Ministry of Trade and Industry (MTI) & 1 \\
\hline Export Processing Zone Authority (EPZA) & 2 \\
\hline Expont Promotion Center (IPC) & 1 \\
\hline Investment Promotion Council (TPC) & 2 \\
\hline \multicolumn{2}{|l|}{ Technology Policy } \\
\hline Ministry of Education, Science and Technology (MEST) & 1 \\
\hline National Council for Science and Technology (NSCT) & 1 \\
\hline \multicolumn{2}{|l|}{ Competition Policy } \\
\hline The Monopolies and Prices Commission & 1 \\
\hline \multicolumn{2}{|l|}{ (6) } \\
\hline Kenya Bureau of Standards (KEBS) & 2 \\
\hline Kenya Industrial Research Institute (KIRDI) & 1 \\
\hline They include Kenya Industrial Training Institute (KITT) & 1 \\
\hline 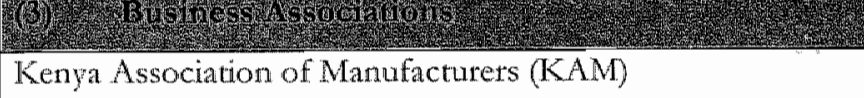 & 2 \\
\hline \multirow{2}{*}{$\begin{array}{l}\text { Fresh Ptoduce Exporters Association of Kenya (FPEAK) } \\
\text { Kenya National Chamber of Commerce and Industry } \\
\text { (KNCCD }\end{array}$} & 1 \\
\hline & 1 \\
\hline \multirow{2}{*}{ 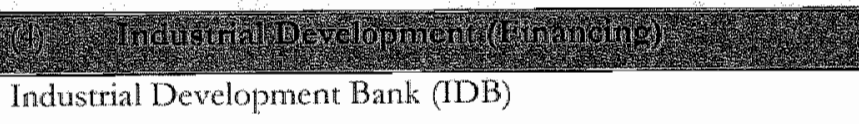 } & \\
\hline & 2 \\
\hline I.C.D.C & 1 \\
\hline Development Bank of Kenya (DBK) & 1 \\
\hline \multirow{2}{*}{$\begin{array}{l}\text { Kenya Industrial Estates (KIE) } \\
\text { (b) }\end{array}$} & 1 \\
\hline & \\
\hline IPAR, ECEG, ATPS, IDS & At least 1 each \\
\hline Unversity of Nairobi \& Colleges & several \\
\hline Kenya Institute of Public Policy and Research Analysis & 2 \\
\hline
\end{tabular}


The purpose of this chapter was to provide an analysis of technological spillower literature and develop a theoretical framework for guiding the implementation of this study. A critical assessment of both theoretical and empirical literature on FDI and rechnological spillovers was presented. The analysis of the literature revealled that most of the past work relied on productivity models based on the theories af production function. It was also observed that although estimation techniques had cvolved significantly since the pioncering work, the results of spillower accurrence and their impact remained inconclusive. While one side of the literature based on prodactivity approach produced evidence supporting spillover accurtence, the other side produced contradictory evidence that showed lack of spillowers from FDI. As observed, the differences in the results obtained could be attributed to mary things ranging from methodologies employed, firm differences, industry variations to country specificities.

This chapter cliscussed in detail the weaknesses of earlier approaches, mainly productivity techniques in spillover analysis. On the basis of the emerging issues and following developments in the endogenous and evolutionary literatute, an alternative framework was suggested. Technological spillowers were viewed as complex in nature, uncertain, imperfectly understood and thus required an equally complex approach. An endogenous, evolutionary and institutional approach that views enterprises as embedded in dynamically changing economic and social-economic-institutional networks would be required. Hence, in addition to the spillover literature, two strands of theoretical literature from which this study drew much insight were adopted. The first one was cluster and network dynamics. The second one was the literature on technological innovations which particularly emphasises the importance of NSI in the spillovers process.

This thesis seeks to examine production spillovers from foreign firms to local firms by conceptualising the process in terms of learning, capability building and innovation. An integrated spillower index was developed which was taken as the measure of technological spillovers. This index was then used in quantitative analysis of spillovers including determinants of spillover occurrence. Based on the determinants identified using this framework, several hypotheses were identified for our investigation. The hypotheses formulated sought to determine the influence of certain parameters on the spillower process. We shall test the hypotheses using the framework set, survey and case study approach with a few firms and institurions. The subsequent chapters of this study will present detailed analytical chapters mainly based on empirical analysis and later backed by several case studies. 


\section{MANUFACTURING INDUSTRY AND FOREIGN DIRECT INVESTMENT IN KENYA: ORIGIN AND INSTITUTIONAL SETTING}

\subsection{Introduction}

In Chapter 2 we presented a critical analysis of FDI and spillover literature. An alternative theoretical framework was presented on which an analytical framework was developed to guide this study. The purpose of this chaprer is to motivate our study by putting FDI analysis into context through a critical examination of their origin and their industrial effect focusing on spillover occurrence, industrial capability development and performance. Given the importance of institutions in FDI and industrial capability development, their role will be equally examined in this chapter. Similarly, since industrial policies pursued in Kenya are believed to have had significant influence on FDI including $\mathrm{FDI}^{\prime}$ s role in manutacturing industry; analysis undertaken in this chapter will therefore take such policies into consideration. Further, Kenyan manufacturing industry has a long history that dates back to the colonial days and industrial policies pursued from that period ate believed to have largely determined the existing structure of manufacturing in the country. As will be shown in this chapter, manufacturing in Kenya started with establishment of a few manufacturing industries during the colonial em, which were all foreign owned located mainly in agro-based industries performing simple and basic manufacturing activities characterised by limited value added. As a result of Foreign capital investment in manufacturing received from Britain during this period, colonial period, it is claimed that Kenyan manufacturing enjoyed an early coloniat manufacturing experience from British firms. In addition, the country continued to enjoy most of the infrastructure ${ }^{3 y}$ and a vast of revenue earning primary sectors (such as tea, sisal and coffee estates) all developed in that period. In light of these early developments and subsequent changes with time, a historical backdrop coupled with instirutional analysis become relevant if we are to understand origin of FDI and its perceived impact on industrial development.

Similarly, institutions created and FDI policies adopted after independence are bellieved to have had tremendous infuence on FDI and their effect in manufacturing. For example, at independence; institutions erected and policies enacted helped attract move foreign investment, mainly Huropean, into the country. Since then, a relatively large FDI stock has been accumulated in Kenya's manufacturing. Due to their participation in manufacturing after independence; i.e. capital investment, contribution in exports, value added, employment and revenue generation to the economy etc the country is over time believed to have benefited tremendous manufacturing expetience in the form of technological spillovers from the foreign investments. "This is more so with the facilitation and coordination role undertaken by institutions established. The ditect consequence of this is that FDI plays a positive role in industrial capability development. However, this is still a contentious issue since to date no concrete studies on FDI have

\footnotetext{
39 A good example under cransport and communication is the Uganda tailway line, which was comstructed in the period 1895 - 1901 . A few other internal railway lines were built thetcarter in the country but primarilly designed to serwe the interests of the Europenn setters. The first roads were built during bis periond eg. the Nombasa - Kisumu road completed in 1896 . The first aitr transport was also introduced with the furst neroplane imported into the country in 1925. Postal and tetephone services were introduced in the santic period; 1900 and 1908 respectively. Another important facility developed during this period was the Mombasa port cacility
} 
been conducted in the country to confirm technological spillovers, their form, and mode of occurrence or perceived impact on domestic firms. This not withstanding, the role of supporting institutions in FDI, spillover and industrial capability development has not been critically addressed either. As discussed in Chapter 2 , occurrence of technological spillovers in the industry can be a complex phenomena due to theit tacit and noncodifiable nature, takes place through interactions between domestic firms, $F D I$ and host country institutionsti . Institutions in this context are taken as outlined in Chapter 2 , as organisations - economic agents whose systemic embeddedness in the NSI stimulates spillovers occurtence, firms" technological capability, innovation and performance. Conseguently, this chapter will address the following issues:

- Examine how the industrial policies pursued, over time, influenced FDI in Kenya's manufacturing industry.

- Examine broadly the role of FDI in Kenyas industralisation process by investigating spillover occurrence and their consequences on industrial capability development and performance.

- Fxamine the role of institutions established, over time, in supporting industrialisation with regard to $\mathrm{FDT}$, spillower occurrence, capability development and performance.

This chapter is divided into five sections. Section 3.2 presents a brief overview on Kenya's history, population and economy at a glance. In section 3.3, we address the industrial policies and FDI. "The section examines the origin and institutional setting. This is done in four sub-sections. First anz is during the colonial period. Sacond one is during the eatly decades of import substitution. Thind ane is during the structural adjustments period. The fowrth ane is during the recent period concentrating on recent performance and effort towards industrialisation. In the last section, 3.4, we present the summary and conclusion.

\subsection{Kenya: A Brief Overview}

\section{History and Political Situation}

The Kenyan history spans over many centuries ago. However, given that this study focuses on $\mathrm{FDI}$, we will not delye much into the history but it is important to mention something briefly about early foreigners into the country. According to the Kenyan history, Arab traders were among the first foreigners to establish their settlement along the Kenyan coast. However, in the $16^{\text {th }}$ and $17^{\text {th }}$ Centuries the Portuguese people also artived at the Kenyan coast and gradually established a stronghold there until 1700 , when Kenya became a British protectorate. In the $18^{\text {th }}$ Century, Kenya saw an influx of exploters and Christian missionaries followed by European setrlers. The country gained independence in 1963 and became a republic in 1964 under one political party, Kenya African Nation Union (KANU). Kenya remained a one party state until 1992 when elections were held for the first time under a multiparty system.

\section{Plyical Ceogrably}

Kenya is a relatively big country with a total land area of $580.4 \mathrm{KM}^{2}$. It shares a border with Ethiopia, Somalia, Sudan, Tanzania and Uganda (see Map 3.1 for more details). The country is well endowed with a broad range of natural resources, flora and fauna, and arable land. Kenyan highlands comprise the most successful agricultural production

\footnotetext{
40 Ewen then a host of other factors must be present as discussed in Chapter 2 such absomptive capacity, strong human capital, supportive infrastructure and accompanying policies erc.
} 
regions in East Africa. Its savanna is a home to thousands of wild animals, birds and snakes. The Great Rift Valley cuts through the country presenting one of the most magnificent geographical sceneries. The $K$ enyan $\mathbb{R i f t}$ ralley is a section of about 6,000 Km rift system which stretches from the Dead Sea in the Middle East; South through the Red Sea, Ethiopia, Kenya, Tanzania, Malawi and into Mozambique (see Map 3.1). The country shares Lake Victoria wh other East African Countries. Also the country has long coastal line (with Indian Ocean) that stretches $536 \mathrm{~km}$, richly endowed with nice habours and beaches that serve as a great attraction to the tourists.

Kenya has a tropical climate characterised by an average temperature of 23 degrees centigrade. The country has wo tainy seasons spanning the periods April-May and October-November. The altitude ranges from sea level to 5,199 meters and thus produces a wanied average daily temperature.

\section{Population Development and Society}

The Kenyan population was estimated at 31.3 million in 2002 with approximately $65 \%$ of the population living in the rural areas. More than 40 ethnic groups reside in Kenya with the principle ethnic groups being Kikuyu (22\%), Luhya (14\%), Luo (13\%) and Kamba (11\%). All other African groups accounted for $27 \%$, while all non-Africans (Asian, European and Arab) accounted for a paltry $1 \%$. The population annuall growth rate which used to be one of the highest in the world, above $3 \%$ until early 1900 s, has now fallen below $2.5 \%$ since 2000 . The life expectancy for males was 46 years in 2002 and that of fernales was 45 years (see Table 3.1 for details). Fertility in terms of number of births per woman also fell from 8.1 in 1970 to 4.2 in 2002 . The mortality rate in terms of infants per 1,000 live births was 78 in 2002 .

Table 3.1: Selected Population and Social Indicators for Kenya, 1970-2002

\begin{tabular}{|c|c|c|c|c|c|c|c|c|c|}
\hline Indicator & 1970 & 1975 & 1980 & 1985 & 1990 & 1995 & 2000 & 2001 & 2002 \\
\hline \multicolumn{10}{|l|}{ POPULATION } \\
\hline Population, total (Mn) & 11.5 & 13.7 & 16.6 & 19.9 & 23.4 & 26.7 & 30.1 & 30.7 & 31.3 \\
\hline Population growth (annual \%) & 3.4 & 3.7 & 4.2 & 3.5 & 3.0 & 2.6 & 23 & 2.1 & 2.0 \\
\hline Rural population (\% of total population) & 90 & 87 & 84 & 80 & 76 & 72 & 67 & 66 & 65 \\
\hline \multicolumn{10}{|l|}{ LIFE EXPECTANCY AT BIRTH (years) } \\
\hline Both sexes & 50 & 52 & 55 & 57 & 57 & 53 & 47 & & 46 \\
\hline Females & 52 & 55 & 57 & 59 & 59 & 53 & 47 &. & 46 \\
\hline Males & 48 & 51 & 53 & 55 & 55 & 52 & 47 & 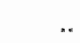 & 45 \\
\hline \multicolumn{10}{|l|}{ FERTILITY RATE (TOTAL) } \\
\hline total birchs per woman & 8.1 & 8.0 & 7.8 & 6,9 & 5.6 & 49 & 4.4 & . & 4.2 \\
\hline \multicolumn{10}{|l|}{ MORTALITY RATE } \\
\hline Infart per 1,000 live births & 96 & 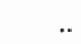 & 73 & .. & 63 & 73 & 77 & . & 78 \\
\hline \multicolumn{10}{|l|}{ LITERACY RATE (\% aged 15 and above) } \\
\hline Both sexes & 41 & 48 & 56 & 64 & 71 & 77 & 82 & 83 & 84 \\
\hline Females & 26 & 34 & 43 & 52 & 61 & 69 & 76 & 77 & 79 \\
\hline Males & 56 & 63 & 70 & 76 & 81 & 85 & 89 & 89 & 90 \\
\hline \multicolumn{10}{|l|}{ SCHOOL ENROLLMENT (\% Gross) } \\
\hline Secondary both sexes & 9 & 13 & 20 & 21 & 24 & 24 & 31 & 32 & . \\
\hline Secondary, Eemales & 5 & 9 & 16 & 16 & 21 & 22 & 29 & 30 & . \\
\hline Secondary, males & 13 & 17 & 23 & 26 & 28 & 26 & 32 & 34 & - \\
\hline Tertiary both sexes & 1.0 & 1.0 & 1.0 & 1.0 & 2.0 & 2,0 & 3.0 & 4.0 & . \\
\hline Terviary, females & .. & . & 0.0 & 1.0 & 1.0 & 1.0 & 3.0 & 3.0 & \\
\hline Terviary, males &.. & $\ldots$ & 1.0 & 2.0 & 2.0 & 20 & 4.0 & 4.0 & \\
\hline
\end{tabular}

Source: World Devellopment Indicators, WDI 2004; Central Bureau of Statistics 
The propotion of Kenyans living in extreme conditions of poverty was high. According to the awailable poverty report, it was estimated that in 1997 the prevalence of poverty was 52.3\% - people who conld not achieve the minimum expenditure to acquire the basic food and non-food items ${ }^{45}$. Overall there was high poverty in the rural areas. compared to the urban areas.

The adut literacy tate for people aged abowe 15 years has risen by more than twofold to stand at $84 \%$ in 2002 from low level of $41 \%$ witnessed in 1970 . The literacy rate for males was notably higher at $90 \%$ compared to that of women at $79 \%$. In 2001 , secondary school enrolment for both sexes was $32 \%$ while tertiary enrolment for both sexes was: $4 \%$. Tertiaty enrolment is lower than in most developing countries especially those in Asia, Thailand (37\%), Malaysia (26\%) and Indonesta (15\%) (World Bank, 2004).

\section{The Kengan Economy at a Glance}

Time setics data on selected economic indicators is shown in Table 3.2. Although the GDP in constant US continued to expand and had teached 10.1 billion by 2002 , the GDP growth rate had decined steadily to an annual average tate of $1 \%$. Itonically, the downward trend in economic growth seemed to have started moments after commencement of the structural adjustment programmes in the country. This point will be tevisited at a later stage. The GDP per capital in constant prices was US\$ 322 qualifying the country as a low-income economy. According to the World Bank classification a country with less than US $\$ 765$ is classified as a low-income economy.

Most of the other economic indicators seemed to indicate a downward trend in economic performance compared to what was observed in 1970 s and early 80 s. With regard to value added, only services recorded an increase while industry and agriculrure did not. Gross capital formation was also on a downward trend. Foreign direct investment as percentage of gross fixed capital formation depicted a mixed performance - erratic trend. This is discussed at a later stage.

As noted in Table 3.2, trade in goods also appeared to be on a downward trend. Although high tech exports are on an upward trend, exports of goods and services seem to have declined. Kenya is a main exporter of agricultural commodities such as coffee, tea and horticultural products. Kenya also exports textile and garments mainly to USA undei $A G O A$ program. Its main imports include primary industrial inputs which include crude peroleum and refined petroleum products, industrial machinery and equipment, iron and steel, agricultural and transport machinery, fertilisers and pharmaceuticals.

The number of fixed line and mobile phone subscribers per 1,000 people was approximately 52 while those with telephone main lines were approximately 10. However, while in the case of mobile phones the number of subscribers is on the increase that of telephone lines seems to have stagnated at 10 per 1,000 people. Similarly people with personal computers and Internet users per 1,000 people had increased substantially to about 6 and 13 respectively compared to the lower levels witnessed in the in the 1990 s and before.

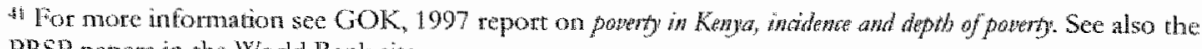
PRSP parpers in the World Bank site.
} 
Map 3.1 Kenya, Provinces, Principal Cüties and Neighbours

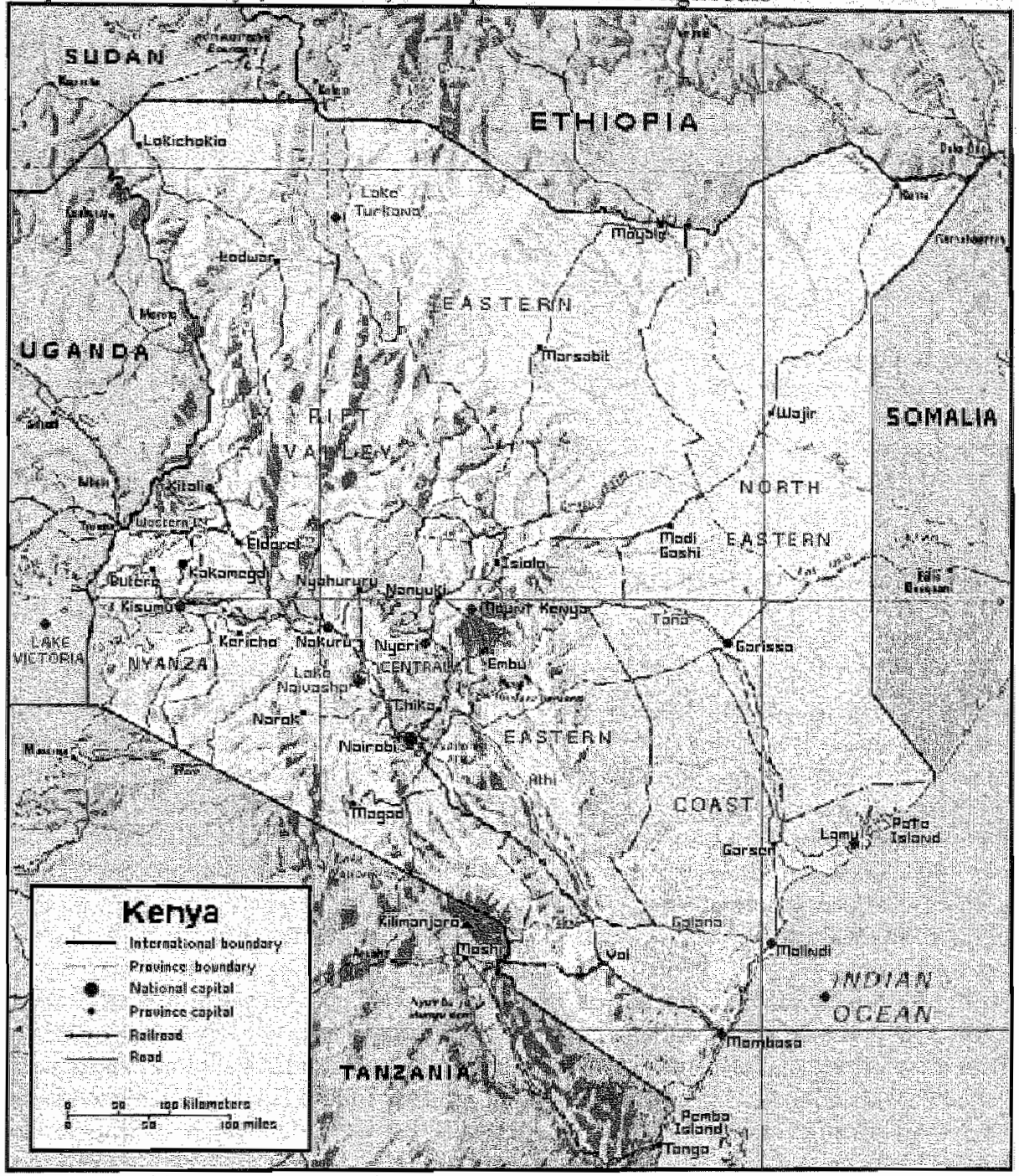

Source: http://www.blissites.com/kenya/map.hml 


\begin{tabular}{|c|c|c|c|c|c|c|c|c|c|}
\hline Indicator & 1970 & 1975 & 1980 & 1985 & 1990 & 1995 & 2000 & 2001 & 2012 \\
\hline \multicolumn{10}{|l|}{ ECONOMY } \\
\hline GDP (constand 1995 USS) & 2.6 & 4.1 & 5.6 & 6.4 & 8.4 & 9.0 & 9.9 & 100 & 10.1 \\
\hline GDP (current USS) & 1.6 & 3.3 & 7.3 & 6.1 & 8.6 & 9.0 & 10.4 & 11.2 & 123 \\
\hline GDP growth (annual $\%$ / & .. & ... & 6 & 4 & 4 & 4 & 0 & 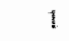 & 1 \\
\hline GDP per capira (constant 1995 USE) & 226 & 301 & 337 & 320 & 358 & 339 & 328 & 325 & 322 \\
\hline Agriculourc, value added (\% of GDP) & 33 & 34 & 33 & 33 & 29 & 31 & 20 & 19 & 16 \\
\hline Services, ete, value added (\% of GDP) & 47 & 40 & 47 & 48 & 52 & 53 & 62 & 63 & 65 \\
\hline Industry, value added (\% of (ODP) & 20 & 20 & 21 & 19 & 19 & 16 & 19 & 18 & 19 \\
\hline Gross capital formation (\% of CDD) & 24 & 18 & 25 & 22 & 20 & 18 & 15 & 15 & 14 \\
\hline 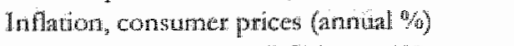 & 22 & 19.1 & 13.9 & 13.0 & 17.8 & 1.6 & 10.0 & 5.7 & 20 \\
\hline $\begin{array}{l}\text { Official exchange rate (LCU per USS, } \\
\text { period awerage, }\end{array}$ & 7.1 & 7.3 & 7.4 & 16.4 & 22.9 & 514 & 76.2 & 78.6 & 78.7 \\
\hline \multicolumn{10}{|l|}{ TRADE AND FINANCE } \\
\hline Trade in goods ( $\%$ of GDP) & 47 & 48 & 46 & 39 & 38 & 54 & 47 & 46 & 44 \\
\hline Exports of goods and services (of of GDP) & 30 & 30 & 28 & 25 & 26 & 33 & 26 & 26 & 27 \\
\hline Imports of goods and serwices (\% of GDP) & 31 & 35 & 39 & 26 & 31 & 39 & 36 & 36 & 30 \\
\hline $\begin{array}{l}\text { Higli-tectinology exports (\% of } \\
\text { manutactured exporss) }\end{array}$ & 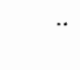 & .. & . & 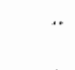 & 4 & 4 & 4 & $\ldots$ & 10 \\
\hline $\begin{array}{l}\text { Foreign direct investment, net inflows for } \\
\text { of gross capial formation }\end{array}$ & 4.0 & 3.0 & 4.0 & 2.0 & 3.0 & 2.0 & 8.0 & 3.0 & 3.0 \\
\hline $\begin{array}{l}\text { Total debt service (9\% of exports of goods } \\
\text { and services) }\end{array}$ & .. & 15 & 21 & 39 & 35 & 30 & 19 & 16 & 14 \\
\hline \multicolumn{10}{|c|}{ TECHNOLOGY AND INFRASTRUCTURE } \\
\hline $\begin{array}{l}\text { Fixed line and mobile phone subscribers } \\
\text { (per 1,000 people) }\end{array}$ & .. & 3.9 & 4.5 & 5.9 & 79 & 10.1 & 1.4 .6 & 29.6 & 51.8 \\
\hline $\begin{array}{l}\text { Telephone average cost of local call (US\$ } \\
\text { per three minutes) }\end{array}$ & .. & . & .. & .. & .. & 0.1 & 0.0 & a.1 & 0.1 \\
\hline Telephone mainines (per 1,000 people) & .. & 3.9 & 4.5 & 5.9 & 7.9 & 10.0 & 10.5 & 10.4 & 10.3 \\
\hline Personal computets (per 1,000 people) & .. & ... & .. & .. & 0.4 & 0.7 & 4.9 & 5.6 & 6.4 \\
\hline Internet users (per 1,000 people) & .. & * &. &.. & $\ldots$ & 0.0 & 3.3 & 6,4 & 12.5 \\
\hline Roads, paved (\% of total roads) &. &. & .. &. & 12.8 & 13.8 & 12.1 &.. & \\
\hline
\end{tabular}

Source: World Development Indicators, WDI 2004; Central Bureau of Statistics Kenya

\subsection{Industrial Policy and FDI: Origin and Institutional Setting}

Kenya's industrial policy can be classified into two main categories; the import substitution and the export orientation. As will be discussed in a moment, import substitution industrialisation, which was the main mode of industrialisation during the colonial days, continued to be encouraged until mid 1980 s when it was gradually replaced with expott-oriented industrialisation dawning the era of liberalisation measures also advocated as part of World Bank structural adjustment programme (SAPs). Given that import substitution was initiated in Kenya before her independence, an analysis of industrial policies in Kenya without a backdrop to import substitution policies pursued during the colonial period would be incomplete. This is more so because as noted earlier; the mode of industrialisation pursued influenced during this period the inflow and kind of FDI as well as facilitating instirutions including those established to support industrialisation. This section therefore starts by examining, albeit briefly, the industrial policies that existed before Kenya's independence, during the colonial days and their influence on FDI and broad industrial capability development. Since industrial policies followed after independence kept changing at different time periods, this would have direct and/or indirect conseguences on FDI and hence their effects in manufacturing industry. Consequently, for a comprehensive examination of industrial policies pursued 
and their anfuence on FDI, our analysis will be done in three distinct phases. The early decades of mport substitution will be examined first followed by the en of structural adjustments and liberalisation and export promotion, and finally the recent performance and efort towards industralisation in Kenya.

\subsubsection{Pre-Independence: The Colonial Period}

The history of Kenyan manufacturing industry dates back to the colonial period from which the existing manufacturing characteristics including those depicted by FDI are likely to have taken their bearing. To appreciate this observation, an examination of industral policies during the entire colonial period, would have to be examined, albeit briefly, alongside various modes of capital investment with particular emphasis to the kind of manufacturing industries established and their ownership stucture. Thus this analysis is presented in two phases: the period before 1945 and the period 1945-63. The choice of the two time periods is not arbitraty. The period before 1945 can be regarded as the pre-war period (i.e. First and Second World War) while the period after 1945 can be considered as the post war period. The period 1945-63 differs significantly from the period before 1945 in that in the period 1945-63 there was a nadical transformation towards industrial development in the British colonies. In the later period, Britain encouraged its MNCs to invest in Kenya - as it did in its other colonies. Thus while the former period was characterised by little industrial development activity, the latter petiod was marked by an improved effort to promote mantufacturing industry in Kenya with significant participation by British MNCs.

\section{(i) The Period Before 1945}

Kenya was founded as a British colony in 1890 s and converted into a Crown colony in 1920. Existing literature on colonial history reiterates that several factors induced the formation of colonies in the nineteenth and twentieth centuries. Fitst, the rush for colonial expansion during this period was to develop and control sources of strategic primary goods, taw materials and foodstuffs. Second, it was assumed that by controlling the activities undertaken in the colonies, the colonial territories would provide an export market "protected markets" for the colonial manufactured products. As a British colony, Kenya's role was reduced to that of raw materiall production to supply the British manufacturing industries. It was also clear that Kenya would serve as a growing market for British marufactured products - once these products are manufactured in Britain they would then be exported back to the Kenyan matket including those of other British colonies in the region ${ }^{42}$. This had a negative implication in that it would not stimulate strong domestic manufacturing capability development.

In order to achieve the colonial objectives, several things were put in place; first, the British government provided funds for infrastucture development, which included roads and railway to facilitate transportation of primary goods - food crops and raw materials from the mainland. 'The funds availed facilitated the building of the Kenya Uganda raikay in the period (1895-1901). Port facilities were also developed and export-import warehouses established to facilitate export of primary goods and import of consumer goods. Second, the British government encouraged European settlers to settle in Kenya and participate in commercial agriculture directed towards exporting. The commerctal agricultural activities were undertaken in the so-called 'white highlands" in Kenya with

\footnotetext{
42 As noted in Jorgenson (1975), the incomoration of the Kenynt conomy into the international capiatlet system under the aegs of British commercial indereste consigned Kenya to the role of raw materiats supplier to the British industry.
} 
Labout supplied by indigenous Africans (Pearson, 1969). Since commercial agriculiure turned out to be the main mode through which raw materials were generated and expotted to Britain, the European settlement was further encouraged in 1920 when Kenya was declared a Crown colony in 1920 making the number of European setrlers in early 1920 s reach about 20,000 . Formation of a Crown colony in 1920 was the official sanctioning of settlet dominance in Kenya (Swainson, 1980: pp. 5-6, 21-6). Examples of major MNCs from UK, which made their investment during this period, included James Finlay (1924) in tea production; Brooke Bond (1924) in tea and coffee production; Mitchell Cotts (1936) in sisal production [Kaplinslky, 1978; Swainson, 1978: pp. 50-2; 1980: $\mathrm{pp}$. 63-5 - see Table 3.3]. By participating in raw material generation, the European settlers would enable the British government to recover the costs incurred in the construction of the Kenya-Uganda raiway line. Finally, in order to encourage and support production for exports by European settlers, import protection and export incentives were offered.

The effort by the settlers to have full control and dominate in all social and economic activities reflected a clear emerging pattern of de-indigenisation. Jorgensen (1975) offered a luminous illustation of how the de-indigenisation process of the Kenyan economy took place during the collonial days. He examined the role of MNCs in the deindigenisation process using a three-level analytical framework that constituted structure of the economy, control over individual production and the distribution of firms, and the racial division of labour within firms. Jotgensen showed how Kenya entered into the vertical international division of labour during the colonial period by participating in international trade suited to the colonial masters. By so doing the "structure of the domestic economy was transformed to produce agricultural goods needed by the external economy and to import consumer goods and machinery from the external economy." De-indigenisation at the second level took place in the form of ownership of farms, firms and other commercial entities. Africans were not supposed to participate in either the interior or external trade with the rest of the world. These were left exclusively in the hands of non-indigenous Europeans and Asians ${ }^{4}$. Africans were also denied control over units of production and over production itself. At the third level, division of labour within firms, Africans were forced to become labourers. Under pressure from European setters, Jorgensen (1975) noted that the colonial regime ralegated the African population to a subservient role as labourers meant to produce largely fot expont to satisfy needs of non-Africans. They were not allowed to participare in production of trade goods except peasant production of foodstuffs for consumption within their native reserves (Jorgensen, 1975: pp.143 155). Asians participated in production but were restricted to light small scale manufacturing, characterised by low capital and thus value added. The phrase below explanins it all:

Europeans controlled the colonial administation apparatus, financial institutions, the larger import-export firms, shipping, mining (gold and soda ash), plantations, large farms, large scale food processing firms (breweries, bacon factories, co-operative creameries and canneries), and the larger commercial firms in urban areas. Astans controlled smaller importexport firms, most of the retail shops in cities and towns, financial institutions serving the Asian community, and small-scale manufacturing (aluminum pors, soap, wegetable oils, and sawmills). In addition, Asians, filled most of the positions of artisans and clerks in European and Asian firms and in the colonial

\footnotetext{
4. Wote that Astans first arrived in Kenya in the mid of 1890 s. History has it that in 1896, a gloup of 2000 coolies (unskilled labourers) and hundreds of stone masons, black smiths, draftsmen, clerks, carpenters and sumeyors artwed in Kenya. They were all brought by the British govemnent, 'colonial gowernment' to participate in the consmuction of Kenya - Uganda malwy line.
} 
sdministration. Afticans controlled pety trade; subsistence farming and subsistence pastoral agriculture within the Native reserves or worked as labourers for Eutopens and Astans (Jorgensen, 1975: p. 147).

Based on the colonial setting laid out in Kenya, it is clear that from the outset of British colonial rule emerged as a policy of simple primary production without any substantive and immediate policies towards industrial development. Lack of an industrial policy demonstrated unwillingness and lack of effort by the British government towards the dextelopment of a manufacturing industry in Kenya. Hence the manufactuting temained mascent characterised by low technological capability dewelopment and thus low value added manufacturing activities. The existing policies were in favour of investment in commercial agriculture and a few metcantile activities strictly dominated by foreign and non-indigenous firms - Asians firns. Existing literature on Kenya's industrialisation explicitly articulates lack of political will from the British colony in support of manufacturing industry i.e. Swainson (1980) puts it that:

During this time it is not surprising that the colonial office were indifferent and often hostile to colonial artempts to develop manufacturing industry. The work of the socalled development agencies before 1939 illustrates the general tinwillingness on the part of the British gowernment to encourage colonial industries. The Empire Marketing Board, for instance, gave no assistance to any forms of manufacturing and colonial development advisory committee in theory placed no limit on its spheres of activity, but in practice it totally ignoted the industrial secton (Swainson, 1980; p. 26).

Analysis done indicates that very few manufacturing industries were established in the early colonial days and most of the agricultural commodities $(78 \%$ ) were exported to Britain in their traw and unprocessed form (Vaitsos, 1991: p. 10). As Swainson (1980) frames it "... the settler bourgeoisie in Kenya was involved in a process of primirive accumulation of capital' (Swainson, 1980: p. 6). The processing was undertaken under strong tariff wall and trade policies that only allowed processing of a few agricultural commodities for local consumption. It is important to emphasise at this point that a few investments were also made outside the agro-based industries by subsidiaries of major MNCs to supply certain essential services and goods e.g. cement, salt, power and lighting (see Table 3.3 for more details). Such subsidiaries of British MNCs included; Magadi Soda Co LTD (1911) for the extraction of soda ash; East African Power and Lighting Co LTD (1922) for electrical power generation; Gailey and Roberts (1924) for import and distribution of agricultural machinery and East African Portland Cement (1933) for cement clinker grinding. Since imports were protected, generally no imports from other countries were allowed into the Kenyan market during this period as the source of external products remained United Kingdom to a large extent. As mentioned earlier, no strong manufacturing promotion would be encouraged since Kenya was supposed to serve as a protected market for the British manufactured goods and as such emergence of strong manufacturing firms was bound to create competition for the British manufactared goods in the country and other neighbouring colonies. However, during the Second World War, the European settlers in East Africa were unable to get their imports from Britain by sea culminating in a severe shottage of consumer goods Munene and Wandibba, 1989: pp. 111-3). Due to intense pressure by the setters, there was a slight change in the imperial policy in 1940 allowing selective kind of processing for import substitution and only by foreign and settlers firms (Swainson, 1980: p 31). Nonetheless, no concrete policy was fomblated in favour of industry which still reflected lack of colonial will, commiment and effort to establish a dynamic manufacturing base in the country. 
Table 3.3: Principal Foreign-Based Firmsin Kerry before 1945

\begin{tabular}{|c|c|c|c|}
\hline Estates & Firmi & Business & Country of Origin/ / Paremit \\
\hline \multicolumn{4}{|c|}{ Estates and primary Processing: } \\
\hline 1006 & Britush bast Arta $C o$. & $\begin{array}{l}\text { Exporters of primaticy } \\
\text { ptoduce, manufacturing } \\
\text { agents }\end{array}$ & $\begin{array}{l}\text { BEA, Michell Cots (aftet } \\
1945)\end{array}$ \\
\hline 1007 & East A frican Tobacco Co. & $\begin{array}{l}\text { Trading and growing robaco } \\
\text { products }\end{array}$ & $\begin{array}{l}\text { Brivis Imperall Tobacco } \\
\text { Co. (UK) (later British } \\
\text { Americam Tobacco Co.) }\end{array}$ \\
\hline 1922 & East African Breweries & Berer manulacture & Ind Coope Itd (UK) \\
\hline 1924 & Arican Highlands Produce $\mathrm{Co}$ & Tera manufacture & James Finlay ( $\mathrm{CK})$ \\
\hline 1931 & Ango-trench Sisal $C o$. & Sisal growing & $\begin{array}{l}\text { Amglo-French Sisal Co. } \\
\text { (Paris) }\end{array}$ \\
\hline 1924 & Kenya Ta Co. & Tea and coffee processing & Brooke Bond (UK) \\
\hline 1932 & $\begin{array}{l}\text { East African Taning \& Extract } \\
\text { Co. }\end{array}$ & $\begin{array}{l}\text { Warte bark ard extracti } \\
\text { manuficture }\end{array}$ & $\begin{array}{l}1 \text { Naral Tanning \& Fxtract } \\
\text { Co. } \\
\text { 2Forestal Land \& 'Timber } \\
\text { (UK }\end{array}$ \\
\hline 1935 & Enst African Meat Co. & Meat pronessing & $\begin{array}{l}\text { Liebigs (UK) (1969 Brooke } \\
\text { Bond, Liebig) }\end{array}$ \\
\hline \multicolumn{4}{|c|}{ Trading: } \\
\hline 1920 & Bird $\mathrm{COO}$ & $\begin{array}{l}\text { Merchants, transport } \\
\text { shipping, warehousing }\end{array}$ & Bitd \& Co. (UK) \\
\hline 1920 & Gibson \& $\mathrm{Co}$ & $\begin{array}{l}\text { Manulacture gents, expotr of } \\
\text { primary produce }\end{array}$ & Gibson \& Co. (UK) \\
\hline 1924 & Gailey and Robers & $\begin{array}{l}\text { Import and servicing of } \\
\text { machinery }\end{array}$ & $\begin{array}{l}\text { United Africa Co. Unilever } \\
\text { Led, UKo }\end{array}$ \\
\hline 1934 & Holland Soda Co. & $\begin{array}{l}\text { Shipping agents and } \\
\text { watelyotisting }\end{array}$ & $\begin{array}{l}\text { Holland Afica Line } \\
\text { (Holland) }\end{array}$ \\
\hline \multicolumn{4}{|c|}{ Mfornufacture and Mineralls: } \\
\hline $19 \| 1$ & Magadi Soda Co. & $\begin{array}{l}\text { Sola extraction and } \\
\text { processing }\end{array}$ & $\begin{array}{l}\text { 1. East African Syndicate } \\
2 \text { Imperial Chemicals lno. } \\
\text { (CT) UK. }\end{array}$ \\
\hline 1922 & East African power & Power generation & $\begin{array}{l}\text { Balioun Beaty (UK) and } \\
\text { Power Secutites (UK) }\end{array}$ \\
\hline 1933 & East African Portand Cement & $\begin{array}{l}\text { Cement-processing, clinket- } \\
\text { grinding }\end{array}$ & $\begin{array}{l}\text { Associated Porthand } \\
\text { Cement (UK) }\end{array}$ \\
\hline
\end{tabular}

Source: Aclopted from Swanson (1980) with minor changes.

The discussion held for the period before 1945 indicates that a few things are important to take into consideration when examining FDI in relation to Kenya's industrialisation process and policy. The first one is that extremely few and simple manufacturing activities were undertaken during this period. Only products meant to substitute imports that were scarce during the war petiod could be manufactured under high ariff wall. No policy existed in support of an industriall development, one chatacterised by a strong entrepreneurship culture, hence low technological capability development. Second, despite the simplicity of the manufacturing undettaken, it was fully controlled by the British settlers and FDI from other countries with no involvement of indigenous locals the indigenous firms remained absent. Third, the British settlets and other foreign investors also dominated commercial agriculture stricty excluding Asians and the indigenous Africans. The investment done was concentrated on estate-based expott commodities such as tea, coffee, watte and sisal which were exported in theit taw form. Fourth, while a few settlers showed interest and actually moved into construction and real estate, foreign firms went into large scale trading where they became dominant. Fifth, Asian firms were concentrated in small trading activities. However, some of the Asian-owned fims originally in the mercantile trade branched gradually into light 
manufacturing, which formed the basis for their inital capital accumulation in Konya [Leys, (1975: 1996); Kaplinsky, 1978; Swainson, 1980; Himbara, 1994].

\section{(ii) The Period Between 1945 and 1963}

The period after the Second World War was characterised by major changes in the international capital movement [Dunning, (1972: 1993)]. There was free movement of capital across national boundaries with MNCs serving as the main conduit of capital flow across national and international boundaries. This culminated in stiff international competition to expand international capital with United States taking a dominant position. United States had assumed a dominant position as a result of increased domestic investment in technology, extensive capital accumulation and great uransformation of its industrial organisation with tremendous increnses in labour productivity. It is argued that, the lnge advance by the United States in 1940 s was the main cause of upheavals witnessed in technology, organisation of labour and relations of procluction in the world after the Second World War. There was a change in the pattern of international capital when United States industrial capital started tuming outward in search of new global markets (Dunning, 1972).

The dominance of the United States capital in the international market had long-term effects to Britain"s political and economic levels (Louis, 1977). The increased international competition to expand capital globally made Britain feel threatened over its colonial territories ${ }^{44}$. Economically, Britain was at a disadvantage in that it had just incurred huge expenses during the wat resulting in increased foreign ald and dependence on the US. There was also the looming danger of severe unemployment in Britain if production slowed down to match avallable materials and foreign exchange (Cowen, 1980 p 145). To take care of these constraints, the British government had no option than to try and channel more government resources into primary and industrial production. In addition, the British government encouraged the British firms, MNCs, to invest in colonial territories-both in the production sector and in the nyanufacturing industry. The British government, therefore, implemented a radical policy change from 'extraction of taw materials and restriction of industrialisation' to promotion of industrialisation alongside agricultural production. An industrial development policy was therefore designed after 1945 to promote development of secondary industries in addition to agricultural production (see Lee, 1967: $\mathrm{p} 85$ ).

In response to this policy change, FDI initally concentrated in the field of commercial farming and taw material extraction began to change in favout of foreign investment in manufacturing industry, albeit gradually (Swainson, 1980). Many Btirish mamufacturing firms went to Kenya after 1945 to manufacture goods previously inported under protected conditions - quota testriction and high tariff walls. Available statistics show that by mid 1960 , approximately $78.8 \%$ of FDJ in Kenya was British owned Vaitsos, 1991: p. 14). Nevertheless, there was also intensified penetration of foreign firms and an inflow of predominantly industrial capital from other countries was witnessed such as: United States, West Germany, Denmark and Canada among others (Eglin, 1978 pp. 106121; Swainson, 1980 pp. 130-5). A few examples of such MNCs included Del-Monte (1950), Pepsi Cola (1953) and Coca-Cola (1956) all from USA; Jensen and Nicholson (1959) from Denmatk and Bata Shoe Company (1958) from Canada (see Table 3.4 for more derails). The period after the Second World War in 1945, therefore, marks a significant point of departure in the history of Kenya's manufacturing industry with

4h For mare detals on this see Lous (1977) writings "The Role of US in the De-colonisation of the British Empire". 
dynamics of inport substitution and participation of FDI in manufacturing becoming more apparent.

Table 3.4: Major Foreign Investments 1945-63

\begin{tabular}{|c|c|c|c|c|}
\hline Corde & Company & Date & Product & Owned $\mathrm{By}$ \\
\hline \multicolumn{5}{|c|}{ Food Products and Bevetages } \\
\hline Np & Schwnppes (EA) Led & 1954 & Soda drinks & Allsops \& Schweppes \\
\hline Eximt & Allops Jas Africa & 1954 & Beer & Allsops (UK) \\
\hline $\mathrm{Ne}$ & Papsi Cola & 1953 & Sodn drinks & PepusíColla (USA) \\
\hline$N p$ & Fitzgerald Thymes & 1953 & Sodn dunks & Canada Dry (LK) \\
\hline $\mathrm{Ng}$ & $7-\mathrm{Up} \mathrm{H}_{\mathrm{p}} \mathrm{Hang} \mathrm{Co}$ & 1954 & Souds drinks & 7-UP Company (USA) \\
\hline Np & Kenya Canners & 1950 & $\begin{array}{l}\text { Canned fruits and } \\
\text { vegetables }\end{array}$ & $\begin{array}{l}\text { (a) pickerng \& West (UK) } \\
\text { (b) Det Monte (USA) }\end{array}$ \\
\hline To & Associated Packers & 1956 & $\begin{array}{l}\text { Fruite squashes, puddings, } \\
\text { juices, jellies }\end{array}$ & Mirchell Cotts (UK) \\
\hline Tio & MBC Foods & 1954 & Animal teeds & $\begin{array}{l}\text { Baumann \& Con and Sted } \\
\text { Bros (UK) }\end{array}$ \\
\hline To & Lyons Mraid & 1950 & Ice cream & Lyons (UK) \\
\hline Np & Coon Cola Mid Africa & 1956 & Soft soda dranks & Coca Cola (USA) \\
\hline $\mathrm{Np}_{\mathrm{p}}$ & EA Tobacco & 1954 & $\begin{array}{l}\text { Manufacture tobacco and } \\
\text { cigaretres }\end{array}$ & $\begin{array}{l}\text { British Ametican Tobacco } \\
\text { BAT) (UK) }\end{array}$ \\
\hline To & Kenya Orchards & 1948 & $\begin{array}{l}\text { Canned fuits and } \\
\text { vegetables }\end{array}$ & Marshalle Ltd (UK) \\
\hline Ext & BA Breveries & 1952 & beer & Ind Coope (UK) \\
\hline \multicolumn{5}{|c|}{ Non-Food Manufacturing } \\
\hline $\mathrm{Mp}$ & $\begin{array}{l}\text { Carbacid Manufacturing } \\
\text { Co. }\end{array}$ & 1954 & Carbon dioxide & Carbacid (USA) \\
\hline $\mathrm{Mp}$ & Robbiane Paines & 1056 & Paints and Vamishes & Robbialac (UK) \\
\hline $\mathrm{Np}$ & Leyland Paines EA & 1954 & Paints and Varnishes & $\begin{array}{l}\text { Baumann \& Co. and Leyland } \\
\text { Paints (UK) }\end{array}$ \\
\hline $\mathrm{Mp}$ & Cassmann Brown & 1953 & Roofing felts & Cassmann (UK) \\
\hline $\mathrm{Np}$ & Sadolins $\mathbb{I}_{\text {and }}$ & 1959 & Paints and Vamishes & Sadolins \\
\hline$N p$ & Jensen \& Nicholson & 1959 & Paints and Varnishes & $\begin{array}{l}\text { Jensen \& Nicholson } \\
\text { (Denmark) }\end{array}$ \\
\hline Np & East Alrican Oxygen & 1949 & Orygen & British Oxygen (UK) \\
\hline $\mathrm{Np}$ & Bamburi Portand Cement & & Cempent & $\begin{array}{l}\text { Amalgamated Road-Stone } \\
\text { Corp. (UK) } \\
\text { Cementia floldings } A G\end{array}$ \\
\hline Ext & FA Porthand Cement & 1956 & Cement & Assor. Portand Cement \\
\hline $\mathrm{Np}$ & Awon Tyre & 1958 & Birycle inner nubs & Avon Tyres (UK) \\
\hline Fint & EA Bara Show Co & $\begin{array}{l}1940 \\
1958\end{array}$ & $\begin{array}{l}\text { Birycle ander tubes } \\
\text { l.eather and shoes }\end{array}$ & Bata Shoe Co. (Canada) \\
\hline $\mathrm{Np}$ & $\begin{array}{l}\text { WA Stacionary } \\
\text { Mantiactuters }\end{array}$ & 1949 & stationatry & Dickinson Co. (UK) \\
\hline Nip & Men Box EA & 1948 & Metal containers & Metal Box (UK) \\
\hline$M p$ & Crown Cork Co. $1 \mathrm{AA}$ & 1948 & seails & Ctown seals (UK) \\
\hline$N p$ & Var lies Containers $1 \mathrm{~A}$ & 1952 & Steel drums, pains & $\begin{array}{l}\text { Van Leer Containers } \\
\text { (Holland) }\end{array}$ \\
\hline $\mathrm{Np}$ & Shell Chemical & 1952 & Industrial Chemicals & Shall-BP (UK) \\
\hline $\mathrm{Np}$ & Sterling Wathrop & 1953 & chemicals & Storling Winthrop (USA) \\
\hline$M$ & Finlay Industries lid & 1952 & Brushes, wooden articles & James Finlay (Scotland, UK) \\
\hline$N p$ & EA Oil Returery & 1959 & Refling of ondes oil & Shell-BP (UKK) \\
\hline $\mathrm{Np}$ & Waparmur AA Let & 1961 & Paints and Vamishes & Walpamur (UKy \\
\hline
\end{tabular}

Source: Adopted from Swainson (1980) with minor changes

Key: Ext - extension of existing plant; To takeovet of existing firm and $\mathrm{Np}$ - formation of new plant

From the brief discussion undertaken for the period 1945-1963, the following things have emerged. First, it can be argued that the first major drive towatds industrialisation in Kenya started in the pertiod 1945-1963. This period can be regarded as the starting point 
of actual manufacturing in Kenya with policy support from the authotities, in this case the British govemment. Howewer, in this early stage, industrial capabilities and their dewelopment remained rather weak. Also with the exception of Asians of the Kenyan origin, the indigenous Africans had not wentured into the manufactaring - thus entrepreneurship capability on their side was extremely weak or atogether missing. Second, that the mode of industrialisation adopted at this time was import substitution supported largely by the state. This mode of industrialisation was implemented to a large extent under strong tariff wall and trade batriers. Third, that in comparison to the period before 1945 when investment was largely concentrated in commercal farming and metcantile, thete was a significant increase in foreign investment into manufacturing industry in the period after 1945, which was teflected in a major shift in the sectoral pattern of investment by FDI. The fourth one is that comparing settlers' capital to that of the incoming MNCs, the settlers' capital remained weak after their failure to take it into manufacturing industries. In actual fact the incoming MNCs and the Kenyan Asians ended up acquiring most firms that had previously been owned by local settlers making the incoming MNCs and a few Asian firms become dominant in the latge manufacturing category especially in the period 1945-1955.45. Although Asians had wentured into manufacturing before 1945, they were only a few "due to the constraints of capital and lack of credit facilities from European banks" (Swainson, 1978: pp. 124-6).

\subsubsection{Post-Independence: The Early Decades of Import Substitution}

At independence, Kenya inherited import-substitution industrialisation pursued during the colonial days ${ }^{\text {th }}$. Adoption of import-substitution appeared to be the trend world-wide in that during the period $1950 \mathrm{~s}-60 \mathrm{~s}$, import-substitution industrialisation strategy appeared to be the nom in most developing countries (Van Arkadie, 1964; Bruton, 1998). In the Kenyan context, the import-substitution framework mainly advocated for a large role of public sector participation and protection of infant manufacturing industries ${ }^{47}$. Broad based economic controls in favour of industrial sector were implemented such as: combination of tariffs and quotas supplemented by foreign exchange allocation measures; use of overvalued exchange tates to maintain import costs low; favourable credit and interest rate policies intended to subsidise manufacturing of consumer goods. As a result of hight increase in overall demand for consumer products in the domestic market, the implementation of import substitution framework encouraged production for domestic market shielded from imports and intemational competition (Van Arkadie, 1964; Mekkelsen, 1986; Nyongo, 1988; Coughlin and Ikiata, 1988; UNIDO, 1996). Under import substitution, the economy was characterised by rapid economic growth - in the Kenyan economic history this period is usually referred to as the "golden economic period" due to the high GDP growth levels recorded. "The GDP growth rate averaged above $7 \%$ in the period $1965-1972$ (sec Gachino, 1998), while manufacturing value added grew by over 10\% in the period 1964-1971.

At independence, Kenya was ambitious to diversify her foreign investment by attracting FDI from different countries in the world. Unfortunately, during this period of reansition to independence, the country was faced with capital disinvestment problem; severe outflow of foreign capital was taking place following the eroding confidence among

\footnotetext{
45 For elabotate detals on Asian capitat in Kenya sec Swainson (1978) and Himbata (1994).

4h This was specifically enfowed an the period $1945-1963$ after the Second World War.

4 Various policy instruments to enforce protection in Kenya included arifs and quanditave restrictions such as import quotas. Exchange rates wete overvalued to contain the costs of imported maw materials while credit and interest rates wenc implicity subsidised for manufacturing fims - broad based conomic controls in favour of industrial sector.
} 
foregin investment resulang from the intended indigenisation of economic acuivies contained in the "Kenyanisation" policy" In order to revert this process and to atract more diverse foreign investment, the Kenyan government decided to enact the Fongix Itwestyntw Protection Ad (FTPA) in 1964, which guaranteed foreign investors the right to transfer profits, divideds and capital out of the country. Under FIPA Act, foteign investors were supposed to apply for a "Certificate of Approved Enterprise" from the Ministry of Finance. The determining criterion was the firm's participation on the economy and thus onlly foreign enterprises viewed as capable to participate in Kenya"s economic development would be granted this certificate. These investors would also be assured that their firms would not be compulsorily acquired under the indigenisation policy, which was launched upon independence (Iangdon, 1978: p. 162). This was also supported by sessional paper no. 10 of 1965 entitled: Afrian Soratism and Its Applowaton to Planing in Kenya. The sessional paper reaffimed the government's commitment towards attracting more foreign firms with no nationalisation unless state intervention was deemed necessary to prevent wastage of raw materials (Langdon, 1978: pp. 162-3; Nyong'o, 1988).

Continued effort to attract investment and to reduce capital outflow seemed to gather momentum with time. A New Projects Consnittee (NPC) was set up in 1968 to review more vigorously the foreign applications interested in making investment in Kenya. This committee which drew representatives from various institutions and govermment ministries acted as the negotiation team on all issues pertaining to investment ranging from level of tariff protection, shateholding, and management among others (Langdon, 1978: pP. 162-3). Capital Issmer Commithee (CTC) was set up in 1971 to cut down continued capital outfow from Kenya following the perpetual fever at the time that foreign investment in the country would be forced to go public and allow Kenyans to become shareholders. The aim of CIC was therefore to revert this trend by approving all future issues and capitalisations of reserves in firms with majotity foreign interest (Leys, 1974: pp. 128-9 and Swainson, 1980: p. 209). On the international front, Kenya became a member of Multateral Investor Guarantee Agency (MGA), which issues guarantees against non-commercial risk to enterprises that invest in member countries. Kenyalso became a member of International Center for the Settlement of Investment Disputes (ICSID), and of Africa Trade Insurance Agency (ATIA) (IPC, 2001). As a result Kenya attucted a substantial amount of FDT in the period 1960s-70s - where in most cases the investors were subsidiaries of wholly owned MNCs and occasionally joint participation between MNCs and the state. A large share of this investment went into importsubstituting industries (Kaplinsky, 1978; Swainson, 1980; Nyong"o, 1988).

Compared to the period before independence there was a drastic change in this period with foreign firms showing a clear dominance in Kenya's manufacturing industry. Available statistics show that by 1967 , about $33 \%$ of the FDI stock in Kenya was in manufacturing (Hveem 1975: p. 86-7). From the Censw of Industral Production undertaken in Kenya in 1967 and covering 607 establishments, it was noted that 4.33 of these establishments with 50 or more employees were mainly or wholly foreign owned by noncitizens. Detailed analysis of the Census of Industral Production data further revealed that these enterprises accounted for $71 \%$ of the value added and $72 \%$ of the total sales for manufacturing firms employing 50 people and above, which in turn, generated mote than $82 \%$ of the gross manufacturing product (Eglin, $1978 \mathrm{p} \mathrm{97).} \mathrm{This} \mathrm{clearly} \mathrm{demonstrates}$ the significance of foreign investment in the early decades of Kenya's independence and as noted by Vaitsos (1991) on the Kenya's development plan for 1970-74:

4 Kenganisation was a form of nationalisation as discussed in chapter 2. 
.... long-term capital infloxws, especially by TNCs, strongly intuenced the evolunion and growth of modem manutacturing and services during the first decade after independence as confirmed by macro, sectoral and sub-sectoral evidence (vaitsos, 1991 . p. 13).

Besides the fact that most foreign companies saw potential market opportunity in the East African region, the region was also richly endowed with taw materials and cheap labour. An analysis of FDI inflows to Kenya in comparison with other developing contrities in Aftica revealed that while $32.4 \%$ of $\mathrm{FDI}$ in Kenga went into manufacturing by 1967 the average for the whole of Africa that went inro manufacturing was ony $18.8 \%$. FDI going to commercial agriculture in Kenya was also relatively high at $21.4 \%$ in comparison to $7.5 \%$ for the whole of Africa. The average for FDI in Africa going into trading activities was $19.4 \%$ which was slightly higher than FDI going into trading activities in Kenya which was $16.9 \%$. Finally, there was almost negligible foreign invested in petroleum and mining in Kenya while the average investment for Africa was $19.4 \%$ and 29.6\% respectively (Kaplinsky, 1978: p. 6). This supported empirically the thesis that after independence foreign capital, FDT, in Kenya was not concentrated in primary production but rather in manufacturing and services following increasingly high inflow especially into the two sectors and especially manufacturing industry. It is therefore argued that this trend of foreign investment flow into the manufacturing industy affected significantly the evolution of import-substitution strategy at the time. For instance in 1977 , imports of consumer goods dropped shatply to just $15 \%$ of the total imports while imports of intermediate goods rose to about $67 \%$ of the total imports Vaitsos, 1991: pp. 13-5). This seemed to indicate success in the pursuance of the import substitution mode of industrialisation. More so, it also indicated transfer of technology to be used in their production processes - although participation by domestic firms was still minuscule, this is important as it would result in demonstration effects, training of the local labour, learning by performing and in turn all these would serve to stimulate broad industrial capability development.

Apart from availability of raw materials and cheap labour, Kenya was also favourable for among other factors stable political climate and macroeconomic conditions, a rapid economic growth rate, a large and growing market encompassing countries of the then East African Community and high tarff protection. Given their keen interest on the protection level, MNCs wanted and in fact sought involvement even in the determination. of the extent and structute of protection to be granted JSwainson, (1978: 1980); Figlin, 1978; Vaitsos, 19911. As an example, protection from imports was a key pre-investment negotiation is ue at the time: effective rates of protection were therefore very substantial, particularly for consumer goods industries. In about $90 \%$ of the cases studied by Langdon and Godfrey (1973), it was observed that the type and range of existing protection was largely influenced by the MNCs' bargaining strength and position. Most MNC firms therefore enjoyed a virtual monopoly, which ensured their profits (Eglin, 1978: pp. 97-111). The inflow of equity capital in the 1960s-70s was mainly in the agrobased industries with textile taking a clear lead [Leys, (1975: 1996); Eglin, 1978; Langdon, 1978: Kaplinsky, 19781. As will be shown at a later stage, this trend has however been reversed since 1980 s with food processing and beverages manufacture taking a lcading position. Other manufacturing industries like machine and engineering industry and

\footnotetext{
49 The extended demand for consumer goods to the entire East Aftican Community (E) An dhe period $1967-77$ provided for a large market which prompted many MNCs no invest in Konya or expand their exirting investment. Kenya semed to serve as the regional hub due to its locational advantages such an proximity the sea and advanced infrastructure netwotk of tansport.
} 
more recently chemicals, pharmaceutical and plastic industries have also obtained substantial amount of foreign capital investment.

At independence, the Kenya's economy and in particulat manufacnuring ownership structure was dominated by the European and Astan firms. MNCs from United Kingdom dominated in the European firm's category, which were engaged in heavy manufacturing processes while Astan firms dominated in the light manufacturing industrics almost sharing the entire cake with no portion of it left for the indigenous locals (Kaplinsky, 1978; Swainson, 1980; Himbara, 1994; Leys, 1996). Although by this time Kenyan manufacturing industry was relatively the most advanced in comparison to those of the other countries in the tegion there was a need to integrate the Africans into the mainstream of the economy despite their low entrepreneurship skills, lack of experience and finance. As a preamble to the indigenisation policy; it is recalled that during the colonial days, Africans served as labourers in the commercial firms owned by the foreigners and were not allowed to participate in any form of trade or manufacturing activities - this denied them a chance to become entrepreneurs from early on. Africans could not obtain any form of loan or financial credits to support and nurture their ambition into either trade or entrepreneurship. Incidentally, they had no collateral since at the rime, they were not even allowed to acquire and own land title deeds, which could serve as collateral with existing frnancial institutions. This notwithstanding, the existing Banks viewed Africans as depositors but not as potential borrowers claiming that Africans had a different mentality on repaying loans as they failed to see it as an obligation. The banking style trelied to a large extent on social interaction with British banks funding British firms, Asian banks funding Asians and since there were no African banks, no one had the will to extend loans to indigenous African firms (Jorgensen, 1975: pp. 159).

As a result of this disequilibrium in the economic setting, there was a need to indigenise commerce and manufacturing inclustry at independence. The Kenyan government established a Kentanisation of Persontel Burean (KPB) with an aitn to Africanise senior positions in the civil service including parastatals and to also regulate the number of foreign workers in the private sector by introducing work permits. In addition to encouraging MNCs, the Trade Licensing Act of 1967 was enacted, to help Africans venture into commerce and trade. To this effect, foreigners were excluded from trading in certain locations and from dealing with certain kinds of goods. Such goods included basic foodstuffs and clothing and a few other items such as cigarettes, soft drinks, farming implements and basic hardware which were all produced or processed locally under MNCs import substitution industries (Jeys, 1974: pp. 151). Since the Asians were testricted from joining retail and wholesale trade this forced them to venture into light manufacturing. The greatest effort by the gowernment towards indigenisation took place in the creation of support institutions such as Industrial and Commercial Development Cotpotation (ICDC), Industrial Development Bank (IDB) and Kenya Industrial Estates (KIE) etc. Some of these institutions allowed joint partnetship with MNCs as well as providing soft loans and technical support to the Africans who were by then being encouraged to become entrepreneurs. Some institutions encouraged establishment of linkages berween indigenous firms and foteign fitms. This was the first significant attempt to integrate indigenous firms into the manufacturing. An interesting scenario that emerged from the intended indigenisation policies was that of Asians in Kenga. After being restricted from participating in trade and commerce, the Kenya Asians ventured into light and medium manufacturing asing own finance, and from which they were able to entrench themselves, have developed some manufacturing capabilities and have dominated ever since (Pearson, 1969: p. 12; Swainson, 1980; Himbara, 1994). 
Nevertheless, despite the spirited effort by the government to implement indigenisation policy especially in the manufacturing industry not much progress has been achieved. The nature and characteristics of manufacturing industry thas virtually remained the same as it was in the early decades of Kenya's independence. Taking as an example, the ownership structure by race in 1990, we note that according to Himbara (1994: p. 49), in a sample of 100 large scale manufacturing firms; Asians accounted for $75 \%$; Foreign and JVs $11 \%$; Kenya Africans $5 \%$; Publicly held $4 \%$; State firms $4 \%$; African/Indian $1 \%$. Although these percentages do not represent performance, they somewhat support the critique that indigenisation policy had not succeeded as the disequilibrium was still widely reflected in Himbara's study. It is common knowledge that the country has not succeeded in transforming its manufacturing industry, which is still clependent on foreign technology as domestic industrial capability remains weak and manufactured export goods with little value added. Jorgensen (1975) offered a strong critique of the Kenyan indigenisation process which still seems to hold regarding it as lacking in credibility. He argued that, "since independence the process would have required integration of the various sectors and sub-sectors of the economy to increase self-reliance and decrease dependence on the import of foreign technology, foreign machinery, foreign intermediate goods and components, and foreign consumption patterns on the one hand and decreased dependence on the export of agricultural taw materials and of minerals on the other" (Jorgensen, $1975 \mathrm{p} \mathrm{156)}$. This has however not been the case and African indigenous firms remained small in size and both technically and financially weak.

Following her ambitious plan for industrialisation in 1960s-70s, Kenya enacted and implemented several industrial promotion policies within import substitution framework particularly meant to stimulate and strengthen the industrial base and especially within manufacturing sector, which was at the time characterised by weak technological capabilities ${ }^{50}$, weak supporting institutions and lack of finance for business expansion. Several development finance and industrial promotion institutions intended to cater for small and large scale firms were established. Ideally, these institutions were supposed to play a facilitation role in industrial development by advancing indigenous manufacturing technology; assisting in technology transfer; offer industrial training, promote industries that exploit locally available raw materials; promote linkage (e.g. between locally owned firms and MNCs); offering financing capital, enhance production of goods that are competitive for exports. Such institutions included Industrial and Commercial Development Corporation (ICDC); Development Finance Company of Kenya (DFCK); Industrial Development Bank (IDB); Kenya Industrial Estates (KIE); Kenya Bureau of Standards (KEBS); Kenya Industrial Research and Development Institute (KIRDI). Others included Kenya Industrial Training Institute (KITI); National Council for science and Technology (NCST) and Universities and Polytechnics. A brief discussion on the role played by some selected institutions in line with their objectives is presented in the next section.

\subsubsection{FDI and Industrial Capability Development: The Role of Institutions During the Import Substitution Period}

In the section above, we have shown that at her independence, Kenya inherited a manufacturing industry characterised by relatively weak indigenous industrial capability with low value added activities and performance. There was however increased FDI

sto African tums ane well below international 'best practice' technical lewels, and below lewels by other developing countries (Biggs and Stivastava, 1996; Mazumdar and Mazahen, 2003). 
inflow and participation in the manufacturing. At this time supportive institutions were missing while new ones were getung established and still grappling with leaming to perform. In such a context where institutions ate missing or weak in perfomance, then their role in systemic cootdination becomes equally weak. This results in weakened role fot instance in financing, knowledge generation and diffusion and consequently low lewels of industrial capability development and performance. Given this background, this section examines the type and specific role played by institutions during the import substitution period. We sthall however limit our discussion to some selected institutionsincluding those in the financial and technology infrastructure domain.

\section{(i) Industrial and Commercial Development Corporation}

Industrial and Commercial Development Corpontion (ICDC) was first established in 1954 by the colonial government. ICDC acts as government's main conduit for joint venture investments and has made equity investments in many industrial and commercial ventures along with local and MNC subsidiaries. It was first established as the Industrial Development Corpotation (IDC) to promote the colonial industrial development. $A$ fret Kenya attained her independence in 1963, the role of IDC was expanded and diversified in the economy to provicle project and commercial finance to enterprises. As a result of this expansion, IDC was changed to industrial and commercial Development Corporation (ICDC), a wholly oxwed corporation by the Kenya government.

The responsibilites of ICDC included promotion of industrial capabilities by promoting participation of indigenous Kenyans in industrial and commercial development, encouragement of industries with capacity to eam foreign exchange, facilitate rural development, increase use of locally avallable raw materials, create job opportunities and enhance diversification of the economy. "The industrial and commercial development was facilitated through: venture capital frnance; secured long \& medium tem loan funds and export financing; management, support \& consultancy services; administration of funds on social-economic programmes at agreed termsis.

ICDC has co-invested in varions leading commercial and industrial ventures in Kenya that are either local fims or MNC subsidiaries. This is important as it hamesses the resoutces and expertise of MNCs in the promotion and financing of joint venture projects. From the interviews conducted, it was noted that $\mathbb{C C D C}$ had invested in a cumulative total of 105 companies in its equity portfolio. Projects financed included some of the established local companies such as ICDC Investment Company Limited (ICDCIC), Uchumi Supermarkets Limited, Kenya Wine Agencies Limited, Kenya National Trading Corpotation (KNTC), Kenya National Transport Company (KENATCO) Taxis. ICDC is also into partnership with several MNC subsidiaries in Kenya among them the General Motors Kenya (GMK) Limited (20\%). General Motors Kenya limited is the largest vehicle assembler and distributor in the region accounting for approximately $80 \%$ of the total vehicle exports from Kenya, targeting markets within the East and Central African region. GMK has established linkages in the auto industry with domestic firms including body builders. ICDC also owns Nairobi Bottlers jointly with Coca Cola Sabco, with the ICDC controlling (28\%) and Sabco (72\%). Coca Cola Sabco brings along processing and production techniques as well as management and marketing skills. It commands one of the widest distribution netwotks with distributors of its manufactured products. ICDC has a joint venture with Eveready Batteries Kenya Limited (25\%) whose parent company is Eveready Batteries Inc, St Louis, USA - the largest battery producing MNC. ICDC was responsible for the supervision and finance

51 The ICOC websire sire: herp://www.iedc.co.ke/ provides background information on this. 
of the Kenya Industrial Estates (KIE) programme until 1978 when KIE became an autonomous institution. ICDC is an important shareholder in two nain industrial financing institations; it owns $12 \%$ of Industrial Development Bank Litd. and $31 \%$ of Dewelopment Bank of Kenya Ltd. This kind of cootdination and establishment of financial linkages is important for the support of firms in an industry for their capability development and eventual growth, innovation and performance.

We provide an example of a joint activity coordinated and facilitated by ICDC between a locally owned firm and a MNC subsidiary. Kenya Bus Services (KBS), a locally owned firm in the local transport industry embatked on the provision of specialized, comfortable, commuter services in 1999. At this time there was high demand for this kind of services in the transport industry, hence $\mathbb{S B S}$ approached $1 C D C$ and General Motors Kenya Limited for their support both financial and technical. As a response to this, ICDC and General Motors introduced a special scheme in 2002 meant to finance KBS "Metro Shuttle buses". On its party, ICDC set aside an initial financial tacility of KSh. 60 million to finance the purchase of 20 Metro Shuttles. General Motors would provide the engine and the chassis while other locally owned companies would build the body of the coaches with technical/mechanical guidance of engineers from General Motors. The engineers from KBS would also undergo technical training with the General Motors which would enable them maintain the coaches undertake repairs.

However, despite a telatively good performance in ICDC it has been criticized for failing to meet one of its prime objectives to reach the small entrepreneurs, the security required for ICDC's loans has tended to favour the already well-established entreprencurs and to those already owning other enterprises. The implication of this is that firms owned by indigenous Africans would not qualify for financial support. ICDC officials interwiewed felt that ICDC was not playing its tole of promoting participation of indigenous Kenyans in industrial and commercial clevelopment effectively. Performance in venture capital and export finance had declined. They were severely constrained in that they have to rely on the government for finance making its capacity limited.

\section{(ii) Development Finance Company of Kenya}

Development Finance Company of Kenya (DFCK) was incorporated as an investment company in 1963 and as one of the main financial institutions to promote industrialisation in the post independence era. Although DFCK was established with the govemment as the main shareholder through ICDC, other bodies including foreign. finncial institutions and developmental agencies were also shareholders ${ }^{52}$. The sources of finance to DFCK therefore included share capital and loans from shateholders, and other institutions and loan repayment and intermally genetated funds ${ }^{53}$.

Although DFCK initally fawoured existing industrial and agricultural enterprises, there was a change in DFCK investment trend towards new projects by the mid 1970 s. From this time onwards, DFCK increased its participation in new projects. "There was especially large annual increase in new projects, including indigenous projects, financed by the DFCK in the period 1976-1981 manly resulting from the 1976-1977 coffee boom in the country. Despite DFCK participation in many economic sectors, by the end of the second decade of its operations, its capital investment was concentrated in engineering and construction $(18.3 \%)$, agricultutal processing, food and beverages $(15.4 \%)$ and

\footnotetext{
SExamples of such shareholders included the German Developmerat Corporation, the Common Wealth Development Corporation (CDO) and the Netherlands Finance Company.

s. For a detailed synthesis of DFCK and other financial institutions sec worls by Swainson, 1980; 1kiart, 1988 and KIPPRA, 2001.
} 
textiles (12.2\%) [For more details on this see 1kiara, 1988]. Priority was accorded to economically viable projects deemed to have the necessary capacity to contribute to economic development efforts such as creation of employment, earn foreign exchange and increase the use of locally available raw materials.

Since inception, the operations of DFCK had been explicitly biased towards the already well established firms that wete either large or medium in size, neglecting the small-scale enterprises and start ups. This was comparable to the ICDC case discussed earlier. To rake care of this anomaly, DFCK decided to establish a progtamme in 1978 that could help identify and offer support to the indigenous enterptises that had failed to obtain any support due to the outright bias in favour of large enterprises - established culture of habits and practices that discriminated a certain category of firms. It incorpotated a new programme in 1983 known as Small Enterprises Finance Company Limited (SEFCO) mandated to worls out new modalities that could help to atract funds to finance small enterprises.5. SEFCO promoted indigenous enterprises by providing finance and advisory services necessary for expansion, modernization or rehabilitation of existing enterprises owned and managed by indigenous African enterprises (Ikiara, 1988: p. 222). The conditions gowerning SEFCO support e.g. financial assistance were made more flexible in order to reduce the problems hindering the penetration by indigenous enterprises into the manufacturing industry. However this was not very effective in the long run due to lack of financial constraints.

From the interviews done with the DFCK officers, several constraints were noted that seemed to hinder the progress of the institution. As noted earlier, the financial institurions were funded primarily through loans and grants received from multilateral and bilateral development institutions, as well as from the Kenyan government. The government allocations of development finance institutions have been virtually eliminated following a government policy to stop funding all the parastatals. More so, the government was gradually declining its role as an active guarantot to loans obtained by development finance institutions from other financial institutions most of which are foreign (KIPPRA, 2001: p. 5). However, despite these changes in its role, the government continues to be a key shareholder in these development finance institutions (DFI) hence making willing lenders and shareholders shy off from lending their funds to DFI. Without privatization foreign lenders are reluctant to continue their participation. To get round this problem, the adoption of universal banking policy affects DFI's and has already resulted in the converstion of the DFCK into a bank. This has worsened the situation as the interest rates remain high and hence not favourable of industrial promotion. Firms will shy from taking loans at such high interest rates, implying that they could not acquire new machinery and technology using loan facilities from DFCK and thus in the long run this works out to weaken firms' entrepreneurship and capability development and thus their ability to learn from and compete with the MNCs present in manufacturing.

\section{(iii) Industrial Development Bank}

Industrial Development Bank (IDB) was established in 1973 as a financial institution with an authorised share capital of KShs 40 million, which was shared between the Kenya govemment $(49 \%)$, ICDC $(26 \%)$, the National Bank of Kenya $(12 \%)$ and the Kenya National Assurance Company (12\%) [1kiara, 1988; KIPPRA, 2001]. The Kenya government established IDB for the purpose of furthering industrial and economic

\footnotetext{
54. As explained, creation of $S E F C O$ was necessary, as w would increase tesources for the small indigenous emrerprises whout affecting the DFCK's main objecrive of financing latge and inediun enterprises.
} 
dextelopment by promoting, establishing, expanding and modemising of the medwm and large scale industrial enterprises, including mining, agro-industries, engineering, 10 uism, and transport and shipping. IBD strictly excluded operations of enterprises that engaged in commerce, real estate and farming activities. Industral Development Bank provides the following forms of financial services: medium and long-tem finance, working capital, machinery finance and export trade related banking facilities; direct equity investment; guarantees for loans from other sources; underwriting of security issues, shares, stocks and promissory notes. IDB charges interest, fees or commission guided by the prevailing market rates, or which enable it to earn a reasonable return on its operations. To facilitate international trade transactions for its clients, IDB maintains a global network of correspondent banks worldwide (IDB, 2002).

In addition to the finance obtained from equity and accumulated reserves, the government as the main shareholder is supposed to provide funance to IDB. But due to the balance of payments problems, the government role as the chief financier has declined. It was noted from interwews done that the problem was so severe to the extent that IDB had to look for alternative sources of finance - a process faced by its own unique problem. The main source of finance is foreign with key lenders including the World Bank's international bank for reconstruction and development (IBRD); "The European Investment Bank (EIB); the Germany Investment Corporation (DEG); Swiss Investment Corporation (SIC); the African development bank (ADB). The Kenya government would act as the guarantor to all the loans obtained (KIPPRA; 2001: pP. 323).

In its operations, IBD has been faced with severe constraints: the government of Kenya no longer invests in IDB given its blanket rule to stop investing in parastatals. In addition the government no longer guarantees its lines of credits. To overcome these problems, officers from this instirution explained that IDB decided to offer banking services with mobilization of deposits. Nevertheless, this has not been very successfull, as customer deposits have remained yet very low. IDB continued to face severe difficulties in securing credut from foreign financiers, who demand that the government guarantees or privatise IDB to qualify for funding. This has resulted in a declining industrial role of IDB over time. In 1997, the bank approved investments in 10 projects compared with 16 projects in 1996 for a total of KShs 365 and 495 million respectively. It is critical to note that with the introduction of quasi banking activities its interest rates and other services are not different from any commercial Bank, hence no real industrial promotion done by the bank.

\section{(iv) Kenya Industrial Estates}

Another institution formed soon after Kenya"s independence was Kenya industrial estates Limited (KIE). KIJ was formed to encourage entry of indigenous firms into the manufacturing industry since this would result in indigenous manufacturing capability in the long tun. Indigenous firms entering into the manufacturing industry were basically characterised by extremely small scale, they were basically 'start ups' small and medium enterprises (SMEs) faced with severe financial constraints and with weak technical skills $(\mathrm{KJE}, 2003)$. They needed Finance for capital investment alongside technical support mainly on how to set enterprises and manage them. To promote the development of SMEs, KIE was established in 1967 as a supportive institution and as a subsidiary of ICDC to extend assistance by a way of offering technical and financial support to indigenous firms. KIE remained a wholly owned subsidiary of ICDC, then under the Ministry of Commerce and Trade, until 1978 when it became an independent state 
textles (12.2\%) [For more details on this see lliara, 1988]. Prionity was accorded to economically vable projects deemed to have the necessary capacity to contribute to economic development efforts such as creation of employment, earn foreign exchange and increase the use of locally available raw materials.

Since inception, the operations of DFCK had been explicitly biased towards the alteady well established firms that were either large or medium in size, neglecting the small-scale enterprises and statt aps. This was comparable to the ICDC case discussed eartier. To take cate of this anomaly, DFCK decided to establish a programme in 1978 that could help identify and offer support to the indigenous enterprises that had failed to obtain any support due to the outright bias in favour of large enterprises - established culture of habits and practices that discriminated a certain category of firms. It incorpotated a new programme in 1983 known as Stmall Enterprises Finance Company Limited (SEFCO) mandated to wotk out new modalities that could help to attract funds to finance small enterptises: SEFCO promoted indigenous enterprises by providing finance and advisory services necessaty for expansion, modernization or rehabilitation of existing enterprises owned and managed by indigenous African enterprises (1kiara, 1988: p. 222). The conditions governing SEFCO support e.g. financial assistance were made more flexible in order to reduce the problems hindering the penetration by indigenous enterprises into the manufacturing industry. However this was not very effective in the long run due to lack of financial constraints.

From the interviews done with the DFCK officers, several constraints were noted that seemed to hinder the progress of the institution. As noted earlier, the financial institutions were funded primarily through loans and grants teceived from multilateral and bilateral development institutions, as well as from the Kenyan government. The government allocations of development finance institutions have been virtually: eliminated following a government policy to stop funding all the parastatals. More so, the government was gradually declining its role as an active guarantor to loans obtained by development finance institutions from other financial institutions most of which ate foreign (KIPRRA, 2001: p. 5). However, despite these changes in its role, the government continues to be a key shareholder in these development finance institutions (DFI) hence making willing lenders and shareholders shy off from lending their funds to DFI. Without privatization foreign lenders are reluctant to continue their participation. To get round this problem, the adoption of universal banking policy affects DFI's and has already resulted in the conversion of the DFCK into a bank. This has worsened the situation as the interest rates remain high and hence not favourable of industrial promotion. Firms will shy from taking loans at such high interest rates, implying that they could not acquire new machinety and technology using loan facilities from DFCK and thus in the long run this works out to werken firms" entrepreneurship and capability development and thus their ability to learn from and compete with the MNCs present in manufacturing.

\section{(iii) Industrial Development Bank}

Industrial Development Bank (IDB) was established in 1973 as a financial institution with an authorised share capital of KShs 40 million, which was shared between the Kenya government $(49 \%)$, ICDC $(26 \%)$, the National Bank of Kenya (12\%) and the Kenya National Assurance Company (12\%) [Ikiara, 1988; KIPPRA, 2001]. The Kenya government established IDB for the purpose of furthering industrial and economic

54 As explained, creation of SEFCO was necessary, as it would increase resources for the small indigenous enterprises without affecting the DFCK's main objective of financing large and medium enterprises. 
development by promoting, establishing, expanding and modenising of the mediun and large scale industrial enterprises, including mining, agro-industries, engineering tourism, and tansport and shipping. IBD strictly excluded operations of enteprises that engaged in commerce, teal estate and farming activities. Industrial Development Bank provides the following forms of financial services medim and long-tem fnanca; wotking capital, machinery finance and export trade related banking facilites; direct equity unvestment; guarantees for loans from other sonuces; underwriting of secunity issues, shares, stocks and promissory notes. $I D B$ charges interest, fees or commission guided by the prevaling market rates, or which enable it to earn a reasonable teturn on its operations. To facilitate international trade transactions for its clients, WDB maintains a global network of correspondent banks worldwide (TDB, 2002).

In addition to the finance obtained from equity and accumulated reserves, the government as the main shareholder is supposed to provide finance to IDB. But due to the balance of payments problems, the government role as the chief financier has declined. It was noted from interviews done that the problem was so severe to the extent that IDB had to look for alternative sources of finance - a process faced by its own unique problem. The main source of finance is foreign with key lenders including the World Bank's international bank for reconstruction and development (TBRD); The European Investment Bank (EIB); the Germany Investment Corporation (DEG); Swiss Investment Corporation (SIC); the African development bank (ADB). The Kenya government would act as the guarantor to all the loans obtained (KIPPRA; 2001: pP. 323).

In its operations, IBD has been faced with severe constraints: the government of Kenya no longer invests in $\mathrm{IDB}$ given its blanket tule to stop investing in parastatals. In addition the government no longer guarantees its lines of credits. "To overcome these problems, officers from this institution explained that $\mathrm{DB}$ decided to offer banking services with mobilization of deposits. Nevertheless, this has not been very successful, as customer deposits have remained yet very low. IDB continued to face severe difficulties in secuting credit from foreign financiers, who demand that the government guarantees or privatise $\mathrm{IDB}$ to qualify for funding. This has resulted in a declining industrial role of IDB over time. In 1997, the bank approved investments in 10 projects compared with 16 projects in 1996 for a total of KShs 365 and 495 million respectively. It is critical to note that with the introduction of quasi banking activities it interest rates and other services are not different from any commercial Bank, hence no real industrial promotion done by the bank.

\section{(iv) Kenya Industrial Estates}

Another institution formed soon after Kenya's independence was Kenya industrial estates Limited (KIE). KIE was formed to encourage entry of indigenous firms into the manufacturing industry since this would tesult in indigenous manufacturing capability in the long run. Indigenous firms entering into the manufacturing industry were basically characterised by extremely small scale, they were basically 'start ups' small and medium enterprises (SMEs) faced with severe financial constraints and with weak technical skills (KIE, 2003). They needed finance for capital investment alongside technical support mainly on how to set enterprises and manage them. To promote the development of SMEs, KIE was established in 1967 as a supportive institution and as a subsidiary of ICDC to extend assistance by a way of offering technical and financial support to indigenous firms. KVE remained a wholly owned subsidiary of ICDC, then under the Ministry of Commerce and Trade, until 1978 when it became an independent state 
owned corportion registed under the companies act with the govenment of Kerya as the sole share holder.

While finatincing industral projects, KIE attached a lot of emphasis on new or expansions that were likely to generate foreign excharge, create substantial employment, and make use of locally avallable saw materials increasing linkage formation between locally owned firm and MNCs. KIE ratgets enterprises ranging from micro enterptises commonly referted to as Jua Kall artisans to modern scale industmes. The enterprises must be statups or expansions solely owned and managed by indigenous Kenyans and located in the country. KTE also advances short-term working capital loans to existing entrepteneurs who have run their business for a period of time. The loans are to be used to finance procurement of machinery and equipment or working capital.

Interviews done showed that KIF attached a lot of importance to some key elements, which onght to be clearly articulated in the business plan before its submission for consideration. There must also be some guranteed minimum return on assets employed. The owner must possess managerial skills and knowledge necessary to run an enterprise. This is ustally determined by past achievements, qualifications of experience obtained while working with MNCs. The entrepreneur is supposed to contribute at least 20-30\% of the total capital tequired. KIE requires some tangible securities in the form of landed security and/or a debenture over the company's assets. Labour intensive projects particularly those that exploit local raw material are given preference. Alhough nates are generally lower that those charged by other financial institutions, these rates are somehow high making many clients shy away from seeking financial loans. Credit and loan documents collected from KIE showed that interest wate were $24.4 \%$ per annum for the formal sector and $2.7 \%$ per month for the informal sector. This is already too high making KIE operate once again like a commercial bank - hence reducing it role in industrial promotion through offering finance.

Despite the effort made by KIE, its perceived role to promote industrial development has not been achieved. Operations of KIE are still faced by many constraints. Finance is one of them. The government has not been able to provide adequate finance. It was noted that the funding which used to be obtained from donors declined drastically especially in the 1990s when most international financial bodies and donors pulled out of the country. More so most of them tefused to show commitment in funding resulting in KIE's due to its poot performance. KIE also lacks adequate capacity to offer effective technological training and supervision. While this may not be viewed as a serious problem since qualified personnel can teadily be obtained. The severe problem is lack of enough working capital requited for KIE's recurrent expenditure given the reduced. financial support from the government as well as from donots and international funding agencies. "This means that $\mathrm{KIE}$ was unable to hire and sustain qualified personnel. This leads to the next problem in that KIE lacks the capacity to study the industry and play an more active role in the match making process, which would in tum promote linkage proliferation in the industry. For instance, discussions held with KIE officers revealed that only a few cases existed of linkages formed between SMEs and MNCs as a result of facilitation done by KIEs:

Similarly, KIE's role to promote industrial parks/incubators had not been a success with only a few cases of such parts surviving from bankruptcy and collapse. Although one of KIE:'s mandates was to pass information, interestingly it does not exen have an internet

\$5 Intervews conducked by the author $2003 / 4$. 
site where information could be placed for easy access by hms, trom the point of firms, complaints have been launched that interest rates charged were very high. This being the case coupled with the fact that these firms have been subjected to the forces of biberalisation under the aegis of structural adjustments, it is then expected that most of them would face stiff competition from MNCs and perhaps exit business. This has actually been the case with most of them remaining static in capability development and thus poor performance. These results in low profitability, reduced working capital and most a times inability to meet debt obligations. The implication of this is that KIE plays a very minimum rolle in industrial development.

\section{(v) Kenya Bureau of Standards}

The Kenya Bureau of Standards (KEBS) was established in Kenya by an act of parliament in 1974. The setting of KEBS came at a time when issues pertaining to standards and quality management were becoming important wotld wide and competitiveness of most manufactured goods was to a large extent being determined on the basis of quality standards. To this end, formation of KEBS served to promote and make manufactured goods competitive in both the local and external markets by raising quality. KEBS was set up at a time when Kenya's manafactured goods had failed to penetrate the expont market and were also facing rejection in the domestic matket following significant preference attached to the impotted manufactured goods. Kenyan manufactured goods were perceived to be of low quality and thus substandard (Ikiaria, 1988: p. 235). KFBS was therefore formed as a regulatory body mandated to deal with strengthening of manufactured goods and services through the application of standards, 'metrology' (science of measurement and calibration) and by providing technical advice on quality management in Kenya. The standards are formulated by technical committees constituted from experts and professionals drawn from various stake holders and interested parties such as producers (MNCs and domestic firms), consumers and research organisations.

Enhanced standatdisation in an industry can stimulate technology transfer and diffusion. As a technical language needed for communicate industrial and service specifications, it: can equally lead to industrial growth and capability development. This would come a long as firms and industries strive to achieve minimum set standards or existing intemational standands. A lot of time, effort and resources would be required involving interactions of stakehoiders. From the interviews conducted it was reported that in some cases research officers from KEBS learnt certain standatd and metrological aspects from MNCs operating in the country. A few of these MNC whose skill and technology is higher than that of KEBS have often been accredited to conduct metrological or laboratory tests for local firms on behalf of $\mathbb{K E B S}$. In some cases experts from these MNCs are invited during training sessions organised by KEBS to serve as resource persons. Examples include Unilever Kenya, Nestle, Coca Cola and Canaud Metal Box.

KEBS operates a Certification Marking Scheme (CMS) whereby firms whose products meet the expected Kenyan standards are issued with permits to use the 'Mark of Quality's. To ensure continuous compliance, KEBS conducts random inspections in the firms' processing lines as well as from open market. This forces firms to keep their quality standards high and by doing so they are forced to build their capabilities. In collaboration with international standard bodies (SGS), KEBS is also involved in the training and auditing process of quality management assurance systems such as ISO 1400

5t The cerification marking schemes administered by KEBS inclucte; The Diamond mark of quality, Quality Systems Registration Mark. Calbration Mark and Safety Mark. 
for environmental management, ISO 9000 for quality management of tevised $1 \mathrm{SO} 200 \mathrm{l}$ : 9000 for production quality management, continuous changes and customer service ${ }^{50}$.

Through increased effort, some of KEBS testing laboratories dealing with Food and Agriculture Labotatory, inotganic Laboratory, Organic Isabotatory and Microbiology labotatory have been accredited to ISO 17025; 2000 by United Kingdom Accreditation Services (UKAS) ${ }^{5 *}$. Products approved by the bureau ate therefore accepted in the regional and intemational markets. Preparation for this award required heavy fim level invesment about KShs. $48 \mathrm{Mn}$ was invested in equipment, staff training and modern testing procedures. This has a positive bearing towards enhancing capability building in the manufacturing industry. Interestingly also, two of KEBS metrology labotatories in the current, voltage \& resistance and volume \& flow fields of measurements have been accredited by German Calibtation Service - Deutsche Kalibrier Dienst (DKD). This implies that these labotatories can issue DKD calibration certificates that are recognized within the European Union and all the countries with mutual recognition agreements with the EU.

KEBS organises trainings and seminars to promote and develop standardisation mainly in manufactufing and service at all levels. Participants would be drawn from local and MNCs. This way the participants get to intetact and share knowledge, ideas, skills etc. This is sometimes extended to include attachments and firm wisits by the KEBS officers. Mainly the trainings are offered in the following areas: Industrial standardisation (implementation of ISO standards); Quality and Environmental Management (QEM); Hazard Analysis \& Critical Control Point Analysis (HACCP); Regional metrology conferences; internal quality audit and statistical quality control; and laboratory testing. In these trainings and seminats, the resounce persons are drawn from public and private sector - with MNCs as the dominant contributors.

KEBS maintains a Standards In formation Resource Centre (SIRC) purposely designed to promote flow of information and standards related documentation from regional and international organisations and national standard bodies world wide. It has a collection of over 1,800 printed Kenyan Standards and well over 250000 foreign standards. This is remarkable given that only 450 standards had been established by late 1980 s. Information is processed and systematically stored for easy retrieval for individuals interested in standards information.

One of the WTO agreements dealing with matters pertaining to trade information related to standards, standard-type documentation and technical regulations is the Agreement on Technical Bartiers to Trade (WTO-TBT). This Agreement requires that ench of its signatories sets up and operate a National Enquiry Point (NEP) - a standards and technical regulations trade information reference point linked to a network of similar NEPs world-wide. The Kenya Bureau of Standards is the officially designated WTOTBT National Enquiry Point that provides information on standards and technical regulations affecting trade worldwide, including WTO members' notifications on Technical Barriers to Trade. NEP is also supposed to notify WTO of all proposed government regulations, conformity assessment procedures and standards-related trade information that might significantly affect international trade. The NEP's main objective is to improve Kenya's competitiveness in domestic and world markets.

\footnotetext{
5T The Kenya Burean of Standands website: htp://www kebsorg/provides more information on this

5 btp:/ /www.kebsorg/
} 
In sum, despite the achievements made so far, there are sull many problems facing KEBS. Inadequate funding to facilitate training, dissemination of information by a way of exhibiting in show grounds and others such as trade exhibitions; seminars and symposia to educate the manufacturers as well as consumers on standatdization work and increase their awareness. There is extremely low patronisation by manufacturers blaming it on lack of capacity such as recent metrology techniques coupled with few skills available in terms of professionals required. Although it was indicated that with regard to human resources development some of the research officers had been sent abtoad to countries like Japan, USA, Gemany, UK and Sweden for further training, there is still inadequate capacity to cleall with standardisation and metrology. Although KEBS maintains a website providing background information on the institute and the services offered, there is lack of a strong ICT back up from where queries can be launched. Information, say on training placed on the intenet site would reach a lager audience. Another problem is that there are few testing centres in the country subjecting manufacturers to unnecessary delays waiting. KVBS also need to strengthen it: modalities to come up with a meaningful cooperation between players from both the public and privare sectors.

\section{(vi) Kenya Industrial Reseatch and Development Institute}

Kenya Industrial Research and Development Institute (KIRDD) was established in 1979 under the Ministry of Science and Technology to conduct industrial R\&D. Its specific mission was "to enhance the national industrial innovation process through the development of a sufficient national capacity in disembodied and embodied industrial. technologites for the attainment of self-sustaining industrialisation process ${ }^{5 n "}$.

Functions of KIRDI can be classified into four major divisions. First, project studies and development division conducts feasibility studies, conducts market intelligence studies, undertakes economic/statistical analysis of industrial projects and provides extension. services. Second, process and product development division conducts laboratory studies for the purpose of improvement and development of industry processes and products. for instance food technology, ceramics, textile and leather technology, microbiology and cereals technology. Third, analytical and testing division concentrates in analytical chemistry, biological and orgaric chemistry, physical chemistry and materials testing. The research undertaken attempts to develop new analytical techniques or modify analytical methods to suit local conditions. Fourth, engineering and design diwision deals with: development of indigenous designs of products machinery and equipment primarily with maintenance, electrical and electronics, mechanical engineerng and chemical engineering.

All the services offered by each of these centres are done at a specified fee. Many firms in the manufacturing industry including small and large firms, locally and foreign owned firms have sought the services from all these divisions. Interviews conducted indicated that due to the increased demand in their services fitom the industry, KIRDI has recently started outsourcing for professional services from the private sector. They contended that there are many firms, especially MNCs with higher technological capabilities. This strategy seems successful and is now being extended to include other institutions and universities where experts will be talken on contract or part time bases. This coordination strategy is expected to reduce the time manufacturing firms spend waiting for certain services.

\footnotetext{
3w "The KIRDI website: hrtp:/ /www.hirdi.org/ has more elaborate information.
} 
Arhough relatively good progress has been made at KIRDI, internal constraints have hindered KITDI from acheving its full potential. To begin with, there is extremely high staff mobility, which seems to be in one direction, from KIRDI to the private sector or learning universities. "This makes tetention of trained workers difficult. As is the case with many public institutions, the salaries paid are low, this factor makes the retention of workers difficult and once they get trained they leave to join private firms or teaching instimutions, universities and polytechnics. This is alright since it would indicate that KIRDI generates human capital for the industry but because of this, most of the time the core staff constitute young graduates with little experience in research. The effect of these is that the productivity of the institute is reduced in terms of research conducted or services offered to the indusery. As noted in recent studies almost all the researchers and engineers had less than three year stay at the institute (Mwamazingo, 1999 p. 80-1). Another interesting thing noted was that although KIRDI used to have large employment size, this was drastically reduced by more than half from about 700 in early 1990s. In a study done by Mwamazingo (1999), he found out that KIRDI employed 340 staff in 1992 . The showed that in 1992 only about 50 of the staff, about $14 \%$ of the total consritured what could be described as the core professional employees either PhDs, maters or bachelors degree. However, considering core professionals to include only those with PhDs and masters the number reduced to only 26 staff which accounted for $7.3 \%$ of the total.

With the activities of KIRDI funded by the government, it is obvious that this funding may not be enough as this is usually the case with the institutes funded by the government. For instance in 1992 , KIRDI spent over $81 \%$ of its recurrent expenditure budget in personnel expenses such as salaries with the remaining devoted for actual research. Due to lack of working capital, it becomes difficult to purchase adequate machinery and facilities for use in the laboratories or stock and maintain library. Lack of funds also does not permit improvement in remunetation and conditions of service... It becomes also difficult to contract services of qualified professionals from the private sector. With availability of funds such professionals could be engaged for instance to carry out surveys or experiments or train in management such ISO. Lack of all these denies Kenya flow of spillovers which are necessary for industrial development. To some extent this has an effect to the weak co-operation between KIRDI and the industrialist as they think KIRDI has little to offer. For its development expenditure, KIRDI relied mainly on foreign donors which was no longer enough or assured.

When the government adopted strict fiscal control, especially with $S A P s_{\text {, the }}$ implication was that institutions relying on treasury for grants were forced to reduce their operations drastically: To overcome this problem of funds KIRDI established a National Industrial Research Programme (NIRP). NIRP would draw funds from government, private sector and donors. As a response to this, the government in 1999 more than doubled its allocation to the institute to KShs. 900 Million. A technical advisory board to co-ordinate industrall research programmes was launched. The NIRP would play a more active role for technology development, identify constraints to linkage formation and information flow and maintain a database for industrial technologies. The body would also actively play the matchmaking role to identify and connect for instance SMEs to MNC firms for technical assistance etc. However, to-date KIRDT has not been able create a technologically vibrant culture. It has for instance failed to trigger technology and innovation interests in most large firms including $\mathrm{MNC}$ in the manufacturing sector. This problem is compounded by the fact that there is no attempt from the government to link and co-ordinate the research institutions in the country. Lack of such intermediation reduces spillovers in an industry and thus learning and capability building. 


\subsubsection{Brief Summary of Emerging Issues Based on the Role of Institutions Examined}

Analysis of post independence period has shown that at independence the Kenyan government continued to pursue import substitution mode of industrialisation initiated during the colonial days. The government encouraged this mode of industrialisation by offering a wide range of protection measures and subsidies. For instance, trade batriers and high tariff walls were erected; foreign exchange and exchange tates were controlled and interest trate and credit policies were introduced to subsidise manufacturing.

In the transition period after independence, the country witnessed an outflow of sone FDI present in manufacturing. This was perpetuated by the exusting fever emanating from impeding implementation of nationalisation policies. The government formulated policies and created institutions to reduce the outflow of capital and more so to atract new and diversified FDI. As a result of the friendly investment policies, sound macroeconomic performance coupled with the rapid increase in demand for consumer goods (demand for consumer goods was extended to the entire East African Community) at the time, there was high inflow of FDI into manufacturing all targeted at import substiturion. Analysis done showed that FDI dominated in manufacturing industry in the period. Similarly, increased inflow of MNCs into other sectors of the economy was equally observed e.g. trade and setrices such as banking. The first nwo decades of Kenya's independence under import substitution were characterised by generally good economic performance generally attributed to the presence of FDI - GDP and manufacturing industry growth tates were among the fastest ever recorded in the country.

The institutions established played a substantial supportive role in industrial development by facilitating formation of joint ventures between MNCs and local firms; offering finance for start up firms or for expansion; advance indigenous manufacturing technology; assist in technology transfer; promote industries that use locally available raw materials and stimulate linkage formation. All these factors were in favour of industrial capability development and spillover occurrence from FDI. However, as time went by some of the institutions were faced with severe constraints such as lack of capital to finance R\&D, acquisitions of technology and machinery, training to develop required and adequate human capital to support industrial capability development. Some of the industrial development financing institutions were transforming and re-orienting some of their services to include banking services by solicining public deposits. "They were therefore forced to charge high interest tates similat to those charged by commercial banks implying declined supportive role to industrialisation - as firms will shy from taking loans for development purposes which would result in capability building. This meant a reduction in their role of nurturing indigenous industrial capability promotion.

One of the consequences of the above was that the indigenisation process launched to nationalise jobs, encourage and support Africans to venture into trade and manufacturing did not turm out very successful. The policy was intended to implant and nurture an entrepreneurship culture to the indigenous, a process expected to result in capability development inspired by the existing FDI in manufacturing. However, weak or declined role of the institutions were not the only things to blame; there was also slackened commitment from the government side and by the end of the first two decades a clear distribution pattern in the structure of the manufacturing emerged greatly skewed in favour of MNCs and the Asians. The large manufacturing industries in the country were dominated by either MNCs or parastatals; Asians dominated small and medium 
enterprises white Africans dominated the micro and firms in the informal sector Athough Kenyan Asian and Africa furms benefited from FDI, spillover occurrence, it is impossible to quanify that in this chapter. This is done in the subsequent chapters.

\subsubsection{Structural Adjustments: The Era of Liberation and Export-Promotion}

So far we have examined the role of FDI in industrial capability development during the colonial period and in the early decades of import substitution. The institutions established to encourage foreign investment and support indigenous capability development were also examined. In this section our analysis is done in the context of structural adjustments. This section is divided into a number of sections starting with economic crises of 1980 s which served as the stimulus to the adoption of SAPs. We also examine the economic adjustments with the commencement of SAPs and expotr promotion. Finally we relate that to FDI and discuss how policies adopted affected FDI, spillover and broad industrial capability development.

\section{The Economic Crises of 1980s: Stimulus for Structural Adjustments}

Contrary to the high level of economic growth witnessed until late 1970 s, in the period 1981 - 1985 the GDP growth rate declined to a bout (3.6\%) from a growth tate of $(6.2 \%)$ witnessed in the period (1977-80). The tate of growth in manufacturing output slowed down - the growth rate declined from $(10.3 \%)$ in the period $1977-80$ to $(3.8 \%)$ in the period 1981 85. Similarly both agriculture and service sectors recorded substantial declines in the same periods. The breakdown of GDP and sectoral growth rates is provided in Table 3.5. As a result of the economic stagnation, the manufacturing recorded a corresponding decline in manufactured exports. As noted in Glenday and Ndii (2000), merchandise export earnings as a percentage of GDP declined from $(19.6 \%$ in the 1970 s, to $(16.97 \%)$ over the period $1980-84$ and a further $(13.6 \%)$ over the period 1985-89 reaching an all time low of $(11.5 \%)$ in 1987. Compared to the other main sectors of the Kenyan industry, manufacturing share in GDP stagnated at $(13 \%)$ in the period 1981-1985. The share of agriculture and services in GDP stood at (33\%) and (47\%) respectively in the same period (see Table 3.6). As will be shown this had some negative ramifications for FDI in terms of inflow and performance.

This decline in economic petformance was blamed on the inward-oriented strategy stipulated in the ISI strategy and of course other factors such as break up of the EAC in 1977 had their toll as welltr. Ensuing economic distortions resulted in severe structural constraints and macroeconomic imbalances - problem of technology upgrading, lack of information on technology sources, lack of managerial and technical skills and financial constraints ${ }^{6}$. Firms failed to develop competitive capabilities to penetrate international markets (Lall, 2001; Wangwe, 1995). The efficacy and efficiency of the institutions formed at independence was declining with little co-ordination among them and lack of finance [see Lall and Pietrobelli (2002)]. Admittedly, inward looking policies pursued at the time under import substitution made it difficult to effectively participate and compete keenly in the export markets. Participation in the domestic and immediate regional market seened to have had negative implications for Kenya's manufacturing in that by so doing Kenya lost its global competitiveness, which would have cumulatively resulted from participation in the international market - path towards accumulation of export and

\footnotetext{
(65) Hor a detabled analysis on economic instability in Kenya" Theory and evidence see Vandemoortele (1985). Also for demiled analysis of conomic crises witnessed in this period see Nyongo (1988; p. 36-9).

thot For detailed analysis on finnoncial constraints see KIPPRA (2001).
} 
matreting capabilities. It was believed that following the import substitution path, Kenyan exports would never compete internationally and especially at a time when the global matkef was becoming increasingly competitive and production for exports highly innovation based.

Table 3,5: Sectoral and GDP Annual Average Growth Rates, Kenya, 1972-2002

\begin{tabular}{lrrrrrrrr}
\hline Sector & $72-76$ & $77-80$ & $81-85$ & $86-90$ & $91-94$ & $95-00$ & 01 & 02 \\
\hline Agricullare & 3.1 & 4.2 & 2.8 & 4.2 & -1.1 & 1.9 & 1.3 & 0.7 \\
Manufacturing & 9.6 & 10.3 & 3.8 & 5.7 & 2.2 & 1.8 & 0.8 & 1.2 \\
Services & 3.7 & 6.4 & 4.4 & 5.4 & 3.0 & 3.0 & 2.6 & 2.3 \\
GDP & 3.6 & 6.2 & 3.6 & 5.0 & 1.5 & 2.46 & 1.2 & 1.1 \\
\hline
\end{tabular}

Source Sessional Paper No. 2 of 1.997 , Economic Survey and Statistical abstact various issues.

Table 3.6: Average Sectoral Share of GDP, Kenya, 1972-2002

\begin{tabular}{lrrrrrrrr}
\hline Sector & $72-76$ & $77-80$ & $81-85$ & $86-90$ & $91-94$ & $95-00$ & 01 & 02 \\
\hline Agriculture & 35 & 34 & 33 & 31 & 28 & 27 & 27 & 26 \\
Manufacturing & 10 & 12 & 13 & 13 & 14 & 13 & 13 & 13 \\
Services & 47 & 47 & 47 & 50 & 52 & 54 & 55 & 55 \\
Others & 5 & 7 & 7 & 6 & 6 & 6 & 5 & 6 \\
GDP & 100 & 100 & 100 & 100 & 100 & 100 & 100 & 100 \\
\hline
\end{tabular}

Source: Sessional Paper No. 2 of 1997, Ecomomic Survey and Statistical abstract varicours issues.

As noted in most studies, high levels of protection seemed to have distorted resource allocation, constricted foreign competition and restricted technology inflows from abroad. There were very few incentives to build technological capabilities and upgrade imported technologies. Not much emphasis was put on things like cost reduction, productivity improvement, quality control, inventory control among others (see Wignaraja and Ikiara, 1999). The import substitution industrial strategy was not achieving its perceived industrial and subsequently overall economic development agenda. As a result the manufacturing industry failed to play a more dynamic role enough to function as "an engine of country"s growth" and had not contributed significantly to foreign exchange (Kenya Govemment, 1994).

\section{Towards Structural Adjustments Programme and Export Orientation}

In light of the above developments, there was a need to pursue an outward-otiented industrial policy in order to re-orient industrial production in favour of exports. Faced with economic stagnation and increasing debt, the government had no alternative than to adopt the structural changes, which were at this time being recommended in the structural adjustment programme ( $\mathrm{SAP}$ s) and economic stabilisation programs advocated by Word Bank and MF receptively (see Logan and Kidane, 1993). Hence, in the second half of 1980 s, there was a change in public policy and the govemment started implementing SAPs ${ }^{62}$. One of the majot objectives of SAPS was restoration of internal and external balances through a strong policy of export promotion coupled with drastic

\footnotetext{
62. The Government acloped SAPs through the publication of sessioral paper No. 1 of 1986 on Fonomic Matagewn. for Renend Growth. "Government's strategy for industrialisation must concentrate on two approaches. First, the domestic market for manufactured goods must be expanded matkedly. Second, Kena's industry must be restructured to become mench mote efficiont and capabie of exporting goods proftalbly ard compering against imported goods with moderate protection".
} 
reduction in public spending and expenditure switching. There was a strong recommendation towards institutional refoms - for the purpose of encoutaging FDI inflow, exports and industrial capability development. New FDI was being cncouraged following increased openness to local and foreign investment. Price controls were eliminated and trade protection relaxed. There was free entry into production, services and trade (Mwamazingo, 1999; Glenday and Ndii, 2000). This culminated in a slight recovery in the economic performance in the subsequent years, the GDP grew by $(5.0 \%$ ) in the period 1986-1990, Table 3.5. The growth rate in manufacturing suddenly rose to $(5.7 \%)$ in the same period (1986-90), agricullure $(4.2 \%)$ and services $(5.4 \%)$ (see Table 3.5). Avallable figures on metchandise exports indicated that merchandise exports as a percentage of GDP jumped to (13\%) between 1978 and 1992 (Glenday and Ndii, 2000).

Howewer, despite this improvement in economic performance, the rewards were short lived. Part of the blame was put on the government failure to show setious commitment to the reforms it was andertaking. For instance, the liberalisation measures introduced in mid 1980 s were being reverted some were getting halled ox applied intermitrently (Mwamazingo, 1999, Ronge and Nyangito, 2000). The economy once again seemed to have been headed for another doomsday as reflected by the figutes in Table 3.5 for the interval (1991-94). The government, however, started showing keen commitment in the first half of 1990s. By 1993, the government undertook far reaching structural reforms to reverse the declining trend in Kenya's economic activities: removal of price controls, removal of import licenses, tariff reductions, liberalisation of foreign exchange matkets, and privitisation of public enterprises ${ }^{64}$. Reforms aimed at packaging more attractive investment incentives, streamlining public exterprises and strengthening financial institutions were made.

\section{Deeper Economic Crises under Structural Adjustments and the Consequences on FDI}

Despite the introduction of $S A P S_{s}$ in the 1980 s and introduction of new reforms by early 1990 s, the initial years prior to 1990 s tecorded very low economic growth than any other period before. During the period 1991-1994, the economy recorded a GDP growth averaging below $2.0 \%$. The manufacturing sector growth rate continued to decline tremendously. It declined from (5.7\%) in the period $1986-90$ to (2.2\%) in the period 1991.94 (see Table 3.5). Major monetary indicators such as inflation, real interest rates and exchange mates all shot up during the period 1991-1.994 (see Figure 3.1). This scenario presents a weak and un-conducive learning atmosphere hence reduced effort towards industral capability development in the period.

\footnotetext{
6.) There was an high element of uncertainty; infant industries were being exposed to internarional competition. Manufacturing capability was weak as were infrastructure and supporting institutions,

64 These reforms were contauned in a publication of the sessional paper No. 1 of 1994 on Recovery and Sustainable Development to the year 2010. This paper was meant to complement the sessional paper No.1 of $198 \%$
} 


\section{Figure 3.1: Inflation, Real Interest Rates and Exchange Rates, Kenya, 1980-2000}

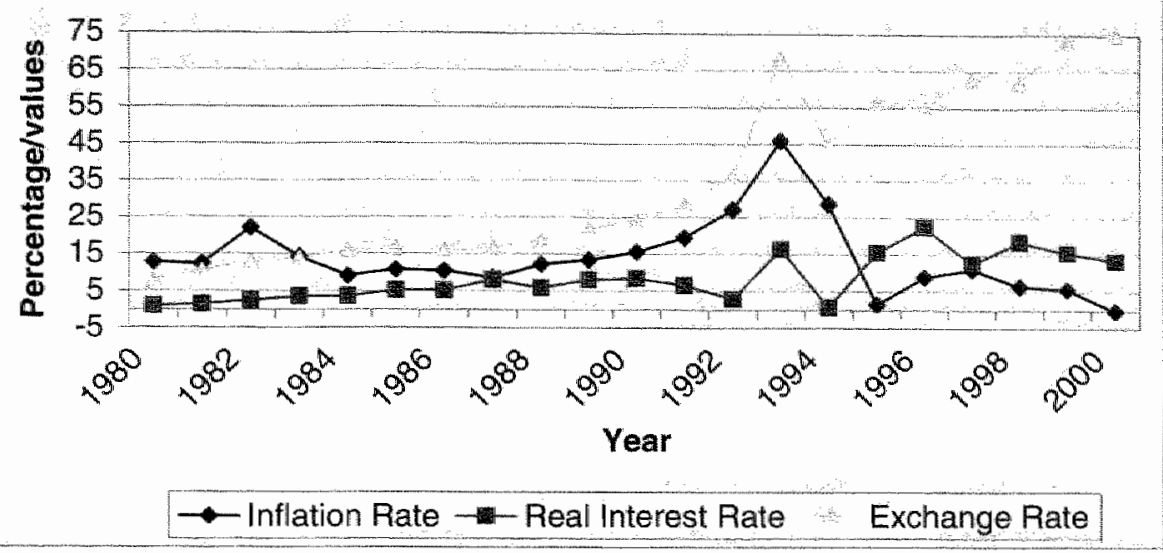

Several reasons were responsible for the poor economic performance: withdrawal of foreign aids, political unrest, and high oil prices during the Gulf war and the world economic recession. The major one was the multiparty politics which led to immense political unrest resulting in anxiety and uncertainties of foreign aid, which in turn had negative consequences on the inflow of FDI. This also affected the performance of institutions resulting in reduced effort in their role in industrial capability promotion. FDI inflows in Kenya, which was relatively high in the $1970 \mathrm{~s}$, began to decline. Table 3.7 shows that FDI inflow that averaged US $\$ 60$ million in the period $1977-80$, declined to US 31 in 1986-90 and had US $\$ 8$ as the lowest ever recorded in 1991-94. During this period, 1991-94, FDI accounted for less than 1\% in gross fixed capital formation as it did in the period 1996-98. Investors complained of high taxation and delays in profit and divided repatriation, which had fallen three years in arrears and excessive government regulation (Kimuyu, 1999). During this period, corruption increased and infrastructure deteriorated - making the cost of operating in Kenya escalate. However, in the last couple of years inwatd FDI has tisen fairly rapidly relative to the past years reaching US \$ 42 and US $\$ 127$ million in 1999 and 2000 respectively. The FDI stock has remained on an upward trend; increasing from US $\$ 344$ million in $1977-1980$ to US 732 million in 1995 and US $\$ 1,047$ million in 2000 . FDI stock had an average growth rate of $12.7 \%$ (in current terms) for the period 1977-2001 and a GDP average share of $9.4 \%$ for the period (2000-1). Despite this increase in the recent years, Kenya still. lies behind many other countries in Africa as a recipient of FDI but with high levels of FDI (95\%) concentrated in manufacturing and services (Wignaraja and Ikiara, 1999: p. 69). This will also be shown to be the case in Chapter 4 using data gathered from secondary sources. 
Table 3.7: FDI Inflow and Stock, Kenya, 1977-2001

\begin{tabular}{lrrrrrrrrrrrr}
\hline Year & $77-80$ & $81-85$ & $86-90$ & $91-94$ & 95 & 96 & 97 & 98 & 99 & 00 & 01 \\
\hline Kenya & & & & & & & & & & & \\
FDI Inflows & 60 & 40 & 31 & 8 & 35 & 13 & 40 & 42 & 42 & 127 & 50.4 \\
FDI (\% GFCF) & 5 & 1 & 2 & 1 & 2 & 1 & 1 & 1 & 3 & 8 & 3 \\
FDI Stock & 344 & 434 & 668 & 694 & 732 & 745 & 785 & 827 & 869 & 996 & 1047 \\
FDI Stock (\% GDP) & & & & & & & & & & 9.5 & 92 \\
\hline
\end{tabular}

Note: FDI Inflowss and FDI Stock are in Million of Dollars

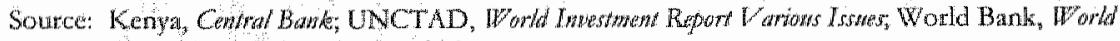
Deperopingedat Tutidiators CD-ROM

As an attempt to attract FDI, stimulate external trade and expand exports the government enacted policies towards investment and export promotion. Investment Promotion Council (IPC) was established and mandated to attract FDI into the country. Export schemes which wete introduced in the early 1990 s included introduction of Expott Processing Zones (FPZ) in 1990 with the enactment of the export processing zones Act to promote export oriented industrial investment. Export Promorion Center (EPC) was established in 1992 to formulate market strategy, promote an export culture and to identify export opportumities regionally and internationally. Manufacturing Under Bond (MUB) established in 1986 and administered by the investment promotion council (IPC) was strategised to exempt from duty and VAT those exporters who imported machinery and raw materials in manufactured goods for exports. Finally Export Programmes Office (EPPO) was established in 1992 as a kind of duty draw back scheme administered by the Treasury (Kimuyu, 1999: Glenday and Ndii, 2000). It is believed that this helped jump the Exports from (13\%) of GDP in 1992 to over (20\%) between the period 1993.96 (Glenday and Ndii, 2000). Nevertheless FDI has remained low in Kenya, albeit high in some selected sectors of the manufacturing industry.

\subsubsection{FDI and Industrial Capability Development: The Role of Institutions During the Export Orientation Period.}

In the above section we have shown that due to the economic turbulences of $1980 \mathrm{~s}$, SAPs were adopted in Kenyal by mid 1980s. All the liberal instruments adopted were outlined such as, liberalisation through decreased deregulating, openness to trade and foreign investment. As noted, this did not appear useful to the country as the economy was plunged into deepened crises until 1993 when the government undertook further reforms to revert the crises trend. "The reforms inclucled establishment of a number of institutions for promoting exports, FDI, technology transfer, linkage formation, capability building and performance in manufacturing. In light of this backgtound, this section examines the specific role played by institutions during this period focusing on IDI, spillovers, industrial capability and performance.

\section{(i) Export Processing Zones}

"The Kenyas Export Processing Zones (FPZ) program managed by the EPZ Authority was established by an act of parliament, The Export Processing Zoves Act, in 1990 for the promotion of export industrial investment in the country. The programme was initiated with the following objectives: to promote investment and technology transfer in exportoriented activities, to diversify the country's export structure by promoting nontraditional exports, to create direct and indirect employment opportunities in the country and to strengthen linkages (between MNCs and domestic firms) within various economic sectors. Despite having been set at a time when Kenya's economic performance was at 
its worst, EPZ has tecorded substantial growth on many frotis . The progrmme has attacted MNC investors from Europe (e.g. Denmark, UK, Belgim, Germatry and Netherlands); USA; Asia (e.g. Tarwan, Pakistan, China, India, Sri Lanka, and Hong Kong); Africa (e.g. South Africa). The programme has also generated slow but progressive interest from domestic investors. In $2002,11 \%$ of the total $E P Z$ firdas wete wholly Kenyan firms; joint ventures between local and foreign firms accounted for $15.0 \%$ while wholly foteign owned firms accounted for $75 \%$ [Figure 3.2].

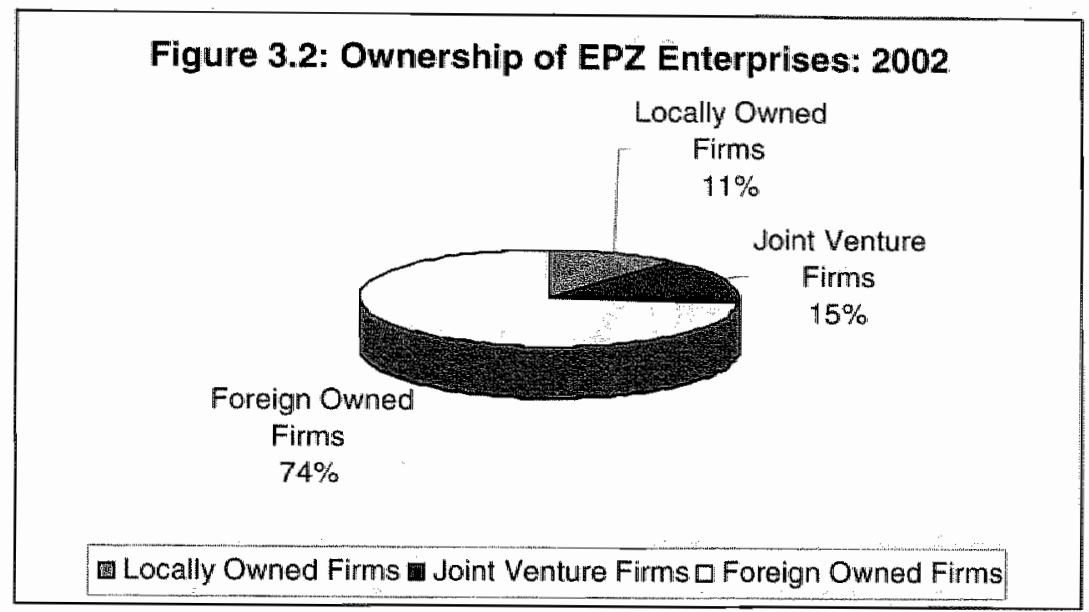

To attract investors (mainly FDI) $\mathbb{E P Z}$ has designed a scheme, which includes among others; attractive fiscal incentives, simplified operating procedures and lower operation costs, faster set up and smoother operations. As is the case in most countries, under fiscal incentives, the EPZ scheme offers 10-year corporate tax holiclay and $25.0 \%$ tax thereafter; 10-year withbolding tax holiday on remittance of dividends; duty and VAT exemption on raw materials, machinery and other inputs; stamp duty exemption; $100 \%$ investment deduction on capital expencliture within 20 years. To facilitate easicr procedures and smoother operations, the EPZ scheme offers procedural incentives which include rapid project approval (30 days) and operations under essentially one licence; allows any investment level (no minimum) and unrestricted investment by foreigners; allows access to offshore borrowing operations of foreign curtency accounts (no exchange controls); removes autonomous control of investment proceeds; exempts firms from industrial registration act, factories act, statistics act, trade licensing act, imports, exports and, essential supplies act; allows work permits for senior expatriate staff; on-site customs documentation and inspection; provides one-stop-shop service by the EPZ Authority for facilitation and aftercare. The EPZ scheme also provides infrastructure such as high quality zone infrastructute - factory buildings, serviced land and common services (EPZA, 2002) (6). $^{\circ}$

In issuing enterprises, EPZ authority acconds priority to three major export-oriented activities: Manufacturing, Commercial activities and Services. In order to promote

4: A detailed analysis of EPZ in Kenya is provided in (kiara and Odhiambo, 2001).

twe website: hatp: / / www epzakenyacom/ provides information on this. 
expots, enterprises located in EPZ must export $80 \%$ of their output. The $\mathbb{E P Z}$ enterprise licences are evaluated under strict criteria to include only enterprises that would lead to development of new export products and new export markets, technology transfer and shill training, job creation, new productive investment in buildings and machinery, and finally establish backwatd linkages with the Kenyan economy - hence playing an important role in clewelopment of industrial capability.

An assessment based on the objectwes of $1 \mathrm{PZ}$ and based on data available (Table 3.8 ) indicated growth in performance. For instance, the number of gazetted zones had risen From 11 in 1994 to 31 in by 2002 . The number of operating companies in the gazetted zones had also increased from 15 to 54 implying that 39 new enterprises had become operational during the petiod. From the interviews conducted, it was noted that an increasing number of firms in the EPZ were in agro-processing, especially in cotton weaving, horticulture and tea processing. Diversification was taking place and there were increased investments in textille and garment, electronics, printing, pharmaceutical. Textiles and gatments accounted for $55 \%$; electronics $27 \%$; chemicals and phamaceuticals $11 \%$ with the remaining $7 \%$ shared among the remaining products. Capital investments in the same period grew by over $500 \%$ (in current prices) to stand at Kshs 12.728 billion in 2002 from Kshs 2.097 billion in 1994.

Value added in EPZ output has been increasing over the last few years and was estimated at 34\% of the EPZ's turn over (Kenya Economic Survey 2001). Total turn over for the $\mathbb{E P Z}$ companies expanded by $1000 \%$ (in current prices) from Kshs 945 million in 1994 to a record Kshs 10.673 billion in 2002 (see Table 3.8). The impetus behind the high growth in performance especially after 2000 came as a result of the enactment of African Growth Opportunity Act (AGOA). As a share of total sales, exports increased from $53.7 \%$ in 1994 to $82.8 \%$ in 2000 and to $91.3 \%$ in 2002 . Garments accounted for over $81 \%$ of the total EPZ exports. High export performance has been attributed to the opering up of the United States market to textiles and garments under AGOA and also preferential access to the common market for Eastem and Southem Africa (COMESA), as well as European Union markets ${ }^{68 .}$. Exports to United States accounted for $79 \%$ of the total exports; Europe 8\%; EAC/COMESA 7\% and others 6\% (EPZA, 2002). On the other hand, imports into EPZ stood at Kshs 635 million in 1994 compared to Kshs 7.043 billion in 2002 .

Table 3.8 shows that direct employment in the EPZ had risen to 26,447 in 2002 from only 1,865 in 1994 depicting an average annual growth tate of $43.7 \%$ in the entire period, 1994-2002. Interviews conducted revealed that an estimated 4,480 jobs were created in 2001 in sub-contracting and supplies. It was also noted that over $60 \%$ of the EPZ employment are female. Employment of expattiates had grown significantly and over 700 foreign expatriates were employed in EPZ by 2002. "The average anmul growth tate for the employment of expatriates was $47 \%$. The highest annual growth rates recorded after 2000 would be expected as it coincided with the enactment of the AGOA programne. It was also noted that availability of on-the-job and other training opportunities for the employees were provided. Over 25 EPZ companies offered warious kinds of training including, computer assembly, garment making, weaving technology, and quality control.

4) The EPZ website hrop//waw.epakeny.com/ provides backgtound information on this.

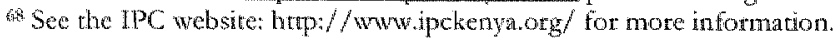


The data obtained provides exidence of a deepening linkage system between the EPZ and the rest of the economy. Between 2000 and 2002 local purchases increased by more than double from Kshs 1.2 billion to 3.2 billion. Domestic sales also uncreased by mone than wow fold from Kshs 438 million to $\mathbb{K}$ shs 1.3 billon (period 19942002 , Table 3.8 ).

Table 3.8: Performance of Expott Processing Zones, Kenya, 1994-2002

\begin{tabular}{|c|c|c|c|c|c|c|c|c|c|}
\hline Years & 94 & 95 & 96 & 97 & 98 & 99 & 90 & 01 & 102 \\
\hline Gazerted Zones & 11 & 13 & 14 & 15 & 16 & 16 & 19 & 23 & 31 \\
\hline Enterprises Operating & 15 & 19 & 22 & 17 & 18 & 22 & 24 & 39 & 54 \\
\hline $\begin{array}{l}\text { Employment Locals } \\
\text { Employment }\end{array}$ & 1,865 & 2,718 & 2,884 & 2,824 & 3,645 & 4,684 & 6,487 & 13,444 & 26,447 \\
\hline Expatriates & - & 79 & 71 & 61 & 74 & 83 & 133 & 314 & 701 \\
\hline $\begin{array}{l}\text { Total Employment } \\
\text { Exports Sales }\end{array}$ & & 2,797 & 2,885 & 2,885 & 3,719 & 4,767 & 6,620 & 13,758 & 27148 \\
\hline $\begin{array}{l}\text { (KShs Mn) } \\
\text { Domestic Salles }\end{array}$ & 507 & 716 & 1099 & 1,263 & 1,805 & 3,020 & 3,635 & 5,962 & 9,741 \\
\hline $\begin{array}{l}\text { (KShs Mn) } \\
\text { Total Sales }\end{array}$ & 438 & 620 & 496 & 503 & 649 & 706 & 755 & 538 & 1,299 \\
\hline $\begin{array}{l}\text { (KShs Mn) } \\
\text { Foreign Imports }\end{array}$ & 945 & 1,336 & 1,595 & 1,766 & 2,454 & 3,726 & 4,390 & 6,500 & 10673 \\
\hline $\begin{array}{l}\text { (KShs Mn) } \\
\text { Local Purchases }\end{array}$ & 635 & 940 & 1,009 & 1,258 & 2,056 & 2,126 & 2,349 & 3,990 & 7,043 \\
\hline $\begin{array}{l}\text { (KShs Mn) } \\
\text { Investment }\end{array}$ & 192 & 209 & 292 & 402 & 511 & 955 & 1,229 & 2,235 & 3,218 \\
\hline (KShs Mn) & 2,097 & 3,899 & 4,370 & 4,657 & 5,747 & 5,941 & 0,107 & 8,950 & 12,728 \\
\hline
\end{tabular}

Source: Obtained from Kenya, EPZ Awthonity and Central Burted of Stathatas; http://www.epzakenya.cony/

Despite this performance, some critiques had it that EPZ programme has not lived to its expectations particularly in the area of employment generation and stimulation of industrial growth and development in the country (Chabari, 1999). Another cringue was that the EPZ programme had failed to steer the country's industrialisation process (Mireri, 2000). As an example, EPZ had not generated strong linkages both in manufacturing and in the farming sector as anticipated. This implies less spillover benefits through such linkages. With regard to training, it has been argued that skills employed in those industries are not really high especially in the textle firms; can be acquired easily by personnel without a university degree. Graduates working in some of these firms faced with a possibility of de-skilling and low remunerations. Interviews with officers from EPZ indicated that the Kenyan export processing zone follows the traditional assembly-for-export-only pattern. Failure to have singled out specific industry groups for specialisation; facilities are pootly maintained ot not promoted to prospective investors" expectations. Nevertheless it is still early and more time should be allowed before a concrete conclusion can be made as the analysis was done within a very short span of time and under severe prevailing economic envitonment. EPZ has also been faced by some wealknesses.

\section{(ii) Investment Promotion Centre}

The Investment Promotion Centre (IPC) was established in Kenya as a statutory body in 1986 through an Act of parliament to promote private investment in Kenya. The investment centre wotks closely with all government ministries to facilitate acquisition of relevant approvals, license and permits ${ }^{\text {so }}$ IPC encourages investments that ate: labour

${ }^{69}$ The IPC website: hrtp:/ /www.ipckenyatorg/ provides background information on this. 
intensive; utilises locally avalable waw materials; stimulate foreign exchange earning or saving and promote fficient transfer of technology. Although there are no legal requirements in equity ownership levels, IPC highly encourages MNCs to form joint ventures with locally owned firms ${ }^{70}$. To facilitate this, IPC maintains a database of locally owned firms interested in forming joint ventures with foreign firms. These firms would then be matched to the incoming foreign investors who are interested in operating joint ventures with locally owned firms. IPC is supposed to facilitate acquisition of all the requited approwals and licences from government ministries (TPC, 2001).

Available statistics from IPC does not depict a steady trend in projects processed by IPC. Total capital costs and employment showed high fluctuations in the period 1990-2000. Total capital costs by local firns seemed to have increased tremendously from 1998 while that of foreign fims has been on an upward trend until 1994 when it started declining (Table 3.9). A more or less the same trend is observed with employment. Employment of the locals as well as the expatriates was only high in the early 1990s. However, very slight growth seems to be appearing from 2000 perhaps due to the enactment of $A G O A$.

Table 3.9: Capital and Employment of IPC Processed Project, Kenya, 1990-2000

\begin{tabular}{lllllll}
\hline TCC in 000' & 90 & 92 & 94 & 96 & 98 & 100 \\
\hline Total Capital Cost & & & & & & \\
Local & 3,530 & 2,027 & 3,859 & 3,533 & 7,831 & 10,610 \\
Foreign & 1,918 & 1,935 & 2,874 & 2,053 & 2,315 & 2,349 \\
Employment & & & & & & \\
Local & 11,235 & 12,730 & 12,435 & 7,083 & 3,308 & 3,971 \\
Expatriate & 205 & 184 & 203 & 223 & 116 & 156 \\
Total & $\mathbf{1 1 , 4 4 0}$ & $\mathbf{1 0 , 9 2 6}$ & $\mathbf{1 2 , 6 3 8}$ & $\mathbf{7 , 3 0 6}$ & $\mathbf{3 , 4 2 4}$ & $\mathbf{4 , 1 0 7}$ \\
\hline
\end{tabular}

Source: Obtained from Kenya, Intestment Promotion Confocil (IPC) and Central Burean of Statistics (CBS).

Total projects approved declined significantly from an annual average of 109 in the period 1990-95 to only 50 in 1995-2000 (Table 3.10\%. During the entire period 1990 2000 , an annual average of $69.5(84.6 \%)$ of all the projects approved by IPC were conventional while $12.3(15.4 \%)$ were within MUB. Following annual average computed following IPC's classification (see Table 3.10) the projects approved ranked as follows: manufacturing (15.5), services (14.6), tourism (11.4) and textile (10.6).

\footnotetext{
7it From the interviews conducted it was noted that pery tew joint ventures had been formed ats a result of IPC's active role of match making or otherwise (Interviews by author, 2002: 2003)
} 


\begin{tabular}{llllllllllll}
\hline Sector & 90 & 91 & 92 & 93 & 94 & 95 & 96 & 97 & 98 & 99 & 00 \\
\hline Tourism & 11 & 25 & 17 & 15 & 14 & 12 & 7 & 7 & 5 & 7 & 5 \\
Phamacy & 4 & 1 & 7 & 6 & 4 & 3 & 2 & 0 & 0 & 1 & 0 \\
Texule & 18 & 14 & 13 & 29 & 23 & 5 & 1 & 0 & 4 & 4 & 6 \\
Leather & 0 & 2 & 7 & 3 & 3 & 0 & 0 & 1 & 1 & 4 & 2 \\
Service & 14 & 17 & 15 & 16 & 16 & 15 & 22 & 18 & 17 & 3 & 8 \\
Agro & 20 & 18 & 13 & 12 & 3 & 7 & 6 & 1 & 3 & 3 & 0 \\
Fond & 2 & 11 & 10 & 8 & 5 & 6 & 8 & 6 & 5 & 12 & 8 \\
Computer & 4 & 1 & 3 & 3 & 1 & 2 & 2 & 2 & 1 & 2 & 3 \\
Fish & 7 & 11 & 4 & 6 & 1 & 3 & 1 & 0 & 1 & 1 & 1 \\
Manufacturing & 27 & 30 & 24 & 15 & 16 & 14 & 15 & 5 & 10 & 13 & 2 \\
Building & 4 & 9 & 6 & 5 & 4 & 1 & 1 & 1 & 2 & 2 & 0 \\
Mining & 2 & 2 & 0 & 2 & 1 & 2 & 0 & 4 & 0 & 2 & 0 \\
TOTAL & 113 & 141 & 119 & 120 & 91 & 70 & 65 & 45 & 49 & 56 & 34 \\
MUB & 18 & 14 & 8 & 30 & 27 & 15 & 3 & 1 & 6 & 6 & 11 \\
Conventional & 95 & 127 & 111 & 90 & 64 & 55 & 62 & 44 & 43 & 50 & 23 \\
TOTAL & 113 & 141 & 119 & 120 & 91 & 70 & 65 & 45 & 49 & 56 & 34 \\
\hline Sour & & & & & & & & & & &
\end{tabular}

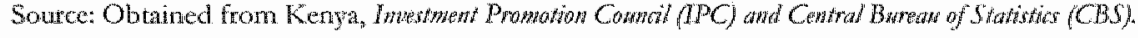

Analysis done by countries of capital origin paints a similar picture. Total capital investment of projects approved decined significantly from an annual average of $2,242.23$ in the period 1990-94 to only 1911.14 in 1996-2000 (Table 3.11). This represents a decline of $14.8 \%$ (in current prices) in foreign investment capital. Thete was growth in capital investment in the two periods in five of the countries reported in "Table 3.11. These countries included United States whose capital investment increased from an annual average of 69.3 in 1990-94 to 157.1 in 1996-2000; United Kingdom from 608.6 to 656.8; China from 95.3 to 170.2; India from 55.0 to 138.4 and Pakistan from 42.6 to 275.7. There were severe declines in capital investment from Germany, Swiss and Italy. An interesting observation that emerges from the data analysis is that there seems to be increasing investment from advanced developing countries compared to developed countries. It would therefore be interesting to know the nature of processing activities they are undertaking and level of value added. Only then we would be in a better position to talk about technology transfer and spillover occurrence.

One of the major constraints is that although IPC is supposed to work closely with government ministry, it does not seem to have much influence. This is explained by the fact that modalities of how to do that have not been laid down properly. JPC lacks the capacity to do that. Staff employed are few against many ministries and their departments and given the normal government salary their motivation/morale is equally not boosted. In a few cases, they have not received the co-operation they expected from the ministries and have not been able to play its facilitation role of one stop shop effectively. "This means that the bureaucracies which are supposed to be eliminated by making IPC one stop shop are still far from being eliminated. A report on Kenya's investment TSG (1998) noted that IPC was still "too bureaucratic and understaffed and that the General Authority it issues which authorises an investor to start operations provided that applications for all necessary licences are made within 180 days was ineffective". "The country lacked formal guidelines to assist would-be investors seeking to acquire land, obtain a trade licence or clear imports (TSG, 1998). 
Table 3.11: Forejgn Irvestment Capital, KShs. Million, Kenya, 1990-2000

\begin{tabular}{lllllll}
\hline Country & 90 & 92 & 94 & 96 & 98 & 90 \\
\hline United States & 55.23 & 14.57 & 138.23 & 465.70 & 0.00 & 5.50 \\
Unired Kingdom & 919.03 & 137.39 & 769.26 & $1,097.84$ & 796.10 & 76.40 \\
Italy & 46.75 & 120.65 & 263.60 & - & 30.00 & 2.00 \\
China & 13.71 & 61.54 & 210.50 & 91.40 & 185.62 & 233.45 \\
Indial & 62.83 & 21.00 & 81.24 & 17.00 & 13.13 & 385.20 \\
Swiss & 428 & 10.62 & 32.00 & - & - & - \\
Pakstan & 76.94 & 12.88 & 38.07 & 15.00 & 812.13 & - \\
Germany & 27.54 & 154.24 & 3.27 & 17.32 & 27.20 & - \\
Others & 711.46 & $1,402.54$ & $1,337.33$ & 348.92 & 777.55 & 362.80 \\
Total & $1,917.77$ & $1,935.43$ & $2,873.50$ & $2,053.18$ & $2,614.90$ & $1,065.35$ \\
\hline
\end{tabular}

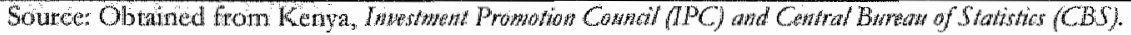

From the interviews conducted with several officers from IPC, it was observed that the centre lacks the necessary capaciry to undertake an analysis of incoming investors strategies so that this can be matched with strategies of locally owned firms. In comparison to countries in the East Asia the match making process remains largely unexploited in Kenya. It was also noted that IPC failed to effectively market the country internationally. An explanation to this is that the funding from the government has not been adequate for IPC whose budgets are planned in annual cycles. With adequate funding, IPC in collaboration with Kenyan embassies abroad is supposed to market the country investment opportunities, which would perhaps change the countries tarnished image over corruption and bad governance witnessed during Moi"s regime. This would perhaps attract more MNCs targeted especially in areas where Kenya would benefit technological spillovers alongside employment. Another aspect, which ought to be strengthened, is the personnel training as most of them seemed misplaced in the sense that they held totally different qualifications from those required in investment. Staff training ought to become continuous in-house, locally and even in abroad for exposure especially to other countries investment promotion centers. However, according to interviews done significant developments have been undertaken whose achievements will be assessed in the near future. IPC has prepared Kenya's investment code expected to govern and guide all investments in the country.

\section{(iii) Export Promotion Centre and Export Promotion Programme Office}

The Export Promotion Council (EPC) was established in 1992 to co-ordinate and harmonise export development and promotion activities in Kenya. Working in collaboration with both private and public sectors, EPC identifies new export markers, disseminating export-related information, reviewing the country's export performance on a regular basis and advising government on new policy initiatives designed to boost. exports" . The EPC also co-ordinates national strategies for artracting export investment and finance for export sector. EPC collaborates strongly with Export Promotion Progianme Office (EPPO) which was set up in 1992 under Ministry of Finance to promote manufacture for exports in the country. This was done by offering tax incentives, which included administration of duty and VAT waivers on imported materials used by enterprises manufacturing products for export, as well as on materials produced locally for use by industries, which manufacture goods for export. The funding for EPC comes mainly from the Kenyan govemment. Since this funding is not enough the council also seets funding from international financial organisations such as: The

The IPC website: htp://www.cbik.or.ke/epchum provides background information on this. 
European Union/GTZ Protrade - Gemany; Japan International Co operation Agency; Japan External Trade Organisation; Centre for the Promotion of Imports from Developing Conntries.

To promote agricultural exports, EPC undertakes the following activiries: identification of bottlenecks relating agricultural exports and making recommendations for government intervention; export market development for agticultural products; product development and adaptation of agricultural exports; training of exporters. EPC also promotes commercial crafts by maintenance of database of reputable commercial craft producers and exporters; selection of producers/exporters to participate at sponsored fairs/exhibitions for the crafts sector; training on business management skills; training on product design, development and adaptation..

EPC has an external liaison division that deals with matters concerning council and other organisations both in Kenya and internationally. Its functions include: developing rapport with Kenya's commercial artaches abroad; production of publications and documentaries; maintaining contacts of public and private organisations, Kenya missions abroad, particularly the commercial attaches, foreign missions based in Kenya and bilateral and mulvilateral bodies; advertising (It also has a Business Information division in (CBIK)).

The export market development division is responsible for development and implementation of the national export development programme in close collabonation with relevant public and private sector organisations. Acrivities include: marker investigations and surveys; trade missions; buyers/sellers meetings; contact promotion programmes; trade fairs and exhibitions; incoming buying mission. To do this, EPC collaborates with government ministries, organisations and institutions. EPC also maintains a research division responsible for conducting research on policy analysis pertaining to exports promotion this is done with support from collaborating organisations and institutions.

It was noted during the interviews that the funding from treasury was not enough. There was also a need to employ more professionals and to train them continuously extending the training to abroad for exposure. The amount voted for EPC was just enough for staff remunerations and personal emoluments, leaving very little for the actual business of export promotion. Since EPC had come up with a strategic plan covering the period 20042007 with an aim to improve the council's efficiency in trade promotion and the services it offers to importers, it wa interesting to see if the government would increasc its EPC's proposed budget. The council also intends to expand its departments to further its role and to offer a support service. The strategic plan proposes the development of export development fund to finance trade development and product diversification. Nevertheless the council hoped to generate funds by providing trade information services through its Centre for Business in Kenya (CBIK).

\section{(iv) Kenya Industrial Property Office}

Kenya Industrial Property Institute (KMP) was first established in 1990 as Kenya Industrial Property Office (KIPO) after enactment of the Industrial Property Act in Kenya. In 2002, KIPO was changed to KIPI upon the coming into force of Industrial Property Act in 2001. The institute was established under the Ministry of 'Trade and Industry as one of its deparments. The main functions of the Institute were to: adminuster industrial property rights; provide technological information to the public, promote inventiveness and innovativeness in Kenya; and provide training on industrial 
property. Under Industrial Property Act four elements of intellectual property rights ane registered: patents, utility models, industrial designs, trade and service Marks ${ }^{72}$. The act also provides for technology transfer agreements and licences. KIPI handles disputes related to patent infringements. The law on patents borrows heavily from the UK law, with some features of the European and US systems. Patents can be granted for a maximum period of 20 years. This is done with conformity with the TRIPS agreement at the WTO.

Kenya is a member of African Regional Industrial Property Office (ARIPO) and World Intellectual Property Organisation (WPO), which administers the Patent Cooperation Treaty (PCT) ${ }^{3}$. African regional Industrial Property Office has its headquarters in Zimbabwe. This is a regional organisation of 14 countries. Patents tegistered with both KJPI and ARIPO are valid in all the member countries. Although almost none of the Kenyan Manufacturing firms has patented with $\mathrm{KIPI}$, most local applications are from individuals and research institutions, a clear reflection of the weak state of local technological activity.

One of the constraints noted is that although KIPI obtains fees from registration, renewal and maintenance of patents, it is usually remitted to the government. The government, through treasury, controls and authorises all the expenditures undertaken by KIPI. This denies KIPI budget autonomy. Whatever comes back from treasury is hardly enough for its operations.

In order to create awareness on the importance of intellectual property rights, KIPI organises confetences and seminars which draws participants from all industrial enterprises, R\&D institutions including private and public research institurions. KIPI offers ttaining and information to local institutions, incustry and SMEs on patenting. The established international links with European patent office, WIPO, United State \& Trade Marks office, serve as source of international information, which is stored in the data centre at the institute. Assistance is offered to the applicants who would sometimes require specialised kind of information.

From the interviews conducted, KIPI appeared not to have the expected technical skills to play the role expected of a functional intellectual property office under the new WTO. It is faced with a general shortage of qualified staff: 'This implies that the institution is not able to meet these training and advisory functions adequately. The fact that KIPI undertakes the advisory role to its clients as well as examining patent applicants means that, it ends up doing too much. There is perhaps a need to separate the rwo roles or have them placed in different institutions.

It comes out clearly that due to low levels of innovation undertaken in Kenyan industry, KIPI's role in technology promotion is relatively small. Lack of legal skills in intellectual property rights needs to be addressed.

\footnotetext{
T2 The KIPI website: tntrp// www kipokewiponet/provides background information on this.

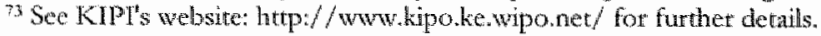




\subsubsection{Brief Summary of Emetging Issues Based on the Role of Institutions Examined}

As a summary to the above discussion, it has been shown that Kenya statted pursuing export promotion under SAPs in the mid 1980s following the decline recorded in economic activities under import substimtion. The inward-onented strategies under import substitution strategy were to blame for the decline witnessed in economic performance. The break up of East African Community ( $E A C$ ) in 1977 culminated in a diminished market for Kenyan manufactured goods. The ensuing economic distortions resulted in severe structural problems and macroeconomic imbalances. The role and efficiency of the institutions created at independence was declining due to constraints facing them, hence little co-ordination among them and little role in industrial capability development.

High levels of protection under import substitution distorted resource allocation, constricted foreign competition and restricted technology transfer. There was little technological development and imported technologies were not upgraded and thus I-S was not achieving its perceived industrial and economic development. As a consequence of this structural problems and lack of stability there was a change by mid 1980s and Kenya began implementing an outward-oriented industrial policy in tavour of industrial production for exports. Export promotion was done under structural adjustment programs SAPs with support from World Bank and IMF to restore internal and external balances through a strong policy of export promotion coupled with strong domestic protection, sharp cuts in public spending and expenditure switching. The existing supportive institutions would also be teformed and new ones would be opened. Price controls were eliminated and trade protection relaxed. There was free entry into production, services and trade. There was a slight recovery in economic performance in the subsequent years as witnessed in GDP, manufacturing and manufactured exports.

However, due to intermittent application of liberalisation measures and lack of commitment to the reforms the government was undertaking, the rewards of economic performance were short lived. Nevertheless, the government undertook further structural reforms in 1993 to reverse the declining trend in Kenya's economic actiwities. Among other reforms discussed included reforms aimed at packaging more attractive investment incentives, streamlining public enterprises and strengthening financial institutions. This did not seem to have significant impact since economic growth recorded in the early 1990 s was lower than for any other period before. Many reasons accounted for the continued poor economic performance ranging from withdrawal of foreign aids, political wnrest, high oil prices during the Gulf war to world economic recession. FDI inflows declined making Kenya lie behind most countries in Africa although maintaining relatively high levels of FDI stock in manufacturing. Within the period of SAPs the government policies to promote exports and stimulate FDI resulted in the creation of institutions such as: Investment Promotion Council to attract FDI, Export Processing Zones to promote export oriented industrial investment; Export Promotion Council to formulate market strategy, promote an export culture and to identify export opportunities regionally and internationally; Manufacturing Under Bond administered by IPC to exempt from duty and VAT exporters who imported machinery and raw materials in manufactured goods for exports; $\mathbb{K}$ IPI to administer industrial property tights. As noted, most of these institutions have had a substantial performance. Nevertheless this performance is not as expected due to a multitude of problems ranging from lack of adequate financial support, lack of required skijls, sometimes poor governance and weak co-ordination. 
In a mutshell, we note that the period of export promotion under SAPs, was characterised by poor and intermittent implementation of liberalisation measures with minimal support and sometimes withdrawal of government support by World Bank and IMF. There was severe institutional failute due to minimal and sometimes lack of support from the govenment; there was macto-economic instability; widening internal and exterial imbalances. All these factors wonked to reduce the inflow of FDI, capability development and thus general performance in the period.

\subsubsection{Recent Perfomance and Effort towards Industrialisation}

On recent economic perfomance, it is obvious that the economy was still in turmoil and was faced with a maltitude of problems ranging from interrupted trade liberalisation process by the onset of stabilisation crises in 1997 following the collapse of an IMF programme? This led to significant instability of shilling and foreign exchange markets resulting in macro-economic instability. The economy was characterised by low domestic savings. Comparatively, high interest rates, inadequate and high-terrified electricity supply elevated the cost of production. This was compounded by increased transaction costs due to deteriotating institutions, poor infrastructure mainly roads and railway lines all of which undermined competitiveness of exports. These factors eroded the investment climate; there was a decline in inwestor confidence, leading to a sharp fall in FDI. The fact that $S A P_{S}$ were still being implemented a decade down the road, did not seem to bare meaningful fruits [Kenya Eiconomic Survey, (1997: 1998: 1999); Phillips and Obwana, 2000; Todaro 2000: p.284; Soderbom, 2001]. In the period 1991-2000, the economy recorded the lowest and worst economic growth level since the country's independence with GDP growth tate averaging $1.5 \%$ and $2.46 \%$ in $1991-94$ and 1995 2000 respectively. Manufacturing declined from (2.2\%) in the period 1991-94 to (1.8\%) in the period $1995-2000$.

Liberalisation has been criticised as lacking in credibility - existing manufacturing firms could no longer maintain their export competitiveness and many more were unable to keep up with cheap imports. This was happening at a time when the international trade regime was no more in favour of poor economies riddled with macro instability and failure to develop competitive capabilities. The rules advocated by WTO recommended for removal of protectionist measures and opening up more to international trade and investment.

In the midst of all these problems the government launched a new effort to have its industry industrialised with the industrialisation policies clearly outlined in sessional paper No. 2 of 1997 whose objective is to transform. Kenyan economy into a newly industrialised country by the year $2020^{75}$. Two main strategies are being considered: First, to consider industry as the leading sector in economic development and second, to earmark specific industries for government support. The proposed industrialisation strategy outlines some of the measures to be implemented, to industrialise over a twostage pertiod. In the first phase, the government will selectively encourage labourintensive, resource-based and light manufacturing industries, where the country enjoys comparative advantage. In the second phase, policy will target intermediate and capital goods industries that are more technology and capital intensive but that must await the

\footnotetext{
"An elaborate analysis on implementation of SAPS in six African countries including Kenya can be seen in Bonaglia and Fukasaku (2002).

35 "The eighth development plan (Kenya Gowernment 1997 (b) is the first 5 year planned programme impletwentation.
} 
removal of infrastructure, technology, and human capial and savings constraints. The policy framework for industrialisation, therefore seeks to provide incentives, improwe technological capabilities and provide an approprate instrational framexork that will ensure an industralisation process led by the private sector (see Kenya government; 1997; Ronge and Nyangito, 2000). FDI was expected to play an moortant role through increased capital investment, technology transfer through formation of linkages in manufacturing industry.

On the basis of the discussion presented on recent performance, four important developments have emerged. Finrt, that due to a wide range of factors discussed - weak infrastructure, weak technological capabilities, lack of sound instrtutions and cootdination among them, macro-economic imbalances etc - the last one decade the Kenyan economy literally underwent stagnation. Second, the poor economic performance alongside poor inconsistent policies under SAPs translated into low levels of FDI and domestic investment. Third, the country is still committed to the path of SAPs and stabilisation measures started in 1986, followed with more reforms and commitment in 1993. Fownh, Kenya follows a strong policy mission towards industrialising the country by the year 2020. Increased tole and participation of FDI was expected to be important in achieving this mission. Kenya now belongs to expanded COMESA tariff free trading block and has been accredited to the AGOA export progtamme, which has boosted mainly textile and garments industries in EPZ. This has revived the textile industry, which had collapsed following the ban of Kenyan textile and appatel in 1994 due to the transshipment from other regions - mainly Asia.

\subsection{Summary and Conclusion}

This chapter has attempted to examine how industrial policies pursued influenced FDI in Kenya's manufacturing. The broad role of FDI in Kenya's industrialisation process focusing on spillowers, capability development and performance was examined. Similatly, this chapter examined the institutions established for promoting FDI and supporting industrialisation.

Since the commencement of manufacturing in Kenya, the country has only pursued two main modes of industrialisation: import substitution and expont orientation. Import substitution industrialisation was adopted in 1945 when the first major drive towards industrialisation took place in Kenya. This mode of industrialisation continued to be encouraged in the courntry until mid 1980 s when it was gradually phased out and replaced with expont orientation industrialisation dawning the era of structural adjustments programme in Kenya.

Since industrialisation was initiated before independence and was widely dominated by European MNCs, the analysis undertaken revealed that Kenya enjoyed an early colonial manufacturing experience from capital investment made in the manufacturing industry from foreign investment and in particular British fitms as they were the majorty during the colonial period. These benefirs can be interpreted as spillowers into manufacturing. The country also enjoyed most of the revenue earning primary sectors developed during colonial days as well as infrastructure such as railway line, roads and port facilities. Under I-S industrialisation, the country was characterised by rapid economic growth with most economic activities witnessing high growth rates. There was increased consumer demand for consumer goods in the domestic market. This resulted in increased FDI inflow into manufacturing mainly in the agro-based industries. In addition to their high capital 
investment in manufacturing, contribution in exports, walue added, employment and reverue generation to the conomy, the country benefited marufacturing experience spillowers. Based on this chapter's findings, this is no longer a hypothetical case although it needs to be empirically ascertained despite difficulties involved in doing that. This will be attempted in the subsequent chapters; Chapter 4 using productivity approach. Chapter 5 will exame spillowers using direct consequences based on learning and capability building Chapter 6 examines spillovers from the angle of MNCs while Chapter 8 will do that from the angle of locally owned firms.

The economic crises of late 1970 s and 1980 s were largely blamed on inward looking policies purstued under import-substitution. As a result, manufacturing growth, value added and exponts all declined steadily. It was becoming increasingly difficult to effectively participate and compete in export matkets. To stop this trend, the import substitution policy was dropped in favour of an outward-oriented industrial policy to reorient industrial production in favour of exports under libetalisation in aegis of SAPs. This was followed by a slight recovery in the economic performance, which lasted for only a short time. There was lack of commitment to the reforms being undertaken, hence in 1993, fartreaching structural reforms were undertaken to teverse the declining trend but again without much success. $A$ further decline in most economic activities including those of PDI was noted e.g. most sectoral growths declined. A few factors were touted for that: world economic recession, multiparty politics that led to immense political unrest; withdrawal of foreign aids and high oil prices during the Gulf war. The political unrest, resulted in anxiety and uncertainties of foreign aid, which in turn had negative tamifications on the inflow of FDI, which could be rated as only modest at the time. Nevertheless, FDI stock in manufacturing remained high and continued to generate lighest levels in employment, revenue generation, value added, export performance etc.

In short, export orientation under SAPs in the last decade was characterised by first, economic stagnation due to weak infrastructure, weak technological capabilities, lack of sound institutions and coordination among them, macro-economic imbalances etc. Second, the poor economic performance alongside poor inconsistent policies translated into low levels of domestic investment as well as FDI in the country. The consequence of this was that, reduced spillovers which would occur had FDI activities been wibrant would certainly reduce. As a result of all the factors advanced, the capability development process slows down. Nevertheless, based on the analysis done, we conclude strongly that FDI played a role in the industrial development. Although presence of spillovers will be confirmed econometrically in the subsequent chapters, we have strong qualitative evidence from our analysis that they existed in Kenya's manufacturing. Aso despite severe constraints, instifutions examined played an important role in the $\mathrm{FDI}$ vis-à-vis industrialisation process. 


\section{FOREIGN DIRECT INVESTMENT AND FIRM LEVEL PRODUCTIVITY A PANEL DATA ANALYSIS}

\subsection{Introduction}

In Chapter 3 we examined FDI, instirutional setting and industrial policies and how their interaction influenced further FDI inflow, spillover benefirs, industrial capability development and performance. The chapter showed that FDI had played an important role in the Kenyan industrialisation process implying positive benefits of spillover occurrence into the manufacturing industry. Analysis and findings of Chapter 3 were considered to provide a useful background for empirical/econometric analyses in the subsequent chapters. Hence, this chapter uses firm level panel data to examine econometrically the effects of foreign presence on productivity performance in the Kenyan manufacturing. Stated differently, the chapter adopts productivity rechniques and estimates a production function in an attempt to examine technological spillovers in the Kenyan context. The production techniques are employed in our estimations despite weaknesses outlined in Chapter 2 in order to provide a broader set of results for Kenyan manufacturing based on the pteliminary data obtained from the official sources. Insights drawn from early contributions based on Caves (1974) as well as recent methodological developments such as those by Aitken and Harrison (1999) will be taken into consideration to enable btoad comparisons of this chapter's findings. To the best of our knowledge, to date, not a single concrete study exists based on Kenyan manufacturing industry that uses a rigorous productivity technique for spillover analysis; the results obtained in this chapter will therefore contextualize spillovers in the Kenyan manufacturing and provide a wider set of results for comparisons. One such important comparison will be done with existing studies that have largely remained inconclusive in terms of effect, direction and magnitude of spillover occurrence. Simillarly, results obtained in this chapter will be compared to those obtained in the subsequent chapters in line with emerging issues and critiques raised in the preceding chapters.

Most important, the analysis done in this chapter will enable a comparison of foreign and locally owned firms in manufacturing on the basis of general trends on firm and sector level characteristics. The chapter also examines whether technological spillovers occur in Kenyan manufacturing industry by determining the impact of foreign presence on local firms' performance based on total factor productivity. The influence of firm size and technological gap (absorptive capacity) in the spillover process will equally be examined. Data used for empitical analysis comes from an industrial survey conducted annually in Kenya - an eight-year balanced paned database is constructed for the current analysis. This chapter specifically addresses the following issues:

(1) Undertake a comparative analysis of the behaviour of foreign and locally owned firms in Kenyan mamufacturing industry (by whole ind ustoy and sector).

(2) Determine whether foreign presence affects productivity of locally owned firms in Kenyan manufacturing industry for the basis of labour and wow fachor productivity).

Determine using productivity techniques whether firm size influences spillower occurrence to the locally owned firms.

Determine using productivity techniques whether technological gap (absorptive capacity) influences spillover occurrence to the locally owned firms. 
The Chapter is organised as follows. Section 4.2 presents the theoretical framework, data description and the estimation techniques used in this chapter. In section 4.3, a compantive behaviour of foreign and locally owned frms is undertaken based on the descriptive characteristics derived from the panel data. This involves a detaled and indepth analysis of panel sample characteristics. In section 4.4 , we determine econometrically the effect of forcign presence on labour productivity and total factor productivity using panel data estimation technique. In section 4.5 , we also determine using a productivity technique whether firm size influences spillover occurrence to the Jocally owned firms. Similarly, in section 4.6 we determine using productivity technique whether technological gap infuences spillover occurrence to the locally owned firms. Finally, section 4.7 presents summary and conclusion:

\subsection{Theoretical Framework, Data and Estimation Technique}

In this secton, we present a discussion of the productivity approach in spillover analysis. This is briefly done as much of its analysis, including critiques, were extensively discussed in Chapter 2. The discussion done here is intended to outline the existing disjuncture in spillover analysis more appropriately and in line with the objectives of this chapter. In this section, we also discuss the data and the outlined estimation techniques to be used. Under data description, data source, data type and creation of the panel database for use in the analysis are presented. For estimation technique, the section discusses panel data technique analysis, which will be used for econometric analysis in this chapter.

\subsubsection{Theoretical Framework: The Productivity Approach Revisited}

As discussed in Chapter 2, most of studies examining spillovers from FDI have been. largely based on production function approach. The seminal contribution by Caves (1974) is considered to have pioneered in this approach as he presented the first systematic production function framework examining FDI spillovers. According to Caves, technological spillovers included all aspects resulting from the presence of MNCs in a host country that increases the productivity efficiency of locally owned firms. He angued that spillovers occurred since "MNC cannot capture all quasi tents due to its productive activities or to the removal of distortions by the subsidiary's competitive pressure." Since then, a plethora of empirical studies conceptualising spillovers in terms productivity gains have emerged. Key studies have been discussed in the literature section such as Globerman (1979); Blomstrom and Pearson (1983); Blomstrom and Wolffe (1994); Blomstrom (1986); Wang and Blomstrom (1982); Blomstrom and Kokko (1997: 1998); Kokko (1994:1996); Kokko, Tansini and Zejan (1996) among others. All these studies, which in actual sense replicated Caves approach, found positive spillovers.

To the contrary, some of the studies conducted have failed to find technological spillovers [Aitken and Harrison, 1992; Haddad and Harrison, 1993; Aitken, Hanson and Hartison, 1997; Aitken and Harrison, 1999]. Interestingly, these studies seem to have something in common, belong to a new generation of spillowers studies, which attempts to advance the frontiers of spillover understanding by extending the original approach, or put in other words, extend the pioneering instruments that Caves had used. In doing so, these studies have refined their methodologies to address among other things; national, locational, industry and firm-level specificities, scale, technological gap, trade orientation and demonstration effect variables. However, on the basis of arguments taised in this 
thesis, we stil emphasise that despite the considerable evolution demonstrated in estimation techniques of aggregate spillowers, relationships traced througli these methodologies cannot be equated with actual spillovers - see critiques outlined in Chapter 2. Technological spillovers were shown to be complex and difficult to capture given their uncertain, incomplete mastery and tacit nature of techology. This is more so when spillover occurrence mechanisms, fum and industry dynamics as well as institutional environment are hardly understood. It is in this understanding that this thesis uses case studies in an attempt to adwance spillower undetstanding beyond the aggregate level econometric methods.

In light of this divergence in spillover analysis and findings, this chapter attempts to make a contribution to this debate by examining spillovers from FDI to domestic fims in the Kenyan context. Contrary to all the studies done in the past, we intend to combine 'traditional estimations' and 'new developments" approaches for comparison purposes. The new developments will be conducted in line with more recent studies such as Aitken and Harrison (1999). Accordingly, we will therefore undertake a panel data anilysis taking into consideration industry specificities (industry dummies) and time dynamics (time dummies). Panel data analysis is believed to capture the dynamics of change because of inclusion of both cross-sectional and time series dimensions. Due to the limitation of data (observation required in the panel analysis) we will nor be in a position to capture geographical location and other factors as outlined above.

The panel data approach differs from the early contributions, which mainly uses cross sectional data that might lead to spurious biased results. Firm level panel data analyses are prefered for a number of reasons. Ir allows an investigation of domestic firms" productivity development over a longet time period. This is contrary to a survey data that would have to rely on a specific data point. It would also allow an investigation of technological spillovers after controlling for other factors such as industry differences. As noted in Gorg and Strob). (2001) "cross sectional data, in particular if they are aggregated at the sectoral level, fail to control for time-variant differences in productivity across sectors which might be correlated with, but not caused by foreign presence". In such a case the results obtained would be spurious and biased. As elaborated in Chapter 2, if productivity in a given industrial sector is much higher than in others, MNCs might be attracted into the formet in which case a basic cross sectional analysis would produce positive and statistically: significant correlation between the MNCs and productivity of the locally owned firms ${ }^{76}$. According to the early contributors, Caves antecedents, these results would be interpreted as indicating spillover occurrence even though MNCs were only artracted in the sector and were not responsible for the high productivity witnessed.

The assessment undertaken here also compares foreign and local firms taking into consideration possible dynamics of the results obtained. Although Kenya is endowed with low levels of FDI at the national level, it has high foreign presence in the manufacturing industry. Overall FDI accounted for 0.32 and $0.96 \%$ in Gross Fixed Capital Formation (GCF) in 1994 and 1999 respectively. Its commensurate shares in manufacturing were $69.1 \%$ in $1994,66.2 \%$ in 1999 and $63.0 \%$ in $2001^{7 k}$. Results obtained would therefore enable a policy-relevant assessment of FDI's conduct and performance

\footnotetext{
36 This aspect of selectivity bias was discussed extensively in Chater 2

\% Computed from the Work Bank (2001).

* Computed from dat suppliad by the Minisury of Trade and Induery, Natrobi.
} 
in a country that typifies most developing economies - countries in Sub Sahatan Africa chiaracterised by low levels of $\mathrm{FDI}$ inflows.

\subsubsection{Data Description}

For the purpose of this study, the empirical data comes from unpublished plant level data collected in an annual survey by the Ministry of Trade and Industry, Kenya

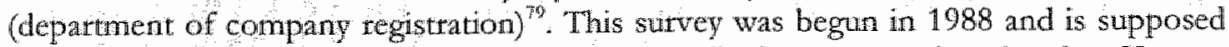
to collect annual data and information on all firms operating in the Kenyan manufacturing industry. The information collected consists of ownership, year of establishment, domestic and export sales, domestic and imported raw materials. Capacity utilisation and value of utilities consumed e.g. electricity, coal, diesel, lubricating oil and water. It also consisted of fixed assets and capital investment by nationality. Other information included employment size inchuding technicall, skilled, semi-skilled and unskilled workers, clerical and casuals. It also included firm expenditure on plant, equipment and machinery. Firm's physical location and sectoral classification by international standard of industrial classification (ISIC) are also captured in the survey. The survey data enabied us to create a panel database for the period 1994-2001"

Despite our effort to construct a comprehensive panel database, several firms still had severe cases of missing data points in certain years, either due to non-response or failure by firms to provide all the tequired data and information. One of the screening criteria for a firm to be included in this study was that the firm must have responded in all the years and must have done so in almost all the required variables. A balanced panel of 420 firms was created comprising firms that showed consistent time series responses to all the relevant questions over the period 1994-2001 making a panel with 3,360 observations $^{84}$. The data set is fairly representative as it represents an average of $40 \% 0^{82}$ for both manufacturing output and employment over all the years included in our sample. This representation provides a reasonably good level justifying a meaningful policy relevant assessment of FDI's role in industrial development.

For the purpose of this study, firms with at least $10 \%$ of their nominal capital owned by foreigners are defined as foreign firms. All the other firms were defined as locally owned firms 8 . "This definition was adopted simce the Kenyan national authonties also used the

\footnotetext{
90 We are grateful to the Ministry of Thade and Industry, Deparment of Company Registration, Kenya for allowing us the access to the data.

Wince the inception of this survey, it has been characterised by abysmally low levels of response rates. To revert these low rates of response, we Ministry issued a ster waming, made it mandatory for afl the companies to respond to the survey on anmual basis in which case defanlets tisked prosecution and heawy fine. This therat led to a remarkable improvement in the survey tesponse tate begining 1994 justifying the sclection of this year as the base year for our pand datanalysis.

4a The 8-yen panel data for the period 1994-2001 compares well to the 5-year parnel data for the period 1985-1989 used for the Moroccan study Haddad and Harrison (1993).

siz This comparison is based on figures obtained from Central Burean of Statistics (CBS), manutacturing section - Kenyat.

${ }^{8}$ This definition follows that of OECD and UNCTAD. Other benchmaris taken by other resenthers studying other countries include sjoholm (1997) who had a benchmark $15^{\circ}$ of equity owned by foreigners, Haddat and Harrison (1993) considered foreign hims as those with at least $5 \%$ equity owned by foreignets while Diankov and Hoekman (1998) had a bench mark of $20 \%$.
} 
same benchmark. On the basis of this definition, about 175 firms were classifect as foreign frms and the remaining 245 firms as locally owned.

Similar to most economic analysis based on data from underdeveloped countries, this analysis was beset by lack of suitable deflators for our data sets. Kenya is no different from most Sub-Saharan economies (poor and technically underdeveloped economy) where it is extremely difficult to identify a relevant deflator to convert he nominal data to constant prices. Data deflation is a necessary condition especially in time seties analysis in order to remove data fluctuations that might exist due to inflationary effects over time in an economy. Hence, this study uses the best option that was available. Consequently, sales and capital investment values were deflated using gross domestic product (GDP) deflator - based on GDP price indices. The export walues were deflated using export price indices for manufactured goods. The expenditure values of machinery and equipment were deflated using import price indices for machinery and transport equipment.

Another limitation with this data set is that the analysis conducted at 2-digit level ISIC will be limited to only 9 sectors - even then one of the sectors will be dropped due to lack of FDI while two engineering sectors will be combined leaving only 7 sectors for analysis $^{85}$. In Kenya, the 2-digit level classifies the manufacturing industry into 9 sectors, 3 -digit classifies it into about 28 sectors while 4-digit level classifies it into 58 sectors. It is impossible to undertake panel analysis at three or four digits as this reduces firms to only a few in each ISIC and would therefore not suffice for the intended panel examination and analysis.

\subsubsection{Empirical Analysis: A Panel Data Estimation Technique}

Panel data estimation technique is used here to examine the direct contribution and impact of foreign presence on productivity (both labour and total factor productivity) in Kenyan manufacturing. Besides controlling for certain factors that also impinge on productivity, we also intend to control for time effects and industry specificities. Thus our curtent task is therefore to come up with an empirical specification that will enable us to adequately capture time effects and variations in sector characteristics actoss sectors. Our attempt to model all these aspects together commences with a generall illustration of our panel data as follows:

$$
Y_{i n}=\alpha_{i}+\sum_{j=1}^{k} \beta_{i j} X_{i j t}+\varepsilon_{i t}
$$

Where $\mathrm{i}=1,2, \ldots, \mathrm{n}$ denotes a cross sectional unit ( $\mathrm{a}$ firm), and $\mathrm{t}=1,2, \ldots, \mathrm{T}$ denotes a given period. Thus $Y_{i r}$ is the value of the dependent variable for firm i at period $t$ and $X_{i j r}$ is the value of $j^{\text {th }}$ non stochastic explanatory variable for firm $i$ at period t. The random error term $\varepsilon_{i t}$ is assumed to be normaly distributed with al mean of

\footnotetext{
84 Even where such deflators existed they were notmaly based or outdated base years as was the case in the current study where the deflators used had 1982 as the base year.

:5 The wo sectors combined were ISCI 37 and ISIC 38 that deal with metal, metal fabrication, machine works etc-also referted in the Kenyan classification as engineering. We refer to it here as machine tool nadustry (SCI 37).
} 
zero, $E\left(\varepsilon_{i}\right)=0$ and $a$ constant variance, $E\left(\varepsilon_{i j}\right)=0$ and $\beta_{i j} s$ are anknown response coeffichents to be modeled.

The above frameworls can be generalised into two basic frameworks - fixed effects and randon effects models. The two are different in the way the constant is taken and interpreted. In the fuxed effects model $\alpha_{i}$ is capured as the group specific constant tem. The assumption in the fixed effects model is that differences across units can be captured in differences in the constant term and thus $\alpha_{i}$ is unknown parameter to be estimated. On the other hand, random effects approach specifies $\alpha_{i}$ as group specific disturbance, similar to $\varepsilon_{g r}$ "The residual term for random effects can then be expressed as: $\mu_{i t}=\vartheta_{i}+\varepsilon_{i t}$. The component $\vartheta_{i}$ is the random disturbance characterising the $i^{\text {th }}$ observation and is constant through time.

As mentioned above, several effects across industries would be expected to correlate with independent variables. For instance food-processing being ane of the most productive and dynamic sectors in Kenya and would therefore attract higher foreign presence than other industries. As a result, an empirical modeling that treats the correlation more explicitly would be required. We attempt to do this by including dummies in our panel model specified in equation (1) above.

$$
Y_{i r}=\alpha_{i}+\sum_{j=1}^{k} \beta_{i j} X_{i j t}+D U M M Y_{i}+D U M M Y_{t}+\varepsilon_{i r}
$$

Where DUMMY, represents sectoral dummies considered at 2-digit ISIC level.

DUMMY, represents annual time dummies over the specified panel period 1994-2001.

In our endeavour to examine the impact of foreign presence on productivity, we consider equation (4.2) modeled above as the basis for empirical estimations. Given the nature and amount of data we are dealing with, it is imperative to undertake several estimates for the purposes of checking consistency, valicity and robustness of the estinated tesults across different techniques. Hence, the model was subjected to some preliminary estimations. Estimations done inchuded ordinary least squares (OLS), fixed effects, random effects and gencralised least square (GIS) estimations ${ }^{\text {st }}$. In addition, the difterent techniques allow the modeling of specific statistical phenomena for instance gross data outliers, autocorrelation and heteroscedasticity that normally affect econometric data analysis. Preliminary estimations using Hausman specification analysis indicated that random effect had mote efficient results compared to the fixed effects model. Hence, the study adopted OLS, GLS and random effects model -.. very comprable results were estimated by the three rechniques.

It is important to make a few further clarifications tegarding these techniques. Since we ate dealing with a balanced panel, the results obtained with OILS, GLS and random effects are expected to be exactly the same. In this regard the OLS and GLS were estimated allowing for certain statistical aspeets - differences in approach. In the case of OIS, we estimated the robust type estimates. Under normal circumstances, three kinds of regressions are commonly known. They are standard regression estimates OLS

* GLS estimates cross-ectonal times-series lineat models using feasible generalised least squares (Stata, 2003 
primarly based on predicting the mean; quartile regnession based on predicting the median and robust regression which performs an nital screening based on spatal distance to eliminate gross outliers pror to compoting the estimates using multiple iterations.

The GIS technique, which is a more rigorous technique than OLS nethod, allows for heteroscedasticity and correlation to be modeled across panels. GLS tedinique also allows for autocorrelation within panels to be modeled in which case the structure with no autocorrelation, correlation parameter common for all the panels or a unique correlation parameter for each panel can be modeled separately (see Green, 2002: Stata 2003). In the curtent case, GLS will be estimated allowing for heteroscedasticity and

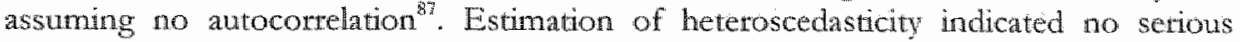
problem of heteroscedasticity since all estimates easily passed the white (1980) test for: heteroscedasticity.

We now turn to random effects. Random effects model can be estimated based on maximum likelihood (ML) or GLS. Our estimations were based on the latter and were thus performed assuming homoscedasticity and no autocorrelation. Given the advancement in modelling panel data, it is also possible to make estimations allowing for autocotrellation. However, we did not find significant differences in the results obtained. Thus for simplicity we decided to restrict ourselves to the panel estimates controlling for both heteroscedasticity and autocorrelation.

As a beginning point to our empirical tests, all the independent variables were tested for possible statistical correlation. The results of this correlation showed that none of the independent variables posted high and significant correlation, which meant that the variables were not cotrelated.

\subsection{Comparative Behaviour of Foreign and Locally Owned Firms: Analysis Based on Panel Data Trends in the Manufacturing Industry}

This section presents an analysis of foreign participation in the manufacturing industry using the panel data created. The section is divided into two sub-sections; the first section is intended to give a brief synopsis of the manufacturing industry on the basis of the whole manufacturing industry by ownership. In the second sub-section, a more detailed analysis is presented comparing foreign and locally owned fitms by manufacturing industrial sectors. This section therefore lays the foundation for the subseguent sections and chapters, as one of the central issues this thesis sceks to determine is the level of MNC participation i.e. in which sectors of Kenyan Manufacturing industry are the MNC activities concentratred This question for instance can be addressed by looking at shares of significant trends in the panel data. Are the MNCs located equally in all the sectors, sub-sectors or ate they just witnessed in a few selected sectors? If so, is it possible to identify them? Could it be so that sectors with high foreign presence levels are also the most dymamic sectors, chancterised with high levels of technological related characteristics sach as physical and human capital investment, value added and productivity of labour or raw materials? To answer these

The dara ser used did nor sem to have serious autocortation problem - this was not expected to pose a serious problem since the dime span covered was not very long. 
questions it is therefore gemane to begin by conducting an analysis of general data trends based on key variables for the enrire manufacturing industry in Kenya.

\subsubsection{Important Firm Trends in the Panel Data Sample: Comparing Foreign and Locally Owned Firms based on the Entire Manufacturing Industry}

In this section, we examine the participation of MNCs in the mamufacturing industry by comparing their telative shares with those of locally owned firms ${ }^{2}$. Unlike in all other spillover studies, the unique data collected for a country that typifies poot and technically backwatd economies, gives us a new insight into foreign shates using more data and/or indicators than has ever been done before. In such a context, this is particularly useful for concrete findings from which informed policy dialogue on the role of FDI in manufacturing industry could be based on. The comparison done here is based on certain manufacturing chatacteristics that can be examined using some key manufacturing industry indicators/variables. They include productivity indicators such as value added (VAD) and labour productivity (VADL) see Table 4.1. Other indicators include factors of production such as capital (KALF), taw material (RMAT) and employment (EMPT). Other indicators include human capital and processing capability usually measured by skilled labour (SKILL) and machinery and equipment (TECHN) respectively. Indicators of firm market performance include output sales (TSALES) and expotts sales (EXPTS) while internal firm performance is estimated by capacity utilisation (CAP). Table 4.1. presents the computed percentage shares of both foreign and locally owned firms.

Before discussing the shares computed, we provide a brief analysis of firm age. All the firms were compared in terms of their ages computed in absolute numbers on the basis of their year of establishment. The average age of all the firms in manufacturing was 25 years. A comparison of firm ages revealed that locally owned furms were generally younger with an average age of 24 years while foreign firms were older with an average age of 28 years. This was not surprising given that foreign firms were mainly the pioneers in the Kenyan manufacturing industry. As discussed in Chapter 3, some of the foreign firms were established in Kenya long before independence while locally owned firms were largely started moments after independence and in some cases much later during the rationalisation period in the 1970 s and 1980 s [Kaplinksy, 1978; Swainson, (1978: $1980)]$.

According to the shates computed and provided in Table 4.1, foreign firms had higher shares than locally owned firms with virtually all variables. Examination of the data resulted in an interesting finding where foreign firms appeared to literally dominate Kenyan manufacturing with over $50 \%$ in all the variables throughout the panel period 1994-2001 (Chart 4.1) ) $^{\text {(6) }}$. Taking for instance capital, value added and output sales, the data showed that foreign shares remained relatively high, above $70 \%$ in the entire period 1994-2000. Employment shares remained above 60\% - suggesting that MNCs were the largest employers and larger in size than locally owned firms if employment is considered an indicator of firm size. Another interesting finding was that apart from consumption of raw materials whose foreign share remained constant $(68 \%)$ for both 1994 and 2001 , shares of all the other variables demonstrated a declining trend over the period. Contrarily, Table 4.1 showed that all the variables except raw materials shares and capacity utilisation of locally owned firms had increased over the same period.

\footnotetext{
80: "The shates were computed in percentages using the panel database created.

8 The chart show averages across 8 yeats for each variable.
} 
Table 4.1 Important Firm Trends in the Pancl Data Sample: Percentage based Shares, Kenya, 1994-2001

\begin{tabular}{|c|c|c|c|c|c|c|c|c|c|c|c|c|c|c|c|c|}
\hline \multirow{2}{*}{ Variable L } & \multicolumn{2}{|c|}{1994} & \multicolumn{2}{|c|}{1995} & \multicolumn{2}{|c|}{1996} & \multicolumn{2}{|c|}{1997} & \multicolumn{2}{|c|}{1998} & \multicolumn{2}{|c|}{1999} & \multicolumn{2}{|c|}{2000} & \multicolumn{2}{|c|}{2001} \\
\hline & & & & $\pi$ & & & & $F_{n}$ & & & & & & & & For \\
\hline RMAT & 32 & 68 & 31 & 69 & 2 & 68 & 2 & 68 & 3 & 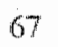 & 30 & & 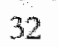 & & & 68 \\
\hline & & 70 & 22 & 78 & 8 & 72 & 29 & 72 & & 7 & 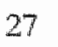 & & 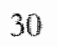 & & & 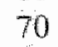 \\
\hline & & 70 & 39 & 61 & & 65 & 6 & 6 & & & & & & & & 60 \\
\hline & & & 37 & 4 & 5 & 62 & 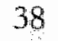 & 6 & & 0 & & & 1. & & & 58 \\
\hline & & 82 & 22 & 78 & 3 & 77 & & 8 & & 7 & & & 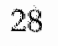 & & & \\
\hline & & 59 & 37 & 63 & 7 & 53 & 5 & & & & 50 & & 4 & & & 46 \\
\hline & 2 & 80 & 26 & 74 & & 74 & 2 & 13 & & & 27 & & 9 & & & 71 \\
\hline & 32 & 68 & 31 & 69 & 29 & 71 & 33 & 6 & & 6 & $\zeta$ & & 6 & & & 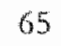 \\
\hline & 41 & w & +10 & 60 & $T<$ & 58 & & & & 3 & 48 & 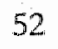 & 50 & & & 51 \\
\hline $\mathrm{CAI}$ & 62 & 65 & 62 & 63 & 62 & 64 & 62 & 63 & 62 & 6. & 61 & 62 & 62 & 6. & 62 & 62 \\
\hline
\end{tabular}

Source: Computed by the author from Kenya, Annual Industrial Survey Undertaken by Ministry of Trade and Industry, Kenya.

Two reasons could account for this interesting phenomenon. The first one is that the observed increase in variable shares over the period could demonstrate that domestic firms were gradually catching up with foreign firms. Second, this process could be explained by disappearance (closures and relocations) of some of the MNC subsidiaries as a result of worsened conditions of doing business that characterised the economy in the 1990s. As discussed earlier, the country witnessed massive institution, infrastructure and government faillures. Lack of incentives and other support systems led to high cost of operations resulting in economic stagnation. In order to discern what was happening, we computed growth rates of these variables by ownership. Annual growth rates computed for all variables confirmed that foreign firms had a decline in the period 1994 2001 despite their continued dominance in terms of shates. Locally owned firms enjoyed positive growth rates in value added $(2.9 \%)$, labour productivity $(2.2 \%)$, skilled labour $(2 \%)$ and total employment $(1 \%)$ in the same period ${ }^{9 \%}$.

Specifically, in the period 1994-1997, the average annual growth in exports, skilled labour, value added, labour productivity, capital, raw material, employment, output sales, machinery and equipment of locally owned firms were $-4.5,1.5,5.1,7.7,-19.7,-7.7,0.12$, $1.7,1.9 \%$ respectively (Appendix 4.1). Between 1997.2001 , the average anjual growth in exports, skilled labour, value added, labour productivity and capital, taw material, employment, output sales, machinery and equìpment of local masufacturing firms was $14.4,1.9,-3.7,-5.0,-3.0,-5.7,1.7,-4.6,-8.7 \%$ respectively (Appendix 4.1). Most of these variables are performance indicators and hence proxy for upgrading in products and processes and indicate increased ability to compete. This analysis based on growth rates confirmed that locally owned firms were gradually catching up. A plausible task is then to try and discern if EDI spillovers played any role in the carching up process - which is virtually at the heart of this thesis. As discussed elsewhere, the decline in the growth of FDI's activities could be attributed to the restructuring undertaken to face the newly emerging environment characterised by external competition and entry of new domestic firms. During this period many things were happening. The country was still grappling

9n "The growth rates were computed from data supplied by the Ministry of Trade and lndustry, Nairobi, Kanya. 
wh $S A P S-$ liberalisation and export orientation. The country was no longer favoured by donors - hence less aid. Institutions continued to weaken, infrastructutal decay, poor economic governance ete.

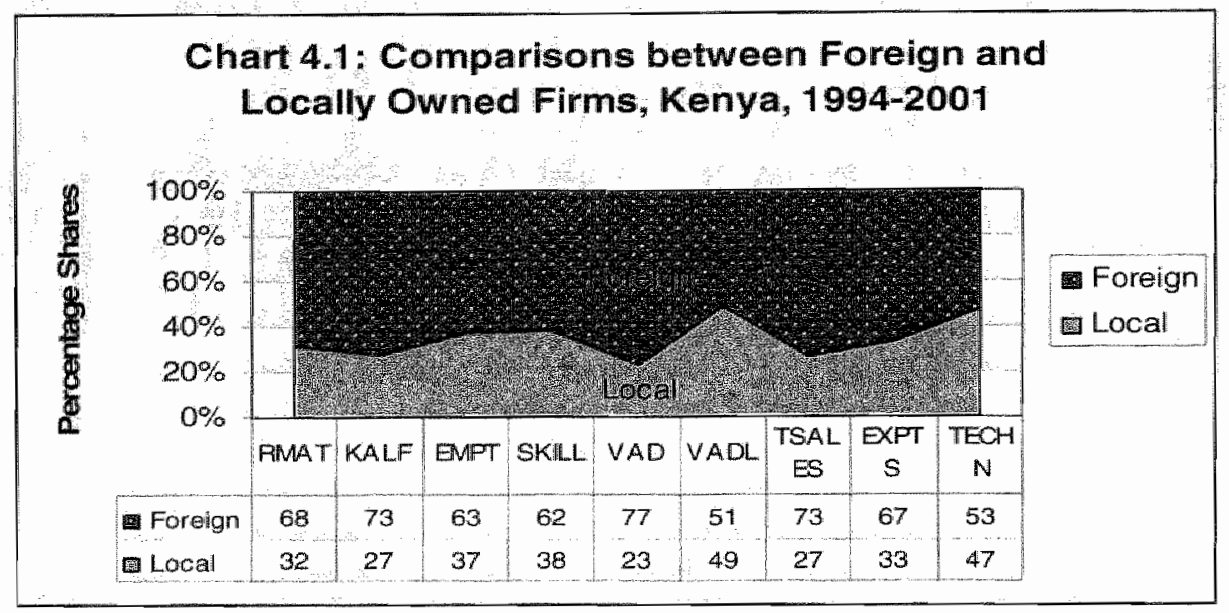

Three important distinctions must be addressed from this section when examining Kenyan manufacturing data econometrically. First, despite the economic stagnation witnessed in the $1990 \mathrm{~s}$, foreign firms continued to enjoy over $50 \%$ dominance in all the variables for the period 1994-2001 (Chat 4.1). For instance foreign furms enjoyed high levels of productivity in terms of valued added and labour productivity. With regard to factors of production, foreign furms had high investment levels as they controlled higher shares in capital investment, had high employment and raw material consumption levels. Taking employment as a size proxy, then MNCs were larger in size than locally owned firms. Foreign fims also had high processing capability levels based on high expenditure shares of machinery and equipment. On the side of human capital, foreign firms dominate - with more skilled labour force than domestic firms. Similarly, firm performance, foreign firms had higher shares in output sales and exports than locally wowed trims. Local firms maintained a constant level of capacity utilisation $(62 \%)$ while foreign firms recorded a slight decline from 65 to $62 \%$ in the period 1994-2001. Sulowd, with the exception of raw material, ix all the vatubles analysed foreign firms appeared to decline in real terms in the period 1994-2001. Thbrh, in terms of growth rates locally owned firms performed better than foreign firms in this period since they recorded positive growths in a number of variables: valued added, labout productivity, skilled habour and employment of $2.9,2.2,2.0$ and $1.0 \%$ respectively (see $A$ ppendix 4.1 ).

\subsubsection{Important Trends in the panel Data Sample: Comparing Foreign and Locally Owned Firms based on the Manufactuting Industrial Sectors}

The discussion below provides further comparison between foreign and locally owned tirms by manufacturing sectors. We begin this section by examining foreign presence at the sectoral level on the basis of capital, employment and output sales. Foreign presence computed is derived from the average for the entite panel period 1994-2001 (Chart 4.2). Computation of foreign presence follows Aitken and Harrison (1999) - discussed in Chaprer 2 - who used employment values in computing a proxy of foreign presence in 
Mexico at the sector level. Capital and ouput figures have equally been used in many studies in other parts of the world. The most interesting finding was that all the thee variables produced wery comparable and consistent results. Chan 4.2 shows that foreign presence estimated by all the warables, exceded $8 \%$ only in three manufactuming sectors; ISIC 31 (tood, beverages and robacco), ISIC 35 (chemical, pertroleum and plastics) and ISI C 37 (machine and engineeting industry). Empinically the three manufacturing sectors can therefore be regarded as sectors with highest levels of foreign presence in the Kenyan manufacturing. One of the emerging implications of this finding is that foreign presence is not evenly distributed but is concentrated in just a few manufacturing sectors. Therefore, it becomes interesting to probe further if $\mathrm{MNC}$ activities are also spread in a similar pattern. Hence in order to understand the distribution of MNC activities, in the section below we attempt to investigate specific manufacturing sectors where MNC activities are particularly concentrated.

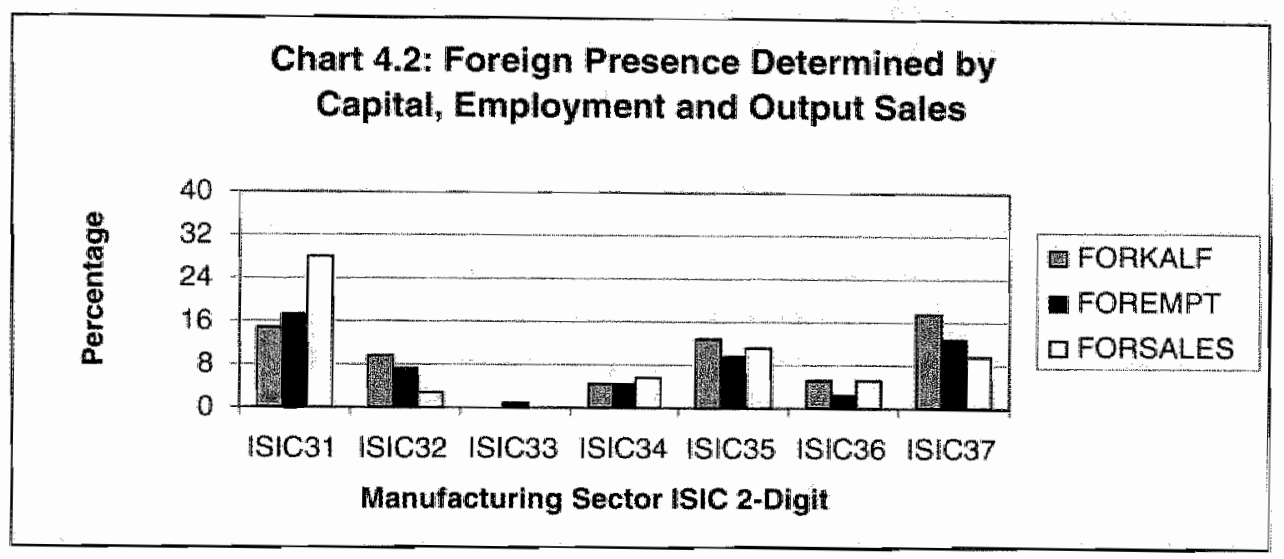

Next, before we discuss manufacturing shates and growth rates computed, we examine the firm age variation by manufacturing sector. Chart 4.3 shows the sectoral age distribution by ownership orientation. It is observed that the age differential between foreign and locally owned firms is mainly high in three sectors; paper, printing and publishing, chemicals, petroleum and plastics, and machine and engineering industry sectors (Chan 4.3). Interestingly, in all these sectors foreign firms wete older than locally owned firms at $30.6,29.4$ and 26.9 years respectively. Similarly, in food, beverages and tobacco (27.1 years) and textile, wearing apparel and leather $(25.6$ years) sectors, foreign firms were relatively older than their local counterparts. Folding other things constant ${ }^{32}$, these results signify that foreign firms joined the respective sectors earlier than their local counterparts. Locally owned firms seemed to have entered manufacturing earlier only in wood and wood products sector. In non-metallic mineral sector, locally owned firms and foreign firms appeared to have joined manufacturing around the same time. Given the observed age differences, then the question that arises is whether locally owned firms did learn something from foreign frims being the entry leaders in the manufacturing

\footnotetext{
9u Refers to forcign presence defined as foreign equity participation aweraged over all plants in a secror: wejghred by ach plant's share of secroral capical, employment and salks (put as perceratage).

92 High fin awerage age mighe be affected slighty when entry and exin are considered during the pertiod; we used a balanced database as explained eartier.
} 
(sectors), which forms part of what the study seeks to find out in the subsequent chapters.

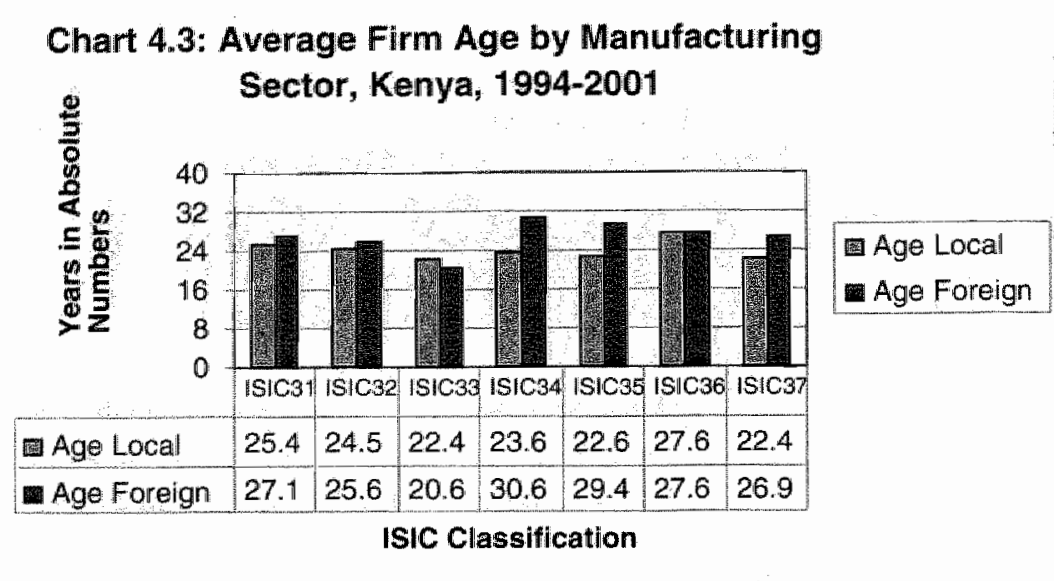

We now turn to the comparison of shares computed based on the same variables used above - in section 4.3.1. The emerging results indicate that at two-digit ${ }^{93}$ level, foreign firms still dominated in wirtually all the variables considered. The three sectors with bigh levels of foreign presence; i.e. food, beverages and tobacco; chemicals, petroleum and plastics and machine and engineering were specifically unique in that foreign furms had over $60 \%$ in all the variables (Table 4.2 ). In this regard, the three sectors were the most dominated by FDI as well as their activities. This was an important finding. Since the focus of this study is to analyse FDI in sectors where foreign presence is high, we will therefore limit our discussion to the three sectors identified. While foreign shares remained above $70 \%$ for value added, it remained above 50 for labour productivity in the three sectors identified. Over time, the capital share of locally owned firms tended to increase, albeit slightly, in chemicals, petroleum and plastics and machine and engineering. Although foreign firms were virtually the largest employers in all the manufacturing sectors, employment shares in food, beverages and tobacco seemed to increase for locally owned firms from 38 to $42 \%$ in period 1994-2001. Taking employment level as a proxy of firm size, foreign firms were bigget in size than localy owned firms in the three sectors. Foreign firms tended to increase their shares of raw material consumption over the period. On human capital, an equally interesting observation emerged where the level of skill shates tended to increase in all the three sectors for locally owned firms (Table 4.2).

\$ ISIC at rwo-digit (revision 2) represents: (ISIC 31) Food, beverages and robacco; (ISIC 32) Texrile, apparel and leather, (ISIC 33) Wond and Wood Products; (ISIC 34) Paper and paper products; (ISIC 35) Chemicals and petroleum producrs; (ISIC 36) Non-metallic mineral products; (ISIC 37) Basic metal industries; (ISIC 38) Fabricated metal products, machinery and equipment; (ISIC 39) Other manufacturing industries. 
Table 4.2 Important Trends in the Panel Data Sample: Percentages Based on Annual Averages, Kenya, 1994-2001

\begin{tabular}{|c|c|c|c|c|c|c|c|c|c|c|c|c|c|c|}
\hline & \multicolumn{2}{|c|}{ ISIC 31} & \multicolumn{2}{|c|}{ ISIC 32} & \multicolumn{2}{|c|}{ ISIC 33} & \multicolumn{2}{|c|}{ ISIC 34} & \multicolumn{2}{|c|}{ ISIC 35} & \multicolumn{2}{|c|}{ ISIC 36} & \multicolumn{2}{|c|}{ ISIC 37} \\
\hline 1994 & Loc & For & Loc & For & Loc & For & Loc & For & Loic & For & Loc & For & $\mathrm{LOC}$ & For \\
\hline RMAT & 43 & 57 & 26 & 74 & 81 & 19 & 16 & 84 & 43 & 57 & 5 & 95 & 42 & 58 \\
\hline KALF & 32 & 68 & 20 & 80 & 98 & 2 & 11 & 89 & 12 & 88 & 55 & 45 & 23 & 77 \\
\hline EMPT & 38 & 62 & 32 & 68 & 53 & 47 & 24 & 76 & 46 & 54 & 41 & 59 & 30 & 61 \\
\hline Skill & 32 & 68 & 32 & 68 & 55 & 45 & 18 & 82 & 41 & 59 & 38 & 62 & 35 & 65 \\
\hline VAD & 11 & 89 & 25 & 75 & 73 & 27 & 20 & 80 & 28 & 72 & 36 & 64 & 10 & 90 \\
\hline VADL & 21 & 79 & 82 & 18 & 70 & 30 & 43 & 57 & 46 & 54 & 62 & 38 & 18 & 82 \\
\hline TSALES & 20 & 80 & 25 & 75 & 78 & 22 & 18 & 82 & 34 & 66 & 17 & 83 & 19 & $B 1$ \\
\hline EXPTTS & 30 & 70 & 53 & 47 & 0 & 100 & 7 & 93 & 31 & 69 & 7 & 93 & 32 & 68 \\
\hline $\begin{array}{r}\text { TECHN } \\
1996\end{array}$ & 38 & 62 & 22 & 78 & 48 & 52 & 52 & 48 & 37 & 63 & 66 & 34 & 35 & 65 \\
\hline RMAT & 45 & 55 & 29 & 71 & 76 & 24 & 15 & 85 & 44 & 56 & 4 & 96 & 19 & 81 \\
\hline KALE & 23 & 77 & 20 & 80 & 98 & 2 & 11 & 89 & 12 & 88 & 39 & 61 & 37 & 63 \\
\hline EMPT & 38 & 62 & 37 & 63 & 51 & 49 & 20 & 80 & 48 & 52 & 35 & 65 & 18 & 82 \\
\hline Skill & $3 \hat{3}$ & 67 & 41 & 59 & 53 & 47 & 19 & 81 & 44 & 56 & 59 & 41 & 36 & 64 \\
\hline VAD & 10 & 90 & 29 & 71 & 83 & 17 & 54 & 46 & 26 & 74 & 22 & 78 & 15 & 85 \\
\hline VADL & 22 & 78 & 88 & 12 & 81 & 19 & 58 & 42 & 37 & 63 & 22 & 78 & 31 & 69 \\
\hline TSALES & 20 & 80 & 29 & 71 & 79 & 21 & 40 & 60 & 34 & 66 & 14 & 86 & 17 & 83 \\
\hline EXPTS & 31 & 69 & 44 & 56 & 28 & 72 & 10 & 90 & 25 & 75 & 2 & 98 & 1.4 & 86 \\
\hline $\begin{array}{r}\mathrm{TFCHN} \\
1998\end{array}$ & 42 & 58 & 23 & 77 & 49 & 51 & 49 & 51 & 38 & 62 & 44 & 50 & 49 & 51 \\
\hline RMAT & 45 & 55 & 26 & 74 & 79 & 21 & 15 & 85 & 43 & 57 & 5 & 95 & 19 & 81 \\
\hline KAIF & 20 & 80 & 20 & 80 & 98 & 2 & 10 & 90 & 17 & 83 & 45 & 55 & 34 & 60 \\
\hline EMPT & 39 & 61 & 33 & 67 & 55 & 45 & 23 & 77 & 44 & 56 & 35 & 65 & 22 & 78 \\
\hline Skill & 35 & 65 & 41 & 59 & 56 & 44 & 21 & 79 & 34 & 66 & 52 & 48 & 39 & 61 \\
\hline VAD & 11 & 89 & 24 & 76 & 82 & 18 & 40 & 60 & 31 & 69 & 28 & 72 & 17 & 83 \\
\hline VADL & 20 & 80 & 93 & 7 & 85 & 15 & 37 & 63 & 32 & 68 & 43 & 57 & 38 & 62 \\
\hline TSALES & 20 & 80 & 25 & 75 & 81 & 19 & 34 & 66 & 37 & 63 & 1.7 & 83 & 18 & 82 \\
\hline ExpTS & 37 & 63 & 14 & 86 & 30 & 70 & 8 & 92 & 36 & 64 & 28 & 72 & 18 & 82 \\
\hline $\begin{array}{r}\text { TECHN } \\
2000\end{array}$ & 41 & .59 & 26 & 74 & 48 & 52 & 89 & $11{ }^{\prime \prime}:$ & 43 & 57 & 48 & 52 & 48 & 52 \\
\hline RMAT & 43 & 57 & 27 & 7.3 & 81 & 19 & 13 & 87 & 43 & 57 & 4 & 96 & 19 & 81 \\
\hline KALF & 27 & 73 & 20 & 80 & 98 & 2 & 10 & 90 & 17 & 83 & 45 & 55 & 32 & 68 \\
\hline FMPT & 42 & 58 & 24 & 76 & 53 & 47 & 24 & 76 & 51 & 49 & 35 & 65 & 30 & 70 \\
\hline Skill & 39 & 61 & 33 & 67 & 58 & 42 & 20 & 80 & 49 & 51 & 54 & 40 & 39 & 61 \\
\hline VAD & 11 & 89 & 36 & 64 & 82 & 18 & 61 & 39 & 31 & 69 & 20 & 80 & 24 & 76 \\
\hline VADL & 22 & 78 & 92 & 8 & 79 & 21 & 69 & 31 & 34 & 66 & 48 & 52 & 36 & 64 \\
\hline TSALES & 21 & 79 & 31 & 69 & 82 & 18 & 42 & 58 & 37 & 63 & 12 & 88 & 21 & 79 \\
\hline EXPTS & 41 & 59 & 65 & 35 & 79 & 21 & 7 & 93 & 30 & 70 & 15 & 85 & 28 & 72 \\
\hline $\begin{array}{r}\text { TECGN } \\
2001\end{array}$ & 42 & 58 & 27 & 73 & 49 & 51 & 77 & 23 & 41 & 59 & $4 \cdot 4$ & 56 & 47 & 53 \\
\hline RMAT & 42 & 58 & 26 & 74 & 80 & 20 & 18 & 82 & 41 & 59 & 4 & 96 & 19 & 81 \\
\hline KALF & 27 & 73 & 22 & 78 & 98 & 2 & 9 & 91 & 16 & 8.4 & 45 & 55 & 32 & 68 \\
\hline EMPT & 42 & 58 & 25 & 75 & 54 & 46 & 26 & 74 & 50 & 50 & 35 & 65 & 30 & 70 \\
\hline Skill & 40 & 60 & 36 & 64 & 60 & 40 & 22 & 78 & 47 & 5.3 & 54 & 46 & 39 & 61 \\
\hline VAD & 11 & 89 & 31 & 69 & 83 & 17 & 53 & 47 & 30 & 70 & 20 & 80 & 26 & 74 \\
\hline VADL & 21 & 79 & 93 & 7 & 80 & 20 & 75 & 25 & 29 & 71 & 48 & 52 & 49 & 51 \\
\hline TSAMES & 20 & 80 & 28 & 72 & 81 & 19 & 43 & 57 & 35 & 65 & 12 & 88 & 22 & 78 \\
\hline EXPTS & 40 & 60 & 63 & 37 & 79 & 21 & $?$ & 93 & 27 & 73 & 15 & 85 & 25 & 75 \\
\hline TECHN & 38 & 62 & 29 & 71 & 50 & 44 & 76 & 24 & 39 & 61 & 43 & 57 & 47 & 53 \\
\hline
\end{tabular}

Source: Compured by the author from Kenya, Annual Industrial Survey Undertaken by Ministry of Trade and Industry, Kenya. 
Sumilaty, domestic firms seened to be taising their processing capability in chemicals, petroleum and plastics and machine and enginering. Their shares seemed to increase from 37 to $39 \%$ and 35 to $47 \%$ in the period respectively (see Table 4.2 ). Nevertheless foreign firms still temained the largest employers of skilled labour fotce in most of the sectors. Indicators of firm market performance showed that shares of domestic firms tended to increase for chemicals, perroleum and plastics and machine and engineering from 34 to $35 \%$ and 19 to $22 \%$ for the period respectively (Table 4.2). An increase in export shares for domestic firms was only registered in food, beverages and tobacco from 30 to $40 \%$ for the petiod 19942001.

Interestingly, sectoral analysis tends to arrive at similat conclusion to the one obtained carlier when the andysis on the whole industry was undertaken; that locally owned firms tended to be gradually catching up with foreign firms based on their observed rising shates in the study period. We put this in more context by confirming it using sectoral growth rates computed for both foreign and locally owned firms in the period 1994 2001.

Interestingly, in terms of growth rates domestic firms performed better than foreign firms in this period 1994-2001. "This is so because locally owned firms recorded positive growth tates in more variables than foreign firms did (see Appendix 4.1). Starting with food, beverages and tobacco sector, while foreign frms recorded a declining trend for all the variables in the period, their local counterparts had positive growth in four variables; employment (1.4), skilled labour force (3.6), value added (2.0) and technology (0.8). Specific annual growth rates in the period 1994-1997 and the period 1997-2001 can be seen in Appendix 4.1.

Similarly, in chemicals, petroleum and plastics sector, locally owned firms recorded positive growth rates in more variables than foreign firms (see Appendix 4.1). The most interesting case was that of machine and engineering sector where all the variables recorded positive growth rates except total sales, which recorded a slight decline, below 1\%. Foreign firms in the same sector had only four cases of variables with negative growth rates. The findings based on these sectors do confirm our findings above; that domestic firms were gradually catching up with the foreign firms.

Next we would like to investigate whether manufacturing sectors observed to have high levels of foreign investment and high levels of foreign activities in the period 1994-2001 are the same sectors that are characterised with high conomic performance in Kenya. This will be done by computing annual growth rates and sectoral shares of manufacturing sectors using long time-series data for the period 1963-2000 (Box 4.1. and Table 4.3). However, before we proceed with this analysis, we wish to emphasise that no direct causalities can be established here yet and thus the analysis done here does not indicate how FDI generally affects manufacturing. Determination of productivity spillovers is done in the next section and even then it will, in actual sense, still be impossible to establish whether rechnological spillovers from foreign to domestic firms do occur or not. Determination of spillover occurtence and its determinants due to foreign presence will be undertaken in the subsequent chapters using a different as approach introduced in Chapter 2.

\footnotetext{
94 This is an aggregate data gathered from Contral Buteau of Statistics (CBS) and UNIDO databases. The database does not disaggregate data in tems of foneign and locally owned frms.
} 


\section{Box 4.1}

\section{Synopsis Based on Aggregate Data from Secondary Sourees}

Generally almost all the manufacturing industries had their fastest growth in watue added during the periods 196471 and $1972-76$ when the growth rate for the total manufacturing was $10.6 \%$ and $16.7 \%$ respectively (see Table 4.3 ). Interestingly, these growh rates were witnessed during the import substitution period. This was followed by a general deoline in growth in all the other periods except $1986-90$ and $1995-2000$ when the growth rates rose to $5.3 \%$ and $5.8 \%$ respectively. Total manufacturing value added had an average annual growtl rate of $7 \%$ for the period 1964-2000. The period 1991-94 had the lowest growth rates with most of the manufacturing industries growing at a negative rate. During this period: the country faced severe drought, there was also high fever for multiparly elections, which were being introduced in the country for the first time, all the donor support had been withdwawn [Kenya Economic survey, (1997: 1998: 1999); Phillips and Obwana, 2000; Todaro, (2000: p.284); Soderbom, 2001]. In Chapter 2, it was shown that between the period 1986,90 and 1991-94, the GDP annual growth rate declined from 5\% to $1.5 \%$ while growth rate in manufacturing also declined from $5.7 \%$ to $2.2 \%$ in the same period. The relatively high growth rate in the period $1986-90$ can be explained by incentives offered upon the implementation of SAPs, which emphasised on exports and thus there was an effort to increase manufacturing value added.

Food, beverages and tobacco had a positive growth except for the period 1977-80, when its growth rate declined from $24.1 \%$ in the period $1972-7610-3.5 \%$ in the period 1977-80 (Table 4.3). In period 1995-2000, food, bewerages and tobacco with an average annual growth rate of $7.7 \%$ was among the fastest growing manufacturing industrial sectors. Other fast growing industries in the period included; metal products, machinery and equipment with an average anmual growth rate of $7.3 \%$, other manufacturing with $7 \%$ and basic metal industries with $5.7 \%$.

Table 4.3 also shows that the industrial share for food, bewerages and tobacco increased from $38.2 \%$ in 1964 to $45.5 \%$ in 2000 . This was as a result of shift in capital investment mainly by MNCs from other industries into food, beverages and tobacco. Data on gross capital formation examined but not reproduced here supported this observation. There was also a slight increase in textile from $6 \%$ in 1964 to $7.2 \%$ in 2000 . Basic metal increased from $1.3 \%$ in 1977 to $5.8 \%$ in 2000 . Although metal products, machinery and equipment declined from $25.8 \%$ in 1964 to $13.8 \%$ in 2000 , it had the second highest level of value added share to food, beverages and tobacco.

Similar to the trends witnessed, all the manufacturing inclustries had their fastest growth in employment during the periods 1964-71 and 1972-76 when total manufacturing employment grew at $6.9 \%$ and $9.9 \%$ respectively (Table 4.3 ). This was followed by a general decline in growth in all the other periods. Total manufacturing employment grew at $4.7 \%$ in the 1964 2000 .

Only wo manufacturing industries had positive growth rates that were greater than $2 \%$ for the entire period under examination. These industries included food, beverages and tobacco and chemicals, petroleum and plastic, which grew at an average rate of $5.5 \%$ and $6.5 \%$ respectively for the period 1964-2000. In terms of shares; only four manufacturing industries had a share greater than $10 \%$ by 2000 . Food, beverages and tobacco was the highest generator of employment contributing $37.6 \%$ of the total manufacturing employment. Textile, wearing apparel and leather generated $17.7 \%$; metal products, machinery and equipment generated $12.4 \%$ while chemicals, petroleum, and plastics generated $10.8 \%$ of the total employment. Since labour productivity was estimated by normalizing value added with employment then its trend compares to that of value added and employment presented. 


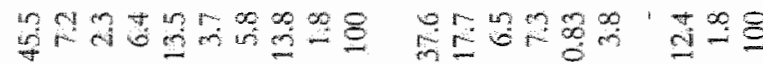

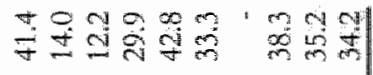

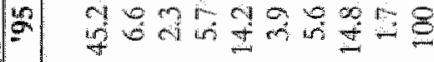

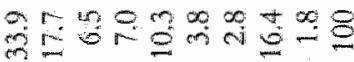

matrandra

2099000

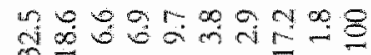

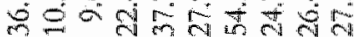

Om nom m m m m

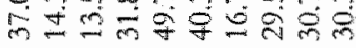

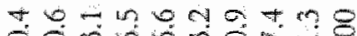

$=32 n \infty m-3$

$\infty-a,-m a+\infty$ 을 mon 0 -

m

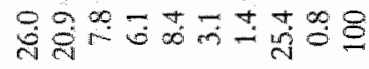

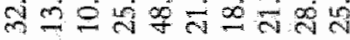

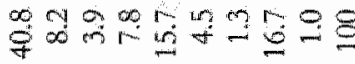

तो

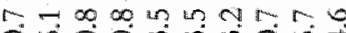

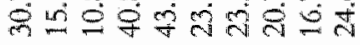

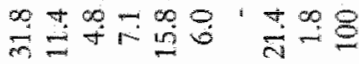

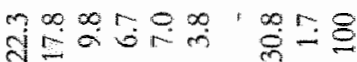

r.

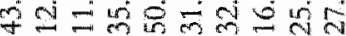
and

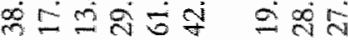

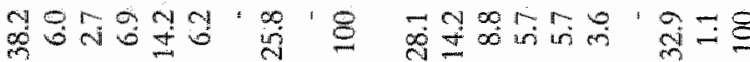
dis

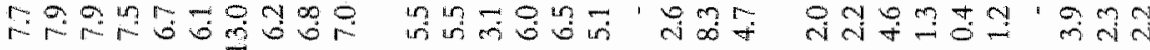

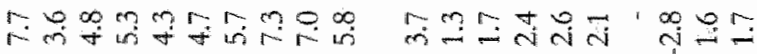

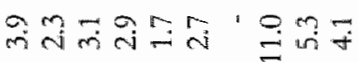

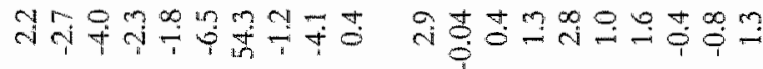

今.

m+

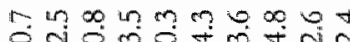

내

mome m m m

यु

$m 0$ व

क m m

सम

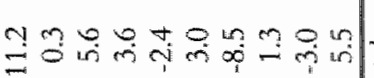

mog

mog

(⿻)

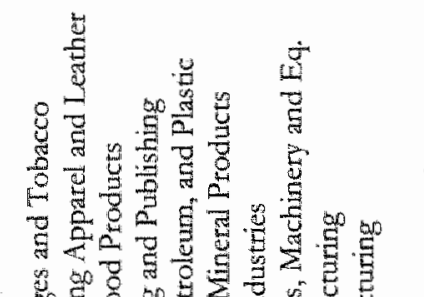

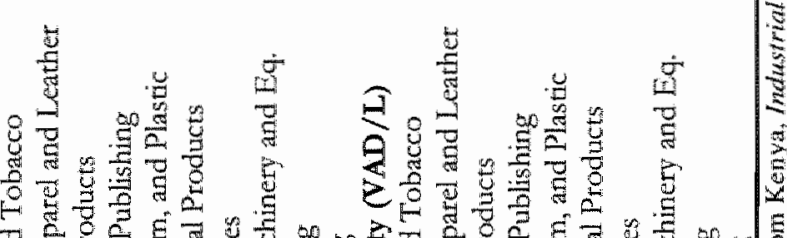

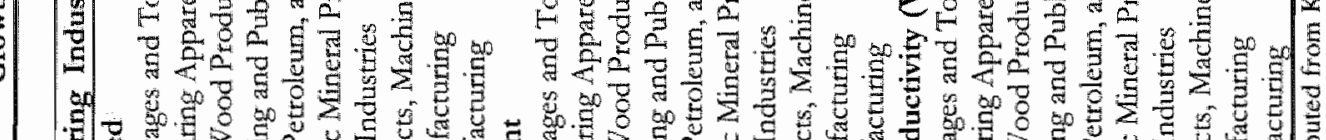

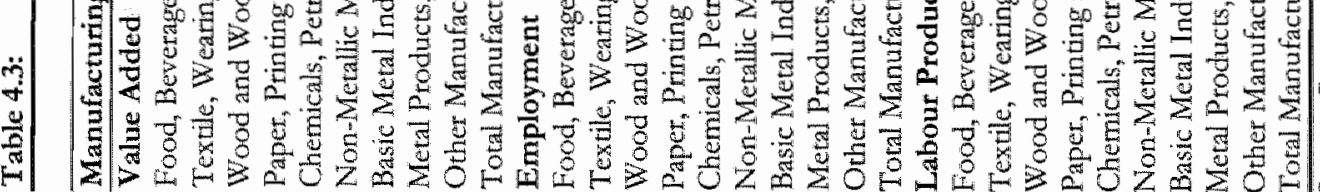


To minimize the bulk of computations and result interpretation, examination of the time series data was only limited to wahe added, employment and labour productivity. Analysis of this database is presented in Box 4.1 below whilk the computed growth rates are presented in Table 4.3. The following condusions were made: First, high growth levels witnessed in value added in the early years had deched tremendously until in the period 1995-2000. Nevertheless, the growth recorded in the period 1995-2000 was not as strong as that witnessed in the early days during the import substitution era. Second, food, bererages and tobacco; metal products, machinery and equipment, and chemicals, petroleum and plastics were the highest generators of value added in 2000 . Third, all the manufacturing sectors had their fastest growth rates in employment during the first wo periods, 1961-1971 and 1972-1976. Food, beverages and tobacco was the highest generator of employment followed by textile, wearing apparel and leather, then metal products, machinery and equipment, and then chemicals, petroleun and plastics. Fowm, manufacturing sectors with the fastest growth rates and high relative performance (shares) to the total manufacturing were the same industries characterised by high foreign presence identified based on above analysis using data for the period 1994-2003. These manufacturing sectors were; food, beverages and tobacco; basic metal industry and metal products, machinery and equipment and chemicals, petroleum and plastics. The time series data for the period 1963-2000, indicated that the same sectors had higher levels of value added and employment.

A comprehensive study of comparative behaviour of foreign and domestic firms can not be completed without conducting some econometric tests to confirm our findings especially so with productivity which is the main focus in this chapter as a means to determine spillover occurrence. In this final section, we therefore undertake some concrete econometric tests to compare the productivity of foreign fitms and locally owned firms. For this purpose we examined the statistical significance of differences in means of productivity indicators using $\mathbb{T}$-tests. The approach used here differs from Haddad and Harrison (1993) in that more productivity indicators were used for consistency checks and instead of just computing ratios; ours do a direct comparison using a two tailed T-test statistical analysis. For firm productivity, we used the following indicators: value added, labour productivity, productivity of raw materials. More to our analysis, two intensities were computed to enrich our comparisons; capital intensities and skill intensities. Table 4.4 reports the T-test results comparing productivity of performance of foreign and locally owned firms. As an example, in column three, the value of -7.337 for food, beverages and tobacco was statistically significant at $1 \%$. Also in column seven the value -6.625 for food, beverages and tobacco was statistically significant at 1\%. The two examples suggest that mean value added and skill intensities for foreign firms were both significantly higher than that of locally owned firms. These results confurmed that foreign firms wefe empirically more productive than locally owned firms with all the indicators used in food, beverages and tobacco and in chemicals, petroleum and plastics. In all the cases the T-values produced were statistically significant at various levels 1,5 or $10 \%$.

Interesting results wete also obtained with machine and engineering industry as well as textile, wearing apparel and leather. In the former, results in favour of foreign firms dominating in productivity were produced with value added, labour productivity and taw material productivity. Capital intensity was not statistically significant alrhough it showed that foreign firms dominated. Interestingly, domestic firms seemed to be more skill intensive in machine and engineering industry. In textile, wearing apparel and leather, foreign firms were confirmed empirically dominant by value added, raw material 
productwity and capital intensity. Alhough foreign firms appeated to more skill intentive, the results were not statistically significant. Interestingly, results of labour productivity showed that locally owned firms were more productive than foreign firms.

At least the results obtained here do confirm that foreign firms were actually more productive and capitat intensive in the thee sectors identifed to have high foreign presence (Talble 4.4). These are: food, beverages and tobacco and chemicals, petroleum and plastics and machine and engineering industry. Results obtained here tend to also include textile, wearing apparel and leather.

As a general conclusion to this section we can state the following: First, foreign presence was relatively high in only a few sectors and not evenly distributed across the manufacturung industry. These manufacturing sectors were food, beverages and tobacco; chemicals, petroleum and plastics and machine and engineering. Second, on the basis of the variables examined, FDT's activities were highly concentrated in the three sectors where foreign presence was the highest. Thind, based on the same indicators, foreign firms dominated in the three sectors. T-tests performed showed that foreign firms were mote productive than domestic firms. Fonth, in terms of growth rates calculated, locally owned firms performed better than foreign firms in this period 1994-2001. This suggested a gradual catching up process. Nevertheless; they still dominated and thus controlled most of the manufacturing activities. This decline in the growth of FDl's activities conld be attributed to the restructuring by firms, foteign firms especially, to face the newly emerging environment characterised by greater extemal competition and entry of new locally owned firms. Note that obserwed contraction should not be viewed as a trend towards disappearance of foreign presence in Kenya since MNCs continued to grow in some variables within sectors. The point to be emphasised here is that performance of FDI in a host country is dependent on many things and if one of them (or more) is not favourable then MNC's performance begin to dwindle. This was likely to be the case in Kenya during this period - examples mentioned earliet included weak and missing institutions, infrastructural decay, poor economic governance etc. 


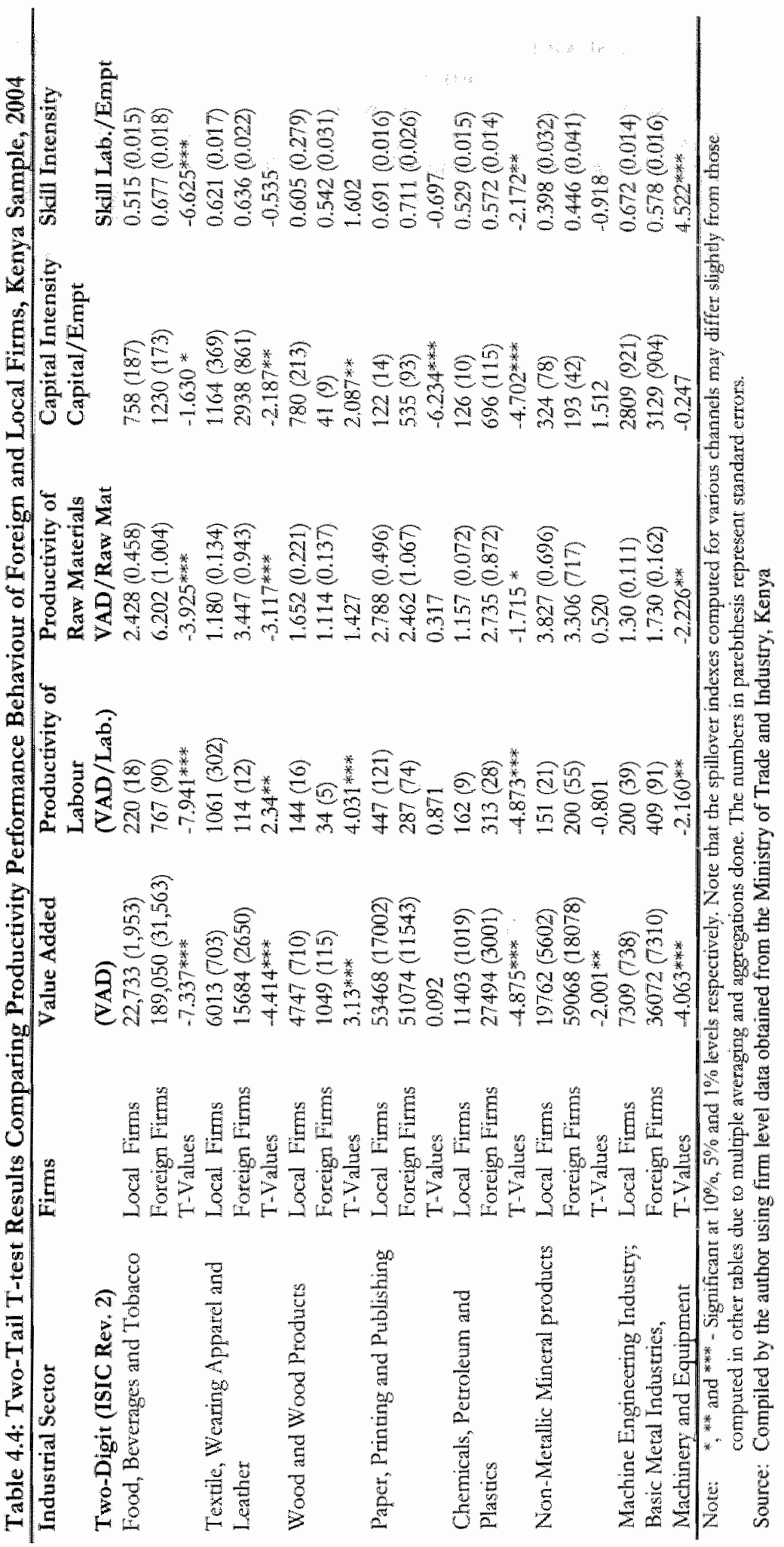




\subsubsection{A Brief Summary of Emerging Trends in Kenyan Manufacturing Industry Based on Panel Data Examined.}

The comparative behaviout between MNCs and domestic firms undertaken above was done in two stages, first by the entire manufacturing industry and then by manufacturing sectors. In this secrion, we provide a brief summary of the emerging issues which will then be presumed to characterize the Kenyan manufacturing. The results will therefore serve to guide and further motwate the remaining analysis in the subsequent sections and chapters. The results ptovide important distinctions that must be taken into consideration when analysing technological spillovers in the Kenyan manufacturing context.

\section{Entire Manufacturing Indastry Level}

On the basis of firm age in Kenyan manufacturing, foreign firms were older than locally owned firms. While the average age of all firms was 25 years that of domestic and foreign firms was 24 and 28 years respectively. On the basis of employment levels, foreign firms were larger than the locally owned firms.

With regard to firm productivity, foreign firms enjoyed high levells of productivity in terms of valued added and labour productivity. On factors of production, foreign firms controlled high shates in capital investment, employment and raw material consumption levels. Similarly, foreign firms had high shares of labour force - human capital and processing capability observed from high expenditure shares of machinery and equipment."

Foreign firms dominated in market performance based on total sales and exports. Nonetheless the local firms market performance grew more than the foreign firms did over the period. With regard to intemal firm performance, the average capacity utilization for all the firms in the period stood at $62 \%$. Foreign firms thad an average of $63.1 \%$ while local firms had $61.7 \%$ capacity utilisation.

An interesting observation showed that foreign firms appeared to decline in real terms in the period 1994-2001. However, locally owned firms performed better than foreign firms since they recorded positive growth rates in several variables that included value added, labour productivity, skilled labour and employment. This supported the argument that locally owned firms were in a gradual process of catching up.

\section{Manufacturing Industrial Sector Level}

Empirical estimation of foreign presence showed that foreign presence was highest in three manufacturing sectors; food, beverages and tobacco; chemical, petroleum and plastics and machine and engineering industry. 'Thus the implication is that in the perspective of foreign presence, sectors were different in that foreign firms were concentrated in only a few sectors and not evenly distributed in Kenya's manufacturing.

With regard to firm age, foreign firms were particularly older than locally owned furms in all the sectors apart from wood and wood products where domestic firms appeared to be older. Taking employment as a proxy for firm size, foreign firms were larger in size than locally owned firms in these sectors. Foreign firms also had a higher capacity utilisation than their local counterparts. 
In all the three sectors with high foreign presence, foreign fims dominated in all the variables over the period 1994-2001, further confirming that activities of MNCs were concentrated in a few sectors of the manufacturing industry. However, despite foreign firms dominance in these sectors, most of their shates seemed to decline over the study period, while those of locally owned firms seemed to increase, albeit gradually. Compratation of annual growth rates showed that foreign fims appeated to decline in real terms in the period 1994-2001 while locally owned firms performed bether as they recorded positive growth rates in more variables than foreign firms. Interestingly, computational of growth tates using a longer time series data confirmed that the three sectors identified to have high foreign presence were the same ones that continued to perform well since 1963. Productivity analysis using T-tests indicated that foreign firms had higher levels of productivity than the locally owned firms, at least in the three sectors with high foreign presence.

\subsection{Effect of Foreign Presence on Firm Level Productivity}

In addition to the descriptive analysis done in the preceding sections, this chapter aims to empirically determine the role of foreign presence in manufacturing industry on firm level productivity. This is done by examining total factor productivity. The essence of this undertaking is to have a broad set of results, which will form a wider basis for further argument and reseanch given that very few studies existed in Kenya on FDI. Departing from the assumption that technology skills, knowledge and technology embodied in foreign owned firms ate transmitted to the domestic firms, then this should result in increased performance levels of local firms in tems of their productivity. We therefore begin analysis by specifying a general form of the production function. We assume a production function of the Cobb-Douglas type where a firm's output is presented by say $Y_{i r}$ which depends on three input factors capital $K_{i r}$, labour $L_{i r}$ and raw materials $M_{i j i}$. Such a production function can be specified as follows:

$$
Y_{i j r}=A_{i j t} F\left(K_{i j t}, L_{i j t}, M_{i j t}\right)
$$

Where $i$ denotes the firm, $j$ the industry and $t$ the year; all the properties of production function are assurned to hold ${ }^{95}$. As discussed earlier in the recent past use of a production function approach has been increasingly adopted in determining FDI's impact on firm level productivity [Haddad and Harrison, 1993; Hatrison, 1996\% Aiken and Harrison, 1999; Kinoshita, 2000]. Following Lucas (1988) skilled and unskilledlabour $L_{i, j t}$ force can also be categorised into skilled SKILL and unskilled UNSKMLL workers. Thus equation 4.3 above becomes:

$$
Y_{i j t}=A_{i j r} F\left(K_{i j t}, S K I L L_{i j t}, U N S K I L L_{i j t}, M_{i j t}\right)
$$

\footnotetext{
95 This follows Griliches (1992) standard approach to modelling externalitios in industry productivity growth. In which case the level of productiping achieved by enterprise or industrial scctor depends on the level of knowledge acessible to it in addition to its own internal resedrch ef fortt. In telated modetling cases, total factor productivy has been used as al procedure to measure productivity growth $1 \mathrm{Caves}$ (1974: 1982); Grtliches and Lichtemberg, 1984; Coe and Helpman, 1995].
} 
In the alsowe specification $Y_{i j}$ is total production whete $A_{i j}$ is the total factor productivity, which is assumed to vary across firms, sectors and at the same time fluctuate with time. According to this specification the output production changes only if the inputs into production change. A lot of significance is usually attached to $A_{i j t}$ as an indicator of certain components in a firm all demonstrating the levels of existing slisll, usefulness of knowledge, firm capabilities and other characteristics. [Such include managerial capabilitics and organisational competence, inter-sector transfer of resources, $\mathrm{R \& D}$, increasing tertrns to scale, embodied technical progress and diffusion of technology]. Hence, taking the log level specification of equation 4.4 above and including. an error tem $\mu_{\text {in }}$, yields:

$$
\begin{aligned}
\log Y_{i j r}=\quad & \log A_{i j i}+\beta_{1} \log K_{i j,}+\beta_{2} \operatorname{LogSKLLL} L_{i j r}+\beta_{3} \log U N S K I L L_{i j t} \\
& +\beta_{4} \log M_{i j,}+\mu_{i j r}
\end{aligned}
$$

Where $\mu_{i j r}=\alpha_{i j t}+\vartheta_{i j,}$, this is the standard random effects model as explained in the methodology section?. The analysis undertaken here examines the impact of foreign investment on all firms in. Kenya and then on domestic firms only. Although $A_{i j t}$ can be decomposed into just a few determinants as mentioned, for simplicity, we intend to decompose it into only a few components as follows:

$$
L O g A_{i j t}=\quad \beta_{3} P A R T_{i j \mathrm{it}}+\beta_{4 .} F O R P S_{i j,}+\beta_{s} D U M M Y_{i j t}+\beta_{6} D U M M Y_{i j t}
$$

Where $P A R T_{i j,}$ is foreign ownership at firm level, FORPS $S_{i j}$ is foreign presence at sector level, $D U M M Y_{i j,}$ and $D U M M Y_{i j,}$ are dummy variables for sector and time respectively. These two dummies are important in controlling for the industry specific and inter temponal fluctuations. All the standard traditional models failed to control for these phenomena and thus did not include these dummies primarily due to their data constraints. Results of such studies were based only on cross-sectional data at a point in time. Combining equation (4.5) and (4.6) above yields the estimating equation.

$$
\begin{aligned}
\log Y_{i j i}= & \beta_{0}+\beta_{1} \log _{i j t}+\beta_{2} \operatorname{LogSKILL}_{i j t}+\beta_{3} \log U N S K I L L_{i j r}+\beta_{4} \log M_{i j t} \\
& +\beta_{5} P A R T_{i j t}+\beta_{6} \text { FORPS }_{i j t}+\beta_{7} D U M M Y_{i j t}+\beta_{8} D U M M Y_{i j t}+\mu_{i j r}
\end{aligned}
$$

In this estimation, the dependent variable $Y_{i j}$, is proxied by the value added for each firm. Capital was proxied by value of capitall investment $K_{\text {ijt }}$. Labour force was classified into skilled SKILLLijr and unskilled UNSKILLLijr workers and both of them were measured in absolute numbers for each firm. Raw material was proxied by the value of naw materials consumed $M_{i j}$ by each firm. Both industry dummy $D U M M Y_{j}$ and time dummy $D U M M Y_{r}$ were also included to capture various fluctuations due to nonobservable sectoral and time effects.

All the estimated coefficients for the factor inputs (capital, skill, unskilled and raw materials) were expected to be positive and significant, while the expected sign for the 
foreign presence coefficient both at firm and sector level were expected to be either positive or negative. A posinve sign coefficient would suggest a positive correlation - a positive impact of foreign presence on productivity in Kenga while negative sign would mean a negative impact. A positive correlation would mean that foreign firms contributed positively to the total factor growth in Keny. This would mean that fims in Kenya would benefit from technology transfer from foreign firms, knowledge, skills and other forms of spillovers. To the contrary, negative correlation would imply that domestic firms in Kenyan manufacturing do not benefit from foreign presence. It could also mean that foreign firms in Kenya operate in clusters that might be characterised by high concentration and perhaps high technology gaps between foreign and Kenyan firms that do not permit such benefits to occut. It could also be that foreign firms have few established wertical and horizontal linkages with domestic fums hindering steady flow of techniques, knowledge and other useful information. It could also be due to the nature and level of employment in the foreign firms. Employment in tax material seeking is not expected to result in much acquisition of knowledge and skills. Similarly, employment at low level cadres only is not likely to result in acquisition of much knowledge and stillls. Finally, industy and time dummies were included to capture the non-obserwable sectoral and time effects; these were expected to be significant. The results of the estimated model 4.7 are presented in Table 4.5 and 4.6 .

Table 4.5 presents the OLS, GLS and random effects results of all the firms included in the panel sample. As was done with labour productivity, for each of the econometric techniques used, the model estimation was repeated three times. The first estimation excluded dummies, the second included only time dummies while the last included both time and industry dummies. Based on the three econometric techniques, the coefficient estimated for foreign presence at the sector level were positive and statistically highly significant when no dummy was included. A similar trend was witnessed when only time dummy were included. The coefficient estimated with time dummies only and with no dummies was the same 0.0046 with OLS and was significant at $1 \%$. Similarly results of GLS and random effects were highly comparable and consistent with no dummies and with only time dummies included. In both cases the coefficient estimated was 0.004 which was significant at $1 \%$. The results obtained without any dummies supported those of the carly contributors suggesting that an increase of $100 \%$ in foreign presence results to an increase of 0.4 to $0.46 \%$ in firm productivity.

Interestingly, when time and industry dummies are included, the coefficients obtained in all the cases decreased substantially in magnitude and became insignificant. With OLS a coefficient of 0.001 was obtained, 0.003 with GLS and 0.002 with random effects which were all statistically insignificant. This confirms that results obtained without dummies and with industry dummies are not robust in the context of the three estimation techniques employed. This implies that the effect of foreign presence on fim productivity is reduced when sectoral dummies are considered. These results are in support of tecent developments in spillover analysis econometrically. Given that industry differences are important and ought to be taken into consideration, this thesis tends to support these results but emphasises that more work is needed employing different techniques and case studies as will be done in the next chapters.

With regard to foreign presence at the firm level, OLS, GLS and random effects produced wery consistent and comparable tesults were estimated with the three techniques. However, the coefficients tended to change their statistical significance with all dummies included. The estimated coefficient without dummies was 0.0018 with OLS 
significant at $5 \%$ and 0.002 with GLS and 0.002 with random effects which was significant at $1 \%$. The coeffictent estimated with industry dummies was 0.002 with GLS and 0.002 with andom effects, all significant at $5 \%$. Although OLS results were not significant, note that they were near significant at $10 \%$. The implication hete is that an increase of $100 \%$ in foreign presence at the firm level would inctease labout productivity by berween 0.18 and $0.2 \%$ when industry dumimies are included. These results suggest that foreign participation at the firm level plays a positive and significant role towards productivity of firms in Kenya.

All the other independent watiables had the expected results, produced appropriate signs of the estimated coefficients with a high degtee of statistical significance at $1 \%$ even when time and sectoral dummes were included (see Table 4.5). Capital had a coefficient of 0.13 with Gls and 0.14 with both OIS and random effects. It means that if a firm increases its capital by $100 \%$, it was lifely to increase its firm productivity by between 13 and 14 percentage points. Capital is important as it is the main driver of production. With time and sectoral dummies included the estimated coefficients for taw material was 0.54 with GLS and 0.55 with both OJS and tandom effects. Implication that if a firm in the Kenyan manufacturing industry increases its raw material consumption by $100 \%$ it was likely to increase its productivity by between 54 and 55 percentage points. The estimated tesults for skilled labour were 0.56 with random effects and 0.54 with both OTS and GIS. Skilled labour is important for firm innovation and to drive production. In the case of unskilled labour, a coefficient of 0.38 was obtained with random effects and 0.39 with both OLS and GLS. Unskilled labour is also necessary for productivity especially more so in technically backward countries like Kenya.

Table 4.6 presents the OLS, GLS and random effects results for only the domestic firms. As in the above, model 4.7 was estimated three times for each econometric technique. The results based on foreign presence at the sector level were positive and significant suggesting that Kenyan manufacturing industry indeed benefited from an increase in foreign presence. The results obtained here confirm results estimated in the above cases. Consequently, results obtained with and without taking industry differences into consideration (industry dummies) were completely different. The results obtained without including any dummies compared to those obtained with time dummies included

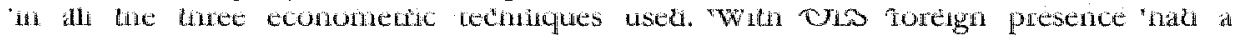
coefficient of 0.0028 while GLS had a coefficient of 0.0024 both of which were statistically significant at $5 \%$. The coefficient estimated with time dummies was 0.0027 for OLS and 0.0024 for GIS both of which were statistically significant at 5 and $10 \%$ respectively. Even though a similar coefficient of 0.002 was obtained in the case of random effects it was only near significant at $10 \%$. All these estimates suggest that an increase of FDI presence at the sector level by 100 percentage points would increase productivity output in domestic firms by approximately between 0.2 and $0.3 \%$. We emphasise that results obtained here are in line with traditional models - standard productivity models estimated in the past without taking into consideration industry, time, and locational effects among other things. As discussed extensively in Chapter 2 , such studies mainly concentrated on cross-sectional studies, instead of firms, with aggregate industry data and without controlling for productivity differences among industries.

Results estimated with time and industry dummies included were not significant. The results confirm other findings produced above and are in further support of recent developments proponents of spillover analysis. Once again the methodological apptoach 
considered seems to largely determine the outcome of the spillovers analysis. Since we support the argument that for spillowers to occur a mone complex approach is needed, one that includes as many factors we would be tempted to support these findings but however emphasise that extra work is required employing diverse techniques as will be done in the subsequent chapters.

All the other independent variables had the expected results, positive and were significant at $1 \%$ when time and sectoral dummies were included. Capital had a coefficient of 0.11 with GIS and 0.12 with both OLS and tandom effects. It means that if a firm incteases its capital by $100 \%$, it was likely to increase its productivity by between 11 and $12 \%$. Wita time and sectoral dummies included the estimated coefficients fot taw material was 0.61 with OLS, 0.62 with GLS and 0.63 with random effects. This suggests that if a firm increases its raw material consumption by $100 \%$ it was likely to inctease its productivity by between 61 and $63 \%$. The estimated coefficient for skilled labout was 0.50 with OJS, 0.53 with GLS and 0.54 with random effects. In the case of unskilled labour a coefficient of 0.45 was obtained with OLS and 0.43 with both GLS and random effects. In all these cases the results were consistent. 


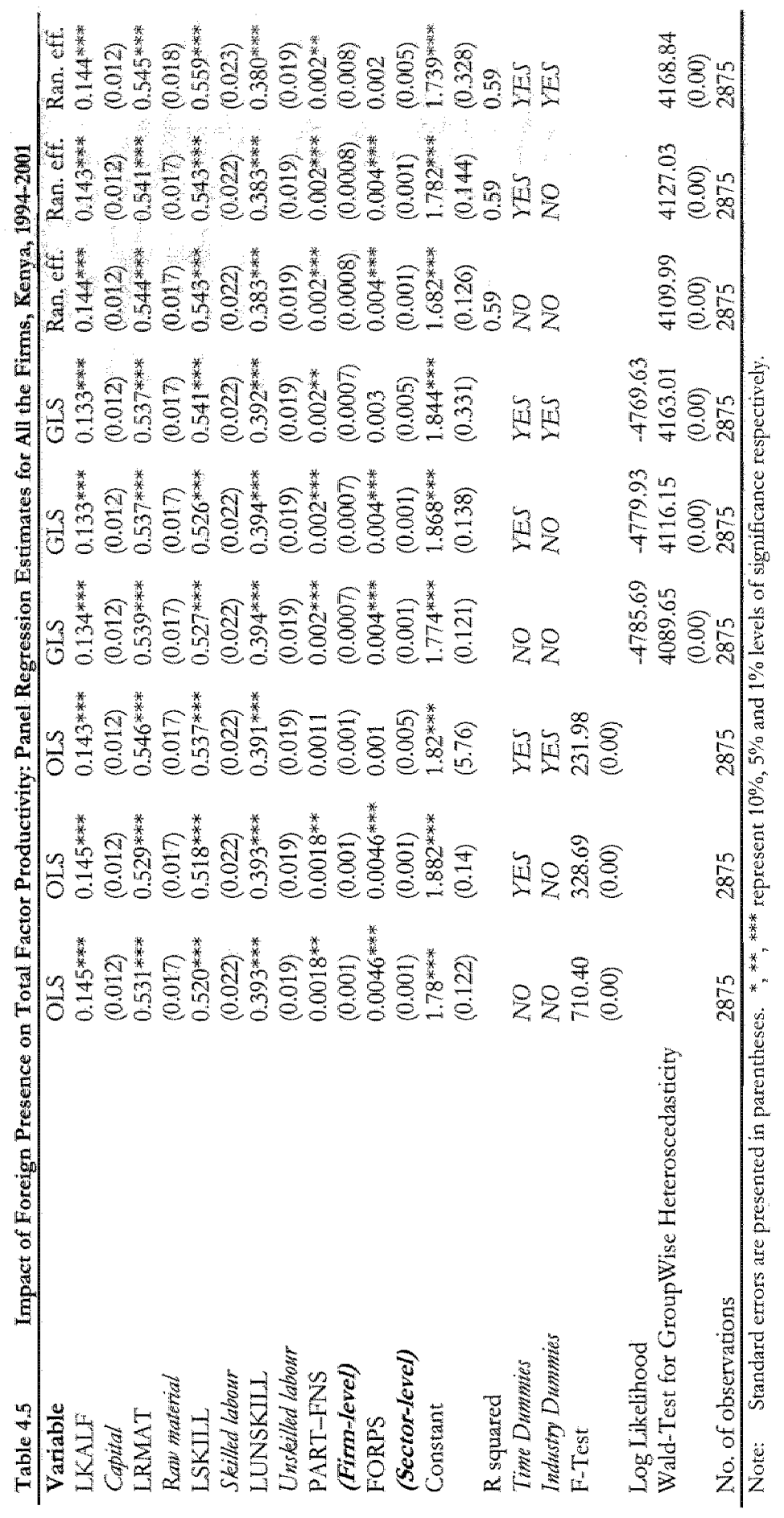




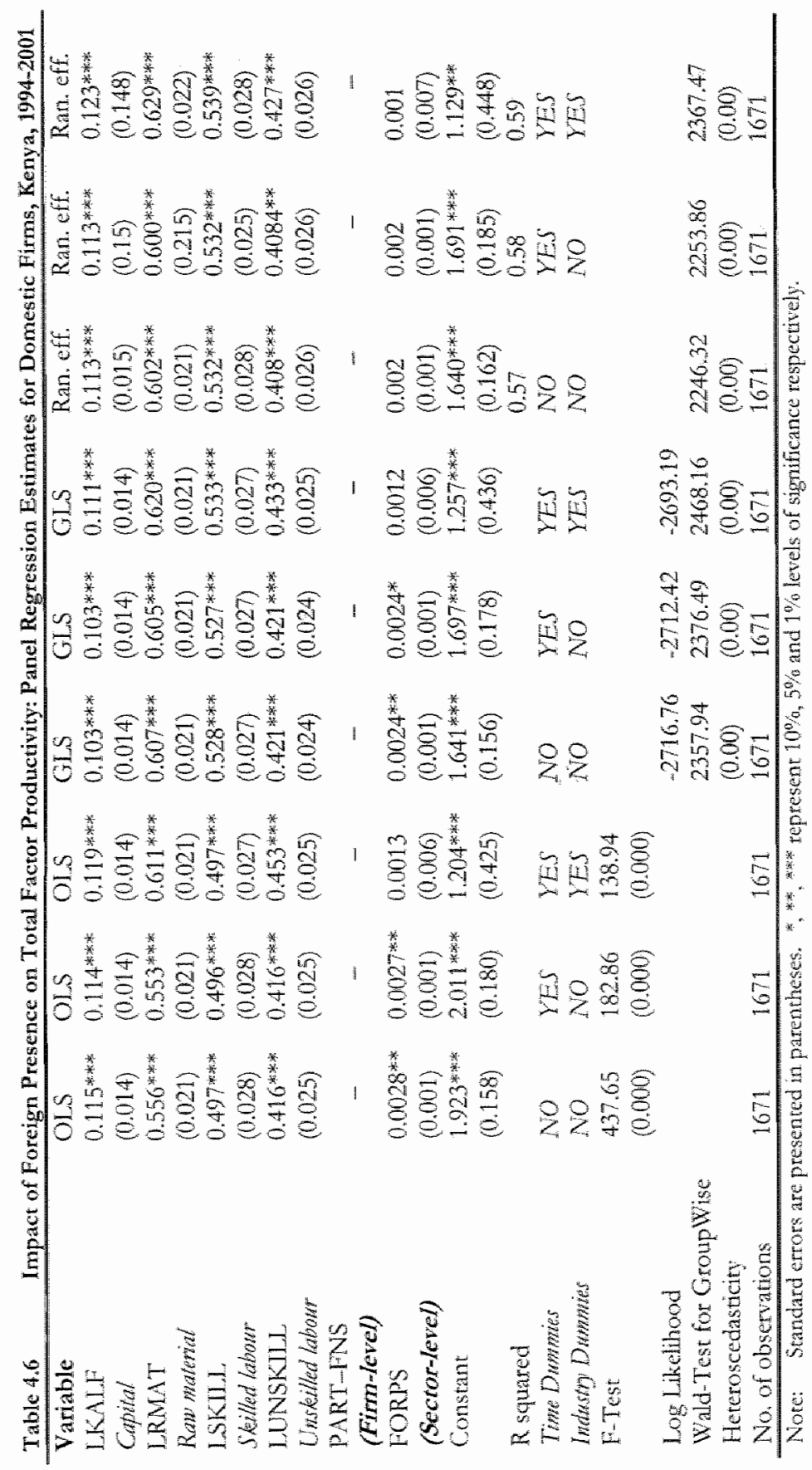


In this section, we analyse the impact of foreign presence on total factor productivity by scale orientation. In all the earlier estimations conducted, the firms were pooled together without regard for the variation that could arise due to differences in firm size or technology gap. In this section, we attempt to analyse total factor productivity by size orientation and in the next section by technological gap. However, we must first reemphasise an emerging conclusion from above as this will guide the next round of results. So far, it is clear that results obtained with dummies included differed significantly from those obtained without inclusion of dummies. When dummies ate included the estimation tends to be in accondance with the recent contributions and when dummies ate ignored the estimation tended to replicate traditional estimations. In the rext sections, we intend to include dummies to enable comparison between estimates with dummies and without dummies as was done in the above cases. Thus industry and time factots will be taken into consideration in all the estimation.

The influence of scale on spillover occurrence can either be positive or negative. As explained in Chapter 2 , for industries involved with economies of scale then minimum efficiency scale is involved and in such a case scale would influence productivity. On the contrary, due to the importance of flexibiliry offered by scope, small firms are likely to perform better in specific industries. In order to account for the size factor, all the firms in the sample were considered at three levels. The first level included all the firms in the sample, the second included only domestic firms while the last level included only the foreign firms. Each level was then classified into two groups as shown in Table 4.7. Firms employing less than 138 were classified as "small firms" while firms employing above 138 were classified as "large firms". Large firms in all the categories dominated in the industry with large shares in all the variables except for labour productivity. This was interesting since small firms did not appear to control a high share of value added or employment. Small firms controlled a very small proportion of employment level. Large domestic firms employed over $90 \%$ of the skilled labour force and accounted for over $70 \%$ of the total expenditure on machinery and equipment, capital and VAD.

Table 4.7:

Key Indicatorsi Percentage Shares by Scale Dummy and Firm Ownership

\begin{tabular}{|c|c|c|c|c|c|c|}
\hline & \multicolumn{2}{|c|}{ All Firms } & \multicolumn{2}{|c|}{ Domestic Firms } & \multicolumn{2}{|c|}{ Foreign Firms } \\
\hline & Smadl & Lawge & Small & Lange & Small & Lange \\
\hline RMAT & 13.5 & 86.5 & 20.5 & 79.5 & 11.0 & 89.0 \\
\hline KALEF & 24.1 & 75.9 & 27.9 & 72.1 & 26.2 & 73.8 \\
\hline EMPT & 6.7 & 93.3 & 7.1 & 92.9 & 6.7 & 93.3 \\
\hline SKIILL & 8.3 & 91.7 & 8.0 & 92.0 & 8.9 & 91.1 \\
\hline VAD & 7.8 & 92.2 & 11.4 & 88.6 & 7.4 & 92.6 \\
\hline VADL & 56.4 & 43.6 & 56.4 & 43.6 & 57.0 & 43.0 \\
\hline TSALES & 10.0 & 90.0 & 15.2 & 84.8 & 8.7 & 91.3 \\
\hline EXPTS & 15.9 & 84.1 & 33.6 & 66.4 & 7.9 & 92.1 \\
\hline TECHN & 18.9 & 81.1 & 22.1 & 77.9 & 15.1 & 84.9 \\
\hline
\end{tabular}

Source: Computed by the author from Kenya, Anmual Industrial Survey undertaken by Ministry of Trade and Lndustry 
The estimated tesults of foreign impact on total factor productinty based on size orientation are presented in Table 4.8. It was interesting to obtain consistent and robust results with the classification done. The results of all the vartables included were as expected. They produced a high degree of statistical significance with the appropriate signs of the estimated coefficients. Their interprettion follows the above section which prowided sufficient evidence that they all contributed posinely to the productivity of the firm. So in the current analysis, we shall concentrate on interpreting the results estimated with foreign presence alone. For all small firms, estimation by GLS produced a coefficient of 0.004 which was statistically significant at $1 \%$ without dummies inchded. Results estimated for random effects without dummies were near significant at $10 \%$. With dummies the results estimated were not significant for both GLS and random effects. On the contrary, results estimated for all large firms wete more robust without dummies in the case of GLS and random effects models. The coefficients estimated were positive 0.016 and 0.017 for GLS and random effects and significant at $1 \%$ respectively. These tesults showed that for large firms FDI spillovers contributes positively to the productivity of the firm. As in the above, with dummies included the results were not significant. Two interesting conclusion emerge. Firrt, results obtained with large firms are more robust than those obtained from the small firms. The implication of these findings is that large firms in Kenyans manufactuting industry are likely to benefit from spillovers occurrence more than the small firms. In other words the effect of foreign presence is influenced by size. However, the empirical evidence is not very strong in support of that and more analysis in the form of further studies needs to be done. Serond, results estimated without inclusion of dummies are mote robust than those obtained with dummies. Results obtained without dummies tend to support results obtained by the early contributors while results obtained with dummies included support results observed with recent developments in the productivity analysis.

Results obtained for large domestic firms were more robust than those obtained for small domestic firms. While results estimated for small domestic firms were not significant, results of large firms were positive and statistically significant at $5 \%$. The estimated coefficients by GLS and random effects were 0.013 and 0.019 respectively. As in above results obtained with dummies included supported results observed with recent developments in the productivity analysis. 
Table 48 Impact of Foreign Presenice on Toull Factor Productivity by Scale; Panel Regresion Estimates for All the Firms by Scale, Kenya, 1994-2001

\begin{tabular}{|c|c|c|c|c|c|c|c|c|}
\hline \multirow[t]{2}{*}{ Vatrable } & \multicolumn{4}{|c|}{ Al 5 mall Firms } & \multicolumn{4}{|c|}{ Small Domestic Firms } \\
\hline & Cis & CILS & $\begin{array}{l}\text { Roshd } \\
\text { Ey. }\end{array}$ & $\begin{array}{l}\text { Rond } \\
\text { Ef }\end{array}$ & GLS & GLS & 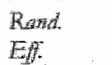 & $\begin{array}{l}\text { Rond. } \\
\text { Efol. }\end{array}$ \\
\hline LKAW & $0.129^{\circ+2}$ & 0,130 ats & 0.1348 wathe & 0.134 & $0,088^{*}$ & 0.096 & $0,080 \%$ & 0.101 \\
\hline Capitar & $(0.012)$ & 10.129 & $(0.013)$ & $(0.013)$ & $(0.014)$ & $(0.014)$ & $0015)$ & $(0.0 \mathrm{H})$ \\
\hline CRMAT" & 0.558 & 0.5007 & $0.571 \infty$ & 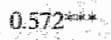 & 0.605 anduc & 0.618 \% & $0,608 \%$ & $0631^{\text {riskin }}$ \\
\hline Raty ghotheriat & $(0,019)$ & $(0.019)$ & $(00019)$ & $0.019)$ & $(0.022)$ & $(0.022)$ & $(0,23)$ & $(0.023)$ \\
\hline ISKLUL & $0.510^{\text {rin }}$ & 0.512 & $0.508^{2}$ & 0.508 & $0.528^{2}$ & $0.517^{\text {***an }}$ & $0.522^{\text {edin }}$ & 0.510 pix \\
\hline Shilled habout & $(0.026)$ & $(0,017)$ & $(002 \pi)$ & $(0027)$ & $(0.032)$ & $(0.032)$ & $0033)$ & $(0.034)$ \\
\hline WUNSKHLO & $0.377 \%$ & 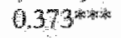 & 0.354 & 0.352 w & $0.425 \%$ & 0.431. & $0.412^{*}$ & $0.422 \times$ \\
\hline 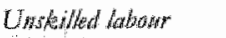 & $(0,023)$ & $(0,023)$ & $(0.024)$ & 0.024 & $(0.028)$ & $(0.030)$ & $(0.031)$ & 0,031 \\
\hline HORPS & $0,00 \%=4$ & 0.001 & 0,002 & 0001 & 0.002 & 0.002 & 0.0012 & 0,002 \\
\hline (Sector-lencl) & $(0001)$ & $(0,005)$ & $(0.002)$ & $(0.005)$ & $(0.001)$ & $(0.007)$ & $(0.001)$ & \\
\hline Constart & $\begin{array}{l}1.873 \\
0.135\end{array}$ & $\begin{array}{l}1.901 \times 4 \\
(0.333)\end{array}$ & $\begin{array}{l}1.888 \\
(0.161)\end{array}$ & $\begin{array}{l}1.871 \\
(0.351)\end{array}$ & $\begin{array}{l}1.763345 \\
(0.171)\end{array}$ & $\begin{array}{l}1.310 \\
(0.461)\end{array}$ & $\begin{array}{l}1.794 \\
(0.179)\end{array}$ & $\begin{array}{l}1.256 \% \\
0.480\end{array}$ \\
\hline R squated & & & 0.49 & 0.50 & & & 0.51 & 0.52 \\
\hline 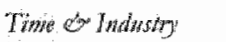 & $\mathrm{NO}$ & YRS & $\mathrm{NO}$ & YES & NO & MTS & $\mathrm{NO}$ & YES \\
\hline \multicolumn{9}{|l|}{ Dwhoming } \\
\hline Log Lalledifonod & .3656 .45 & -364098 & & & -2231.97 & .2214 .76 & & \\
\hline Wald-Test for & 2320.62 & 2380.22 & 2120.27 & 2216.64 & 1545.17 & 1617,52 & 1428.28 & 1.495 .90 \\
\hline Group Whe Hoter. & $(0.000)$ & $(0.000)$ & $(0.000)$ & $(0.000)$ & $(0.000)$ & $(0000$ & $(0.000)$ & $0.000 \mathrm{y}$ \\
\hline $\begin{array}{l}\text { No. ot } \\
\text { obserwartors }\end{array}$ & 2258 & 2258 & 2258 & 2258 & 1389 & 1389 & 1389 & 1389 \\
\hline \multirow[t]{2}{*}{ Variable } & \multicolumn{4}{|c|}{ All Large Firms } & \multicolumn{4}{|c|}{ Large Domestic Firms } \\
\hline & GLI & CLosit & $\begin{array}{l}\text { Rasud. } \\
\text { Edj. }\end{array}$ & $\begin{array}{l}\mathrm{R} u W d^{\prime} \\
E g f\end{array}$ & GIS & GLS & $\begin{array}{l}\text { Ruayd } \\
\text { Effol }\end{array}$ & $\begin{array}{l}\text { Ronat } \\
E H\end{array}$ \\
\hline $\mathrm{N} K \mathrm{~K} A \mathrm{LI}$ & 0.23 万舟** & $0212^{* * * * * *}$ & $0.212 *$ * * * & $0,178 \times \cdots$ & $0.303^{*}$ & 0.271 米然的 & $0.314^{* * 45}$ & $0278^{219}$ \\
\hline Capitan" & $(0.028)$ & $(0.028)$ & $(0.032)$ & $(0.033)$ & $(0.1042)$ & $(0.049)$ & $(0,045)$ & $(0.052)$ \\
\hline LRMAT" & $0.472 * * *$ & $0.408^{\text {in }}$ & $0.472^{* * 4}$ & $0.408 * 2 \%$ & 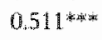 & $0.484^{*}$ & $0.528 * * *$ & 0.494 \\
\hline Rawn horateriad & $(0,039)$ & $(0.038)$ & $(0.042)$ & $(0.044)$ & $(0.061)$ & $(0.067)$ & $(0.063)$ & $(0.072)$ \\
\hline ISKILI & 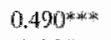 & 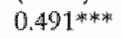 & $0.544^{\text {*an }}$ & $0.518^{\text {*a* }}$ & $0.229^{* * *}$ & $0.226 *$ & $0.232^{\text {* }}$ & $0.2112 \ldots$ \\
\hline Sikillod hobour & $(0.050)$ & $(0.057)$ & $(0.059)$ & $(0.061)$ & $(0.096)$ & $(0.098)$ & $(0.104)$ & $(0.110)$ \\
\hline LUNSKIJL & 0.384 & 0.31 .4 & $0.368^{*}$ & $0.296 \%$ & $0.227 \%$ & $0.222^{*}$ & $0.201 * *$ & $0.188^{\text {m. }}$ \\
\hline Unstilled Latown & $(0.054)$ & $(0.047)$ & $(0.048)$ & $(0.050)$ & $(0.063)$ & $(0.069)$ & $(0.067)$ & $(0.074)$ \\
\hline FORPS & $0.016^{\text {max }}$ & 0.005 & $0,01.7+2 \ldots$ & 0.003 & $0.013^{\text {*3* }}$ & 0.001 & $0.019^{\text {rick }}$ & -0.003 \\
\hline (Scotor-level) & $(0.005)$ & $(0.012)$ & $(0.005)$ & $(0.013)$ & $(0.006)$ & $(0.014)$ & $(0.007)$ & $(0.018)$ \\
\hline Constant & $\begin{array}{l}0.822^{4} \\
(0.443)\end{array}$ & $\begin{array}{l}2.588^{\text {* * * }} \\
(0.877)\end{array}$ & $\begin{array}{l}0.778 \text { a } \\
(0.601)\end{array}$ & $\begin{array}{l}3,024 * \ldots \\
(0.940)\end{array}$ & $\begin{array}{l}2.249 \\
(0.942 x\end{array}$ & $\begin{array}{l}3.466 * \% \\
(1.200)\end{array}$ & $\begin{array}{l}1.819 * 1 \% \\
(1.001)\end{array}$ & 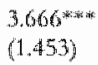 \\
\hline$R$ squared & & & 0.40 & 0.44 & & & 037 & 0,43 \\
\hline Tho ch lodwsty & $\mathrm{NO}$ & $\mathrm{YTS}$ & $\mathrm{NO}$ & $\mathrm{YES}$ & No & YWS & $\mathrm{NO}$ & Tes \\
\hline Dombmiter & & & & & & & & \\
\hline Log litreliluood & -1096.33 & -1038.41 & & & -45804 & -43555 & & \\
\hline Wal-Test for & 7100.03 & 730,29 & 461.05 & 470.01 & 166.39 & 475.71 & 1.58 .83 & 200.22 \\
\hline GronpWyse Heter. & $(0.000)$ & $0.0000)$ & $(0.000)$ & $(0.009)$ & $(0.000)$ & $0000)$ & $(0.000)$ & $(0.000$ \\
\hline $\begin{array}{l}\text { No. of } \\
\text { observarions }\end{array}$ & 624 & 624 & 624 & 624 & 282 & 282 & 282 & 282 \\
\hline
\end{tabular}

- Standard etrors are ptesented in parentheses.

- *** * * represent $10 \%, 5 \%$ and $1 \%$ levels of significance respectively. 
The impact of foreign presence on productivity was also examined by technology gap orientation. Firms were classified into two categories; those chatacterised by lowy technology gap and those by high technology gap. Except for foreign presence, results estimated for all other wariables were as expected - produced appropriate signs of the estimated coefficients with a high degree of statistical significance. Since their interpretation is in the same way as in above, we shall concentrate on the interpretation of results obtained with foreign presence. Table 4.9 shows that results of GLS and random effects methods estimated for all firms in the low technology gap category, without inclusion of dummies produced comparable results. In both cases foreign presence coefficients was 0.006 for GLS and 0.005 for random effects and both were highly statistically significant at $1 \%$. These results compared to those of the early contriburors. Results obtained with dummies were not significant and thus comparable with those obtained with recent developments to the empirical spillover literature.

Contrarily, results obtained with high technology gap were somewhat amazing. When all firms were considered, the coefficients of foreign presence produced without dummies remained positive but became insignificant. From the perspective of early contributors, these results could be interpreted to mean that high technology gap does not farour spillover occurrence. Similar to the above, results estimated with dummies included were not statistically significant.

Discussing from the perspective of early contributors, these results fail to support high technology gap requirement for spillover to occur and suggests that a relatively low technology gap was inevitable for spillovers to occur in the Kenyan context. This observation differs with Findlay's (1978) conjecture that a relatively wide gap created the necessary pressure for change in the developing country. A similar school of thought was forged by Abramovitz (1986) seminal contribution in his catching up model whereby countries lagging behind were in a position to generate more growth but only if their social capabilities were sufficiently developed. The observation is in support of low technology gap advocates [Cantwell, 1989; Kokko, 1994; Kokko, Tansini and Zejan, 1996; Sjoholm, 1997]. When technology gap are too latge they usually require irputs of far more sophisticated machinery embedded in wider systems of controll, qualiry etc that takes years to acquire through high levels of training and education. Therefore, the wider the gap, the less likely that a locally owned firm could make such a jump without either a foreign partner or a huge amount of public sector support (knowledge flows, technology assistance, finance etc).

The results obtained for domestic firms were comparable to those obtatned in the context of all the firms although coefficients estimated were relatively small in magnitude. Table 4.9 shows that results of GLS and random effects estimated without inclusion of dummies produced a similar coefficient of 0.003 that was significant at $5 \%$ respectively. This would mean that domestic firms with a low technology gap benefited slightly less than when all the firms were considered. This is not surprising since in the category of all the firms, foreign firms are included who are mote endowed with resources necessary in the spillover process than their domestic counterparts. 
Table 4.9: Impact of Foneign Presence on Total Factor Productiry by Technology Gap: Panel Regression Estimates by Technology Crap, Kenya, 1994-2001

\begin{tabular}{|c|c|c|c|c|c|c|c|c|}
\hline \multirow[t]{2}{*}{ Variable } & \multicolumn{4}{|c|}{$\begin{array}{c}\text { Lwow Technology Gap } \\
\text { All Hims }\end{array}$} & \multicolumn{4}{|c|}{$\begin{array}{c}\text { Low Technology Cap } \\
\text { Domestic Firms }\end{array}$} \\
\hline & $C L$ & GS & $\begin{array}{l}\text { Rand } \\
\text { fof }\end{array}$ & $\begin{array}{l}\text { Raval } \\
E x f\end{array}$ & $\cos$ & GIS & $\begin{array}{l}\text { Ruated } \\
\text { Euth }\end{array}$ & $\begin{array}{l}\text { Rufd } \\
\text { Bf }\end{array}$ \\
\hline $\mathscr{L W} K_{L} J^{*}$ & 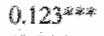 & $0.122^{254 t}$ & 0.1374 & $0.137^{*} *$ & o.poburax & 0.066 & 0.034 ank & 01096 \\
\hline Cutphtal & $(0.0113)$ & $(0,044)$ & $(6014)$ & rool 40 & $(0.017)$ & $(0.017)$ & $(0.018)$ & $(0.018)$ \\
\hline IRMAJ" & $0.5244^{3}$ & 0.523 m & $0.526^{* \%}$ & $0.528 x$ & 0.574 & $0.587 \%$ & $0.580^{*}$ & $0,605 \%$ \\
\hline Rhow nhateringl & $00020)$ & $(0.020)$ & $(0020)$ & $(0,12)$ & $(0.023)$ & $(0,024)$ & $(0.024)$ & $(0,025)$ \\
\hline MSKMI & 0,574 的的 & 0.598 & $0.598 \%$ & $0.614^{\text {*at }}$ & 0.557 * & $0.563^{3}$ & $0.560^{\text {max }}$ & 0.567 m \\
\hline Shllad towosit & $(0.026)$ & $(0,026)$ & $(0.026)$ & $(0.027)$ & $(0.031)$ & $(0.031)$ & $(0.033)$ & $(0.033)$ \\
\hline IUNGSKIL & 0.371 atrap & 0.3711 & 0.345 a d ax & 0.344 & $0.378 \%$ & $0.387^{\mathrm{tak}}$ & $0.359^{\text {m.x. }}$ & 0.3744 \\
\hline HWollowod laboir & $(0,922)$ & $(0,022)$ & $(0.022)$ & $(0.022)$ & $(0.027)$ & $(0,028)$ & $(0.029)$ & $(0.029)$ \\
\hline WORPS & $0,006 \%$ & Q0104. & $0.005 y$ & 0.003 & $0,0033^{x+2 x}$ & 0,001 & $0.003 \%$ & 0,0003 \\
\hline (sector ilevel) & $0001 \mathrm{y}$ & $(0,012)$ & $(0.001)$ & $(0.011)$ & $(0.001)$ & $(0.015)$ & $(0.001)$ & $(0,014)$ \\
\hline Constant & $\begin{array}{l}1.833^{\text {pestat }} \\
(0.138)\end{array}$ & $\begin{array}{l}1.943 \% \\
(0.759\end{array}$ & $\begin{array}{l}1.738 \% \text { \% } \\
(1.467)\end{array}$ & $\begin{array}{l}1.883^{*} \\
(0.704)\end{array}$ & $\begin{array}{l}20489 \\
(0.177)\end{array}$ & $\begin{array}{l}1.873 \\
(0.904)\end{array}$ & $\begin{array}{l}1.941 \text { (1) } \\
(0.185)\end{array}$ & $\begin{array}{l}1.674 \text { a } \\
(0.864)\end{array}$ \\
\hline The squared & & & 0.59 & 0.60 & & & 0.57 & 0.58 \\
\hline 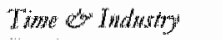 & $\mathrm{NO}$ & $\mathrm{Mes}$ & $\mathrm{NO}$ & MES & $\mathrm{NO}$ & $X \mathrm{~B}$ & $\mathrm{NO}$ & TES \\
\hline \multicolumn{9}{|l|}{ Drifisyrits } \\
\hline $10 \mathrm{~g}$ lithelihood & -3357.96 & -334203 & & & -1922.63 & -1906.80 & & \\
\hline Wrald-inest for & 3020,52 & 3103,00 & 2903.65 & 2060.07 & 165217 & 1723.93 & 1557.24 & 1633.65 \\
\hline Grouphowe leter. & $0000)$ & $(0.000)$ & $(0,000)$ & $(0.000)$ & $(0.000)$ & $(0.000)$ & $(0.000)$ & $0.000)$ \\
\hline $\begin{array}{l}\text { No. of } \\
\text { obstarations }\end{array}$ & 2033 & 2033 & 2013 & 2033 & 1195 & 1195 & 1195 & 1195 \\
\hline Variable & \multicolumn{4}{|c|}{$\begin{array}{c}\text { High Technology Gap } \\
\text { All Firms }\end{array}$} & \multicolumn{4}{|c|}{$\begin{array}{c}\text { Higl Technology Gap } \\
\text { Domestic Eirms }\end{array}$} \\
\hline & GS & $G L$ & $\begin{array}{l}\text { Remal. } \\
\text { Byo }\end{array}$ & $\begin{array}{l}\text { Rotwd } \\
\qquad \mathbb{N}\end{array}$ & GIS & $G r$ & $\begin{array}{l}\text { Rand } \\
\text { Bff }\end{array}$ & $\begin{array}{l}\text { Rant } \\
\text { Efor }\end{array}$ \\
\hline EKAIEF & 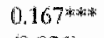 & $0.167^{2}$ & $0.163^{k+2 x}$ & $0.163^{2 x}$ & 0.174 & $0.174 * *$ & 0.16 .5 & $0.162^{*}$ \\
\hline Capitat & $(0.021)$ & $(0.021)$ & $(0.021)$ & $(0.022)$ & $(0.023)$ & $(0.023)$ & $(0,025)$ & $(0.025)$ \\
\hline LRAAI' & 0.6044 & $0.605^{5}$ & 0.608 & $0.6088^{2 x-a n}$ & $0.679^{* 24}$ & $0.682^{* * i}$ & $0.702 \%$ & $0.710^{w}$ \\
\hline Ran matatial & $(0.033)$ & $(0.033)$ & $(0.034)$ & $(0.034)$ & $(0.042)$ & $(0,042)$ & $(0.04)$ & $(0,045)$ \\
\hline WSKIIL & $0.420 \%$ & 0.42114 & (1). $22^{2}$ & 0.425 ink & 0.436 & $0.447^{*}$ & 0.434 & $0.452^{2}=$ \\
\hline Shillod hoour & $(0.042)$ & $(0,042)$ & $(0,042)$ & $(0.043)$ & $(0.054)$ & $(0.055)$ & $(0.057)$ & $(0.058)$ \\
\hline LUNSKIII & $0.466^{*}$ & $0.469^{*}$ & $0.477 \times$ & 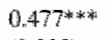 & $0.630 * \ldots$ & 0,624 & 0.661 w & $0.650^{3 * x}$ \\
\hline Unokidisd habour & $(0.038)$ & $(0.038)$ & $(0,038)$ & $(0,030)$ & $(0.055)$ & $(0.055)$ & $(0.057)$ & $(0.056)$ \\
\hline WORPS & 0.002 & 0.1004 & 0.0002 & Onolon: & 00005 & 0.005 & 8.0007 & 0.004 \\
\hline (Sector-leved) & $(0.003)$ & $(0,012)$ & (0.003) & $(0.012)$ & $0003)$ & $(0.015)$ & $(0.0018)$ & $(0.015)$ \\
\hline Cotmsat & 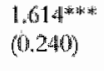 & $\begin{array}{l}4.43 \\
(0.339)\end{array}$ & $\begin{array}{l}1.66) \\
(0), 264)\end{array}$ & $\begin{array}{l}1.377^{4}+w^{2} * \\
(1.115)\end{array}$ & 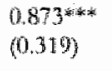 & $\begin{array}{l}0.615 * 3) \\
(0.436)\end{array}$ & $\begin{array}{l}0.782+2 \\
(0.343)\end{array}$ & $\begin{array}{l}0.666 \% \\
0.453)\end{array}$ \\
\hline R squared & & & 0.59 & 0.60 & & & 0.62 & 0.63 \\
\hline 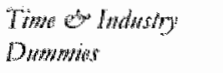 & $\mathrm{NO}$ & $\| \mathbb{S}$ & MO & $\mathrm{KJS}$ & 10 & $\mathrm{YPS}$ & $\mathrm{NO}$ & $\mathrm{WTS}$ \\
\hline Dog litkelihood & -1417.80 & -1413.63 & & & $-765,60$ & -700.25 & & \\
\hline 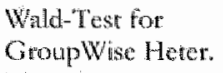 & $\begin{array}{l}1240.20 \\
(0.000)\end{array}$ & $\begin{array}{l}1271.5 .5 \\
(200009)\end{array}$ & $\begin{array}{l}1230,07 \\
(0,000)\end{array}$ & $\begin{array}{l}1237.01 \\
0.009\end{array}$ & $\begin{array}{l}807.58 \\
(0,000)\end{array}$ & $\begin{array}{l}836.87 \\
(0,0000)\end{array}$ & $\begin{array}{r}769,92 \\
(0.090)\end{array}$ & $\begin{array}{l}20030,96 \\
0,000 y\end{array}$ \\
\hline $\begin{array}{l}\text { No. ot } \\
\text { absarmatons }\end{array}$ & 849 & 849 & 849 & 840 & 476 & 470 & 476 & 476 \\
\hline
\end{tabular}

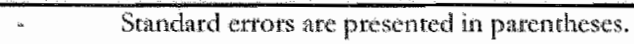

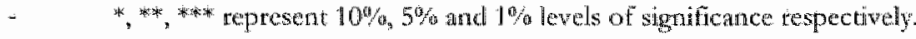


The results obtained with dummies were not statistically significant $A$ s in the above, these results supported the work and findings of the early contributors Results estimated for domestic firms in the high technology gap category with dummies included werte not significant. This supported the proponents of low technology gap for spillower to occur. Further, the estimated results with all dummies included were insignificant. This supported the work of the recent developments in the spillower literature.

\subsection{Summary and Conclusion}

The objectives of this chapter were four fold; to undertake a comparative behaviour of foreign and locally owned firms, to examine whether spillovers occurred in Kenyan manufacturing industry, to detemine the influence of scale and technological. gap in the spillover occurtence process.

The theoretical issues in this chapter draw insights from the productivity literature. Interestingly, it was shown that while studies done following early contributors usually found spillovers, those based on proponents of recent developments failed to find spillovers. For a wider set of tesults meant for comparison putposes, spillover estimations were done taking "early contributors" and 'recent developments' into consideration.

Analysis of comparative behaviour underaken for the whole manufacturing industry showed strongly that foreign firms continued to enjoy higher shares of most economic activities throughout the study period (1999-2001). However, in terms of growth rates, locally owned firms performed better than foreign firms in this period since they recorded positive growths in a number of variables while foreign firms did not. Such variables included value added, labour productivity, skilled labour and employment of $2.9,2.2,2$ and $1 \%$ respectively. This trend could be explained by economic stagnation. infrastructural and institutional failure witnessed in the 1990 s, resulting in massive restructuring by most firms - making the MNCs the hardest hit. During the same period there was a new face of emerging environments characterised by tremendous extemal pressure. Nevertheless, foreign firms continued to enjoyed high dominance in all the variables in the period 1994-2001.

Empirical analysis by mamufacturing sectom showed that only three sectors laad particularly high levels of foreign presence: food, beverages and tobacco; chemical, petroleum and plastics and machine and engineering industry. 'This implied that sectors in Kenya"s manufacturing were different with regard to distribution of foreign Eims, foreign presence, as they were concentrated in only a few sectors. Subsequently, in the three sectors with high foreign presence, foreign firms dominated in all the variables over the period 1994-2001. Howver, although foretgn firms enjoyed complete dominance in these sectors, their shares tended to decline over time. On the contrary, the shares of locally owned firms depicted a gradual but increasing trend. Annual growth rates computed showed that foreign firms appeared to decline in real terms in the period 1994-2001 while locally owned firms recorded positive growth rates. In that case, locally owned frms seemed to be catching up with the foreign furms, albeit gradually. 
Al the independent waribles used in our estimations had the expected results. The conclusions presented here will be based on foreign presence in line with the focus of the chapter. foreign participation at fitm level was observed to have a significant infuencebased on total factor productivity. These results which were consistent and robust with and without dummies implied that foreign equity participation at the firm level influenced productivity positively - suggesting productive benefits from foreign owners. Foreign presence at the sector level produced two sets of results depending on the methodological approach adopted at a point in time. Estimated results following the early contributors approach indicated spillover occutrence in the Kenyan manufacturing. However, results estimated taking the new developments into consideration produced no sign of spillovers. A similar trend was observed while spillovers were estimated taking size and technology gap into consideration. Hence, the existing divergence in the spillover literatute was witnessed in the Kenyan context - reflecting inconclusiveness of spllover analysis using productivity technigues.

Due to recent developments in spilloxer analysis we would be tempted to agree with their approach and conclude in their favour that no spillovers exist in the Kenyan manufacturing. Nevertheless, we tend to differ and argue that these results ought to be interpreted with a caution: in strict sense these results need not be interpteted to mean no effect on productivity. This could suggest that manufacturing sectors; sub sectors are different on diverse fronts; in terms of FDI presence, stucture, conduct, levels of FDI activities etc. It may be the case that sectors with negative effect or low effect due to foreign presence offsetted that of sectors with strong positive impact making the resultant effect neutral sometimes negative hence insignificant. The results of comparative behaviour indicated that FDI activities had a skewed distribution towards sectors with high foreign presence. This observation illuminates an important point in the Kenyan manufactuting industry that an ideal FDI analysis ought to be undertaken sector-wise and if possible by sub sectors while maintaining firm as the basic unit of analysis. This is further inspited by the findings of Chapter 3 which indicated that foreign firms tended to play an important role in Kenya's industrial development, and more so in specific manufacturing sectots.

Hence, before a concrete conclusion that no spillovers exist in the Kenyan context can be made, we emphasise that an altermative framework must be considered as advocated for in Chapter. 2. Total factor productivity was observed to be widely used in examining spillowers despite multiple caveats chatracterising the apptoach - some of which we were able to confirm from our analysis. A different framework as advocated for in Chapter 2 must be considered before a concrete conclusion can be drawn tegarding spillovers. We therefore emphasise that in depth analysis through interviews with the enterprises and derailled case studies would be the only approach through which a meaningful examination of spillovers can be done. This would be a great source of inspiration on our learning effort towards understanding what really happens in both foreign and local firms in the Kenyan Manufacturing. So the broad findings produced in this chapter which we regard as inconclusive serve as a necessary prelude, provide tremendous motivation that provokes further work beyond productivity technique approach - this is what we attempt to do in the subsequent chapters where spillovers are conceptualised differently in terms of tecinological learning, capabiliry building and innovation. 
Appendix 4.1: Annual Growth Rates for All Firms and Some Sellected Manufacturing Sectors, Kenyal

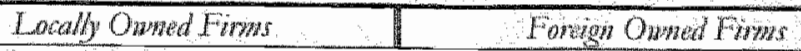

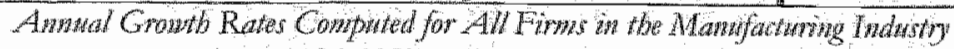

$\begin{array}{lllll}1994-1997 & 1997-2001 & 1994-2001 & 1994-1998 & 1997-2002\end{array}$

All Firms

\begin{tabular}{|c|c|c|c|c|c|c|}
\hline RMAT & -7.7 & -5.7 & -6.0 & -7.0 & -6.0 & -10.5 \\
\hline KALF & -9.7 & -3.0 & -5.7 & -16.0 & -4.5 & -9.2 \\
\hline EMPT & 0.1 & 1.7 & 1.0 & -8.4 & -1.9 & -4.6 \\
\hline SKILI & 11.5 & 1.9 & 2.0 & -1.8 & 2.1 & -1.8 \\
\hline $\mathrm{VAD}$ & 5.1 & -3.7 & 2.9 & -6.7 & -6.4 & -6.5 \\
\hline VADL & 7.7 & -5.0 & 2.2 & -10.9 & -4.0 & -5.0 \\
\hline TSALES & -1.7 & -4.6 & -2.1 & -6.8 & -6.3 & -6.2 \\
\hline EXPTS & -4.5 & -14.4 & -5.6 & -5.5 & -16.1 & -8.9 \\
\hline "TECHN & 1.9 & -8.7 & 0.8 & -6.6 & -9.7 & .7 .1 \\
\hline \multirow{2}{*}{\multicolumn{7}{|c|}{$\begin{array}{l}\text { Amnual Growth Rater Computed for Same Selected Manufactuning Sectors } \\
\text { Food, Beverages and Tobacco }\end{array}$}} \\
\hline & & & & & & \\
\hline RMAT & -9.9 & -5.5 & -7.3 & -12.0 & -3.0 & -6.8 \\
\hline KALF & -10.1 & 3.0 & -1.4 & 5.0 & -2.6 & 3.6 \\
\hline EMPT & 0.5 & 1.9 & 1.4 & 0.7 & -2.2 & -1.1 \\
\hline SKILT & 2.4 & 3.2 & 3.6 & -0.1 & -2.9 & -1.9 \\
\hline $\mathrm{VAD}$ & 3.3 & -0.9 & 2.0 & 2.2 & -0.1 & 1.1 \\
\hline$V A D I$ & -4.0 & -15.0 & -7.8 & -14.5 & -6.2 & -7.8 \\
\hline TSALES & -9.0 & -6.3 & -7.2 & -9.3 & -6.1 & -7.6 \\
\hline EXPTS & -5.9 & -10.1 & -3.3 & -11.3 & -16.7 & -11.5 \\
\hline TECHN & 0.4 & 1.0 & 0.8 & 0.2 & 0.6 & -0.5 \\
\hline \multicolumn{7}{|c|}{ Chemicals, Petroleum and Plastics } \\
\hline RNAT & -3.3 & $-5,0$ & -3.3 & -4.7 & -2.2 & -3.3 \\
\hline $\mathrm{KAIF}$ & -3.3 & -0.9 & -0.6 & -9.0 & -5.3 & -7.3 \\
\hline EMPT & -3.0 & 6.2 & 3.1 & -1.2 & 1.3 & -0.4 \\
\hline SKHLL & -3.4 & 5.1 & 6.7 & -0.2 & -4.0 & -2.8 \\
\hline $\mathrm{VAD}$ & 4.7 & 3.8 & 5.7 & 1.3 & 3.8 & 2.6 \\
\hline VADL & -16.7 & -6.1 & -11.1 & -3.4 & 0.6 & 0.6 \\
\hline TSALES & -4.7 & 4.2 & -3.6 & -7.6 & -2.8 & -5.1 \\
\hline EXPTS & 2.2 & -16.3 & -2.3 & -1.3 & -10.1 & -3.0 \\
\hline $\mathrm{HECHN}$ & 10.8 & $\mathbb{1 . 7}$ & 8.0 & 4.8 & 3.8 & 4.7 \\
\hline \multicolumn{7}{|c|}{ Machine and Engineering } \\
\hline RMAT & -6.0 & -6.2 & 0.2 & -6.9 & -8.9 & 0.9 \\
\hline KALF & -14.2 & -6.7 & 25.7 & -38.0 & -0.7 & -11.3 \\
\hline EMPT & 2.7 & -3.2 & 0.9 & -24.0 & -8.6 & -1.0 \\
\hline SKILL & 4.1 & -2.2 & 5.9 & 1.3 & -0.1 & 2.2 \\
\hline $\mathrm{VAD}$ & 3.7 & 2.4 & 5.3 & 14.2 & -8.2 & 15.9 \\
\hline VADL & 20.4 & -6.3 & 10.7 & -13.7 & -8.2 & 1.4 \\
\hline TSALES & -6.6 & -5.4 & -0.9 & -3.4 & -11.1 & -2.0 \\
\hline EXPTS & -9.0 & -14.6 & 18.9 & 10.2 & -26.2 & -0.4 \\
\hline TECHN & 3.8 & 0.4 & 4.8 & 4.3 & 1.4 & 3.4 \\
\hline
\end{tabular}

Sonec: Computed by the author from Kenyas Annual Industrial Surveg underaken by Ministry of "Thade and Industry 


\section{Chapter Five}

\section{FOREIGN PRESENCE AND TECHNOLOGICAL SPILLOVER: EXTENT; DETERMINANTS AND MODE OF OCCURRENCE}

\subsection{Introduction}

This chapter uses the analytical framework designed in Chapter 2 to examine the extent of spillower occurrence in the Kenyan marufacturing industry. The kind of spillowers occurting will be examined as well as the channels through which technological spillovers occur. A limited dependent variable estimation technique, ordered logit, is also used to investigate the determinants of spillover occurrence. The data used comes from a survey undertaken in the Kenyan manufacturing industry covering food processing and beverages, and machine and engineering industries. This chapter attempts to answer the following quiestions:

(1) To what extent do technological spillovers occur in Kenya's manufacturing industry?

(2) To what extent does the presence of foreign firms stimulate technological spillovers to local manufacin ring enterptises?

(3) What kind of technological spillovers occur most?

(4) What are the channels (modes) through which technological spillowers occur?

(5) Under what conditions do technological spillovers occur?

This chapter is organised in a number of major sections as follows: Section 5.2 presents an overview of the sample chatacteristics. Detailed descriptive anallysis of each mode of spillover occurrence in the two industries is presented. In section 5.3 , the spillover index is computed which gives an idea of the extent to which technological spilloxers in terms of technological changes; learning and capability building occur in the manufacturing industry. In section 5.4, the determinants of spillover occurrence ate examined using binary and ordered logit technique while summary and conclusions are presented in section 5.5 .

\subsection{Sample Characteristics}

The data used in this study comes from a survey undertaken in Kenya in 2003-4 covering food processing and machine engineering industries located in six most industrialised cities in Kenya". "The questionnaire used in data collection is included at the end of this thesis. The two manufacturing industries were selected on the basis of analysis done in the Chapter 3 and 4 ; that the two industries were the most dynamic in Kenya; were the most productive with the fastest growth rates; high FDI levels, value added, employment generation and contribution to the GDP.

The sample was drawn using proportionate probability sampling (PPS) sampling technique. The frame from which the sampling was drawn from was compiled from various sources. "The first list of firms was drawn from firms that are included in the monthly survey of industrial production (MSIP) conducted on a monthly basis by Central

\footnotetext{
96 For the sake of simplicity, we sometimes refer to food and beverages as just food processing sector. 97 "The survey was conducted by the author in the following cities: Nairobi, Mombasa, Nakurt, Kisurnu and Fildoter.
} 
Bureau of Statistics (CBS) in Kenya. Since this survey does not exhaust all the firms, a comparison with the firms in the "master fle" was done - whe master file is the frame maintained by CBS containing names of all the firms operating in Kenya. The National Directory of Industries (NDD prepared by the "Ministry of Trade and Industry' and the directory of firms and industries prepared by $\mathbb{K}$ eny Association of Manufacturers were also consulted.

From an initial sample of 250 firms selected for this survey (125 for each industry) about 183 firms were successfully surveyed. This represented approximately $73 \%$ retrieval rate of the toral firms initially sampled ${ }^{39}$. Nevertheless, information from 3 firms was tejected for incomplete information provided leaving 180 firms for this analysis. According to the breakdown provided in Table 5.1, there were 78 foreign firms, which accounted for $43.3 \%$ of the total firms considered for this analysis and 102 local firms, which accounted for $56.7 \%$. Note here that as in Chapter 4, a firm was defined as foreign owned if it had foreign ownership of nominal capital (equity) of at least $10 \% \%^{100}$ otherwise the firm is taken as a locally owned firm. Similarly from International Fund (IMH) point of wiew, a significant impact to a host industry/economy is possible when the foreign investor holds a share of at least $10 \%$ of the nominal capital (IMF, 1993,86F) ${ }^{101}$.

The term foreign firm was preferred as opposed to MNCs or TNCs. This was as a result of many cases identified of foreign firms in Kenya which could neither be classified as MNCs not TNCs as they did not have foreign affiliates abroad but 'stood alone'. In the food processing industry there were 14 "stand alone' foreign firms which accounted for $28 \%$ of the total foreign firms in food processing industry while there were 9 'stand alone' foteign firms in machine and engineering industry accounting for $32.1 \%$ of the total foreign firms in machine and engineering industry. The analysis sample included $105(58.3 \%)$ food-processing firms and $75(41.7 \%)$ machine and engineering firms. Classification by firm ownership shows that foreign firms in food processing accounted for $48 \%$ of the total food processing firms while locally owned firms accounted for 52 $\%$. In the machine and engineering industry, foreign and local firms accounted for $37 \%$ and $63 \%$ respectively of the total firms in machine engineering and industry, Table 5.1 . The data collected was representative; both foreign and local firms accounted for well over $50 \%$ of manufacturing production for both sectors (interms of output sales) and employment hence the results obtained would enable a policy-tellevant assessment.

\footnotetext{
MB I am grateful to Central Bureau of Statistics (CBS), Department of Company Registation and Kenya Association of Manufacturers for allowing me access to their firm directories.

This survey was a success following the logisticall and technical support from Central Bureau of Statistics, Kerrya.

167 This is the benchmark wsed by the Kenyan national authoritics as well as OECD, non-OECD transition conomies as well as UNCTAD.

101 For more information see IMF (1993), Balance of Payments Manual. Fifth Edition. Washington: International Monetary fund.
} 


\begin{tabular}{lrll}
\hline Fim Trpe & $\begin{array}{l}\text { Food Processing } \\
\text { and Beverages }\end{array}$ & $\begin{array}{l}\text { Machine and } \\
\text { Engineering }\end{array}$ & Total \\
Local Fims & $55(52.0 \%)$ & $47(63.0 \%)$ & $102(56.7 \%)$ \\
Foreign Fims & $50(48.0 \%)$ & $28(37.0 \%)$ & $78(43.3 \%)$ \\
Total & $\mathbf{1 0 5 ( 5 8 . 3 \% )}$ & $\mathbf{7 5 ( 4 1 . 7 \% )}$ & $\mathbf{1 8 0 ( 1 0 0 . 0 )}$ \\
\hline
\end{tabular}

Sontre: Tabulated from authox's field survey $(2003 / 2004)$.

In the conceptial framework presented in Chapter 2, four mechanisms/chanmels of spillover occurrence were identifed, which included competition, linkage, labour mobility and demonstration. In the next section, we present a brief descriptive analysis for each of these channels. However, in doing so the discussion is restricted to the relationships with local firms, joint ventures and wholly owned foreign firms. To reduce the Bulk of descriptive wottk in this section, this is done by firm ownership. However analysis by industry (food processing and beverages and machine and engineering) and Firm ownership has been presented in the appendix in a tabular form, see Appendix 5.1a; $5.1 \mathrm{~b}, 5.2,5.3$ and 5.4 .

\subsubsection{Labour Mobility in Food and Beverages and Machine and Engineering Industries}

Labour mobility is one of the channels through which spillovers can occur between and among firms ${ }^{102}$. Labour mobility is an extremely difficult thing to determine empirically since firms hardly maintain databases on wotkers movement. Firms did not keep record of where staff joined from or where they left to join. In order to investigate labour mobility at firm level and at the same time examine occurrence of spillovers through labout mobility, both workers hast to orher forms and employed frow other forms, are considered. "The firms were asked whether" they had lost any of their workers to other firms in the past and if they could identify the kind of firms they went to join. Since firms were at least expected to have lost at least some of their workers in their lifetime, they were specifically asked whether the caliber of workers lost to other firms included some of their skilled and technically trained workers (such as professionals and managers, and/or technicians, engineers and scientists). This was of particular importance to us since this category of employees is believed to comprise skilled personnel who have acquired skils from their firm by participating on job training or through experience at work. This makes them acquire experiential tacit knowledge and thus their mobility is likely to result in occurrence of knowledge spillover to the firms which they leave to join. The Kind of firms they went to join wete classified into three; wholly owned foreign firms, joint venture firms and local firms. $A$ fouth category of firms emerged during the survey, own firms, where workers left their employment to start their own firms ${ }^{103}$. Table 5.2 presents

\footnotetext{
10: Labour mobility as one of the channels through which spillovers can occur has been examined in several studies [Caves, 1972; Dunning, (1993: p. 372]; Rajah, 1995; Blomstrom and KKokko, 1997; Gershenberg, 1987; Katz, 1987; Wasow and Hill, 1986; Yoshihata, 1988; Behman and wallender, 1976; Hill 1982.

10 During the survey it was noted that workers from both local and foreign firms had left their employment to join own firms. However, as discussions with workers revealed these would have been more but lack of financial assistance is an obstacle.
} 
descriptixe statistics of workers lost to other firms by ownexship. Descriptive statistics by ownership and industry are presented in Appendix 5.1a:

Analysis of workers lost to other fims by ownershp showed that both local and foreign frrms lost skilled and technically trained wotkers to other firms within the manufactuning industry. A high proportion of firms in both local $(62.7 \%)$ and foreign firms $(80.5 \%)$ had lost some of their skilled workers to the locally owned firms. Based on the reported cases for the caliber of workers lost, foreign firms seemed to be losing more skilled workers than domestic frms do. Comparing the calibre of workers lost, both locally owned and foreign firms seemed to lose more engineers and technichans than the professionals and managers $^{\text {i0t4 }}$. Table 5.2. Interestingly, there was a high proportion of skilled and technically trained workers leaving foreign firms $(52.6 \%)$ to start their own firms than was the case with the local firms $(12.7 \%$ ). This indicates that in addition to local firms, foreign firms in Kenya's manufacturing industry also act substantially as a breeding ground for local entrepreneurs. This is similar to what was noted in Saggi (1999, pp. 23 4) where some of the workers employed by Desh left after obtaining technological training to set up their own firms.

Similat to the above, the firms were also asked whether they had employed workers from other firms in the past, their skill level and the kind of firms they came from. Table 5.2 presents descriptive statistics of workers employed from other firms by ownership. Generally, high proportions of both local and foreign firms had employed skilled and technically trained wotkets from other firms in the past. Skilled workers here is used to represent managers and professionals; skilled scientists and engineers; technicians, craftsmen and attisans as shown in Table 5.2. As noted from the computed proportions, there were more cases of local firms teceiving skilled workers from other firms (local fitms) than they lost them (skilled warkers) As expected there were high cases of skilled workers joining local firms from local firms than local firms losing to local firms. Interestingly there were high cases of skilled workers joining locall fitms from wholly owned foreign and JV firms than they had lost to them. Comparing the percentages of local and foreign firms; more foreign firms received workers wholly owned foreign firms, JV and locally owned firms than local furms did. A more or less the same percentage of foreign firms that reported losing skilled workers to local firms $(88.5 \%)$ reported getting workers from local firms $(89.7 \%)$. The implication here is that there is an equal gain and lose of workers between local and foreign firms. The proportions computed indicated that foreign firms were employing mote managers and professionals $(51 \%)$ than they were losing ( $32 \%$ ). Since the skills required might not be awailable from the local firms, such could only come from wholly owned foreign fitms and joint fitms and that is why the two categories reported high proportion levels $53.8^{1 \%}$ and $47.4^{0 / 5}$ respectively. Lower caliber engineers would then have to come from local firms. This supports the atgument that low waged labour exists in this kind of countries. As a conclusion to this section we note that mobility of skilled workers exists in Kenya's manufacturing industry and thus spillovers ate likely to occur.

\footnotetext{
whas This based on the firm tesponses and gives an iden of what is happening. It is possible to hawe a few cases of firms responding but wht more workers involwed in the mobility - this was however imposwible to rell as firms did not teep information which would have enabled us to make a concrete assessment.
} 
Table 5.2: Labour Mobility Hood Processing and Bewerages, and Machine and Engincering Industries, Kenya, 2004

Labour Mobillity: Analysis of workers lost by Ownership

\begin{tabular}{|c|c|c|c|c|c|}
\hline $\begin{array}{l}\text { Jocal } \\
\text { Jirms }\end{array}$ & $\begin{array}{l}\text { Number of } \\
\text { cases }\end{array}$ & $\begin{array}{l}\text { Caliber of } \\
\text { workers lost }\end{array}$ & $\begin{array}{l}\text { Number of } \\
\text { cases }\end{array}$ & $\begin{array}{l}\text { Workers lost to } \\
\text { other firms }\end{array}$ & $\begin{array}{l}\text { Number } \\
\text { of cases }\end{array}$ \\
\hline \multirow{4}{*}{$\begin{array}{l}\text { Lost } \\
\text { workers to } \\
\text { other fitms }\end{array}$} & \multirow[t]{4}{*}{$\begin{array}{l}71 \\
(69.6 \%)\end{array}$} & $\begin{array}{l}\text { Managers and } \\
\text { professionals }\end{array}$ & $\begin{array}{l}21 \\
(20.6 \%) \\
\end{array}$ & $\begin{array}{l}\text { Wholly owned } \\
\text { Foreign firms }\end{array}$ & 8 \\
\hline & & \multirow[t]{3}{*}{$\begin{array}{l}\text { Fingineers and } \\
\text { rechnicians }\end{array}$} & \multirow[t]{3}{*}{$\begin{array}{l}58 \\
(56.9 \%)\end{array}$} & Joint Ventures & $98 \%$ \\
\hline & & & & Local firms & $\begin{array}{l}64 \\
(62.7 \% \%)\end{array}$ \\
\hline & & & & Start own firms & $\begin{array}{l}13 \\
(12.7 \%) \\
\end{array}$ \\
\hline $\begin{array}{l}\text { Foreign } \\
\text { Finms }\end{array}$ & $\begin{array}{l}\text { Number of } \\
\text { cases }\end{array}$ & $\begin{array}{l}\text { Caliber of } \\
\text { workers lost }\end{array}$ & $\begin{array}{l}\text { Number of } \\
\text { cases }\end{array}$ & $\begin{array}{l}\text { Workers lost to } \\
\text { other firms }\end{array}$ & $\begin{array}{l}\text { Number } \\
\text { of cases }\end{array}$ \\
\hline \multirow{4}{*}{$\begin{array}{l}\text { Lost } \\
\text { workets to } \\
\text { other fitms }\end{array}$} & \multirow[t]{4}{*}{$\begin{array}{l}72 \\
(92.3 \%)\end{array}$} & $\begin{array}{l}\text { Managers and } \\
\text { professionals }\end{array}$ & \begin{tabular}{|l|}
25 \\
$(32.1 \%)$ \\
\end{tabular} & $\begin{array}{l}\text { Wholly owned } \\
\text { Foreign firms }\end{array}$ & $\begin{array}{l}20 \\
(25.6 \%) \\
\end{array}$ \\
\hline & & \multirow[t]{3}{*}{$\begin{array}{l}\text { Fngineers and } \\
\text { technicians }\end{array}$} & \multirow[t]{3}{*}{$\begin{array}{l}64 \\
(81.1 \%)\end{array}$} & Joint Ventures & $\begin{array}{l}30 \\
(38.5 \%)\end{array}$ \\
\hline & & & & Local firms & $\begin{array}{l}69 \\
(88.5 \%) \\
\end{array}$ \\
\hline & & & & Start own firms & $\begin{array}{l}41 \\
(52.6 \%) \\
\end{array}$ \\
\hline \multicolumn{6}{|c|}{ Labour Mobility: Analysis of workers employed by Ownership } \\
\hline $\begin{array}{l}\text { Local } \\
\text { Firms } \\
\end{array}$ & $\begin{array}{l}\text { Number of } \\
\text { cases }\end{array}$ & $\begin{array}{l}\text { Caliber of } \\
\text { workers employed }\end{array}$ & \begin{tabular}{|l|}
$\begin{array}{l}\text { Nurnber of } \\
\text { cases }\end{array}$ \\
\end{tabular} & $\begin{array}{l}\text { W/orkers } \\
\text { employed from }\end{array}$ & $\begin{array}{l}\text { Number } \\
\text { of cases }\end{array}$ \\
\hline \multirow{4}{*}{$\begin{array}{l}\text { Employed } \\
\text { workers } \\
\text { from other } \\
\text { firms }\end{array}$} & \multirow[t]{4}{*}{$\begin{array}{l}93 \\
91.2 \%\end{array}$} & $\begin{array}{l}\text { Managers and } \\
\text { professionalls }\end{array}$ & \begin{tabular}{|l|}
36 \\
$(35.3 \%)$ \\
\end{tabular} & $\begin{array}{l}\text { Wholly owned } \\
\text { Foreign firms }\end{array}$ & $\begin{array}{l}21 \\
(20.6 \%) \\
\end{array}$ \\
\hline & & $\begin{array}{l}\text { Skilled scientists } \\
\text { \& engineers }\end{array}$ & $\begin{array}{l}18 \\
(17.6 \%)\end{array}$ & Joint Ventures & $\begin{array}{l}30 \\
(29.4 \%)\end{array}$ \\
\hline & & $\begin{array}{l}\text { Technicinss, } \\
\text { craftsmen \& } \\
\text { artisans }\end{array}$ & $\begin{array}{l}69 \\
(67.6 \%)\end{array}$ & Local fitms & $\begin{array}{l}88 \\
(86.3 \%)\end{array}$ \\
\hline & & Others & $\begin{array}{l}3 \\
(2.9 \%)\end{array}$ & Others & - \\
\hline $\begin{array}{l}\text { Foneign } \\
\text { Finms }\end{array}$ & $\begin{array}{l}\text { Number of } \\
\text { cases }\end{array}$ & $\begin{array}{l}\text { Caliber of } \\
\text { workers employed }\end{array}$ & $\begin{array}{l}\text { Number of } \\
\text { cases }\end{array}$ & $\begin{array}{l}\text { Workers } \\
\text { employed from } \\
\text { other firms }\end{array}$ & $\begin{array}{l}\text { Number } \\
\text { of cases }\end{array}$ \\
\hline \multirow{4}{*}{$\begin{array}{l}\text { Employed } \\
\text { workers } \\
\text { from other } \\
\text { firms }\end{array}$} & \multirow[t]{4}{*}{$\begin{array}{l}76 \\
(97.4 \%)\end{array}$} & $\begin{array}{l}\text { Managers and } \\
\text { professionals }\end{array}$ & \begin{tabular}{|l|}
52 \\
$(51.0 \%)$ \\
\end{tabular} & $\begin{array}{l}\text { Wholly owned } \\
\text { Foreign firms }\end{array}$ & $\begin{array}{l}42 \\
(53.8 \%)\end{array}$ \\
\hline & & $\begin{array}{l}\text { Skilled scientists } \\
\text { \& engineers }\end{array}$ & $\begin{array}{l}31 \\
(39.7 \%)\end{array}$ & Joint Ventures & $\begin{array}{l}37 \\
(47.4 \%)\end{array}$ \\
\hline & & $\begin{array}{l}\text { "Technicians, } \\
\text { ctaltsmen } \& \\
\text { attisans }\end{array}$ & $\begin{array}{l}62 \\
(79.5 \%)\end{array}$ & Local firms & $\begin{array}{l}70 \\
(89.7 \%)\end{array}$ \\
\hline & & Others & $\begin{array}{l}2 \\
(2.6 \%)\end{array}$ & Orhers & - \\
\hline
\end{tabular}

Source: Tibulated from author's field survey $2003 / 2004$

lus Note that the figures in the table represent cases observed by firm and are therefore not supposed to add up to $100^{0 \%}$. 


\subsubsection{Linkages in Food and Beverages and Machine and Engineering Industries}

The firms were asked if they maintained any form of backward and forward linkages with other fims in the manufacturing industry. Given the weat nature or non-existence of technological linkages (non-pecuniary linkages) in developing countries especially with R\&D institutions this study conceptualised linkages in a wder form to include both pecuniary and non-pecuniary linkages. Backwatd linkage included relationships with suppliers of raw materials, technical support and other services, machinery and equipment etc while forward linakge included relationships with buyers, distributors among others. Broad consideration of linkages ensured that some kind of relationship would definitely be captured since even in the most backward of the developing countries there exists at least some form of linkage formation. The firms were also asked to explain the kind of firms they had their linkages with. Table 5.3 shows the distribution of linkage formation by ownership based on the survey done.

As expected both locally owned and foreign firms had high proportions (over $95 \%$ in both cases) of firms with both backward and forwatd linkages with other firms in the manufacturing industry. Similarly, over $80 \%$ of both locally owned and foreign firms had either backward or forward linkages formed with locally owned fims, Table 5.3. Although locally owned firms had a relatively high proportion of firms with both backward and forward linkages with wholly owned foreign and JVs firms, interestingly, there were mote cases of local firms with backward linkages with wholly owned foreign and JVs firms than was the case with forward linkages. This was not surprising since locally owned firms relied on foreign firms and joint venture firms for machinery and equipment, sophisticated maintenance services, consultancy, some taw materials etc. For instance all the locally owned dairy firms relied on Tetra Pack International, a MNC from Sweden for their tetra pack containers to package milk. This is unsurprising since foreign firms were actually the main suppliers of machinery and equipment, technical services needed to support ptoduct and process technologies. Similarly the example of many soft drink firms relying on Coca Cola for technical support in product. Although a similat: trend was noted with foteign firms, a comparison between foreign and local fitms shows that foreign firms had higher proportions of relationships with foreign firms and joint ventures than was the case with local firms. This tends to support argument that for specinlised services, foreign firms would tend to relate with wholly owned foreign and JWs firms more than local firms did. This is expected as foreign firms and joint ventures tend to be more technically adwanced and with highly skilled workforce. Foreign firms tended to develop forward linkages mote with wholly owned foreign and JVs firms than local firms. Descriptive statistics by ownership and industry is presented in Appendix 5.2 . 
Table 5.3: Linkage Effects: Food Processing and Beverages, and Machine and Engineering Industries, Kenya, 2004

\begin{tabular}{|c|c|c|c|}
\hline Locall Finms & $\begin{array}{l}\text { Number of } \\
\text { cuases }\end{array}$ & Kind of frims & $\begin{array}{l}\text { Number of } \\
\text { cases }\end{array}$ \\
\hline \multirow[t]{3}{*}{ With backward linkage } & \multirow[t]{3}{*}{$\begin{array}{l}100 \\
(98.0 \%)\end{array}$} & Wholly owned Foreign firms & $\begin{array}{l}42 \\
(41.2 \%)\end{array}$ \\
\hline & & Joint Ventures & $\begin{array}{l}29 \\
(28.4 \%)\end{array}$ \\
\hline & & Local fums & $\begin{array}{l}87 \\
(82.3 \%)\end{array}$ \\
\hline \multirow[t]{3}{*}{ Win forward linkage } & \multirow[t]{3}{*}{98} & Wholly owned Foreign firms & $\begin{array}{l}30 \\
(29.4 \%)\end{array}$ \\
\hline & & Joint Ventures & $\begin{array}{l}18 \\
(17.6 \%)\end{array}$ \\
\hline & & Local firms & $\begin{array}{l}94 \\
(92.2 \%) \\
\end{array}$ \\
\hline Foreign Firms & $\begin{array}{l}\text { Number of } \\
\text { cases }\end{array}$ & Kind of firms & $\begin{array}{l}\text { Number of } \\
\text { cases }\end{array}$ \\
\hline \multirow[t]{3}{*}{ With backward linkage } & \multirow[t]{3}{*}{$\begin{array}{l}78 \\
\left(100^{\circ} \%\right)\end{array}$} & Wholly owned Foreign firms & $\begin{array}{l}60 \\
(76.9 \%)\end{array}$ \\
\hline & & Joint Ventures & $\begin{array}{l}46 \\
(59.0 \%)\end{array}$ \\
\hline & & Local firms & $\begin{array}{l}74 \\
(94.9 \%)\end{array}$ \\
\hline \multirow[t]{3}{*}{ With forward linkage } & \multirow[t]{3}{*}{$\begin{array}{l}77 \\
(98,7 \%)\end{array}$} & Wholly owned Foreign firms & $\begin{array}{l}49 \\
(62.8 \%)\end{array}$ \\
\hline & & Joint Ventures & $\begin{array}{l}31 \\
(39.7 \%)\end{array}$ \\
\hline & & Local firms & $\begin{array}{l}74 \\
(94.9)\end{array}$ \\
\hline
\end{tabular}

Source: Tabulated from author's ficld survey $2003 / 2004$

\subsubsection{Competition in Food and Beverages and Machine and Engineering Industries}

The tirms were asked to tate the competition they faced from competing firms domestically. The firms were also asked to identify who their competitors were in terms of tirm ownership. Table 5.4 presents the description of competition intensity, rated in an ordinal form from "none" to "very stiff" competition. A high proportion of both local and foreign firms faced stiff competition $(42.2 \%)$ and $(55.1 \%)$ respectively. This was an indication that stiff competition existed in the two industries considered. Moteover, a high proportion of local firms $(36.3 \%)$ faced very stiff competition compared to that of the foreign firms (17.9\%). It can be argued that this stiff competition could be emanating from the foreign firms. There are also imports from South Africa and other COMESA regions. In addition to local firms facing competition from other local firms, it was observed that wholly owned foreign and JV firms similarly competed with the local firms. Over $25 \%$ of the local firms reported to have had competition from either foreign or joint venture firms. High proportions of foreign. firms had wholly owned foreign and IV firms as their competitors. This tended to indicate that a high proportion of foreign firms aced competition from wholly owned foreign firms $(50 \%)$ and JV firms $(50 \%)$ than local firms did from wholly owned foreign firms (25.5\%) and JV firms $(27.5 \%)$. Some of the managers interviewed contended that it would take the country some time 
before the locally owned firms could effectively compete with forelgn farms $\|$ an $W$ Hal

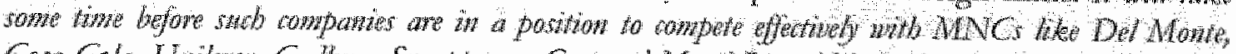

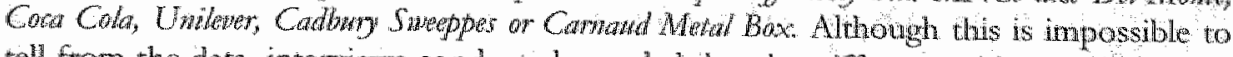
tell from the data, interviews conducted tevealed that the stiff competition conda be as a result of the foreign firms. Descriptive statistics by ownership and industry is presented in Appendix 5.3 .

Table 5.4: Competition Effects: Food Processing and Beverages, and Machine and Engineering Industries, Kenya, 2004

\begin{tabular}{|c|c|c|c|}
\hline \multicolumn{4}{|c|}{ Jocal Firms } \\
\hline Compention rating & Number of cases & Competion by kind of firm & Number of casies \\
\hline None & $\begin{array}{l}3 \\
(2.90 / 0)\end{array}$ & Wholly owned Foreign firms & $\begin{array}{l}26 \\
(25.5 \%)\end{array}$ \\
\hline Moderate & $\begin{array}{l}19 \\
(18.6 \%)\end{array}$ & Joint Ventures & $\begin{array}{l}28 \\
(27.5 \%)\end{array}$ \\
\hline Stift & $\begin{array}{l}43 \\
(42.2 \%)\end{array}$ & Local fitms & $\begin{array}{l}98 \\
(96.1 \%)\end{array}$ \\
\hline Very stiff & $\begin{array}{l}37 \\
(36.3 \%)\end{array}$ & Others & 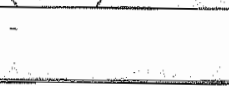 \\
\hline \multicolumn{4}{|l|}{ Foteign Firms } \\
\hline Competition rating & Number of cases & Competitor by kind of firm & Number of cases \\
\hline None & 0 & Wholly owned Foreign firms & $\begin{array}{l}39 \\
(50.0 \%)\end{array}$ \\
\hline Moderate & $\begin{array}{l}21 \\
(26.9 \%)\end{array}$ & Joint Ventures & $\begin{array}{l}39 \\
(50.0 \%)\end{array}$ \\
\hline Stiff & $\begin{array}{l}43 \\
(55.1 \%)\end{array}$ & Local firms & $\begin{array}{l}77 \\
(98.7 \%)\end{array}$ \\
\hline Very suiff & $\begin{array}{l}14 \\
(17.9 \%)\end{array}$ & Others & - \\
\hline
\end{tabular}

Source: Tabulated from anthor's field survey $2003 / 2004$

\subsubsection{Demonstration Effects in Food and Beverages and Machine and Engineering Industries}

Similar to the above cases, the firms were asked if they had ever introduced ot adopted new products and new techniques observed from other companies in Kenya's manufacturing industry. Such techniques included ptoduction techniques, management. and organisation techniques, marketing techniques and strategies.. The firms were also asked if they were indeed able to make similar but own products. About 78 (76.5\%) locally owned firms were able to make similat but new products while $74(94.9 \%)$ foreign firms were able to make similat but own products. The firms were also asked to idencify the kind of firms they enjoyed demonstration effects from. The choice was made from their competing firms, ordinaty firms, supplying firms, processing firms that buy their products and marketing firms that distribute their products. Table 5.5 shows the distribution of firms with regatd to demonstration effect, nature of firms and kind of firms from which demonstration effect occurred. Although both locally owned and foreign firms had substantially high proportions of demonstration effects, foreign firms had a bigher proportion of firms with demonstration effects than the local firms. This would be expected given their capacity (firm financial resoutces and human capital) to do 
that as they are technically advanced and can employ skilled wotkers more than the local firms. For both local $(64.7 \%$ ) and foreign firms $(79.5 \%$, most of the demonstration effects seemed to come from competing firms. This further shows influence of compettion. There was a high proportion of foreign firms $(52.6 \%)$ with demonstration effects from processing firms than was the case with local firms (13.7\%). As expected both local and foreign firms had their highest demonstration effects from local firms. This is expected as locally owned firms are the majority in the manufacturing industry. About $28 \%$ of the local firms had demonstration effects from either wholly owned foreign and JV firms while about $67.9 \%$ and $43.6 \%$ of foreign firms had demonstration effects from wholly owned foreign firms and JV firms respectively. The conclusion here is that demonstration effect exists and hence technological spillovers. Descriptive statistics by ownershp and industry is presented in Appendix 5.4 .

Table 5.5: Demonstration Effects: Food Processing and Beverages, and Machine and Engineering Industries, Kenya, 2004

\begin{tabular}{|c|c|c|c|c|c|}
\hline $\begin{array}{l}\text { Local } \\
\text { Firms }\end{array}$ & $\begin{array}{l}\text { Number of } \\
\text { cases }\end{array}$ & $\begin{array}{l}\text { Nature of } \\
\text { firms }\end{array}$ & $\begin{array}{l}\text { Number of } \\
\text { cases }\end{array}$ & Kind of firms & $\begin{array}{l}\text { Number of } \\
\text { cases }\end{array}$ \\
\hline \multirow{5}{*}{$\begin{array}{l}\text { With } \\
\text { dernonstration } \\
\text { effect }\end{array}$} & \multirow[t]{5}{*}{$\begin{array}{l}78 \\
(76.5 \%)\end{array}$} & $\begin{array}{l}\text { Compering } \\
\text { firms }\end{array}$ & $\begin{array}{l}66 \\
(64.7 \%)\end{array}$ & $\begin{array}{l}\text { Wholly owned } \\
\text { Foreign furms }\end{array}$ & $\begin{array}{l}28 \\
(27.5 \%)\end{array}$ \\
\hline & & $\begin{array}{l}\text { Ordinary } \\
\text { firms }\end{array}$ & $\begin{array}{l}17 \\
(16.7 \%)\end{array}$ & Joint Ventures & 28 \\
\hline & & $\begin{array}{l}\text { Supplying } \\
\text { firms }\end{array}$ & $\begin{array}{l}17 \\
(16.70 \%)\end{array}$ & Local firms & $\begin{array}{l}71 \\
(69.6 \%)\end{array}$ \\
\hline & & $\begin{array}{l}\text { Processing } \\
\text { firms }\end{array}$ & $\begin{array}{l}14 \\
(13.7 \%)\end{array}$ & Others & - \\
\hline & & $\begin{array}{l}\text { Distributing } \\
\text { firms }\end{array}$ & $\begin{array}{l}6 \\
(5.9 \%)\end{array}$ & & \\
\hline $\begin{array}{l}\text { Foreign } \\
\text { Firms }\end{array}$ & $\begin{array}{l}\text { Number of } \\
\text { cases }\end{array}$ & $\begin{array}{l}\text { Nature of } \\
\text { firms }\end{array}$ & $\begin{array}{l}\text { Number of } \\
\text { Cases }\end{array}$ & Kind of firms & $\begin{array}{l}\text { Number of } \\
\text { cases }\end{array}$ \\
\hline \multirow{5}{*}{$\begin{array}{l}\text { With } \\
\text { demonstitation } \\
\text { effect }\end{array}$} & \multirow[t]{5}{*}{$\begin{array}{l}74 \\
(94.9 \%)\end{array}$} & $\begin{array}{l}\text { Competing } \\
\text { firms }\end{array}$ & $\begin{array}{l}62 \\
(79.5 \%)\end{array}$ & $\begin{array}{l}\text { Wholly owned } \\
\text { Foreign firms }\end{array}$ & $\begin{array}{l}53 \\
\left(67.9^{\circ} \%\right)\end{array}$ \\
\hline & & $\begin{array}{l}\text { Ordinary } \\
\text { firms }\end{array}$ & $\begin{array}{l}27 \\
(34.6 \%)\end{array}$ & Joint Ventures & $\begin{array}{l}34 \\
(43.6 \%)\end{array}$ \\
\hline & & $\begin{array}{l}\text { Supplying } \\
\text { firms }\end{array}$ & $\begin{array}{l}27 \\
(34.6 \%)\end{array}$ & Local firms & $\begin{array}{l}60 \\
(76.9 \%)\end{array}$ \\
\hline & & $\begin{array}{l}\text { Processing } \\
\text { firms }\end{array}$ & $\begin{array}{l}41 \\
(52.6 \%)\end{array}$ & Others & - \\
\hline & & $\begin{array}{l}\text { Distributing } \\
\text { tirms }\end{array}$ & $\begin{array}{l}11 \\
(14.1 \% \%)\end{array}$ & & \\
\hline
\end{tabular}

Source: Tabulated from anthor's field survey $2003 / 2004$

\subsection{Occurrence of Technologicall Spillovers: Technological Spillover Index}

The rechnological spillover index computed here attempts to quantify firm level technological behaviour based on information collected from survey interviews undertaken in the Kenyan manufacturing industry - restricted to food and beverages, and machine and engineering industries. This section uses the methodology developed in Chapter 2 and briefly" repeated below to guide the computation of the spillover index, SPO INDEX, as a simple arithmetic mean. Since "knowledge effects" of spillovers are impossible to quantify and measure them, spillovers were conceptualised in terms of technological changes taking place in the firms. Firms were relied on to provide 
information on what technological changes were taking place, what the catises of these changes were and how they were undertaking these changes, Four nodes of spillower accurtence wete considered for this study: competition, linkage, labour noblity and demonstration effects (see Table 5.6).

Table 5.6: Computation of Technological Spillover Index, SPO MNDEX

\begin{tabular}{|c|c|c|c|c|c|}
\hline $\begin{array}{c}\text { Spillower } \\
\text { Conceptualisation }\end{array}$ & $\begin{array}{l}\text { Competition } \\
\text { (c) }\end{array}$ & $\begin{array}{c}\text { Linkage } \\
\text { (1) }\end{array}$ & $\begin{array}{l}\text { Labour } \\
\text { Mobility } \\
\text { (m) }\end{array}$ & $\begin{array}{l}\text { Demonstration } \\
\text { (d) }\end{array}$ & $\begin{array}{l}\text { Average } \\
\text { Scote }\end{array}$ \\
\hline $\begin{array}{c}\text { Product Changes } \\
(\mathrm{Pd})\end{array}$ & $\mathrm{Pd}_{\mathfrak{c}}$ & $\mathrm{Pd}_{\mathrm{l}}$ & $\mathrm{Pd}_{\mathrm{in}}$ & $\mathrm{pd}_{\mathrm{d}}$ & PD \\
\hline $\begin{array}{c}\text { Process Changes } \\
(\mathbf{P r})\end{array}$ & $p_{\mathbf{r}_{6}}$ & $\mathrm{Pr}_{\mathbf{r}_{1}}$ & $\mathrm{Pr}_{\mathrm{rnR}}$ & $\mathrm{Pr}_{\mathrm{ri}}$ & $\mathbf{P R}$ \\
\hline $\begin{array}{c}\text { Repair \& Mantenance } \\
(\mathbf{R m})\end{array}$ & $\mathrm{Rm}_{c}$ & Rny & $\mathrm{Rm}_{c}$ & Rund & $\mathbf{R M}$ \\
\hline $\begin{array}{c}\text { Mrrketing Strategy } \\
(M \mathrm{~s})\end{array}$ & $\mathrm{Ms}_{c}$ & $M s_{1}$ & $\mathrm{Ms}_{\mathrm{m}}$ & $\mathrm{Ms}_{\mathrm{d}}$ & MS \\
\hline $\begin{array}{l}\text { Mamagement \& } \\
\text { Organisation } \\
\text { (Mo) }\end{array}$ & $\mathrm{Mo}_{\mathrm{c}}$ & $\mathrm{Mol}$ & $\mathrm{MO}_{\mathrm{m}}$ & Mod & MO \\
\hline $\begin{array}{l}\text { Awerage } \\
\text { Scote }\end{array}$ & $\mathrm{C}$ & L & $\mathbf{M}$ & $\mathrm{D}$ & $\begin{array}{c}\text { SPO } \\
\text { INDEX }\end{array}$ \\
\hline
\end{tabular}

Soure: Author $2003 / 2004$

Spillover index is estimated for of all the four modes of spillower occurtence shown in the table, competition $C$, linkage $L$, labour mobility $\boldsymbol{M}$ and demonstration $\boldsymbol{D}$. The spillover index is computed for each one of these modes using equation:

$$
\text { SPO INDEX } X_{\text {finm-levet }}=\text { Composite Average }(C, L, M, D)
$$

Similar results of the SPO INDEX can be computed by column average using the following equation.

$$
\text { SPO INDEX, firm-level }=\text { Composite Average }(P D, P R, R M, M S, M O) 5.2
$$

The spillover index for the whole mamfacturing industry can then be computed from any of the two equations above as sample's arithmetic mean. As an example using the equation 5.2 we have:

SPO INDEX Isthstry-lewt $=1 / N \sum_{i=1}^{N}\{$ Composite Average $(P D, P R, R M, M S, M O)\}$

Where $N$ is the sample size, equal is to 180 in this case.

The SPO INDEX will assume an ondered framework tanging between 0 and 5 on a Likert scale as follows:

SPO INDEX $=0, \quad 1$,

2. 


\subsubsection{Occurrence of Technological Spillovers in the Manufacturing Industry}

Employing the abowe framework, the spillover index for the Kenyan manufacturing indastry is computed in this section. The first spillover index computed indicates the extent of spillover occurrence in food processing and beverages, and machine and engineering industries combined, Table 5.7. Since one of the aims of the study is to determine to what extent spillovers occurted in the local firms from foreign firms, spillower indexes for spilloves occurrence specifically in locally owned firms from foreign and local furms separately were computed, Table 5.8. In addition to the spillover indexes computed for the two industries pooled, spillover indexes were also computed for each industry separately, which enabled us to compare the two industries in terms of spillover occurrence, section 5.3 .2 .

\section{(i) Spillover Ocoumene in Food and Mabine and Enginering Industries - pooled}

Table 5.7 provides the results of spillover index computed for food processing and beverages, and machine and engineering industries combined. The computed spillover

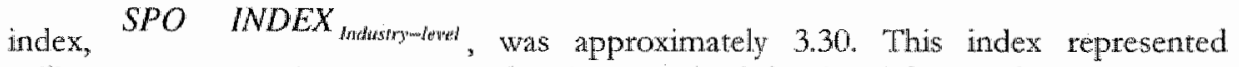
spillover occurrence into the two industries from both local and foreign firms. Based on the ordinal framework developed, with a range from 0 "None" to 5 "Highest", the spillover index computed for the two industries combined indicated an "average" spillover occurrence. Despite the different conceptual setting and methodology used in this study, with spillovers conceptualised in terms of learning and capability building, the results obtained shows that technological spillovers do occur in Kenya's manufacturing industry.

Although following different approaches, ont results compare to those obtained in other studies, which have found FDI spillover occurrence in developed and deweloping countries. Contrary to the approach adopted in this study, their studies use a production framework to examine the impact of FDI on productivity of locally owned firms.

Among the four modes of technological spillover occurence considered in this analysis, competition generated the highest level of spillover occurtence (3.52) followed by demonstration (3.44), labour mobility (3.16) and finally linkage (3.08). This showed that competition and demonstration effects resulted in more learning and technological changes. This further indicates that compared to competition and demonstration, linkage system and labour mobility have weaker learning effects and thus by implication weaker capability building in manufacturing. Comparisons done using Twtest analysis showed the difference to be statisatically significant (see 'Table 5.9). Interestingly, the highest type of spillowers conceptualised in terms of learning and technological changes (new and/or incremental) occurred in products changes occurred in products (3.63) and process (3.58). Marketing strategy had an index of 3.19; while both management and organisation; and repair and maintenance had 3.05 each. 
Table 5.7: Occurrence of Technological Spillower in Local and Fonelgn Firms, Food and Machine and Engineering Induscries Combined, Kenyt, 2004

Computed Index for Spillover Occurrence in the two Industries from both Loeal and Foreign Firms

Spillower

Conceptualisation Competition Linkage

Product Changes (Pd)

Process Changes (Pr)

Repair \& Maintenance (R\&M)

Markering Strategy (Ms)

Mamagement \& Organisation

(Mo)

Average

Score (c)

3.90

(1)

3.47

3.36

3.45

3.18

2.78

2.95

2.79

3.08

3.16

3.52
Demonstration

(d)

3.73

3.71

3.13

3.46

3.18

3.44

3.30

Score

3.63

3.58

3.05

3.19

3.05

3.16

Computed Index for Spillover Occurrence in the two Industries from Foreign Firms Only

$\begin{array}{cccccc}\begin{array}{c}\text { Product Changes } \\ \text { (Pd) }\end{array} & 4.09 & 3.73 & 3.80 & 3.85 & \mathbf{3 . 8 7} \\ \begin{array}{c}\text { Process Changes } \\ \text { (Pr) }\end{array} & 3.96 & 3.53 & 3.75 & 3.88 & \mathbf{3 . 7 8} \\ \begin{array}{c}\text { Pair \& Mantenance } \\ \text { (R\&) }\end{array} & 3.18 & 2.97 & 3.41 & 3.24 & \mathbf{3 . 2 0} \\ \begin{array}{c}\text { Marketing Strategy } \\ \text { (Ms) }\end{array} & 3.63 & 3.16 & 3.07 & 3.57 & \mathbf{3 . 3 6} \\ \begin{array}{c}\text { Management \& } \\ \text { Organisation } \\ \text { (Mo) }\end{array} & 3.37 & 2.95 & 3.21 & 3.37 & \mathbf{3 . 2 3} \\ \begin{array}{c}\text { Average } \\ \text { Score }\end{array} & 3.63 & \mathbf{3 . 2 7} & \mathbf{3 . 4 4} & \mathbf{3 . 5 9} & \mathbf{3 . 4 8}\end{array}$

Computed Index for Spillover Occurrence in the two Industries from Local Firms Only

\begin{tabular}{cccccc}
$\begin{array}{c}\text { Product Changes } \\
\text { (Pd) }\end{array}$ & 3.70 & 3.21 & 3.06 & 3.61 & $\mathbf{3 . 4 0}$ \\
$\begin{array}{c}\text { Process Changes } \\
\text { (Pr) }\end{array}$ & 3.63 & 3.19 & 3.14 & 3.53 & $\mathbf{3 . 3 7}$ \\
$\begin{array}{c}\text { Ppair \& Maintenance } \\
\text { (R\&M) }\end{array}$ & 3.01 & 2.63 & 2.94 & 3.02 & 2.90 \\
$\begin{array}{c}\text { Marketing Strategy } \\
\quad \text { (Ms) }\end{array}$ & 3.41 & 2.79 & 2.50 & 3.34 & $\mathbf{3 . 0 1}$ \\
$\begin{array}{c}\text { Management \& } \\
\text { Organisation } \\
\begin{array}{c}\text { (Mo) } \\
\text { Average } \\
\text { Score }\end{array}\end{array}$ & 3.1 .8 & 2.63 & 2.69 & 2.98 & $\mathbf{2 . 8 7}$ \\
\hline
\end{tabular}

Sounce: Compuled from authot's field survey $2003 / 2004$ 
Examination of spillower occurrence by fim ownership revealled that more spillovers occurted in the rwo industries from foreign firms than from local firms. The spillower index computed from foreign funs was 3.48 while that of the local frms was 3.11 , Table 5.7. Comparative T-test analysis showed this difference to be statistically significant, Table 5.14. By the ordinal scale developed, it can be concluded that there is "high" spillover occurrence into the two industries combined from foreign froms and average spillover occutrence from locally owned firms. The implication of this is that foreign firms generate more knowledge spillovers than the local firms in the two industries. In all the cases, competition generated the most spillovers followed by demonstration effects. Surprisingly, while foreign firms generated more spillovers through labour mobility (3.44) than through linkages (3.27), it was opposite with local firms as they tended to generate mote spillowers with linkage (2.89) than with labour mobility (2.87). Similarly most of the spillovers occurring were of product, process and marketing strategy in that order.

Spillower Occurrence into only locally onmed forms in Food and Machine and Engineening rindustries

Examination of spillover occutrence to the local firms from both foreign and local firms showed an average spillower index of 3.31, Table 5.8. This index compared to that computed for both food processing and beverages, and machine and engineering industries combined (3.30) in Tabte 5.7. The most kind of spillowers generated was in product changes followed by process changes and the marketing strategy with $3.61,3.52$ and 3.29 respectively. As noted in the above, spillover occurrence to the local firms from foreign firms was significantly different from that of local firms, Table 5.7. Similarly, a comparison by mode and type of spillower accurtence shows that more spillovers occurred to the locally owned firms from foreign firms (3.44) than from local firms (3.19). The implication for this is that foreign firms in the two industries generate more spillovers into the local firms than the local firms do.

These findings are very interesting as they confirm two things: First that that spillovers occur from foreign firms to the local firms in the Kenyan manufacturing industry. Second that spillovers occurring from foreign firms were much more than spillovers occurring from locall firms. Occurrence of these spillowers was highest through the demonstration channel, 3.66, "Table 5.8. This supports the argument in the spillover literature that demonstration served as one of the mechanisms through which spillover occurs from foreign to the local firms. Langdon (1981) had noted that local firms in Kenya introduced mechanised techniques in soap production following the introduction of mechanised production of soap by the entry of MNCs forced.

The second channel through which high technological spillover also occurred from foreign to the local firms was competition ${ }^{106}, 3.64$. Similarly, this is supported in the spillover literature by Langdon (1981) who found that a combination of demonstration and competition pressure resulting from the entry of MNCs forced locally owned firms to introduce mechanised techniques. Competition in the footwear industry as a result of foreign firm entry in Kenya, led to significant changes in the production techniques of the locally owned firms (Jenkins, 1990).

I06 Comparison done by T-test analysis showed that the difference between diemonstration and comperition on one had and linkage and labout mobility on the other were statistically siginificant, (see Table 5.9) 
Another channiel with more than average spillover occurrence from foreign to the local firms was labour mobility ${ }^{107}$, 3.35. Although this chapter uses a different methodological approach, the results obtained are in support of some studies in developing countries, which examined occurrence of spillovers from foreign to locally owned firms through labour mobility. For example, Gerschenberg (1987) observed cases of tramed managers while working with MNCs who had later moved to join locally owned firms contributing to the diffusion of managerial skills and knowledge. In South East Asia, Yoshikara (1988) found out that mobility of trained workers from foreign firms had contributed to the flow of knowledge into Chinesemowned firms. In detailed case studies of electronic and garments and textile industries in Malaysia, Rasiah (1995) noted that labour mobility from MNCs had contributed to technological spillovers to the local firms. At an international level, the inter-firm mobility of managers from Japan to the United States and Europe contributed to the spread specific management practices (Caves, 1996).

The last channel through which average spillovers occurred from foreign firms to the local firms was linkage, 3.10. This offers empinical support to the fact that linkage between foreign and local firms is crucial in diffusion of skills, knowledge and technology. In Malaysia, production linkages between local firms in the electronic, machine and engineering, and garments and textile industries resulted in tremendous technological spillovers to the local firms [Rasiah, (1995: 2002)]. Similarly, looking at vertical inter-firm linkages in less developed countries Lall (1980) noted that MNCs contributed in raising the productivity and efficiency in locally owned firms. Foreign firms assisted in setting up production facilities, offered training and technical assistance, and assisted in looking for new markets. In Argentina, MNCs forced domestic suppliers to adopt productive processes and techniques similar to those used by suppliers of their main firms in their country of origin (Katz, 1969, p 154). Although not many studies exist on determining the effect of forward linkages on spillover occurtence to the local firms, a few cases however do exist [Reuber, Crookell, Emerson and Gallais-Hamonno, 1973; McAleese and McDonald, 1978]. This has been studied by others in the context of increasing local content [Helleiner, 1973; Watanabe, 1983; Belderbos and Capannelli, 2001 .

\section{(iii) Simwing $U p$}

Analysis done for all the firms has shown that technological spillovers do occur in the Kenyan manufacturing industry. Comparison done by ownership revealed that spillovers occurred more in the two industries from foteign firms than from local firms. "T-test analysis showed the difference to be statistically significant. The main kinds of spillover occurring were of product and process followed by marketing. The main mechanisms of spillover occurrence included competition and demonstration effects. The pattern of results obtained when the analysis was done for only locally owned fims was more or less the same.

10 Saggi (1999) provided several examples where employes left their jobs with MNCs to set up their own firms or to join other newly established companies. 
Table 5.8: Occurrence of Technological Spillover in Local Firms Only, Food and Machine and Engineering Industries Combined, Kenya, 2004

\begin{tabular}{|c|c|c|c|c|c|}
\hline \multicolumn{6}{|c|}{$\begin{array}{c}\text { Computed Index for Spillower Decurrence in Local Firms (For Both Industries) from } \\
\text { both Local and Foreigm Firms }\end{array}$} \\
\hline $\begin{array}{c}\text { Spillover } \\
\text { Conceptualisation }\end{array}$ & Competition & Linkage & $\begin{array}{l}\text { Labour } \\
\text { Mobility }\end{array}$ & Demonstration & $\begin{array}{l}\text { Average } \\
\text { Score }\end{array}$ \\
\hline & (c) & (I) & (m) & (d) & \\
\hline $\begin{array}{l}\text { Product Changes } \\
\text { (Pd) }\end{array}$ & 3.85 & 3.34 & 3.40 & 3.83 & 3.61 \\
\hline $\begin{array}{l}\text { Process Changes } \\
\text { (Pr) }\end{array}$ & 3.75 & 3.34 & 3.31 & 3.67 & 3.52 \\
\hline $\begin{array}{l}\text { Repair \& Maintenance } \\
\qquad(\mathbf{R} \& \mathbf{M})\end{array}$ & 323 & 2.60 & 3.03 & 3.32 & 3.05 \\
\hline $\begin{array}{l}\text { Marketing Strategy } \\
\qquad(\mathrm{Ms})\end{array}$ & 3.72 & 294 & 2.91 & 3.58 & 3.29 \\
\hline $\begin{array}{l}\text { Management \& } \\
\text { Organisation } \\
\text { (Mo) }\end{array}$ & 3.44 & 2.77 & 2.88 & 3.35 & 3.11 \\
\hline $\begin{array}{l}\text { Average } \\
\text { Score }\end{array}$ & 3.60 & 3.00 & 3.11 & 3.55 & 3.31 \\
\hline \multicolumn{6}{|c|}{$\begin{array}{l}\text { Computed Index for Spillover Occurrence in Local Firms (For Both Industries) from } \\
\text { Foreign Firms Only }\end{array}$} \\
\hline $\begin{array}{l}\text { Product Changes } \\
\qquad(\text { Pd) }\end{array}$ & 3.89 & 3,48 & 3.69 & 3.88 & 3.74 \\
\hline $\begin{array}{l}\text { Process Changes } \\
(\mathbf{P r})\end{array}$ & 3.79 & 3.44 & 3.57 & 3.80 & 3.65 \\
\hline $\begin{array}{l}\text { Repair \& Maintenance } \\
\text { (R\&M) }\end{array}$ & 3.33 & 2.67 & 3.21 & 3.51 & 3.18 \\
\hline $\begin{array}{l}\text { Marketing Strategy: } \\
\qquad(\mathrm{Ms})\end{array}$ & 3.72 & 3.00 & 3.16 & 3.63 & 3.39 \\
\hline $\begin{array}{l}\text { Management \& } \\
\text { Organisation } \\
\text { (Mo) }\end{array}$ & 3,46 & 2.86 & 3.10 & 3.50 & 3.23 \\
\hline $\begin{array}{l}\text { Average } \\
\text { Score }\end{array}$ & 3.64 & 3.10 & 3.35 & 3.66 & 3.44 \\
\hline \multicolumn{6}{|c|}{$\begin{array}{l}\text { Computed Index for Spillower Occurrence in Local Firms (For Both Industries) from } \\
\text { Local Firms Only }\end{array}$} \\
\hline $\begin{array}{l}\text { Product Changes } \\
\qquad(\mathbf{P d})\end{array}$ & 3.81 & 3.20 & 3.12 & 3.79 & 3.48 \\
\hline $\begin{array}{l}\text { Process Changes } \\
\text { (Pr) }\end{array}$ & 3.71 & 3.23 & 3.06 & 3.53 & 3.38 \\
\hline $\begin{array}{l}\text { Repatit \& Maintenance } \\
\text { (R\&M) }\end{array}$ & 3.13 & 2.53 & 2.85 & 3.12 & 2.91 \\
\hline $\begin{array}{l}\text { Marketing Strategy } \\
\text { (Ms) }\end{array}$ & 3.72 & 2.82 & 2.67 & 3.53 & 3.19 \\
\hline $\begin{array}{l}\text { Mlantigement \& } \\
\text { Organisation } \\
\text { (Mo) }\end{array}$ & 3.43 & 2.69 & 2.67 & 3.20 & 3.00 \\
\hline $\begin{array}{l}\text { Average } \\
\text { Score }\end{array}$ & 3.56 & 2.89 & 2.87 & 3.43 & 3.19 \\
\hline
\end{tabular}

Source: Computed from anthor's field survey $2003 / 2004$ 


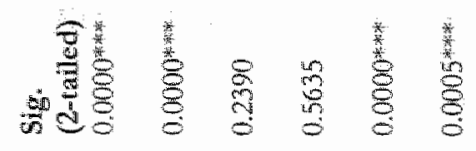

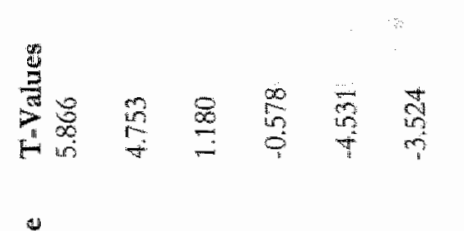

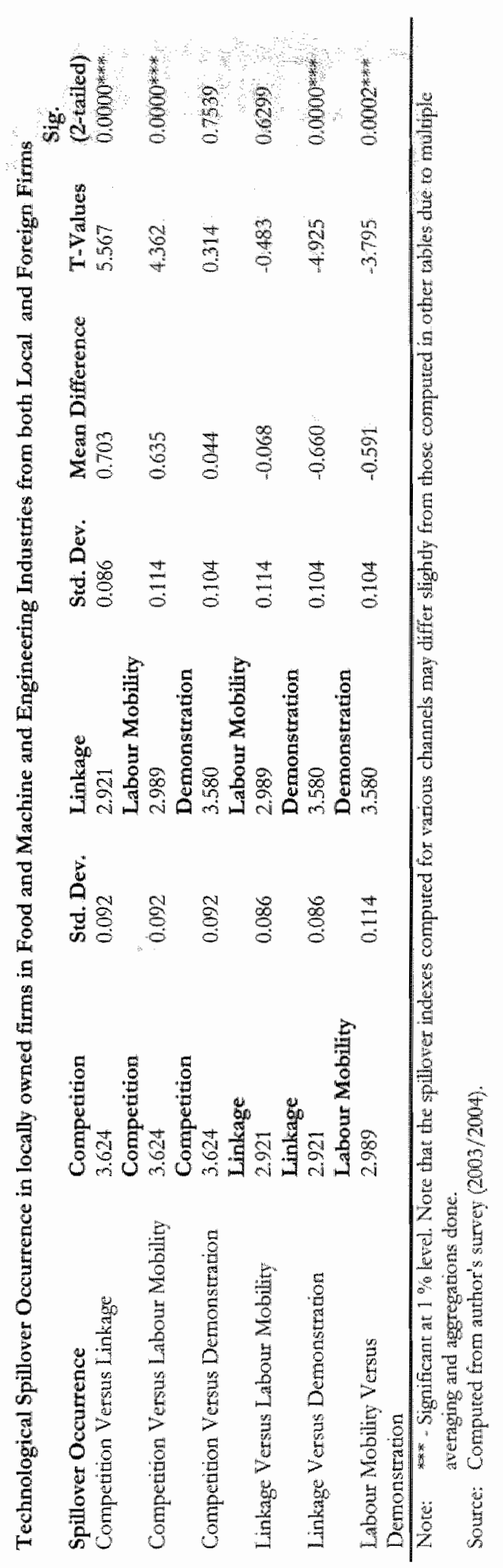




\subsubsection{Comparison of Technological Spillover Occurrence by the Two Industries}

(1) Onwrence of Spillowets in Ford Processing and Bewerages Indwstry

Table 5.10 provides the results of spillover index SPO INDEX Ford-processing computed for food processing and beverages industry from both local and foreign firms. The spillover index computed was approximately 3.25 representing an "awerge" spillower occurtence in food processing industry. Competition generated the high level of spillover occurtence (3.53) followed by demonstration (3.32), labour mobility (3.12) and finally linkage (3.03). Spillovers of product (3.57) and process (3.56) changes were the highest followed by marketing strategy (3.12): while tepait and maintenance, and management and organisation had 3.02 and 3.00 respectively.

By firm ownership, mote spillovers occurred in food processing and beverages industry from foreign fims than from local firms. The spillover index computed from foreign firms was 3.45 while that of the local firms was 3.05 , Table 5.10. Results of T-test analysis done showed this difference to be statistically significant at 5\%, Table 5.14. By the ordinal scale developed, it can be concluded that there is "high" spillover occurrence in food processing industry from foreign firms and an "average" spillover occurrence from local firms. Foreign firms therefore generated more knowledge spillovers in food processing than local furms dicl. $A$ s in the above cases discussed competition generated the most spillovers followed by demonstration effects for both local and foreign firms. Foreign fitms generated more spillowers through all the mechanisms than the local firms. The difference was statistically significant with the exception of backward linkage mechanisms, Table 5.14. In addition, foreign firms generated mote spillovers through labour mobility (3.43) than through linkage effects (3.22), while local fitms generated more spillovers through linkage effects (2.85) than through labour mobility (2.81). Similar to the above most of the spillovers occurring were of product, process followed by marketing. Interestingly, spillovers of repair and maintenance ranked third after product and process while in the case of foreign firms marketing strategy ranks third. 
Table 5.10: Occurrence of Technological Spillover in Local and Foreign Firms in Food Processing Industry, Kenya, 2004

\begin{tabular}{|c|c|c|c|c|c|}
\hline \multicolumn{5}{|c|}{ Computed Index for Spillover Occurrence in Food Processing from both Locell and } & ifand \\
\hline \multirow{3}{*}{$\begin{array}{c}\text { Spillover } \\
\text { Conceptualisation }\end{array}$} & Compecition & Linkage & Labonir & \multirow{3}{*}{$\begin{array}{c}\text { Demonstation } \\
\text { (d) }\end{array}$} & \multirow{3}{*}{$\begin{array}{l}\text { Average } \\
\text { Score }\end{array}$} \\
\hline & & & Mobiliry & & \\
\hline & (c) & (I) & (m) & & \\
\hline $\begin{array}{c}\text { Product Chatnges } \\
\text { (Pd) }\end{array}$ & 3.93 & 3.40 & 3.31 & 3.64 & 3.57 \\
\hline $\begin{array}{c}\text { Process Changes } \\
\text { (Pr) }\end{array}$ & 3.85 & 3.27 & 3.46 & 3.66 & 3.56 \\
\hline $\begin{array}{l}\text { Repair \& Maintenance } \\
\text { (R\&M) }\end{array}$ & 3.07 & 2.76 & 3.29 & 2.94 & 3.02 \\
\hline $\begin{array}{l}\text { Marketing Strategy } \\
\text { (Ms) }\end{array}$ & 3.56 & 2.98 & 2.56 & 3.38 & 3.12 \\
\hline $\begin{array}{l}\text { Management \& } \\
\text { Organisation } \\
\text { (Mo) }\end{array}$ & 3.27 & 2.76 & 2.98 & 2.98 & 3.00 \\
\hline $\begin{array}{l}\text { Average } \\
\text { Score }\end{array}$ & 3.53 & 3.03 & 3.12 & 3.32 & 3.25 \\
\hline
\end{tabular}

Computed Index for Spillover Occurrence in Food Processing from Foreign Firms Only

$\begin{array}{cccccc}\begin{array}{c}\text { Product Changes } \\ \text { (Pd) }\end{array} & 4.19 & 3.69 & 3.78 & 3.79 & \mathbf{3 . 8 6} \\ \begin{array}{c}\text { Process Changes } \\ \begin{array}{c}\text { (Pr) } \\ \text { (Pr) }\end{array}\end{array} & 4.01 & 3.41 & 3.77 & 3.86 & \mathbf{3 . 7 6} \\ \begin{array}{c}\text { Repait \& Maintenance } \\ \text { (R\&M) }\end{array} & 3.20 & 2.92 & 3.53 & 3.01 & \mathbf{3 . 1 7} \\ \begin{array}{c}\text { Marketing Strategy } \\ \begin{array}{c}\text { (Ms) } \\ \text { Management \& }\end{array}\end{array} & 3.67 & 3.14 & 2.83 & 3.48 & \mathbf{3 . 2 8} \\ \begin{array}{c}\text { Organisation } \\ \text { (Mo) }\end{array} & 3.42 & 2.92 & 3.23 & 3.18 & \mathbf{3 . 1 9} \\ \begin{array}{c}\text { Average } \\ \text { Score }\end{array} & 3.70 & \mathbf{3 . 2 2} & \mathbf{3 . 4 3} & \mathbf{3 . 4 6} & \mathbf{3 . 4 5} \\ & & & & & \end{array}$

Computed Index for Spillover Occurrence in Food Processing from Local Firms Only

\begin{tabular}{|c|c|c|c|c|c|}
\hline $\begin{array}{c}\text { Product Changes } \\
\text { (Pd) }\end{array}$ & 3.67 & 3.11 & 2.85 & 3.50 & 3.28 \\
\hline $\begin{array}{c}\text { Process Changes } \\
(\mathbf{P r})\end{array}$ & 3.68 & 3.14 & 3.16 & 3.46 & 3.36 \\
\hline $\begin{array}{l}\text { lepair \& Maintenance } \\
\text { (R\&M) }\end{array}$ & 2.93 & 2.61 & 3.04 & 2.86 & 3.11 \\
\hline $\begin{array}{c}\text { Markering Strategy } \\
\text { (Ms) }\end{array}$ & 3.45 & 2.82 & 2.28 & 3.27 & 2.96 \\
\hline $\begin{array}{l}\text { Management \& } \\
\text { Organisation } \\
\text { (Mo) }\end{array}$ & 3.13 & 2.59 & 2.73 & 2.77 & 2.81 \\
\hline $\begin{array}{l}\text { Average } \\
\text { Score }\end{array}$ & 3.37 & 2.85 & 2.81 & 3.17 & 3.05 \\
\hline
\end{tabular}

Soutce: Computed from author's field surtey $2003 / 2004$ 


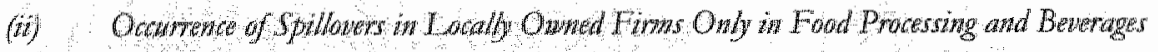

Table 5.11 shows the results of spllover index SPO INDEX Foodmpracessing computed for food processing industry from both local and foreign firms occurring in local firms only in food processing industry. The spillover index computed was approximately 327 representing an "awerge" spillower occurrence in locally owned frms in food processing industry. Competition generated the high level of spillover occurrence (3.68) followed by demonstration (3.39), labour moblity $(3.07)$ and finally linkage (2.94). Spillovers of product $(3.55)$ and process $(348)$ changes were the highest followed by matketing strateg $(3.26)$ while repair and maintenance, and management and organisation had 3.02 and 3,03 respectively.

By tirm ownership mone spillovers occurred in locally owined firms from foreign fims than from local firms. The spillower index computed from foreign firms was 3.40 while that of the local firms was 3.14, Table 5.11. By the ordinal scale developed, it can be concluded that there is "average" spillower occurrence in locally owned firms from both foreign and local firms. Despite a similar ordinal ranking, foreign fims generated slightly more spillovers in locally owned in food industry than local firms did. For both local and foretgn firms, competition generated the most spillovers followed by demonstration effects. Foreign firms generated more spillovers through labout mobility (3.32) than through linkage effects (3.00), while local furms generated more spillovers through linkage effects (2.88) than through labour mobility (2.82). While there were "high" spillovers of product and process with foreign firms there were only "average" spillowers of product and process with local firms. 
Table 5.11: Occurrence of Technological Spillover in Local Fims Only in Food Processing Industry, Kenya, 2004

\begin{tabular}{|c|c|c|c|c|c|}
\hline & \multicolumn{2}{|c|}{ Computed Index for Spillover Occurrence into Local firms in Food Prociesising from } & ign Firms. & Afoctests & 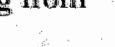 \\
\hline Spillover & Competition & Linkage & Labour & Demonstration & Average \\
\hline Conceptualisation & (c) & (a) & $\begin{array}{l}\text { Mobility } \\
\text { (m) }\end{array}$ & (d) & Scone \\
\hline $\begin{array}{c}\text { Product Changes } \\
\text { (Pd) }\end{array}$ & 3.90 & 3.22 & 3.31 & 3.80 & 3.55 \\
\hline $\begin{array}{c}\text { Process Changes } \\
(\mathrm{Pr})\end{array}$ & 3.82 & 3.28 & 3.33 & 3.52 & 3.48 \\
\hline $\begin{array}{c}\text { Repair \& Maintenance } \\
\text { (R\&M) }\end{array}$ & 3.35 & 2.60 & 3.09 & 3.05 & 3.02 \\
\hline $\begin{array}{c}\text { Marketing Strategy } \\
\text { (Ms) }\end{array}$ & 3.85 & 2.92 & 2.82 & 3.46 & 3.26 \\
\hline $\begin{array}{l}\text { Management \& } \\
\text { Organisation } \\
\text { (Mo) }\end{array}$ & 3.49 & 2.70 & 2.80 & 3.14 & 3,03 \\
\hline $\begin{array}{l}\text { Average } \\
\text { Score }\end{array}$ & 3.68 & 2.94 & 3.07 & 3.39 & 3.27 \\
\hline
\end{tabular}

Computed Index for Spillover Occurrence in Local Firms in Food Processing from

Product Changes

(Pd)

Process Changes

(Pr)

Repair \& Maintenance

(R\&M)

Marketing Strategy

(Ms)

Management \&

Organisation

(Mo)

Average

Score

3.93

Foreign Firms Only

$$
3.82
$$

3.37

3.75

3.92

3.74

3.59

3.29

3.55

3.72

3.60

2.65

3.24

3.20

3.17

3.85

2.99

3.00

3.48

3.33

3.58

2.71

3.05

3.28

3. 16

3.75

3.00

3.32

3.52

3.40

Computed Index for Spillover Occurrence in Local Firms in Food Processing from Local

\begin{tabular}{|c|c|c|c|c|c|}
\hline \multirow[b]{2}{*}{$\begin{array}{l}\text { Product Changes } \\
\text { (Pd) }\end{array}$} & \multicolumn{3}{|c|}{ Fitms Only } & \\
\hline & 3.87 & 3.06 & 2.86 & 3.67 & 3.37 \\
\hline $\begin{array}{c}\text { Process Changes } \\
\text { (Pr) }\end{array}$ & 3.81 & 3.26 & 3.11 & 3.31 & 3.37 \\
\hline $\begin{array}{l}\text { Repair \& Maintenance } \\
\text { (R\&M) }\end{array}$ & 3.10 & 2.55 & 2.93 & 2.89 & 2.87 \\
\hline $\begin{array}{c}\text { Marketing Strategy } \\
\text { (Ms) }\end{array}$ & 3.85 & 2.84 & 2.64 & 3.43 & 3.19 \\
\hline $\begin{array}{c}\text { Management \& } \\
\text { Organisation } \\
(\mathrm{Mo})\end{array}$ & 3.40 & 2.69 & 2.55 & 3.00 & 2.91 \\
\hline $\begin{array}{l}\text { Average } \\
\text { Sicore }\end{array}$ & 3.61 & 2.88 & 2.82 & 3.26 & 3.14 \\
\hline
\end{tabular}

Source: Computed from author's fielid survey 2003/2004 
The spillover inder computed was approximately 3.36 representing an "average" spillower occurtence in machine engineeting industry. Table 5.12 provides the results of spillower

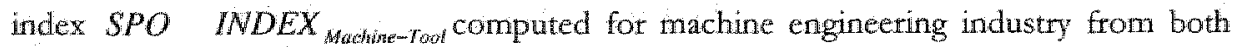
local and foreign firms. The spillower index computed for machine and engineering industry was higher than that of food processing computed above by about $3.4 \%$. Another difference is that whle in food processing competition generated the most spillovers followed by demonstration effects, in machine and engineering industry demonstration effects generated the most spillovers (3.59) followed by competition (3.49). Labour mobility had 3.21 and linkage 3.14. Spillovers of product (3.71) and process (3.60) changes were the highest followed by marketing strategy (3.27): while repari and maintenance, and management and otganisation had 3.10 and 3.11 tespectively.

By fim ownership more spillovers occurred in machine and engineering industry from foreign firms than from local firms. The spillower index computed from foreign firms was 3.53 while that of the local firms was 3.19, Table 5.12. This difference was statistically significant at $5 \%$, Table 5.14 . By the ordinal scale developed, it can be concluded that there is "high" spillover occurrence in machine and engineering industry from foreign firms and an "average" spillover occurrence from local firms. Foreign firms therefore generated more knowledge spillovers in food processing than local firms did. Comparing the two industries we note that spillovers generated by foreign firms were more in machine and engineering than in food processing and beverages. However, the difference was not statistically significant.

As in the other cases discussed above; both local and foreign firms generated most spillovers through demonstration effects followed by competition. Foreign firms generated more spillovers through labour mobility (3.47) than through linkage effects (3.34) while the two had similar results for local furms (2.94). Comparison of spillower mechanisms using T-test analysis by ownership and industry is provided in Table 5.14 and 5.15 respectively. Foreign firms generated higher spillovers statistically through all the mechanisms than the local firms with the exception of competition mechanism, Table 5.14. A comparison of the spillover mechanisms by the two industries showed that foreign spillovers were statistically and significantly higher in machine and engineering in demonstration and backward linkage effects Table 5.15.

Product, process and marketing strategy spillovers generated by foreign firms were rated "high" while only spillovers of product alone were rated "high" in case of local firms. Spillovers of management and organisation, and repair and maintenance generated by local firms were rated "low". 
Table 5.12: Occurrence of Technological Spillover in Local and Foreign Firms in Machine and Engineering Industry, Kenya, 2004

Computed Index for Spillover Occurrence in Machine and Engineering from both Local and Foreign Firms

Spillover

Conceptualisation

Product Changes

(Pd)

Process Changes

(Pr)

Repair \& Maintenance

(R\&M)

Marketing Strategy

(Ms)

Management \&

Organisation

(Mo)

Average

Score
Competition Linkage Inabour

Mobility

(c)

3.84

(I)

3.57

3.49

2.85

2.98

2.84

3.14

3.21

(m)

3.59

3.43

3.03

3.09

2.92

3.42

3.59

(d)

3.83

3.77

3.38

3.57

3.11

Computed Index for Spillover Occurrence in Machine and Engineering from Foreign Firms Only

Product Changes

3.93

3.79

3.82

3.93

3.87

(Pd)

Process Changes

3.86

3.71

3.73

3.91

3.80

(Pr)

Repair \& Maintenance

3.14

3.03

3.26

3.54

3.24

(R\&M)

Marketing Strategy

(Ms)

Managenent \&

Organisation

(Mo)

Average

Score
3.57

3.18

3.37

3.70

3.46

3.29

3.00

3.18

3.61

3.27

3.56

3.34

3.47

3.74

3.53

Computed Index for Spillover Occurrence in Machine and Engineering from Local Firms

Product Changes

(Pd)

Process Changes

(Pr)

Repair \& Maintenance

(R\&M)

Marketing Strategy

(Ms)

Management \&

Organisation

(Mo)

Average

Score
Only

$\begin{array}{llll}3.74 & 3.35 & 3.35 & 3.73\end{array}$

3.54

3.58

3.26

3.12

3.62

3.40

3.14

2.60

2.79

3.21

2.95

3.36

2.77

2.81

3.43

3.09

3.26

2.68

2.65

3.23

2.96

3.42

2.94

2.94

3.44

3.19 
Iable 5.13 shows the results of spillover index SPO INDEX machine and enginecring industry from both local and foreign furms occurring in local firms only in machine and engineering. The spillower index computed was approximately 3.35 representing an "datage" spillover occurrence in locally owned firms in machine and engineering industry slighty higher than 3.27 recorded for food processing industry: Demonstration effects generated high spillowers (3.69) followed by competition (3.50), labour mobility (3.15) and linkage (3.05). Spillovers of product (3.66) and process (3.54) changes were the highest followed by marketing strategy (3.30): while repair and maintenance, and management and organisation had 3.05 and 3.18 respectively.

By firm ownership more spillowers occurred in locally owned firms from foreign firms than from local firms. The spillower index compured from foreign firms was 3.46 while that of the local firms was 3.23, Table 5.13. By the ordinal scale developed, it can be concluded that there is "high" spillover occurtence in locally owned firms from foreign and "average" occurrence from local firms. Foreign firms therefore generated more spillovers in locally owned in demonstration machine and engineering industry than local firms did. For both local and foreign firms demonstration effects generated the most spillovers followed by competition. More spillovers were generated through labour mobility than through linkage effects for both local and foreign firms. While there were "high" spillovers of product and process with foreign firms while there was only" "high" spillovers of product with local firms.

Analysis done by industries separately has further shown that spillovers do occur in the Kenyan manufacturing industry. From the two industries studied; the difference between spillovers occutring from foreign firms and spillowers occutring from local firms was shown to be statistically significant. A comparison of spillover occurrence from foreign firms by the two industries showed higher foreign spillover occurrence in machine and engineering than in food processing and beverages. The difference was however not statistically significant. The main kinds of spillover occurrence remained of product and process followed by marketing. Similarly, competition and demonstration effects were also observed to be the main mechanisms of spillover occurrence in the two industries. Spillovers genegrated by foreign firms through all the mechanisms were statistically higher than spillowers generated by the local firms, Table 5.14. There was however the exception of backwatd linkage mechanim in food processing and competition mechanism in machine and engineering industry. A comparison of the spillover mechanisms by the two industries showed that foreign spillovers were statistically and significanty higher in machine and engineering in demonstration and backward linkage effects Table 5.15. The pattern of results obtained when the analysis was done for only locally owned firms was more or less the same with foreign firms generating higher spillovers than local furms. 
Table 5.13: Occurrence of Technological Spillower in Local Firms Only in Machine Tool Industry, Kenya, 2004

Compured Index for Spillover Occurrence in Local Firms Machine and Engineering from both Local and Foreign Firms

$\begin{array}{cccccc}\begin{array}{c}\text { Spillower } \\ \text { Conceptualisation }\end{array} & \begin{array}{c}\text { Competition } \\ \text { (c) }\end{array} & \begin{array}{c}\text { Linkage } \\ \text { (l) }\end{array} & \begin{array}{c}\text { Labour } \\ \text { Mobility } \\ \text { (n) }\end{array} & \begin{array}{c}\text { Denonstation } \\ \text { (d) }\end{array} & \begin{array}{c}\text { Average } \\ \text { Score }\end{array} \\ \begin{array}{c}\text { Product Changes } \\ \text { (Pd) }\end{array} & 3.80 & 3.47 & 3.52 & 3.87 & 3.66 \\ \begin{array}{c}\text { Process Changes } \\ \text { (Pr) }\end{array} & 3.67 & 3.40 & 3.29 & 3.81 & 3.54 \\ \begin{array}{c}\text { Repair \& Maintenance } \\ \text { (R\&M) }\end{array} & 3.09 & 2.58 & 2.97 & 3.56 & 3.05 \\ \begin{array}{c}\text { Marketing Strategy } \\ \text { (Ms) }\end{array} & 3.57 & 2.97 & 2.98 & 3.69 & 3.30 \\ \begin{array}{c}\text { Management \& } \\ \text { Organisation } \\ \text { (Mo) }\end{array} & 3.38 & 2.86 & 2.97 & 3.53 & 3.18 \\ \begin{array}{c}\text { Average } \\ \text { Score }\end{array} & 3.50 & 3.05 & 3.15 & 3.69 & 3.35\end{array}$

Computed Index for Spillover Occurrence in Local Firms in Machine and Engineering from Foreign Firms Ordy

\begin{tabular}{|c|c|c|c|c|c|}
\hline $\begin{array}{c}\text { Product Changes } \\
\text { (Pd) }\end{array}$ & 3.85 & 3.60 & 3.65 & 3.84 & 3.74 \\
\hline $\begin{array}{c}\text { Process Changes } \\
\text { (Pr) }\end{array}$ & 3.75 & 3.59 & 3.58 & 3.87 & 3.70 \\
\hline $\begin{array}{l}\text { cepair \& Maintenance } \\
\text { (R\&M) }\end{array}$ & 3.00 & 2.67 & 3.20 & 3.77 & 3.16 \\
\hline $\begin{array}{c}\text { Markeving Strategy } \\
\text { (Ms) }\end{array}$ & 3.55 & 3.14 & 3.26 & 3.74 & 3.42 \\
\hline $\begin{array}{c}\text { Management \& } \\
\text { Organisation } \\
\text { (Mo) }\end{array}$ & 3.30 & 3.02 & 3.13 & 3.68 & 3.28 \\
\hline $\begin{array}{l}\text { Average } \\
\text { Score }\end{array}$ & 3.49 & 3.20 & 3.36 & 3.78 & 6 \\
\hline
\end{tabular}

Computed Index for Spillover Occurrence in Local Firms in Machine and Engineering

\begin{tabular}{|c|c|c|c|c|c|}
\hline \multirow[b]{2}{*}{$\begin{array}{c}\text { Product Changes } \\
\text { (Pd) }\end{array}$} & \multicolumn{3}{|c|}{ from Local Firms Only } & \\
\hline & 3.74 & 3.34 & 3.39 & 3.90 & 3.59 \\
\hline $\begin{array}{c}\text { Process Changes } \\
\text { (Pr) }\end{array}$ & 3.59 & 3.20 & 3.00 & 3.74 & 3.38 \\
\hline $\begin{array}{l}\text { epair \& Maintenance } \\
\text { (R\&M) }\end{array}$ & 3.17 & 2.48 & 2.74 & 3.34 & 2.93 \\
\hline $\begin{array}{l}\text { Marketing Strategy } \\
\text { (Ms) }\end{array}$ & 3.59 & 2.80 & 2.70 & 3.63 & 3.18 \\
\hline $\begin{array}{l}\text { Management \& } \\
\text { Organisation } \\
\text { (Mo) }\end{array}$ & 3.46 & 2.69 & 2.80 & 3.37 & 3.08 \\
\hline $\begin{array}{l}\text { Average } \\
\text { Score }\end{array}$ & 3.51 & 2.90 & 2.93 & 3.60 & 3.23 \\
\hline
\end{tabular}

Source: Computed from author's field survey 2003/2004 


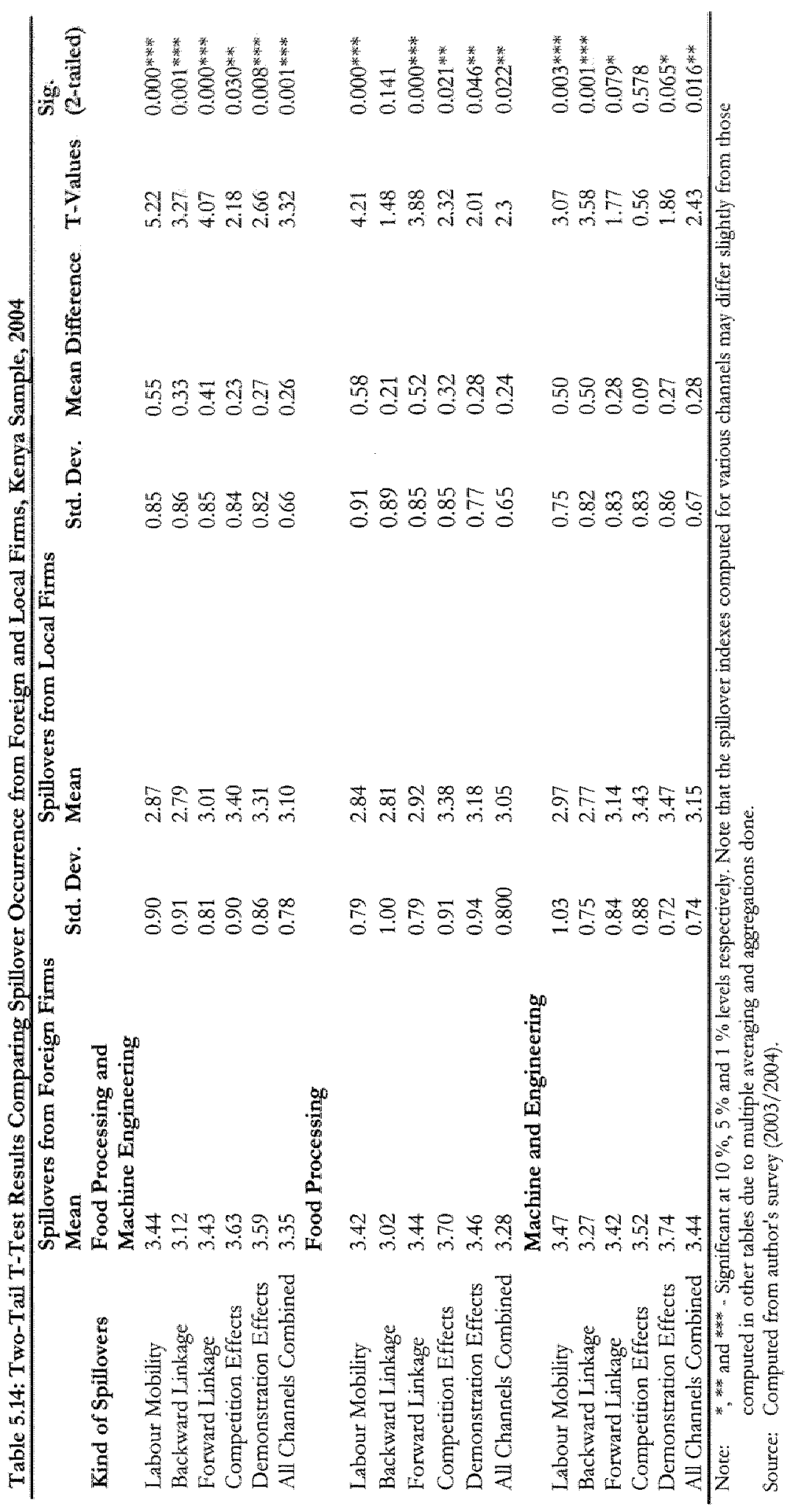




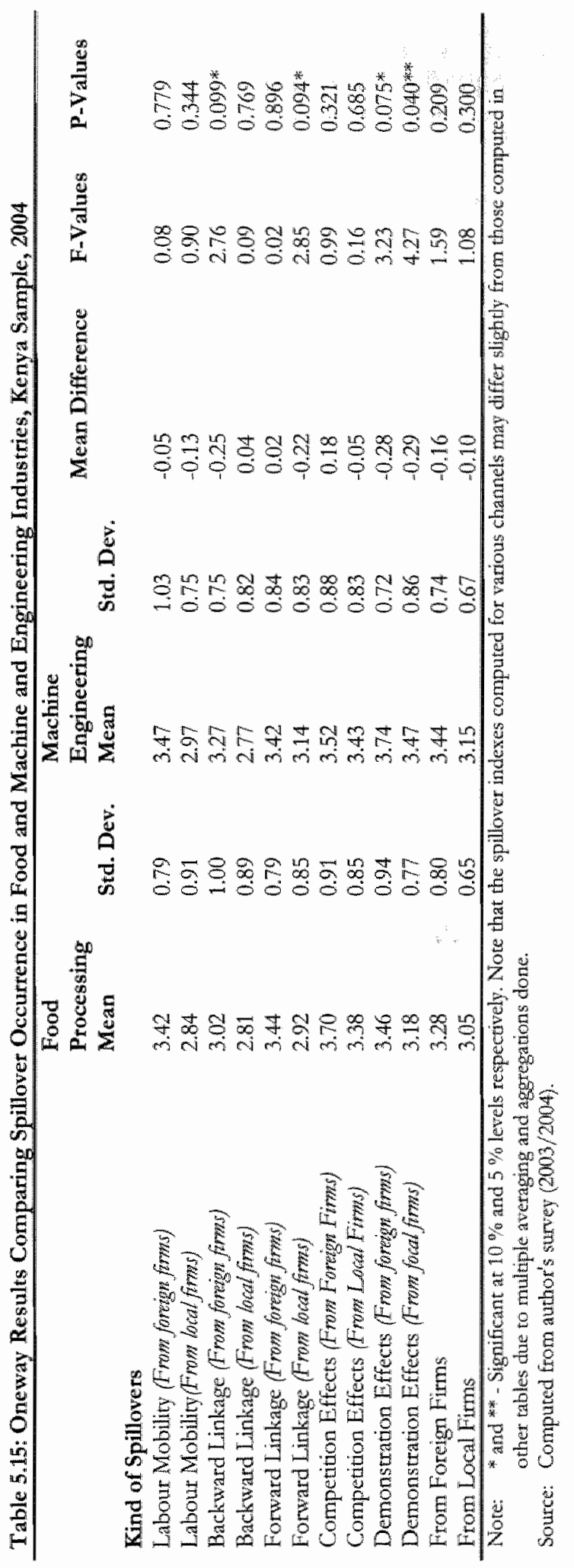




\subsection{Determinants of Technological Spillover Occurrence in the Kenyan Manufactuting Industry}

In this section, an econometric determination of spillover occurrence is undertaken. The secrion begins with a detailed descriptive statistics of the sample firms, followed by binomial logit estimation and then multinomal logit estimation of spillover occurrence.

\subsubsection{Descriptive Statistics of the Sampled Firms}

Table 5.16 presents a descriptive analysis of each of the spillover determinants identified in the conceptual framework developed in Chapter 2 . The toral sample for the stadly was 180 firms of which $102(56.7 \%)$ were selected from locally oxwed firms and $78(43.3 \%)$ were selected from foreign firms. There was an average spillover occurrence in both food processing and machine and engineering industries. Although spillover occutrence in domestic firms seemed higher than in foreign firms in the two industries; it was however not statistically significant. As observed in Chapter 4, foreign presence was higher in food processing than in machine and engineering industry. Similar to Chapter 4 , the foreign presence was computed following Aitken and Harrison (1909: p. 608) by normalising foreign equity with the firm's share of employment in the industry ${ }^{10 \%}$.

An important firm characteristic expected to influence spillover occurtence is firm size which was considered in terms of employment size. Foreign firms were bigger in size than the local firms with an average employment level of 456 and 113 in food and machine and engineering industries respectively: versus 117 and 102 for the local firms. Similar findings wete arrived at in Chapter 4 based on industrial survey data from official sources. Further, this compares to the results of RPED study where Ramachandran and Shah (1998) found firms with foreign ownership to be generally larger than those without in Kenya, Ghana and Zimbabwe. Similarly, in Czech Republic Djankov and Hoekman (1998: p. 10) observed a similar trend where firms with foreign patmerships tended to be significantly larget than firms that remained independent. This is however not surptising since foreign firms hawe more resources than local firms to invest in big firms abroad or to expand existing local firms once they have merged or acquited them. It is consistent with the literarure on MNCs, which reiterates that foreign firms have ownership advantages (both intangible and rangible ownership characteristics) which enable them to invest internationally [Hymer, 1960; Kindleberger, 1969; Dunning, (1973: 1993); Caves, (19741982); Buckley and Casson, 1976 .

The average age of all the firms in the two industries was 29 years. Foreign firms had a higher average firm age (39 years) compared to the local firms (22 years). Interestingly, local fitms in the two industries had a similar average age of about 22 years. Foreign firms in food processing were older with an average age of 45 years in comparison to those in machine and engineering with an average age of 29 years. Again these results compare well to those obtained in Chapter 4 . The age differential between foreign firms in the two industries is not suprising given that early foreign investment in Kenya was mainly in agro-based industries [Leys, 1975; Jorgensen, (1975: pp. 143-155); Kaplinsliy, 1978; Swainson, (1978: 1980); Vaitsos, 19911. However, two possible teasons could

4hs This was defined as $F S_{j t}=\frac{\sum_{i} F S_{i j t} * E m p_{i j t}}{\sum_{i} E_{i m p l o y m e n t}}$, which is foreign equity participation averaged over all plants in the sector, weighted by each platt"s shate in sectoral employment (Aitken and Harrisn, $1999 \mathrm{p}$. 608). 
account for the wide age differential bewween local ( 22 years) and foreign frms ( 39 years). The first one is that as outined in Chapter 3, accoiding to the history of Kenya's industrialisation process foreign firms started their production activites much earlier than local firms. For instance, many foreign firms invested in Kenya long time before her undependence in 1963. Examples of early foreign investment included James Finay-Uk (1924), Brooke Bond-UK (1924), Unilewer-UK (1953), Del Monte-US (1948) in the agro-based industry and Greif-US (1952) in machine and engineering industry [Swainson, $(1978 ; 1980)]$. The second reason is that the rate of foreign mamafacturing investment in Kenya declined tremendously in the late 1980 s and 1990 s after extensive institutional failure, infrastructure decay and inconsistent policies (Gachino and Rajah, 2003; WDI-CDROM, 2003). The observed trend on Kenya's investment patrern showed that most of the new firms were local firms and mainly Asian firms [Himbara, (1994: p. 35-74); Bigsten and Kimuyu, (2002: p. 22)]. This is supported by a study on Ghana under structural adjustments which showed that local firms were relatively newer than foreign firms (Lall, Navaretti, Teitel and Wignaraja, 1994).

The firm age factor is also reflected in the age of the core production machinery. With an average of 22 years foreign firms had the oldest production machinery compared to local firms with an average age of 17 years. To some extent this observation contradicts the argument in the literature that foreign firms would tend to use relatively newer production machinery. However this age difference could be explained as in the above by looking at the differences in investment trend between local and foreign firms. It may also imply that foreign firms in Kenya do not replace or introduce new production machinery and technology regularly. A possible explanation for this could be that the nature of manufacturing undertaken has little value added, supporting the argument by Kimuyu (1999, p. 166) that from a comparative perspective, the manufacturing sector in Kenya suffers from low value added. This has a negative consequence for learning and innovation.

"The avetage capacity utilisation in the two industries averaged $64 \%$ indicating existence of excess capacity in the two manufacturing industries. Foreign firms had higher capacity utilisation in food processing (70\%) than local firms $(61 \%)$ while the converse was true in machine and engineering industry ${ }^{109}$. This would be expected given that most of the foreign firms in food processing industry are expotters (internationally and regionally) and thus the relative demand for their products is higher than that of local firms. High capacity utilisation by the foreign furms could allso be atuibuted to their ability to engage skilled workforce and more efficient and well maintained production machinery and equipment. For the industry in general, insufficient domestic demand sometimes due to competition from imports was observed to be the main cause of low capacity utilisation $^{\text {the }}$. This supports an earlier finding by Coughlin and Ikiara (1991) and Mazumdar and Mazaheri (2003 p. 231-240) who using RPED data found out that the highest obstacle to capacity utilisation in Kenya was lack of demand followed by lack of working capital and then shortage of raw materials. Interviews conducted revealed that in addition to weak demand, lack of working capital and shortage of raw materials, there

hat These tresults compate well to those obtained by Mazumdar and Mazaheri (2003) who found out that average capacity ufilisation in food processing industry was $68.8 \%$ while that of metal un our case machine tool industry) was $63.9 \%$. Using the first round of RP ED data, Nairobi University, 1993 Found out that food processing had a capaciny urilisation of $70.87 \%$ whille metal had $65.77 \%$

"10 This is supported by theory which posits that excess capactry rurises when firms fail to determine the anticipated growth in demand, cyclical downturns in demand or existence of a seculat decline in demand over bime (Shaw and Surtom, 1976 ). 
were other factors contributing to low capacity utilisation which included poor transportation facilities that resulted in high transport cost, high cost of fuel and power and machinery and equipment breakdown.

On infrastructural and institutional support; firms were asked to rate the provision of key inffrastructural and institutional support on an ordinal scale tanging from 1 wery poor to 5 wollent. A simple index was computed, which allowed us to classify the firms into two groups, those rating the provision of infrastructure as good and those rating it as poor. With the exception of food processing where $50 \%$ of the total foreign firms rated prowision of infrastructure as good, in all the other cases only about a third felt they were prowided with relatively good infrastucture. This is rather low but it is not surprising in Kenya since in the last one-decade, there was little attention paid to the infrastructure dewelopment, expansion and maintenance which resulted in massive degradation of inftastructure. The transport services especially roads and railway services deteriorated after several years of neglect resulting in increased inefficiency and cost of transport. The cost of electricity and power supply remained high while telecommunication network (telephone) improved only a little ${ }^{\text {int }}$. A number of studies found poor infrastructure to be a big obstacle to the industrialisation process in Kenya [Kimuyu and Kayizzi-Mugerwa, 1993; Deparment of Economics, (1994: 1995); Kayizzi-Mugerwa and Kimuyu, 2002; and Rasiah and Gachino, 2004].

A similar trend was observed in the case of institutions where on average only at third of the firms felt they were receiving above average institutional support. This is an expected case in Kenya where most of the institutions just like the infrastructure had deteriorated performing below expectation. This was extensively discussed in Chapter 3. The problem was and is still compounded by poor policies and lack of coordination among the existing institutions meant to promote industrialisation in Kenya. Access to capital is constrained by high cost of credit, legal system and judiciary is weak, academic institutions are isolated from industry (rarely are they industry demand driven), R\&D institutions are weak with few incentives for R\&D activities [Department of Economics, (1994: 1995); Himbara, 1994; Pietrobelli, 2001; Gachino, 2003]. These characteristics typify a developing country as discussed extensively by Tybout (2000) in this review of manufacturing firms in developing countries.

The firms, which benefited from the services offered by business organisations, were equally very low. Foreign firms in food processing which benefited from business. otganisations were $33 \%$ while in the machine and engineering industry were $24 \%$. Of the food processing firms only $15 \%$ and $20 \%$ benefited from businesses organisations. This. is not surptising given the weak capacities of most of the business associations and therefore a more or less the same story to that of infrastructure and institutions advanced above also holds in the current situation.

Table 5.16 also shows the extent to which a firm benefited from 'formal and informal interactions' writh machinery and raw material suppliets, government and private institutions, universities and technical training institutions, industry and business associations, investment and export promoters, buyers and distributors. While $43 \%$ of the foreign firms reported having benefited from this kind of interactions, only $28 \%$ of the locally owned firms had benefited from such interactions. For both local and foreign firms, the firms that benefited from interactions were more in food processing than in

"11 The litde improvement in the rellephone industry was as a resulc of partial liberalisacion undertaken in the trelcommunication industry. 
machine and engineering industry. In general terms the level of benefit reported from interacting formally and informally was very low given that it remained below $50 \%$ on average for the two industries. This is expected for two reasons. First is that the lewel and frequency of interactions are usually low. This links to the second reason that most of the institutions or business associations to interact with are often faced with major drawbacks such as inadequate physical and human resources; finance and working capital. Third, lack of adequate support and facilitation from the gowemment to institutions as most of them remain inefficient. Moreover, the government has also falled to offer an appropriate institutional and legal framework to provide entrepreneurs with the required guidance, which would promote interactions and foster knowledge spillovers in the industry. To cite an example, which emerged during the interviews, most MNCs interested in investing in Kenya were affected by the immature structure and inefficient state of institutions and business associations. For instance, they were faced with lack of comprehensive information on the existing research institutions and their specific capabilities, operations of the judiciary and legal system, business partners with whom they can match make as well as on how to conduct business in Kenya. This made MNCs stay away or shy from full engagement in the industry.

In order to determine the firm's absorptive capacity, the proportion of staff with uniwersity, techrical and vocational training was considered. In the two industries foreign firms had the highest levels with $39 \%$ and $58 \%$ in food and machine and engineering respectively. Locally owned firms had $29 \%$ in food processing and $51 \%$ in the machine and engineering industry. The observation that foreign firms had a high proportion of skilled workers employed ${ }^{12}$ was nor surprising since according to the literature on MNCs, foreign firms have the resources to spread over heavy capital investment and to engage technically qualified manpower [Caves, 1974; Dunning (1973:1993); Aitken and Harrison, 1999]. For both local and foreign firms, machine and engineering industry had the highest levels of staff with university, technical and vocational training. "This would be expected as machine and engineeting industry requires engineering activities and thus skilled labour force would have to be engaged - engineers and vocationally trained technicians and craftsmen. This supports the argument that metal working activities in Kenya are more technologically exacting than other activities (Kkiara, Kimuyu, Manundu and Masai, 2002).

Technology gap was considered by taking the value of firm's core production machinery. A firm with the highest value of production machinery (obviously a foreign firm) was taken as the reference point. All the firms whose value of production machinery was below the reference point but above the industry average were considered to have a low technology gap while those below the industry average were considered to have a high technology gap. Although this conceptualisation of technollogy gap is narrow; the approach is the best placed for an empirical analysis particularly when examining issues pertaining to production capability and the associated spillowers. Table 5.16 shows that as expected the value of core production machinery used by foreign firms was higher than that of the local firms and thus the existence of technology gap between forcign and local furms. The existing difference in value of production machinery was higher in food processing than in machine and engineering industry. The value of production machincry for foreign firms in food industry was $4.16 \mathrm{e}+08$ Kenya Shillings while that of local firms was 7.74 e+07 Kenya Shillings. This is not surprising given that some of the largest MNCs with heavy capital investment in Kenya today can be traced in food processing.

112 This observation is supported by the earliet findings in Chapter 4 that foretgrn firms employed more skilled statit than the locally owned frms. 
Hexamples include CocamCola, Nestle, Unilever, Cadbury Schweppes, Del Monte, Unga Jimited, Brooke Bond and James Finlay. In the case of machine and engineering Industy, the value of production machinery for the forcign firms was $3.10 \mathrm{e}+08$ Kenya Shillings while that of domestic firms was $1.35 \mathrm{e}+08$ Kenya Shillings. While the value of production machinery for foreign firms was higher in food ptocessing than in machine and engineering industry, the converse was true with the local firms. This could be explained by the fact that while foreign firms got more attracted to the agro based industries and invested accordingly, locally owned firms mainly of Asian origin got more attracted to the machine and engineering industry [Swainson, $(1978$ : 1980); Himbara, 1994 .

A high proportion of foreign fims in food processing had a strategy of diversifying their proclucts $(56 \%)$ and process techrology $(63 \%)$ compared to those in the machine and enginecring industry at $(27 \%)$ for products and $(31 \%)$ for process. The same trend was observed in the local firms. It is interesting however to note that a higher proportion of local firms in machine and engineering industry had a continuous strategy to change their products and processing technology than the foreign firms. This could be expected as the local firms try to introduce changes to match with those of foreign firms. As indicated elsewhere, local firms were observed to learn more from demonstration effects.

The proportion of firms offering technological training averaged $30 \%$ in the two industries. While the same proportion of locally owned firms $(28 \%)$ offered training in both food and machine and engineering industry, foreign firms seemed to offer more training in food processing $(37 \%)$ than in machine and engineering industry $(26 \%)$. Interestingly, the difference between the propottion of local firms (28\%) offering training in machine and engineering industry from that of foreign furms $(26 \%)$ was not much. Although these figures show that firms in Kenya offer technological training to an extent, the proportions are however low but do compare to those obtained in the World Bank RPED study (Biggs, Shah and Srivastava, 1995). It was also noted that the kind of training offered differed substantially between firms while in the case of foreign firms raining was routine, internal and often external including internationally, most of the local firms just offered simple in house training usually done on ad hoc basis.

On R\&D, a high proportion of foreign firms conducted R\&D in food processing ( $54 \%$ ) and machine engineering industry (31\%) compated to only (18\%) of the local firms in the food industry and $(15 \%)$ in the machine engineering industry. This is expected given that foreign firtms have resources to sptead over R\&D and to engage skilled scientists and engineers. However as noted from the survey done, the kind of R\&D done mainly involves simple activities such as quality control, materials and chemical analysis, reverse engineering, adaptive engineering and trouble shooting. This supports the argument that MNCs usually concentrate their R\&D in their home countries - parent companies and conduct very little abroad [Lall, (1979; 1980); Cantwell, 1995; OECD, 1998; Patel and Vega, 1999; Amsden, Tschang and Goto, 2001; Rasiah, 2003] ${ }^{113}$. The overall low levels of R\&D for local firms conld be explained by weak demand of high value added commodities as most of them just produced for local consumption compared to foreign firms. Nevertheless some of the processed products are exported in their raw form (low value added) in anticipation of further value addition in the export market as is often the case with tea or coffee.

1.3 Sukel (1989), Furtato (1973) and Cardoso (1977: 1979) argued that TNCs stimulate manufacturing in Latin American Economies, but he nature of their operations tends to confine technological capabilicies to low value added netivitis. 
As expected a higher proportion of foreign firms participated in exports that the local firms. This supported the finding obtained in Chapter 4 . White $20 \%$ and $18 \%$ of the local firms were exporters in the food and machine and engineering industry nespectively, $55 \%$ and $22 \%$ of the foreign firms exported in food and machine and engineering industiy respectively. The average of firms exporting in the food industry was about $38 \%$ and about $29 \%$ in machine and engineering industry. This is expected given that foreign firms are more endowed with export capabilities than the local firms. These results compare to those obtained by Graner and Isaksson (2002: p. 181-2) who using RPED time series data for three years $1993-5$, found that $38 \%$ and $31 \%$ of firms in food processing and machine and engineering were exporting respectively.

"The difference between local and foreign firms in import of raw materials was not significant. While $13 \%$ and $15 \%$ of the local frrms in food and machine and engineering industry respectively imported their raw materials, a similar proportion of foreign firms $\left(17^{\circ} \%\right)$ imported their taw materials in both industries. This implied that apart from the machinery and equipment the rest of the raw materials are sourced domestically.

Under labour market conditions, wages were considered. Union was also taken into consideration but given that one of the main roles of such unions is to lobby for salary increases and better wotking conditions, wages was therefore considered to be the best indicator of labour market conditions. There was tremendous difference between the local and foreign firms in terms of annual wages paid per person. The data collected showed that the annual wages paid per person in foreign firms in food processing industry was 637.3 thousand Kenya Shillings annually compared to local firms which paid 132.4 thousand Kenya Shillings annually. Similarly, foreign firms in machine and engineering industry paid 279.2 thousand Kenya Shillings anmually while local firms paid 194.0 thousand Kenya Shillings annually. This is not surprising as high salaries paid in foreign firms could be due to technologies used that ate more skill biased than those used in local firns. It could also be due to the fact that shilled workers in foreign firms ate equally skilled and effective in bargaining for high wages (Velde and Morrissey, 2001). The difference in wages between foreign and local firms was similarly noted in other studies: Aitken, Harrison and Lipsey (1996) for Venezuela and Mexico; Mazumdar (1995) for Cameroon and Zambia; Lipsey and Sjoholm (2001) for Indonesia; Velde and Morrissey (2001) for Cameroon, Ghana, Kenya, Zambia and Zimbabwe. 


\begin{tabular}{|c|c|c|c|c|c|c|}
\hline Variables & $\begin{array}{l}\text { Locall } \\
\text { Firms } \\
\text { Food }\end{array}$ & $\begin{array}{l}\text { Local } \\
\text { Firms } \\
\text { Machine }\end{array}$ & $\begin{array}{l}\text { All } \\
\text { Local } \\
\text { Firms }\end{array}$ & $\begin{array}{l}\text { Foreign } \\
\text { Fürms } \\
\text { Food }\end{array}$ & $\begin{array}{l}\text { Foreign } \\
\text { Firms } \\
\text { Machine }\end{array}$ & $\begin{array}{l}\text { All } \\
\text { Foreign } \\
\text { Firms }\end{array}$ \\
\hline $\begin{array}{l}\text { Technological Spillover } \\
\text { (Index) }\end{array}$ & 3.3 & 3.4 & 3.4 & 3.1 & 3.3 & 3.2 \\
\hline $\begin{array}{l}\text { Foteign Presence } \\
\text { Firm Characteristics }\end{array}$ & 9 & 18 & 14 & 62 & 27 & 45 \\
\hline 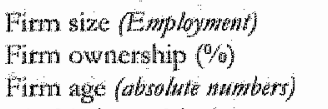 & $\begin{array}{l}117 \\
52\end{array}$ & $\begin{array}{l}102 \\
63\end{array}$ & $\begin{array}{l}109 \\
58\end{array}$ & $\begin{array}{l}456 \\
48\end{array}$ & $\begin{array}{l}113 \\
37\end{array}$ & $\begin{array}{l}285 \\
43\end{array}$ \\
\hline $\begin{array}{l}\text { Machine age (abrolute } \\
\text { mushiners) }\end{array}$ & $\begin{array}{l}22 \\
15\end{array}$ & $\begin{array}{l}22 \\
18\end{array}$ & $\begin{array}{l}22 \\
17\end{array}$ & $\begin{array}{l}45 \\
24\end{array}$ & $\begin{array}{l}29 \\
19\end{array}$ & $\begin{array}{l}39 \\
22\end{array}$ \\
\hline Firm Perfomance & & & & & & \\
\hline $\begin{array}{l}\text { Capacity Utilisacion (\%) } \\
\text { Infrastructural and } \\
\text { Instirutional support }\end{array}$ & 61 & 63 & 62 & 70 & 62 & 60 \\
\hline Tnfrastructure Support (\%) & 35 & 35 & 35 & 50 & 31 & 41. \\
\hline linstitutionall Support $(\%)$ & 37 & 26 & 32 & 51 & 21. & 36 \\
\hline Business Assoctations (\%) & 15 & $\begin{array}{l}20 \\
25\end{array}$ & 18 & $\begin{array}{l}33 \\
58\end{array}$ & 24 & $\begin{array}{l}29 \\
43\end{array}$ \\
\hline $\begin{array}{l}\text { Firm Interactions (\%) } \\
\text { Absorptive Capacity }\end{array}$ & 31 & & 28 & & 27 & \\
\hline $\begin{array}{l}\text { Univtechwoc (o/\%) } \\
\text { Technology Gap (halue of } \\
\text { core mach) } \\
\text { Firm Strategy }\end{array}$ & $\begin{array}{l}29 \\
7.74 \mathrm{e}+07\end{array}$ & $\begin{array}{l}51 \\
1.35 e+08\end{array}$ & $\begin{array}{l}40 \\
1.06 \mathrm{e}+08\end{array}$ & $\begin{array}{l}39 \\
4.16 e+08\end{array}$ & $\begin{array}{l}58 \\
3.10 \mathrm{e}+08\end{array}$ & $\begin{array}{l}49 \\
3.63 e+08\end{array}$ \\
\hline $\begin{array}{l}\text { Diversify products }(\%) \\
\text { Process technology }(\%) \\
\text { Broanden Knowledge base }\end{array}$ & $\begin{array}{l}35 \\
43\end{array}$ & $\begin{array}{l}34 \\
41\end{array}$ & $\begin{array}{l}35 \\
42\end{array}$ & $\begin{array}{l}56 \\
63\end{array}$ & $\begin{array}{l}27 \\
31\end{array}$ & $\begin{array}{l}42 \\
47\end{array}$ \\
\hline $\begin{array}{l}\text { R\&D } \\
\text { Human Resource } \\
\text { Dexelopment }\end{array}$ & 18 & 115 & 17 & 54 & 31 & 43 \\
\hline $\begin{array}{l}\text { Technological training }(\%) \\
\text { Teade Oricntation }\end{array}$ & 28 & 28 & 28 & 37 & 26 & 32 \\
\hline $\begin{array}{l}\text { Expors }(\%) \\
\text { Imports }(\%) \\
\text { Labout } M \text { Marther Conditions }\end{array}$ & $\begin{array}{l}20 \\
13\end{array}$ & $\begin{array}{l}18 \\
15\end{array}$ & $\begin{array}{l}19 \\
14\end{array}$ & $\begin{array}{l}55 \\
17\end{array}$ & $\begin{array}{l}22 \\
17\end{array}$ & $\begin{array}{l}39 \\
17\end{array}$ \\
\hline Wages (000 KShs) & 132 & 194 & 163 & 637 & 279 & 458 \\
\hline
\end{tabular}

Sonrce: Tabulated from author's field survey $2003 / 2004$

\subsubsection{Econometric Setting: Binomial Logit Estimation for the Determinants of Spillover Occurrence}

In determining spillover occurrence, a gradual way of measuring spillowers using an ordinal scale ranging from a minimum score of 0 to a maximum score of 5 where 0 represented "nothing - no spillowers" and 5 a "highest spillovers occurrence" was 
adopted, see figure 5.1. The ordinal scale employed would require use of limited dependent rariable estimation techniques - binomial and ordered logir estimation techniques.

Figure 5.1: An Ordered Structure of Technological Spillover Occurrence

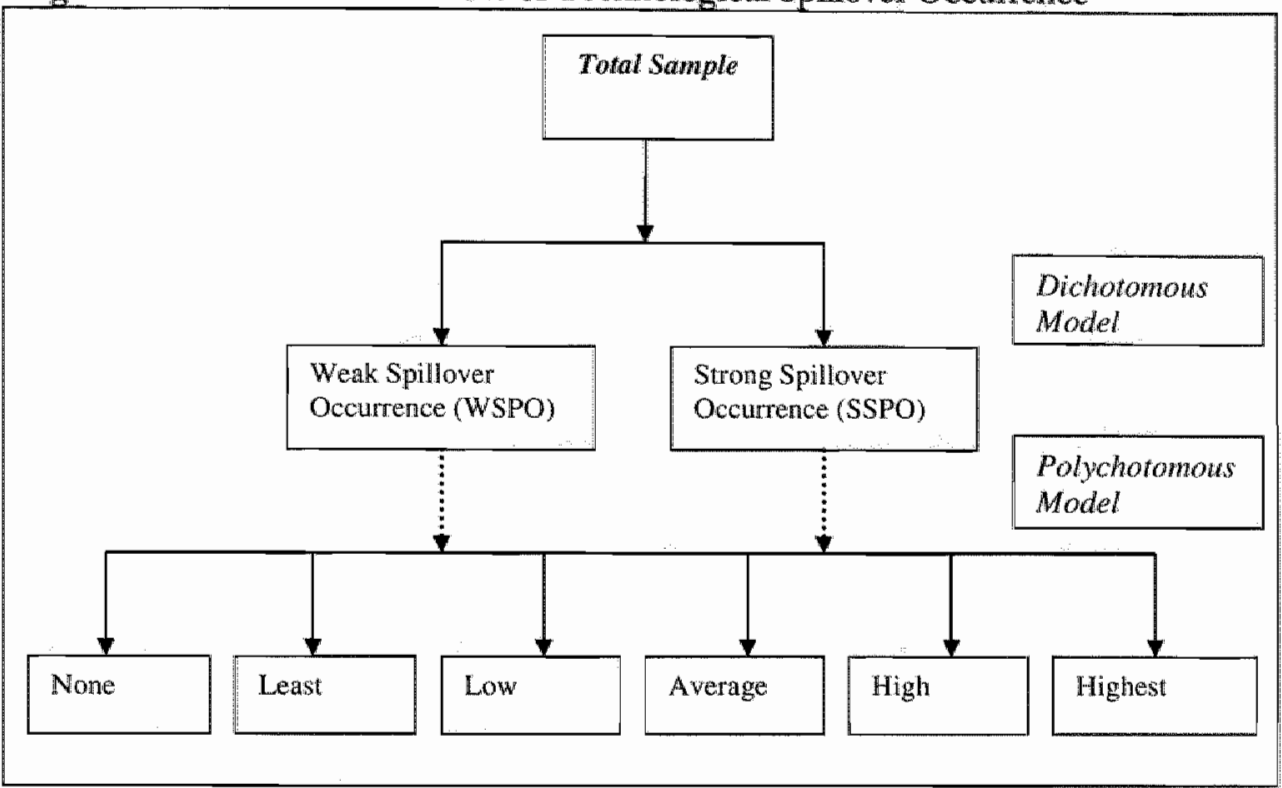

As observed in Figure 5.1, the data can be put into two distinct categories. On the basis of SPO INDEX, enterprises rated above 3 score were classified as enterprises with strong spillover occurrence whille those tated below 3 score were regarded as firms with weak spillover accurrence. Due to the dichotomous nature these responses then assumes a binary procedure: weak spillover occurrence (WSPO) and strong spillover occurrence (SSPO). In this case the empirical analysis will start with a simple dichotomous logit estimation of spillover determinants followed by multinomial ordered logit estimation. The use of twomstage estimation is important to check the consistency and robustness of the results. Moreover this approach would provide us with a wide set of results to examine spillovers in the context of a country that is technically backward.

The formulation of a logit binary model proceeds as follows: the dependent variable in the econometric model is taken as a single explanatory variable ( $\mathrm{Y}$ ) that is treated as a dichotomous variable taking discrete values 1 (for yes responses), otherwise 0 . A binary qualitative response model that links the decision or outcome to a set of factors is constructed as:

$$
Y_{s_{i}}=\beta_{0}+\sum_{j=1}^{k} \beta_{i} X_{i j}+\vartheta_{i}
$$

Where $Y_{\mathrm{x}_{i}}$ is taken as a latent variable since it is unobservable, $\vartheta_{i}$ is an error term whose cumulative distribution is assumed to follow a logistic distribution. Hence in addition to the multinomial analysis, logit analysis will also be performed just to compare the results 
to hose obtained by multinomial analysis techtique. Logit analysis is one of the limited dependent variable estimation procedures and is different from linear estimations: In dichotomous cases a lineat model techntque like the otdinary least squares technique is normally faced with several shortcomings. An obvious one is that of the complication, which arises because the residual is heteroscedastic in a way that depends on parameters (Gujarati, 1995; Green, 2002). Since ${ }^{*_{\text {i }}}$ is not observable, what we therefore observe is

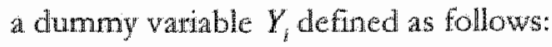

$$
\begin{aligned}
& Y_{i}=1 \text { if } Y_{s_{i}}>0 \text { (Strong spillower occurs SSPO) } \\
& Y_{i}=0 \text { oiherwise (Weak spillovers occurs WSPO) }
\end{aligned}
$$

From the above, we obtain the probability of spillover occurrence as follows:

$$
\begin{array}{ll}
\operatorname{Pr} o b(S S P O=\text { occurs }) & \operatorname{Pr} o b(Y=1)=F\left(\beta_{0}+\sum_{i=1}^{k} \beta_{i} X_{i j}\right) \\
\operatorname{Pr} o b(W S P O=O \text { Ocuurs }) & =\operatorname{Pr} \circ b(Y=0)=1-F\left(\beta_{0}+\sum_{i=1}^{k} \beta_{i} X_{i j}\right)
\end{array}
$$

- Fis the cumulative distribution function

- $X_{i j}$ is a vector of independent variables which detemine spillover occurtence, see Table 5.17 .

- $\beta_{0}$ is a constant parameter and $\beta_{i}$ is the set of parameters reflects the impact of changes in $\mathrm{X}$ on the probability. These are the parameters to be estimated in the model.

As indicated earliet if the distribution of $\vartheta_{i}$ in equation 5.4 is symmetric ${ }^{1 / 4}$, then

$$
P\left(Y_{i}\right)=\quad F\left(\beta_{0}+\sum_{i=1}^{k} \beta_{i} X_{i j}\right)
$$

If $\vartheta_{i}$ has a logistic cumulative distribution then it is regarded as a logit model. If the model is written in terms of $\log$ odds then direct impacts of $\beta_{i}$ can be estimated as:

$$
\frac{P\left(Y_{i}\right)}{\left.1-A Y_{i}\right)}=\quad \beta_{i}+\sum_{i=1}^{k} \beta X_{i j}
$$

From equation 5.6 above, it can be noted that log odds tatio becomes a linear function of the independent variables. The logit model was estimated with Stata version 8 using maximum likelihood estimation technique. The dependent variable is spillover occurrence index defined as a binary variable taking 1 when strong spillovers occurred (SSPO) and 0 if weak spillovers occurred (WSPO).

\footnotetext{
114 More details on this can be obraned in Madelala (1983); Gujatat (1995) and Green (2002).
} 


\subsubsection{Econometric Setting: Multinomial Ordered Logit Estimation for the Determinants of Spillover Occurrence}

By categorising spillover occurrence into weak or strong spllover occurrence, determinants of spillover occurrence were examined using binomial logit estanation in the preceding section. Binomial logit can only be used when the dependent varable is a dichotomous variable. A polychotomous dependent variable requires a different approach - a polychotomous model (Multinomial ordered logit) to determine spillover occurrence. Use of a polychotomous model allows the full spectrum (ordinal setting) of spillover occurtence as shown in Figure 5.1 to be considered in the estimation. Note that the two lowest levels in the ordinal scale were dropped since on average none of the firms recorded spillover occurrence index below 2 - "low". In addition to providing a wide set of results from which conclusions for spillover occurrence can be drawn, the ordered logit approach is expected to be more illuminating since mote information is included ${ }^{15}$ compared to the binary logit estimates.

Multinomial ordered logit technique is built around a latent regression in the same manner as the binomial logit model above. Assume that there are institutional factors defined by a vector I, structure factors defined by a vector $S$, conduct factors defined by a vector $C$, performance factors defined by a vector $P$ and spillover occurrence defined by a vector SPO. For a given enterprise say i, the relationship between spillover occurrence and the factors can be formulated as:

$$
S P O_{i}=\operatorname{SPO}\left(I_{i}, S_{i}, C_{i}, P_{i}\right)+\vartheta_{i}
$$

Where $\vartheta_{i}$ is the usual stochastic disturbance term assumed to be independent and normally distributed across observations. Supposing the subscript i in our model is dropped then we have:

$$
S P O^{*}=\beta^{*} x+v
$$

In this expression, $S P O^{*}$ is unobserved as in the case of binary logit or probit models. $x$ is a vector containing all the independent variables $I, S, C, P$ and $\beta$ is a vector for the associated coefficients for all the independent variables.

\footnotetext{
${ }^{115}$ Binary takes into consideration only two alternatives for the binary variable while polychotomous is designed to allow more than two dependent wariables.
} 
Subsequently, it can be observed that:

$$
\begin{array}{lll}
S P O=0 & \text { if } & S P O^{*} \leq 0, \\
S P O=1 & \text { if } & 0<S P O^{*} \leq \mu_{1}, \\
S P O=2 & \text { if } & \mu_{1}<S P O^{*} \leq \mu_{2} \\
& \\
S P O=y & \text { if } & \mu_{j-1}<S P O^{*} .
\end{array}
$$

which in itself is equivalent to censoring with SPO observed in I ordered categories - in our case $J$ is 5. $\mu_{i}$ are unknown parameters to be estimated with $\beta$, separating the specific adjacent SPO categories. With minor modification that allows us to make estimations with a logistically distributed disturbance, we obtain the following probabilities:

$$
\begin{gathered}
\operatorname{Pr} o b(S P O=0)=\Phi\left(-\beta^{\prime} x\right) \\
\operatorname{Pr} o b(S P O=1)=\Phi\left(\mu_{1}-\beta^{\prime} x\right)-\Phi\left(-\beta^{\prime \prime} x\right) \\
\operatorname{Pr} o b(S P O=2)=\Phi\left(\mu_{2}-\beta^{\prime} x\right)-\Phi\left(\mu_{1}-\beta^{\prime} x\right) \\
\cdot \\
\operatorname{Pr} O b(S P O=J)=1-\Phi\left(\mu_{1}-\beta^{\prime} x\right)
\end{gathered}
$$

D reptesents the cumulative logistic distribution function.

The condition required for all the probabilities to be positive is that they must have

$$
0<\mu_{1}<\mu_{2}<\mu_{3} \ldots \ldots \ldots \ldots \ldots \ldots \ldots \ldots \ldots \ldots \ldots \ldots \ldots \ldots \ldots
$$

which is a generalisation of the logit/probit models. Under normal circumstances, the first parameter is normalised to zero hence reducing the number of parameters to be estimated by one.

An interesting phenomenon chatacterising limited dependent analysis is that it allows us to enrich our empirical analysis by computing the marginal effects. Usually marginal effects of the independent variables on the probabilities are nor equal to the coefficients. The sum of marginal effects should equal to zero flowing from the requirement that under all circumstances the probabilities must add up to 1 . It should however be emphasised that computation of marginal effects differs depending on the nature of independent variables and the level at which they are computed - the most common level being at the mean. We first consider the case of a continuous independent variable. A marginal change in the predicted probability of the outcome $m$ (say in the interval 
$\mu_{m-1}$ to $\mu_{m n}$ ) for a change in a particular independent variable $x_{k}$ at its nean is determined as follows:

$$
\frac{\partial \operatorname{Pr}(S P O=m \mid \bar{x})}{\partial x_{k}}=\beta_{k}\left[\Phi\left(\mu_{m}-\dot{x}^{\prime \prime} \beta\right)\right]
$$

In the lowest caregory the marginal effect would be:

$$
\frac{\partial \operatorname{Pr}(S P O=0 \mid x)}{\partial x_{k}}=-\left[\Phi\left(\beta^{\circ} x\right)\right] \beta
$$

and for the highest category the matginal effect would be:

$$
\frac{\partial \operatorname{Pr}(S P O=j \| \bar{x})}{\partial x_{k}}=\Phi\left(\mu-\beta^{\prime} x\right) \beta_{k}
$$

In the case of discrete explanatory variables, the approacll is slightly different. The change in the predicted probability of outcome $m$ as a particular explanatory variable $x_{k}$ changes from $\mu_{0}$ to $\mu_{1}$ while the rest of the variables ate sustained at $\mathbf{x}$ is determined by the following expression:

$$
\frac{\Delta \operatorname{Pr}(S P O=m \mid \bar{x})}{\Delta k_{k}}=\operatorname{Pr}\left(S P O=m \| \bar{x}, x_{k}=x_{i}\right)-\operatorname{Pr}\left(S P O=m \mid \bar{x}, x_{k}=x_{0}\right) 5.14
$$

The dependent variable is spillover occurrence index defined as a binary variable taking 1 when strong spillovers occutred and 0 if weak spillovers occurred. As discussed in Clapter 2 , spillover occurrence was influenced by at variety of factors. Since one of the main objectives is to determine the influence of foreign presence on spillover occurrence, foreign presence was therefore regarded as an important independent variable among others considered. Other independent variables consideted include firm characteristics (size, ownership, Astan, firm and machine age); firm performance (capacity utilisation); infrastructural and institutional (business, infrastructure and institution support); firm interaction (with support institutions). Additionally other independent ratiables included absorptive capacity (proportion of workers with university, technical and vocational education background and technology gap); firm strategy (diversification of products, acquisition of process technology and R\&D); human tesource development (technological training); trade orientation (exports and imports); labour market conditions (wages) and industry type. The hypothesised direction of influence on all these variables was extensively discussed in Chapter 2 and is once again shown in Table 5.17 which in addition provides detaled characteristics of all the variables. 
Table 5.17: Variables Included in the Empirical Models and their Hypothesised Influcnce on Spillower Occurrence in Kenya's Manufacturing Industry

antables

Tothnological spilower (STOMNDX)

Fonign Presence (CORPS) Variable Detcription

Wariable Measuremen

Hypothesized Infuence

Firm Characteristics

Firm size (s) $2 \mathrm{E})$

Foreign ownership?

(1) Doreign equily (PART)

(2) Ama $(K A S \pi A N)$

Finm Age (HTMACila)

hige square (ACESQRD)

Machine age (MACHACE)

Fitm Performance

Capaciry Urilisation

(CAPUTIS)

Infrastructurnal and

Instrutuonat support

Infratructure (NNFSPT)

Tostututional (INSTSPT)

Business (BUSASPT)

Fistm Intetactions

(MTERACTONS)

Absorptive capacty

Slkilled intensing (SKILL)

Tacthology gep (ROAP)

Wum Suntegy

Diversity products

(STRTPDCH)

Process rechnolog;

(STRTPRCS)

Broaden Knowledge base

(S!R"RT)

Htaman Resounce

De relopment:

Terhnologixal thaining

(TRANING)

"irade Oricnation

Exports (EXPORTS)

Import (NAPORTS)

I. abour Market

Condtituns

Wages (WAGES)

Wages per person in an firm

Industry type (industry dummy)
Spillover oceurrence index

Frongin presence at Grm level

5 if highest, 0 if aone

Aithens method

1 if lagge, 0 othenwise

+ or -

as Foreign equiry

1 if Asian, 0 otherwise

Yerars in absolute numbers

Agre.2/100

Age of firm squared

Age of core prodaction machinery

Fitm capacity tulisation

Years in abolute numbers

of Capacity urilised

$+$

$+$

Infrastructure stpport to firm

Institutional support to firm

Support from business associations

Presence of rims interactions

Shate of unverstry \& technical

$\checkmark$ alue of core production machinery

Diversily inno new producrs

Acquire new process technology

Undertakes R\&D

Exports of manurac med goods Troports tav matertals
Wodrtakes trining
Iif exports, 0 oherwise

1 if impore, 6 atherwise

H

1 Infatsucture, 0 otherwise

1 Institurional, 0 onlerwise

1 Business, 0 othenwise

Iif interacts, 0 ot]erwise

\% Share in total employment +

1 high tech. gap, 0 otherwise +or -

1. if to diversify, 0 otherwise

1 if to accquire, ortherwise +

1 if to do R\&D, 0 otherwise +

1 if to train, 0 olhetwise

4

Wages per person

1 if food, 0 otherwise $\quad$ or -

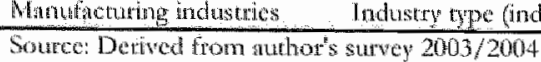




\subsubsection{Binomial and Ordered Logit Model Estimation: Results and Discussion}

Table 5.18 and 5.19 presents the results of the binomial and ordered model estimatted respectively. To avoid the problem of multicollinearity, backward selection procedure was employed to select the independent variables to be included in the final models. Nevertheless, the results of correlation tests in Appendix 5.5 showed that none of the independent variables posted high and significant correlation and thus there was no multicollinearity problem. The two estimated models passed the White (1980) test for heteroscedasticity. The overall goodness-of-fit statistics - Log likelihood, Uilkelihood ratio LR-Test and Pseudo $R^{2}$ - indicated good overall performance of the two models. In comparison however, and based of the goodness-of-fit statistics, ordered logat model performed better than the binomial model estimated.

For the two models, estimated backward selection was done in such a way that only variables with probability values bellow 0.2 would be retained. Accordingly, only marginal effects of these variables were computed and reported. Results of full model with ordered logit are however included in the Appendix 5.6. With backward selection the independent variables dropped after failing the significance test included R\&D, subscribed equity, firm performance, infrastructure, and firm's strategy to introduce product changes regularly.

Table 5.18 and 5.19 shows that as expected: most of the estimated coefficients had the a prioti expected signs and were statistically significant at $1 \%, 5 \%$ and $10 \%$ levels. From the empirical analysis performed, foreign presence was positive and statistically significant at $5 \%$ in both binomial. and ordered logit estimarion. The data produced statistically significant results confirming our hypothesis that spillover occurrence in Kenya's manufacturing industry is stimulated by foreign presence. For example, an increase of foreign presence in the industry by 1 unit increased spillovers occurtence by 1.86 and 1.37 points for binomial and ordered logit models respectively. Moreover, an increase in foreign presence increased the probability of high and highest spillover occurrence lewels by about $2.98 \%$ and $2.6 e-05 \%$ respectively, Table 5.19 . These findings are in accordance with the theoretical and conceptual framework formulated in Chapter 2 that MNCs in a host country are associated with knowledge spillovers. For instance, Teece (1977) had argued that introduction of new products and production processes by foreign firms may benefit domestic furms through the accelerated diffusion of rechnology. Further, these results are supported by other empirical studies, which found spillover occurrence due to the presence of MNC firms. Examples of such studies include detailed case studies by Rasiah (1994: 1995) and Lall (1985) ${ }^{16}$.

The size of the firm was statistically significant at $10 \%$ level. This implied that firm size had a positive influence on spillover occurrence. Spillovers were more likely to occur in large firms than in the small firms. If a firm changed in size from being small to large it: was likely to increase its spillover occurrence by 3.62 points. The positive relationship between spillovet occurrence and firm size could be based on a number of propositions. Besides enjoying greater conomies of scale large firms are able to engage the services of skilled technical personnel. Large firms are favoured by the capital market imperfections,

Tro These results compate to those of eaty conrrbutors based on production function estimation of spilovers following Caves (1974). Such studies applying a similat approach we me man fGloberman, 1979; Blomstrom and Pearson, 1983; Kokko, (1994: 1996); Btomstrom and Sjoholm, 1999 etc. Ous results in this chaper contradiet those studies that falled to arrive at tochnological spillovers. 
which confer advantage on large firms in obtaining finance for technological activities [Tybout, (2000: p, 12)]. With these advantages (skilled labour, finance and extended knowledge networks etc) large firms ate capable of undertaking more innovations than smalli firms, which results in knowledge generation and accumulation from learning by interaction and learning by doing effects. As a result of these learning processes over time, the accumulated stock of knowiledge and experience increases a firm's absorptive capacity, which in turn enables the firm to assimilate, adapt and exploit external knowledge (spillovers). In the long rum, the knowledge accumulated results in increased firm's rechnological capability and thus efficiency. It is not surprisingly thetefore that empirical analysis using a variety of data from developing countries showed a positive felationship between firm size and rechnological capalitity (Wignaraja, 2001; Westphal, Kritayakirana, Petchsuwan, Sutabutr and Yuthavong, 1990; Romijn, 1999). In other studies large firms have been wiewed as mote efficient than small firms Gavonic, 1982; Little, Mazumdar and Page, 1987).

Two of the proxies of experience and knowledge accumulated were significant at $5 \%$ for the two models. Furm age and age-square had positive influence on spillover occurrence. However, based on the magnitude of their marginal effects, the two variables do not seem to hawe much influence on spillower occurrence. The age results imply that spillovers were more likely to occur in old firms than in young firms. The learning process in the firm could explain the age influence on spillover occurrence. Over time learning by doing effects results in experiential and tacit knowledge and consequently the accumulated stock of knowledge enhancing a firm's absorptive capacity, which in turn enables the firm to assimilate, adapt and exploit external knowledge spillovers (Cohen and Levinthal, 1990; Rasiah, 2002; Criscuolo and Narula, 2002). The tesults obtained in Table 5.19 showed that as the firm grows older, it increases its probability of high and highest spillower occurrence by $0.77 \%$ and $6.67 \mathrm{e}-06 \%$ respectively. The estimated marginal effect of age squared was negatiwe in the two models and significant indicating that growth of spillover occurrence decreased with age "an inverted- $U$ shaped relationship". Age of the cone production machinery was also positive and highly significant in the two models estimated. The results showed that old production machinery was characterised by high levels of spillover occurrence compared to the relatively new production machinery. As an example, old production machinery increased the predicted probability of average level of spillover occurrence by $5.9 \%$, Table 5.19 .

The Kenyan Asian variable was significant at $5 \%$ and $1 \%$ level, with a strong marginal effect of 7.53 and 5.29 for binomial and ordered logit estimations respectively, Table 5.18 and 5.19. The implication of this tesult is that more spillovers are likely to occur in firms owned by Asians compared to non-Asian firms in Kenya. 'The multinomial ordered results showed that a firm changing ownership and becomes Asian owned it reduces its probabiling of low and average spillover occurrence by $4.55 \mathrm{e}-03 \%$ and $26 \%$ and at the same time inctease its predicted probabilities of high and highest levels of spillover occurrence by $26 \%$ and $2.96 \mathrm{e}-04 \%$ respectively. These results were in support of our hypothesis as expected given that the Asian firms in Kenya are more dynamic, entrenched in high value added activithes compared to the African firms. This argument was discussed in detail in Chapter 3. Similarly, it is supported by other studies (Chandaria, 1963; Leys, 1975; Murray, 1978; Himbara, 1994). Himbara (1994: p. 35) noted that in comparison to African, Asians firms were characterised by high entrepreneur and commercial stills; efficiency and competitive edge; hard working and survived with modest resources with family tmits and collective otganisations playing a pivotal role in providing mechanisms to engender discipline and cohesion. 
The data suggested that interaction was an important determinant of knowledge spillover accurrence. Although interaction was not statistically stgnificant in the binomial estimation, multinomial ordered estimated a strong positive marginal effect that was statistically significant at $5 \%$ level. The results in Table 519 shows that a fim which interacts reduces its probability of low and average spillover occurrence levels by $7.79 \mathrm{e}$ $03 \%$ and $3.2 \%$ and increases the predicted probability of high and highest spillover occurrence by $3.3 \%$ and 2.85 e- $05 \%$ respectively. This finding is supported by the literature on learning and innovation, which emphasises the importance of interactions (with suppliers, customers, support institutions and industry business associations) in firm learning and new knowledge acquisition including accumulation of tacit knowledge. Such interactions are likely to provide information about technologies and new matkets and other inputs to complement the internal learning process, such as external staff training, consulting services, and R\&D grants [Lundwall, (1988: 1992); Freeman, (1991* 1995); Rothwell and Dodgson, 1991; Dodgson, 1993; Edquaist, 1997..

Table 5.18 Marginal Effects: Determinants of Spillover Occurrence, Binomial Logit Estimation, Food Processing and Machine and Engineering Industries - Pooled

\begin{tabular}{|c|c|c|c|c|}
\hline Variables & $\mathrm{d} y / d x$ & Std. Errors & $\mathrm{Z}$-Values & P-Values \\
\hline LFORPS & 1.858 & 0.876 & 2.12 & 0.034 \\
\hline $\mathrm{SIZE}^{\psi}$ & 3.618 & 1.980 & 1.83 & 0.068 \\
\hline FIRMAGE & 0.444 & 0.197 & 226 & 0.024 \\
\hline AGESQRD & -4.318 & 1.982 & -2.18 & 0.020 \\
\hline MACHAGE & 0.212 & 0.083 & 2.55 & 0.011 \\
\hline KASTAN & 7.530 & 3.007 & 2.50 & 0.012 \\
\hline SKILL & 2.811 & 1.268 & 2.22 & 0.027 \\
\hline TGAP & 6.976 & 2.771 & 2.52 & 0.012 \\
\hline STRTPRCS & 7.613 & 3.695 & 2.06 & 0.039 \\
\hline TRAININGG" & 6.189 & 2.973 & 2.08 & 0.037 \\
\hline EXPORTS & -6.330 & 3.036 & -2.09 & 0.037 \\
\hline IMPORTS" & 1.977 & 1.519 & 1.30 & 0.193 \\
\hline NWAGES & -2088 & 0.754 & -2.77 & 0.006 \\
\hline Cons & -25.560 & 12.397 & -2.06 & 0.030 \\
\hline Industry dummies & $Y e s$ & & & \\
\hline No. of observations & 73 & & & \\
\hline Log Likelihood & -13.867 & & & \\
\hline LR-Test & $\begin{array}{l}61.620 \\
(0.000)\end{array}$ & & & \\
\hline Pseudo $\mathrm{K}^{2}$ & 0.6896 & & & \\
\hline
\end{tabular}

Note: Spillower Index computed is talken as the dependent variablewproxy for spillower occurrence $(\psi)$ $\mathrm{dy} / \mathrm{dx}$ is for discrete change of dummy variable from 0 to 1

Source: Computed from author's field survey $2003 / 2004$

The variables for absorptive capacity had the expected results. "The first one defined as proportion of staff with university, polytechnic and vocational education was important in explaining spillover occurrence. The direction of the estimated marginal effect was 
positive and significant at $5 \%$ in the two models. If a firm increases the proportion of its staff with university, polytechnic and vocation graduates, it would increase its predicted probabilities for high and highest levels of spillower occurrence by $3.67 \%$ and $3.20 \mathrm{e}-05 \%$ respectively. The resulfs supported our hypothesis that skilled personnel are important for spillover occurtence in the Kenyan furms. An adequate stock of technically qualified. manpower is necessary to absorb new technologies, modify them, create and transfer new technological knowledge and information (Lall; 1992; Ernist, Ganiatsos and Mytelka, 1998). Adequate stock of knowledge in a firm is necessary if it has to recognise the value of new external infomation and knowledge, be able to assimilate and exploit it for vatious objectives [Cohen and Levinthal, (1989: 1990: p. 128); Benhabib and Spiegel, 1994].

The technology gap variable was positive and significant at $5 \%$ and $1 \%$ for binomial and ordered estimarions respectively. From the results obtained, a change from high to low technology gap resulted in an increase of 6.98 and 7.44 points for binomial and ordered logit estimations respectively. This results supported our hypothesis that low technology gap had a positive influence on spillover occurrence in the Kenyan industry. For example, "Table 5.19 shows that low technology gap reduces the probability of low and average levels of spillover occurrence by $1.47 \mathrm{e}-01 \%$ and $8.52 \%$ and at the same time increase the probability of high and highest levels by $8.67 \%$ and $7.90 \mathrm{e}-05 \%$ respectively. This is contradicted spillover literature part, which supports existence of a relatively large technology gap for spillover occurrence [Findlay, 1978; Abramovitz, 1986; Cohen and Levinthal, (1889: 1990); Benhabib and Spiegel, 1994; Gershenkton, 1962). The importance of available local skills and in house technologicall capacity in adapting and using techniques developed elsewhere has been documented (Lall, 1992; Evenson and Westphal, 1994). This is the same if technological spillovers are to occur from foreign firms (Cantwell, 1989; Kokko 1994; Sjoholm, 1997).

A firm with a strong strategy of constant modification and upgrading of its processing technology was more likely to obtain high levels of spillover occurrence compared to a firm with no strategy on machine modifcation or upgrading. This variable had a strong positive marginal effect of 6.19 with binomial and 7.31 with ordered logit estimation, which significant at $5 \%$ and $1 \%$ respectively. Table 5.19 shows that a firm which engages in the process of upgrading and undertaking changes on its production machinery incteases its predicted probability of high and highest levels of spillover occurrence by $3.99 \%$ and $3.46 \mathrm{e}-05 \%$ tespectively. One of the ways in which technological capability is acquired is by undertaking continuous, incremental modifications that adapt new technologies to the firm to fit specific situations or production conditions (Katz and Ablin, 1979; Dahlman and Westphal, 1982; Bell, Scott-Kemmis and Satyarakwit, 1982; Dosi, 1988; Bell and Pavitt, 1993; Kim, 1997; Kline and Rosenberg, 1989). Once technological capability has been accumulated then it enables high spillovers to occur since absorption capacity is enhanced.

The training variable in the firm was also very important in explaining spillover occutrence. The estimated marginal effect was strong, positive and significant at $5 \%$ with binomial estimation and $1 \%$ with ordered logit estimations. This supported the hypothesis that the more a furm undertakes technological training in the Kenyan industry the more the spillovers were likely to occur. As observed in Table 5.19, firm training resulted in reduced probabilities of low and average spillover occurrence by $1.91 \mathrm{e}-04 \%$ and $12.34 \%$ and increased the probability of high and highest by $12.36 \%$ and $1.18 \mathrm{e}-04 \%$ respectively. The observed results of training on spillovers can be explained with regard 
to accumulation of technological capability. Firm traning results n accumalation of fim rechnological capability, which in turn determines the magnitude of potertial knowledge spillovers (Pack and Westphal, 1995). Logically, a firm that offers training and also conducts R\&D is better placed to detect new extemal knowledge and its walue than a fin, which does not. Thus when a firm invests in traing as well as R\&D we can assume that in the process it increases its technological capability as well as absorptive capacity [Coken and Levinthal, (1989: 1890); Lucas, 1988. Basant and Wukert, 1996 .

Interestingly and contrary to expectation, the results of expotts obtained showed a negative influence of exports on spillover occurrence. The maxginal effects estimated in the two models were negative and significant at $5 \%$. This is possible given that exporting fims have already reached the threshold to export. ${ }^{117}$. Non-exporting firms have a lot to learn and they are therefore likely to introduce many technological changes. Exporting increased the probability of low and average levels of spillover occurtence by $7.09 \mathrm{e}-04 \%$ and $42.11 \%$ and reduced the probability of high and highest levels of spillover occutrence by $42.11 \%$ and 6.25 e-04 respectively, Table 5.19 . This result contrasted those obtained in other studies which reiterated the importance of learning by exporting (Clerides, Lach and Tybout, 1998). The results also contrasted the widely acknowledged facts regatding East Asian miracle that exports contributed tremendously to development of technology capability building as a result of intemational spillovers occurring from interactions with more sophisticated foreign clients based abroad (Drahlman and Westphal, 1982; Westphal, 1990; Lall, 1990).

Although binomiall logit estimation failed to produce significant results for imports, the marginal effect obtained with ordered logit was high, positive and significant at $5 \%$. The implication of this result is that mote spillovers occurred in importing firms than in firms that did not import. By participating in imports, a firm was likely to increase its predicted probability of high level of spillorer occurrence by $9.75 \%$ and decrease its probability of low and average levels by $8.32 e-04$ and $9.74 \%$ respectively. These results are in support of the literature which wiews imports of new capital and differentiated intermediate goods as one of the main channels for international transmission of technology (Posner 1961, Vernon 1966; Romer, 1990; Feenstra, Markusen and Zeile, 1996; Grossman and Helpman, 1995).

The labout market conditions, which were proxied by firm wages, had a negatrive influence on spillowet, which was statistically significant at $1 \%$ level. This was not surprising in that if a firm was paying efficiency wages then their workets were not expected to leave the companies. As an example, high wages boost workers monale and motivation and thus reduce workers mobility and the accompanying spillover [Manda, (2002: p. 60-79)]. The resules obtained from the models estimated on labour market conditions were comparable. The labour market conditions, which were proxied by firm wages, had negative influence on spillover occurrence. The estimated marginal effect of log annual wages per person for the rwo models was negative and significant at $1 \%$ level showing that a high wage was not an impottant deteminant of spillovet occurrence. It implies that higher wages in a firm is likely to reduce spillover occurrence. For instance, as a firm increases its wages, say for instance by paying efficiency wages, the probability of high and highest levels of spillover occurrence reduces by $4.72 \%$ and $4.11 \mathrm{e}-105 \%$ and the predicted probability of low and average levels of spillover occurrence increases by $7.82 \mathrm{c}-04 \%$ and $4.72 \%$ respectively.

147 This would imply that an export theshold exists bolow which all spillowers matter to achiewe expot status. Nevertheless a clear drection of causality berween learning and exporting is yec wo be detected. 
Table 5.19 Determinants of Spillover Occurrence, Ondered Logit Analysis, Food Processing and Machine and Engineering Industries Pooled

\begin{tabular}{|c|c|c|c|c|c|c|}
\hline \multirow[b]{2}{*}{ Variables } & \multirow[b]{2}{*}{$d y / d x$} & \multicolumn{5}{|c|}{ Changes in Predicted Probabilities } \\
\hline & & Change & Low & Average & High & Highest \\
\hline LTOMPS & $\begin{array}{l}1.360 \% \\
0.545)\end{array}$ & Martionst affert & $-4.93 \mathrm{e}-06$ & -0.0298 & 0.0298 & $2.60 \mathrm{e}-07$ \\
\hline FIRMAGE & $\begin{array}{l}0.351^{\text {mix }} \\
(0.143)\end{array}$ & Marysted afteat & $-1.27 \mathrm{e}-06$ & -0.0077 & 0.0077 & $6.67 e-08$ \\
\hline AGESQRD & $\begin{array}{l}-4.066^{\circ+40} \\
(1,600)\end{array}$ & Maurgivial offect & $1.47 \mathrm{e}-05$ & 0.0886 & -0.0886 & $-7.72 \mathrm{e}-07$ \\
\hline MACHAGE & $\begin{array}{c}0.270^{*} \\
(0.093)\end{array}$ & Marginal effect & $-9.74 \mathrm{c} 07$ & .0 .0059 & 0.0059 & $5.12 \mathrm{e}-08$ \\
\hline KASIAN" & $\begin{array}{l}5.293^{*} \\
(1.823)\end{array}$ & $\begin{array}{l}\text { Nome Asian } \\
\text { ta Anian }\end{array}$ & $-4.55 e-05$ & -0.2621 & 0.2622 & $2.97 e-06$ \\
\hline INTERACTIONS & 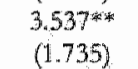 & $\begin{array}{l}\text { None interration } \\
\text { to shotractipe. }\end{array}$ & $-7.79 e-05$ & -0.0323 & 0.0330 & $2.85 e-07$ \\
\hline SKILL & $\begin{array}{l}1.686^{*} * 21 \\
(0.847)\end{array}$ & Marginal effet & $-6.09 e-06$ & -0.0367 & 0.0367 & $3.20 \mathrm{e}-07$ \\
\hline TGAPW & $\begin{array}{c}7.438^{*} \\
(2.590)\end{array}$ & $\begin{array}{c}\text { High teds gap to } \\
\text { How tets. Gupp }\end{array}$ & $-1.470 x-03$ & -0.0852 & 0.0867 & $7.90 \mathrm{e}-07$ \\
\hline STRTPRCS & $\begin{array}{l}7.306 * 2 \\
(3.205)\end{array}$ & $\begin{array}{c}\text { No proce Strat to } \\
\text { proc. Silant. }\end{array}$ & $-2.94 e-03$ & -0.0369 & 0.0399 & $3.46 \mathrm{e}-07$ \\
\hline TRAINING & $\begin{array}{c}5.797 \\
(2.038)\end{array}$ & $\begin{array}{l}\text { No tratniting } \\
\text { to traxinumg }\end{array}$ & $-1.91 \mathrm{e}-04$ & -0.1234 & 0.1236 & $1.18 \mathrm{e}-06$ \\
\hline $\mathbb{E X P O R T S}^{4}$ & $\begin{array}{l}-4.199 \% \\
(1.834)\end{array}$ & $\begin{array}{c}\text { None expoxting to } \\
\text { exporting }\end{array}$ & $7.09 \mathrm{e}-00$ & 0.4211 & -0.4211 & $-6.25 e-06$ \\
\hline "MPORTS" & $\begin{array}{l}2.509^{* *} \\
(1.312)\end{array}$ & $\begin{array}{c}\text { None inporting to } \\
\text { importing }\end{array}$ & $-8.32 \mathrm{e}-06$ & -0.0974 & 0.0975 & $9.17 \mathrm{e}-07$ \\
\hline I.WAGES & $\begin{array}{c}-2.166^{*} \\
(0.644)\end{array}$ & Marginat effect & $7.82 \mathrm{e}-106$ & 0.0472 & -0.0472 & $-4.11 \mathrm{e}-07$ \\
\hline Cur1 & $\begin{array}{l}1.756 \\
(6.344)\end{array}$ & & & & & \\
\hline$-\operatorname{Cut} 2$ & $\begin{array}{l}18.069 \\
(8.501)\end{array}$ & & & & & \\
\hline _Cut3 & $\begin{array}{c}29.764 \\
(10.963)\end{array}$ & & & & & \\
\hline Industry dummies & Yes & & & & & \\
\hline No of observations & 73 & & & & & \\
\hline Log I Litkelihood & -20.092 & & & & & \\
\hline L.R-Iest & $\begin{array}{l}98.100 \\
(0.000)\end{array}$ & & & & & \\
\hline Pseudo R2 & 0.7094 & & & & & \\
\hline
\end{tabular}

Note: Spillover index computed is atken as the dlependent watiable-proxy for spillover occurrence (W) $\mathrm{dy} / \mathrm{dx}$ is for discrete change of clummy wariable from 0 to 1 ***, *** represent $5 \%$ and $1 \%$ levels of significance respectively

Source; Computed from author"s field survey 2003/2004

\subsection{Summary and Conclusion}

This chapter used the analytical framework developed in Chapter 2 to examine the extent of spillover occurrence, kind of spillovers occurring and the mechanisms through which such spillovets accurred in Kenyan manufacturing industry. Binomial and multinomial ordered logit estimation techniques were used to examine the determinants of spillover occurrence. The data used in the andysis was collected from a survey undertaken in the Kenyan manufacturing industry, covering firms sampled from food processing and beverages, and machine and engineering industries. A sample size of 180 firms was used 
with 105 frms in food processing and 75 firms in machine and engineering industry. Locally owned fums accounted for $56.7 \%$ of the total firms while foreign firms accounted for $43.3 \%$

The four mechanisms of spillover occurrence considered in the two industries were competition, linkage, labour mobility and demonstration effects. From the desctiptive analysis done, a high proportion of locally owned firms faced very stiff competition compared to the foreign firms. Over $25 \%$ of the local firms and $50 \%$ of the foreign firms faced competition from wholly owned foreign firms or joint ventures. Defining linkages to include both pecuniary and non-pecuniary linkages, foreign firms had higher proportions of firms with both backward and forward linkages compared to locally owned firms. With regard to labour mobility, firms were observed to have gained and at the same time lost some of their professionals and managers, engineers and scientists, and other skilled and technically trained wotkers to other firms. Local firms employed more professionals and managers, engineers and scientists, and other skilled and techmically trained workers than they lost to the foreign firms and joint ventures. This was an indication that locally owned firms benefited from spillovers associated with Jabour mobility. As an example, about $7.8 \%$ of the local firms lost their workers to wholly owned foreign firms and $8.8 \%$ to joint ventures. However, about $20.6 \%$ reported having employed workers from wholly owned foreign fims and $29.4 \%$ from joint ventures. A high propontion of workers left their jobs with foteign firms to start theit own firms compared to that of the locally owned firms. The immediate implication of this observation is that foreign firms in Kenya's manufacturing industry serve as breeding grownds for local entreptenevirs. Demonstration effects also existed in the two industries. About $28 \%$ of the locally owned firms had demonstration effects from either wholly owned foreign or JV firms while about $67.9 \%$ and $43.6 \%$ of foreign firms had demonsination effects from wholly owned foreign firms and JV fums respectively.

\section{To what extent do tedbological spillowers occur in Kenva's manufachuring indwsto?}

The extent of technological spillover occurrence was determined using spillover index based on a gradual ordinal ranking developed in Chapter 2. The computed spillover index based on food and machine and engineering industries combined was approximately 3.30 indicating "average" spillover occurrence in Kenya's manufacturing industry - based on the two industries. These findings supported our hypothesis that in general knowledge spillovers do occur in Kenya's manufacturing industry. More spillovers appeared to occur in machine and engineering (3.36) than in food processing industry (3.25). The spillower index computed for the two industries from foreign furms was 3.48 indicating a relatively "bigh" spillover occurrence. The index computed for food processing was 3.45 while that of machine and engineering was 3.53 implying that more spillovers from foreign firms occurted in machine and engineering than in food processing. The spillover index computed for the two industries from local firms was 3.11 , for food processing was 3.05 while that of machine and engineering was 3.19. This represented "aterage" spillover occurrence from local firms. A comparison done by $T$ Tests showed that the spillover indexes computed by ownership were different implying that foreign fims in general generated mote spillovers compared to the local firms.

\section{To what exten does the presence of foregign finms stimulate technologial spillowers to locally onwed mathafacturing entertrisies?}

The analysis also investigated the extent to which foreign firms stimulated spillovers to the local mamufacturing enterprises. Examination of spillover occurrence in the local firms from both foreign and local firms showed an average spillover index of 3.31 for the 
two industries. food processing and beverages had 3.27 while machine and engineeting had 3.35. Although the spllower index for machine and engineering was slightly higher than that of food processing, the two industries have an average spillover occurrence. The index computed for spillovers occurting in local firms in the two industries from foreign firms only was 3.44. Food processing had 3.40 while machine and engineering industry had 3.46. The index computed for spillovers occurring in local firms in the two industries from local froms only was 3.19. Food processing had 3.14 while machine and engineering industry had 3.23. These results show that local firms in machine and engineering industry enjoyed mote spillovers from foreign firms compared local fims in food processing. Moreover foreign firms generated mone spillovers in the rwo industries in comparison to the local firms. Based on the new approach, considered in this study, the results obtained supported our hypothesis that knowledge spillovers occur in Kenya's manufacturing industry from foteign firns.

\section{What kind of tochological spillowers acm thost?}

By conceptualising spillovers in terms of technological changes, the results obtained showed that the kind of knowledge spillovers occurring most were in product changes followed closely by process changes and then changes in marketing strategy. Lowest spillovers seemed to be in management and organisation changes and in repairs and maintenance changes. These were interesting findings as they indicated that the existing spillovers were mainly in products and in process. Moreover, in all these kinds of spillovers, foreign fitus generated higher spillovers compared to the local firms strongly supporting Teece (1977) argument that introduction of new products and production processes by foreign firms was likely to benefit domestic firms through accelerated diffusion of technology.

\section{What are the mechanisms through which technolegiand spilovers oow?}

Examination of mechanisms through which technological spillovers occurred showed that compecition and demonstration generated the highest level of spillover. Results of $T$-Tests showed stgnificant differences between competition and demonstration and linkage and labour mobility implying that the first two mechanisms were important in spillover occurrence compared to the latter wo. This is perhaps a clear indication of the weak linkage system and labour mobility as well as immature state (less supportive) of institurions in the manufacturing industry. T-Tests conducted by industry showed statistically significant differences in spillovet occurrence by demonstration and backwate linkage effects. The implication of this was that more spillovers occurted by detnonstration effect in machine and engineeting industry than in food processing.

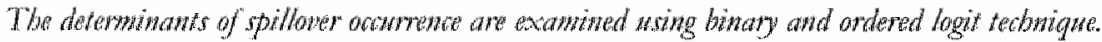

In this chapter the deteminants of spillover occurtence were examined using binary and otdered logit estimation techniques. Most of the determinants had the expected signs, were statistically significant and made intuitive sense. The data suppotted the hypothesis that spillover occurrence in Kenya's manufacturing industry was influenced by foreign presence implying that an increase in foreign presence increased spillover occurrence in firms. These fundings ate in accordance with the theoretical and conceptual framework formulared. The results are also supported by other empirical studies, which found foreign presence to be important in detemining spillower occurrence.

The estimated results of firm characteristics had the expected results. Firm size, firm age and age of the machine had significant and positive influence on spillover occurrence. Spillovers were more likely to occur in large firms than in the small firms; in old firms 
than in young firms and in furms with old production machnery than with young machinery. However, the firm age-squared had negative influence on spillover occurrence implying non-linear "inverted-U" spillower occurence. Whete majbe spillovers fail to occur in the young and in the old firms but occur in the midelle aged firms. Results obtained on the Kenyan Asian frms showed that more spillovers occurred in firms owned by Astans compared to non-Asian firms in Kenya.

On infrastructure and institutional suppott, the data supported the hypothesis that interactions with business, private and public institutions were important for spillover accurrence. Although the variable interaction was not statistically significant in the binomial estimation, multinomial ordered estimated a strong posinve marginal effect, which was statistically significant at $5 \%$.

The vatiables for absorptive capacity had the expected results. The proportion of staff with university, polytechnic or vocational education, was important in explaining spillover occurrence. The results supported our hypothesis that skilled personnel are important for spillover absorption and assimilation. Low technology gap variable was also positive and significant in the two model estimations. This results supported our hypothesis strongly that low technology gap had a positive influence on spillover occurrence in the Kenyan industry. This is in accordance with spillover literature, which supports low technology gap - certain threshold, for spillover occurrence.

Results of firm strategy showed that a firm with strong strategy to constantly modify and upgrade its processing technology was mote likely to obtain high levels of spillover occurrence compared to a firm without such a strategy. "The training strategy in the firm was also important in explaining spillover occurrence. This supported the hypothesis that the more a firm undertakes technological training in the Kenyan industry the more the spillowers were likely to occur.

The results obtained with trade orientation were contrary to expectation. The marginal effects estimated for exports in the two models were negative and significant at $5 \%$ implying that exports had a negative influence on spillower occurrence. Spillovers seemed to occur to none-exporting firms. None expotting firms have a lot to learn and they are therefore likely to introduce many technological changes. Results of imports obtained with ordered logit were positive and significant meaning that spillovers were more likely to occur in importing firms than in non importing firms. By participating in imports, a firm was likely to increase its predicted probability of high level of spillover occurrence.

The results obtained from the two models estimated on labour market conditions were comparable. The labout market conditions, which were proxied by firm wages, had negative influence on spillover occurrence. These presented strong evidence that higher wages reduced spillover occurrence in Kenya.

As a conclusion, the findings in this chapter confim accurrence of technological spillovers in the Kenyan manufacturing - at least based on food and machine, and engineering industries. The findings obtained motvate this study to attempt even a more comprehensive analysis of spillovers, their determinants and their effect on innovation by conducting in-depth analysis in a few selected case studies in the two industries studied here. By so doing we will clarify mote concretely how the spillovers take place and most important why in some firms and not in others. This task is taken up in Chapter 6 and 7. 
Appendix 5.1a: Labout Mobility: Analysis of Workers lost by Ownership and

\section{Industry}

\begin{tabular}{|c|c|c|c|c|c|c|c|c|}
\hline $\begin{array}{l}\text { Socal } \\
\text { Firms }\end{array}$ & $\begin{array}{l}\text { Number } \\
\text { of cases } \\
\text { lood }\end{array}$ & $\begin{array}{l}\text { Mumber } \\
\text { of cases } \\
\text { Machine }\end{array}$ & $\begin{array}{l}\text { Calibre of } \\
\text { workers lost }\end{array}$ & $\begin{array}{l}\text { Wumber } \\
\text { of cases } \\
\text { Food }\end{array}$ & $\begin{array}{l}\text { Number } \\
\text { of cases } \\
\text { Machine }\end{array}$ & $\begin{array}{l}\text { Worturers } \\
\text { lost to }\end{array}$ & $\begin{array}{l}\text { Number } \\
\text { of cases } \\
\text { Food }\end{array}$ & $\begin{array}{l}\text { Number } \\
\text { of cases } \\
\text { Machine }\end{array}$ \\
\hline \multirow{4}{*}{$\begin{array}{l}\text { Lost } \\
\text { workers } \\
\text { to } \\
\text { other } \\
\text { firms }\end{array}$} & \multirow[t]{4}{*}{$\begin{array}{l}36 \\
(65.5 \%)\end{array}$} & \multirow[t]{4}{*}{$\begin{array}{l}35 \\
(74.5 \%)\end{array}$} & $\begin{array}{l}\text { Mlanagers } \\
\text { and } \\
\text { profersionals }\end{array}$ & $\begin{array}{l}15 \\
(27.3 \%)\end{array}$ & $\begin{array}{l}6 \\
(12.8 \%)\end{array}$ & $\begin{array}{l}\text { Forelign } \\
\text { firms }\end{array}$ & $\begin{array}{l}3 \\
(5.5 \%)\end{array}$ & $(12.8 \%$ \\
\hline & & & \multirow{3}{*}{$\begin{array}{l}\text { Engineers } \\
\text { and } \\
\text { technicians }\end{array}$} & \multirow[t]{3}{*}{26} & \multirow[t]{3}{*}{$\begin{array}{l}33 \\
(70.2 \%)\end{array}$} & $\begin{array}{l}\text { Joint } \\
\text { Ventures }\end{array}$ & $\begin{array}{l}3 \\
(5.5 \%)\end{array}$ & $\begin{array}{l}6 \\
(12.8 \%)\end{array}$ \\
\hline & & & & & & $\begin{array}{l}\text { Local } \\
\text { firms }\end{array}$ & $\begin{array}{l}36 \\
(65.5 \%)\end{array}$ & $\begin{array}{l}29 \\
(61.7 \%)\end{array}$ \\
\hline & & & & & & $\begin{array}{l}\text { Start } \\
\text { own } \\
\text { fiturns }\end{array}$ & $\begin{array}{l}3 \\
(5.5 \%)\end{array}$ & $\begin{array}{l}10 \\
(21.3 \%)\end{array}$ \\
\hline $\begin{array}{l}\text { Eoreign } \\
\text { Fums }\end{array}$ & $\begin{array}{l}\text { Number } \\
\text { of cases } \\
\text { Fond }\end{array}$ & Machine & $\begin{array}{l}\text { Calibre of } \\
\text { workers lost }\end{array}$ & $\begin{array}{l}\text { Number } \\
\text { of cases } \\
\text { Food }\end{array}$ & Mabine & $\begin{array}{l}\text { Workers } \\
\text { lost to }\end{array}$ & $\begin{array}{l}\text { Number } \\
\text { of cases } \\
\text { Food }\end{array}$ & Machise \\
\hline \multirow{4}{*}{$\begin{array}{l}\text { Lost } \\
\text { workers } \\
\text { to } \\
\text { other } \\
\text { firm }\end{array}$} & \multirow[t]{4}{*}{$\begin{array}{l}4.5 \\
(90.0 \%)\end{array}$} & \multirow[t]{4}{*}{$\begin{array}{l}27 \\
(96.4 \%)\end{array}$} & $\begin{array}{l}\text { Managers } \\
\text { and } \\
\text { professionals }\end{array}$ & $\begin{array}{l}38 \\
(76.0 \%)\end{array}$ & $\begin{array}{l}10 \\
(35.7 \%)\end{array}$ & $\begin{array}{l}\text { Foneign } \\
\text { firms }\end{array}$ & $\begin{array}{l}16 \\
(32.00 \%\end{array}$ & $\begin{array}{l}4 \\
(14.3 \%)\end{array}$ \\
\hline & & & \multirow[t]{3}{*}{$\begin{array}{l}\text { Engineers } \\
\text { and } \\
\text { technicians }\end{array}$} & \multirow[t]{3}{*}{$\begin{array}{l}40 \\
(80.0 \% \%)\end{array}$} & \multirow[t]{3}{*}{$\begin{array}{l}25 \\
(89.3 \%)\end{array}$} & $\begin{array}{l}\text { Joint } \\
\text { Ventures }\end{array}$ & $\begin{array}{l}22 \\
(44.0 \%)\end{array}$ & $\begin{array}{l}8 \\
(28.6 \%)\end{array}$ \\
\hline & & & & & & $\begin{array}{l}\text { Local } \\
\text { firms }\end{array}$ & $\begin{array}{l}45 \\
(90.0 \%)\end{array}$ & $\begin{array}{l}25 \\
(89.3 \%)\end{array}$ \\
\hline & & & & & & $\begin{array}{l}\text { Start } \\
\text { own } \\
\text { firms } \\
\end{array}$ & $\begin{array}{l}21 \\
(42.0 \%)\end{array}$ & $\begin{array}{l}20 \\
(71.4 \%)\end{array}$ \\
\hline
\end{tabular}

Source:" Tabulated from author's field survey $2003 / 2004$ 
Appendix 5.1b: Labour Mobility: Analysis of Workers Employed by Ownership and Industry

\begin{tabular}{|c|c|c|c|c|c|c|c|c|}
\hline $\begin{array}{l}\text { Local } \\
\text { Fims }\end{array}$ & $\begin{array}{l}\text { Number } \\
\text { of calses } \\
\text { Food }\end{array}$ & $\begin{array}{l}\text { Number } \\
\text { of cases } \\
\text { Machine }\end{array}$ & $\begin{array}{l}\text { Calbre of } \\
\text { workers } \\
\text { employed }\end{array}$ & $\begin{array}{l}\text { Number } \\
\text { of cases } \\
\text { Food }\end{array}$ & $\begin{array}{l}\text { Number } \\
\text { of cases } \\
\text { Machine }\end{array}$ & $\begin{array}{l}\text { Workers } \\
\text { employed } \\
\text { from }\end{array}$ & $\begin{array}{c}\text { Number } \\
\text { otcuses } \\
\text { Tood }\end{array}$ & $\begin{array}{l}\text { Number } \\
\text { of eases } \\
\text { Machine }\end{array}$ \\
\hline \multirow{4}{*}{$\begin{array}{l}\text { Employed } \\
\text { workers } \\
\text { from } \\
\text { other } \\
\text { firms }\end{array}$} & \multirow[t]{4}{*}{$\begin{array}{l}47 \\
(85.5 \%)\end{array}$} & \multirow[t]{4}{*}{$\begin{array}{l}46 \\
(97.9 \%)\end{array}$} & $\begin{array}{l}\text { Managers } \\
\text { and } \\
\text { professionals }\end{array}$ & $\begin{array}{l}24 \\
(43.6 \%)\end{array}$ & $\begin{array}{l}12 \\
(25,5 \%)\end{array}$ & $\begin{array}{l}\text { Coreign } \\
\text { frms }\end{array}$ & $7(2.70)$ & $\begin{array}{l}14 \\
(29,80 \%)\end{array}$ \\
\hline & & & $\begin{array}{l}\text { Scientists \& } \\
\text { Engineers }\end{array}$ & $\begin{array}{l}8 \\
(14.5 \%)\end{array}$ & $\begin{array}{l}10 \\
(21.3 \%)\end{array}$ & $\begin{array}{l}\text { Joint } \\
\text { Ventures }\end{array}$ & 12 & $\begin{array}{l}18 \\
(38.3 \%)\end{array}$ \\
\hline & & & $\begin{array}{l}\text { Technicians } \\
\text { \& artisans }\end{array}$ & $\begin{array}{l}32 \\
(58.2 \%)\end{array}$ & $\begin{array}{l}37 \\
(78.7 \%)\end{array}$ & $\begin{array}{l}\text { Local } \\
\text { fitms }\end{array}$ & $440.0 \%$ & $936 \%$ \\
\hline & & & Others & $\begin{array}{l}2 \\
(3.6 \%)\end{array}$ & $(2.1 \%)$ & $\begin{array}{l}\text { Statt own } \\
\text { firms }\end{array}$ & 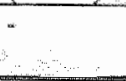 & 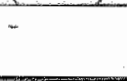 \\
\hline $\begin{array}{l}\text { Foreign } \\
\text { Finms }\end{array}$ & $\begin{array}{l}\text { Number } \\
\text { of cases } \\
\text { Food }\end{array}$ & Maclyente & $\begin{array}{l}\text { Calibre of } \\
\text { workers } \\
\text { employed }\end{array}$ & $\begin{array}{l}\text { Number } \\
\text { of cases } \\
\text { Food }\end{array}$ & Matsine & $\begin{array}{l}\text { Workers } \\
\text { Employed } \\
\text { from }\end{array}$ & $\begin{array}{l}\text { Number } \\
\text { of cases } \\
\text { Food }\end{array}$ & Madbine \\
\hline \multirow{4}{*}{$\begin{array}{l}\text { Employed } \\
\text { workers } \\
\text { from } \\
\text { other } \\
\text { firms }\end{array}$} & \multirow[t]{4}{*}{$\begin{array}{l}49 \\
(98.0 \%)\end{array}$} & \multirow[t]{4}{*}{$\begin{array}{l}27 \\
(96.4 \%)\end{array}$} & $\begin{array}{l}\text { Mamagets } \\
\text { and } \\
\text { professionals }\end{array}$ & $\begin{array}{l}40 \\
(80.0 \%)\end{array}$ & $\begin{array}{l}12 \\
(42.90 \%)\end{array}$ & $\begin{array}{l}\text { Foneign } \\
\text { firms }\end{array}$ & $\begin{array}{l}31 \\
(62.0 \%)\end{array}$ & $\begin{array}{l}11 \\
(39.3 \%)\end{array}$ \\
\hline & & & $\begin{array}{l}\text { Scientists \& } \\
\text { Engineers }\end{array}$ & $\begin{array}{l}24 \\
(48.0 \%)\end{array}$ & $\begin{array}{l}7 \\
(25.0 \%)\end{array}$ & $\begin{array}{l}\text { Joint } \\
\text { Ventures }\end{array}$ & $\begin{array}{l}20 \\
(40.0 \%)\end{array}$ & $\begin{array}{l}17 \\
(60,7 \% / 0)\end{array}$ \\
\hline & & & $\begin{array}{l}\text { Technicians } \\
\& \text { artisans }\end{array}$ & $\begin{array}{l}42 \\
(84.0 \%)\end{array}$ & $\begin{array}{l}20 \\
(71.4 \%)\end{array}$ & $\begin{array}{l}\text { Local } \\
\text { firms }\end{array}$ & $\begin{array}{l}46 \\
(92.0 \%)\end{array}$ & $\begin{array}{l}24 \\
(85.7 \%)\end{array}$ \\
\hline & & & Other's & $\begin{array}{l}2 \\
(4.0 \%)\end{array}$ & 0 & $\begin{array}{l}\text { Start own } \\
\text { firms }\end{array}$ & - & $\ldots$ \\
\hline
\end{tabular}

Source: Tabulated from author's field survey $2003 / 2004$ 
Appendix 5.2. Linkage Effects: Analysis by Ownership and Industry

\begin{tabular}{|c|c|c|c|c|c|}
\hline Loweal Firms & $\begin{array}{l}\text { Number } \\
\text { of cases } \\
\text { Food }\end{array}$ & $\begin{array}{l}\text { Number of } \\
\text { cases } \\
\text { Matabise }\end{array}$ & Kind of firmis & $\begin{array}{l}\text { Number of } \\
\text { cases } \\
\text { Food }\end{array}$ & $\begin{array}{l}\text { Number of } \\
\text { cases } \\
\text { Madyin }\end{array}$ \\
\hline \multirow[t]{3}{*}{ Has backwand linkage } & \multirow[t]{3}{*}{$53(96.4 \% 0)$} & \multirow[t]{3}{*}{$47\left(100^{4 / 0}\right)$} & Foreign firms & $22(40.0 \%)$ & $20(42.6 \%)$ \\
\hline & & & Joint Ventures & $16(29.1 \%)$ & $13(27.7 \%)$ \\
\hline & & & Local firms & $48,(87,3 \%)$ & $39(83.0 \%)$ \\
\hline \multirow[t]{3}{*}{ Has forward linkage } & \multirow[t]{3}{*}{$53(96.4 \%)$} & \multirow[t]{3}{*}{$45(95.7 \%)$} & Foreign frems & $13(23.69 \%$ & $17(362 \%)$ \\
\hline & & & Joint Ventures & $9(16.4 \%)$ & $9(19.1 \%)$ \\
\hline & & & Local firms & $50(90.9 \%)$ & $44(03.6 \%$ \\
\hline Foreign Firms & $\begin{array}{l}\text { Number } \\
\text { of cases } \\
\text { Food }\end{array}$ & $\begin{array}{l}\text { Number of } \\
\text { cases } \\
\text { Matbins }\end{array}$ & Kind of firms & $\begin{array}{l}\text { Number of } \\
\text { cases } \\
\text { Food }\end{array}$ & $\begin{array}{l}\text { Number of } \\
\text { cases } \\
\text { Maching }\end{array}$ \\
\hline \multirow[t]{3}{*}{ Has backwated livalkage } & \multirow[t]{3}{*}{$50(100 \% / 0)$} & \multirow[t]{3}{*}{$28(100 \%)$} & Foreign Fims & $44\left(88.0^{\circ} \%\right)$ & $16(57.1 \%$ \\
\hline & & & Joins Ventures & $28(56.0 \%)$ & $18(64.3 \%)$ \\
\hline & & & Local firms. & $48(96.0 \%)$ & $26(92.9 \%)$ \\
\hline \multirow[t]{3}{*}{ Hass forward linkage } & \multirow[t]{3}{*}{$50(100 \%)$} & \multirow[t]{3}{*}{$27(96.4 \%)$} & Foreign firms & $37(74.0 \%)$ & $12(429 \%)$ \\
\hline & & & Joint Ventures & $20(40.0 \%)$ & $11(39.3 \%)$ \\
\hline & & & Local firms & $48(96.0 \%)$ & $26(92.9 \%)$ \\
\hline
\end{tabular}

Sounce: Tabulated from atuthor's field survey $2003 / 2004$

Appendix 5.3: Competition Effects: Analysis by Ownership and Industry

\begin{tabular}{|c|c|c|c|c|c|}
\hline \multicolumn{6}{|l|}{ Locial Furms } \\
\hline Competition rating & $\begin{array}{l}\text { Number of } \\
\text { cases } \\
\text { Food }\end{array}$ & $\begin{array}{l}\text { Number of } \\
\text { cases } \\
\text { Machine }\end{array}$ & $\begin{array}{l}\text { Competitor } \\
\text { by kind of } \\
\text { firm }\end{array}$ & $\begin{array}{l}\text { Number of } \\
\text { cases } \\
\text { Forod }\end{array}$ & $\begin{array}{l}\text { Number of } \\
\text { cases } \\
\text { Machine }\end{array}$ \\
\hline None & $3\left(5.5^{\%}\right)$ & - & Foreign fitms & $14(25.5 \%)$ & $12\left(25.5^{\%}\right)$ \\
\hline Moderatie & $6(10.9 \%)$ & $13(27.7 \%)$ & Joint Yentures & $19(35.5 \%)$ & $9(19.1 \%)$ \\
\hline Stiff & $24(38.2 \%)$ & $22(46.8 \%)$ & Local firms & $52(94,5 \%)$ & $46(97.9 \%)$ \\
\hline Very stiff & $25(45.5 \%)$ & $12\left(25.5^{10} / 1\right)$ & Others & 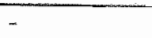 & - \\
\hline \multicolumn{6}{|l|}{ Foreign Firms } \\
\hline Comperiton rating & $\begin{array}{l}\text { Number of } \\
\text { cases } \\
\text { Fond }\end{array}$ & $\begin{array}{l}\text { Number of } \\
\text { cases } \\
\text { Maching }\end{array}$ & $\begin{array}{l}\text { Competitor } \\
\text { by kind of } \\
\text { firm }\end{array}$ & $\begin{array}{l}\text { Number of } \\
\text { cases } \\
\text { Food }\end{array}$ & $\begin{array}{l}\text { Number of } \\
\text { cases } \\
\text { Marthine }\end{array}$ \\
\hline None & - & - & Foreign furms & $33(66.0 \%)$ & $6(21,4 \%)$ \\
\hline Mouderate & $14(28.0 \%)$ & $7(25.0 \%)$ & Joint Ventures & $23(46.0 \%)$ & $16(57.1 \%)$ \\
\hline Suiff & $29(78.0 \%)$ & $14\left(50.0^{\oplus} \%\right)$ & Local firms & $49(78.0 \%)$ & $28(100 \%)$ \\
\hline Verstiff & $7(14,0 \%)$ & $7\left(25.5^{\circ} \%\right)$ & Others & 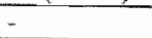 & - \\
\hline
\end{tabular}


Appendix 5.4: Demonstration Effects: Analysis by Owaership and Industries Tood Processing

\begin{tabular}{|c|c|c|c|c|c|}
\hline $\begin{array}{l}\text { Local } \\
\text { Fampins }\end{array}$ & $\begin{array}{l}\text { Number of } \\
\text { coses }\end{array}$ & Natume of firms & $\begin{array}{l}\text { Number of } \\
\text { cascus }\end{array}$ & Kind of finns & Numurrof \\
\hline \multirow{5}{*}{$\begin{array}{l}\text { Wh } \\
\text { demonstation } \\
\text { eflect }\end{array}$} & \multirow[t]{5}{*}{$36(65.5 \%)$} & Conpering fims & $32(582 \%)$ & Foresga frims & $4(255 \%$ \\
\hline & & Ordinary titms & $9(16.4 \%$ & Joine wentures & $13(23,680)$ \\
\hline & & Supplying firms & $7(12.70 \%$ & Loch furms & $33(60,09 / 0)$ \\
\hline & & Processing fims & $6\left(10.9^{0} \%\right)$ & Othent & - \\
\hline & & Distributing firms & $2(3.6 \%)$ & & \\
\hline $\begin{array}{l}\text { Foreign } \\
\text { IHints }\end{array}$ & $\begin{array}{l}\text { Number of } \\
\text { cases }\end{array}$ & Wathute of firmo & $\begin{array}{l}\text { Number of } \\
\text { chises }\end{array}$ & Kindol Dims & $\begin{array}{l}\text { Numberm or } \\
\text { atse }\end{array}$ \\
\hline \multirow{5}{*}{$\begin{array}{l}\text { With } \\
\text { demonstration } \\
\text { effert }\end{array}$} & \multirow[t]{5}{*}{$47(94.0 \%)$} & Competing fitms & $37(74.0 \%$ & Foreign finns: & $38(760 \%$ \\
\hline & & Ordinary firms & $15(30.0 \%)$ & Joinctertures & $19(380 \% / 0)$ \\
\hline & & Supplying firms & $17(34.0 \mathrm{p} /)$ & Local firms & $38(7600 \%)$ \\
\hline & & Processing firms & $32(64.0 \%)$ & Ortimers & 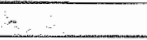 \\
\hline & & Distributing tirms & $9(18.0 \%)$ & & \\
\hline \multicolumn{6}{|c|}{ Mlachine and enginecting Industry } \\
\hline $\begin{array}{l}\text { Local } \\
\text { Girms }\end{array}$ & $\begin{array}{l}\text { Number of } \\
\text { cases }\end{array}$ & Nature of firms & $\begin{array}{l}\text { Number of } \\
\text { cases }\end{array}$ & Kind of firms & $\begin{array}{l}\text { Number of } \\
\text { casses }\end{array}$ \\
\hline \multirow{5}{*}{$\begin{array}{l}\text { With } \\
\text { demonstration } \\
\text { lhect }\end{array}$} & \multirow[t]{5}{*}{$42(89.4 \%)$} & Competing firms & $34(81.0 \%)$ & Forcign firms & $14(29.8 \%$ \\
\hline & & Ondinary firms & $8(17.0 \%)$ & Joint ventures & $15\left(31.9^{0 \%}\right)$ \\
\hline & & Supplying firms & $10(21.3 \%)$ & Jocal firms & $38(80,9 \%$ \\
\hline & & Processing firms & $8(17.0 \%)$ & Orhers & - \\
\hline & & Distributing firms & $4(8.5 \%)$ & & \\
\hline $\begin{array}{l}\text { Foreign } \\
\text { Firms }\end{array}$ & $\begin{array}{l}\text { Number of } \\
\text { cases }\end{array}$ & Nature of firms & $\begin{array}{l}\text { Nimber of } \\
\text { cases }\end{array}$ & Kind of firms & $\begin{array}{l}\text { Number of } \\
\text { cases : }\end{array}$ \\
\hline \multirow{5}{*}{$\begin{array}{l}\text { Witi } \\
\text { demanstration } \\
\text { effect }\end{array}$} & \multirow[t]{5}{*}{$27(96.4 \%)$} & Compering furms & $25\left(92.6^{\circ} \%\right)$ & Foreign arms & $15(55.6 \%)$ \\
\hline & & Ordinary firms & $12(42.9 \%)$ & Joint entures & $15(55.6 \%)$ \\
\hline & & Supplying firms & $10\left(35.7^{\%} / 0\right)$ & Locall firms & $22(81.5 \%$ \\
\hline & & Processing firms & $9(32.1 \%)$ & Others & - \\
\hline & & Distributing firms & $2(7.1 \%)$ & & \\
\hline
\end{tabular}

Source: 'Trbahated from author's field survey $2003 / 2004$ 


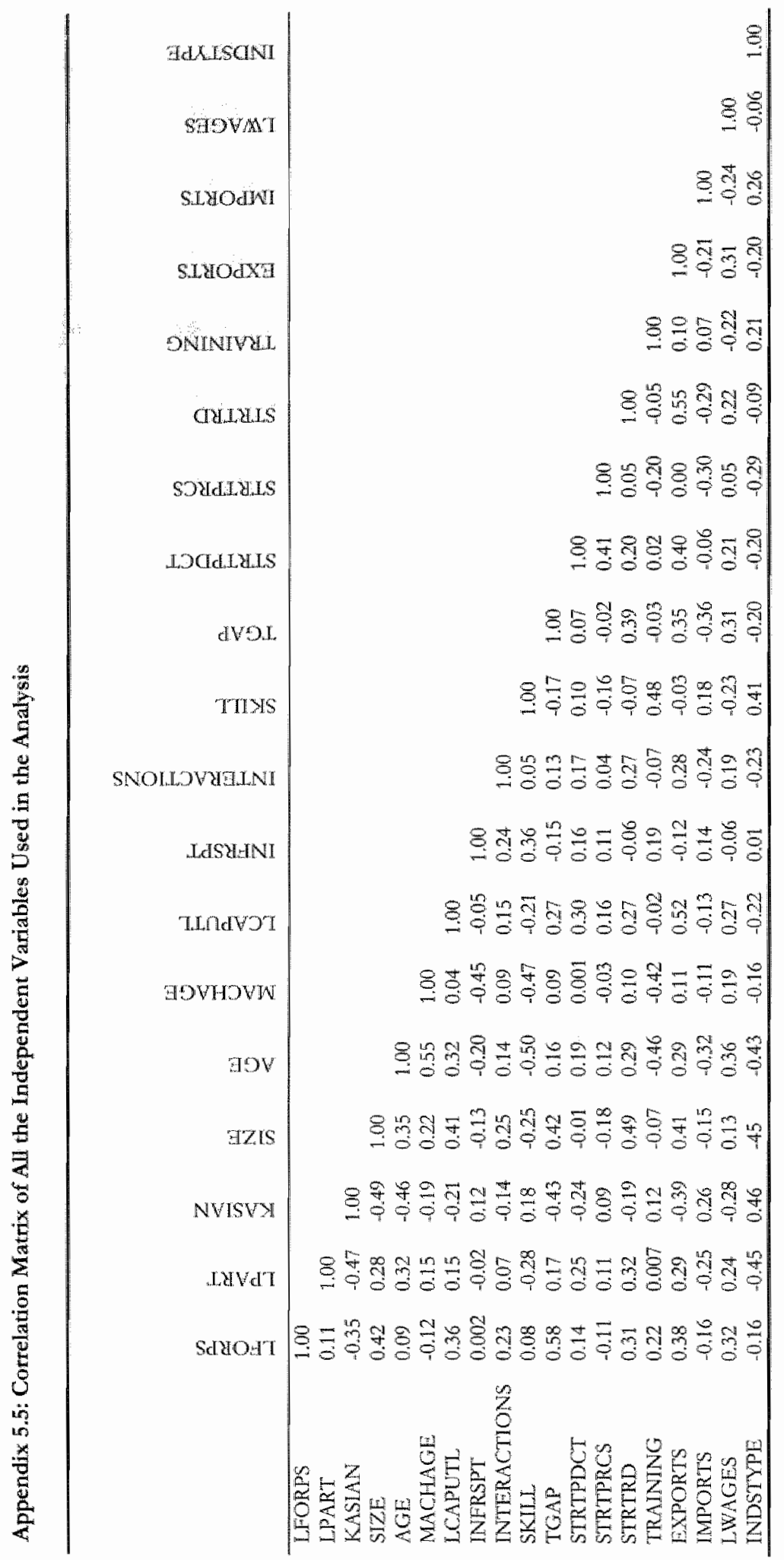


Appendix 5.6: Determinants of Spillover Occurrence, Ordered Logit Analysis, Food Processing and Machine and Engineening Industries Pooled

\begin{tabular}{|c|c|c|c|c|c|c|}
\hline \multirow[b]{2}{*}{ Variables } & \multirow[b]{2}{*}{$\mathrm{Dy} / \mathrm{dx}$} & \multicolumn{5}{|c|}{ Changes in Predicted Probabllities } \\
\hline & & Change & Low & Average & High & Highest \\
\hline LFORPS & $\begin{array}{l}1.678^{*} \\
(0.740)\end{array}$ & Marghrion affert & $-1.07+07$ & 0.0130 & 0.0130 & $1.58 e-08$ \\
\hline LPART & $\begin{array}{l}0.593 \\
(1.092)\end{array}$ & Matrgitmat effect & -3.8008 & .0 .0046 & 0.0046 & $5.59 \mathrm{e}-00$ \\
\hline KASMAN" & $\begin{array}{l}7,678 \text { \% } \\
(3.156)\end{array}$ & $\begin{array}{l}\text { Name Astat } \\
\text { to Astan }\end{array}$ & $-254 e-06$ & -02999 & 0.3000 & $5.1400 \%$ \\
\hline $\operatorname{SIZE} \mathrm{W}^{.9}$ & $\begin{array}{l}3.448^{*} \\
(2.573)\end{array}$ & $\begin{array}{c}\text { Small to large } \\
\text { firm }\end{array}$ & $-7.95 \mathrm{e}-07$ & -0.0184 & 0.0184 & $2.25 e-08$ \\
\hline FIRMAGI & $\begin{array}{l}0.440^{*} \\
(0.244)\end{array}$ & Marginal effect & $-2.82 e-08$ & -0.0034 & 0.0034 & $4.140-09$ \\
\hline AGESQRD & $\begin{array}{l}-4.792^{* *} \\
(2.779)\end{array}$ & Marymar afed & -3.07 e-07 & 0.0372 & .0 .0372 & $.4 .52 \mathrm{e} .08$ \\
\hline MACHAGE & $\begin{array}{l}0.307^{* *} \\
(0.127)\end{array}$ & Margingat effect & $-1.97 e-08$ & -0.0024 & 0.0024 & $2.89 \cdot \mathrm{e}-09$ \\
\hline LCAPUTL & $\begin{array}{l}-4.610 \\
(3.850)\end{array}$ & Marnginat affect & $-2.95 \mathrm{e}-07$ & 0.0358 & $.0,0358$ & $-4.35 \mathrm{c} \times 08$ \\
\hline MNERST & $\begin{array}{l}0.370 \\
(2.176)\end{array}$ & 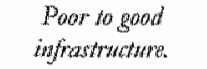 & $-2.67 e-08$ & -0.0026 & 0.0026 & $3.1 .4 \mathrm{e}-109$ \\
\hline $\begin{array}{l}\text { TNTERACTION } \\
s^{q^{2}}\end{array}$ & $\begin{array}{l}4.003 * \\
(2.273)\end{array}$ & $\begin{array}{l}\text { None interractive } \\
\text { to inderradipe. }\end{array}$ & $-2.10 e 00$ & -0.01 .25 & 0.0125 & 1.52008 \\
\hline ESKILL & $\begin{array}{l}2.676^{*} \\
(1.645)\end{array}$ & Marginal effect & $-1.71 \mathrm{e}-07$ & -0.0208 & 0.0208 & 2.520 .08 \\
\hline TGAP & $\begin{array}{l}8.937^{* * 4} \\
(3.905)\end{array}$ & $\begin{array}{l}\text { High tech gatp to } \\
\text { dow ted G Gop }\end{array}$ & $-8.78 e-05$ & -0.0418 & 0.0419 & $5.25-08$ \\
\hline STRTPDCT ${ }^{4 \prime}$ & $\begin{array}{l}-1.086 \\
(1.923)\end{array}$ & $\begin{array}{c}\text { No prod. Stants to } \\
\text { prod. Stant }\end{array}$ & $5.07 \cdot-08$ & 0.0126 & -0.0120 & $-1.55 e-08$ \\
\hline STRTPRCS $^{\mu \prime}$ & $\begin{array}{c}10.985^{* \text { *ik }} \\
(5.068)\end{array}$ & $\begin{array}{c}\text { No prom Strat. to } \\
\text { prac Start }\end{array}$ & $-1.53 e+03$ & -0.0175 & 0.0191 & $2.33 \mathrm{e}-08$ \\
\hline STRRRD" & $\begin{array}{r}-3.284 \\
(3.288)\end{array}$ & $\begin{array}{l}\text { From no Reso } \\
\text { To RedD }\end{array}$ & 8.83 & 0.1225 & -0.1225 & $-1.69 e-07$ \\
\hline TRAINING & $\begin{array}{l}7.416^{* * *} \\
(3.144)\end{array}$ & $\begin{array}{l}\text { No troising } \\
\text { fo trainitg }\end{array}$ & $-1.03 \mathrm{e}-05$ & -0.0754 & 0.0754 & $9.78<-0.08$ \\
\hline EXPORTS ${ }^{4}$ & $\begin{array}{l}-2.933 \\
(2.205)\end{array}$ & $\begin{array}{c}\text { None exporiting to } \\
\text { exporting }\end{array}$ & -9.82 e-08 & 0.0789 & -0.0789 & $-1.04 c-07$ \\
\hline "MPORTS" & $\begin{array}{l}3.163^{*} \\
(1.659)\end{array}$ & $\begin{array}{l}\text { None insporting to } \\
\text { impionting }\end{array}$ & $-1.89 \mathrm{e}-07$ & -0.0544 & 0.0544 & $-0.94 a-08$ \\
\hline CWAGES & $\begin{array}{l}-2.640^{* *} \\
(1.047)\end{array}$ & Maryinal offot & $-1.69 e-07$ & 0.0205 & 0.0205 & $-249) \in 08$ \\
\hline _Cut1 & .8 .295 & & & & & \\
\hline$-C u t 2$ & $\$ 3.111$ & & & & & \\
\hline _Cut3 & 26.745 & & & & & \\
\hline Industry dummies & Yes & & & & & \\
\hline $\begin{array}{l}\text { No of } \\
\text { obserwions } \\
\text { Log Likelihood }\end{array}$ & $\begin{array}{c}73 \\
-18.000\end{array}$ & & & & & \\
\hline LR-Tesit & $\begin{array}{l}102.27 \\
(0.000)\end{array}$ & & & & & \\
\hline Pserudo R? & 0.7396 & & & & & \\
\hline
\end{tabular}

Note: Spillover index computed is taken as the dependent variable-proxy for spillover occurtence (W) $\mathrm{dy} / \mathrm{dx}$ is for discrete change of dummy vatiable from 0 to 1 **, * represent $5 \%$ and $10 \%$ levels of sigraificance respectively

Source: Computed from author's field survey $2003 / 2004$ 


\section{Chapter Six}

\section{TECHNOLOGICAL CHANGE FROM FOREIGN FIRMS IN KENYA}

\subsection{Introduction}

Chapter 6 presents ten detailed firm level case studies of foreign firms operating in the Kenyan manufactunng industry to illustrate the spillover process. This is intended to make a more comprehensive and qualitative examination of spillovers and thus supplement the empirical findings obtained in Chapter 4 and 5 . The ten case studies selected included both wholly owned foreign firms and joint ventures (VVs). The case study firms were drawn from food and beverages, and machine and engineening industries. In Chapter 4, the two industries were shown to be the most dynamic with regard to high growth rate performance, $V A D$, contribution to GDP, FDI presence etc. In food and beverages industry, 6 firms were studied while only 4 firms were considered in machine and engineering industry. This chapter will attempt to provide individual firm level accounts based on the selected case study firms to illustrate the spillover process in the two industries chosen. This is done by examining the rolle played by foreign firms in stimulating learning and technological change in the locally owned firms with a possible accurnulation of technological capability. The chapter is divided into six sections. Section 6.2 presents framework of analysis. In section 6.3, a brief analysis of foreign firms is presented. Section 6.4 presents the case studies in food and beverages industry while section 6.5 presents the case study illustrations in machine and engineering industry. Section 6.6 presents summary and conclusions of the chapter.

\subsection{Framework of Analysis}

In Chapter 2, we criticised the productivity technique due to its inherent weaknesses in examining the spillover process. An alternative analytical framework was used in Chapter 5 which enabled a rich examination of spillovers on the basis of occurrence mechanism, kinds and determinants. Taking a more qualitative approach, this chapter intends to illustrate the spillover process in order to improve our understanding of the actual spillover process on the basis of individual firm level accounts. However, before we proced, it is important to point out some general and well known problems in dealing with spillovers. Although most of these problems will be explained in the relevant sections, we would like to provide an example in the context of food and beverages industry. The point we want to raise here is that spillovers from MNCs should not be assumed to always be good. Here, we have in mind a situation where domestic firms simply copy MNC products especially in food and beverages where high fat content, hormone and chemically based products are known for their negative health impact etc.

We now outline the framework to be followed in this section. On the basis of the analytical approach in Chapter 2 and 5, the spillover process involves activities (e.g. technological and innovation) in both foreign and local firms. Hence, it is extremely important to examine the spillover process from both sides. In this chapter, we will provide individual accounts of foreign firms while that of locally owned firms will be presented in Chapter 7. It should be pointed out from the onset that this exercise is not meant to quantify the amount of spillovers occurring nor is it meant to determine who generates more spillovers than the other with regard to foreign or locally owned firms. 
Since that was done in Chapter 5 , this chapter will only provide a qualitative illustration of the spllover process - e.g. by looking at the ways in which presence of foreign fims opens opportunities for technological spillovers ${ }^{1 / B}$. A new analytical method moroduced here, therefore, takes into consideration four conceptual ejements extensively discussed in Chapter 2 and 5. A combination of these elements is expected to improve oun understanding of the less understood spillover process in the context of least developed countries particularly so in sub Saharan Africa. This is expected to have wide ramifications for policy.

We look at each of the conceptual elements at a time. Fingr, the case study makes an intensive examination of human resource development (training) undertaken in foreign firms. This is important due to the direct relationship it has with spillover occurence. For instance, we can only expect spillowers due to mobility of staff from foreign firms if foreign firms have strong measutes in place on human tesoutces development. Hence, we try to examine the kind of training offered to the local personnel and its usefulness to their firms. Foreign firms are claimed to offer more training than locally owned furms. We equally attempted to understand the extent to which the training done, including other forms of skill entichment programmes offered, might have resulted in accumulation of capability necessary to manage and operate production technology in the firm. Additionally, we also investigated whether the acquired experiential and tacit knowledge resulted in any hietarchical or upward mobility with regard to the local personnel. In oxder to understand whether technological skills and experiential knowledge acquired in foreigin firms were transferred to the locally owned firms, considerable effort and time was put to examine labour mobility in foreign fums. Cases of mobility have been identified to result in technological spillovers (Gerschenberg, 1987; Behrman and Wallender, 1976; Pack, 1993; Enst, Mytelka and Ganiatsos, 1998; Fosfuri, Massimo and Ronde, 2001; Lin and Rasiah, 2003). All these investigarions were intended to provide insight as to whether foreign firms participated in the human capital development effort in manufacturing.

Second, we studied extensively various kinds of linkages formed by foteign firms. Linkages between MNCs and domestic firms ate believed to be a strong mechanism of spillover occurtence (Hirschman, 1958; Lall, 1980; Rasiah 1995; Rodriguez-Clare, 1996; UNCTAD, 2002; Belderbos, Capannelli and Fukao, 2001; Smarynska, 2003). We investigated and mapped out the linkages and networks that existed between firms and indigenous firms, institutions and business associations. The two classifications of linkages known to exist include pecuniary and non-pecuniary linkages. In both cases, forward and backward linkages can be traced. Pecuniary linkages differ from nonpecuniary linkages in that the former is considered to be purely monetary in nature. We examine the extent to which pecuniary linkages are formed. Further to the business advantages, pecuniary linkages are likely to be useful to the foteign firms in wiew of the feedback obtained which helps them make improwements on their products, processes, organisation and marketing approach. We also attempted to find out how pecuniary linkages formed with locally owned firms might have helped the growth and development of locally owned firms by providing them with capital to finance

\footnotetext{
118 Howerer, in the context of long time scries data this is a difficult exereise and one that is almost impossible due to limitation of the appropriate data. For instance few frms had time sectes data on humn resource, labour mobility or linkages (ug. domescic purchases). Time series data on wiming and even whete it was done was impossible to get. More so it is extremely difficult to know where staff fonce from or which firms they left to join. Similam, it is diffeult to know who the suppliets are ower time.
} 
technology, machinery and equipment etc. The demand of supply created by these MNCs sometimes creates new opportunities for locally owned firms to make imptovements and/or introduce new investments. Non-pecuniary linkages were also studied. They included machine and engineering linkages (user-supplier relationshps) and rechnical assistance through interactions with the local support systems such as business associations and institutions such as R\&D/academic and financing institutions.

Third, competition between foreign firms and local firms was also extensively examined. This was done by investigating foreign firms in industrial sectors where MNCs were in competition with locally owned firms either for raw materials or markets. This is important in order to investigate the sources, intensity and effect of comperition pressure. Competition between foreign and domestic firms creates pressure, which forces local firms to learn and build capabilities (Caves, 1982; Das, 1987; Wang and Blomstrom, 1992; Glass and Saggi, 2002). We examined technological changes undertaken by foreign firms as a result of this competition. This also helps us understand how local firms react to competition pressure from foreign firms in such industrial sectors making them survive. This could serve as a trigger effect to both kinds of firms teflecting occurrence of spillovers of knowledge, learning and capability building. In Chapter 7, we will explore this aspect by investigating whether locally owned firms are forced to learn something from MNCs and if so what and how? Do they introduce any technological changes? And if so what kinds of technological capabilities have been built as a result of these spillovers in the form of trigger effect? Competition pressure however, can also have some negative effects on the domestic firms such as crowding out of domestic firms. Also when competition shifts to advertising there can be a problem in that resources tend to be misallocated away from learning to compete and innovation (Chudnovsky, 1988). These issues will be examined in Chapter 7 .

Fowrth, in weak developing countries, locally owned firms have been known to benefit from substantial demonstration effects from foreign firms or imported machinery and technology as witnessed in the Newly Industrialised Countries in East Asian countries [see Fransman, 1985; Amsden, (1989: 1994); Lall, 1996; Kim, (1988: 1997); Enst, Mytelka and Ganiatsos, 1998]. This was unlikely to be absent and had not received any attention in the Kenyan industry. Thus as a fourth element, we examined the extent to which foreign firms offered dixectly or indirectly to demonstrate their products, processes, marketing skills, management and organisation etc to the locally owned firms. We will attempt to find out from them whether their processes or products have been copied and/or imitated by the locally owned firms and if so to what extent that had resulted in learning, capability building and innovation. Note however that imitation can also have a negative impact when firms simply try to copy goods with no real competitive advantage apart from lower wages and this does not last if not accompanied by learning: to innovate. This will be investigated in detail in Chapter 7.

The foreign furms included in the case study were selected on the basis of the descriptive and empirical analysis done based on the data collected from the firm level survey. 10 firms were selected; 6 wholly owned firms and 4 joint ventures. As noted in Table 6.1 , six firms were selected in food and beverages while four were selected in machine and engineeting industry. The firm selection criterion in the two industries was based on the nature of production technology as well as learning and innovation observed in the firms during the survey phase - the selection and technological characteristics of the firms considered are discussed extensively in sections 6.4 and 6.5 . The case study involved face-to-face interviews with production managers and general scientists \& engineers 
[mechanics, technicians, artisans, craftsmen \& maintenance crew] using semi-structured questionnaires comprising both closed and open-ended questions. The engineers provided information on technology while managers provided information on how prewalling govemment policies and incentive systems in Kenya infuenced company's strategies.

In most cases, the MNCs allowed us at least a day to view their production processes and acquaint ourselves with the machinery and technology utilised right from raw material reception, processing line to warehousing. This created an opportunity to discuss openly with a wide cross-section of staff. At the end of such visits, firms' books, magazines and annual reports would be collected to beef up our analysis. In some of the firms, detailed interviews were conducted during the international trade fairs and agticultural shows ${ }^{1 / 3}$ where they often exhibited (demonstrated their products and processing techniques). If enough information was obtained for a particular firm then an organised firm visit was not requested. Similarly, useful information was obtained during marketing campaigns and promotions done by these firms in supermarkets, in restaurants and bars etc ${ }^{20}$. We maintained active contacts with most firms during the analysis phase for two reasons: First, to clatify any queries that arose during the analysis phase. Second, to provide any extra information becoming available - which may have been missed during the case study period. Clarifications were sought regularly even for the details posted in the firms' Internet Websites. An equally important link was maintained with the Central Buteau of Statistics and investment promotion council to provide base line information for some of the firms ${ }^{12 !}$.

\subsection{Brief Analysis of the Firms: Background and General Information}

\subsubsection{Food and Beverages Industry}

Six foreign owned firms were interviewed in the food and beverages industry. FBF2, FBF3 and FBF5 firms were relatively old firms having been established in Kenya before her independence in 1963. FBF1 and FBF4 were established in 1970s while FBF6 was established in 1980s. All the six firms are classified as large scale firms by Kenya"s manufacturing industry standard. FBF1 is a vertically integrated company involved with mass production of wide range of consumer items tanging from cooking fats to versatile cooking oils, from laundry bar soaps to glycerine and from baking powder to detergent powder. FBF2 manufactures a wide range of foods, home and personal care products. FBF3 is involved in the production and distribution of alcoholic beverages, malt and glass while FBF4 manufactures beverages, infant food products and culinary products. FBF5 deals with extensive farming and agro-processing of fruits mainly

\footnotetext{
"us Two of such internanonal trade exhibitions and agricultural fairs were attended in $\mathbb{N a i r o b i}$ and Mombasa.

\$20 More information fot some of the companies was obtained from friends of my fruends. Organised drinks and functions were uxilised e.g. churches and weddings and it was amazing how useful and informative such links and networks were.

121 Since most of the froms were not comfortable with their details being disclosed, confidentality was assured. It is for this reason that the names of the firms studied during the case study could not be disclosed. Howewer to people familiar with the manufacturing statistics (or involved writh Kenya's manufacturing industry study) it is possible to make a right guess of some of the firms discussed. In stich unfortunate and unlikely cases, the information taken from this research must be cited and must be used only for academic purposes.
} 
pineapples and passion fruts for exports. FBF6 manufactures and distributes carbonated brands of Cola packages mineral water and a variety of fresh fruit juices.

FBF2, FBF4 and FBF5 are wholly owned affliates of foreign MNCs. FBF1 is $99.9 \%$ Btitish owned with only $0.1 \%$ share temaining locally owned by a Kenyan of Asian origin $^{122}$. FBF2 is an affiliate of a European MNC conglomerate, which has over 529 companies worldwide with interests in mining, farming and manufacturing activities. The decision by the European MNC to invest in Kenya was prompted by the effects of Second World War which resulted in Britain encouraging its firms to invest in its colonies. As discussed in Chapter 3, the risks involved during the war made it impossible to ship essential goods from Europe to Kenya resulting in their scarce supply in the country as well as the East $A$ frican region as a whole. To counteract this problem, the colonial government encouraged local industry to statt manufacturing of the required goods. Kenya Industrial Management Boatd Organisation (KIMBO) was established to encourage and manage the establishment of statt up manufacturing firms. Under its management; FBF2 was established in 1949 to commence immediate manufacture of the needed goods. However, due to a lack of adequate local management and technical skills, the colonial government decided to invite the $\mathrm{MNC}$ into Kenya through the establishment of a subsidiary $\mathbf{F B F} 2$ and as a strategic partner owning $50 \%$ equity share in 1953. Through FBF2, the European MNC was expected to bring in, its procluct and processing technology, management and organisation techniques as well as its marketing experience to the newly formed partnership. This supported the argument of MNCs ownership advantages [Caves, (1974: 1982); Hymer, 1976; Dunning (1973: 1993)]. After Kenya's independence, the shares initially owned by the colonial government were shated between the Kenya govemment and FBF2. By 1978, FBF2 had bought and controlled $66 \%$ of the total shares while the Kenya government had sold and controlled the remaining $34 \%$ through its investment organ ICDC123. In 2000, FBF2 purchased the remaining government minority stake in FBF2 from ICDC becoming a $100 \%$ wholly foreign owned subsidiary ${ }^{124}$ of the European MNC. FBF4 belongs to another European group of companies whose parent company headquarters are based in Switzerland. It has an extended branch of affiliates in Africa including South Africa, Ghana, Ivory Coast and Nigeria. The MNC was founded in Switzerland over 130 years ago following a successful seatch for infant fomula.

FBF5 is one of the most successful. large scale agro-processing subsidiaries of MNC in Kenya. Its history and evolution dates back to 1948 , when a local canning firm, Kenya Canners Limited (KCL), was established in Kenya to produce, process and supply tropical fruits to the growing derriand in the European matket. One of such tropical fruits whose denand was extremely high at the time in Enrope was pineapple. The local firm was the main pineapple processing and exporting firm in Kenya. In 1965, an American based MNC was invited to assist in processing and management of pineapple operations. The two firms entered into an agreement in that the American MNC through its formed affiliate - FBF5 would assist in the processing and management of the

\footnotetext{
122 FBFI had no parent affliate and was thus a stand a lone foreign firm in the Kenyan industry.

123 TCDC was nored eatiex to have been instrumental in facilitating joint patinership benween locally owned firm and govemment with MNCs.

12: As a result of its in-house R\&D supported by the parent company and through mengers and acquisition, FBF2 teconded tremendous expansion ower time. For instance in 1987 FBF2 acquired two furms, which. were involved in the manutacture of fast moving personal care products in the region. In 2002 FBE2 also acquired Bestoods affliate firm in Kenya after its parent form acquired Bestoods worldwide operations in 2000 .
} 
pineapple operations for KCL. However, thee years later, FBF5 acquited majority shares in KCL and assumed full control and management of all the operations:

FBF3 and FBF6 were joint wenture firms. At its inception, FBF3 was a $100 \%$ foreign owned firm but with no foreign affliate. The public was however, tnvted for the first time to become shareholders, when the fim was declared a public company in 1934. FBF3 ownership structure by 2002, was $54.0 \%$ Kenyan owned and $46.0 \%$ foreign owned by Gunness international/Diageo - an Irish based MNC. Local fitm employees and members of the general public in Kenya held the remaining stake, $54 \%$ As a result, FBF3 is therefore a publicly quoted firm on the Nairobi stock exchange with an impressive market capitalisarion of approximately KShs 50.0 billions and over 110 million shareholders ${ }^{125}$. The Irish MNC partners, Guiness International provided FBF3 with technical advice on production technology, management and organisation expertise, marketing skills and human resource development as will be shown at a later stage. FBF6 is jointly owned by South African Beverages Company (SABCO - 73\% and Industrial and Credit Development Corporation (ICDC $-27 \%$ ). SABCO and ICDC acquired the firm from its American owners in $1995^{126}$. SABCO contribution to the joint venture was mainly in technology, distribution and maxket development and staff training. The firm produces under license from the USA owners of the soft drink brands, which are among the world's most well known bewerages.

With regard to performance, FBF3 had the highest turn over of KShs 27.7 billion in 2002, Tables 6.1 and 6.2 . The firm was also among the highest contributor to the exchequer in Kenya with KShs 13.29 billion payment in the form of indirect taxes and KShs 1.10 billion as income corporate tax, Table 6.7. According to the annual company reports, FBF3's total assets were in excess of KShs 17.99 billion. FBF2 had a turnover of KShs 8.04 billion making it also one of the largest firms in fast moving consumer goods in East Africa. Its revenue contribution to government exchequer was in excess of KShs 1.5 billion. This reflects the participatory role the firms play in Kenya's economic development. FBF4 had approximately KShs 5.97 billion whille FBF1 had KShs 5.79 billion with fixed assets worth over KShs 1.5 billion. FBF6 had annual turn over of about KShs 6.30 billion with total fixed assets amounting to KShs 1.50 billion. FBF5 had more than KShs 10.0 billion invested in fixed assets but had an annual average rumover sale of KShs 4.97 billion (See Table 6.1 for more details).

With regard to product market orientation and exporting experience, FBF5 had the longest export expenience spanning ovet 60 years. With over $90 \%$ of its processed pineapples meant for export mainly to Europe, FBF5 enjoyed being one of the Africa's largest exporters of pineapples to the European market. It ranked among top five exporting firms in Kenya - in this case one of the largest foreign exchange earners to the country. FBF5's biggest export markets are the United Kingdom, Italy, Germany, Belgium and France. Other markets include Spain, Netherlands, and the rest of Europe. This was expected to increase with the accession of the new members from the Eastem Europe block to the European Union. The regional marker (that inchudes Kenya and COMESA region) accounted for approximately $10 \%$ of the firm's total sales. FBF2 had equally a long history of exporting spanning over 40 years. The firm's products enjoyed a

\footnotetext{
125 In $2004,13 B F_{3}$ ranked as the second fastest growing company on the Nairobi stock Exchange (NSE) after Kenya Oil Company (Acoording to the Kenya Daily Nation of 30-8-2004).

26 During apartheid in the $1980 \mathrm{~s}$, $\$ \mathrm{ABCO}$ as was the case with other companies was prevented from investing abroad and thus grew by acquiring businesses domestically.
} 
strong dominance in the regions major export destinations that included East Africa and the Central Aftican tegion. Limited quantities of some of FBF2 manufactured products wete exported to the European Union market. FBF3 exported approximately $34 \%$ of its products to both the immediate region and African market as well as in the intemarional market - this included new export destinations such as USA. Europe and Canada. FBF1 has been exporting for about 14 years. The firm exported $15 \%$ of its total sales. Their main export destination is the COMESA regional market and throughout the East and Central Africa Region. PBF4 products are sold in Kenya where it has a relatively high market share for its products and in the immediate region (within East Africa region). The firm also exports some of its products beyond East Africa to other countries of the COMESA region. Export markets outside Africa included Middle East and Btitain. FBF6 has an expont expenience of over 10 years to the COMESA region. 


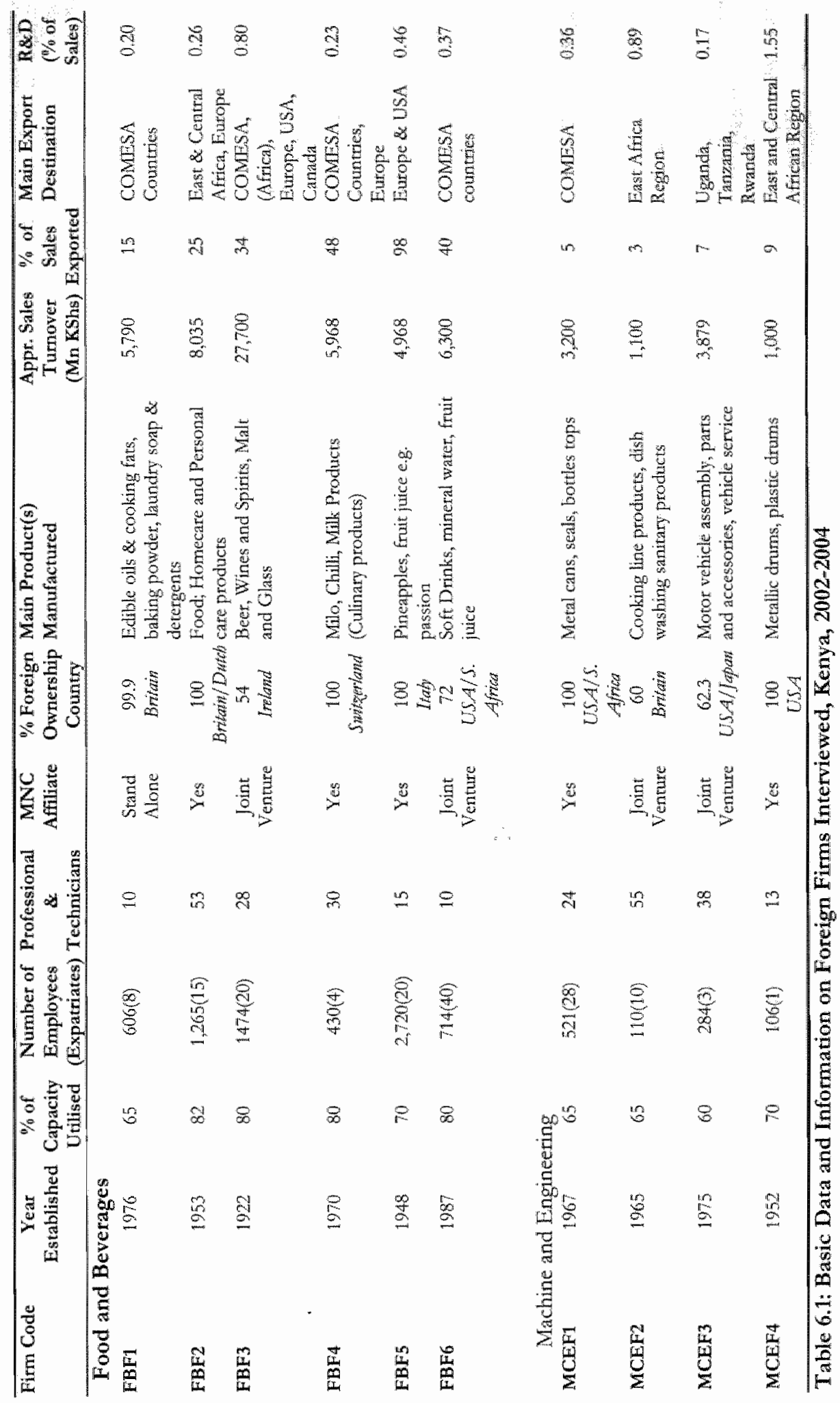




\begin{tabular}{|c|c|c|c|c|c|c|c|c|}
\hline & 1996 & 1997 & 1998 & 1999 & 2000 & 2001 & 2002 & $\%$ Change \\
\hline Gross Turnover: & 22,351 & 22,953 & 25,778 & 25,249 & $25,4,48$ & 26,813 & 27,734 & 3.43 \\
\hline Indiret Thares & 12,005 & 12,103 & 12,905 & 12,409 & 12,534 & 12,844 & 13,290 & 3.47 \\
\hline Net Turnover & 10,346 & 10,850 & 12,873 & 12,840 & 12,914 & 13,969 & $14,4,4$ & 3.4 \\
\hline Openting Profit & 1,651 & 1,374 & 2,219 & 2,361 & 1,974 & 2,512 & 3,256 & 29.62 \\
\hline Interese Recble & 23 & 37 & 153 & 8 & 14 & & & \\
\hline Interest Payable & $(401)$ & $(386)$ & (398) & $(254)$ & -190 & & & \\
\hline Profit Before Trxation & 934 & 1,158 & 494 & 1,507 & 1,798 & 2,499 & 3,400 & 36.05 \\
\hline Taxation & $(429)$ & (251) & $(160)$ & $(379)$ & $(623)$ & (947) & $(1,100)$ & 16.32 \\
\hline Profit Afrer Taxation & 506 & 907 & 327 & 1,128 & 1,175 & 1,552 & 2,300 & 48.20 \\
\hline Minotity interest & $(88)$ & (36) & 96 & 52 & 59 & & & \\
\hline Profit attrib to $\$$ /holders & 418 & 871 & 231 & 1,076 & 1,234 & 1,500 & & \\
\hline Dividends & $(328)$ & (393) & $(562)$ & $(655)$ & $(717)$ & & & \\
\hline Retained Profir & 90 & 478 & -331 & 421 & 517 & & & \\
\hline Net Sales (Bn) & 10.35 & 10.85 & $12: 87$ & 12.84 & 12.91 & 13.96 & 14.97 & 3.43 \\
\hline$O /$ Protar (Bn) & & 1.51 & 0.74 & 1.75 & 1.97 & 2.51 & 3.31 & \\
\hline PBT $(\mathrm{Bn})$ & & 1.16 & 0.49 & 1.51 & 1.79 & 2.49 & 3.16 & 42.94 \\
\hline EPS & 6.45 & 13.29 & 2.82 & 11.49 & 12.91 & 14.88 & 21.27 & 27.78 \\
\hline DPS & & 6 & 6 & 7 & 7.5 & 9 & 11.5 & \\
\hline
\end{tabular}

Source: Compilled by the aurhor from groups anneal reports for various years.

\subsubsection{Machine and Engineering Industry}

Four large scale foreign firms were considered for our case studies in machine and engineering industiry. Out of the four, thetee of them (MCEF4, MCEF2 and MCEF1) were established before 1970. MCEF4 was actually established in Kenya in 1951 but began its actual processing operations in 1952. MCEF2 was established in 1965 while MCEF1 was established in Kenya in 1967. MCEF3 was relatively younger having been established in mid 1970s. Upon establishment, a MCEF4 core business was to manufacture steel drums using steel rolls sourced both locally and externally. Daring the period 1970 s-80s, the firm diversified its operations to include plastic drum manufacture. Nevertheless, the mamufacture of steel drums accounts for $60 \%$ of the rotal production while manufacture of plastic drums accounts for $40 \%$. While MCEF3 was established with the sole aim of procuring, assembling and selling motor vehicles, MCEF1 production activities included making of metal cans $(53 \%)$, seals $(25 \%)$ and making of botte tops (22\%). Products manufactured by MCEF2 included cooking line products, dishwashing products, sanitary ptoducts etc.

Two of the firms studied (MCEF1 and MCEF4) were wholly owned subsidiaries of foreign firms. MCEF1 was established in Kenya as a $100 \%$ affiliate of a British owned MNC. However, in 2002-3, MCEF1 was acquired by South African MNC firm itself an affiliate of a world-wide conglomerate with interest in a wide array of manufacturing interest. MCETF1, a wholly foreign owned firm, is jointly owned by Europe and South. Africa. MCEF4 was established as a $100 \%$ owned affiliate of an American MNC. In 1998 the firm merged with a Finnish company but broke up after wo and a half years. A North American company with interests sptead worldwide, acquired MCEF4 parent company with all its group companies worldwide. Thus, since 2003 MCEF4 started its operations under the new North American owners. The remaining firms MCEF2 and MCEF3 were joint venture firms. MCEF2 was a joint venture with local equity $40 \%$ and 
forejgn equity of $60 \%$. MCEF3 was a joint venture wh approxinately $52 \%$ wol equity shaves and $48 \%$ foreign equity shares. However, in 1998 there wa change in the ownershp status when the foreign shares increased to $60 \%$. Official secondary sources indicated that in the period before 1998 , the government sold a substanthamount of its shates to MCEF3 retaining a local equity shate of $37.7^{\circ} \%$ and forem ecanty shate of $62.3 \%$. The foreign equities are slared between USA and Japan as follows: The American MNC owns the majorty equity interest at $57.7 \%$ and andertakes the management and technical responsibilities of the joint venture company. A Japanese MNC owns $4.5 \%$ of the equity interest. The rest of the equity shares are locally owned as follows: the government of Kenya owns $20 \%$ through an investment organ, the Industrial and Commercial Development Comporation (ICDC). The remaining $17.8 \%$ are owned by the industrial and commencial Development Company, Investment Company (CDCIC), a publicly owned company and an affiliate of ICDC.

Assessing performance in terms of sales tumover, it is noted that in 2002, MCEF1 and MCEF3 had turnover in excess of KShs 3.0 billion with totall fixed assets of KShs 6.5 bullion and $\mathbb{K}_{\text {SSh }} 0.65$ billion respectively. MCEF4 had a higher turnover than MCEF2 and had fixed assets of about KShs 12.0 million. With regard to exporting experience, all the firms had export experience spanning over 20 years with the exception of MCEF4 whose export experience by 2002 was below 15 years. Interestingly, all these firms targeted the regional market for their export products. The markets included the Fast African countries, COMESA and sometimes the SADAC region.

\subsection{The Case Studies of Foreign Firms in the Food and Beverage Industry}

In this section, we present the case study illustrations of the spillover process in the food and beverages industry following the framework of analysis outlined in section 6.2 above. Presence of foreign firms was observed to have stimulated spillover occurrence to domestic firms supporting our theoretical and empirical approach in Chapter 2 and 5. This section starts by outlining in detal the selection procedure of each of the firms considered.

\subsubsection{Firm Selection and Justification: Emphasis on Production Technology, Learning and Innovation}

As indicated above, the choice of firms to be included in the case studies was based on production technology, learning and innovation. We therefore targeted specific firms whose production technology appeated important in human capital development. Similarly, we targeted foreign firms that seemed to have the nechanisms which stimulated locals employed to accumulate tacit and experiential knowiledge - that is normally acquired through on-the-job training and learning by performing. If the locals ate observed to have acquired tacit and experiential knowledge from forcign firms, we can then argue conctetely that learning by participating in the firm's production activities does contribute to the development of human capital in the industry. The tacit and experiential knowledge accumulated could benefir local firms in the form of knowledge spillovers when such workers leave their jobs with foreign firms to join locally owned firms - or when they leave to become own entrepreneurs. The extent to which this phenomenon takes place is examined from the perspective of local firms in Chapter 7 .

We now tum to individual firms and offer explanation as to why they were selected. FBF1 was selected as it urilised the most sophisticated technology in its sectort. However 
all of it was acquired from abroad - mainly from Europe. As a result of its state-oftheart ptoduction technology and the scale of operation, FBF1 posed stiff competition to the locally owned firms in its sector. Another interesting factor that influenced the choice of this firm was the need to have at least one stand alone firm in our case study - stand alone in the sense that it did not have a foteign affliate. The analysis done in Chapter 5 showed that many stand alone furms operated in the Kenyan manufacturing industry. Hence, consideration of FBF1 in our case study would enable us to compare stand alone fitms and MNC affiliates with regard to opportunities they create for spillover occurrence.

FBF2 was the most advanced firm in its sector. It uses completely foreign technology, machinery and equipment for its manufacturing activities. Given its wide set of manufactured products, FBF2 operated many processing lines and had several refineties located in different cities. The firm utilised over $80 \%$ of the total capacity installed. Since the firm is considered to be one of the leading MNC frms in its sectot;, we provide a brief discussion of its processing technology which we observed. In 1989, FBF2 installed a major edible-oll refinery sourced from Germany. The installation was done by the suppliers - a German company known as LURGI - who are among the world leaders in the supply and installation of edible ofl refineties. This was a sophisticated plant whose processing technology was computer controlled and as explained, comparable to those used in Europe. The plant consisted of three main components: a continuous deodorising - stripping plant, pre-treatment equipment and an oil blending system. The continuous deodorising/stripping plant was the most innovative component process introduced in the new plant. It enabled FBF2 to operate a continuous process as opposed to the conventional batch type used before. With the innovation introduced, FBF2 was capable of deodorising different types of vegetable oils at high quality level. The second component of the plant serwes to pre-treat oil by remowing unwanted colour and any traces of metal ions present before it was fed through the deodorising column. This process innovation had actually been patented by the parent company. At the time of installation, FBF2 was among the first subsidiaries to utilise it. The third innovation was a sophisticated oil-blending component that enabled FBF2 to produce many blends of oil. The advantage of production technology introduced was capacity expansion and flexibility enhancement. "The flexibility of the process enabled rapid introduction of product changes as dictated by dynamics in the market - changing consumer tastes and preferences such as changes in shape, sizes and packaging. Products of meeting international quality standards could be produced.

Turning to the training and learning acquired from the refinery process, the firm. indicated that both training and leatning commenced with the installation of the refinery and were a continuous process. Locals were involwed in the entire process from plant installation to commissioning. The local personnel involved included senior managers, production and machine operators, and engineers and technicians from the engineering and maintenance department. Note also that earlier, a few engineers had been sent for training abroad to acquire experience with the machine suppliers. The engineers from the suppliers spent several weeks introducing locals to all the stages through formal trainings and in the form of discussion forums. A lot of emphasis was attached to production operations and routine maintenance. Much time was therefore spent with the production operators (machine operators) and the engineers and technicians who wonld later ensure that the operations of the installed machinery and equipment were smooth and efficient. Tremendous production capability has been built. Over time the engineering and maintenance department had accumulated capability and could handle most types of trouble shootings, make minor modifications, undertake major overhaul and do 
maintenance and repair most of the plant components. An international link is maintained with machinery suppliers for consultations and technical support in coses of major: breakdown.

The product technologies used in this firm were also fully foreign. The firm does not involve itself with serious search of product technology. The search activites to introduce new or improve the products are left with the parent company abroad. In actual fact, the firm confirmed that the parent company was the main driver of product technological knowledge and imnowation. Nevertheless, the firm spends a substantial amount of money on R\&D which is only in quality control, materials and chemical analysis. This money is spent adopting 27 the international products to the local conditions, tastes and preferences. Therefore, the local workers are trained on how to manufacture the products following the innovations done abroad. Unfortunately, much of this training was on know-how but not know-why. There was also technological leatning from quality control practices. The quality control department was very strong and well equipped for analytical purposes. The firm had adopted Total Productive Maintenance (TPM), a Japanese model that allows continuous improvement in quality and management aspects. TMP ensures, total employee involvement, total equipment effectiveness and total absence of wastage. FBF2 was awarded ISO 9001 certification in 2000 for quality management, ISO 14001 certification in 2001 for strict adherence to environmental management and Occupational Health and Safety Assessment Series $\left(\right.$ OHSAS) ${ }^{128} 18001$ in 2003.

FBF3 was also selected as it utilised processing technologies that were quite sophisticated despite being completely foreign. "The implication of this is that the firm does not undertake major process innovation as foreign technical partners are maintained as the sole sources of core processing technology. As a result of high technology used, scale of operation and human capacity possessed, this firm poses stiff competition to the other fitms in its sector. The firm enjoyed several bottling lines due to its wide portfolio of alcohol products. We provide an example of a processing technology used in one of FBF3's subsidiaries which manufactures beer. At the time of this reseatch, the firm launched its fourth and the newest investment in quality and capacity. "This was a KShs 1.4 billion state-of-the-art bottling line with a filling capacity of 66,000 bottles per hour, making it $200 \%$ more efficient than previous lines. The bottling line manufactured by KHS in Germany was the most modern and according to the production manager only a few breweries in Africa enjoyed such technology in bottling. Accordingly, this process innovation enhanced quality of beer, improved packaging efficiency, reduced beer loss and was more energy conserving. The Germany firm was involved in the installation of the ultra modern bottling line including all the civil work.

The firm contended that investment was not only made in the line and equipment installation, but also on staff training for the new line. Given that the line was more technically advanced than all the previous lines, staff training was extremely inevitable. The plant comprised a highly integrated computer controlled process that required a thorough mastery by local staff in order to operate it. The firm therefore lacked the

127 This suppotts the fact that foreign firms do not conduct much R\&D in developing countrics [Lall, (1979: 1980); Patel and Vega, 1999; Amsden, Tschang and Goto, 2001; Rasiah, 2003].

128 Through OHSAS, the firm had reduced the consumption of fuel oil, water and electricity by over $50 \%$ per ton of production in the last five years. At the time of receiving this certificate the firm had recorded over 500 days accident free. 
tequited skills at the onset to operate it. Experts from $\mathrm{KHS}^{\mathrm{i} 2}$ Germany were engaged in training the local production staff for several months. The KHS engineers left after the local staff had acquited skills and accumulated the necessary technological capability to manage and operate the botting line. As explained during the interviews, the production staff spent an estimated 40,000 man-hours training sessions for the bottling new line. The firm contended that the training was aligned to international standards of best practice and once trained; the staff was capable of operating any wotld-class botting lines. Locals were introduced to the enture process management (machine operations, trouble shooting procedures, maintenance and safety procedures). This indicates that technological spillovets pertaining to process technology occurred as a result of tremendous training offered by the foreign expatriates. This discussion supports the argument that spillovers of technological learning in firms could equally result from imported technology and machinery as it does from mobility of wotkers internationally. If these workers later left their jobs with FBF3 to join locally owned firms, the locally owned firms would then benefit spillovers as well.

As far as product technology is concemed, the firm acknowledged the importance of innovation and thus undertakes R\&D. As a result of in-house R\&D the firm had acquited enormous product technology that enabled it to manufacture its own brands of alcoholic beverages. As far as product technology is concemed, the staff had learnt and accumulated experience over time as a tesult of continuous training.

FBF5 was selected as it utilised the most advanced technology to process its products in the fruit processing and packaging sector. Although most of the production technology utilised by FBF5 was fully foreign, some of it was a combination of local and foreign. The firm was operating over $70 \%$ of the total installed capacity. The firm uses a large electronic 'Ginaca' machine for efficient processing of pineapple fruits. Local personnel had been trained and were operating the machinery. The locals had also been trained to operate the sugar recovery plant that was used to extract high-grade refined sugar from waste pineapple skins. At the time of this research, FBF5 had just acquired two new machines, Moeller MCCS, for pineapple processing sourced from South Africa. These machines were capable of removing the fruit skins, wash, slice and can the fruits ${ }^{130}$.

FBF5 has a well-equipped engineering unit (technical workshops) capable of making simple to complicated fabrications. This department was also the custodian of technicall equipment used for technical training, which this firm offers. Virtually all the technical operators were Kenyans who had either been trained in-house or externally and had accumulated engineering experience over time while on the job through learning by doing or through interaction either formerly or informally. One of the rematkable innovations of this unit was a massive 120 -feet-span boom harwester. Another significant innovation was that of manufacturing fumigants that were more adapted to the locall rerain among other local conditions. The department had also introduced many other minor innovations that included mechanical slicers, crushers and sterilizers/coolers. Every modification introduced was tailored to fit the equipment to the local needs. "The fabricated equipment were usually more reliable, cost effective and were easily serviceable. A second workshop is also maintained to deal with maintenance and regular: servicing of the firm's fleet of motor vehicles and tractors used in the firm. These

\footnotetext{
12 KHS Kisters was a German firm involved in the manufacture of processing lines for foods, beverages cre.

13m Locns had to be trained not only to operate the machinery but also to manage it. For hygiene purposes and to comply with international tequirements the MCCS are housed in specially constncted cabinets of stainless stcel to prewent corrosion.
} 
examples support the angumert that locals learnt from the technology and machnery

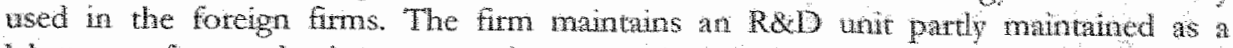
laboratory for conducting agronomic tests and as quality control laboratory. The fim had acquired an 1509002 quality certification as part of its quality assumance strategy.

FBF6 also utilised quite sophisticated and state-of-he-art bothng lines that were tully foneign for its soft drink production. Most of the machines and technology were sourced from Europe (Gemany-France) and party from South Africa. At the time of this interview, the firm was installing a newly acquired machine equipment expectad to improve the production efficiency. Engineers from Sonth Africa were involved in collaboration with the firm engineers, supervisors and technicians. This indicated that with respect to process innovation, the firm does not undertake any innovation. The frm relied on foreign technical partner for the supply of machinery and equipment with guidance from the brand suppliets. Although the firm had a strong foreign technical arrangement for regular maintenance of machinery and technology, it however mantained a separate engineering unit responsible for ensuring smooth processing operations and for undertaking routine repairs and maintenance.

The firm maintains three major sections for the pupose of soft drint: manufacture: bottling unit, syrup preparation unit and water treatment unit. The firm enjoyed four fully operational botting lines. Operations in one of the lines were highly sophisticated with its activities cootdinated by a computet-programmed robot. "The Robot could load empty bottles from their crates and place them on the washing line and at the same time remove filled bottles from the filling line and place them inro emptied crates for dispatch to the warehouse. In each of these sections different kinds of learning existed. With regard to bottling, locals were trained on all the bottling stages ${ }^{i 3}$. The staff in the syrup preparation and water treatment section had also learnt a lot by doing and from formal traning. The implication of this is that should staff leave in future to foin domestic firms, they would share skills and other forms of spillovers of knowledge they have acquired from these trainings.

The firm has no R\&D department. Whenever new products have to be launched, FBF6 relied on the brand suppliers for product innovation and technology. Product R\&D waS done abroad, mainly from the MNCs home country. The R\&D done involved improvement of the existing flavours or development of new ones which are then licensed to FBF6. FBF6 however, maintains a well-equipped laboratoty with modern analytical capabilities to make sure that the quality of the brands was maintaned. The brand suppliers audit the performance of this labotatoty, a process that has made the firm improve its production and quality control capability tremendously. Quality control management was monitored through out the entire value added chain. This included standard laboratory for performing notmal analytical tests and monitoring efficiency of the entire process. The laboratory was therefore manned by highly qualified staff most of whom held degrees in food science, biochemistry or micro-biology. Employeets in this department are intensively trained and are all local staft. To ensure quality standards, the department makes sure that the raw materials received are of the expected qualiry by subjecting them to tests. The ingredients, syrup and microbial tests are done. The bottles are randomly sampled for analysis from the process, filling lines and taken to the laboratory for analysis and examination. The products are also followed in the market for

\footnotetext{
2.11 The process begins with washing and rinsing of the bottas. This is followed by filling the bortes whin the sofr drink. This is done afrer the syrup is numed with purifed water find duen cabor dioxide added using a machine called cabonator. The botwes are then capped using metal caps. Then here is a final inspection before storage in the warehouse awaing delivery to the mathet.
} 
analysis (market survey) just to make sure that they teach the intended customers in the right and expected quality. This also ensures that locational watiation in, say weather, handling during and after transportation does not affect the initial quality. Although the firm did not have ISO standard they clamed to follow standards set by the brand suppliers, which were higher than $1 S O$ standards. Nevertheless, the firm had quality assurance certification from $\mathrm{KEBS}$.

\subsubsection{Human Resources Development and Labour Mobility}

This section examines firm level training and labour mobility in the case study firms selected in the food and beverages industry. Firm training thas positive and direct correlation with spillower occurrence. Technological training leads to human capital. accumulation which in itself enhances firms' absorptive capacity necessary to absorb and assimillate knowledge, skills and ideas. Interesting cases of firm training and labour mobility which resulted in spillover occurrence were found. This supported our theoretical arguments in Chapter 2 and our empirical finding in Chapter 5 that training and labour mobility stimulated spillover occurrence to the locally owned firms.

\subsubsection{Human Resources Development (Firm Training)}

All the foreign firms emphasised the importance of human capital development in their operations. The firms contended that rapidly changing technologies, competition and continuously changing quality control requirements forced them to be conscious of human resources development particularly staff trainings. The firms had created human resources department with budgets set aside for training purposes including other forms of self-entichment programmes. The firms studied devoted approximately $10 \%$ of their annual payroll for training purposes. We highlight a few examples of how firms viewed technological training. FBF2 reiterated the importance of continuous improvement of employees if thad to keep up the pace of a sustained improvement of its quality management systems, effective marketing and efficient delivery of products to the marker. FBF3 contended that strong human capital was the driving force behind its. steady productivity and performance. It was therefore committed to continuous staff training and up-sikilling particularly due to the complexity of technology and machinety used for its operations, rigotous marketing operations needed and high management and organisation standard required. Similarly, both FBF4 and FBF5 ncknowledged the impottance of strong human capacity for theit production operations, organisation and co-ordination. Both firms therefore place much emphasis on human capability development through trainings and through offering other forms of human resource enrichment progtammes. 'The firms' employees were assessed annually for their training needs (capacity development needs) and in line with their career/promotional expectations. Due to its large workforce, FBF5 operated a diverse training progtamme meant to cater for everybody from field worker in the firm's plantations, technical and processing personnel to managers and professionals.

Four forms of trainings were identified during the interviews. In the first case, staff benefited on-the job training. Secondly, the training was offered in-house but in a training department. Thind, the training was offeted externally, either in an external training department/institute or in the local training institutes. Finaly, training involved external trainings done outside the country (abroad and/or overseas). The firms studied depicted at least mote than two of the four forms of training outlined. As observed in Box 6.4.1, FBF2 is a good example of a foreign firm with training policy that reflected all the four forms of trainings outlined. We address each one of them at a time. The on-the-job training was the most common form of training witnessed in all the firms studied. It 
involved all hinds of staff training and differed from fin to firm. However some lind of trainings were notable training on machinery opertion and maintenance, safety precantions, how to diagnose trouble shootings, cost and energy saving measures, quality control management.

The sewnd form teferred to tratning done in house and in the firm's own traning department. While FBF1 had a rather simple training unit, all the other firms (FBF2, FBF3, FBF4, FBF5 and FBF6) had well-established in house training deparments where employees underwent staff training. For instance, FBF2 had a saparate department for human resource development and training headed by a full director. The department was responsible for identifying the needed capacities and then organise training and other forms of human development needed. This way, the firm offered continuous training at all employment levels with a policy that each employee must attend some form of training at least three tmes in a year. FBF3 had a human resources department for human development purposes. The employees were therefore subjected to intensive in-house training. Extemal trainers and subject mater specialists were regulatly invited to offer trainings in-house. The trainings offered were diverse and could range from quality to process control and management or from individual attitude towards work to market labour conditions and trade disputes. Managers and professionals also attended regular courses on good corporate governance principles and code of best practice. FBF4 and FBF6 had their training designed and supported by their parent companies. FBF6 has a human resources department headed by a human resources manager. Each department has capability heads and section heads below them. By involving the capability heads and section heads, each section conducts skill gap analysis to assess capability needs of the staff. On the basis of the skills gap analysis, appropriate training is then recommended. The human resource depattment then takes over and organises for the required training to fll in the required capabilities and to improve existing capabilities. In-house, the firm has a routine schedule of raining Every member of staff must go through such trainings a few times in a year.

The thind form of training identified involved sending staff to the frims' external training departments or to the local training institutions. FBF2 had an organised external training with the local training institutes and business associations. The firm also organises intensive training seminars in secluded places where full boatd hotel accommodations are organised in different locations from the firm and away from the cities so that everyone fully concentrates in the taining conducted without having to leave the premises. This was commonly done with marketing. Due to FBF3 commitment to staff technological training and up-skilling, if certain skills are requited, the employees are sent for training, sometimes externaly in the local technical training institutions. FBF5 sends its employees for training in some of the local training institutions such ats Kenya or Mombasa polytechnic. At the time of this interview the firm had over 50 of its staff taking such courses with Kenya Polytechnic. FBF6 sponsors staff to go for external training such as science and technical training courses with national polytechnics. In all the cases studied the staff wrete allowed to attend regular staff enrichment programmes organised externally say with KAM, KEBs or KIM. 


\section{Human Resource Development: The Case of FBF2}

FBF2 is a whily owned subsidiary of European MNC. It was established in Kenya in 1953 for the manuacture of food, home and personal cate products. With regard to taming FBF2 reiterates the importance of continuous improvenent of employees if it has to keep up the pace of a sustained continuous improvement of its quality management systems From the intetvews, the fim is fully awate of the fact that skilled labour force is the drung force of its nonowave activites, manufacture of high guality products and ther efficient delivery to the narket

In this light, the fitm advocates for critical on the job learning. It has a special induction programme fot new employees. The experienced staff tran by demonstration to the new ones and the less expertenced $\mathrm{FBF} 2$ has separate deparment for human resource development and traning headed by a full directot. This depatment is involved with tentifyng the needed capacities and then organises training including other forms of human development needed. This way, the firm offers continuous training at all levels whete each employee must attend some form of training at least three times each year The training ts either done in an in house taining depattment of externally in one of the local twaning institutes. Intensive training seminars are also offered in secluded places where full board hotel accommodation are organised far away from the cities so that extryone fully concentrates to the trating without having to leave the premises.

FBP2 also attempts to tap into international resources by offering trainings tnretmationally. Thts is done in liaison wirh the parent company, which proposes and. eften provides additional and advanced raining programmes. It is important to mention that technical and other professional managers who are Kenyans are among those who have benefited in this programme as they are periodically sent on international training courses, which take place at the parent company. Similarly, under the management of the parent firm, the substiaries have an international exchange programme that serves as a neans of training as well as providing other forms of human capacity building at orher affiliates of the MNC (parent company's subsidiaries). Many Kenyans including senior manages have and are still regularly sent for international exchange programmes. For cxample berween 2000 and 2002 about 10 managers had attended an exchange programme in othet countries such as Fingland and Netherlands in Europe and South Africa, Ghana, Ethiopia and Uganda in sub Sahatan Africa.

Through these trainings and long experience gamered at work, Kenyans have acquired the necessary technical and managerial capabilities and have risen to become departmental managers and in some cases full directors. For insance, the corpotate affatrs director was a Kenyan who had acquired tremendous expetience after having workerll with the parent group of companies for over 27 years in different countries. He had worked and undergone training with other subsidiary of this MNC in Furope. The marketing and sales manager was also an indigenous Kenyan who had spent most of her career in commercial functions in FBF2 and its parent company in Kenya and in Europe respectively for over 16 years. The supply chain director and human resounce development and training manager were also Kenyans who had tisen through the ranks to theit current positions as a result of immense training offered to them as well as experience gathered after many years wotking with FBF2. 
The fowth form of traning also included external trainings but this time in the immediate region (regional training instimtions) or abroad. Regional traning occurred mainly when the parent company decided to have a regyonal training institute for all its subsidaries for instance in East and Southem Aftica. Exchange programmes also occurred regulaty where staff would be sent ro the group branches to spend some time for training purposes. All the furms studied sent their staff abroad - mainly techical personnel and professionals for specialized courses or to attend exchange programmes. However, FBF2, FBF4, FBF5 and FBF6 attempted to tap into international resources mote prudently by offering trainings internationally with their parent companies as well as through organised exchange programmes between $2000-2002$ about 10 managers from FBF2 attended such exchange programmes - see the Box 6.4.1). FBF4 had at very elaborate training that included overseas training and regionally coordinated training. In the region, employees are trained within the countries in the region like Zimbabwe and South Africa. Oretseas training involved taking staff to Europe and mostly in the groups" headquarters in Switzerland. Senior professionals interviexwed (Human resources tmanager and the Production manager) claimed to have undergone multiple specialised trainings abroad, often Europe (mainly Switzerland, Britain, Germany and Netherlands).

The firm had also an organised exchange programme, where professionals would remain in a different country for sometime ranging from a few weeks to several montas undergoing training. For instance, durting the interviews, the firm had it visiting production manager from Sonth Africa who would remain there for some months. Experienced engineers and professionals from the firm would even go to tiain in other countries in the region. The production manager was reported to have traveled to Zimbabwe to conduct technical training. As an exporter, FBF5 asserts a lot of importance in tapping into the global knowledge pool by sending staff for training overseas. Additionally, employees are sent abroad to other affiliates/subsidiaries of the parent MNC frrm to acquire practical experience or undertake further training. "This is done on a tegular basis and every year about five employees are selected to attend the programme. FBF6 employees are also sent for trainings outside the country e.g. with regional training headquarters in Africa. Fortunately, when South African Brewing Company (SABCO) acquired this firm, training and development of all staff was one of the major priorities. This resulted in the establishment of a regional learning centre in Nairobi, which was officially opened in 2001 with complete conference centre fully equipped with lecture theatres and a separate unit whete business simulations could be conducted as part of experiential learning. The tegional tmining centre is supposed to cater for the East African Division that comprises Ethiopia, Kenya, Mozambique, Tanzania and Uganda. This is expected to build entrepreneurial skills for both staff and customers.

This discussion indicates that all these firms recognise the importance of human resources development in which case they reciprocated by offering training and other forms of staff enrichment progtammes. Secondly and perhaps the most important is that the foreign firms offered training to the locals (Kenyans). This has for instance enabled them to operate sophisticated machinery; manage production and other logistics including marketing. In all the companies, local staff had even assumed higher ranks in the management levels in some cases becoming full directors. As an example, FBF5 had an annual assessment policy for human resources and skill development needs that enabled Kenyans to take up senior management posts in the firm. The training programmes offered in this frrm had resulted in tremendous human capability development. It is important to emphasise that trainings have often been awarded in line 
with carce development or promotional expectations. The local personnel in this firm have accumulated enough experience over time in profession and in technical aspects. Some of them have become professionals and technical experts with good mastery of their work. In the past two years, the number of expatriate employees has dropped from 20 to 9, all of whom held highly technical or senior management positions. The firm's management generally saw this as an indication of effective transfer of technology by the MNC. FBF6 had a similar policy to groom in-house senior workers. The seniors are supposed to take charge of that. As an example, two of the main departments were headed by Kenyans who had undergone in house raining. There were indications that more senior positions were going to be occupied by Kenyans. A good example is that of assistant planner who joined after fmishing his A-level studies in 1983. After having worked with them for 20 years he had been trained, acquired experience and then promoted to the present position of senior assistant planner. As a planner, he had been trained on many things ranging from taw material planning to production scheduling. The direct implication of training offered in foreign firms is that when staff leave their jobs and later join local fitms, spillovers are likely to occur. The next section attempts to examine labour mobility and opportunities created for spillovers to the domestic firms.

\subsubsection{Labout Mobility}

In the above section, we examined the trainings offered in the firms studied. Next we examine the labour mobility in the same firms. However, we must point out from the onset that details of workers mobility were scarce, as firms did not document such information. Hence, in addition to information obtained from the human resources personnel we had to rely on production managers and other old members of staff in the service for any information and cases they were aware of. We asked them to recall if the firms had lost or received any professionals, scientists, engineers and technicians. This was important to us as this would indicate the level of spillowers through mobility of staff. From the interviews, Jabour mobility was detected to be substantial from the firms' studies. "The firms had lost and at the same time received workers from other firms ${ }^{1.22}$. The workers who left could be classified as productive with long standing experience; such included managers and professionals, scientists, engineers and technicians. This was interesting since this category of workers is normally the one associated with generation and diffusion of knowledge ${ }^{\text {t3 }}$. Among the staff that left, many examples were cited where staff had left to join locally owned firms. It was also noted that these firms had acted as breeding grounds for local entrepreneurs. Local people having acquired work experience and training left the firms to start their own firms. We now look at outward and inward mobility of workers separately.

With regard to outward mobility, all the furms studied had lost staff to other firms. For instance, FBF1 had lost a professional to a local competitor in edible oil industry. FBF4 also indicated to us that it had lost multiple workers to other companies before which included locally as well as foreign owned firms. Some of the key-manufacturing firms, which benefited skilled employees from FBF4, included FBF3 which benefited engineers from FBF4. Other manufacturing companies included Unga group and FBF2 where they have many workers who joined having worked with FBF4 for several years. Such professionals included marketing and management executives. Once again the recipient firms included not only the manufacturing firms but also firms in the services industry. FBF4 had cases of personnel who equally left but to join the service industry.

19 'The fims hat lost and received wotkers from both computing and non computing fims in both manubacturing and service industry.

133 The stilled personel holuding professionals are believed to have accumulated experiential and tacit knowledge and would thus be instrumental in carrying and diffusing knowledge and skills. 
Nevertheless, the examples provided were of staft that left to join firms in the service industry like Safaricom and Kencell ${ }^{34}$ at the managerial and professional levels. At the time of interview these firms were foreign firms. This obserwation was interesting as it indicated mobility of workers between foreign firms and thus labour mobility can not therefore be restricted only to the movement of employees from foreign fitms to the locally owned fims.

Turning to inward mobility, these firms also received professionals and skilled wonkers from other fims in the economy - the caliber of these employees included mainly technicians, craftsmen and artisans. For instance, FBF3 had received a few professional workers and skilled engineers from subsidiaries of MNC fims operating in the country. When SABCO closed its operations in Kenya, FBF3 inherited professionals and most of the techmically skilled staff. Similarly, FBF3 received staff from other firms in the service industry. As an example, the group-managing director in 2004 had worked for Standard Chattered Bank Limited, a British owned bank in Kenya, as the Executive Director of Finance responsible for Kenya, Uganda and Tanzania. Having served in this position and in addition to othet senior positions in finance department had enabled him ro acquire and accumulate invaluable experience in finance and management. He had enjoyed various specialised trainings organised both locally and abroad. He joined FBF3 as the firance and strategy ditector before being appointed to become the overall groupmanaging director.

FBF3 also received staff from Guinness International. An example was cited where the previous group manager was from Guinness International. The group finance and strategy director joined from Irish Life PLC where he was the director and chief financial officer. Another example was that of a professional from Guinness UDV who sat in the board of directors and he]d the group deputy chairman portfolio. As a result of tacit and experiential knowledge acquired while working with $\mathrm{MNC}$, all the people referred to were instrumental in introducing valuable changes pertaining to production, marketing, organisation and management. This example also supports the argument that at least foreign firms in Kenya serve as a 'supply' source of professional expatriates to the local labour market.

FBF5 had equally receiwed staff from other firms. An interesting example was provided of the firm's chief executive who was an Italian born but had lived in Kenya since 1972. He was a Ph.D. holder in Business Administration from Florence University and had a degree in agribusiness marketing and management from Harvard Business School, WSA. He established an edible oil processing firm, which was later bought by a locally owned firm, FBL1 discussed in Chapter 7. He also helped establish another branch of a MNC dealing with production of breakfast products. When he left this MNC in 1993 he worked as a consultant for private and government agro-industrial developments in the East African region. This continued until he was appointed as FBF5's chief executive in 2000. This example demonstrates knowledge spillovers from mobility of workers in the Kenyan manufacturing industry.

These examples support the argument that labour mobility exists from and within the Kenyan manufacturing industry. The examples also support the argument that mobility of workers leaving their jobs with MNC affiliates can result in spillovers of knowledge given that the staff considered here are managers and professionals and technically skilled personnel ${ }^{13}$. Many firms indeed contended that as a result of immense training offered

13:4 Safaricom and Kencel were two key companies in the mobile phone industry - service industry.

1 .5. This category of staff is genernlly tegarded as the carrice of skills and knowledge. 
and experitental tacit knowledge accumulated on-the-job, such workers resulted to spllowers of knowledge to the froms hiring them with possible accumulation of technologicall capability. Nevertheless, this will futher be inwestigated from the angle of the local fims in Chapter 7. It wras noted that those who left their jobs were attracted by figh salaries offered to them by the receiving firms in other sectors of the econony or competing firms in the manufacturing industry.

In Bow 6.42 and 6.4 .3 we present individual and fascinating accounts of mobility of workers from FBF2 and FBF6. With regard to inward mobility of workers, both firms received professional and highly skilled petsonnel who helped introduce technological changes including training of the locals. Outward mobility had also interesting casas of professionals and other skilled personnel leaving to join the local labour marker with potental implications of spillower occurrence.

\section{Box 6.4.2}

\section{Labour Mobiligy. The Case of FBF2}

\section{Inward Mobiliy of Workers}

With tegard to employment of workess from other fims, FBF2 contended that it only: employs vorkets from other firms only in rare cases when certain skills or specified professionals were needed. Win this case, the frm confimed that a few highly skilled workers and professionals had oined FBF2 from affliates of other MNCs in the country such as FBW6. The low absorption of professionals from other firms could be explained b) the faet that when specific skils are needed they are uisualy contracted from the patent company in Eutope or from subsidianes of the parent company in other countries. For unstance, in 2002 FBF2 had ovet 15 non-Kenyan technical and other professional employees who included those on full time employment as well as those on Hrernational exehange programme from subsidaries of the parent company in other counties. Out of the 15 non-Kenyan employees in the managerial category, 10 were techaical while 5 were non-technical, $1 \mathrm{n}$ addition to learning from FBF2 most of the tednucal and other professiond managers ander the incernational exchange programme In turn shared their skills by aftering training on ladking skills in house or provided other forms of himun resource development.

Examples of non-kenyans who were highly qualified technical and non-technical professionals were noted during the intervews. $\ln 2000$, the affiliate's chairman was from Germany who had a wealth of experience for over 30 years in sales and customer service posithons seguired from the paren firm in Europe and from its subsidiaries in South Tast Asia. The chief execurive was a Nigenan who had also worked and acquired immense expenience wodking outh the patent company in many countries where the MNC his subsidiarles. The technical director was also a German, a doctorate and a diplonn holder dn chemistry and chemical engineering respectively with ovet 22 years experience as factory nanaget in various conntries in tiurope. The commercial director responsible for finance was a Brish with equally long-standing career in Europe and Africh working with substaliakes of the parent company. Apart from these senior postions other technical levels also benefited professionals from other countries e.g: Europe, South Africa and Jndia. The most impontant thing here is that in all the cases the professionals concerned shated theit experiences and skills with FBF2 local staff. The foregoing confinms that FBF2 enjoyed skills, trainings and knowledge acquired from local and in eframional mobility of wortkers. 
With regard to workers leaving FBF2, several exanples wete cited where tratied and expenenced workers had let to join other firms uncludug competing firms on had opted to become entrepreneurs by opening tp their own bushesses A explancd, expentence and tacit knowledge acquired while working in the FBF2's matheting depmenent had enabled many people to become distributors with this firm, open up retall shops or strpermarkets while others had started simple products mandfacture. This showed that FBF2 had acted as a breeding ground for local entrepteneurs by a way of providing entrepreneurial skills. A technical person involved in soap producton had also left the firm to join a competing locally owned firm. When he joined the local fim, the firm stanted producing soap very close to FBF2"s own. He was the bran behind the product as well as the process technology. This example confirmed that trating and exponence is usually gathered while working with $\mathrm{MNCs}$ and that knowledge spillovers do occur through mobility of workers.

Similarly, it was confirmed that over 10 senior employees in the thatketing deparment (well trained and highly experienced marketing managers and sales representatwes) had ha the past left FBF2 to join other firms locally and in the region. A marketing managet had left to join British American Tobacco (B.A.T - a USA based MNC) to take up a sentor position as the head of East and Central Africa region. The managing director of one of the leading supermarkets in the country at the time (Uchumi Super Market) was a former professional employe of FBF2. He was behind the re-organisation and management changes at the supermarket. A sales manager had also left to join a cigarette fim in Tanzania and was in charge of two East African countres - Tanzania and Uganda The sales managers' of Reckitt and Colman, and Unga wete formet mployees of FBF2 Mobility of workers from this firm was not only restricted to the manufacturing industry as many stafe had also left to join other services like banking such as Ciri bank or telephone companies such as (Safaricom and Kencell companies). A senion sale representative claimed that "experience acquired in FBF2 was second to none making it obvious that most of the staff would only leave when destined for high salary and better fridge benefits, which would often be the case given that fums looking for them were after their skills".

\section{$\operatorname{Box} 6.4 .3$}

\section{Labour Mobility: The Case of FBF6}

\section{Inwand Mobility of Workers}

FBF6 has at strong policy of employing fresh graduates from universities or polytechnics who often joined as graduate management trainees. Jower and semi skilled workers were employed from high school. The furm only preferted employing staff from other fims only when there were specific skills or protessionals they were looking for. In this case, therefore, staff employed from such firms must be highlly experienced, and thus most of them could come from other subsidiaries of MNCs in the countyy. Such professionals would then be paid high salaries accompanied with better fridge benefits. 
FBF6 confirmed that it had lost nany of its workets in the past to orher frims in manufacturing as well as service industries. The workers lost mainly included professionals and managets as well as engineers and technicians - skilled and experienced workers. The fitm contended that those who left heir jobs were atracted by high salaries offered to them by the competing frms in the nanufacturing industry or in other industries such as the service industry. The firm contended that as a tesult of immense training offered and experietrial tacit knowledge accumulated on the job, such workers iresulted in spillovers of knowledge to the frrms hining hem.

Sereral exanjples were provided of staff who had previously worked in the firm but later on left to join other firms in ovier sectors of the economy. A sales representative, who had worked, trained and acquired experience while working with the firm left to join a local compeding firm in the soft drinks industry (FBI 2). When he joined this firm, he was promoted to become the rnaketing manager in-charge of all the distribution and makleting activilies (this will further be explained in Chapter 7). Another sales representative $1 \mathrm{eft}$ to $10 \mathrm{l}$ a compering foint venture firm in a beet brewing company ${ }^{36}$ (FBF3). At FBE3 he supported the marketing achivities - he organised very successfill beet pronaction eampaighs at a time when FBI3 was facing stiff competition from a subsidiary of South African MNC. Me was rewarded for his marketing lnnovativeness. A senior professional who wais a group finance managet had also left to join a local Kenya Bus Company in the local transport industry, A channel manager had also left to join a local telephone company (service industry) as a narketing manager, The list of examples Was eindless incliding companies like Firestone, Standlard Newspaper and many firms in the fitst noving consumer goods (FMC G) industries:

\subsubsection{Linkage Effects}

We attempted to map out and examine linkages formed by each of our case study firms. We also examined interactions between these firms and other systems of innovation such as business associations, public and private institutions. We identified both pecuniary and non-pecuniary forms of linkages. Pecuniary linkages seemed more dominant than the non-pecuniary linkages. This is however expected given that most of the subsidiaries in food and beverages industries were technology users.

The firms considered in our case studies contended that demand created and purchases made helped spur growth, investment and expansion to locally owned firms as it prowided them with capital. "To the foreign firms the feed back obtained through these linkages were important in that they helped them introduce changes on their processes, products and even marketing techniques. For example, FBF $5^{13 \%}$ has developed good backward linkages with some sectors of the economy. Metal cans for pineapple packaging, for instance, are produced at an adjacent company (MCEF1), while cartons,

136 Although this frrm is in the beer industry, it is referred to as a competing firm since it started producing Malta Guinumess which eats into the non-alcoholic market.

137. FBF5 is located $500 \mathrm{Km}$ inland from the Indian Ocean. It is approximately $1,500 \mathrm{~m}$ abowe sea level with an average remperature range between 12 and 13 degrees centigrade and an awerage annual rainfall of $900 \mathrm{~mm}$. The firm has considerable backward and forward linkage system. Of the total leased area, 5,250 tha is under pineapple cultivation, irrigated from dams and rivers and yielding an average of 270, 000 tonnes of truir annually. 
labels, spare parts and protisions for the cannery and plantation are purchased from various domestic manufacturets. With over 5,000 employees, FBF5 was a major economic force within Thita, one of Kenya's major industrial towns. The economy of the town is closely tied to the performance of FBF5.

Non-pecuniary linkages identified included linkages with the firms in the machine and engineering industry (user-supplier relationships). However, given that the firms relied on foreign suppliers for theit core production technology, local technical links with locally owned firms were only limited to maintenance, repairs and sale of simplified machine and engineering equipment. An appropriate analysis of the two kinds of linkages could not be undertaken due to data constraint. Firms did not have or did not want to disclose data, which would enable us to examine trends in any kind of linkiges and thus we just present a general discussion. We make no effort to separate the two kinds of linkage in our discussion. From the angle of foreign firms, local firms seemed to have acquired skills and spillovers of knowledge through the linkages formed and existing interactions. They audit their local suppliers (NBF4) regularly. "They are involved in offering training to appointed co-packers of their products especially in food safery and marketing operations and advertising services. They are also involved in fixing prices for the copackers. FBF5 has a local company, which does packaging for it. The firm stations some of its experienced personnel there to oversee the opetations. These personnel have offered training in the locally owned firm, quality control and production management. However, the extent to which these might have resulted in accumulation of technological capability in the locally onwed firms is investigated in Chapter 7 from the angle of local firms.

In addition to the linkages mapped, we also identified interactions with the local support systems such as business associations, private and public institutions such as R\&D/academic, financing institutions and government regulatory organisations and enforcement agencies. 'Through these interactions, skills and knowledge were shared, including technical assistance. We provide a few examples here. All the firms (FBF1, FBF2, FBF3, FBF4, FBF5 and FBF6) in our case studies were very active members of KAM. For instance, the chief executives of FBF2 and FBF5 were board members of KAM where they shared their expertise. The executive committee members of the KAM conptised chief executive officers from some of these firms (FBF4, FBF2 and FBF5). The managing director of FBF4 was the chairman of food and beverages sector. The chief executive officer of FBF2 was the chaiman of the social, legal and regulatory committee while the chief executive of FBF5 was the chairman of the industrial linkages committee charged with stimulating collaboration, linkages and strategic alliances in the industry. It is interesting to note that all the chief executives were foreigners who in their capacities definitely shared their wide experience through their participation. This could include labour ethics, corporate governance, policy lobbying technique, intallectual property rights etc.

Some of the firms also interacted with the MSK. The mission of MSK is to "project, promote and uphold matketing as a vital ingredient for success and prosperity." "Two of MSK's council members were drawn from FBF2 and FBF6. Through MSK, annual competitions open to firms in the industry or services are free to enter. The comperition categories involve best launch for new products or services, marketing effort and strategies, best innovation of product brands or services, best development of existing product brands etc. Through these competitions firms exchanged skills and ideas. Another institution that firms interacted with was Kenya Institute of Management (KIM). Firms participated in their annually organised company of the year award 
(COYA). Fums compete in various categories such as sound financial management; innowiveness and creativity, quality management, environmental management and hfomaton management and maketing management. FBF3 was al several times winner of the COYA awatd. Similatly, all firms interacted with government regulatory bodies such as Kenya Bureau of Standard (KEBS), Federation of Kenya Employees (FKE) and Monopolies and Prices Department. For instance, all the firms interacted with FKE for labour issues and disputes. Also, all firms participated in the development of standands with KEBS. They needed to achieve Kenya Quality $A$ ward (KQA) as well as Diamond Mark of Quality all awated by KEBS. KEBS in collaboration with SGS awards ISO 900 sertes for implementation of Quality Management Systems (QMS) and ISO 14000 cerrification for implementation of Environmental Management Systems (EMS). KFBS also organises for quality competitions for the award of Kenya Quality Award (KQA) FBF2 was a winner of $K Q A$. Other memberships included KIRDI (FBF2), with Kenya Dairy Processors Association (FBF4), KIPI (FBF3) and local micro financial institutions (FBF6) etc.

On technology development the country lacks strong R\&D to support industry imnovation and technology development, as there was little involvement of universities reseatch work in industrial activities. The firm has to rely on extemal sources for innovation and technology development. Nevertheless, the firms participate in human capital development in the country. Firms (e.g. FBF3) offer competitive acadenic scholatship to students pursuing higher education. The firms offer industrial attachment annually where graduates from locall universities and polytechnics can have their industrial attachment. The firms sometimes offer jobs to the best candidates after completion of their industrial attachment and deguee programmes. NBF4 contended that it worked closely with the University of Nairobi by offering internship and later absorbed some graduates in food science technology. FBF5 offers technical assistance in a unique way. It worlss closely with the Govemment's Managenent Training and Advisory Centre, the Directorate of Industrial Training and Kenya Polytechnic in developing its training programmes. The fitm's foll-time training manager organises internal courses, which are supplemented by the on-going local management programmes conducted by reputable local firms. At any time, about 40 students are enrolled in trade and technical apprenticestip programmes. The company is usually able to retain about $80 \%$ of its apprentices, with the rest being absorbed by other industries.

In addition to the above discussion, we provide some detailed accounts of linkages and interactions in FBF2 and FBF3. This is done in Box 6.4 .4 and 6.4 .5 below.

\section{Box 6.4 .4}

\section{Linkage Effects. The case of FBF2}

MBF2 integrated production process is supported by good forwated and backward Linkgges, With regard to backward linkages FBF2 has economic relationships with entepprises engaged in primary processing, fatming, packaging, electrical/electronic, machine and engineering and chemical industries, Given the innovativeness of FBF2, At means that its suppliers must not be left belund. As a requitenent in the ISO certification, the enture supply chan must be considered. FBE2 therefore encourages all Its suppliers to introduce uppropriate changes such as qualiry control and safety measures. FBF2 atso encourages its suppliers to develop envitonimentally sound processes and matentals. Whenexer possible; FBF2 sends staff to tratn the staff in the 

has enabled most of them 10 grow and expand

On the side of forward linkages, the company deals with local aistabutors and rethlers. food manufactuing industries and setrice monsth (hotels, hsirance and business

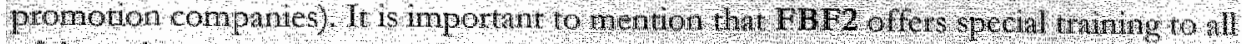
of them that cuts actoss a number of issues: cusiomer telations, salety, handing of goods and efficiency at services delivery. When rew products are betrg invreanced several demonstrations and trinings must be held These are wide tangng and anchde demonstrations on hox to prepare necipes iusing lhe nev products or love to do laundry using new soap products. Specifically, he whing thiroduces then to 1 SO, OHSAS and TPM requirements with main focus being qualit, standhrds and mangement, safergs setwices and production. All the trainings miast be adhered to at all times, levels and inspection are conducted routinely including ad hoc spot checks asing canjeras, jast to nake sure that the training provided are complied with. The distriburors, nanagens and supermatket attendant confirmed having teceved litensive marleting thaning from FBI personnel.

The firm also engages the services of specialised international fitms that ded with logistics and distribution. As an example, the firm contracted the distrbution renices $b$ : a MNe firm in 1996 following the recommendation of its parent company un Britain. The parent company had entered into a contract to have this logisties MNO deal with distribution activities of all its subsidaties wonldwide. The MC was a UK based International company that provides physical distribution and logisical support services for major tetailers and MNC manufactalers. With regand to $F B$ F2, its actividics involve purchasing FBF2's products, and delivering then to the major tetalers such as the big leading supermankets in the country In simple terms, the firm rets lust like the watehouse for the FBE2 and does all the dispatich of he prodicts lt transparts the products to the distributors and this is supposed to be wilun 24 hours tine. Distributots are many and the firm has an extensife netwonk of trained distributors locared all ower the country. FBF2 pianeered in engaging lie distribution services of this firm in Kenya as $1 t$ did in engaging a promotion company to advertise its products. Whis has had demonstration effects as other fims in food ard bevernges and machine and engineering industries engaging the services.

Widh regard to interactions, FBF2 interuets with R\&D ingtivitions, whiversicies/ polytechnics and business associations. The R\&D institates whit interact with FBF2 include KEBS, KIRDI and SGS. Personnel from FBF2 have been very instrumental in: setring standard with KEBS and KJTDI, The firm participates in preparation of trainitg: modules for othet firms in certain trainings organised by local institures a whings like quality management. The fim also interacts with business associations such as $\mathrm{KAM}$ PKE, EPZA, CMA and KNCCI. It is also a menber of MSK. Sone of the employees serve as the resource persons dunng seninars organised by eilhet business or tade associations: It is also a member of Agticultural Society of Kenya (ASI) and tegulanly exhibits its products on the show ground, Other firms benefits we skills denonstrated by FBF2 while lobbying for certain policies. Through these interactions, FBF2 hares with other firms its experience in lobbying for certain policies from he governments cotporate policy, quality management programmes. It utges them to work towards a clean and sustainable envitonment for future generation $1 t$ co-operates with other stake holders for the purpose of improving overall envitonmental perfomance. 


\section{Linkage Effeets: The Caste of FBF3}

PBF3 also taainains both backwatd and fonward linkage system. FBF3 maintains a strong international linkage with the suppliers of the machinety and equipment Nevertheless, EBP3 also mantans backward linkages. with the local machine and engineering industry from which it out-sources the procurement/storage/delivery of a large number of engineeting spares patts that fall in the following categortes mechamical and hardware, electrical items, beating and seals, conveyor belts and chains. Usually PBF3 invites expressions of interests from interested firms who feel capable of offening this service. Then the firms submit documentations clearly indicating stocks held, tinancial data over the last 3 years, management stracture, infomation technology (IT) capalility, expetience in outsourcing etc. Based on the information sabmitted a fer firms are selected and nwited to submit detalled proposals for consideration of the spares outsourcing contract. This process helps the local firm to engage in the process of rechnological capability building.

FBF3 (through its malting firm) maintains a strong link with barley farmers. For instance, the firm's agticultural officers have introduced a new certified barley vatiety that was nore capable of resisting barley related diseases and required less dressings compared to the othen varieties grown in Kenya. The variety was resistant to barley Jellow dwarf virus, which usually wipes entire bafley. The wariery had $20 \%$ more yield than othet barley warietes. The firm produces enough barley for the Kenyan market. It also exports to Seychelles. Uganda and Tanzania. The firm spent KShs 1.2 billion on promoting ond facilutating the growing of malt batley to its contracted growers with $63 \%$, Jeing paid to the barley farmets.

Wilh tegard to fonward linkages, FBF3 maintains very strong links with buyers of its products. Beer distribution is a lind of three-tier beginning with brewers and importers, wholesalers, retallers - retallets include supermarlkets, retail shops and pubs, hotels and lodges. FBF3 organises wining at various levels. The bar attendants are as well trained. These linkages are equaly beneficial to FBF3 for their knowledge feedback, which has enbled it to maintain a continuous improvement of its products. FBF3 has also established strategic marketing linkage (intemational distribution channels) distributors in Wurope, Ganada and United Stares. Participation especially in the international export maket las offered the groap new leatning effects (global exposure). The kind of learning got from this firn includes thiternational marketing logistics, gathering market intelligence etc.

As far as interactions are concerned, FBF3 is a member of KAM. Through this nembership fonum, the finm lobbies for certain industrial policies to be implemented such as tax teduction on solf drink sales and imported machinery etc. It interacts with KIBS and KIRDI both of which offer technical and professional assistance. $K$ EBS regulaily audits qualiry contrel and offers recommendations. FBF3 also interacts with KIII FBF3 sends its staf to participate in trainings offered by KEBS or KIRDI for instance on quality control or ISO requirements. FBF3 participates in competitions organised by KMM to determine imovativeness and firms exercise good cotpotate governance. FBF3 has won company of the year award two years in row and most respected company organsed by Ptice water house and Nation Media group. FBF3 allows students from local universities and polytechnics to have industrial attachment with them. In this tegard FBF3 supports human capital development in the country. FBE3 offers education support more directly by maintaining scholarship programs. 
FBFs runs a project in which it offers computers (enhance compurer literacy) ro high schools and trainings teacher on TT. This is organised with the fumb computer partners Computer Point and Micro Sott, which supplies all the licensing for the sorthwate at no cost. The schools are selected on the basis that they would be un a posinon no offer training to the stadents.

The firm also participates at iniemational level competitions. Some of the FBF3 beex prodicts have won gold nedal award at in international competition oiganised by Monde Selection International Instatute for Quality Selection" - an official insutution established in 1961 in Belgrum for universally maintaing hgl standards of beverage and foods produced for human consumption All prodicts are sublected to exllaustive Laboratory test and amalyses by leading experts in the field. FBF3 success was based on frequent staff training, continued investment in state-of-the at equipment for the brewing process and use of fine beer ingredents oblained in $\mathrm{Kenya}$.

\subsubsection{Competition Effects}

In this section, we analyse the existing competition between foreign firms and locally owned firms. Most importantly, we examine the intensity of competition pressure exerted by foreign presence. In the sectors considered, foreign and locally owned firms competed fiercely with each other. Nevertheless, due to the dominant position of foreign firms with regard to their scale of opetation and technological capability, foreign firms often out-competed the domestic firms often triggering them to upgrade by introducing necessary changes in otder to achieve technical and allocative efficiency. Specifically, foreign firms triggeted learning processes and technological changes in the locally owned firms. The extent to which locally owned firms have been able to learn and accumulate technological capability is evaluated in Chapter 7. This will enable us to understand how locally owned firms reacted and/or survived competition from foreign presence. However as this section will show, locally owned firms were not the only ones forced to introduce changes due to competition pressure, foreign firms also reacted to the competition pressure by introducing technological changes, training among other forms of human resources development etc.

In order to appteciate how comperition from foreign presence might have forced the locally owned furms to engage in the learning process, our discussion in this section will border four observations made in the course of doing these research. These were: mode of entry by some of the locally owned firms, formation of joint venture, international competition and high technology and capital equipment investment. All the firms both foreign and domestic) faced stiff competition from imported goods into the country. The open market operations following liberalisation opened up doors to all kinds of importec goods resulting in an influx of imports particularly from COMESA ${ }^{136}$ and SAD AC region e.g. South Africa. The firms claimed that "an assortment of food product importers existed who did their business behind the back of the government and went tax free. The biggest problem to them was lack of facilitation by the government and the tax paid was extremely high."

138 As the firms clamed thete was severe influw of foreign goods into the market and in some cases with severe violation of the rule or origin. 
In order to understand how mode of entry led to increased competition we discuss experience of FBF2 and FBF4. The rwo fims were among the most competitive MVC subsidiaries in food and beverages processing industry. The two firms also competed for matket in certain goods such margarine. FPF2's competitiveness was largely attributed to a large pool of skilled workers backed up by strong human resource development, innovation backed up by in-house R\&D and in-turn supported by the parent company, adherence to strict quality, environment and safety management systems, Total Preventive Mantenance (TPM) and efficient delivery of services. Similarly, FBF4 source of competitiveness was due to more or less the same attributes: conomies of scale, strict quality management systems, human resources dewelopment, process and product technology with support from the parent company. Consequently, the two firms had an absolute edge over local firms. However, since the introduction of structural adjustments (SAPS) in Kenya in the late 1980 s, FBF2 and FPF4 have continued to face severe competition from new wrants as well as from new products resulting in a substantial decline of the two firms' market shares.

The competition has been based on innovation with regard to new market, products and services delivery. The locally owned firms capitalised on an exisuing window of opportunity in the domestic and regional market. Based on their local market intelligence, they learnt that the MNCS products were expensive and thus targeted for high-income group. The entry strategy by the locals in the sector therefore targeted the middle level group with relatively cheap brands and thus captured a big share of these firms' market. FBL1 is an example of a locally owned firm that made its entry targeting the middle income level group. As will be shown in Chapter 7 , this firm has made a major boost, has started exporting and has recorded further expansion by acquiring another firm in the industry and has made new investment in Uganda and Tanzania.

Many changes took place in this sector, apart from introduction of cheap brands, the sector for the furst time changed containers used in packaging cooking fat and margarine to plastic containers. This happened when FBF2, for instance, was still using metal tin containers. FBF2 was forced to adopt the Kenyan version of its parent company's global strategy aimed at teducing its brands worldwide ${ }^{139}$. Following this strategy, FBF2 whose brand portfolio was over 30 brands had to reduce them to only 10 leading brands that are well known in the domestic and the immediate regional market. Interestingly, this strategy resulted in FBF2 selling its eclible oil and cooking fat product line to its local rival, FBL1. This product which was one of the FBF2's flagship brand, with an annual tumover of US $\$ 25.0$ million was acquired together with other brands of cooking fat, and laundry soap. The selling of product and processing technology to the local firm represented a typical example of technological spillover as a result of foreign presence. This was so since the domestic firm did not have to engage in any search effort through R\&D. On their side, both firms (FBF2 and FBF4) have increased their advertisement levels. FBF2 has since increased its advertisement level to an annual expenditure of about US 1.2 million making the company rank among the top in the country with the highest advertising expenditure. The firm has launched a strong campaign of relaunching its products to create awareness and attract more customers. It has intensified its tainings and adoption of quality management systems and occupational health and safety analysis system (OHSAS). All these are done with the facilitation by the parent company.

139t The parent company"s global strategy launched in 1999 was aimed at reducing its 1600 brands worldwide to only 400 . 
Similarly, due to comperition pressure, FBF4 has adopted various techniques patticulaty in matkening. As in FBF2, this firm has started re-lanching ins lagships products done in line with and following a major international relaumch policy of parent fim products organised from the headquarters in Switzerland. The re-launching is innowatively done to contain a particular theme for instance illustrated by comperitive sports depicting its uniqueness of the product as an energy giving drink. To further product promotion campaigns, FBF4 holds a corporate horse acing day in Kenya with an objective to create exposure for the firm's products and to intetact with its product consumers, business partners and colleagues. It also involves itself in physical education (PE) lessons of some schools similarly meant to promote the firm's products to the youth. Other skills employed in the marketing include branding policy where small promotional items such as caps, mugs, Twshirts, pens, pencils etc, are offered for sale or given out. This, however, must comply with the parent company's marketing and safery policy requirements. From the information gathered, the frm can invest up to an average of KShs 0.5 million for the purpose of a single product re-launch. As the production personnel claimed, FBF4 was still a leader virtually in all aspects of production in its sector and locally owned firms were followers with lots of things to learn from FBF4. The firm claimed that the quality management system were above ISO quality standards.

Another interesting point to illumimate here is that the changes implemented by the foreign firms' in-turn created intensive competition to the locally owned firms. Following the foreign fims' strategies to regain or expand theit market the domestic fims loses their market. Hence the domestic firms would have to equally undertake strategies to counteract the competition pressure from the foreign presence. The bottom line of this discussion is that competition in this sector headed by the foreign firms' presence serves as a trigger for the leaming process and introduction of technological changes. This supports out approach in Chapter 2 and 5.

Next we consider a unique case where entry by a MNC subsidiary from South Africa into the beer processing industry created stiff competition for the incumbents who had enjoyed monopoly for several decades. As expected, the incoming MNC subsidiary was characterised by high product and state-of-the-art processing technology. Had high skills in corporate management coupled with international exposure with well-established links. This firm's entry into the sector recorded one of the highest capital investment to have ever been made in the brewing industry. What makes this case particularly fascinating is the fact the pressure introduced forced the one of the local incumbents to form a joint venture. As discussed in Box 6.4.6, the formation of a joint venture intutn helped transform the firm from loss making to profit making and becoming one of the most efficient firms with sound management and employing state-of-the-art machinery. Subsequently, the firm created intense competition to the other lacals especially in the wines and spirits sectors such FPL2. This helped them to engage in the learning process. 


\section{Competition Effects: The Case of FBE3}

FBI3 whs established in 1922 as a beer manufacturing firm. This firm operated as a monopoly for many years. However, in 1990 s the firm was faced with stiff competition In addition to the conpetinion FBP3 faces from beer manufactarers, the firm faces 8 tiff competilion from the nanufacurers of carbonated and non-carbonated soft drinks. ABF3 faced competilion from imports following a huge influx of products in the sector with the Iberalisation of he economy in the 1990s. Linterestungly, other sectors like the serrice industry posed indirect comperition to FBE3. As an example, the onset of the moblle phomes in Kenya saw a dramatic teduction in the alcolnol consumption and at one Folnt the denand had declined by about $4 \%$ die to slumping purchasing power coupled whl he eneigence of altetnative drinks:

The competilon faced by PBF3 was as a consequence of several episodes. TO FBF3, Wings statted changing in the late 1980 s and the whole of 1990 s due to the effects of SAP and globalisation coupled with political and economic uncertainty in Kenya at the time, Another change was that of joint venture $\mathrm{UV}$ ) formation between Tanzanian governiment and South African Brewertes (SAB) linited to run Tanzania Breweries in 1903. 4 lie IV resulted in er hanced efficiency in brewing resulting in tremendous lacrease 10 Thnzania Breweries Lmited (MBI) productivity and marketing capability etc This resulted in severe loss of EBF3's signficant watket in the region, which ir had controlled In the 1970 s and 1980 s to the Tamanian Brewertes. In adiliton to this, South A frican Breweries entered nto partnershp with a brewery in Uganda in 1997 , in competition will FBF3. These changes cuhininated in stiff competition for FBF3 that was further intensified in 1998 when the SAB opened a subsiding (brewery) in Kenya in partmership with . Kenyon businessman.

In light of the prevailing changes in the industy and the intensive conpetition pressure created PBP3 decided to form a joint venture with an lish $\mathrm{MNC}$ - Guinress International who acquired $46 \%$ of the equity stake in FBF3. Guinness Iaternational has wide expertence in international brewing and was expected to bring into the venture technical advice on production technology (processing and product), corporate governance and managenent matketing etc. As a reswl, FBF3 launched a tadical comporate restucturing. Guinness lnternitional helped PBP3 to improve productivity by cuttirig staff costs, embracing interisive training and changing techniques. Employment was dirsteally cut to reduce redundancy and stimulate efficiency. Guinness International Injected capital in FBF3. New state-of-the-att bottling lines weete nistalled to improve the Iitro's efficlency while old machinery and equpinent wete rehabilitated. An example was provided where one of the factores had a sophisticted bottling inspector machine Installed to increase efficiency and ehinee product quality. Some of its associated Iactortes which were inefficient in theit produerion were closed down while in others operations wete scaled down. The firm winessed a radical transformation in its processing operations. It was estimated that the restructuring process cost was in excess of KS 1 , 4 bllion,

Additionally, the firm iniroduced new products, A non-alcoholic Guinness brand was for the first ume introduced in the Kenyan market. This was an entry to non alooholic carbonited soft drinks which in tuin created stiff competition to the locally owned firms in the non-alcoholic soft drinks sector. FBF3 in conjunction with its major interiational sharelolder Guiness Interinational also launched itself into production of wines and 
Spirts dhrough an affinate company-UDV Kenya. Similarl, this wiso created intersire

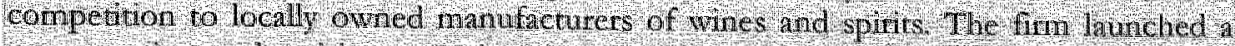

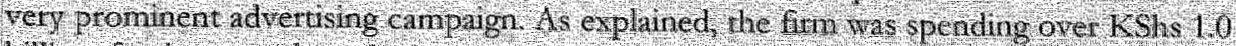

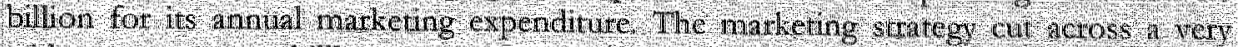

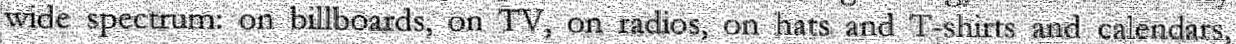
Panted on the sides of commuliter buses etc.

The testructuing process that kesulted in nassive rehibilition and modenubation of technology coupled with strong marketing, tiaiting and use of the state-ofthe art

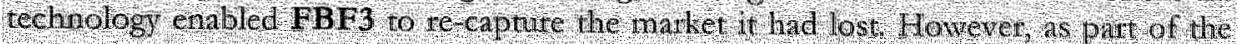
restructuring proeess PBP3, decided to sel. its business opetations in TBI. This happened at a thie when the Soun African MNC was conceding defeat arid was intending to whilaw from the Kenyan narket. The two conpetitous decided to nuake pact sharing deal. FBF3 signed a license agreenent with SAB in Kenjo and $1 \mathrm{BH}$ and agrees terms for shate exchange in FBP3 and Tanzania Breveries Linuted According to the teims of the agreement, $S A B$ would close all its brewing operation th Leny bit Would retain an investment by taling a $20 \%$ sharcholding in FBF3. in dhat case. PBF3 would have to undertale all the past opestations of S AB subsidiary in Kenga that comprised brewing and distribution of certain SAB brands under license ron SAB for the local market. Similanly, PBF3 would close its biewery operations in Tanzana bul Hetain a similar shareholding of $29 \%$ in 1 anzania Breweres which is in JV will SAB in Tanzania. SAB would then undertake all the opertions where: brew and distalbute FBF3 and Guinuess UDV brands under license for the lanzamian maket $1 \mathrm{n}$ this tegati, and as

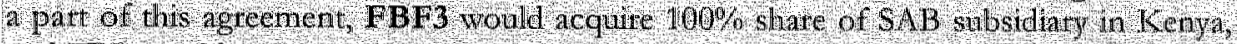

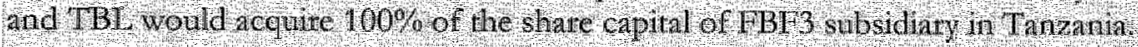

Wy yet another form of restruchuing PBP3 statted souicing for new contracts for balley

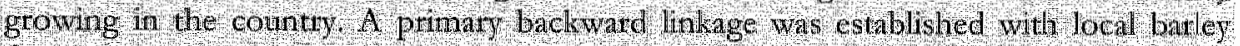
farming comnunuid. FBF3 naling plant pitchases bartey directly from famets.

FBE3 entered ho a F wll Mamtenance lease hire agreenen with a Motor company n Kenya. The lease included a fleet haragenent deal that covered lease hite of 260 vehicles for FBF3's subsidiafies in IEast Africa, technological suppoit to vehicle petfermance and fuel efficiency. The strategy would allow the finm to focus on its cone business. Some benefits included mproved cash flow. The lease hite would help keep the moner in motion by livesting in areas such as natkeding and ingprovement of the breweries.

This focus on cote activities and process re-engmeering culminated in a dose look at the way in which the divisions of the group communicate, tansact and co-orclinate with each other. There was duplication of many operations and actixities, 1 or the purposes of group level co ordination, inter-division comparisons needed to be avallable prompily In 2000, FBF3 approved a project to ser up a Shared Services Cente mandated to establish best practice and standard business ptocessing diviston capable of providing requirements of lindividual group companies. Replicated comnon practices would be removed. The physical distance berween the group oftaces was bithed. Tor this prippose a state-of the art information technology to facilitate communications between the groups was invested. This wrould be done by nounting vety stnall aperture terminals (SSA1) that enabled reallone satelite links between the countules. The VSAT offers centralised processing of transactions such as payments to supplicrs, irrespective of location. It also enables online verification, checking and approwil of suich transactions from linked offices. Accounting and ptocutenent transactions, banking and financlal. 
reporting as well as human resources records have been electronically processed. The staf manning the unt would benefit from the lexiblity and challenges of adapting to the unique requirements of each division. The secung and verfication systems are epectedy rigorous and advanced.

To-date the effort by this fin to lean as a resul of reacung lo competion pressure makes it one of the most adwanced and with the hghest tamover. It has worn the most tespected company of the year award Its comperitieness is cue to price- due to lom overhead cosis. It has increased uts product diversity naintaining strict quality control. It has acquired enorouous capablity and experience in narketing the quality of services to customers, ad wetisenent, promotion campaigns and distribution, The volume capacity and scale of production has cqually incteased 1 he firm has become mote efficient and flexible (Speed of delvery, ability to accommodate changes in customer tastes and preferences)

The future strategles include further diversification of products and services delivery. Another inponthnt strateg) includes continuous acquistion of new processing teelnigues, machnery and equpment. In the pipe line, was a strategy to invest in new hariufacturing nachinery and equpment for is brew house at a cost of KShs 0.60 billon. Whe nachinery wovild be more automated, inproved energy utilisation through hear recovery and energy storage. FBF3 plans to undertake expanded forms of humat tesources development and mainly in the form of training. Improve narketing strategies; maintain a conilnuoms search and penetration into international market for exported beer Mantan a process of conrinuous improvenent in organisation and management structute maintaing a sound form of corporate gorernance observing tule of law.

Another interesting case, which we discovered, inwolved effect of international competition in the fruit-processing industry. FBF5 was involved in processing and export of canned fruits to the European market for a long time. This creared a window of opportunity in the local and regional matket, which locally owned firms were exploiting. Unfortunately, due to international business cycles, there was a decline in international demand that resulted in stiff international competition for the Earopean market. FBF5 faced stiff competition from Asian countries that were able to offer cheap products to Europe. Due to the increased international competition, FBF5 decided to look for alternative market domestically and in the immediate regional trading blocks, see Box 6.47. Consequently, this created intensive domestic competition for the market, which has fotced locally owned firms to learn, introduce drastic changes in mechanization to their processes and adoption of qualiry systems.

\section{Box 6.4.7}

\section{Competition Effects: The Case of FBF5}

FBF5 processes and expon canned fruts to the turopean market. Less than $5-10 \%$ of toral production is marketed locally or in the immediate tegion. FBF5 success in the expont maket was based on its high quality contro and ability to fulfill international onders on tine. Production and export orders wete complaterized and closely monitored to ensure rimely deliyery. Addicionally, the firms distribation system to export destimations is well organised and effictent 
Unformutely, due to global economic recession thete wh $\mathrm{a}$ declne wh wemalonal demand, which culminated in stit competton in the international maker FBH5 taced stiff competition from Asin countries such as Philppines and Thaland that were ble to offet their products at cheaper price to the Buropean market. This was possible due 10 lower costs of production compared to FBF5, which has to transport their products to the seaport 500 Kilometers away and their producton is done whthour migation. Mote that while FBF5 concentrated on the intemational marker, the locally onved fims capiralised on an exrsting window of opportunity the domestic and tegional market. In hat case FBF5 and domestic firms served two different makets.

Faced with intense competition internationally, FBF5 had decided to retreat and seek an altemative market locally as well as in the tegional trading blocks. As indicated, "COMESA has prowided increased marketing opportunities for existing and new products from pineapples as well as from other fruits and vegetables." There has been an increase of new start-aps that targeted an existing window of opportunity in the locat and regional market. FBF5 requested parent company headquatters to approve his stiategy to develop the local and regional market. The granting of the go a head coincided with the appoinment of an African regional director to cootdinate the efforts to build markets in East, West and South Africa.

Having been granted an opportunity to develop local products for the local and regional market bur with an international blend, FBF5 set up a full-fledged regional and marketing department in order to launch itself forcefully into the African regional market. The frim therefore initiated an "industrial and commerciat programme of divetsification and expansion of locally processed food consumer products and regional markets."

We should not lose sight of the fact that, although FBF5 was fuming to the domestic and regional market and build on its local presence, locally owned firns frad already rentured there earlier. There was a large number of new start-ups that started processing products targeted at the existing window of opportanity in the local and tegional market Subsequently, FBF5 entry created intensive domestic competition, which has forced locally owned firms to learn, introduce drastic changes in mechanization to their processes and adoption of quality systems. "The FBF5 products wete now in the matket: wide range of fruit juices, canned and fresh pineapples have been introduced.

In order to exercise effective and efficient delivery of services, FBF5 has been forced to set aip systems where it can reach their final consumers. FBF5 set up Strategic Sales Depot (SSD) distribution system in Kenya by placing branded shipping containets along busy highways and near densely populated residential ateas to directly sell theit products to consumers at wholesale prices. This is a popular. approach that has also been adopted by other firms including domestic frms.

The firms planned strategies included embarking on packaging of pineapple juices. In line with the current firm owners, who are renown worldwide for the ir tomato productsis FBF5 intends to embatk on processing of tomato among other food products. FBF5 therefore next strategy is to invest in an advanced technology for processing tomatoes. FBF5 plans to continue with an aggressive capital expenditure programme with the hope of increasing its efficiency continuously. 
So fur the firm has intensified comperition in the sector I ts source of competitiveness is based on its hyh quality heritage for all the new products as well. The frin is 1509002 cetiffed as part of its quality assurance strategy.

Finally, we discuss a case where MNC subsidiaries in the soft drink industry creates intensive competition by making huge investment in capital machinery and equipment coupled with vast product diversification with strong support by the parent company. For mote details on this, see Box 6.4.8. The emanating competition pressure forced the locals in the sector to look for altematives means of survival some resulting to establishment of international linkages for support in product and process technology. These will be taken up in more detail in the next chapter.

\section{Box 6.4.8}

\section{Competition Effects: The Case of PBF6}

FBF6 was among the pioncers in the soft drink industry with a subsidiary of an American MNC, which exited the market after intense competition in the sector There fore, in the entire petiod before liberalisation, in 1982, FBF6 had nomopolised the soft dink (cabonared) market. There were basically no other firms in the soft drinks Industiy. The firms enjoyed over $90 \%$ of sof drink maket in the county. Unfortanately Wh the late 1980 s and 90 s the firm faced lear times following stiff competition from new entrants into the industiy. In particular, stiff competition was posed by several domestic finms, which joined the industry introducing products lhat were nore or less similar to those of FBF6 but relatively cheap. The local firm's pice-competilixe strategy was very effective as they made stire that they priced their products always lonver than the FBF6. The competition was furthet exacerbared by the re-arientation of production modes by existing major firms operating in other industries that included local, oint venture firms and subsidiaries of MNCs operating in the country, As an example, a few of these Companies such as FBF5 and FBL4 started producing, packaging and distributing juice products that offered an altenalive to the carbonated drinks produced by FBF6. Also. one of the leading breveries in the region stasted producing, packaging and distributing Malta Guinness, new non-alcoliolic which also penetrated into the FBF6 (non-alcoholic matket) madket in a significant way. The Mala Guinness 18 a non alcoholic drink made of nalted batle, hops and water.

To deal with the increased competition, FBF6 has restructured nost of its opetrations ranging from produetion to marketing in a bid to reduce cost in the face of dimüishing remtns. 1 BF6 had withdrawt 1 large share of its openations. All those factors led to a decline in FBF 6 sales und thus profit earnings, In the face of the ensuing compertion, FBF6 has undertaken to maintail and improve quality standards. Undertake more huitan resoutce developnent. The firm has advanced technology and it is a part of Global network of companies with wide experience in the field. The new strategy is to diversify nto other products, acquire new processing techniques and training.

FBF6 under the patent company from US introduced new products in the noncarbonated products in the soft drinks (beverages) makket to augment its carbonated soft drinks pontfolio. The soft drinks were targeted for consumets below 12 years. As explained, this was a part of a large strategy targeting the young consumer market 
Mithout affected carbonated soft drnks natket categorn. Whis nualket lard largely. been: anexploited. The distribution of these products is done through the existing net work.

The frm has also started packagng mineral water and other plastic bottled pactuged drinks. This has intensifed the non alcolnolic beverages vars, The FBH6 wih he support from the soft drinks giant, that has strong culnure of interna ionally-entorced quality control and natheting sasm, nakes a stab ar we present dommance of locally owned firms. FBF6 will however have introduced heallhy competition in the hinerd vater industry and in the packaged fruits juice industry

Another form of stategy exccured by FBF6 was to lanch a smaller rersioul of ins

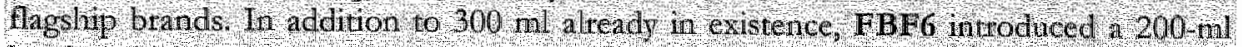
bottle, which was priced at a lower puce and thus increase affordability. (The nove whs meant to widen its natker niche by reaching out to low and middle-inconte carners). It was also seen as counterviling measure to out compete one of the local firm's soft drinks whidh were trading at that price, KShs 10 . This nove wa also seen as a preparation for another US subsidiary whilh was preparing to rejom the nuallet, it wis Wliready operating in Uganda and Tamzania vatming up to join the Kenyan narket dgain. FBF6 had also introduced the $500 \mathrm{ml}$, 1 lite, 2 lire bottles. Pirces were reduced. The 300 mil and $500 \mathrm{~m}$ prices were lowered by $15 \%$ and $17 \%$ tespectively.

FBF6. launched a new distribution system lanown as Manual Distrilunion Centes (MDr's) that had a posinive impact on efficiency and in andition created new jobs in the value chain. FBF6 added new coolers improving the availabily of cold produicts in the marlet FBF6 also introdriced a depot concept to sell case lots to consumets, The firm also replaced all the old wooden fin kiosks with new metal ones units. 1 hese provided business opportunities to oyer 1090 kiosks operators (entrepreneurs)

FBF6 las also dedided to concenttate more on the way its prodicts are distribated and marketed. In doing so, it has te-organised the distribufion partern so as to meet more customers and at the sane time sarsfring their needs. FBF6 has decided to dilocale a defined area to each of their key distributors. FBF6 has invested significanily in a leet of vehicles, which transpont the beverages to various distribuitors who would in tun do the delivery to all the customers on their regions. FBF6 supplied het kej distributers with. new vehicles to improve their efticlency in service delvery. The distributors were then allowed to pay for the veliucles over time and once they completed paying for the wehreles ther loecome the owners. As Lidieated to us during the interwiews, this prart of matketing re-organisation improved tremendously the reliability and consistent of services offered to the tetallers and had a positwe bearing towards sales improventent:

The effect of competition from ABP6 has callsed severe competition toples in soft drinks and beverages, beer, wines and spitits. Ditectly and nitirecty, it has forced trwals In the indisstry to invest in new plants (machinery and equpment) for exanjple FBI2 who argue that the competive process has enabled hem to go regional, export and expand 


\subsubsection{Demonstration Effects}

Investigation of demonstration effects indicated that all the foreign firms studied had demonstration effects which created opportunities for spillover occurtence to the locally owned firms. Foreign firms indicated that locally owned firms had copied, imitated products and technques from them. These findings supported our thesis that foreign presence can stimulate spillovers - Chapter 2. They further support our findings in Chapter 5 where demonstration effect was observed to be one of the strong mechanisms. through which spillowers occurred after competition. However, the extent to which demonstration effects tesults in learning, capability building and innovation in locally owned firms will be explored in detail in Chapter 7 .

We now present individual firm accounts of demonstration effects, which stimulated technological spillowers. FBF1 and FBF2 claimed that domestic firms had introduced new products and techniques taken after them. The domestic firms were able to make similat but own products implying they had learnt and accumulated the necessary capabilities. As an example, FBF2 were the pioneers in the mechanised production and supply of cooking fat and edible oil, margarines, and finally washing soaps and detergent in the country. FBF2 started its operations in the country before independence. llocal firms used to make hand made soap but in the course of time they introduced and adopted mechanised process of making soap. This was confirmed by Iangdon (1978) study which noted that local firms adopted mechanised soap production techniques similas to that used by the MNC subsidiaties in the country. Similarly, local firms have started producing cooking fat, edible olls and margarine in a similar way to FBF2. The case of margarine was particularly exciting in that a domestic firm also covered in Chapter 7 used the same model and technique as in FBF2 in its processing, promotion and marketing. In actual fact, FBF2 had a case in court with this particular domestic firm claming that it had imitated and used a component of its margarine trademark. According to FBF2, the local firm was packaging its margarine using the "same shape and colour, configuration, design and general appearance that had an integral part of its trade mark". FBF2 has therefore served to increase the portfolio of products and has thus reduced the product search process for the local firm. FBF2 was also the first company to engage the services of a separate promotion, logistics and delivery. This served as demonsteation to other frms both local and foreign who statted using similar services. Use of such services triggered organisational, management and marketing changes. "This case supports the argument that MNCs can bring new knowledge, management and matketing skills where local firms observe them and imitate them. Some of the firms have started exporting:

Another area in which locally owned firms were observed to have enjoyed demonstration effects was in staff training. As a result of ensuing competition, the locally owned firms have been stimulated to embrace firm training as done in most foreign firms. Another demonstration effect comes in the atea of quality management. The foreign firms were usually the first in acquiring quality assurance standards after which the locally owned firms followed. As an example, FBF2 and FBF4 were among the first foreign firms to have obtained an ISO. FBF4 was explained to have the best quality control in Africa in culinary industry. FBF2 was also the first to achieve OHSAS. When the foreign firms acquired intemational quality standard they also enjoyed expanded export market as a result of high quality assurance. In this case we can argue that foreign firms demonstrates not only quality standards but also export market. Examples will be presented in Chapter 7. 
FBF6 clains to haxe many demonstration effects to the local fims Simillaty, FBF6 has also enjoyed from demonstration effects from competing fims. As an example; the firm started a strong campaign to diversify. For instance, the firm ventured into the manufacture of non-carbonated drinks and started botwling of mineral watef and fruit juices. Demonstrations enjoyed by the domestic firms from FBF6 included processing techniques, product technology, organisation and marketing strategies. Luet us provide a few examples. The first example includes use of micro-finance progtamme to support distributors. The domestic competing firms have now imitated this programme and have intiated similar programmes backed by strong campaigns to solicit for funding from various sources. FBF6 also contended that local competitors had also copied the use of container method used by theit distributors. FBF6 clained to have been the pioneers of this process as a marketing strategy. We provide another example of how demonstration effects can stimulate spillovers in domestic firms. Since FBF6 follows marketing strategies designed by the brand owners (USA soft drink MNC), it therefore changes the style of its marketing and advertising often. At the time of this research, FBF6 was renturing into a new advertising campaign following the new marketing strategy launched by the brand owners in the United States. It would include new advertising campaign, strong music and digital components, promorions, propetties, one-to-one marketing initiatives and new packaging and graphics. The advertising component featured radio, television, on line, print, cinema and outdoor executions. From time to rime it would also inchude participation in sponsorship of certain activities. Such marketing strategies present a lot of learning to the domestic firms. However, this is only useful if it does not re-allocate resources away from leatning to innovate in the local firms. Chapter 7 will attempt to examine this phenomenon.

Finally we provide an example from FBF5. This furm has had demonstration effects to local firms such as FBL4 studied in Chapter 7. As will be shown the local firms started manufacturing and packaging of fruit juices in the same style as FBF5. Other local firms have even started packaging other wide tanging juices such as passions, orange, mangoes etc. Learning from FBF5, a few domestic firms including FBL4 have started exporting in the region.

\subsection{The Case Studies of Foreign Firms in the Machine and Engineering Industry}

This section presents the case study illustrations of the spillovet process in machine and engineeting industry using the framework of analysis oudined in section 6.2 . Interesting cases of how presence of foreign firms created opportunities for spillover occurrence to the domestic fims were observed which also supported our theoretical arguments and empirical findings in Chapter 2 and 5 respectively. This section begins with an outline of the firms' technological characteristics which enables us to understand production technology, leaming and innovation in the case study firms. This is also intended to provide a justification of the firms selected.

\subsubsection{Firm Selection and Justification: Emphasis on Production Technology, Learniling and Innovation.}

Case study furms in machine and engineering industry were also selected on the basis of production technology, learning and innowation. The role of production technology in learning - human capital development was taken into consideration. In this regard, only foreign firms where local personnel seemed to acquire tacit and experiential knowledge 
from the production technology utilised were selected. Subsequently, this was important in that knowledge and experience accumulated could benefit local fims in the form of knowledge spillowers when experienced workers leave their jobs with foreign firms in future to join locilly owned firms or to set-up own jobs. This phenomenon is further investigated in Chapter 7 from the angle of local firms.

We now outline reasons and justification why each firm was selected. MCEF1 was obriously the most sophisticated firm in its sector. Its core production machinery and technology comes from Britain. At the time of this research the frim utilised $65 \%$ of the total installed capacity. It had many machines of different sizes, ages and complexities. Nevertheless, the firm does not undertake any serious search for processing machinery and technology and thias relies on foreign suppliers for the supply of production technology and for major technical support. The firm, however, has the capacity to make major in house modifications on most of its machinety. The firm had seven major sections, each of which presented some form of technological learning to the locals. The fitst section was the Raw Material Section. The raw materials used are imported from Germany and Japan and comprise steel coated with tin. Here local employees are trained to examine and verify that the received taw materials are of the expected specifications and standards. They are also trained in planning operations and process scheduling in order to know how much and when to procure raw materials or how much and when to use in the processing lines.

The second section was the prass shop section that comprises a proof print shop and a printing ${ }^{1 / 6}$ shop. According to the technical director, all the printing operations were complex and required rigorous training of the personmel. This not withstanding, he confirmed that welltrained locals who had acquired tremendous experience over time handled all the activities of the press shop. For instance, the locals had mastered the right chemical combinations, preparation of printing plates and operations of the complex printing machines. Technicians from the engineering department who were equally trained ensured that operations were smooth and efficient. As a result of capabilities accumulated over time, local technicians in this department were capable of undertaking major renovations.

The third section was the cromn conte sertion equipped with two kinds of crown machines the press machine and a lining machine. Similarly, local technicians from the machinery workshop had ncquired the necessary capability over time and were responsible for all the repaits and maintenance work. Thee years ago the firm acquired another machine ftom Italy which was quite sophisticated and locals needed intensive training to handle production with these machines. At the time of this project, the employees were still mastering the full opetations of the machine including toutine maintenance procedures and possible adaptations in the future.

"The fourth section was the general line section. This section was perhaps the most interesting one. It was equipped with different kinds of machines such as lathe machines, press and punching machines, shapers, bending and folding machines etc. From observations, this section presented tremendous practical learning to the locals. There was a lot of leatning by doing, by using and by interacting. The skills and experience acquired here were very useful, practical and most people found them relevant if they wanted to become own

\footnotetext{
1:00 The printing shop enjoys five sophisticated printing lines: "Whe first one was a two-colour printer. The second one was a coating line. The third one was single colon printre while the fith was a coating line. The hat one was a conplex double colour printer with a varishing machine.
} 
entrepreneurs in the jua kali sector. Many products were designed and/or fabricated in this section. Skills acquired in this section are in demand ontside in other frms.

The fifth section was than manfachning fonde equipped with over five different processing lines for metal cans manufacture. Three of the lines manufacture tins for FBF5 who consume $60 \%$ of the firm's production output. FBF4 orders also occupy some lines. All the tin can manufacturing lines were foreign and comprised complicated processing machines and technology. The process of tin manufacture was tedious, wanging from metal sheet levelling, folding, rolling and welding, corrugation, seaming and so on. In this regard, organised training was offered to all the machine operators - about 12 locall personnel manned each tin can manufacturing line. As observed, locals had acquired good mastery of all the machine operations. Machime suppliers imparted the initial skills to the local production operators and the engineers and technicians through training.

The last section was a well-equipped mathing workshop-engineering dopantment, with seven units (referred to as cells) each headed by a full manager. The seven cells included a toolreconditioning cell where machine equipment, tools and other components from various departments were reconditioned and tested. There is a control system to monitor the frequency of breakages for each tool. The customer service cell provided technical services to the customers. In the calibration cell, master gauges from KISBS and Germany were used for calibration to international standards. Compurer Numerical Control (CNC) programmes are also used for drilling and cutting of tools used in worksthop. The spare manufacturing cell was responsible for fabricating required spares parts for watious machines used. The ellectrical cell handled motors and other electrical equipment. The heat treatment cell provided heating whenever needed in the workshop. Finally, all the general repairs were conducted in the general-purpose cell. Similat to the general line section, the machinery workshop presented tremendous learning to the locats. In fact some of the engineering and technical trainings were done in this department. The multiple skills and experience acquired here enabled personnel leaving the firm to get jobs easily in other firms or become own entrepreneurs in the jua kali sector. The firm was reputable for producing skilled personnel - generate local entrepteneuts.

With respect to product technology, the firm utilised a combination of foreign and local product technology. Tin and seals making were foreign product technologies as was crown cork. The firm involves itself with some local search for product technology. In the last five years the firm introduced new products for a local MNC. Clients usually present a rough idea of what the equipment they want. The firm then designs the equipment with reedback from the client and then manufactures them. In addition, the firm makes continuous improvement of its existing products. This process makes the local employees learn and accumulate experiential tacit knowledge. The locals also acquired skills from quality control systems, which the firm follows strictly. The firm follows World Class Petformance - WCP. It is ISO 9001.2000 accredited and it has also quality assurance certification with KEBS.

MCEF3 was the leading firm in motor vehicle assembling - from completely knocked down kits (CKDs) mainly imported from lapan. The main activity of this firm is motor vehicle assembly, 84\%. "The first section therefore deals with un-boxing and sorting out. CKDS. This is important to ensute that all the parts are received in good condition and in the required specifications. Nuts and bolts that come in hundreds of thousands were also sorted out in a different section. This is one of the most complicated asks to check all the bolts and muts, identify them, certify that they are of the required speciftcation, 
sort them out and put them in to specific categonies awaing their use in the assembly line. $A$ lot of skill and expenience is required in the sort process. The local technicians have been trained and have also garneted experience from learning by doing over time most of the technicians were diploma holders in automotive, mechanical or electrical engineering from the local polytechnics. Whenever a new model was being introduced, the engineers would first demonstrate all the accessories to the local technicians. The engineers themselves will have spent several months abroad also undergoing similaw training from the suppliers. The last secrion that dealt with raw marerials was involved with the local procurement and storage of auto parts. As will be shown, training trickles down to the supplier of auto parts.

The assembly line begins with simple joinery of the body parts done in the firm's body shop section using sophisticated Japanese technology - for spot welding and soldering. Well-trained local technicians wete in full control of the opentions. They had mastered the technology in use and easily assembled various body kits (parts), which formed the body of the vehicle. Only body parts for pick-ups and the light buses were assembled inhouse - that included the carrier and the body cabin. The body building process entailed three stages statting with assembly of various parts. Metal finishing was also done to ensure no dents existed on the metal surface before paint was sptayed on it. Qualified engineers ensured no faults existed on the body surface by making a thorough inspection. The body is then taken for spraying (body painting). In the spray room, the body is washed to remove any ashes and traces of oil. The body is then dried in a special oven for 5-15 minutes. "Then the body is sprayed underneath first to prevent rusting followed afterwards by rest of the body. Each of these steps is manned by specially trained personnel.

Once the body has been sprayed it is then taken to the trim line where the body moves gradually from one stage to another with accessories such as brakes, linings, belts seats etc being fitted. Once all these accessories have been fitted, the body is then ready for mounting on to the chassis. Each of these stages presented learning opportunities for the locals. The chassis assembly on the other side involved a number of steps. This is so because the chassis also comes in the form of completely knocked down kits and must therefore be assembled. Chassis assembly starts from a layout known as jig - fabricated in house using firm's own machine and equipment in the engineering unit. The jig helps put the chassis pieces together and holds them firmly as they get mounted and welded in position $^{1 \text { t1 }}$ "The jig reduces faults while assembling; It was interesting to learn that the local engineers and technicians in the firm had acquired enough capabiliry to fabricate the jig equipment. Once the chassis layout is done then the parts are welded together using another Japanese Mig-welding machine. The body of the vehicle is then mounted on the assembled chassis. At this time the wheels are mounted, petrol tank is affixed, lamps ate fitted and the process comes to an end. "The vehicle is finally inspected and then dispatched to the owner ot the body building firms mainly for big trucks and buses.

Since the firm does not conduct in-bouse R\&D, it relies on foreign supply of product technology with the main supplier being Japan. The firm also relies on the parent company in America for product technology. At the time of this project, all the vehicles assembled in the firm followed a set platform standard from Japan and the main task was only to understand the assembling manuals. As indicated earlier, the assembling parts come in the form of completely knocked down kits. Fully built units came mainly from Germany and USA. This somehow limited the knowledge that could be acquired by the local staff since the knowledge acquired by enployees is only limited to assembling. For

wi None that the jig is also used to make for onet compantes-contractad out. 
instance, the engine came intact and thus litte know-how as to how an engne is buitt would be acquired. Nevertheless, the locals have accumulated tremendous skills in assembly given that the firm introduces new products (new wehicle models) reguhaty at least $1-2$ years. The vehicle models introduced are often new in the local and regional market. The firm maintains strict and international quality control managenent systems. Although the firm clamed to incur expenditure on in-house R\&D, only quality control could be observed and some substantal in house innovations. MCEF3 is ISO 9000 and ISO 1400 for quality and environment management systems. The impottant point here is that locals have acquired experience by participating in qualiry control management systems.

MCEF4, was selected as it was the most advanced in sted drum making. The machines and technology used were mainly obtained from Gemany. Manufacture of steel drums and plastic drums accounted for $60 \%$ and $40 \%$ respectively. At the time of this research, the firm thad a capacity to make about 3000 small drums and about 1500 big drums per day.

With regard to drums manufacture the production director contended that locals had accumulated cnomous technological capability. This was confirmed to be true after examining how the locals acquired skills by following the drum making process. The process was long and for each stage a different technology was used and thus it's mastery. Locals had been rained and were in charge of the production activities. The production manager cited a few examples where the locals had ewen introduced some innovations on the drums all by themselves. An example was cited where new drums had been introduced with special trings making them easy to pack. Locals had also introduced safery jackets to all the machines for safety purposes. These were introduced in such a way that the machines would only work if fitted with the specified jackets otherwise they wouldn't. This was in compliance with firm's quallity management systems and safety srandards by KFBS.

The product technology comes from the patent company. "The firm does not do R\&D for product technology. At best the firm observes strict quality control management systems. This has to be strict as their customers who include MNC subsidiaties in the countries and United Nations (UN) agencies audit them. "The qualiry control management systems prowide a lot of learning to the locals. Quality control spreads across the whole value added chain. When the raw materials are received they must be checked for qualiry, rust, ofl and gauge. Problems with quality control were noted to occasionally serve as sources of leaming to the locals in the firm. For instance, sted coils imported from Egypt had a problem at one time. There was a lot of breakage during processing and this was a big constraint. "They had Jeatrot that treating the sted with oil helped overcome the problem. This skill as accuired after several trials. This was an example of a constraint creating an oppontunity to learn. Similarly, for all the raw materials obtained nwo tests must be performed. The first one is known as erichneer test. This involves application of a very strong force slowly on the steel to test the malleability strength. The second test involves use of a strong force suddenly so that the force lands on the steel suddenly. This is meant to test reverse impact. When the first test can be tegarded as slow the second one can be regarded as major. The streel would then break. Then a certificate of conformity is issued. 


\subsubsection{Human Resource Development and Labour Mobility}

In this section we examine firm level training and labour mobility in machine and enginewing firms selected. As in food and beverages section, interesting cases of how firm level training and labour mobility created opportunities for spillover occurrence were observed. Once gain this was in support of out theoretical arguments in Chapter 2 and empirical findings in Chapter 5.

\subsubsection{Human Resources Development (Fim Training)}

As noted in food and beverages industry all the foregn firms in machine and engineering were observed to attach a lot of importance to human resources development through tratining. In fact three of these firms (MCEF1, MCEF2 and MCEF3) had set aside 10$15 \%$ of their total paytoll for training purposes while the remaining firm (MCEF4) had set aside 5\%. The discussion held here is done in the same line as in the food and beverages sector since the same kinds of trainings were identified during the interviews in the machine and engineering industry. All the firms studied conducted on-the-job training to their employees but differed on intensity depending on the activities being undcataken.

All the firms studied had an in-house training department but by observation MCEF1 and MCEF3 had well-established in-house training departments in comparison to MCEF2 and MCEF4. MCEF1 maintained World Class Performance (WCP) level that required rigorous technological training to the local personnel. In some of its sections, the firm offered multi skilling training. "The firm also offered small group activities meant to improve the locals' understanding of some technical aspects. In this light, the firm maintains a training department under a human resources manager. It is a requirement. that each department in this firm does a capacity building audit to identify who needs what kind of skills and what skills are needed. This phenomenon came out clearly during the firm interview conducted at the firm. In the workshop and maintenance department, the managers had worked out clear training progtamme, training "skill matrix". In this matrix, it depicted which courses were being offered, who was to offer them and who had attended certain courses and who was to attend the next. Note that the firm has technical training cootdinator. Usually the trainers would come from in house and quite often from outside the firm. From outside the firm, the trainers could be obtained locally of from abroad. MCEF1 was therefore a very good example of a firm that realises the importance of fim technological training (particulatly to the locals), sets a budget for training and has a training department and a programme design for the putpose. It should be emphasised that through the trainings offered, the machine operators are able to control the machinery and equipment and so ate the engineers who are trained on how to maintain the machinery. It was emphasised that the kind of training the employees obtain is in line with World Class Performance (WCP), Statistical Process Control (SPC) and total preventive maintenance (TPM).

Similaty, MCEF3 had a separate department for human tesource development and training headed by a full manager. "This department catered for all the trainings and other forms of human development needed. In order to have a pool of well-traned workers, MCEF3 has made the in-house training a continuous process to all the staff at all levels. In house training can range from simple things like first aid applications to computer applications and marketing. It also includes training on both the management and the technical side of operations i.e. engineers, technicians and machine operators. Qualified engineers, who will have obtained a similat training abroad, often conduct these trainings in-house and on the job. From time to time, extemal trainers and subject matter 
specialists are also invited to offer in-house mining. The trainings offered by subject mater specialists can equally be extensive ranging from safery standards and quality management systems to labour ethics such as attitude and commitment towards work.

On the side of trainings undertaken external to the firm but within the county , literatly all the firms did it. From the interviews conducted MCEF3, MCEF3 and MCEF4 wete observed to have excellent training programmes for all their employees. The programmes included sending employees for training in the local training institutions to sudy professional and engineering courses. Such courses included: (1) Electrical and electronics engineering, which can include things, like compurer packages, computer maintenance and servicing and electrical installations. (2) Mechanical engineering that includes: general fitting, lathe taning, welding and fabrication. (3) Automotwe engineering: motor vehicle mechanic, and motor vehicle systems. (4) Computer maintenance and servicing, computer packages and electrical installations. (5) Others would include; sales and marketing.

The firms also sent their professionals and technical statf for specialized courses abrond. Seweral examples were noted. MCEF3 seemed to send staff abroad regularly for training in motor vehicle assembling and draught (vehicle body designing). While abroad, the engineer would undergo a trainers training so that he can come and do a similat kind of: training at MCEF3. Several engineers have been sent for training in Japan, Europe and America. Japan was preferred as it was the main country from where the raw materials (CKDs) were obtained. As a way of assessing the staff training the trained workers had to be monitored strictly after training.

A number of factors served as a trigger for trainings in this firm. The main factor in MCEE3 was the need to introduce new motor vehicles. Given the increased level of competition, there is a need to increase the rate at which new products are introduced in the market. It is the introduction of these new vehicles, which act as the compelling force for technological training. As an example, when a new vehicle (a new model) is being introduced into the country the automotive mechanical engineer is trained first in the country where the CKDs are sourced from. The engineer would then ransfer the acquired skills by offering training to the rest of the staff (other supportive engineers and the technicians in MCEF3) in the firm. Since the CKDs are sourced from Japan, it therefore happens that most of the trainings take place there. Since the main production mode involves the ability to assemble the motor vehicles, the major training tequires acquisition of skills to be able to do the vehicle assembly. The training offered is therefore geared towards understanding the motor vehicle assembly manuals and acquiring skills on how to translate the contents of these manuals into fully built motor: vehicle units. When the engineer fully masters the assembling procedures of the new models, he then comes back to MCEF3 where he performs demonstrations to the other staft. The trained engineer would have to demonstrate the assembly process before the other staff, engineers and technicians, in most cases this would involve taking all the activities from the body shop, metal finishing, trim line and chassis. In each stage there would be presentation by the engineer followed by brainstorming session, questions would be raised on anything pertaining the assembly of the new model. The other thing would be how to adapt the car to the Kenyan standards in the course of doing the assembly. When all these are taclsled together and the technicians have demonstrated ability to do the assembly on their own they would then be left but with substantial supervision until their capabilities are fully polished. 
The analysts done in this section draws a smilar conclusion to the one arrwed at in the food and bewerages analysis. All the firms in machine and engineering industry recognised the importance of human resources development in their production processes and other operations. Firms therefore endeawoured to offer training among other forms of leaming. In the process the locals were among those who benefited training locally and sometmes abroad. This has enabled them to build technological capability to operate machinery and manage production. Skills and experience acquired have cnabled some locals to get promotion and become section heads or managers. In some cases training offered were geared towards promotion but only through merit. As an example, MCEF4 had a strong policy of conducting in house training meart to groom a successor in most technical aspects. The firn had good training for junior staff to assume sentor positions - a "succession plan" based on specified criterion. This was meant to ensure smooth transition at all times in case of labour mobility, retrenchment, retrement or otherwise. For instance, the quality control manager had trained for a rery long time under senior technical managers. He bad joined the firm about 35 years ago as a technical trainee and had climbed the ladder to become a full technician. Durng this time he had participated in the stripping of most of the machines and equipment used in the firm. This process of stripping and adapting some of them made him leam a lot techrically. After having been trained on several occasions both locally and abroad, he was then appointed to become the quality controls manager. In his capacity as the quality control manager, he was in charge of all the quality control aspects including trainings on quality matters and in liaison with institutions that deal with qualicy matters such as KEBS and SGS.

\subsubsection{Labour Mobility}

'The interviews conducted revealed that foreign firms studied in machine and engineering industry had interesting cases of labour mobility that conld be associated with spillovers of knowledge to the domestic firms. Note that due to lack of data documentation on labour mobility in the firms, we relied on people with long experience to reveal to us any interesting cases of professionals and skilled staff they were aware of. All the firms studied had at least lost a few professionals or a skilled worker at one time or another to other firms - either a locally owned or foreign firm. MCEF4 presented a wery good example where one of the senior technical mangers left the firm to join a locally owned competing firm. The competing firm mamufactures the same products as MCEF4 but utilised a relatively less sophisticated technology dhan that used at MCEF4. In another example, the quality control manager explained that when the business and the logistics controller units were phased out, the managers and some skilled workers left and joined other firms. The firm claimed that a few staff had decided to set their own entrepreneurship. "The important thing to be stressed here is that these were well-trained managers in this firm and definitely where they went they would utilise the skills acquired while on the job. MCEF3 reported similar cases where staft had left to become own entrepreneurs.

MCEF2 contended that as far as labour turnover was concerned it had lost several of its staff in the past mainly to other firms in machine and engineeting industry. The firm confirmed that among those who left were some engineers and many technicians. Some left after they were offered high salaries by competing firms. Since these staff had been trained and had also acquired expertience on-the-job, the receiving firms must have benefted spillovers of knowledge. Such staff went to join locally owned firms.

In the case of MCEF1, the story was tather different. According to the interviews conducted with plant manager and the quatity control manager, it was made clear that 
wery few people had left this firm to join other firms. As they clamed, outward mobility was minimal especially with the professionass and engineers. Only a handfu of professionals and engineers had left but ptimarily went to join other foreign firms. The explanation offered was that rery tew firms actually needed the kind of skills that an individual from this firm had accumulared, and particularly mote so when it comes to the engineers and highly qualified technicians. This is explained by the fact that the technology and machinery used by this company were quite sophisticated and expensive to the extent that domestic firms would not afford to acquire them. It was contended to us that even when the workers proceeded for retirement or decided to become own entrepreneurs (by joining the Jua kali industry) they still would not be in a position to do anything like they ever did before since they would not be in a position to rase enough capital to acquire such machines and technology involved.

This is a very good example of a foreign firm that offers tremendous tranings to its employees and most of who are Kenyans. This implied immense firm contubution to the learning process and technological capability building. The kind of technological leatning offered is expected to match with the WCP practiced in the firm. Turnover is very low in this frrm. Employees generally regard this as a relatively good firm. Not possible to get anywhere to utilise the skills acquired in the firm. Unless in Nairobi industrial area. According to the plant manager the firm wants to come up sith a policy, which will initiate labour tumover.

With regard to inward mobility of wotkers, the firms claimed to have strong policies of recruiting fresh graduates from the local universities and poly-technicues/xocational institutions. According to the intetriews conducted, the firm does not view lack of skilled workers as a severe problem. However, not all firms were interested in employing fresh graduates. MCEF2"s employrnent policy was not in favour of employing fresh graduates from universities or polytechnics or employ from local firms. The firm preferred to employ professionals and technically skilled workers from other firms mainly from foreign firms or from outside the country and to a lesser extent from domestic firms. As expected, staff employed from foreign fims were highly technical and from their experience, they would be in much better position to strengthen MCEF2"s production. capability. It can then be noted that this firm also benefits knowledge spillovers associated with labour mobility from other foreign firms.

MCEF4 had received only a few workers from other firms. The best example provided was that of the managing director who had joined a foreign company bringing in tretnendous organisational changes in the management and organisation of the entire frrm. For MCEF1, it received a huge junk of workers when it acquired a subsidiary of an American firm. It retained most of the engineers who were initially working with the acquired subsidiary. These engineers were the ones who were directly involved with the production processes. Here we obserwe a direct mobility of workers as a tresult of the acquisition, which can be translated to mean direct transfer of skills required for manufacturing activities.

\subsubsection{Linkage Effects}

As in the case of firms in food and beverages industry, both pecuniary and non pecuniary linkages were identifed. However, with regard to machine and engineering industry, non-pecuniary linkages were more dominant than pecuniary linkages. This is not unexpected given that firms in machine and engineering industry usually offer 
technical support. Backward inkages were identified with manufacturing and services - such as utility providers, construction, finance, transport and communication. Within manufacturing, firms had established backward linkages with machinery, wood and furniture, paper and packaging, food and beverages and transport equipment industries. Forward linkages wete fomed with services industry such as supermarkets, distributors etc. These firms considered themselves large, with mote physical and human capital than the domestic firms. They confided that purchases and contractual jobs availed finance and capital to the domestic firms and that in their opinion helped them to grow and expand. Once again due to the firms' reliance on foreign suppliers of machinery and technology, local technical links with locally owned firms were only limited to maintenance, repairs and sale of simplified machine and engineering equipment. Due to data constraints it will be impossible to analyse trends of linkages. So, we shall just present a general discussion of all the firms (MCEF1, MCEF2, MCEF3 and MCEF4). From the angle of foreign firms, local firms seemed to have acquired skills and spillovers of knowledge through the linkages formed and existing interactions. The extent to which these might have resulted in accumulation of technological capability in the locally owned firms will be investigated in Chapter 7.

We now turn to individual firm level cases. MCEF2 maintains both backward and forward linkages. Backward linkages were maintained with suppliers of some of the raw material providers. Over $40 \%$ of the taw materials used in the firm were imported. This can only be regarded as pecuniary linkages without much learning ftom them. The firm also maintains international links with the suppliers of machinery, technology and equipment. It also maintains links with local firms which sometimes offer repair and maintenance services. The firm contended that the local suppliers of some of the machinery and equipment procured locally have been able to grow, expand and build technological capability as a result of learning from the otders placed from this foreign firm. Firm interactions during machine repairs and maintenance or during negotiation on the equipment to be supplied, enabled engineers from the firm to benefit spillovers of knowledge. The forward linkages formed with buyers provided feedback to MCEF2, which also served as a source of learning and thus improvement in the production capability.

On its side, MCEF1 claimed to maintain a strong backward relationship with raw material suppliers. The firm maintained diverse and strong backward relationship. It had strict requirement for all its suppliers. Some of the requirements to be observed by the suppliers included:

* Ali the supplying firms must be audited and certified by MCEF1.

* Since MCEF1 was ISO accredited and follows World Class Performance (WCP); MCEF1 therefore had strict requirement that all suppliers must be credible.

* Must be certified by either ISO or KEBS or both of them (i.e. must maintain certain levels of quality). If not accredited, MCEF1 encourages them to stat the process.

* They must be efficient in all their operations including delivery.

* They must have the right machinery and equipment.

* They must offer technological trainings in their firms.

* They must have sound management (accounting and organisational) practices.

* They must be sound financially.

This was an interesting example in that it indicates how a foreign firm can stimulate learning, capability building and innovation in domestic firms. A similar case is that of 
MCEF3 outlined in Box 6.5.1. This supported our theoretical argunients mal empinical findings in Chapter 2 and 5 respectively.

MCEF4 obtained its raw materials from local firms. For instuce the sted metal used for drum making was obtained from domestic firms. Similatly, the spraying ink for the drums comes from local manufacturers. MCEF4 manufactures its dnums to intemational standard as most of its customers include international organisations such as Unired Nation agencies who use these drum in the transportation of many things including relieve medicine, food etc. So the drums must pass tests such as stacking test. They must also pass the immersion, hydraulic and drop tests. With regatd to colours it is important to mention that the spray must posses certain qualities. They must be matching and must also be easy to cure otherwise the curing process can be problematic. They must be free from adhesion problems and finally they must have the appropriate chatacteristics of gloss - surface shine. As explained, this firm ensures that local suppliers have the capacity to meet the standards expected. In this case the firm encourages and supports suppliets to engage in the quality improvement process as well as tmining. Hence, this firm directly stimulated spillover occurrence to its suppliers.

The firms interacted with business associations and institutions. As will be shown, these interactions resulted in skills and knowledge sharing, including technical assistance. For instance, all the firms studied were members of KAM. The vice-chairman of MCEF3 was a board member of KAM whete they shared their expertise, see Box 6.5.1. Such experience could include corporate governance, policy lobbying technique, labour ethics, intellectual property rights etc.

The frrms also interacted with government regulatory bodies such as Kenya KEBS and FKE. As an example, all the firms interacted with FKF for labour issues and disputes. For instance recently MCEF4 were advised to scrap the position of a personnel manager since the company was actually a small one. They were advised to change it to human resources manager. Also all firms participated in the development of standards with KEBS. They need to achieve Kenya Quality Award (KQA) as well as Diamond Mark of Quality all awarded by KEBS. As noted elsewhere, KEBS in collabontion with $S G S$ awards ISO 9000 series for implementation of Quality Management Systems (QMS) and ISO 14000 certification for implementation of Environmental Management Systems (EMS). KEBS deals with calibration, pressure gauge and vineyard - as an example KEBS calibrates the master instruments for MCEF4. Other memberships included KIRDI (MCEF3 - see Box 6.5.1), Export Processing Council (MCEF2), Kenya Industrial Ptoperty Office (MCEF2) and Kenya National Chamber of Commerce and Industry (MCEF2). MCEF2 does not obtain any finance from the local institutions. The firm felt that collateral arrangements and high interest tates wete big obstacles to obtaining such finances.

All the firms participated in human capacity development in the country. The firms offered industrial attachment anmually where graduates from local universities and polytechnics taking engineering course undertake their industrial internship. The firms such as MCEF3 also allowed students and organised groups to visit and acquaint themselves with the car production assembling processes. 


\section{Linkerge Effects: The Case of MCEF3}

MCEF3 deals with motor vehicle assembly. This fim had a policy to increase its locall content. MCEF3 mantained strong backward and forward linkages. Backward linkages were maintined with the manufactures of (1) paints, warnishes and allied products. (2) Manufactures car leaf springs, bolts, nurs etc. (3) Windscreens; tonghened automobile sidelines (4) body builders for min bus bodies, medium to large vehicles bodies, commercial vehicles, trucks and pick-ups. (5) Tyres and auto vehicle batteries. Forward linkages were mantained with dealers and sometmes direct customers like local bus service companes as will be shown below.

MCEF3 had a spectacular arrangement with most of its suppliers and distributors. As an example, all the dealers - firms that deal with selling and distribution of MCEF3 motor vehicles are also traned. They are usually isvited to come to the headquarters for a few days and sometimes months where they are trained on how to deal with customers, how to conduct repans and provide after sale services to the customers.

Training was not only limited to the few cases highlighted above, MCEF3 also offers tranings to its suppliers. In almost all the cases, all the firms supplying auto parts have to be audited by MCEF3. This was a requitement to all the companies, which have achieved 150 . In this case, the supplying firms have to demonstrate how certain auto parts will have to be made. In this case, the arrangement goes beyond just presenting contractual specifications to include debberations and training in order to make sure that the products supplied are of the right specifications (quality and standards). We therefore see a wery good example of linkage that comes with demonstation and training. An example of a domestic firm, which had maintained a long-tern relationship with MCEF3, was presented. In the contractual arrangement the domestic firm was supposed to supply certain auto parts (exhaust pipes) to MCEF3. The procedure involved proceeded in several stages as follows:

* It stats with MCEF3 placing an onder with the downestic finm manufacturing Its important to note that whises it is a special onder specificaly meant for this domestic fanv, other onders are made

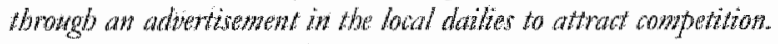

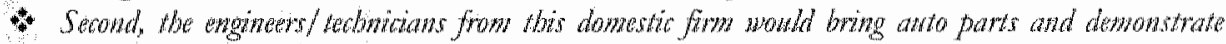
then to the MCEF3 enginerer.

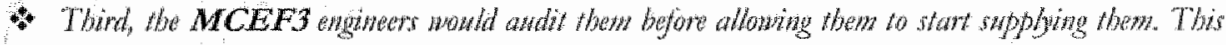

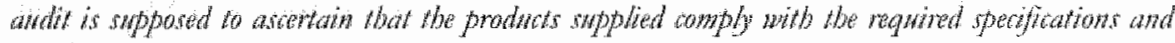
samiards.

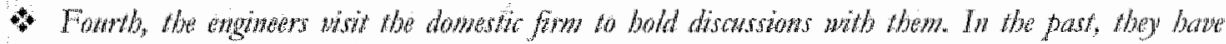

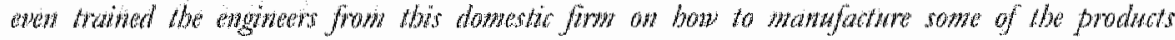

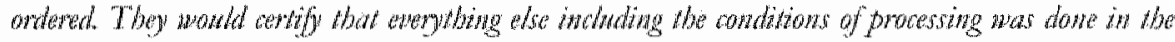
nobt manner.

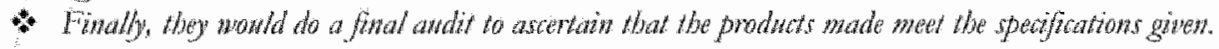

As explained duting interview, this example throws considerable light into the kind of interactions MCEF3 has had with other domestic firms. It clearly shows that other domestic firms have leant a lot from MCEF3. This case supports to a large extent whe argument that a firm is not only for the purpose of production but also for generation of skills and experience which can be shared with other firms in the form of knowledge spillovers. 
MCEF 3 also offers trainings to most of the frrms linked to it. A practral example is

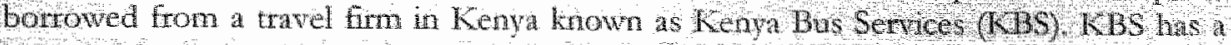
tery strong relationship wh MCEF3. Besides manufactomg the chissis for the KOS, the MCEF3 also offers intensive training to the antomotive nechanical enguneers who undertake mantenance and automotive repair wodk at KBS. The naintenance mechancal engineets at KBS are supposed to mantam the buses and other ruaks bought from MCEF3. The collaboration between MCER3 and KBS is even mate broader by the fact that since MCEF3 has an extensive metwork of dealers nomy rowns: KBS maintains an arrangement to have MCEF3 automotive mechanical engmeers prowde back up to the $\mathrm{KBS}$ team during the up country bus servee hips.

The body builders contracted by MCEF3 must also comply with the MCEF3 standards. Once again this is a tequirement given that MCEF3 has an 180 accredinaton and thus all the suppliers of naw materials and semices must be audited. Whet a fim phaces an order with MCEF3 to have say; some buses or trucks made for them, this is done in two stages. In the first stage the chassis is made at MCEF3. The second stage involves body building. Since MCEF3 does not build bodies for buses and rneks, a second party would have to be inwolved. At this stage, three parties ate in place, MCEF3, the body builder and the bus/truck owner. The bus owner explains if possible by makng arawing exptessions of the appearance he would want his bus to nsstine the anomotive designers at MCEF3 would then come up with draft design of the impression presented to them by the bus/truck owner. This design is then presented to the bus/track ownet for further discussion. In case of any alterations the designet ncouporates any changes. The process is repeated until the required design is obtained. Once the reguired design has been obtained, it is then presented to the designers at the body building fim in this case often locally owned firms. This liaison with the designers at the local fims is to make sure that the exact design and ofher specifications fron their customer ane communicated to the body builders. This would avoid anomales hat usually occut. An example is when an oversize body is buil, of sometimes so heavr caising damage to other parts such as the chassis. This would erode MCEF3 reputator. At ench stage of the body building the designers would visit the body bailding list to thale stive that exerything wa correctly done to the drawing and specification this tnteraction continues until the expected body is built and certified to the contect specification.

4 good example of forward linkage is demonstrated by the ease of KBS, one of the key companies in the public transport industry. KBS, which has of ered transjont services frot several decades, operated only in a few towns in the county thaduling onty Natrobi and Mombasa. In 1995, the KBS started offering upcounty setwices popelarly known as Stagecoach Express'. In order to have enough buses for this pumpose. RBS ordered 20 new buses from MCEF3 valued at KShs 150 Million. The MCEF3 bull the chassis. "The buses' bodies were built by local body builders. In this collaboration, the three bodies were involved. The KBS placed the order and the design of their buses. They also wanted their engineers introduced on how to repair and mantain lle lauses. In actition to building the chassis, MCEF3 was also to train the engineers at KBS. The distributions of MCEF3 in the upcountry would also provide a back up to the engneets in the tield. The local body builders would build the bodies. But the design of the body would have to be agreed upon by all the parties involved. 


\subsubsection{Competition Effects}

This section attempts to examine the effect of competion pressure exerted by foreign firms to the locally owned firms. The results obtained were quite interesting in that many cases of foreign firms were observed where foreign firms created opportunities for learning, skills and knowledge spillovers to locally owned firms. The extent to which the foreign fims might have triggered the learning process leading to accumulation of technological capability will be evaluated in Chapter 7 from the perspective of locally owned firms.

In machine and engineering industry, both foreign and locally owned firms competed with each other. As the following examples illustrate, the competition served as a trigger for locally owned firms to learn including those in the informal sector. MCEF1 faces moderate competition from its local competitors but in-turn poses more competition to them. Its toughest competitors are foreign firms operating in the same industry. MCEF1 was the sole producer of crown cork for several decacles. As explained locally owned firms were able to enter the market by producing low priced crown corks - this will be discussed in Chapter 7. The entry of a domestic firm into the production of crown for bottles resulted in the loss of MCEF1 market. The crown corks produced by MCEF1 wete of high quality standard and thus the cost of producing them was high. The firm could not lower the quality standard given that it follows WCP supported by the parent company. A recent audit conducted by FBF3 awarded MCEF1 over 97\% matks for efficiency, quality of the products, management practices among other checks. As they claimed, one of their locally owned competing firms received only one point above the accepted audit standard by FBF3, which is $70 \%$. But since the local firm is able to provide crown cokes at lower prices it had taken a substantial amount of supply orders from FBF3. FBF3 procures mote from MCEL1 than from MCEF1. Competition with the foreign furm had created the necessary stimulus for learning and training in MCEL1 to the extent that the firm has developed much production and export capabilities. The firm now exports crown corks to many countries in the region. It has also been awarded an ISO 9000 certification for achieving international quality standard.

Another interesting case that resulted in intensive competition happened as a result of a merger and acquisition between two domestic firms. The merger happened between a crown paint manufacturing firm and crown tin manufacturing firm. MCEF1 used to manufacture and supply tin for the crown paint firm until the merger took place. The merger resulted in significant market loss for MCEF1. The domestic firm after the merger and MCEF1 are now stiff comperitors and as we gathered, the domestic fim had tremendous learning effects resulting in capability building. MCEF1 indicated that competition continued becoming stiff, it would have to sell the paint tin processing line and just concentrate in other core businesses. The local firm benefited product skills since the same design was brought. As a part of MCEF1's strategy, it plans to undertake workers training and improve market strategies. The firm was also considering relocating to a lower wage-cost country and had thus started looking for new markets in Tanzania and Uganda.

Interviews with MCEF2 also indicated that it posed stiff comperition to the local firms. This was due to the technology it uses in its operations. It also contended that, it engages qualified personnel and offers continuous training for its staff. When asked whether comperition from these firms triggers certain changes in other firms, the firm answered in the affirmative. This was supported by the fact the locals learnt quickly and introduced things as soon as this firm did. "The competitors seemed to be advancing their technology 
rapidy. This implies that the firm also faces stiff competition from competing firms domestically. As a result of this competition, MCEF2 has had to undertake several things: improve quality control. Become exen more keen human resources development. The immediate strategy is to diversify into other products, new markets and acquistion of new processing techniques.

MCEF4 faces moderate competition as a result of imports into the country by competing firms. However, the firm is into stiff competition with a few domestic firms owned by Kenyans of the Asian origin using relatively advanced technology and machinery. From the interviews done, MCEF4 claimed that the competing domestic firms learnt a lot from it. The firm contended that "Being among the pioneets in drum making in the country, definitely the followers have a lot to leam from us. It is not only in marketing, but also where the raw materials were obtained from and how to undertake certain logistics." Competition has forced MCEF4 to introduce new machinery and equipment continuously. At the same time, the firm decided to venture into the production of plastic drums. This was as a part of diversification and to try and get new markets. This is another area where the firm contended that locally owned fims have learnt from them. Apart from introduction of plastic drums, other innovations included introduction of new minor products, rederelopment of some old products, introduction of new processes and market. Above all, the firm had to undertake a very intensive training campaign just to make sure that their employees were fully abreast of what was required. The firm had to also engage in the process of acquiring ISO 9000 quality certification. Since this firm acts as the leader, its competitors have also launched the process of acquiring ISO certification. This example demonstrates that spillovers did exist by stimulating learning processes and introduction of technological chatnges in the furms.

In the MCEF3 sector, all firms were faced with stiff competition due to the influx of imported motor vehicles and auto parts. Kenya's Motor industry can be regarded as one of the most competitive industry. The competition comes from the imported motor vehicles commonly known in the Kenya market as Mitumbas ${ }^{1421}$. Competition started with the liberalisation of the motor vehicle industry. It was then that imported second hand wehicles found their way into the domestic market. The demand for the newly assembled vehicles therefore declined. This is supported by figures obtaned from Kenya Motors Industries (K.MI) which showed that the annual sales of new vehicles were declining and especially so in the later parts of 1990 s including 2000 . A similar trend was observed with the market share of new vehicles.

Interestingly, between 1999 and 2000 there was a complete change in the market share scenario. The sale of second hand vehicles commanded a high matket share than the sale of new vehicles. From 1999, dealers in second hand wehicles controlled the largest markets share of approximately $60 \%$ up from $43 \%$ in 1998 (IEA). So, three significant changes can be nored in the Kenyan motor vehicle industry: Finst is a major decline in the volume of new vehicle sales. Serond is a major decline in the market shares of new motor vehicles and finally a significant increase in the matket share of second hand vehicles. Several reasons were flouted for the above trend. The main one was that the tax regime was in fawour of importers of second hand vehicles. Repott by KMI indicated that a new vehicle attracted a tax of KShs 500,000 while a second hand vehicle attracted a tax of KShs 100,000. This tax disparity made new wehicles expensive. One school of thought had it that the dealers in new vehicles were not innovative, all the local market wanted

142 This is commonly ased slang languge to represent old or second hand clothes and motor veniches. 
was a chuap, low priced wehicle that was affordable given the existing economic hardships that had resulted in diminishing purchasing power.

The second teason was founded on the notion that in the second hand business there was ease of entry and cxit. This was so because in the importation of second hand cars not much of capital was needed, as would be the case in starting a big business where significant initial amount of capital inwestment wowild be needed. Similarly, for such big investments where sunken capital is enomous, there is usually a huge loss whenever business environment changes. The major critique here is that there has been lack of motor sector policy.

Despite the above stiff competion envitonment, MCEF3 faces from the importers of second hand vehicles, it poses competition to other firms operating in the country. Such include foreign firms and locally owned firms. They range from dealers of auto parts to body builders. There is no doubt that as a result of competition from MCEF3 local firms have been forced to learn and sometimes to introduce certain technological changes. On its side due to competition, MCEF3 has been forced to introduce dynamic changes often and mainly in products and matreting. For instance, the firm tries to introduce a new vehicle each year. Second, the firm has introduced new matketing schernes with intensiwe training of their local dealets. Finally, the firm has introduced new processing machinery and technology. 'The firm's future strategy is to undertake mote staff training, improve market strategies and improve organisation and management structure.

\subsubsection{Demonstration Effects}

This section examines how foreign presence created opportunities for spillower occurrence through demonstration effects in the machine and engineering industry. Using the firms selected, we investigated whether foreign firms techniques are usually introduced or adopted or imitated by the domestic firms and if so whether they are likely to have resulted in learning and innovation. New techniques included production techniques, management and organisation techniques, marketing techniques and strategies etc. Interesting cases of demonstration effect were observed to exist.

We now turn to individual firm accounts. MCEF2 claimed that many domestic firms have benefited demonstation effects from its activities. According to the firms examples were many that included kind of technology and machinery to be used processing techniques), products and martiketing procedures. MCEF1 claimed to have had a tremendous demonstration effect to domestic firms. Such companies included the donestic firm which started making crown Corks in the same industry. MCEF1 clamed that the domestic firm enjoyed demonstration effect that ranged from production technology to the export market.

MCEF3 hins had a few examples of demonstrated products. In the Kenyan transport industry the mode of transport is use of vans. These vans are in two categories - big truck buses and small vans. The big truck buses are assembled by MCEF3 and their bodies are built by the body builders. The first kind of demonstration takes place when MCEF3 demonstrates to the local body builders how the bodies should be built. The second demonstration occurred to MCEF3. The small tucks ate normally imported as second hand from Japan. The trucks have served tremendous demonstration to MCEF3. The firm has keenly learnt from the imported trucks and was now coming up with their 
onn model designed simalar to those trucks initilly imported from fapan as second hand. As explaned, the fims was the same in appearance bat made slightiy big with regard to capacity space. Demonstration to MCEF3 has led to further demonstration to the domestic suppliers of the required raw materals. "This is also a good example where. furm studies the market and then comes up with an innovation facilitated by the in house capability. The innovation then leads to demonstration effects.

Lastly, MCEF4 clamed to have benefited tremendous spillovers from demonstration effects from compering firms and processing firms that buy its products. Eximples cited included introduction of taceability and embossment of their logo in all their products. The suppliers have also demonstrated certan products and MCEF4 has been able to fabricate them coming up with the required products (equipment). Newerthelles, the domestic competing firms had equally benefited a lot of demonstration effects from MCEF4. This was on the side of drum making machinery, drum making rechnique and marketing techniques.

\subsection{Summary and Conclusion}

In this chapter, we presented ten detailed case studies to illustrate the ways in which foreign presence creared/opened opportunities for spillover occurrence. Six case sudy firms were considered in food processing and beverages while four tirms were considered in machine and engineering industry. For the purpose of our case study illustrations, a framework of analysis was developed on the basis of approach developed and utilised in Chapter 2 and 5 respectively. The analytical framework was dereloped along four thematic issues; human resources (training) and labour mobility linkages, competition and demonstration effects that ate perceived important in the spillower process. This framework enabled us to go beyond the productivity analysis conducted in Chapter 4. Interestingly, the findings in this chapter supported the results obtaned in Chapter 5 - that foreign presence stimulated learning, capability and innovation in locally owned firms.

In order to justify and have an informed understanding of the technological characteristics of the firms, an extra component was added which enabled us to cxamine production technology, learning and innovation. Analysis of their production technology showed that these firms mainly relied on international sources for the supply of processing technology and machinery. The same trend was observed with product technology, which was often prowided by the parent companies or licensed from abroad. In light of this, no serious process or product R\&D was conducted in house bur nonetheless the firms maintained strong technical departments and quality control laboratonies. When products were developed locally, the parent companies offered technical support. As a tesult the firms' major innovations to a large extent could be attributed to the introduction of new products and process technology from abroad. This supported the argument that foreign firms do not conduct R\&D in foreign developing countries and if they did it was only to a limited extent [Lall, (1979: 1980); Cantwell, 1995; OECD, 1998; Patel and Vega, 1999; Amasden, Tschang and Goto, 2001; Rasiah, 2003].

Subsequenty, we sought to understand wherher any skills and experience were acquired from the foreign acquited production technology. Based on the discussion presented, it can be argued concretely that foreign production technology and participation in production activities was critical in human capital development, which would in-turn 
latenty benefit locally owned firms in the form of knowledge spillovers should the workers leave to join lexcally owned firms; In all the cases, local employees had accumulated racit and experiental knowledge from on-the-job training and leaming by pertorming. Since most of the time the processing machine and technology obtained were complex, state of-the-art, this was suggestive that local staft would have to be teanived on how to operate, maintain and repair them. This involved people dealing with production such production managers, production operators, as well as engineers and technicians from the technical departments. As gathered, technological trainings often commenced with plant lay out and process installation including commissioning and would entail process operations, process adaptations and maintenance procedures etc. The same case happened with product technology. In all the cases, locals had learnt how to make products including the ones produced under foreign license. Arguably, learning by making changes, by using and by doing enabled local personnel to learn and acquire experience. Similarlly, participation in quality management systems (QMS) presented locals with tremendous leaming oppottunities.

Human resource development was examined in the context of firms' training and other modes of skill enrichment programmes and labour mobility. The analysis showed that local personinel in all these firms acquired technological skills and accumulated experiential knowledge from trainings offered and through learning by doing. At the same time these firms seemed to generate tremendous entichment of local employee skills by allowing them to participate in skill enrichment programmes organised either inhouse or externally. All these firms hacl better organised training modes with good training facilities and resources to even send staff abroad for specialised training. Many local staff benefited enomous training from exchange programme trainings either with the firm's parent companies or with the suppliers of production technology. With regard to labour market conditions, the furms seemed to observe labour ethics, wnion, high wages, transportation, better terms and conditions of service etc. The acquired skills and accumulated tacit knowledge resulted in an upward intra-firm mobility, hieranchical, of the local staff. Discussions presented in this chapter showed convincingly how several locals rose through the ranks from junior levels to become senior managers after training and acquiring work experience.

It was interesting to discover the existence of tremendous labour mobility from these firms to locally owned firms. In all the cases, protessionals, engineers, and technically skilled workers were reported to have at one time left their jobs and taken up new appointments with locally owned firms. In fact, some left to begin theit own entrepreneurs suggesting a possible vital role FDI could be playing in the industry as a breeding ground for local entrepreneurs. We were able to track such locals who confirmed the usefulness and applicability of the skills they had acquired while working with these firms suggesting knowledge spillovers through labour mobility. More details will be provided in the next chapter. 'These investigations shed tremendous insight into the possible and positive role that presence of foreign firms played in the country's human capital development effort. This in-turn could play a vital role in the growth of locally owned firms and the entire industry.

We examined extensively direct linkages generated by these firms with locally owned firms, institutions and business associations. Pecuniary and non-pecuniary linkages were identified from which backward and fotward linkages were traced. This was possible after mapping out all possible and significant production linkages and networks generated by individual case study firms. Some firms formed strong pecuniaty linkages compared to others. This seemed to depend on sectors as firms in food and beverages 
processing seemed to have more and stronget pecumary linkages than machine and engineeting industry. Fven with pecuniary linkages sone fims formed strong fonwath linkages than backward linkages. "That depended on market orientation of the firms given that some of then were mainly exporters while others manufactured purdy for the domestic and regional maket. The demand created by these fims through pecunary linkages with locally owned furms helped the growth of local arms by providing them with capital for growth, investment and expansion. The effort to improve their orders helped them to improwe on theit technological capabilities. Nevertheless, the lin.kages had business advantages to the case study firms in that feed back generated resulted in improvements on products, processes and even matketing appronch.

Non-pecuniary linkages included machine and engineering linkages and technical assistance. In contrast to the above, these lnkages were more in the case of machine and engineering industry compared to the food and beverages sector. It must be mentioned that due to reliance on foreign suppliers of machinery and technology, local technical links were only limited to maintenance, repairs and sale of machine and engineering equipment. Foreign furms andited their local suppliers. They offered training to appointed co-packers of their products especially in food safery and marketing operations and advertising services. They helped in fixing prices for the co-packers. Some forcign firms engaged local, firms in intermediary activities, packaging for them. Others were noted to have positioned some of their experienced personmel in the local. firms to supervise and oversee the processing activities. Interactions of these kind resulted in information sharing, trainings on quality control and prodwction management.

Most of the foreign firms contended that the local suppliers of some of the machinery and equipment procured locally have been able to grow, expand and build technological capability and thus absomptive capacity as a result of leaming from the orders placed from foreign firm. Engineers and technicians from domestic firms benefited spillover of knowledge as a result of interactions with foreign firms during machine repairs and maintenance or duting negotiation on the equipment to be supplied. Some foreign fitms were noted to have offered strict conditions. Many cases were identified where domestic supplying firms had to undergo strict auditing, verting and certification by foreign firms. Just to cite an example almost all of the foreign firms were $15 O$ accredited and a few followed World Class Performance (WCP) in their operations. As a result, the firms had strict tequirements that all domestic suppliers must be credible firms. For instance they must be $1 S O$ certified in order to maintain the required level of quality. If not accredited in terms of quality, foreign firms encouraged them to start the process towards accreditation. Apart from quality, forcign furms required the domestic firms to be efficient in all their operations including delivery. They must have the tight machinery and equipment. They must offer trainings in their firms. They must have sound management practices.

The foreign firms interacted with business associations, private and public instintions such as R\&D/academic institutions, financing institutions and gowernment regulatory organisations and enforcement agencies. These interactions resulted in skills and knowledge sharing and in some cases technical assistance. The foreign firms had direct and active participation in most of these institutions - the firms were actwe members of KAM whose effort to transform the Kenyan manufacturing industry appears promising. While a few chief executives were board members of KAM others held chairmanship in varions sectoral committees within KAM charged with specific tasks. Interestingly, some of the chief executives were foreigners with enormous experience derived from vast international exposure. As a result, the wider association of KAM members definitely 
enjoged shating their wide knowledge and expertise in areas such as labour ethics, trade disputes, corporate govenance, policy lobbying technique, technology transfer, formation of linkage, stategic alliances and mergers and acquisitions, intellectal propery nights etc. Fins interacted with the MSK whose mission is to promote matketing as a vital ingredient for success and prosperity. Similar to KAM, some of the council members of MSK's were drawn from foreign firms (FBF2 and FBF6). Both institutions organised competitions that created good forum for the exchange of information, ideas and skills.

Fifms also interacted with government regulatory bodies such as KEBS where they actively participated in the standards development. To operate in Kenya they need to be awarded the Kenya Quality certification. It is the country's custodian for standards and meastrements in Kenya and thus does instrument and equipment calibration, pressure gatge and wineyard etc for firms. KEBS also collaborates whith SGS in issuing ISO 9000 certification for Quality Management Systems (QMS) and ISO 14000 certification for Environmental Management Systems (BMS) and Hazard Critical Control Point (HACC). It organises trainings whereby resource persons are sometimes drawn from foreign firms. In partnership with foreign firms, KEBS organises annual competitions for quality awards "Kenya Quality Award (KQA)". Firms interacted with FKE whose efforts to deal with local habour issues appeared fairly promising. For instance, all the firms interacted with $\mathrm{FKE}$ for advice on labour issues and trade disputes. Other institutions included KTRDI, Export Processing Council, Kenya Industrial Property Office and Kenya National Chamber of Commerce and Industry. Foreign firms were not keen on obtaining finance from the local institutions and thus had limited interactions with financing agencies for industrial development (IDB and ICDC). However, they also felt that collateral and high interest rate requirements were obstacles to obtaining such finance for investment and expansion more so to the domestic firms. Foteign firms did not interact much with Monopolies and Prices Department, IPC, EPZ and EPC.

The firms were observed to participate in the broader national human capacity development. They offered fellowships to bright sudents to take courses like engineering courses, computing and other professional courses like marketing and business management. Such were very common with the local universities under, parallel degree programmes $^{\text {t*3, }}$, and with intermediary colleges like Kenya Institute of Management (KTM), Strathmore, IAT and school of professional studies. Additionally, they offered industrial attachment to graduates from tertiary institutes of leaming. One of the firms worked closely with the Government's Maragement Training and Adwisory Centre (MTAC), the Directorate of Industrial Training (DIT) and Kenya Polytechnic in developing a special training progtamme. The foreign fims allowed students and organised groups to wisit their production plants for observation. The firms also participated in Agricultural shows of Kenya (ASK) where they exhibired their products. As a form of corporate responsibility these firms have participated in building schools vocational schools. They have also participated in various forms of community development by giving material and money donations to the gowernment to support calamities and disaster victims, or combat diseases like malaria and AIDS etc.

The analysis of competition between these firms and locally owned firms was observed to exist. Stiff competition was noted from imported products into the country, mainly from Egypt and South Africa after the apartheid. The competion was exacerbated by

14, The parallel degree programs were established recently in Kenya where arnbody induding the workers those altrendy in ermploymenc could go back to school on part-time basis and obran diplomas, degrees buchelors ot aven masters) 
the onset of liberalisation. Foreign frms competed wh domestic arms mainly for domestic and regional market (East Africa and COMESA Competiton came out as one of the most important mechanisms through which firms were tiggered to introduce changes in virtually all theiv operations. Locally owned frms nese forced to engage in leaming processes while at the same time introducing technological changes. This was so given that these firms were more dominat due to theit size and scale of operation, complexity of processing and product technology used etc. The technological changes undertaken in domestic firms would be meant to improve firms techical efficiency, thus reflecting occurence of spillovers. This aspect is studied in derail in Chapter 7.

Locally owned fims seemed to have benefted from demonstration effects from foreign frrms. Locally owned frrms quite often copied and/or initated processes or products from foreign firms. This happened during the participation in agricultural shows. It also happened when firms observed things manufactured by foreign firms in the supermarkets and so on. As will be shown in Chapter 7 , the domestic firms therefore benefit a wider set of product and portfolio without having to conduct a prolonged search for new product development.

In light of the above summary, we can conclude that presence of foreign firms in the Kenyan manufactuting industry seems to stimulate spillower occurrence to the locally owned firms. The positive contribution supports the theoretical arguments in Chapter 2 , analysis in Chapter 3 and empirical evaluation done in Chapter 4 and 5. The occurrence of spillovers and their relevance to the building of local capabilities will however be examined in the perspective of locally owned firms in Chapter 7 . This will be patticularly important in enhancing policy relevance with regatd to spillovers, learning and innovation. 


\section{TECHNOLOGICAL LEARNING AND INNOVATION IN THE LOCAL} FIRMS

\subsection{Introduction}

In Chapter 6, whe examined the extent to which foreign presence stimulated spillower occurrence in locally owned firms. The analysis showed interesting indwidual frm level accounts of how foreign presence created opportunities for spillover occurrence to the locally owned firms. In this chapter, we attempt to examine the spillover accurrence from the angle of locally owned fims. The analysis is done using eight detaled case studies of locally owned firms selected from food and beverages and machine and engineering industetes. The two industries were shown in Chapter 4 to be the most dynamic in the entire manufacturing industry in terms of high growth rate levels, VAD, cmployment generation, FDI presence etc. As discussed in Chapter 2 and 5 , this thesis conceptualises technological spillowers in terms of learning, skills and knowledge acquisition and accumulation. This chapter, therefore, examines extensively the extent to which such knowledge spillovers engender technological changes and stimulate learning process with possible accumulation of technological capability and innovation in locally owned firms ${ }^{4 *}$. The chapter is divided into seven major sections. In section 7.2, the framework of analysis is presented. Section 7.3 offers a brief analysis of the frms studied. Section 7.4 presents the case studies on food and beverages industry while section 7.5 presents the case studies on machine and engineeting industry. In section 7.6 , an attempt is made to assess the government's tole in spillover occutrence. The summary and conclusions are presented in section 7.7 .

\subsection{Framework of Analysis}

This chapter uses a framework similar to the one used in Chapter 6 to examine the extent to which foreign presence stimulates spillover occurrence to the locally owned firms. Most importantly, we seck to understand whether spillovers from MNC frms stimulate any kind of technological changes and leatring and if 50 to what extent that leads to technological capability building and innovation in the locally owned firms ${ }^{145}$. Since spillovers as defined in this study are specific to the firm, the framework used allows us to trace and examine spillovers uniquely through their occurrence mechanism ${ }^{\text {lat }}$. The framework of analysis proceeds as follows:

From ous approach in Chapter 2 and 5 , it was shown that spillover occurrence involved activities of both foreign and locally owned firms. Since the activities of foreign presence were presented in Chapter 6 , in this chapter we will look at activities of locally owned firms. The analysis done here is expected to go beyond the productivity technique and examine the mechanisms through which spillowers occur and how they translate into production through learning, capability and innovation. This will further enhance policy

14t It is important to emphasise that althongh locally owned firms could as well stimalate spllower occurence in toregn fims, this chapter will not address that in significant detall and will only be limited to studying how foreign Firms stimulate spillower occurrence in localy owned fims.

14. We emphasise once agatn here that not all spllovers should be interpreted to be good especially so in frod processing when food rich in homones or sugis content get copied by locally owned finms.

146 In Chapter 5 a gencric approach was adopted refering to technology and machinery as process technology and so on. In tais chaper specific spillovers are traced, e.g. machines and technology which are difterent from one firm to anothet. 
relevance in which case informed recommendations for policy necessary for continued development of a dynamic matufacturing sector will be prescribed with regatd to FDI, capability building and innovation ${ }^{147}$. As pointed out in Chapter 6 , the analysis done here is not meant to compare concretely between foreign and locally onned firms as such dat and/or information would not be available in the Kenyan context. Rather it is just meant to provide individual firm level accounts of the spillover process. We now discuss the framework developed in the perspective of locally owned firms 4 . Frm, we examined human resource development undertaken in these firms emphasising on training. Subsequently, we investigated labour mobility. Investigations are made to detemine whether any of the professionals, scientists and engineers or any other skilled workers had previous experience acquired while wotking with other firms and whether the prewious firms were MNC or locally owned. Evidence of spillovers due to labour mobility is still scarce with only a few studies existing (Gerschenberg, 1987; Behrman and Wallender, 1976; Pack; 1993; Fosfuri, Massimo and Ronde, 2001; Lin and Rasiah, 2003). We focused more on workers from foreign firms to locally owned firms. In such cases, we were interested in finding out whether such employees introduced any new technological changes or new forms of learning which would lead to accumulation of technological capability and absorptive capacity. This would provide insight into whether: foreign firms participated in the country's human capital development effort.

Second, linkages formed with foreign firms were mapped out and their importance in terms of contents was investigated. As noted earlier, the importance of linkages between MNCs and domestic firms has been discussed in different contexts (Hirschman, 1958; Lall, 1980; Rasiah 1995; Rodriguez-Clare, 1996; UNCTAD, 2002; Belderbos, Capannelli and Fukao, 2001; Smarzynska, 2003). Examining linkages from the angle of local firms was important in that some linkages which might appear less significant viewed in the lenses of foreign firms could be of tremendous importance in the perspective of locally owned firms. For instance, as indicated above pecuniary linkages might have helped the growth of local firms by provicling them with much needed capital. More so, the demand or supply created by foreign firms sometimes exposes new opportunities for local firms to make new investments and/or expand. The links could also expose and stimulate locally owned firms into joining value-added chains new to them. Non-pecuniary linkages formed with foreign firms were equally studied. They included links with the machine and engineeting (user-supplier relationships) and technical assistance through interactions with the local support systerns such as business associations and institutions such as R\&D/academic and finaning institutions.

The role of institutions as intermediates for spillover occurrence to the locally owned firms was assessed. The impottance of institutions as intermediary organisations that coordinate demand-supply telations between firms, government, and institutions has been emphasised (Rasiah, 2001; Doner, 2001; Aoki, 2001). As discussed in Chaprer 3, institurions were observed to provide support but at different levels of efficiency and performance. We emphasise that support structure provided by the institutions in an industry is likely to enhance domestic firms" capacity to absorb spillovers from foreign firms ${ }^{14 \%}$. To assess this phenomenon, a few institutions were carefully selected from

\footnotetext{
3: The chapter will however carry the discussion only and the policy dialogue and prescriptions will be provided in Chapter 8 .

14: The analytical framework elements are similar to those discussed in Chapter 6 and contained in out appronch in Chapter 2 and 5 .

At9 The support included offering finance, offering rechnical ratining, regulatory purposes, prowiding technical information, providing technical and adwisory support etc. lnstiutions can create for fom for interactions as they hold joint firm trainings and thus can result in krowlewge spillovers and information sharing.
} 
business associations, ministries and institutions - academic as well as financial instrutions (sect Table 2.3 in Chapter 2). The information was obtained through interviews and discussions held with personalives deemed knowledgeable manly in investinent, industry, innovation, privatisation and FDI. The personalities often included local officials, professionals and scholats.

Thinl, competition between the case study firms and foreign firms was examined. Such competion often arises when foreign firms are active in the same markets with local firns. This could often reflect spillovers of knowledge and skills from foreign furms in the perspective of trigger effect (Caves, 1982; Das, 1987; Wang and Blomstrom, 1992). We attempted to understand the technological changes that take place in locally owned firms and how they undergo the process of undertaking them. As an example, we inwestigated how the local firms reacted to the competition pressure? By implementing changes and engaging in various learning processes do the locally owned firms manage to develop their own internal capabilities and respond posirwely to the foreign firms competition pressures? Did the existing business support stucture in the domestic innovative system help eg. get a consultant, get help in taising quality levels etc? Several altenative explanations as to why Kenyan firms might have survived and continued keeping up can be provided. The govermment could offer some subsidies to the locally owtmed firms and second the locally owned firms could be serving a different matket from that serwed by the foreign firms. 'The probing question here to be investigared is; how did the local firms survive or cope up with the competition pressure? Was it because of the reasons provided above or have they learned something from MNCs and if so what and how? If so, what kinds of technologicall capabilities have been built as a result of these spillovers? Note however, that competition pressure can have negative effects to learning and innovation in domestic firms. Firt, competition pressure can result in crowding out of domestic firms - unfortunately this effect will not be examined for lack of necessary data and information. Second, competition ptessure can also result in shutting firm alternatives out of the markers. For instance, when competition is high domestic frms are likely to concentrate their effort in advertising at the expense of learning and innovation.

Fourth, we also examined demonstration effect from the angle of locally owned firms. Locally owned firms have often benefited from demonstracion effects from FDI (Mansfield and Romeo, 1980; Blomstrom, 1986; Rasiah, 1995). We examined the extent to which locally owned firms have managed to copy or imitate products, processes and marketing skills from foreign firms. Demonstration effect provides the imitating firm with a wider choice of products, processes etc without having to engage in a rigonous search process. Similar to competition, imitation can have negative ramifications to the domestic firms. As an example, a negative effect can however occur when domestic firms simply copy products or processes of foreign firms without making much effort to learn and accumulate own technological capability which would enable them become innovate in the long run. Having to rely on low wages without real competitive advantage does not last if not accompanied by capacity to learn and innovate.

On the basis of survey data analysed in Chapter 5 , eight locally owned enterprises were selected for a deeper analysis in the form of case studies. The eight firms included seven private firms and one state-owned enterprise (SOE). Four case study firms were selected for each manufacturing industry (food processing and beverages and machine and enginecring). As in the case of foreign firms, the local firms'selection criterion was based on the nature of production technology as well as leatning and innovation observed in the firms during the survey phase - the selection and technological characteristics of the 
frms considered are discussed extensively in sections 7.4 and 7.5 . As was the case with foteign frms, all the local fums except one offered us guided tours of the plants to wiew their production processes. In most of the cases, senor mangers and often the production managers accompanied us during the tout. As was the case whth foreign fums studied in Chapter 6 , this out of office interaction with the professionals created an informal atmosphere, which provided a good opportunity for us to obtain exrra information. Books, magazines and anmul reports would also be collected. Exra information was obtained during international trade and agricultural show. Active links were maintained with the furms just in case certain clarifications needed to be made on information provided during the interviews. The link maintained with Central Bureau of Statistics proved to be extra useful in providing extra data and information required during the case study analysis.

\subsection{Brief Analysis of the Firms: Background and General Information}

\subsubsection{Food and Beverages Industry Briefly}

The four case study fitms studied in the food and beverages industry included (FBL1, FBL2, FBL3 and FBL4). FBL3 and FBL4 were established in Kenya before 1970 while the other two were relatively young having been established after 1980. All the case study firms can be regarded as large scale firms by Kenyan standard as they employed more than 100 employees (see Table 7.1). Asians of Kenyan origin owned two (FBL1 and FBL3) of these firms. An African of Kenyan origin owns FBL2 while FBL4 is a state owned enterprise.

With regard to production, FBL1 was a slightly large scale firm that refines and manufactures cooking fat and edible oils, margarines and soaps. The firm is run as a family business and has a long history dating back in the 1970 s when it was first established as clothing factory founded in Nairobi. This firm was later sold after the textile industry collapsed undermined by the dumping of imported textile (second hand) and increased cost of ptoduction. The proceeds from the sale of this firm and a loan from industrial development bank (IDB) enabled the family (fathet and his two sons) to establish a soap manufacturing plant in 1985 in Nairobi. In 1991, the family established an oil refinery a few kilometers from Nairobi and in 1998, the firm acquired a firm that marufactures edible oil from sunflower, soya bean and cornflower. FBL1's expansion plan has been gradually rolling over to other countries in the region. In 2001, FBL1 acquired and expanded a soap-manufacturing factory in Tanzania. In 2003, the firm launched an oil refinery in Dat $\mathbb{E}$ s Salam for processing edible oils and toilet soap. Plans to invest in a nucleus palm oil plantation and a tefinery plant in Uganda were also at an advanced stage.

FBL2 was one of the group companies of a large conglometate family business inwolved with mass production and distribution of soft drink and beverages. The firm also packages fresh fruit juices and mineral water ${ }^{150}$. FBL2 has grown over time and can be regarded as one of the most successful indigenous family businesses in Kenya. At its inception the frrm was involved with the manufacture of a South African sorghum beer, originally operated by a MNC subsidiary in Kenya. The business grew tremendously over time with significant diversification which resulted in establishment of five business conglomerates. Out of these, FBL2 was regarded as the flagship of the family

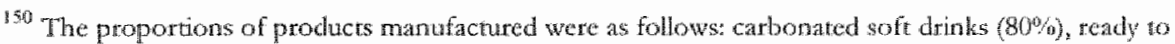
drak juice $(11 \%)$ and drinking water $(1 \%$ ).
} 
buisiness $^{15 !}$. Similar to FBL2, FBL3 was involved in the production of soft dxinks, packing of fresh fruit juices and minetal water. It is authorized to bottle various soft drinks by an American based $\mathrm{MNC}_{\mathrm{s}}$ to import, sell and distribute Coke cans as well as non carbonated beverages of Coke.

FBL4 was initially established in Kenya, as a foreign owned firm (British) dealing with impottation and distribution of wines and spints in the country. However, the firm was transformed into a state owned enterprise (SOE) in 1969 when the Kenya government acquired it from its foreign owners. Upon acquistion, the firm continued importing and distributing wines and spirits in the country. Overtime, the firm has been able to learn and accumulate the necessary technological capability in production enabling it to diversify its operations to include manufacturing of own products - of high quality distilled alcoholic beverages from locally available tropical fruits. As will be shown at a later section, the firm enjoyed a major innovation when it pioneered wine making in the country in 1982. It's activities included ptocurement $65 \%$, manufacturing $25 \%$ and distribution $10 \%$. It also packages minetal water and a variety of fresh fruit juices.

As far as pertformance was concerned, FBL1's total fixed assets amounted to about KShs 2.8 billion in 2002 . FBL1 had the highest sales tumover. The firm had an annual salles turn ower of approximately KShs 4.5 billion with about $30 \%$ of it coming from the expotts to the COMESA tegion where the firm had been exporting for over 15 years. By 2002, FBL2 had total fixed assets of close to KShs 15.0 million and with a turn over of approxmately KShs 110.0 million, Table 7.1. All the manufactured products are meant for the domestic market, as FBL2 does not export any of its products. FBL3's total fixed assets amounted to KShs 0.68 billion at the origin. The firm has a total output of about KShs 0.93 billion. The firm does not export but it sells goods worth KShs 2.0 million to domestic exporting firms. In $2002, \mathbb{F B L} 4$ had a total tutnorer sale of about KShs 0.8 billion. The firm's exporting experience spans over a period of 4 yeats but only to the regional market that includes Tanzania, Uganda, Rwanda and Eastem Congo.

\footnotetext{
151 The second one was involved in the processing of maize flour. The third business dealt with reall estate properties. The fourth was an inter-net firm based in Nairobi, dealing with computer technologies offering diwerse services that included domain registration, web design and web hosting. The last firm dealt with mobile phone businesses.
} 


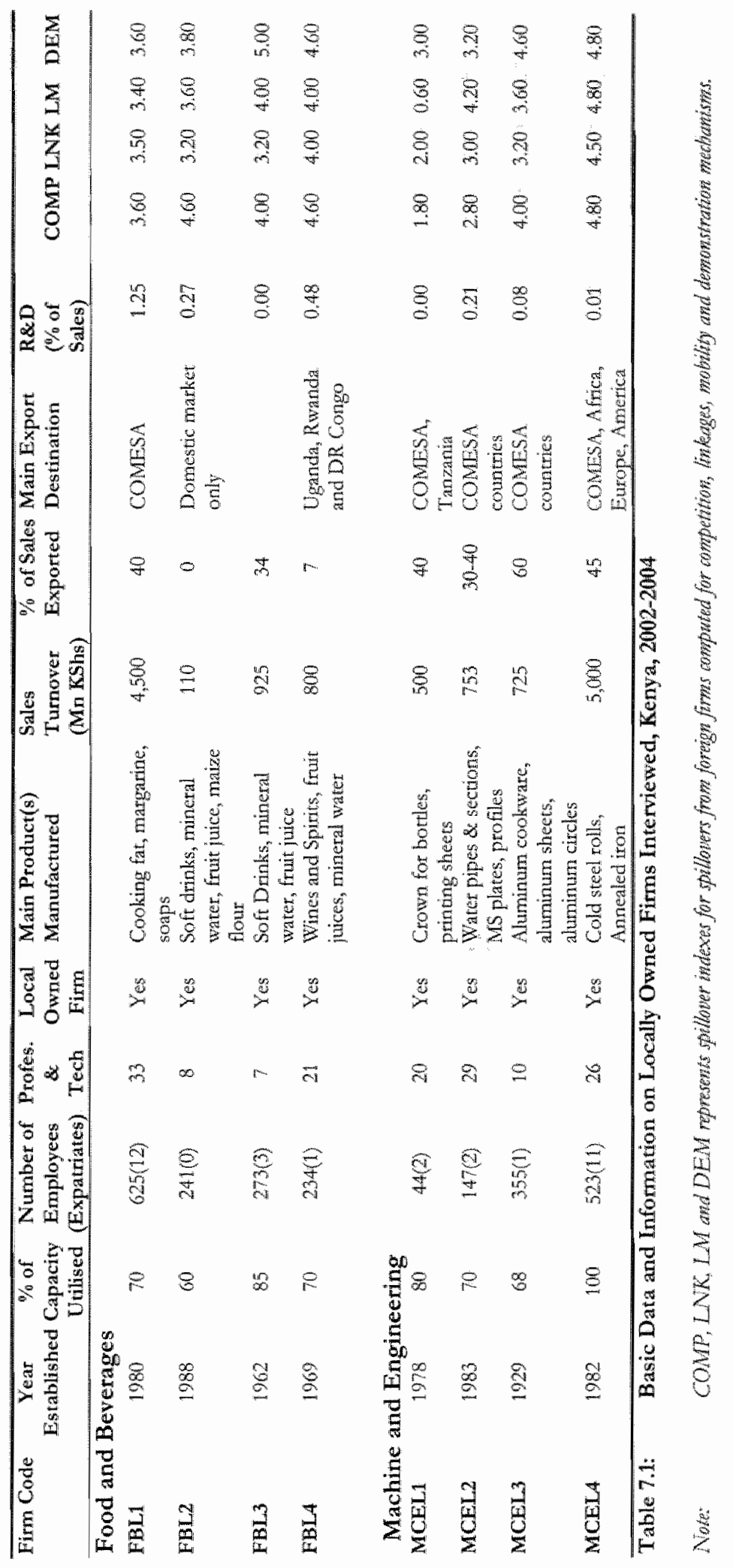




\subsubsection{Machine and Engineering Industry Briefly}

A total of four locally owned fims were intervicwed in the case of machine and engineeting industry (MCEL1, MCEL2, MCEL3 and MCEL4) - see Table 7.1. MCEL3, owned by Asians of Kenyan origin, was the oldest having been established during the colonial days. The firn enjoys three major divisions; one manufactures Auminium circles and sheets, the second one specialises in Aluminim utensils for European export market while the third one manufactures products destined for COMESA region only. MCEL4 was originally established in 1961 as a galvanising plant located in Nairobi. By the close of 1970 s, the firm underwent a major expansion when two new investments, a tube mill and a strapping mill were made. In 1982, the firm opened a major cold rolling mill in Mombasa ${ }^{152}$ where the firm had further expansion in 1999-2000 when it invested in a world-class continuous galvanising line (CGL). This was a US 30 million project with US 11.5 million from Investment Finance Corporation ( $\mathbb{C l}^{\circ} \mathrm{C}$ ), and Euro 9.0 million from the European Union's Investment Bank (EIB). Astans of Kenyan origin established both MCEL1 (Kenyan African) and MCEL2 in 1978 and 1983 respectively. MCEL1 is a part of a large group of companies that comprises financial institutions, banking institutions, insurance brokerage, real estate among other businesses. It is the only locally owned firm that manufactures metal crowns in the country with subsidiary of a MNC as its competitor - this was MCEF1 studied in Chapter 6. As will be shown at a later stage, this firm has accumulated technological capability over time and has turned out to be a great competitor to the MNC subsidiary. At the time of its inception 1983, MCEL2 used relatively state-of-the-art technology to manufacture a wide range of steel water pipes, hollow sections, steel plates and furniture tubes widely used in water projects, building industry and for exhaust pipes industry.

With regard to performance and investment, MCEL1 had a tumover of about KShs 0.5 billion with total fixed assets amounting to about KShs 70 million. The firm has been exporting for over 25 years. Its market destination included COMESA and Tanzania. The firm has a tum over of approximately KShs 1.0 billion. It commands between $70 \%$ and $80 \%$ of the market share in Tanzania and Uganda. The firm also exports its products to Ethiopia, Rwanda, Malawi, Zaire and Eritrea. This firm was also the approved supplier of crown corks to MNCs like Coca-Cola and Pepsi-Cola. MCEL2 had total fixed assets of over KShs 1,20 billion and a turn over of approximately KShs 0.75 billion. The firm controls between $40 \%$ and $45 \%$ of the total domestic steel pipe market. As explained by the production manager engineer, the fitm is highly reputed in the COMESA and SADC regions due to the high quality of its export products. The firm exports between $30.40 \%$ of its products. Some of the main countries where the firm's products are exported include most countries within the COMESA region. Other countries include those outside the COMESA regional block like Mauritus, "Tanzania, Madagascar and Ethiopia. MCEL3 had total assets of about KShs140 million. The three main production activities include Aluminium circles (discs), which accounts for $50 \%$, Aluminium wares that accounts for $45 \%$ of the firms production activities and Aluminium sheets, which accounts for $5 \%$. The firm manufactures for the domestic as well as foreign market. In actual fact the fact the firm has a strong emphasis towards exporting. The firm has been exporting for over 20 years. Mainly the firm exports to the

132 This was the first cold rolling mill in Kenya and the largest in East Africa. When the rolling mill was commissioned in Mombasa, the galvamising division, tube mill and strapping diwisions wete then transferred to other associated companies based in Nairobi. 
COMESA region. In 2002 , the firm had total sales of KShs 0.725 billion and an export value of KShs 0.44 billion. MCEL4 has total fixed assets of KShs 5.0 billion and an annual sales turnover of $K$ Shs 5 billion, Table 7.1. The firm exports $45 \%$ of its processed products while $55 \%$ are consumed in the domestic market. MCEL4 enjoys over $50 \%$ of the local market share. Its products are mainly exported to East and Central African region. MCEL4 also exports to West and North African region. With increased investment in technologically advanced machinery, the firm has acquired the necessary technological capability to manufacture products that match international quality standards. As a result, the firm's export destination and market has expanded to include countries in the Far East, Asia, Europe, North and South America.

\subsection{The Case Studies of Locally Owned Firms in the Food and Beverage Industry}

This section provides some illustrations on spillover process alongside the conceptual elements outlined in section 7.2. It begins with an explanation of how case study firms were selected. In addition to specific firm characteristics provided in section 7.3 , our selection was further based on technological characteristics of the firms. Analysis of production technology in the case study firms in food processing and beverages had positive consequences for spillovers occurrence.

\subsubsection{Firm Selection and Justification: Emphasis on Production Technology, Learning and Innovation}

As Chapter 6, selection of local firms included in our case studies was based on sophistication of production technology as well as learning and innovation effort observed. FBL1's selection was influenced by the flowing reasons: First, it operated in one of the most comperitive sectors alongside MNC subsidiaries ${ }^{153}$. Second, FBL1 had several transactions involving production technology with MNC subsidiaties operating in the country. Finally, the firm operated large scale utilising some of the most versatile and completely integrated manufacturing processes in its industrial sector ${ }^{154}$. While the core processing technology and machinery was primarily sourced from Europe, some of the product and processing technology had been purchased locally from a MNC subsidiary operating in Kenya. The firm, however, does not do search R\&D for process technology and thus it relies totally on foreign supply of process innovation, technology and machinery.

The case of FBL1 was particularly fascinating in that it represented an example of locally owned firm with an extraordinary expansion history and one that benefited tremendous technological spillovers from the presence of MNC subsidiaries operating in the same industry. As a result of these spillovers, the firm acquired significant production capability, which in-turn enabled the firm to innovate. The first example took place when FBL1

\footnotetext{
15:3 "This was the cooking fat and edible oil sector where FBF1 operared. FBF1 was included in our case studies thiscussed in Chapter 6 .

154 The firm urilizes fully foreign technology to manufacture a wide range of products that comprised cooking Eat $(50 \%)$, margarine $(35 \%)$ and soapt ${ }^{15}(15 \%)$. The firm contended that it utilised modern processes in oilsed crushing, extruding, solvent extraction, refining, fractionation, winterization, and hydrogcharion, interesterification and in soap making.
} 
acquired a branch of MNC subsidiary operating in the country. An Italian entrepreneur with vested interest in edible oil processing initially established the acquired firm in 1972. The firm was a stand alone without foreign affiliation for 14 years when the Italian entreprenenr decided to sell it to an American based subsidiary operating in the Kenyan flour milling industry. Later in 1998, FBLI acquired this firm from the American subsidiary. By so doing, FBL1 benefited a broad portfolio of new product brands and processing techniques as well as human capacity. FBL1 inherited an already established management and organisation set up as well as an established sales and distribution network including export market. All these summed up, amounted to strengthening FBLi's technological capability and marked a strong point of departure from which experience and in-house learning took place. The employees had accumulated the necessary production capability having acquired skills in production operations and management in the manufacture of edible oil from sunflower, soya bean and cornflower while working under the foreign firm. As a result of the strong production capability base inherited, coupled with management skills and extra capital injection from FBL1, this firm (now a branch of FBL1) expanded by $400 \%$ in a year. The branch had a further expansion in 2003 after undergoing new machinery and equipment investment raising its production capacity to over 30,000 tones per year. Strong human capacity and new capital investment by $\mathbf{F B L} 1$ were tegarded as the driving force behind the fitm's growth and expansion.

The second example of technological spillovers to FBL1 as a result of foreign presence was equally interesting. In 2002, FBL1 bought major cooking fat brands from a subsidiary of a European MNC operating in the country - FBF1 - considered for case study in Chapter 6. The MNC subsidiary was adopting its parent company's strategy of reducing the number of product brands worldwide to just a few. As a result of this strategy, FBF1 stopped manufacturing, marketing, sale and distribution of some of its brands in Kenya Subsequently, FBF1 offered these products and their processing technologies for sale locally. FBL1 decided to buy the cooking fat brands in addition to their production machinery and equipment, which included the entire processing line. The spillover benefits were wider, in that this transaction created business for other locally owned firms in the machine and engineering industry that were contracted to transfer and install the plant at the FBL1's plant site. This case confirms occurtence of spillovers as a result of foreign presence. Although FBL1 was manufacturing its own cooking fat brands targeted at the middle-income group, this was the first time it was going to engage in the processing and distribution of this particular brands of cooking fat. Both the product and process were new innovations to FBL1 and thus their manufacture meant increased skills of product and process technology, management and marketing skills and new distribution lines for the brands. FBL1 has acquired more capability through learning by doing and has undergone expansion that has included opening new plants in the neighbouring countries.

With regard to $R \& D$ the firm has a relatively advanced $R \& D$ unit by local firms" standard. However, this was more of a quality control laboratory manned by a few food scientists and technicians who were basically charged with ensuring a smooth and efficient running of the plant. The quality control laboratory was charged with testing of raw materials, process control, inspection of packaging and delivery until the products got to the intended consumers. The process control was done by batch checking at regular intervals to guarantee that the expected standards were maintained. FBL1's has ISO 9002 certification by the Bureau Veritas Quality International of Geneva and thus its quality standards complies with 
the ISO standards internationally. The continuous audit by SGS and KEBS and KIRDI ensures that expected standards are maintained. The firm maintains an engineering department charged with undertaking repairs and maintenance. This demonstrates that the firm has had an engineering and technological effort. This department maintains active links with suppliers of technology and machinery who in most cases would also be consulted whenever critical technical problems related to the production process arose or whenever a major modification was required.

The second firm selected was FBL2. This firm was selected as it was the most advanced Kenyan African owned firm we had and one that had survived stiff competition in a sector dominated by $\mathrm{MNC}$ subsidiaries such as $\mathbf{F B F}{ }^{155}$. The firm maintained strong international links as will be shown in section 7.4.3. FBL2 manufactures a variety of soft drinks products, packaged fruit juices and packages drinking mineral water ${ }^{156}$. Its core production machinery for soft drinks was fully foreign - mainly sourced from Germany. This firm benefited technological spillovers from a foreign firm which stimulated it to innowate, grow and expand. Initially, the firm started with the manufacture of an alcoholic beverage, a South African Sorghum beer, which was originally manufactured by a MNC firm in Kenya known as Lontho. FBL2 bought the production machinery and the brand with the intention to develop the brand for the local market. However, due to shrinking market, the firm decided to shift its production to the processing and bottling of soft drinks. FBL2 ventured into soft drinks manufacture by buying two popular local brands from a firm owned by Asians of Kenyan origin. Alongside the two soft drink brands, FBL2 obtained the production process - machinery and a few engineers, technicians and machine operators.

At the time of this research the firm had just commissioned its second bottling process for its soft drinks. However, this was a second hand bottling process obtained at a cost of KShs 115 million from a German firm. Being about four times efficient in terms of performance compared to the old bottling line ${ }^{157}$, the bottling process could be regarded as a remarkable process innovation to the firm. As will be discussed later in this section, competition pressure from the MNCs operating in the sector forced this firm to invest in the bottling process. The new machine was more automated and required less personnel to operate it. The government supported introduction of the new bottling line by waiving the firm from paying tax on the imported machinery and equipment. Further, the line enjoyed commissioning by a government minister. By extending the tax waiver to the firm, the government played a crucial supportive and a facilitative role. For the installation of the new machinery, the firm relied on foreign technical partners to lay the plant and introduce staff to the know-how among other machine operations - see a rough drawing on the process layout in Figure 7.1 below. The technical staff from the machine suppliers interacted with FBL2's technicians. From this interactions and training offered they would then be able to operate, maintain and sometime in future modify the machine without having to rely on the

\footnotetext{
155. 1 BFF 6 was a case study firm studied in Chapter 6.

156 The firm was also involwed in the manufacture of maize flour. The frrm uses Italian and Swiss mills manufactured by Roncanglia and Buhler $A G$ companies respectively. These were the only mills of their kind in East Africa.

157 The new machine had a processing and packaging capacity of 16,000 cases a day compared to 4,000 cases a day with the old bottling process line. As claimed by the corporate affairs manager, the acquired line would enable the firm to produce enough soft drinks to cover domestic and regional market at least in the immediate trading blocks - i.e. Fast Africa COMESA and SADC.
} 
foreign technical partners. To the firm, acquisition and installation of this plant was regarded as a significant process innovation.

\section{Figure 7.1: Simplified Soft Drink Production Process in FBL2 $2^{158}$}

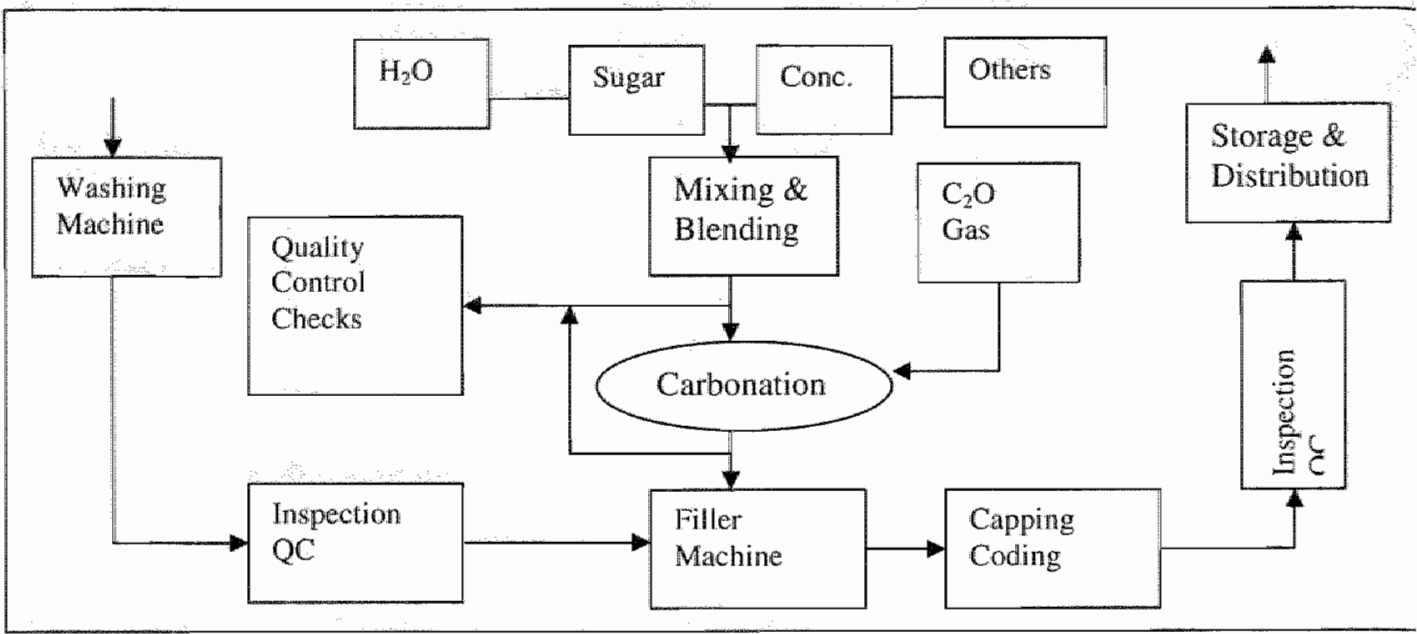

The process and product technology support obtained from Europe (German, Italy, France and Switzerland) enabled FBL2 to successfully develop its own soft drink brands. As an example, product technology backing came from leading firms in the production of flavouring constituents for soft drinks. Dohler Euro Citrus, a firm based in Germany was cited as a leading example from which FBL2 had obtained a few product innovations. Two examples can be singled out. The first example involved the carbonated soft drink flovours, which made FBL2 the only African owned frrm with a large number of soft drink flavour in the carbonated soft drinks industry. In the second example, the German firm also supported the introduction of ready to drink juices in FBL2. This firm continued to supply FBL2 with the required juice concentrates. The firm offered production assistance in setting the required quality standards. Introduction of blackcurrant was an example of a product innovation introduced with the support from Dohler Euro Citrus. Collaborative R\&D efforts between Dohler Euro Citrus and researchers from FBL2 led to the development of high quality blackcurrant flavour, resulting in a blackcurrant ready to crink juice. This was another example of a local firm stimulated by a foreign firm to undertake innovation by introducing new products for a domestic market. This also buttresses a second point that locally owned firms in Kenya can indeed be innovative. It also supported existence though rare of a collaborative R\&D between a locally owned indigenous firm and a foreign firm. In

\footnotetext{
153 The process in this plant proceded as follows: The bottes ate fed into the processing line for cleaning in the washing machine. After that the bottles are then fed into the filling machine for filling. The sofit drink is fed from the mixing and blending machine snd aftet the carbonation has been done. At each stage there are always quality control checks. The blender is a mixing machine for concentrates, syrup and water. After the bottles are filled, they are then taken to a capping machine. The capping machine uses a Germany techomology and corks the botles with crown corks obtained locally. Another unit of inspection and coding using a machine for Fixing expiry dewtes follows the capping unit. The soft drink is then off loaded to the stores or to the warehouse awaiting distribution and delivery.
} 
the light of the above discussion we can conchude that PLL learnt from the foreiga fam and that the production capability acquired enabled FBL2 to manufacture and package its own juice products". As a furher innowation on its own, FBL2 introduced 'dilute to drink juices" or the concentrated juices. "This was a result of infomation gathered from market wesearch and intelligence. The firm discovered an existing niche market for dilute to drink juices. This was supported by requests and feedback from retail customers, distributors and wholesalers triggered the firm to join the concentrated juce market. The firm introduced a dilute to drink juice which was in the form of a concentrate developed maintaining the same tlavours already known by the FBL2 customers. This was a typical example of a case where interactions and feedback from the market triggers learning and innovation in fum. This is consistent with the innowation literature [Lundvall, 1992; Nelson, 1993; Edquist, 1997; Mytelka, 2000:2004)].

In sum and according to the interviews conducted with the firm's public aftairs manager, production engineers and food scientist indicated that as a result of strict path followed towards improvements, FBL2 had improved its product brands to match international standards. They contended that the firm was on its path towatd achieving ISO certification for high and international quality standards. Although the firm can be regarded as innovative in terms of (process and product changes), it cannot be regarded as one with strong R\&D to continuously generate and support strong innovations. The firm had quality assurance certification from $\mathrm{KEBS}$ and planned to work towards achieving ISO for international quality management certification.

The selection of FBL3 was equally exciting in that it represented a case of a fitm, which was one of the franchise firms that bottles soft drink brands of a US based MNC and a world giant. The MNC through FBF6 provides adwice and guidelines on products, processing, marketing, and organisation and management techniques. Al these can be viewed as direct technological spillovers. FBL3 utilises fully foreign production technology and machinery all obtained with support and advice of the brand suppliers. The firm enjoyed three bottling lines at the time of this research. The recent and most efficient bottling line was acquired in 2002 from Germany. This was a new bottling line, completely state-of-the-art; computer numerically controlled (CNC) and was fitted with two robot machines. Acquistion of this process line made an enormous contribution to the firm's production capability ${ }^{\text {igt This was }}$ not only a significant innovation to the firm but also served as a great soutce of technological learning to the staff in the firm. The line had other innovations - it was firted

is The production manager outined the juice making process which staff had fully mastered (production capability) as follows: The first one was syrup preparation process. The second was mastery of the pasteurization process which had to be done at specified temperature and time. Third was knowledge of how constutuents reguired in juice making are mixed and blend. About five separate constiruents are mixed i.e. they include water, concentrates, flavour secret obtained from Germany, preservatives and witamins in the form of ascorbic acid. $\mathrm{A}$ wide variety of flavours are prepared ranging from strawberry, lemon, pincapple, and passion to blackcurrant. The Germany firm offers technical support as well as KEBS which sets the standards for juices in the country.

160 The main imnowations in this production process line, robots, enhanced the firm's efficiency and productivity significantly.

${ }_{16}$. $^{\prime}$ Some of the statistics provided on efficiency showed that, when the old line had a tated capaciry of 500 600 cases for the $300-\mathrm{ml}$ bortles per hour, the new line had a rated capacity of 1,192 cases per hour for the 300 ml bottles. In addition, this line had the capacity to bottle $500-\mathrm{ml}$ and $1,000-\mathrm{ml}$ bottles at a rated capacicy of 954 cases and 1,433 per hour respectively. 
with new quality control machine supplied by a South African firm "Filtec." The machine was automatically programmed to check specific quality characteristics of the bottles that included residual , finishing, base and inner sidewall. The use of ultra violet radiation made the machine particularly very sensitive and accurate.

We now turn to the learning and experience accumulated from this technology and machinery. Before installation of the process line, three engineers were sent to Germany for more than a month to be trained by the suppliers on how to operate the production technology and manage production. During the installation of the processing line including robots, many 'people' were involved. Apart from expatriates from technology suppliers, and firm engineers and technicians, the firm for the first time involved engineering students from a local national polytechnic. The idea behind it was that engineering students from the polytechnic would comprehend and assimilate technical issues quickly given the sophistication and integrated nature of the new process technology. The firm later employed some of the students when they completed their diploma programme. As the interviews confirmed, acquisition of the new process technology and machinery led to significant firm re-organisation in terms of management structure and training. These were further innovations to the firm. This example shows how production processes obtained from the above results in learning, capability building and innovation in firms and institutions like the national polytechnic involved.

Apart from the bottling lines discussed above, the firm maintained a syrup preparation section for the purpose of soft drink manufacture. The section presented a different form of technological learning to the firm. As explained by the production manager, the staff had been trained on the syrup manufacture. Since this firm operated under a franchise arrangement under the US soft drink MNC giant, the training offered was in line with its international standards. In addition, the staff also learnt while on job by doing and had fully mastered the entire process of syrup making. The process learnt and mastered entalled mixing concentrate, sweeteners, water and $\mathrm{CO}_{2}$. Each time a new brand is introduced, the instructions and fresh trainings are provided.

FBL3 does not conduct R\&D in product technology hence it does not perform any product innovation. As in the case of FBF6 discussed in Chapter 6, the firm relies on international brand suppliets for innovations in product technology. The firm is therefore authorised to manufacture, bottle and distribute the products under the brand owner's license. The firm observes strict quality standards set by the brand owners who often audit the firm and thus everyone has to be very well trained. As a response to the firm's effort in quality control, it has achieved ISO 9002 and ISO 9000-2000 certification. The later quality certification emphasises on strict quality control, continuous changes, customer satisfaction and human resources development. The firm has an engineering department employing about 40 to 50 skilled personnel who include: engineers, technicians, mechanics and electricians.

FBL4 was selected due to several reasons. The first one was that we needed at least one case study of a state owned enterprise firm in our sample. Second, this firm had strong links with FBF5; a MNC subsidiary studied in Chapter 6. Third, it had very strong international links. Fourth, the firm operated in a very competitive environment where MNC subsiclaries such as FBF3 also operated. The fifth reason was that FBL4 benefited tremendous technological spillovers after it inherited processing machinery, importation and a whole distribution 
network of wines and spirits from a foreign firm. This provided a sound base of its future expansion. At the time of our survey, FBL4 utilised fully foreign processing technology: The core production technology and machinery were obtained from Europe - mainly Sweden, United Kingdom and German. The estimated age of all the firm's production machines was below 10 years and utilised $70 \%$ of its total installed processing capacity.

Since 1982, the firm has been involved in the importation, packaging and distribution of wines and spirits. It imported wine in bulk (barrels) and then re-packaged it after undergoing partial processing in the firm ${ }^{162}$. The partial processing was done to reduce strength, a process referred to as "dilute to drink" since some of the wines and spirits were imported in their highly concentrated form. Brandy, for instance, was imported in a highly concentrated form and had to be partially processed to reduce its concentration to local specifications and standards before bottling it for the domestic and regional market. The production manager acknowledged that through importation and continuous partial processing of the imported wines and spirits, the firm had over time learnt and accumulated enough production capability, which enabled it to commence manufacture of its own alcoholic brands ${ }^{163}$. The process presented learning opportunities to the firm that resulted in accumulation of proprietary product know-how, which led to development of FBL4's own products. FBL4's first product innovation was in 1982 when it developed its own brand of wine known as 'papaya wine' made from locally available paw paws. There was high demand for this wine in the domestic market given its competitive pricing strategy compared to that of imported wine. Additionally, this wine became a favourite of tourists in the country, making it one of the major products of the firm. Due to the path maintained in production, FBL4 has managed to develop about 20 own brands of wines and spirits. These brands are manufactured from locally available fruits e.g. grape wine made from grapes, pineapple wine from pineapples and passion wine from passion fruits.

FBL4 maintained a relatively advanced winery - the entire process of changing fresh fruit juice into wine. As observed in the firm, the wine making process proceeded in distinct stages which had been fully mastered by the staff. FBL4 enjoyed four packaging lines ${ }^{\text {list }}$ for wines and spirits. All of them were obtained from abroad and each one of them had own contributions to learning. The first tine packaged wine at compressed air (vacuum and gravitational). The second one utilised British technology for packaging whisky. The third line packages carbonated drinks (vacuum filler). The fourth one utilised Germany technology ${ }^{165}$ to package alcohol of lower strength (4.5\%) at high pressure, low temperature while pasteurising the alcohol at $60^{\circ} \mathrm{C}$ for $20-30$ minutes. The firm also enjoyed another line

tha The wines and spirit suppliers provided raining in production and testing. "They offered knowledge in product designs and technical specifications. FBL4 consulted with the suppliers to help them master new technologies.

163. The firm acknowledged that initally there was a lot of product technical support from the wines and spirit suppliers which enabled FBL4 to accumulate its own know-how. The path dependence results in accumulation of technological capability.

16at In all these lines, the processing procedure was more or less the same. All the lines started with a washerthe rechnique being soak-washing botte, a process that takes 50 minutes to complete. Othet stages included rinser, filler, sealing machines, inspection and labeler.

${ }^{165}$ It is a PLC controlled computer programmed, with filling capacity of 600,000 bottles per hour and with less than $1 \%$ defect rate. 
for filling and sealing spirits ${ }^{160}$ in the sachets acquired from Britain. This was one of the latest innovations in the firm with high filling capacity of 80 sachets $^{167}$ per minute. The sachets wete pressure fllled and skillfully sealed in such a way that they could withstand high pressure without butsting.

In addition to the packaging lines, FBL4 also had a fully-automated, PLC controlled Swedish filling machine and technology for aseptic packaging of fresh fruit juices. This machine was bought from a local subsidiary of a Swedish MNC, Tetra Pak Intemational. This could be wewed as technological spillovers from a foreign firm and the same time as a major innovation to FBL4. This was a mote sophisticated process requiring enormous personnel training. When asked to explain about the necessity of training, the production manager explained:

The firm had not operated such a processing line before. Every unit of it required thorough training of our staff. Suppliers from the MNC subsidiary in the country were involved in the training. First, training was needed in the pasteurizerisation process. Second, training was required to operate in a septic and pressurized room where packaging was done. The room is also sterilized to prevent microorganisms from entering into the septic room. Third training was also needed to cope up with the speed of the process ${ }^{16 \%}$.

The filled packets were then packed into cartons ready for dispatch using another sophisticated technique - the tray packing technique. Until 1992, packing was done manually and required many workers who would do the packing manually. The tray packing technique was fully automated and required only two attendants to control the whole packing process. This machine could automatically erect carton blanks, seals the top and after filling, seals the bottom and forms the package. This was another significant innovation in the firm, which brought a tremendous improvement in the packing process ${ }^{169}$.

The firm had another example that supported technologicall learning in the frrms from foreign technology. It had a water treatment plant, which supplied the entire firm with clean water. The machine used at the water treatment plant had a capacity to process 4,000 litres of water per hout thus utilizing about $81 \%$ of the total installed capacity while purifying water up to $99 \%$. It was a highly sophisticated computer controlled process that combined filtering technology to remove impurities with approved ion exchange technology for water softening. The machine used ultraviolet (UV) tadiations to confirm that no microorganisms were remaining in the water. The important thing to mention at this point is that the scientist

\footnotetext{
16th Ar the time of this survey, the spirit packaged had $40 \%$ alcohol content.

167 "These sachets were special, sourced from South Africa. The firm had demonstrated these sachets to local firms to find out if they could develop capability in making them. This would reduce the cost of importing such sachets from abrond.

168 The machinery thad a capacity to fill 3,600 packages per hour for the 500 and $1000 \mathrm{ml}$ packages and 4,500 packages per hour for 200 and $250 \mathrm{ml}$ packages. This translates to about 30,000 packages per day for the 500 and $1000-\mathrm{ml}$ packages.

169 There was significant improwement in efficiency from 6,000 packs per day before the machine was introduced to 32,000 per day with the new machine. This innovation has resulted in not only increased efficiency but also reduced cost due to wastage.
} 


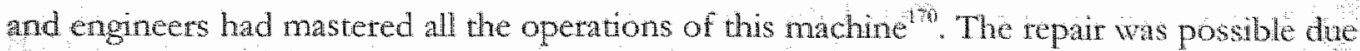
to the rigorous taining that had been provided by the German engineers during the machine and technology transfer phase that tanged from plant layout, installation to commissioning: Two of the firm's engineers had also spent a few months with the suppliers of the machinery in Germany to acquaint themselwes with machine operations.

The firm acknowledges the importance of innowation and thas maintains an R\&D department ${ }^{77}$ that was well equipped and relatively advanced by local fims' standard. According to the production manager "FBL4 believes in research and undertakes continuous research on tropical fruits for the purpose of making alcoholic bevenages". Nevertheless, as a result of in-house R\&D, the firm had acquired product technology that enabled it to manufacture its own distilled alcoholic beverages as discussed above. In the R\&D department quality control is undertaken that includes materials, product and chenical. analysis ${ }^{\text {tr2 }}$. During processing, line quality control was done regularly with the quality control staff conducting routine and random checks after every 15 minutes. The quality control unit was also supposed to release the products including those under contract packaging. The unit also follows the products in the market where further inspections and testing are done. Having developed capabilities in quality control and maintenance the firm was preparing towards achieving ISO for quality assurance ${ }^{173}$. The firm does not undertake major process innovation and thus maintains foreign technical partners for the supply of core machinery and technology. Nevertheless, the firm has acquired the necessary capability to upgrade, adapt, maintain and repair most of its machinery. Some of the simple innovations included the introduction of extemal water jackets on the fermentation tanks to regulate the internal temperature during wine fermentation ${ }^{174}$.

\subsubsection{Human Resources Development and Labour Mobility}

Under this section, we examine firm level training and labour mobility. The case studies revealed interesting cases of firm technological training and labour mobility which resulted in spillovers from FDI to locally owned firms. This supported our hypothesis in Chapter 2 and empirical findings in Chapter 5 that foreign presence stimulates spillovet occurrence through labour mobility.

\footnotetext{
170 An example was given during the intervicw where the machinery had developed a mechanical problem in its internal thow rate known as 'backwashing. The engineers in consultation with the supplicrs were able to rectify the problem without the suppliers having to travel to the firm from Germany.

1" Arhough the firm sets aside KShs 3.8 million budget for its R\&D activities, this is however not enough, as, it was far less than $0.5 \%$ of the firm's total sales.

172 Quatin control started in the field where the fruits are grown. Just to make sure that fruits are of the expected quality, they were tested for sweetness specifications, microorganisms, pests and acidity levels.

Itis was indeed confumed that FBL4 had launched the process of acquiring ISO in early 2002 and all the procedures were in place.

1\% The fackers introduced allow cold water to circulate outside the tank thus maintaining the required temperature. The heated water is then used for general purpose in the plant.
} 


\subsubsection{Human Resources Development (Firm Training)}

The four case studies revealed that all the firms offered training. All the forms of firm level training noted in the foreign firms in Chapter 6 also existed in the locally owned firms studied. As noted after liberalisation, locally owned firms were forced to embrace training more than ever before. This was due to the increased competition especially from foreigm firms as will be shown at a later section and due to the increased influx of imported goods and products. The desire to adopt quality management systems, to acquite sophisticated technology and machinery and improve on management and marketing techniques also triggered the learning processes in these firms. However, from these case studies it was notable that technological training offered by these firms was not comparable to that offered in the foreign firms. While these firms offered rather simple and less organised form of trainings, the foreign firms offered more comprehensive, well coordinated training programmes that inclucled overseas specialised training and regular participation in training exchange programmes regionally and internationally.

From the interviews done, FBL1 indicated that it has decided to embrace a continuous training process mainly in house. The firm has realized that in order to compete and keep pace with the changing product tastes and preferences, it has to engage in rigorous training of its staff. For instance, ISO 9000 series certification emphasises on dynamic changes in the firm and critical staff training in quality control management systems. It thus forces a firm to subject its staff to continuous training to drive such changes and maintain the required quality standards. Moreover, the firm's investment in new technology and machinery has necessitated immense technological training given that drivers of such machinery must have the skills to operate and maintain them. The firm has therefore established a human resources department after realising the importance of strong human capacity. The training is also done in accordance with the identified training needs and occupational levels. In a ferw cases, the training is done externally in some selected local institutions. The firm also otganises workshops for staff enrichment and invites external resource persons. In order to enhance staff motivation and make them develop right attitudes towards goal achievement and tean spirit, the firm had a remarkable programme where it engages consultancy services from international management consultants. This is meant to crystallize personal and business goals as individual staff develops self-confidence and determination in their operations. Despite the importance attached to training in this firm, it has not tapped very much into the international knowledge pool. It plans to do that by sending its employees for international training when it begins its future strategy of exporting overseas.

FBL2 claimed to have adopted a capacity building policy wheteby the firm would strictly maintain a continuous process of training to all its workers. The firm now sets a budget about $5 \%$ of its payroll for training purposes. According to the human resources manager, these trainings mainly take place in house. This mainly happens during the induction of newly recruited staff and is done by the experienced personnel or the supervisors. The firm does not have an in-house training department. External trainings were also offered but these were rare as they were only done in collaboration with other firms, institutions and business associations such as KEBS, KIRDI and KAM. It is important to highlight that due to the seriousness attached to the quality standards, the firm offers more training support to the quality control staff then to the others. Interestingly, although the firm indicated that it offered training for its staff internationally, no single example of overseas training was provided. 
FBL3 also offers technological training. In the last three years, the fim had offered training at an average cost of 5-10\% of the payroll per annum. Athough the firm offered an in-house training it also did not have a training department cteated yet. Once in a year the FBF6 trains people in the furm - this is a spillover benefit. Workets trained include production inspectors and operators, syrup manufactures and statistical process controllers. Trainings are also takem in collaboration with KEBS. On its side, FBL4 contended that since liberalisation, it was forced to adopt human capital development measures. Two reasons accounted for that: First, there was increased entry of MNCs in the sector and second the existing MNCs were increasing their effort to improve their competitiveness. For the purpose of competitiveness in wine processing, FBL4 recognizes the importance of strong human capital. To this end, the firm spends approximately $10 \%$ of its total paytoll on staff training, which is done on a continuous basis. The firm's human resource department is responsible for assessing the firm capacity needed and for organising the required trainings. Although training takes place in-house, the firm acknowledged that trainings are ats well offered externally in the local institutions such as the polytechnic and business associations such KEBS. According to the production matnager, the fitm offers intemational training only occasionally, for instance with the suppliers of raw materials, technology and machinery. However, compared to subsidiaries of MNCs, this firm trains less of its staff overseas. The experienced staff - particularly those who have worked for many years and have acquired experiential tacit knowledge were responsible of conducting the trainings done in-house. As an example, the production manager and his senior technical staff offer training to the less experienced technical staff and section supervisors who in-turn offer training to staff below them. The production manager was highly experienced after having worked in the firm for over 23 years. He was one of the lucky ones to have received extensive training in alcohol production from abroad - many countries in Europe. The trained technical staff and supervisots were also responsible for inducting and training new staff when they joined the production unit of the firm. The trainings offered included production management, machine operations, problem solving (how to handle trouble shootings), repairs and maintenance procedures etc.

\subsubsection{Labour Mobility}

As noted in Chapter 6 , furms hardly documented information on labour mobility. Since the firms wete reluctant to trace employees' background, it was impossible to know from the human tesources and/or personnel records where the staff had joined from or where they went to after leaving their employment. We therefore relied on human resources and/or personnel managers. We also telied on other staff, such as the production manager and more so on long serving employees to reveal to us any cases they were aware of, of professionals, skilled workers and experienced technicians who had joined the firm and where they had come from. We paid particular attention to the importance of skills of the identified employees to the firm. To some of the firms, this information was obtained informally by interviewing the marketers and sales representatives during intemational agticultural and trade fairs annually held in Natrobi and Mombasa. We also endeavouted to find out about those who had also left these firms.

On the side of employment, the firms contended that lack of skilled workers (qualified engineers and technicians) was not severe in the country. As they contended, Kenya has a pool of qualified and experienced workers, engineers and scientists, and it does not require 
much effort to get a replacement for a skilled worket at any time. It was interesting to note that the firms had a strong policy tegarding its employment of fresh graduates. The fims preferred employing fresh skilled graduates from polytechnics/wocational institutions as opposed to the universities. They were preferted because the former had more practical experience, which is not mainly the case with the later where theit concentration seems to have been on the theories. Furthermore the university graduates took long to be inducted not withstanding the fact that the graduates demanded higher wages and salaries which were not commensurate with their output performance.

As expected, the firms had lost some of their staff in the past and at the same time absorbed staff from other fims. As will be shown in a moment, fims had received professional and engineers from foreign firms. FBL1 had received qualified workers - scientists and engineers; technicians, craftsmen and artisans - from local and subsidiaries of MNCs operating in the country. Examples of some major companies and subsidiaries of MNC from which FBL1 had employed workers from included FBF5 and FBF2. From the interwiews, it was confirmed that while some of the incoming employees assisted in the developtment of new products or improvement of existing products to market needs; others assisted in the processing activities, quality control, upgrading machinery and equipment stretching to save energy, cost and raise productivity. All these represented various foms of spillovers which supported our findings in Chapter 5 and 6 . Examples of professionals, scientists and other strilled workers were multiple. They included a chemical engineer who was behind soap making in one of the local subsidiary of a European based MNC. Another professional was a food science technologist, a former employee of another MNC subsidiary, which manufactures margarine for domestic and regional market. Other professionals employed brought in theit experiences and tacit knowledge accuired while working in subsidiaries of MNCs that manufacture cooking fat, edible oil and toillet soaps. Professionals from abroad brought in their skills in plant lay out, setting up of the technology and equipment and making initial processing demonstrations to the local FBL1 staff.

FBL2 also received professionals and skilled workers from both local and foreign firms such as FBF6. The firm indicated that employees from foreign firms had played significant role in the introduction of certain technological changes and trainings to the firm. "To begin with, FBL2 received professionals and expatriates from overseas firms (e.g. Germany) who would work in FBL2 for some time ranging from several weeks to a few months. During their stay they would train FBL2's staft in production activities, thus contributing to the firm's production capability ditectly. At the time of doing this survey, a professional had just joined FBL2 from a MNC subsidiary - FBF6. As discussed in Chapter 6, this was the biggest of all the franchise firms of an American based MNC in the country and was a leading prayer in soft drinks industry controlling over $90 \%$ of the local market. Before joining FBL2, the professional was initially a sales representative in FBF6. After joining FBL2, he was promoted and given the full responsibilities of a marketing manager. But what skils did be bring to FBL2? While working as a sales representative with FBF6 he had undergone several trainings both locally and internationally. Major trainings included marketing, market logistics and gathering marker intelligence. He had also obtained some multi skilling since FBF6 had started offering a multi skilling kind of training where an individual obtained an all round training ranging from processing, management to marketing. As he explained: 
The most important thing I can emphasise here is that the raining I underwert while in FBF6 pertained to soft drink marketing. It also involved gathering market intelligence, which provides extremely imporant feed back for the production purposes. As you perhaps know, effective interface is necessary for immediate feedback, on what changes are taking place in the local and foreign market and to be alole to translate it on time to opportunities for the company.

We therefore note that, as an experienced sales representative from a MNC subsidiary, he joined FBL2 with a wealth of experience, skills and knowledge, which enabled him to introduce wide-tanging changes in the marketing operations of FBL2. This supported our spillover occurrence proposition as a result of labour mobility. The manager was in the process of designing a new marketing strategy, which was to be launched soon. This was easy since the furm had also accumulated some capability in the areat through its own inhouse technological effort. The firms also had the required human capial - highly stilled and qualified staff. According to the manager, the marketing strategy would include trainings in marketing, innovative approaches to mobilise workers, schemes to motivate them and so on.

As expected, these firms have also lost some of their employees in the past to other firms. Examples provided where several employees (a few engineers and many technicians) had left FBL1 to join other local firms or to start their own businesses. This implied that in addition to its production purpose, FBL1 serwed as a breeding ground for local entrepreneurs. "The firm contended that due to the training offered, the wotkers who left had acquired experience, which they definitely shared with the other firms, which they joined. No single case was cited of FBL1 having lost any of its worlsers to a foreign firm. On its side, FBL2 had lost some managers and ptofessionals, engineers and technicians in the past to the competing frims - local and foreign owned firms. FBL3 lost its employees to many other firms especially those dealing with fast moving consumer goods. The firm claimed that the employees were offered competitive salary especially by the foreign firms. This would be expected since foreign firms have the tesources to spread over higher salaries. Similarly and as noted in the preceding chapter they utilize sophisticated technologies, thus efficient with high productivity, profit from which they are then able to pay higher wages and salaries. Loss of staff in FBL4 was reported to be are phenomenon apart from those proceeding for rerirement. With regard to workers retirement, an example was provided where a former managing director had opened a wines and spirits shop and was now retailing FBL4 products. This example shows that local firms as well serve as breeding ground for local entrepreneurs by a way of providing entrepreneurial skills.

\subsubsection{Linkage Effects}

As in Chapter 6 we mapped out significant pecuniary and non-pecuniaty (technological) linkages fomed by each of the case study firms. We also investigated firm interactions with institutions and business associations. We found interesting cases of technological spillovers. In general, firms maintained backward linkages with suppliers of raw matrials, serwices, machinery and equipment. Suppliers of raw materials included manufacturing firms and agro-industy while services included banking or financing institutions. Utility comprised suppliers of energy components mainly petroleum products, gas and electricity. Forward 
linkages were maintained with distributors, sales representarives, supermarkets and hotels. Forward linkages also included transport and communication. In cases where raw materials required were not available locally, international linkages were maintained for the supply. Fot instance, FBL4 maintained a link with USA and Spain suppliers of wooden barrels used for edging wine. This constitutes spillowers in a way in that they are then sold at lower cost to the domestic brew manufacturers mainly in the informal sector. FBL1 maintained international linkages with suppliers of raw materials needed in edible oil manufacture; countries soutced from included Malaysia, Indonesia, USA and Argentina.

Since all the linkages cannot be considered elaborately, we will present onily interesting cases of backward and forward linkages, which resulted in technological spillovers occurrence to the case study and other connected firms. We begin with international linkages maintained by the firms. FBL4 maintains strong international links with its suppliers of raw materials in this case whes and spirits. As elaborated earlier, the firm imports wines and spirits in bulk from Furope, reptocesses it and packages it for the domestic market. As an example, brandy was imported from Spain and Italy in highly concentrated form and then reprocessed to reduce its alcohol content to be in line with local standards and specifications ${ }^{175}$. Reprocessing is done with technical support from suppliets who must examine the wine product before it is dispatched to the local and regional market. The international technical linkage was extremely important when new brands are to be introduced. In complex cases an expatriate visits the firm to offer technical support while in manageable cases samples are sent to the suppliers for testing through couriet services (e.g. DHI) and after 3-4 days they get feedback by fax or e-mail. FBL4 contended that the process of importing, processing and interacting internationally with suppliers presented unique and significant leaming spillowers, which resulted in accumulation of tremendous processing capability in the firm which enabled the firm to innovate as explained eatlier.

Since most of the processing and packaging machines were sourced from abroad, FBLA maintains international links with suppliers of its machinery and technology. All the suppliers have equally been a major source of technological learning spillovers to the firm. Technical support arises in multiple ways. the first one explained is during the initial setting of the production machinery. Firm engineers, technicians including some of the managers were involved in all the installation until commissioning phases. Second, whenever thete are technical problems technical expatriates from the suppliers are usually consulted. Third, most of the machinery and equipment purchased have after sales services, which include suppliers" engineers visiting FBL4 for inspection checks. Fowth, the suppliers are sometimes involved when major adaptations have to be done. By participating in these technical activities with engineers from technology and machine suppliers, FBL4 has incrementally strengthened its production capabilities (production management and engineering, repair and maintenance of capital equipment and quality control) in wines and spirit processing and packaging.

FBL2 maintained many international linkages with MNC firms in countries such as: Switzerland, South Africa, China, Italy and Germany. As explained above, the international linkages were maintained for technical support; either supply of production process or support in ptoduct development including soft drink, juice and mineral water flavours.

${ }^{175}$ This is done following the guidelines provided by the Kenya Bureau of Standards (KFBS). 
These could be interpteted as spillovers which enabled the fim to innovate, grow and expand.

"Tuming now to backward Linkages, a few backward linkages are woth articulating which resulted in substantial technological spillovers. The first one is the technical linkage maintained berween FBL1 and FBF2 - this was a European MNC discussed in Chapter 6. The MNC sold its edible oil and cooking fat brands to FBL1. Although the linkage was maintained for only a short time, the MNC offered substantial technical support in product and process technology to FBL1. This could be interpreted as technological spillovers in process and product technology as FBL1 did not have to engage in substantial searcli effort or heavy R\&D investment for process or product development. This is supported by our finding for the computed spillover index (3.5) with regard to linkages (Table 7.1). The technical support entailed setting the entre plant lay out, setting the plant and training the engineers and technical staff at FBL1 in machine and production operation. The MNC was also supposed to offer technical support in product technology as well. These was done by training the staff in the formulation of the edible oil and cooking fat ranging from the required raw materials, source of the raw materials, mixing to obtain the right chemical formulation and quality control etc. An extra benefit to FBL1 included the supplier and distribution networks inherited. FBL1 has now acquired enormous production capability and has been able to expand the plant by modifying to cope up with the incteased demand of the products. The firm has become more innovative and has even opened new branches in Iast Africa. This example supported our argument that technological spillovers can result in learning, capability building and thus innovation and improved performance.

The next case we present involves FBL3 ${ }^{176}$. This firm maintains backward linkages with many foreign firms such as MCEF1 and local firm such as MCEL1 who supplied metal crowns. However, instead of discussing MNC linkage, we will discuss a linkage with locally owned firms and show how spillower effects trickled down to the locally owned firms through FBL3. FBL3 has long-term relationship with local manufacturers and suppliers of bottles and plastic cases. This linkage was very interesting to us due to existing indirect learning spillovers. Recall that FBL3 is a franchise of one of the global giants in soft drinks manufacture who are the brand suppliers - who also offer advice on production technology, management, marketing etc. The implication of this is that suppliers to this firm must therefore comply with the high standards observed by the global giant. Thus bottles and plastic cases obtained from these firms must be made to specifications as guided by the brand suppliers. We sought to understand whether any learning took place as a result of this relationship. As explained by the production manager:

... At one time the firm had a problem with the plastic cases supplied to us by a locally owned firm. The cases supplied were not meeting the expected standards, in accordance with our brand suppliers. The audit done by engineers from our techrical deparment indicated that the supplying fim needed to improve its production capability in order to continue supplying the plastic cases for our use. The new requirements and specifications were discussed jointly. New conditions were put in place that if the locally owned fim failed to meet the specifications and standard required, a new supplier would be approached.

\footnotetext{
176 "This is one of the few cases that had high levels of spillovers through linkage as indicated by a spillower index of 4.0 (see Table 7.2).
} 
Bnginers and technicians at the locally owned firm at stake put in a lot of effort, time, making many trials until they were finally able to meet the specified quality standards. Surprisingly, the locally owned firm came up with plastic cases that lasted much longer than the carlicr ones they suppe suppling to us. In actakl fact, one of the tough conditions specified; included a five-year guarantee, time for which the plastic cases should withstand damage. Another challenge posed on them, an innovation, was to try and append traceability codes, including the dates of manufacture and batch numbers on the plastic cases.

The above example shows how learning spillovers indirectly spills over to other locally owned firms - sometimes in other branches of manufacturing. This supports the argument mainly fotnded in the NICs that with conscious effort and entrepreneur spirit from the side of the firms, spillowers can reach a wider network of firms [Fransman, 1985; Amsden, (1989: 1994); Lall, 1996; Kim, (1988: 1997)]. The second and related example involves supply of bottles for solt drinks. The bottles were obtained from both foreign firms in the country as well as from locally owned firms. More than one source of supply was preferred for two reasons. The first one was the need to diversify while the second one was the fact that some firms manufactured only colourless, or one type of bortles. Since most of the product brands are coloured e.g sprite then the firm has to look for coloured bottles from different firms. The important point to note here is that tough requirements and specifications must be maintained and follows those of the brand suppliers. The local suppliers must be techrically? and financially stable to be in a position to supply bottles in bulk since FBL3 usually purchases once or twice in a year. When we tried to probe further how simple things like botrle manufacture could result in learning and raining in locally owned firms, the quality control manager explained as follows:

The process is much complex that you can figure out. For instance, there has been a change in the shape, weight and design of some of the soft dtinks bottles. The old bottles had serious wearing out problem, which we refer to as "scarfing". To get round this, the brand suppliers decided to come up with a new design and with reduced weight. They wanted the weight reduced by 20 grams. The new kind of bottle was referred to as lightweight. The new bottle would indicate design, year of manufacture, manufacturer and the mode (so that it becomes easier to detect the problem with a particular mode). The process of introducing this change involves regional office, general managers, general sales and marketing managers among others. Then the agreed specifications are discussed with the manfacturers to determine the possibility of translating that into real bottles. So you can then see the learning challenge in it and due to the capabilities developed gradually by our local suppliers they are able to switch and supply us within a reasonable period of time. Each change that comes leaves them much better in tems of skills and experience acquired.

There were also interesting examples in machine and engineering industry identifed. FBLA claimed that it maintained strong backward linkages with many firms in machine and engineering industry. As an example, a local machine and engineering firm located in the industrial atea supplies FBL4 with wine fermentation and storage tanls. The required tanks are special in that they; (1) must have a capacity to hold $1 / 2$ a million litres, (2) must be of high quality made from stainless steel to avoid cortosion and (3) must regulate the temperature internally. Again these specifications were in accordance with those of the MNCs supplying wines and spirits to FBL4. Through this linkage the supplying firm has bult the necessary technological capability and has become one of the sole suppliers of steel drums in the industry. It was established that the learning opportunity created by this link enabled the firm 
to acquire the necessary production capability to make and supply such tanks to other firms including new entrants in the food processing and beverages industry. As a result of this capability, FBL4 placed more tank orders and has now been able to increase its fermenting tanks from 4 inherited from the previous MNC firm to over 30 tanks including storage tanks. This example further shows that it is possible for a local firm to stimulate learning (spillovers of leaming) in another local firm leading to technology capability accumulation.

We also discovered that some of the case study firms maintained backward linkages with the agro-industry. In the first case, FBLI maintained linkages with farmers who supplied sunflower, soya beans and comflower needed for its edible ol manufacture. It was noted that when FBL1 bought the foreign firm subsidiary that operated in Kenya, it benefited tremendous technological spillovers ${ }^{177}$. This had a trickle down effect not only in the manufacturing industry but to the agro-based industry as well in that new opportunities were opened for the farmers who would enjoy the market created from FBL1's increased demand for agricultural raw material. This can be viewed as an indirect spillover benefit from FBH2 through FBL1. In addition there was technology transfer from FBL1 to the farmers. FBL1 uses field managers, as extension service mangers to deal with out-growers, to discuss and plan harvest strategies and input processes. The firm has published booklets and manuals on agronomical practices, which are availed to the farmers. FBLI also triggers the farmers to adopt the best farming practices by paying more for high quality products.

The second case arose as a result of FBL4 effort to source all the taw materials required in making its own brands of wines and spirits locally. Recall FBL4 as a firm that inherited a production process in the early years from a foreign firm and as a firm that benefited immense technical support from international suppliers of wine and spirit products, all amounting to spillovers. The paw paws used in the manufacture of papaya-wine are obtained from a local irrigation scheme (Perkerra Irrigation Scheme in Marigat). FBL4 maintains relationship with private farmers in the irrigation scheme for a continuous supply of fresh farm paww-paw. The grapes used in grape-wine manufacture are obtained from FBL4's own vineyard located in the country (Yatta Plateau in Machakos District). The vineyard is managed by FBL4. FBL4 uses staff trained both locally and overseas to advice and supervise fruit farmers in the fields. The firm engages the services of professional grape growers. It also engages the services of winemaking consultants. All these ensure that firuits from the fields to the end products are of high standards. Studies have shown that making good wine and sherry depends on growing of good quality fruits and having the necessary tacit knowledge to produce good product from it (Mytellka and Goertzen, 2004). Pineapples and passion juices are obtained from FBF5 who are among the leading manufacturers of fruit juices. As indicated earlier, interactions with FBF5 have resulted in leaming spillovers in FBL4 thus concributing to production capability.

\footnotetext{
Th This examplle shows that presence of MNCs in a host country can lead to an extended or indirect spillover benefits. After buying the edible oil branch of MNCs, FBL1 acquired product and processing capability required in manufacturing edible oil. As a result of $\mathrm{FBL} 1$ 's expansion there were more backward linkages created mainly in the agriculrure sector. These linkages were created with the farmers who would grow and supply the required inputs needed in the processing of soya beans, comflower ot sunflower. The interesting thing is that FBL1 now supports farmers by offering extension services.
} 
We now tum to forward linkages formed. It was noted above that, firms maintained forward linkages for the purpose of matketing their products. Hence, they maintain many distributional channels depending on location, product preferences, resources and capital available. Some firms support distributors e.g. to become a supplier of FBL2 products, they only asked for minimum purchase quantities and enough capital to startup the distribution. In doing so, they promote local entrepreneurship. In this section we again concentrate on those forward linkages, which had spillovers effects.

FBL4 had an interesting forward linkage. Due to enormous production capability accumulated and excess packaging capacity in juice processing and packaging, FBL4 has created forward linkages with several firms to do 'contract packaging'. Two of such linkages, which presented learning spillowers, were identified during our interviews. The first and the biggest contract packaging was done for $\mathbf{F B F} 5^{178}$, which was processing fruit juices but did not have enough capacity to package it. FBF5 therefore relied on FBL4 to do contract packaging for them. FBF5 positions a few of its staff at FBL4 who coordinate and supervise the packaging process. They included staff with tacit knowledge and skills in quality control, septic packaging and marketing. The juice from FBF5 was taken to FBL4 in concentrated form - once seeds are temoved from the fruits, juice is squeezed out and excess water evaporated leaving only the concentrated syrup, which includes only sugar and aroma $^{179}$ concentrated up to about 60 bricks. The process of contract packaging involved reconstituting the water up to a level of 12-13 bricks before packaging the juice-this is in line with local specification set by Kenya Bureau of Standards. FBL4 benefited training and learning by interacting with the staff from FBF5. FBF5 was ISO certified and was therefore very strict on quality control. By adhering to such strict standards, FBL4 continued to accumulate quality control capability - production capability. The second contract packaging was done for a pharmaceutical company, which was a subsidiary of a European MNC operating in Kenya. The MNC subsidiary wanted FBL4 to package certain kind of medicine for it. To win this contract, FBL4 had to be audited by this MNC for a number of things that included a careful verification of its general capacity. The MNC was very strict in its audit and more so in quality control given that it was dealing with manufacture of pharmaceuticals. FBL4 had to comply with the specified quality and hygiene standards set. The MNC regularly visits FBL4 for auditing purposes; collects samples and swaps for onward testing and in-depth analysis in their laboratory. By and large, FBL4 has benefits from the advice provided by this MNC, which have often served as a new source of knowledge to FBL4. Technical effort to maintain high standards stimulated learning processes and thus improved mastery of specific procedures.

Another useful forward linkage is with the buyers of FBL4 products, which include supermarkets, retaill shops and pubs, hotels and lodges. From all these linkages FBLA has benefited knowledge feedback, which has enabled it to maintain a continuous improvement of its products. However, a strategic marketing linkage established by FBL4 with Distell - a MNC led to introduction of new skills in logistics and marketing. This linkage was noted to have offered the most learning to the FBL4. The kind of learning got from this firm

\footnotetext{
17 FBF5 was discussed in Chapter 6. It is one of the most successful large scale agro-processing subsidiary of an American MNC operating in Kenya.

179 One of the advantages of concentrating the fruit juices is that it occupies little space thus economical in tems of storage space and also cheaper to transport and export.
} 
includes marketing, logistics, gathering market intelligence etc. Since this linkage was established as a result of competition pressure, we will discuss it extensively at a later stage undet competition.

Interactions among food and beverages with institutions and business associations were also noted to be important for spillover occurrence (see institutions interviewed in Table 7.1). Hence as in Chapter 6, we attempted to find out whether firms did interact and if so whether there were any spillover benefits. Interestingly, all firms studied (FBL1, FBL2, FBL3 and FBL4) were members of Federation of Kenyan Employees (KAM) and Kenya Association of Manufacturers (KAM). All firms contended that membership to KAM was beneficial in that they interacted with other firms (local and foreign firms) and obtained information, ideas; generally learning spillovers. The firms also interact with KFBS and Kenya Industrial Research Institute (KTRDI). According to the firms, both institutes offered assistance during product developments. "The levels of satisfaction to the services offered differed from firm to firm. In addition, KEBS regularly audits quality control and offets recommendations. KIRDI calibrates the equipment used by the firms. FBL2 and FBL4 consult with KIPI in the area of inteliectual property rights. FBL1, FBL2 and FBL4 send their staff to participate in trainings offered by KEBS and SGS or KIRDI for instance on production management (quality control), ISO standard requirements and management procedures. FBL1, FBL2 and FBL4 participated in competitions organised by Kenya Institute of Management (KIM) to determine firms depicting high levels of innovativeness and good conporate governance. All firms allow student from local universities and polytechnics to have industrial atrachment in their plants (collaborative industrial internship programme). This supported one fact that locally owned firms participate in country's effort towards human capital development. FBL3 recruited some of the best students at the time of internship. At the firm level, firms allso interacted with other firms. As this explanation indicates ... we were the prowers in $I T$ appliations. Many CEOs from other manufacturing fons wisits our company to aquaint themselwes with the worling of the IT in the firm before they go to establish theirs. Interestingly, also some of the case study firms maintained international membetships depicting international interactions. FBL2 has a membership with international associations, which increases its interactions at an international level to take place. It is an international affiliate member of the National Soft Drink Association (NSDA) located in Washington DC, USA. NSDA keeps its members in formed on all the latest developments in the soft drink industry. We sum this in the spirit of FBL1's observation that interactions and close monitoting by the regulatory bodies forced firms party to leam and develop the necessary capabilities in manufacturing theit products.

\subsubsection{Competition Effects}

In the preceding section, we have examined linkages generated and how they resulted in spillowers. In this section, we examine whether the intensity of competition pressure exerted by foreign firms stimulated learning in locally owned firms using the case study firms considered. "To begin with, all case study firms studied faced stiff competition from imports into the country mainly from COMESA and SADAC countries such as Egypt and South Africa respectively. Incidentally, the case study firms were drawn in sectors with fictrce competition between foreign and locally owned firms. "The competition pressure was found to have triggered leaming processes and technological changes in locally owned firms. 
Interestingly, locally owned firms were noted to have learnt and accumulated technological capability as a result of this competition. This supported the argument by Caves (1974), Das (1987) and Wang and Blomstrom (1992) that competition pressure from foreign firms stimulates learning and capability building in domestic firms. We present a few exciting exampless which emerged cluring our case studies.

When we asked a representative from FBL1 at an international agricultural show about competition effect to her firm, this is what she had to say:

We face moderate competition from imported goods. However since establishment, our fitm has faced stiff competition from the MNCs who had dominated the fast moving consumer goods industry which included cooking fats, edible oil and soap products. Out entry into this line of production and market required an innovative mind. An existing window of oppottunity in the industry prompted our firm's establishment. The prices charged by the MNCs for their products were high for the medium and low-income earners. Incidentally, this was happening in the 1990 s when the Kenyan economic growth continued to decline. We had to capitalise very quickly on this advantage. Upon entry, the competition became stiffer. These were the early years of structural adjustments; liberalisation etc and guess you recall how things were. On onu side, we marketed aggressively targeting medium and low-income consumers. The marketing included out-door promotions, radio and television advertisements with strong recommendation of high quality and cheaper priced cooking fats, cooking oil, washing soap and detergents.

As explained, the competition in the industry became intensive and rivalness heightened. Firms imitated each other's tricks in marketing and aclvertising. 'This is discussed in detail at a later section. Although FBL1 strategy was similar to that of MNCs, it seemed to win as it acquired a substantial market of its products. The MNCs were losing their grip on the domestic market and FBL1's products seemed to be preferred by the consumers. FBL1 therefore capitalised on this and manufactured relatively cheap brands without compromising on their quality. Finance from IDB and existing human capital backed by a few foreign expatriates supported their growth. Another innovation introduced was that of product differentiation. FBL1 introduced a wide range of product sizes ranging from "foo granzmes" to "7 kilogrammes". Due to the product differentiation more consumers would afford their products. There was a great transformation in the industry since FBL1 could now provide quality products at affordable prices. Cost advantages were achieved by diverting from expensive can packaging to plastic containets and sachets. This innovation has now been adopted widely in the manufacturing industry ${ }^{18 i}$. So, the source of FBLI's comperitive strength is price. The computed spillover index (3.6) based on competition for this firm supported very high spillover occurrence (see Table 7.2).

This thas enabled the company to grow and expand both in the country and regionally. As at result of maintained competition by this firm and a few other locally owned firms, some of the MNCs in the country were forced to re-organise resulting in the stoppage of some of the product manufacture. We noted earlier, a case where FBL1 bought process and products from FBF2. Acquisition of various products and processing techniques including their market segment from these MNCs seems to have pushed further the growth of FBL1. This

\footnotetext{
${ }^{180}$ This innovation has been adopted despite its adverse enwironmental impact because of inadequare recycling capacity in Kenya.
} 
represented spillower benefits from FDI. As a result, BBL1 has how made investment in Tanzana through which they will also capture and exploit the busmess opportunties including tax-free advantages offered under the $\mathrm{SADC}$ of which Tanzania is a membet. Similarly by investing in Uganda, FBL1 aims to capture the emerging markets such as Rwanda, Burundi, Democratic Republic of Congo (DRC) and even Southem Sudan.

FBL1 success story does not end there, as thete wete more innovations to come. It has developed and adopted a unique proactive distribution network, where channel parners have been appointed to operate exclusively within a dedicated geographical area and hubs created and distributors are appointed to achieve distribution depth. All activities of the channel partners have also been integrated with the frm's Network via satellite-based VSAT and Intemet links and developed transport systems to deliver directly to habs, distributors and sub-distributors. The firm was among the first in Kenya's manufacturing to have V-sat. Operations of all the firms are based on integrated software known as Enterprise Resource Planning System (ERPS) ${ }^{181}$. ERPS is linked to the company's main plant via VSAT and any information that is required can be obtained on a teal time status.

"The second case study firm, FBL2, also indicated that its main competitors were foreign fums - its computed spillover index was also very high at 4.6. The fitm contended that the soft drinks sector in which they operated had the toughest competition having been the domain of the global giants, which in w way had operated as monopoly for many years controlling over $95 \%$ of the soft drink market. When asked how the presence of the FDI in their industry affected them, this is what they had to say:

As a result of competition in the soft drinks industry, we have endeavoured to: introduce new flavouts for out soft drinks and fruit juices; introduce new concentrates adding up to the popular ready-to-cirink product line; introduce new marketing plans; use of whollesale containers; use promotion teams rigorously whereby promotions would include winning some presents with the firm's logo like caps, pens, free drinks etc; launch a new pushcart project placing pushcarts selling the fum's products which help in job creation as well; encourage discounts for retailers and finally, look for altemative financing ways.

The above shows that competition pressure forced FBL2 to introduce many technological changes. We can argue that due to the increased competirion in the soft drinks industry, FBL2 has become mote innovative. In addition to introducing new plant machinery, the firm plans to increase and diversify its products. We present an exciting example presented to us of how the firm took advantage of the prevalling terforism activities in the world. Following the existing antagonism between the Muslims and Americans, the consumption of most American products declined significanty in the Muslim World. The argument forged being that consuming products from US MNCs such as Con Cola was sen as being supportive to the Americans, a phenomenon interpteted as providing funds to the Americats for continued war and antagonism with Muslims.

\footnotetext{
18: ERS incorporates modules on finance, purchasing, warehousing, inwentory, asset management, pricing, quallity management sales control, statistical history and human resource management such as check in time and remuneration calculator. Other modules include project management, order management, budgeting and finance management among others.
} 
As a regult of this, alternative soft drink products were being sought and developed elsewhere in the world. When a new soft drink product was launched, FBL2 decided to take the advantage of processing and bottling it in the country. The launch of this soft drink was a major product innovation primarily due to the existing competition. This product had already been launched in foreign markets in Europe such as in France, the Middle East and West African Region where it had very strong impact. The same was expected in the Kenyan market where the new product was anticipated to cause significant changes in the trends of the soft drinks industry that had been dominated by MNCs for long. In addition, to taking the advantage of the prexailing circumstances, world terrorism and conflicts, the introduction of a new product in the Kenyan market was intended to compere with the MNC soft drink brand products by curving away a portion of its market. FBF6 who are strong competitors thrives on marketing and product diversification.

FBL2 would counter react to this by making sure that the product introduced was of very high quality standard. In order to ascertain that, the company had sought product technical support from a Germany firm reputed for its high quality products and process techniques. As mentioned above the firm has bought an ultra-modern KShs 115 million bottling plant from Germany and has already been commission ${ }^{182}$. As noted above, FBL2 has also employed more technical and professionals such marketing experts. It has embarked on rigorous training, continuous and involving all category of workers. The firm also engaged other firms that are linked to them.

Interviews done indicated that their source of competitiveness was high quality and low prices. The two, especially low prices enabled the firm to contain changes occasioned by changing tastes and drop in purchasing power. In actual fact they interpreted a move by FBF6 to reduce the retail price of its $300 \mathrm{ml}$ soda brands by $25 \%$ as a reactive strategy just meant to recoup the market share FBF6 had lost to FBL2. This would not worry FBL2 as the prices are maintained low purposely to keep the firm competitive. This is one good example where an indigenous firm has struggled to survive in a very competitive environment patronized by MNCs, and has developed specific capabilities and benefited from technological spillovers from foreign firms enabling it remain competitive. To date, the firm is being considered as a major threat by other players including foreign firms in the soft drinks industry.

Interviews conducted, indicated that FBL2 lowered the price of its soda brands by $50 \%$ as a strategy to increase company's market penetration in Kenya and later in the region. This was possible following the government reduction of excise tax on soft drinks from 15 to $10 \%$ included in the budget of 2003. As a result of this price reduction the firm's market expanded to the extent that the production, supply, is unable to meet prevailing demand. This seemed to indicate some level of patriotism whereby the consumers seem to have a preference to consume high quality local products produced by an indigenous firm. The reduction in excise tax contained in the budget enabled the firm to introduce a marketing innovation; the firm organised a marketing campaign known as BOGO (Buy One Get One). This was a very successful marketing campaign, major hit with the soft drink consumers, whereby for every one bottle of soft drink that you buy you would get one for free. It was

182 It was noted elsewhere that this firm was particulatly able to putchase this machinery due to the government waiver at the time on all the taxes on imported manufacturing machinery and technology. This was based on its effort to promote industrialisation, discussions in Chapter 3 . 
also a big advantage to the distributors, since what that meant was that for every 100 crates bonght, the distributor would get 100 crates free. This would enable them eam good profit necessary for their expansion and growth. The FBL2 also eamed good proft and was able to capture a very wide market.

As a result of stiff competition faced by FBL2 particularly from MNCs, we sought to know whether it had any specific planned strategies. The corporate affairs manager explained:

... the firm intends to introduce new bottling plants, new brands, consolidate the existing brands and penetrate the wider Kenyan market and further stretch to the East African and other regional market. We have already started as we have replaced the old production machinery. The new processing machinery offers some leverage for penetration into say three more provinces. Our other strategy is necessitated by lack of capital. However, lack of local entrepreneurs' ready access to credit was hindering our expansion. The high cost of financing which adds to the already high transaction costs in the operations has equally hindered the penetration of the soft drinks market. Interest tates have remained very high and perhaps a reform in the financial sector to support mainly the local entrepreneurs would ensure that local upstarts access credit. Due to this constraint, our company was planning to issue bonds at the Nairobi Stock Exchange. As a statting point we were planning to issue a KShs 100 million bond. This would chable us to taise more money to finance our accelerated expansion into the local market. We have seen accelerated growth in our product portfolio and presence in new parts of the country. We are now planning to enter the bond market to raise more money for our expansion. The past expansion programmes have been financed through borrowing from the local banking system which has been extremely expensive. In addition, our company plans to intensify a newly planned micro-finance project through which the company gives its employees interest free loans to buy and own soft drink containers. The company has put a side a budget of about KShs 8.4 million for the purpose of privitising such containers. As an example, out of 120 containers located in Nairobi, 74 have already been sold to interested entrepteneurs to enable them start their own businesses.

This supports our atgument that as a result of competition pressure, firms introduce rechnological changes despite hardships. These changes were noted to include process, product, marketing, management and organisation etc. The results supported the theoretical arguments in Chapter 2 and empirical findings obtained in Chapter 5 where competition was observed to be among the leading mechanisms of spillover occurrence. Note that unlike FBL2, FBL3 is a franchise of a MNC giant and was thus cushioned from stiff competition pressure.

We take one mote example of competition pressure from MNCs. FBL4 faces stiff competition from imports and competing firms in the inclustry. In the entire period before 1993 when the market was still highly protected, FBL4 was monopoly in the wines and spirits industry. However, after 1993 the prevailing incentive system changed dramatically. The market was fully liberalised, and FBL4 faced stiff comperition from imports into the country and from new entrants into the industry. New entrants included subsidiaries of MNCs mainly from Europe such as Ederman, Wines of the Wotld and London Distillers. In the same period, competition was further exacerbated by the enomous re-orientation undertaken by the firms already in the industry. The existing firms such as Castle (South 
African MNC) and FBF3 in the beer industry introduced brands that targeted the middlemarker, which was the niche market for FBL4. Similarly, proliferation of the informal businesses in alcohol processing targeting the lower end of the market contributed to a further shrinkage of the existing market.

Reacting to the competition pressure, FBL4 reacts in more or less the same way as FBL2 by implementing the following measures: First, it launched a new marketing and distribution strategy. The firm increased its brand advertisement in the local media and organised intensive promotional campaigns on the ground. By 2002, FBL4 had the highest estimated marketing cost ever (including advertisement) that accounted for $7.5 \%$ of the firm's total sales. The other strategy involved formation of strategic marketing alliance with Distell Company. This was important given that FBL4's marketing skills were relatively weak. Given the importance of marketing capability in the industry, the firm acknowledged that it had no choice but to strengthen its capability in marketing by forging a strategic alliance with Distell Company. Distell Company was one of the world's leading wine manufacturers and distributors in the world with wide experience in marketing wines and spirits in North Africa. FBL4 entered into a bottling and distribution contract with Distell to support markering of FBL4's products in East African Region. As the production manager was. quoted in one of the business periodicals, "the entry of otber players in the thorative marleut segntest

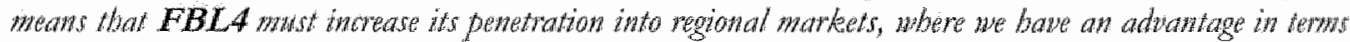
of quality and affordability". At the time of this reseatch, the process had already started in Tanzania; it was being rolled over to Uganda. Entry to Uganda was meant to be strategic, as it would serve as the springboard into the Great Lakes region of Central Africa. This example shows that competition pressure triggered FBL4 to engage in a marketing capability development path.

The second approach to deal with increased competition was through diversification of FBL4"s products. As explained ".... the firm realises that demand for wines and spirit products is bighby walatile and that markets are beterogeneons. To be compexitive, therefore, they bave to be able to serve many market segments at the same time. This is mbat everyone else is doing". For this reason, FBL4 has undertaken to improve its production capability including quality control. FBL4 was also trying to introduce cost cutting innovation measures. Third, FBL4 has also realised the importance of human capial in driving production and innovation. "This has resulted in reorganisation and intensification of training programmes. The firm has also endeavoured to improve its organisation and management structure to enhance its efficiency and reduce cost. In sum, these examples showed spillover occurtence to FBL 4 which tended to support our computed index of 4.6 .

\subsubsection{Demonstration Effects}

Investigation of demonstration effects indicated that all the local firms studied enjoyed demonstration effects from foreign firms but at varying levels. Locally owned firms were able to copy, imitate products and techniques from foreign firms. This supported our thesis that foreign presence stimulates spillovers. It further supported findings of Chapter 5 that demonstration effect was one of the strong mechanisms of spillover occurrence. We present some interesting cases of demonstration effects, which were observed to have technological spillovers. 
We start with FBL1. Growth and expansion of FBL1 has benefited significant demonstration effects (had a spillover inder of 3.6) from presence of foreign firms in the cominty. Frnt, the idea to invest in the cooking fat, edible oil and soaps industry was prompted by the MNCs such as FBF2 as they wete the pioneers in the industry. So, FBL1 did not have to do any product, process or matker seatch as whey could aready see what was in the market. Recall the soap making example which was imitated by the local firms including FBL1. Secowd, it benefited demonstration effects in product, process and maketing. In marketing, for example, the MNC companies were among the first to make use of foreign logistic companies. This served as demonstration effect to FBLI who now uses their services. Thind, FBL1 learnt the importance of advertising strategy to boost sales and marketing from the MNCs. The firm contended that their advertising strategy closely imitated the path followed by FBF2 in its eternal search for medium income eaners. The frm has therefore adopted strong re-launching campaigns of its products. The idea of nelaunching old products is to create new awareness in the consumers mind and to extend the market to the region where the MNCs were already dominant. 'The MNCs started in the country and then formed branches in the Fast African region. Locally owned firms also leant the importance of offering training to become innovative and competitive. Other things learnt from MNCs include need to improxe quality standards to match international standards - becoming ISO 9002 certified. FBL1 has also served demonstration effect to other firms who intend to start computer network and also use of plastic packaging.

Next we discuss FBL2, which benefited tremendous demonstration effects from foreign competing firms. Its first case was the demonstration of the South African alcoholic drink by a foreign firm. FBL2 manufactured the alcohol drink initially which provided a base for their: take off. The second example of a demonstration effect was indirect where the company bought a brand from one of the local firms. "The brand had initially been obtained from a foreign firm. This brand was then developed even though the development was done with the technical assistance of a Germany based company. So in the initial stages, the locally owned firm demonstrated to the FBL2 how to produce these products. "They benefited training on processing and product processing demonstrations. To date the company is able to produce its own products, flavours, compounds, ingredients and concentrates.

Another demonstration effect pertains to the organisation structure of the firm operations. The firm intends to copy MNC's model of soft drinks production whereby the firm plans to open tegional botting plants. The firm plans to open about eleven botting plants in the East African region where eight of these would operate in Kenya's main town.s. According to the firm's managing director, this is "a strategy that is styled along FBF6"s model" "Ts" "Tanzania will have two bottling plants while Uganda will have one to facilitate a further foray into the great lakes region". Although this is due to competition and desire to capture more market, it is also necessitated by the fact that transportation of carbonated soft drinks for long distances is problematic especially due to gas included, carbon dioxide which must be maintained at certain levels of pressure. So this constraint serves as driving force towats decentralization of processing, packaging and distribution of carbonated sofr drink.

[83 Financial standard Tuesday, August 26, 2003. 
Another demonstration effect is that of the plastic cases used in the packaging and transportation of sodas. FBL2 adopts FBF6's red colour and design. This is possible since colour is not patentable. Similarly, the firm uses the design of the old bottles used by MNC, which has changed its old design into a new one, noted elsewhere in this study. What this means is that FBL2 is imitated packaging material from a foreign company. This is on purpose since its likely to carry some impact in the penetration of the new product. Recall that one of its new products will be primarily marketed in the Muslims region and although a different brand it will have the same colour as that supplied by the US MNC subsidiary, marketed in similar packaging materials. The idea is to make the product not look so much different after all.

Another demonstration effect is cliversification. Most of the time in the interviews, it was reported that the firm wanted to diversify, introduce new products, introduce different lines, different business and to look for joint ventures. Similar to other firms, mainly foreign firms, FBL2 has introduced bottled water and fruit juices. It has also introduced a totally different line from processing soft drinks meant for flour milling. In addition, this has made the firm go even a head and introduce businesses as discussed above. Nevertheless, a comparison between FBL2 and FBL3 shows that the latter has substantial demonstration effect from FBF6. As a franchise of a giant MNC, it enjoyed the most demonstration effects that included process, procluct, marketing, management and organisation etc. Hence unlike FBL1, the technological spillovers in this firm are significant due to franchise aspect.

Finally, we look at FBL4, which benefited substantial demonstration from foreign fims from its onset. This is supported by the high spillover index computed of 4.6, Table 7.2. The firm was foreign owned before the Kenya government acquired it. So it benefited an initial investment plan without having to conduct any feasibility studies, R\&D or plane commissioning. As a newly acquired firm it copied/imitated most of the things that were being done by the predecessor. All these amounted to spillover benefits. Also by dealing with wines from foreign suppliers it was able to make its own brands of wine-with time this resulted in incremental accumulation of production capability. FBL4 has benefited tremendous demonstration effects from foreign firms in the country and joint ventures like FBF3. FBL4 acknowledged that FBF3 and Castle had demonstrated to them what could be done, the need to innovate and diversify and also the need to improve human capacity by offering continuous training. FBL4 has now introduced light alcoholic drink for the middle level class. FBL4 also increased its capacity to package juice and has ventured into mineral water packaging. FBL4 has had demonstration effect on marketing and distribution e.g. the importance of strong marketing campaigns, use of bill boards, media and support sporting activities like soft drink and beer MNC giants in the country. Local firms and subsidiaries of MNCs were forming partnership and FBL4 decided to forge a marketing alliance as well. It benefited a lot of demonstration effect from Distell and FBF3. FBL4 has also gone regional. Demonstration effect is from competing firms and firms that distribute its products. FBL4 also started packaging fruit juices for the domestic and regional market. Also from supplying firms e.g. FBF5. 
In this section, we provide case study illustrations of the spillover process in machine and engineering industry on the basis of the four conceptual elements outlined in section 7.2. The section begins with an explanation of how case study firms in machinery and engineering were selected. As in all the other cases, the selection was based on technological characteristics of the firms. This is explained in the immediate section below.

\subsubsection{Firm Selection and Justification: Emphasis on Production Technology, Learning and Innovation}

Case studies of locally owned firms in machine and engineering industries were selected on the basis of their production technology, learning and innovation. As indicated eatlier, production technology in a firm was noted to have a strong positive bearing for spillovers occurrence in machine and engineering firms. This was more so because production technology used alongside production activities and effort undertaken to learn and master it resulits in accumulation of technological capability. This would occur as locals accumulate tacit and experiential knowledge acquired through on-the-job training and learning by doing. The resultant would be human capital development and enhanced absorptive capacity in the firms. Hence, a strong correlation between production technology used and spillover occurrence can be said to exist. We now present individual cases that justiffed selection of the local firm.

MCEL1 was the first case study firm selected. The firm's case was interesting in that it represented a typical firm that receives technical advice and support from MNCs operating in the country (primarily in the soft drink and beer sectors). MCEL1 utilises fully foreign machinery and equipment for crown cork manufacturing and printing. Over $90 \%$ of the firm's activity is manufacturing of crown cork. It enjoys huge supplies of metal crowns to these firms (demand created by the MNCs). The source of core production machinery was United Kingdom, Itally and Germany. The average age of its core production machinery was below 10 years. Over $75 \%$ of the raw materials used in the firm were imported given that the country has no steel, Aluminium or 'Tin. With regatd to training on the basis of production technology, the firm contended that:

Our firm maintains international links with the suppliers of machinery, technology and equipment. We have international links with firms in Italy, Germany, United Kingdom and Japan. Foreign suppliers of technology have been behind the driving force towards achieving our production capability in the firm. We also get advice from the buyers of our products who are mainly foreign firms operating in the country. Interactions with machine suppliers during machine installation and after sales services have some knowledge benefits in that our staff acquires knowledge in the process. All our machine installations were accompanied by a training module meant to introduce the staff to the required machine procedures of how to use, maintain the machine etc.

Training must also be undertaken in all the other process activities. Crown cork is manufactured from electrolyte in plate or Chromium-plated steel. Most of the crown corks. must be printed, at least with the firm's logo or some advertisement as desired by the 
procuring fim. The firm therefore prints the sheets before the crown corks are made. This stage of printing the coated sheets is the most elaborate step in the production of crown conks. As explaned, the furm has acquired capabillty as pressured by existing demand. The firm lias no R\&D department but it maintains a technical/engineering section strong enough to ensure that the process was runang efficiently. "The department also undertakes repairs and maintenance of the machinery and equipment. This section was also responsible for quality control purposes. The quality control systems used in the firm include statistical process control and technical benchmarking. The firm is ISO 9002 certifned. The section makes sure that like all other raw materials, the Tin plate and Chromium-plated steel used in ctown cork making is subjected to stringent quality control. All the products are subjected to $100 \%$ final automatic inspection. All the materials used in the production of crown corks, sealing, vanishes and printing inks do not affect organoleptic characteristics of drinks.

The second firm selected was MCEL2. This was the most adranced firm in the manufacture of products like water pipes, cold-formed sections, open sections and steel door frame sections. The firm's products are widely used for water pipes, vehicle structure body, chairs, exhaust pipes, zed putlins, galvanised steel conduits and hot water cylinders etc. The firm contended that local and foreign demand has enabled it to grow. The striking thing was that foreign firms were singled out to have been the main customers from all the sectors; manufacturing, agriculture and services (mainly building and construction). MCEL2 uses different kinds of production machines. The firm's plant consists of slitting machine, open sections forming; automatic shearing line; 3 tube mills and galvanizing plant. Over time and with technological leaming effort, a few machinery and equipment have been fabricated in house.

The firm's water pipe making process had enabled the firm to leam and accumulate technological capability (see Figure 7.2). MCEL2 was among the few firms to have advanced pipe making technology enabling it to control about $45 \%$ of the pipe market in the country. MCEL2 manufactured water pipes to international standard ${ }^{184}$. The cold-formed sections are manufactured on a tube mill using a high frequency induction welding technique. The process proceeded rigorously from a steel strip. The strip is seam welded while round and gradually made to the desired section using the sizing mill. As explained, the weld seam was put to a "great amount of cold working while being sized." This was meant to lest seam welding to ensure that the entire length of the hollow section was properly welded for the required strength. The hot dip galvanising facility of the firm was allso explained to us, Figure 7.2. The firm had a large hot dip-galvanising tank $8000 \mathrm{~mm}$ long, $1600 \mathrm{~mm}$ deep

184 The process stated by feeding accurately sized steel slits into the tube mill. The steel slits are cut from high steel coils. The tube mills gradually form the steel slits into round profile with open seam along its length. Thi firm utilises a Japanese technology, a high frequency induction welding technique to form a strong continuous scam joint. Affer welding, the formed pipe is then subjected to another process referred to as external scaring and sixing, meane to bring its dimensions within specified tolerances. Pipes are cur to the requited lengths followed by straightening, end facing and thydro testing. The hydro testing is performed to ensure that welding strong enough and free from links. Once the pipe passes this test, it is the taken for galvanising after which it ts screwed and socket. The water pipes ate thteaded to BSPT specification and are fitted with a socker on one of its sides. 
and $1000 \mathrm{~mm}$ wide and can be used to galwanise articles of ap to $10 \mathrm{~m}$ long. MCEL2 is one of the few firms with a capacity to galvanise its products using hot dip galvanizing method ${ }^{165}$.

The firm has a quality assurance certification KS-06-259 \& KS-02-104. The main cuallity control system used is statistical process control. The firm ensures that strict quality control measures are observed. The products usually have to be tested to ensure confomity to the set KEBS standards or customer specifications. The firm treats quality as a continuous process commencing from the point of receiving raw materials to the end product.

Figure 7.2: The Metal Pipe Making Process in MCEL2

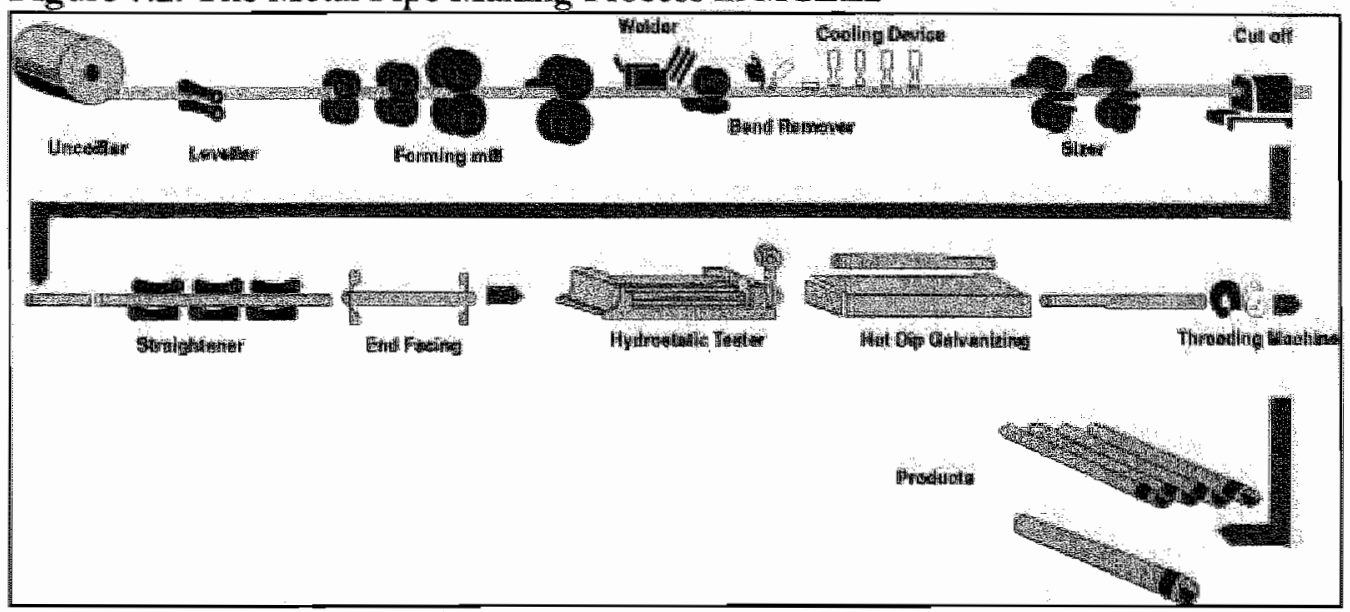

Source: Obtained from the firm's website

The third firm selected was MCEL3. This firm utilised the most sophisticated technology and machinery in its production of Aluminium cookware ${ }^{136}$. The firm commands a big market for sufurias - about 50 to $70 \%$ of the market share. In addition, the firm benefits supply orders from foteign firms. The firm also manufactures specialized orders for international agencies such as UNHCR and WFP. Through these orders, the firm has benefited tremendous demonstration effects - this is explained at a later section. The firm has the capacity to produce between 15,000 and 20,000 sufurias in a day. As shown in Figure 7.3 , production of sufurias involved several stages. The activities taking place in MCEL3 were based on old experience accumulated, strong engineering culture, attitude towards work and problem solving culture. Consequently, the wotkers are subjected to a culture of learning which had resulted in the accumulation of technological capability and absorptive capacity.

\footnotetext{
ang The galwanising method involved a chemical process that uses pure Zinc to coat the steel sutface using over $99 \%$ pure Zinc.

150 The commonly made products are the sufurias that constitute about $80 \%$ of the firm's production. They are used for cooking in almost all the households, hotels, hospitals and institurions in Kenya. In the remaining $20 \%$, manufacture of kettle takes approximately $15 \%$ while the remaining $5 \%$ is taken up by special orders.
} 
The firm had a sophisticated process which commenced with the inspection and olling of the raw materials ${ }^{187}$ - Aluminium circles. The actual process can be observed to start with the pressing of the circles to put the sufurias into shape. This process was referred to as punch \& dye. The firm used three drawing press machines ${ }^{188}$ for this purpose. It has a machining section where sufurias were trimmed using a special lathe machine ${ }^{189}$ with significant in-house fabrication. The fabrications and the trainings of the technicians and machine operators have resulted in tremendous improvement in the sufurias trimming efficiency ${ }^{190}$.

187 The inspection is to make sure that the raw materials are received as per the bathing done at the supplying firm. "This involves physical certification, visual; then the quantity and quality. The computer tesring is done at the sister company before supply is done.

188. The first one is a drawing press acquired from England. This is a very unique machine in the sense that significant adoption has been done on it. For instance this machine has been fabricated to offer protection under the Kenyan law. The second machine is slightly bigger than the first one wile the third one is the largest capable of making items of 36 inches in diameter.

16: The lathe machine is different from a nomal lathe machine with ower $70 \%$ of it being an in-house fabrication. This fabrication has been necessitated by the desire to adapt the machine to cope with the production of changing products as dictated by the dynamics in the market (changes in peoples' taste and preferences).

190 Ahough this may not qualify as major innovation, it can however be tegated as incremental innovation which turther enlanced performance. With this tabrication in place the firm was capable of trimming an average of 4,000 pieces of sufutias compared to 200 pieces before the fabrication. This is innowation took place after the production engineers undertook a study of the work method to find out how changes could be introduced. It was also necessitated by $1509000: 2000$ acquisition 


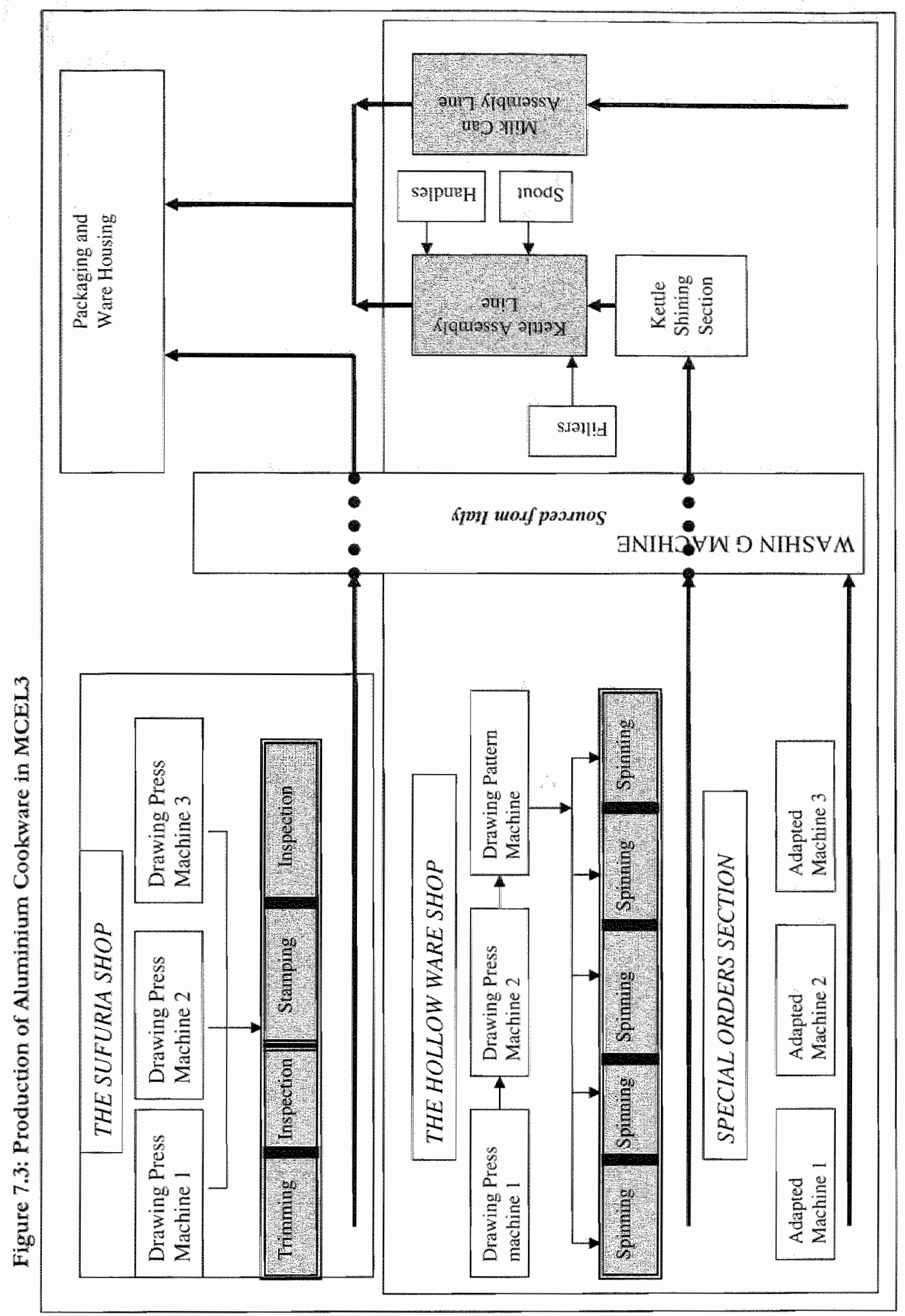


The firm also had a sophisticated kettle making process which was simular to the one used in sufuria making - the kettle making uses more or less the same technology. There were rwo press machines and one machine for putring pattens on the kettles. Each of these machines have undergone in house fabrication to make them comply with the current safety standards and to improve their efficiency. Given that different designs are required from time to time, the adaptation and fabrication, helps the firm to fir certain customers to their tastes and preferences ${ }^{\text {in? }}$. The assembly line for the kettles was equally interesting. This assenbly was an in house innovation by the works manager production manager and quality control managet who wanted improve production schedules and effiency $^{192}$, In the assembly line, ketrles were fitted with handles, spouts, filters etc ${ }^{193}$. As confided to us during the interview, the engineers have to be innovative at all times and they must learn constantly to enable introduction of changes in the working atmosphere for efficient operations. This enables the firm to change swiftly to the market needs, for instance introduction of new designs as will be shown in the demonstration effect section. All these activities are supported by the engineeting workshop. These examples suppott the fact that local firms in technically backwatd countries can also be innovative (Dahman and Westphal, 1982; Fransman, 1984; Lall, 1987; Kline and Rosenberg, 1992). The firm also had another section that dealt with fabrication of specialised orders such as big buckets, milk cans, reflectors, civil engineering and structural works see Figure 7.3 . Their discussion will be done under demonstrations effects section.

The firm does not have an R\&D unt. However, it had a strong engineeting workshop backed up by ateam of 15 technicians. The senior engineers supported technically the technicians. Recently, the general manager came with a new work schedule to where all the workers were supposed to follow a set procedure of doing things: mechanical emergency repair, stretch wrapping, table fabrication, cake dies making, washing line repair and factory roof repair. The firm introduces new products often. The products introduced were ofter new to the local as well as the regional market. In the last 5 years the firm had undertaken significant improvements on the already existing products. This was due to the changes in the tastes and preferences out there, which results in an increased competition atmosphere. The firm was ISO 9001: 2000 certified after having satisfied all the procedures. The quality control systems used by the fitm are statistical quality control and statistical process control.

The last firm selected was MCEL4. The furm utilised bighly sophisticated technology and machinery acquired from abroad. While the process technology was sourced from Japan, the product technology was licensed from USA. At the time of interview the firm was operating $100 \%$ of the total installed capacity as a result of new machine invested and increased demand of its newly launched products. The firm was operating three major plant lines. The first on was a cold rolling mill (CRM) regarded as state-of-the-art technology in Kenya at the time of its establishment in 1982. CRM was a 4-Hi teversing

\footnotetext{
191 As an example the patern of the ketules preferred by the Muslims is different from that required by the Christings.

192 "This was done in house using the accumulated capability from the engineering unic/workshop. Thete was significant change in efficiency in terms of logistics and operations. Shedding more light on this assembly innovation, the production statistics showed that where only about 2,300 kettes could be assembled by 1990 in a shit of 8 hours, after the introduction of the assembly line in 1993 the firm was in a position ro assemble oxet 4800 kettes in a similar shift of 8 hours.

193 "The spouts and handles are also made in house. The raw materials come from MCEL4. The firm has a furnace for manutacturing steel handles which was fabricated in house. Any shape of handles can be made. since the firm hat alnendy installed the necessary capability required.
} 
combination mill ${ }^{104}$ from Hitachi Japan set up in rechnical collabontion with Yodogawa Steel Works. It uses radioisotope gamma ray gauges and deviation signals to determine the strip thickness of the cold rolled stee. The cold rolled coils are futher annealed by heat application to a temperature range of $600-7000 \mathrm{C}$ in an electric bell-minealing furnace to produce deep drawing and enamelling grade materials. This is done in a protective gas environment meant to impart brightness and cleanliness to the sted strip surface. The installed CRM has a capacity to produce 100,000 tonnes of cold rolled steel for varions industrial and domestic applications. It is used in the manufacture of Calvansed, Aluminium coated, Aluminium-Zinc coated and pre-painted roofing sheets. Other common applications include automobile bodies, enamelwate, metal cans and drum manufacturing, steel tubes and pipes. Acquisition of this machinery and the technology embodied provided a lot of in-house learning, through learning by doing and interacting with suppliers who offered basic training on machine operations and sometimes maintained links for continued technical and human capital development support.

The second plant was a colour coating line established in 1989 with a processing capacity of 35,000 tones per annum to paint galvanised, Aluminium-Zinc and Aluminium coated steel. The colour coating line has an oven that cures the painted material for 30 seconds at about 240 degree centigrade to strengthen the painted surface and its bond to the base material. The plant was also a great source of learning to the firm.

The third plant was a contimuous gakanising line (CGL) established in 2000. As the firm indicated, CGL was the most advanced continuous galvanising line in Africa with stateof-the-art technology from world-renowned Kawasaki Heavy Industries from Japan. Thte plant has a capacity of producing 80,000 metric tonnes per annum of galwanised and Aluminium Zinc (Al-Zn) coated steel coils. It has a dual facility for coating both Zinc and $55 \%$ Aluminium-Zinc alloy. A major innovation introduced on this plant was the Non-Oxidising Furnace $\left(\mathrm{NOF}^{-}\right.$) technology. This innovation replaced the conventional pre-treatment process involving chemicals and was thus more environmentally friendly. The NOF uses thermal cleaning with LPG fame and a mixture of Nitrogen and Hydrogen gases for preparing the steel surface to ensure strong adherence of the coating to the strip surface. Once the steel had been treated, it was then fed into molten baths at a speed of 150 meters per minute. Another innovation introduced was the on-line X-ray coating weight gauge to ensure accuracy and unifomity of coating across the length and width of the sheet. The process ends with a tension leveller to ensure flatness of the steel before it was coiled in readiness for dispatch. 'The products of this plant were, galvanised steel coils and sheets. Traditionally, galvanising was the most cost-effective method of preventing atmospheric corrosion of steel. It was commonly done by coating the stee surface with a Zinc layer. The combination of Aluminum and Zinc $(A 1-Z n)$ offered more effective atmospheric barriers to corrosion. This innovation came about in 1972 as a result of extensive R\&D done in USA by Bethlehem Steel Corporation with the aim of developing a new type of coating that would be more effective compared to traditional gallvanising methods. MCEL4 is the sole licensee of this technology in Kenya and in Africa. The firm confirmed that investment in this plant presented an intensive and broad form of learning in the firm. It revolutionised the way things were done in tems of organisation and ptoduction management. As an example, the firm would stat exporting and thus there would be training on export marketing.

\footnotetext{
194 One small mill costed about KShs 1 million while the big mill costed about KShs 8 millon.
} 
Alhough the frm does not do in house R\&D, it however mantains rigorous unit that dents with process anc quality controll. None of MCEL4 process technology was innovated in-house as all of them were sourced and transferred from abroad. Given the sophistication of its latest technology and machinery, it has a process control unit manned by specially trained systems and sofware cngineers to make sure there was efficient ronning of the process. The firm maintains a highly equipped engineering unit that deals with maintenance and in house fabricatons. The fabrications performed were sometimes major and invalved adapting the machinery and its components to operate at a high or low capacity depending on product demand or avalability of raw materials. The team, which comprises technically experienced engineers, had introduced energy saving innowations to the old rachinery whose technology and operations they had carefully mastered. Sumilarly, they had invented an in-house waste ofl and water treament plant. The engineering unit maintains Canadian ctanes installed for lifting steel rolls in place For technical consultation, the firm maintains a technical link with the machine suppliers. With respect to quality control, MCELA is ISO $9000-2000$ certified by SGS who audits them periodically. The quality of its products is also certifed by KEBS. MCEL4 therefore adheres to local and intemational standards. Some examples of standards adhered to include KS 0602; ASTM A-366M; DIN 1623; JIS 3041; BS 1449. Special tests performed in-house include accelerated weathering inspection, salt spray test and spectrometer inspection. Steel must also undergo a series of mechanical or chemical tests depending on the intended application. Since the firm does not do any research on product development, it acknowledged that similar to process technology product technology was developed abroad. Hence, this firm relied on foreign suppliers for technological knowledge and innovation.

\subsubsection{Human Resources Development and Labour Mobility}

This section presents a discussion on training and labour mobility. Interesting cases of firm training and spillover occurrence through labour mobility wete discovered. "These results supported the theoretical atguments in Chapter 2 and empirical findings in Chapter 5 and 6 .

\subsubsection{Human Resources Development (Firm Training)}

All the firms offered training although different in scope, depth levels etc. As indicated earlier, the effects of structural adjustments and liberalisation, created intensive competition that forced locally owned firms to embrace training. Other points advanced earlier wete responsible for triggering training and learning processes in firms: quality management systems, acquisition of sophisticated technology and machinery and management and marketing techniques. From the interviews, it was observed that local firms in machine and engineering industry relied very much on in-house training. However, in a few areas like quality control training was offered outside the firm. Similarly, when a new technology was being purchased training was offered abroad. In all respects, the study revealed that learning and training offered by these firms was not comparable to that offeted in the foreign firms. When locally owned firms relied more on in-house training, learning in foreign firms was wider in scope. Comparatuely, foreign firms traning programmes seemed broader and well organised and included overseas specialised training and participation in regional and international exchange programmes.

ws "The cold rolled colls are uswally heavy and can wary between $4-8$ connes. 
All the frms interviewed in the machine and engineering industry acknowledged the importance of firm training. For instance, MCEL1, MCEL2 and MCEL4 set aside berween 5 - 10\% of their total payroll for training purposes while MCEL3 used $4 \%$ of the total payroll for training purpose. The firms offered various kinds of on job trainings to its entire staff and particularly the engineers involved in the production. All the firms main mode of training was in-house, on-the-job training and to some extent extemal training in the local universities and polytechnics. MCEL3 attached significant attention to the extent that each of the training was followed by strict supervision to ensure that the trained workers indeed assimilated the issues covered during the training. MCEL4 invites external trainers - subject matter specialists are regularly invited to offer training in-house. The trainings offered are diverse and could range from quality to process control and management or from individual atritude towards work to market labour conditions and ethics. MCEL2 in-house programme is recognised to the extent that the firm has made a special arrangement with local universities and polytechnics offering technical and engineering progtammes to bring their interns there for some time. External training in the local institutions is also offered but occasionally. Some of the employees are sent to train with $R \& D$ institutions like KMRDI, business association such as KAM and regulatory bodies such as KEBS. However, they argue that KEBS lacks adequate capacity to undertake certain aspects e.g. testing of certain equipment. As they claimed the government should offer more support.

Although training abroad was rare, we managed to trace a few. MCELA acknowledges the complexity of technology and machinery used for its operations thus reiterating the importance of providing continuous training to strengthen its human development. activities and to motivate the staff. The firm contended that strong human capacity was the driving force behind the firm's productivity and performance and thus in addition to local technical training; some personnel were sent abroad for speciallzed courses. During the time of this interwiew, three senior managers were attending an advanced course with one of the technology suppliers" abtoad. Earlier, there was another course with the suppliers of product technology. According to MCEL3, rigorous and extensive trainings are offered in-house and only in rare occasions, training in abroad was considered. However, a few months ago the production manager had been taken for training abroad, in India. This was a special programme organised and partially funded by UNIDO meant for intemational exchange of technology and ideas. This serves as a very good example where an international agency offers some assistance in identifying the course, identifying and recommending the deserving entrepreneur and goes ahead to offer substantial financial facilitation for this training to be undertaken abtoad, in lndia. The impact of continuous training in the firm has a positive and significant effect on efficiency in the Eirm's production activity. There has been an increase in productivity, increase in marketing capability, increase in in-house fabrication and introduction of new products. This will be elaborated at the relevant sections later.

\subsubsection{Labour Mobility}

As in other cases, these firms did not maintain any comprehensive database of their employees' mobility. No information was also documented for their past employment experience. We asked human resource managers, personnel managers and production managers to explain to ws where the staff had come from. Consequendy, we relied on them to explain the importance of employees skills and experience to the firms. Long serving employees proved to be quite useful as most of them provided useful. information pertaining to workers mobility and their experiences. 
Duning the firm interview with the works manager, production manager, quality controls manager and other engineers, they informed us that the firm had a high preference for graduates from local polytechnics and wocational training institutions. In this regard the firm always accorded students from polytechnics and vocational training high preference during rectuitment. This was nonetheless followed by university. "The firms do not regard the availability of skilled scientists, engineers, technicians and other professional workers as severe. Occasionally the firm has also employed workers from local firms as well as from foreign firms. The contribution of such workers is discussed below:

MCEL1 thad employed from foreign firms highly technical and experienced staff that contributed to strengthening its production capability. Some of them were experienced in mixing colours and printing. Others were managers who introduced useful changes in the organsation structure. In this case therefore the firm has benefited from knowledge spillovers associated with labour mobility from foreign firms. In MCEL3, two examples were provided. The first one included an employee who joined from a joint venture and who helped strengthen the personnel department. In the second example an employee joined the company at a higher professional management level. As claimed, he was the brain behind significant management changes touching on organisation, marketing and logistics.

On its side, MCEL4 had received a few professional workers, engineers and technicians from subsidiaties of MNC furms operating in the country. An interesting case was cited of a sitting director who was a Kenyan African and a holder of B.Sc. degree in engineering from Nairobi Unversiry. He had a wealth of experience acquired while working in Kenya and abroad in Britain as a consulting engineer. He was also a former employee of FBF2 (a subsidiary of European MNC studied in Chapter 6) for over 35 years, where he had worked as the production manager and later as the technical director. As a result of tacit and experiential knowledge acquired while working with FBF2, he was instrumental in introducing valuable changes pertaining to production and organisation management. From the angle of local firms, this example supports the argument that at least foreign firms in Kenya serve as a 'supply' source of professional expatriates to the local firms - local labour market.

Another kind of mobility witnessed introlved employees from MNC in abroad. Such employees introduced substantial technological changes and training in locally owned frrms - see Box 7.5.1 and Box 7.5.2. This is a good example of knowledge spillovers through international mobility of workers. Among the highly rated innovations cmanating from such employees were assistance in the processing activities; quality control; upgrading machinery and equipment stretching to save energy, cost and raise productivity. They also assisted in repair and maintenance of physical capital and inventory control. Significant contribution was also noted to the organisational changes that brought in better management and implementation of high production \& routine accivities enhancing firm's efficiency. This was supported by the spillover index computed for MCEL4 with regard to LM (4.2), see Table 7.2. 


\section{Technological Spillowers through Inter narioned Labour Mobility:} The Case of MCEL2

Alhough MCEL1 contended that lack of shilled workers (qualined enginecrs and technicians) was not severe in the country, it liowever, has a strong policy to employ experienced workers fron outside the country to cater for the high skills reguired for specific processing operations prinarily geared towards qualits control, cost saming: measures and enhanced productivity

This frm however puesents an excellent example of a case where a firm outsaunces: certain skills from international sources. About two jears ago, MCEL2 decided to engage the services of an expatiate engineer from linda. This engineet had a long standing experience gathered fron many yeass working wih T ITA India TATA is an Indtan company, which assembles nucks wifh teclinical support from Metcedes Benz Company limited. When he founed MCEL2, he was made the production manager. He Mitiated several najor tedhnical changes and a few minot changes. Most of them werc geared towards decreasing the eost of production and aso to increase the lite span of certann plant equipment. All these could be viewed as tedhnological spllovens to he firm This engineet was also involved in the technical hegations that involved certan technical contracts in which case the fium had been wa able to wndertake due to lack of technical expertise, A good example was with locally ow ned firn inwolved with the production of exhaust pipes and silencers.

One of the major innovations introduced in the firm ly the new production manager Involved introduction of a better cooling system capable of cooling water to below: nowmal atrospheric temperatures. When the expert engineer foined the firm, the cooling system utilised was inefficient. It consumed a lot of energy $110 \mathrm{~K}$ wh per tone of tubes: made. As the production manager explained.

. Whe technology used in welding of the hubes after the sleeted steel is folded "formed" using forming mill is known as "Higla frequency induction welding technicue". This is a Japanese technology, which heats the tube into a molten form a long whe widh at very high temperatures $13000^{\circ} \mathrm{C}$. At the hent of the high frequency welder is an oscillator tube, which ought ro be water cooled. According to the groduction manager his cooling system used a ot of energy and due to the temperatures, which were in actual sense not effectively mantained at low levels; the equipment life span was bound to detetionate. The water in the pond was extremely hot Trs Like instead of cooling lhe welder if wh being heated'. Even though the vater coming into the pond was mich lhotiter, still the water lenving the cooling pond was hot, "Tt's like the water was just being circulated instead of being cooled". According to the manager within /s to 1 hour the water would be extremely hot and by so doing, the life span of the equipment tisked great deterioration and the power consumed remained high

After taking some time to think aboul it, the production manager decided to come up with a torally different cooling systen. Unfotcunately, the cooling systems in the market were nore expensive than it would cost to huve one' fabricated in house. He therefore opted to design one in house, fabricate it using avallable equipment, skill and his enguneers. A cooling towet was nade which did not employ any significantly new technolog. It just requited simple in house innovation. By fabicating it in-house they axoided high narket cost of puichasing teady made cooling tower. After the installation 
of the newly folsneated cooling wower MCEL1 reduced its power consumption by $36 \%$ from 110 KWh to 70 KWh per tone of pipes made. Whth only that cooling tower, the equipment 1 fespan was significanty enhanced

As an example, the furm used to operate two shifts during the day and night, a total of 24 his including Saturdays and Sundays. At that time, the firm's production stood at 600 620 tones per morm there were a lot of substandard products, rejects resulting in excessive wastage and ineffictency. To improve firm's productivity, the production manager designed 4 training programme to have all the workers trained afresh. Interviews with the expert engineet revealed that he took the initiative himself to design and implement the training programme. He tool all the workers though a rigorous: traning process in production and precision techniques, inventory ard quality control, trouble shootings and logistics etc in the firm s boatdroom. In order to have frequent interactions, the production nanager also statted a new inithave where he would hold meetings with the woilkers at least once in a week to thrash out any throbling issues, get feedback and reports from various production sections, in a few months the firm was gperating only one shift with a prodiction of 500 tontes per month, At the time of this interview, the firm was processing 1,058 tones per month. This was albout $170 \%$ increment in production all done in one shift excluding Saturdays and Sundays. The training condicted plus learning by doing led io technological capability development and enhanced eficiency high production in less ine, energy saving and thus less cost:

The second example of international knowledge spillowers through mobility of workers is provided in Box 7.5.2. "This pertains to wotkers who joined MCEL4 from abroad.

\section{Box 7.5 .2}

\section{Technological Spillovers through International Labour Mobility:} The Case of MCELA

The firm realises the inportance of acquing capable team of management and staff in order to achere its production oljectives. To this effect the firm has a policy that avouts enploynent of qualifed wonkers of strict recruitment of only graduates from whirersilies and polytedhnics. 1 is axpluined below how this firm absoibs some of the excellent students who cone for industrial attrehment from academic institulions of bioller learnog

We fous on enployment of expattintes in he furm. To strengthen its in-house human capacin, the firm engages the servecs of expatinates from abrond. 1 was confinmed hat since 1981 dhe fim lad received and ethployed a substantial number of foreigi expatrates. According to the general managet, when the firm commissioned its first cold rolitg hall in 1981 there vere 12 expatiates engaged to provide an initial back up in production and to impart the staff with the skills required by offering traing on how to operate the machinery and equipment. A fren the local staff had acquired the necessary Skill and accumulated enough technologieal capabilin to operate the wachinery, the expatrates contracts would either be ternulnated or not tenewed. As a restit of this, between 1981 and 1990 the nimber of foreign expatriates reduced from 12 to only 3 Although these expattates cane fom different countries nost of them nanly on the trechnicd sile cane from linda. As explained duelng the interview, Indians had the required knowledge and expetienes, they were highly skilled and helr labour was chenp 
This example provided an nteresting case of lnowledge and learning sphovers though

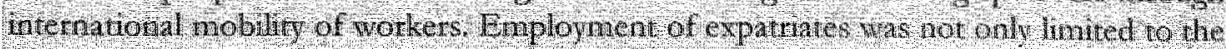

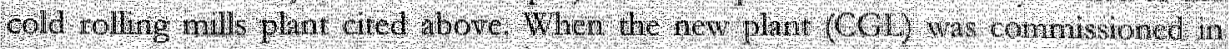
2001, about 7 foreign expatrates on the technical kide were engaged the thit comprised a highly sophisticated and integrated process that regured a horough minster by local staff in order to operate it this was the first ine the fum hat gequited san h t complex, computer numerical controlled (GNC) technolog) and had huer, The futn

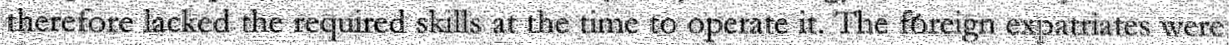

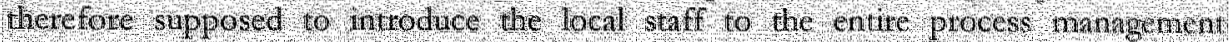

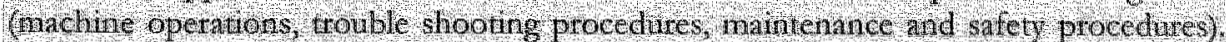

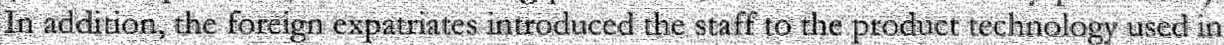
the CGI. Therefore it can be noted hat rechinolbgical spillovers perinining to process and produet technology accurred as a result of themendous trining offered by the foreign expattiates. The discussion supports he argument that spllovers of rechinglogica learning in itms could result from imported rechnology and machnery as well as from moblity of workers intemationally.

With regard to firms losing staff, all the firms contended that they had lost some of their staff in the past. MCELl claimed that employees who were engineers and technicians had left the firm to other local firms in the machine and engineering industry. Since these staff had been traned and had also acquired experience on-the-job, the receiving firms must have benefited spillovers of knowledge. Only a few people had left their jobs in MCEL3 to join other firms. MCEL2 had lost professionals, engineers and technicians to their local competitors. As noted with MNCs the locally owned firms studied had cases of wotkers who left to start own firms - commonly known as Jut kali sector in Kenya. These wotkers included those who had retired and those with intention to set their own productive facilities (to become simple entrepreneurs). "This demonstrated that firms instilled skills through experience and trainings and then sheds these skills to others directly or indirecty. In this case the firms doubled out as production units and as breeding grounds for domestic entrepreneurs within the economy. These examples further support flow of skills and knowledge from one firm to another via labour mobility.

\subsubsection{Linkage Effects}

The discussion on linkages from the angle of locally owned firms follows the same approach as in food and beverages section 7.4.3. Linkages formed by each of the case study firms with other firms were mapped out and examined. Both pecuniary and nonpecuniary linkages were identified with spillover effects. We noted that although linkages may appear small from the perspective of foreign firms, they wete often substantial in the perspective of locally owned firms and were sometimes extremely important in the growth and expansion of the firm.

Backward pecuniary linkages included telationship with fitms' suppliers of machinery and equipment, raw matretials and electricity, telephone, water and fuel consumption. They maintained links with transport and communication. Firms, which did not obtain their taw materials locally, had fewer pecuniary linkages. As an example, MCEL4 lack of 
strong pecuniary backwaud linkages with suppliers of raw materials in the country is accounted by the fact that almost $100 \%$ of the raw materials used are imported. There is no Tron Ore or Coal in the country. Thus (steel rolls) are manly imported from South Alica and Asian countries. Nonetheless the frrm has backward linkages with manufacturing, utility, construction, transpont and communication. This was the same case with MCEL1, which impotred most of its taw materials.

Foward pecuniary linkages wete formed whth manufacturing as well as with the services industry, whollesalles and supermarkets, discributors and hospitals. We focus on only forwatd pecuniary linkages established with foreign firms. Foreign firms created more demand for these firms' products in most cases mote than from locally owned firms. This demand provides finance and capital creating an opportunity for these local firms to grow and expand. This further confirms the argument that demand created by foreign firms stimulates growth, investment and expansion (Rasiah, 1995; Aitken, Haddad and Harrison, 1997; Mitken and Hatrison, 1999: UNCTAD, 2001). We invoke a few examples noted eatlier. MCEL1 supplies crown corks to one of the biggest soft dink manufacturess and beer manufacturer - both of them were MNCs in the country. Although the firm also supplies crown corks to locally owned firms, it claimed that otders from the MNCs were the most significant to the firm. MCEL3 supply of steel pipes followed a similar pattem, MCEL3 supplies MNCS and intemational Aid Agencies operating in Kenya with Aluminium cookware. MCEL4 has forward sales linkages with foreign firms in Kenya including MCEF1, MCEF3 and MCEF4. It also maintains relationship with hardware dealers and the Jta Kal sector. "The firm's exports have also grown especially after acquisition of new technology by the firm. The firm contended that demand created by foreign markets created a stimulus for its growth and expansion.

Interestingly, non-pecuniary linkages were only limited to maintenance, repairs and sale of simplified machine and engineering equipment. This tended to affect spiljover occurrence negatively in the machine and engineering industry. This is so because foreign firms relied on foreign suppliers of their core production technology, machinery and equipment. Foreign firms also maintained foreign technical links with suppliers of technology and machinery. Through these technical links they could then solve serious technical problems. However, one point is clear that local firms seemed to have acquired skills and spillovers of knowledge through the linkages formed with foreign firms and existing interactions through the existing linkages. Foreign firms often audited their local suppliens. The foreign furms offered training in the locally owned firms, in quality control, product design and production management. These resulted in technological capability accumulation and absorptive capacity in the locally owned firms. Let's now turn to nonpecuniary linkages starting with international linkages maintained.

MCEL1 also maintains international links with the suppliers of machinery, technology and equipment. The firm has international links with firms in Italy, Germany, United Kingdom and Japan. As the firm contended, the foreign suppliers of technology have been behind the driving force towards achieving production capability in the firm. Interactions with machine suppliers during machine installation and after sales services had some knowledge spillovers in that the staff acquired knowledge in the process. It was also indicated to us during this reseatch that, all the cases of machine installation were accompanied by a training module meant to introduce the staff to the required procedures of how to use the machine. 
Similarly, MCEL4 maintains strong techrical links with foreign sapoliers of technology and machinery. In this firm, the machmery and equipment were manly sourced from Japan while product technology was licensed from USA, from Bethlehem intemational who are the worldwide licensors of the technology, hnow how and patents associated with 55\% Aluminium-Zinc alloy coated sheet sted. The fim relies on this links for technical support as well as human capital dewelopment through continuous training. At intemational lexel, MCEL4 has membershp with a few Germany Companies. Other international memberships include member of Pacific Zinc Aluminum, USA Zinc Aluminium and Europe Zinc Aluminium.

We now present an interesting indirect case where a firm's backward linkages with its suppliers of machinery and equipment have had profound effect in introducing technological changes, learning and capability building in other firms. This arises often with regard to spare parts for the firm's machinery and equipment. The process begins when MCEL2 imports such spare parts from foreign firms in abroad e.g. from Japan or Britain. When they need replacement, the firm has a policy to take them first to the local manufacturets and request for their fabrication. That way the fim contended, "wo are dowloping local indwritus". Interestingly, all the fitms often approached have developed the necessary capability to supply the required spare parts. These represented spillover occurtence to a wider network since the spare parts could have been bought from outside but the firm decides to develop backward links and engage on serrices of other firms. When we asked the production managet to provide an example, this is what he had to say:

For example you have seen the steel rods, the sunds on which the mills are fitted. These stands are usually sourced from Japar. We do not want to go to Japan for these stands any more. The cost is extrenely high, logistics involved are enomous and testing skill are nor in the country ${ }^{196}$. We would want to source them locally if possible. So we approached a local company to make them for us. The local firm thas casting, workshop (fabricating unit) and foundry section. We had confidence; trust in their technological effort and were able to make the stands for us. They have now developed enough capability to make these components (steel rods). As you can see next time we will not go to Japan for the stands.

This is a good example of a case where a fim faced with a constraint, takes the initiative to make contractual arrangement with other firms producing the required items. This example was rich to us as we could note demonstration effects, interactions and skills sharing to come up with steel rods/stands, which are as good as those previouslly obtained from Japan. Informal inquities with other staff confirmed this to have been a

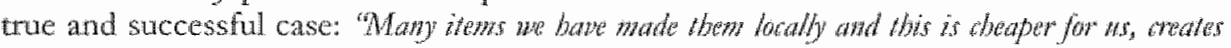
bysiness for the obsers and we store skills". This had a contagious phenomenon in that when a firm sees another local firm supplying to MCEL2, a respected firm and associated with high quality standards, they also want to procure things for them also. Because of that aspect they have got many other contractual arrangements, links, with orher frrms. In such a case MCEL2 acts as a first mover in contract artangement then followed by the others. This in irself represented a form of demonstration effect.

Next we present a few examples of forwatd linkages that had interesting incidences of spillover occurrence. The fitst example, which we provide is an indirect link in that MCEL2 enjoyed a linkage with a locally owned from which had a link with a MNC

196 This was an example of a constraint facing a fitm becoming an opportunity to another firm. 
operating in the atotomolite industry. As explained by MCEL2's production manager, the other locally owned fim enjoyed a long-terin relationship that inwolved supply of exhaust pipes to the MNC. Although the locally owned firm supplied exhaust pipes whose one of the main component was pipe, it did not manufacture pipes and had to obtain them from MCEL2. This relationship often resulted in learning spillovers due to regulat technological changes that used to be introduced by the MNC. At times, it involved deliberations between the engineers and technicians from the firms involved. The production manager explained how one particular episode resulted in learning and accumulation of capability.

\begin{abstract}
I delivered some pipes for silencers to another local firm. The local company was a main supplier of auto parts to a MNC in the automobile industry. The company claimed that the pipes were not acceptable to him. I made a visit to the company: to find out what exacdy the problem was. The pipes were of the required standard, going by KEBS specified standards. The KKEBS standards say the dimension can vary from (D1 \pm ). The company told us that according to them D1 meant D1 and without any room for plus or minus toletance. Their argument was that if the pipes wete loose they would form wrinkles and in that case they needed very smooth pipes with accurate specification. Since out customet was not KEBS we had no option than to strive to satisfy this particular customer. I went to my mill engineers and told them that mill standard for this particular customer was not KEBS standard. If told them that D1 meant D1 and striecly without any tolemance. They had problems in achieving this specification on the immediate as they were used to making pipes with extra tolerance. However, they were able to achieve the zero tolerance after intensive training and brainstorming. Once you have a set objecrive it is always easy to achieve it.
\end{abstract}

The above case suppotted spillover occurrence through indirect linkages formed in the machine and engineering industry. With the capabilicies built, this firm could take more orders from other firms with strict specifications and with minimum problem of rejects since they would be within the KEBS standard.

MCEL1 forward linkage comes rather differently. As indicated above the firm supplies crown corlks to one of the biggest soft drink mamufacturers in the country. The firm also supplies ctown corks to the largest bear manufacturing company in the countiy. This firm is also supplying crown cotks to the local firms also in the soft drinks industry. This benefits others since the firm supplies local firms as well. These links have presented a lot of learning and thus improvement in the production capability. This is the most important part where we have to explain that, this firm benefited a lot from feedback given to them from the buyers who were very strict in quality control. They were already ISO certified and thus this firm needed to comply as well. They needed to source their raw materials from ISO certified firms and had to embrace a culture of continuous changes and staff training.

We finally provide a few examples of how forward 'supply' linkages with subsidiaries of MNCs in Kenya resulted in technological and learning spillovers to MCEL4. As in some of the examples above, the learning spillovers occurred indirectly. We begin with a supplier relationship between MCEL4 and MCEF4. MCEF4 was among the major manufacturers and suppliers of steel drums in Kenya. Their customers included key subsidiaries of MNCs operating in Kenya such as Total Kenya Limited, Caltex Kenya Limited and BP/Shell Kenya Limited in the petroleum and chemical industry who use the drums to transport petroleum chemical products. FBF5 is another subsidiary of a MNC that seasonally places massive orders with MCEF4 for the supply of drums. The drums are used in the exportation of pineapples to Europe and America. United Nation 
(UN) agencies such as UNHCR places massive otders with MCEF4 for the supply of drums to deliver relief and Camine related goods in the region. With regard to each of these cases, we would like to emphasise that MCEF 4 bas to be audited for an number of things, the quality drums used, technology used, skills employed and raw materials used ${ }^{\text {ig/ }}$ to ensure compliance with the accepted international standards. Intermews confirmed that a kind of indirect linkage gets established or trickle down effect from customers of MCEF4 to MCEL4 since they are the direct suppliers of raw materials used by MCEF4. The point we want to emphasise here is that the drums must meet intenationd quality standards. The required qualizy standards and specifications of raw materials are presented to MCEL4 who in turn have to proof that they have the capacity to supply them in the required form. MCEF4 has to further undertake its own audit on MCEL4 to verify that indeed it has the capacity to supply raw materials in line with specifications provided. This example shows that demand from buyers, MNCs, usually comes with unique specifications and standards, which presents tow challenges and opportunities to learn new things. These are some of the facts that forced the MCEL4 to expand and invest in new technollogy. They stimulate the firm to engage more skilled workets and offer more training, strive to acquire ISO standards etc.

A second example involves local body building companies (local and foreign companies) in the automobile industry who use the MCEL4 products for their body building activities. The requirements by the foreign firms and joint ventures are usually very strict. The specifications must meet set standards and thus present learning opportunities to MCEL4. Presence of MNCs creates incentives for MCEL4 to leam and accumulate technological capabilities.

Finally we look at interactions (see some of the instinutions interviewed in Table 7.1). All the case study firms interacted with business associations, institutions such as $\mathrm{R} \& \mathrm{D} /$ academic, financing institutions and government regulatory organisations and enforcement agencies. The interactions enable these firms to interact and share skills and knowledge, including technical assistance with other firms. All the firms were members of KAM. At the time of this research, the chief executive of MCEL4 was an executive committee member of $\mathrm{KAM}$. He was also the chairman of KAM's metal and allied sector and trade promotion committee. Another MCEL4 director cliaired the EAC subcommittee of KAM. The participation by the local frms in the KAM means that their firms shared experience with foreign firms on things like labour ethics, corpotate governance, policy lobbying technigue, intellectual property rights etc.

Firms also interacted with the MSK. MCEL4 participates in MSK competition and for instance in 2002 it won the best product award and best development of existing brand award in 2003 . Firms interacted with KMM by participating in their annually organised company of the year award. For instance, it also participates in the company year award. (COYA) organised annually by KIM. In 2003 , it was the best overall company with best financiall management and marketing practices.

Al firms interacted with government regulatory bodies such as KEBS. In 2003, MCEL4 achieved Kenya Quality Award (KQA) awarded by KEBS. Also, Diamond Mark of Quality by KEBS in the same year. In 2003, it obtained ISO 14001:1996 in Environmental Management Systems. In 2001, it obtained ISO 9001: 2000 for Quality Management Systems from SGS, MCEL4 started implementing Total Quality Management (TQM) in 1995. It obtained ISO 90002000 certification in 2002 for strict

197 Under UN drums must pass the staking test, immersion test, hydraulic and drop test. 
quality management systems. In the same year it was also awarded ISO 14000 certifcation for implementing Envitonmental Maragement Systems.

The Girms interacted with FKE for labour issues and settling trade disputes. Orher memberships included KIRDI, EPZA (MCELI), with KIPI and local financial institutions. MCEL2 interacts with other R\&D institutions like KIRDI. On technology, development the firms felt that the country lacks strong R\&D to support industry innovation and technology development, as there was little involvement of universites rescarch work in industrial activities. For this reasons, the firms have to rely on external sources fot innovation and technology development. Firms do not obtain finance from the local financing institutions. Lack of collateral and high interest rates were big obstacles to obtaining such finances. They also argued that KFBS lacked adequate capacity to undertake certain aspects e.g. testing of certain equipment. All these factors amounted to high transaction costs to the furms and reduce the collective benefits that would otherwise occur.

Some firms have international interaction membership. At international level, MCEL4 has membership with a few Germany companies. Other intemational memberships include member of Pacific Zinc Aluminium, USA Zinc Aluminium and Europe Zinc Aluminium. This has been beneficial for intemational information and knowledge.

With regard to human capacity building, these firms also played an important role in the country similar to the foreign firms. MCEL2 is involved in training programme of the university-engineering students who come for several months of internship/attachment at the plant facilities. Engineering students from vocational and polytechnic are also accepted. The training offered is practical and is conducted in-house. This was the same case even with other training involving firm staff due to the fact that pipe making technology and training was not possible to get elsewhere outside the firm. MCEL3 maintatned a long run relationship with the local technical universities and polytechnics. It accepts stadents from the engineering departments of these institutions to have their industrial attachment with the firm for a period ranging from a few days to several months. The firm has a set programme through which such students must follow. A team from these institutions and from the firm usually works out the program to be followed. This programme is put in such a away that the students must work in all the sections before the end of the course. This is intended to provide the students with multiple practical skills and experience. The firm has a set policy to take a few of the best students from the batch that comes for the intermship from tertiary institutions. One such case was identified where an intern student from a local polytechnic who had his industrial training in the frm and later joined MCEL3 as a supervisor in the spining department after he successfuly completed his studies at the polytechnic. There was a similar case of another university graduate who was at the time wotking as the maintenance engineer.

MGEL4 also participated in human capacity development in the country. It offered competitive academic scholarship to students pursuing higher education in science and engineering subjects. A top student was benefiting from MCEL4 academic sponsorship to take up Bachelor of Science (BSc) degree in engineering at Jomo Kenyatta University of Agriculture and Technology, a local public universiry. MCEL4 also offers industrial atrachment annually under its Young Professionals Programme. It takes 10-12 engineering graduates from Nairobi and Moi universities and 16-20 students from Kenya and Mombasa polytechnics for industrial attachment. It is highly competitive and only 
top students can be considered in the scheme strictly testricted to mechanical, eletrical, production and computer science studies. The firm can offer jobs to the best condidates after their industral attachment. The firm has also established a vocional rechnot training school managed under the MCEL4-Earopean Investment Bank (ETB) Trust and with further technical support from Don Bosco Schools. The growth and expansion, following technology transfer, its exploitation and skill development for instance leatning from foreign expatriates) enabled this firm to participate in the conotries human capacity development.

\subsubsection{Competition Effects}

In this section, we examine the competition effects on the case study firms as a result of competition intensity especially from foreign firms. We found interesting cases where competition pressure from foreign firms had forced locally oxned firms in our case study to introduce technological changes; learn and build capability. We present case by case.

MCEL1 does not face stiff competion from imports. However it faces stiff competion from competing firms domestically. This includes foreign firms operating in the country. As a result of this compexition, the firm has had to undertake several things: improve quality control; offer more training; diversify and statt processing of new products. Their competitors have advanced technology and it is a part of global network of companies with wide experience in the freld. Similarly, MCEL2 taces very stiff competition as a tesult of imports into the country from competing firms. The firm also faces stiff competition in its export tegion due to imports from other foreign companies and especially from Asian countries with the leading one being India. An example was provided where a company located a long the coast in India (Good luck) produces steel (India has steel) and sells it to Ethiopia. In their case since Kenya has no steel, they have to get it from South Africa through the port of Mombasa, process it before once again exporting the processed commodities through the same port. Responding to our question on the effect of comperition pressure from foreign firms, the production manager elaborated as follows:

Since the company is interested in capturing a wider market including Ethiopia, the current strategy being pustued is that of trying to reduce the production cost. As a result of this initiative, the company has closed its galvanising plant to try and undertake some tenovarions geared towards cost reduction. The renovations are intended to introduce certain modifications; all being a plan strakegy to reduce cost of production and be able to compete for export markets. Galvanising cost is very high and the company is not going to be competivive while incurring such high galvanising costs. We antichpate reducing the furnace ofl consumed by about $50 \%$ upon completion from 100 lites to 50 licres per tone of pipes being galvanised. It is also necessary to change the blower since it is not providing sufficient at for combustion. Another innovation would be to change the standard for Zine from the current $600 \mathrm{gm}^{2}$ to $200 \mathrm{gm}^{2}$. As you can sec, we are behind in many things. The technology is very advanced at the moment. In most casses companics use computer controlled machines (CON) but we were still doing cverything mechanically. Our immediate plan would be to introduce a cutting tube machine with a small element of tolerance. It would also be important for ws to obtain a new welder, which would even reduce the power consumption.

MCEL3 faces moderate competition from other firms both locally and foreign owned firms. In addition, the firm faces moderate competition firom imports into the country by 
quality management systems. In the same year it was also awarded ISO 14000 certification for implementing Environmental Management Systems.

The firms interacted with FKE for labour issues and settling trade disputes. Other memberships included KIRDI, EPZA (MCELI), with KIPI and local financiall institutions. MCEL2 interacrs with other R\&D institutions like KIRDT. On technology, development the firms felt that the country lacks strong R\&D to support industry innovation and technology development, as there was little involvement of universities tiescarch work in industrial activines. For this reasons, the firms have to rely on external sources for innovation and technology development. Furms do not obtain finance from the local financing institutions. Lack of collateral and high interest rates were big obstacles to obtaining such finances. They also argued that KEBS lacked adequate capacity to undertake certain aspects e.g. testing of certain equipment. All these factors amounted to high transaction costs to the firms and reduce the collective benefits that would otherwise occur.

Some firms have intemational interaction membership. At international level, MCEL4 has membetship with a few Gemany companies. Other international memberships include member of Pacific Zinc Aluminium, USA Zinc Aluminium and Europe Zinc Aluminium, "This has been beneficial for intemational infomation and knowledge.

With regard ro human capaciry building, these firms also played an important role in the country similar to the foreign firms. MCEL2 is involved in training programme of the universily-engineeting students who come for several months of internship/attachment at the plant facilities. Engineering students from vocational and polytechnic are also accepted. The training offered is practical and is conducted in-house. This was the same case even with other training involving firm staff due to the fact that pipe making technology and maining was not possible to get elsewhere outside the firm. MCEL3 maintained a long run relationship with the local technical universities and polytechnics. It accepts students from the engineering departments of these institutions to have their industrial attachment with the firm for a period ranging from a few days to several months. "The firm has a set programme through which such students must follow. A tream from these institutions and from the firm usually works out the program ro be followed. This programme is put in such a away that the students must work in all the sections before the end of the course. This is intended to provide the students with multiple practical skills and experience. The firm has a ser policy to take a few of the best students from the batch that comes for the internship from tertiary institutions. One such case was identified where an intern student from a local polytechnic who had his industrial twining in the firm and later joined MCEL3 as a supervisor in the spinning deparment after he successfully completed his studies at the polytechnic. There was a similar case of another university graduate who was at the time working as the maintenance engineer:

MCEL4 also participated in human capacity dewelopment in the country. It offered competitive academic scholarship to students pursuing higher education in science and enginecring subjects. A top student was benefiting from MCEL4 academic sponsorship to take up Bachelor of Science (BSc) degree in engineering at Jomo Kenyatta University of Agriculture and Technology, a local public university. MCEL4 also offers indurstrial attachment annually under its Young Professionals Programme. It takes $10-12$ engineering graduates from Nairobi and Moi universities and 16-20 students from Kenya and Mombasa polytechnics for industrial attachment. It is highly comperitive and only 
top students can be considered in the scheme strictly testreted to mechanical, electrical, production and computer science studies. The furm can offer jobs to the best candidates after their industrial attachment. The firm has also estalished a wocatonal technical training school managed under the MCEL4-European lnvestment Bank (EIB) Trust and with further technical support from Don Bosco Schools. The growth and expansion, following technology transfer, its exploitation and skill development for instance learning from foreign expatriates) enabled this firm to participate in the countries buman capacity development.

\subsubsection{Competition Effects}

In this section, we examine the competition effects on the case study firms as a result of competicion intensity especially from foreign firms. We found interesting cases where competition pressure from foreign firms had forced locally owned fims in our case study to introduce technological changes; learn and build capabiliry. We present case by case.

MCEL1 does not face stiff competition from imports. However it faces stiff competition from competing firms domestically. This includes foreign furms operating in the country. As a result of this competition, the firm has had to undertake several things: improve quality control; offer more training; diversify and start processing of new products. Their competitors have advanced technology and it is a part of global network of companies with wide experience in the field. Similarly, MCEL2 faces very stiff competition as a tesult of impors into the country from competing firms. The from also faces stiff competition in its export region due to imports from other foreign companies and especially from Asian countries with the leading one being India. An example was provided where a company located a long the coast in India (Good luck) produces steel (India has steel) and sells it to Ethiopia. In their case since Kenya has no steel they have to get it from South Africa through the port of Mombasa, process it before once again exporting the processec commodities through the same port. Responding to our question on the effect of competition pressure from foreign firms, the production manager elaborated as follows:

Since the company is interested in capturing a wider matket including Fethiopia, the current strategy being pursued is that of trying to reduce the production cost. As a result of this inithative, the company tas closed its galvanising plane to try and undortake sone renovations geared rowards cost reducton. The renowations are intended to introduce certain modifications; all being a plan strategy to reduce cost of production and be ablo to compete for cxport markets. Galvanising cost is wery high and the company is not going to be competitive while incurring such high galwanising costs. We anticipate reducing the furnace oil consumed by abour $50 \%$ upon conpletion from 100 litres to 50 litres per tone of pipes being galvaniscd. It is also necessary to change the blower since it: is not providing sufficient ait for combustion. Another innovation would be to change the standard for Zine from the current $600 \mathrm{gm}^{2}$ to $200 \mathrm{gm}^{2}$. As you can see, we arte behind in many things. The technology is very advanced at the moment. In most cases companies use computer controlled machines (CCN) bur we were still doing everything mechanically. Our immediare plan would be to introduce a cutting tube machine with a small dement of tolerance. It would also be important for us to obrain a new welder, which would cren reduce the power consumption.

MCEL3 faces moderate competition from other firms both locally and foreign owned firms. In addition, the firm faces moderate competition from imports into the country by 
competing firms. According to the managing director, such products were sometrmes rerouted into the country through COMESA member countries such as Egypt. As at result of this competition, the firm had introduced a number of things:

- Introduced several fabrications in the plant.

- Sourcing raw materials from a different location. Initially it used to source cetrain things from France but now they obtain them from India where they are relarively cheaper.

- The firm has undertaken mote ttaining in house.

- The firm has looked for alternative markets.

- The firm has become keen on quality control.

- Introduced new products.

- Started engaging in procedures to reduce energy consumption.

- New machinery dependent on demand.

- Acquire new processing techniques.

- Improve market strategies (serve other markets).

- Improve organisation and management structure

MCEL4 faces stiff competition from imported steel mainly from Asian countries. It also faces stiff competition from local competitors who are mainly locally owned firms and a joint venture firm with a MNC. They have introduced new processing lines. The source of MCEL4's competitive strength has been its heavy investment in capital machinery and equipment. The company has also invested heavily in product technology that has been licensed from Abroad. Although the rival firm's have attempted to invest in machinery they however cannot match the superiority of MCEL4's machinery and technology. The product technology used in the rival firms is still the old one especially in galvanising sheets. In terms of innovation, MCEL4 is far a head of the competing firms. The firm confirmed that it had the highest level of human capacity. It has more linkages established abroad, which serve as a source of information. The newly invested machinery allows more efficiency and flexibility - increased its ability to accommodate changes in customer tastes and preferences. As a result, it has been able to offer reduced prices due to low overhead costs. With the new technologically advanced plant, the firm has become mote efficient and flexible (increased ability to accommodate changes in customer tastes and preferences), high capacity utilisation. It is able to offer its processed products at a low price. The firm is producing at international quality standards that can compete effectively in advanced markets in the Middle East, Europe and the United States of America. Attention is given to quality maintenance through consistent analysis of customer's needs and expectation through intemally organised quality control circles and core team projects. It has a wide experience in product manufacture as well as markering expetience. The fim had a planned strategy to invest US\$ 40 million in expanding its plant and introducing new products. The investment is expected to inprove the firm's capacity. It wants to introduce new products and acquire new processing techniques (a pickling line). This will involve increased workers training and changes in organisation and management. 


\subsubsection{Demonstration Effects}

All the four frms enjoyed demonstation effects from foretgn firms. As will be shown, this occurred either directly or indirectly to the firms. MCEL1 contended that it had benefired tremendous demonstration effects from competing firms. Fowever, this depended on the kind of machinery to be used. The firm contended that since the foreign firms were the pioneers in the production of crown corks in the country most things were then copied from them. These things range from processing tecliniques, product technology and marketing.

MCEL2 has introduced new products and new techniques observed from other ordinaty companies both local and foteign. The firm was able to make simillar but own products. From the example provided, below we note one important thing, a firm fabricating successfully (imitation) a product from a MNC from another comntry. This was a fascinating demonstration effect as explained by the production manager.

We had a special request by a particulat customer who wanted some items done ro his specification. He wanted stecl angles produced and galwanised. The steel angles were required for floriculture (capillary action for the irrigation of floriculture) and about 20, 000 pieces. were required. The customer used to abtain them from South Africa. We asked him to present a sample to us for examination. After examining it, we decided to try it out. We had newer made anything of that kind before. To fabricate these angles, we had to make several trials in our fabricating unit. We had to make many jigs for galvanising as well as a system to test the angles quality. With a large number of trials and errors, we managed to come up with similar if not better angles than he used to get from South Africa. The customer was happy and satisfied with the product. Our firm can now make angles for other interested and needy customers. The learning done made us build the required production capability.

Another example is from MCEL3, which introduced new products and new techniques. observed from other companies through demonstration effects. The interesting thing is that after the firm successfully imitated for the first time it was then able to make similar and own products afterwards. MCEL3 has had demonstration effects from companies mainly based abroad. Such firms included Chinese, German, Egyptian and British firms. This was possible due to the capability built in-house as well as absorptive capacity. When the engineers were asked about the challenges posed by international orders, they answered that each one of them presents own technological challenges. A few examples were provided.

(1) The first example included a case where UNHCR wanted some special fhing pan lids be made for them in 2002. The general manager had interacted with them. So they held discussions of how such could be made at the plant. This was a special kind of pan where an individual could eat from, put something on top to warm up and to cover the fying pan. The company made multiple trials before they eventually succeeded in coming up with the required flying pans, which met all the specifications.

(2) The second example involved manufacture of round bow/s. A visiting high commissioner challenged them to come up with a specific design and volume. These were 5 litres bowls that had not been manufactured in Kenya before. The commissioner was concerned that the space taken by the prewious bowls was extremely high making it: very costly to transport them. The challenge was on how to come up with a bowl still 5 litres but of less rolume (less bulky), high quality and if possible of a betrer design. With much effort the firm was able to come up with a bow that met the exact standards 
required by the commissioner. The bowl was of the exact capacity, better shape and qualiny but less bulky. This is a good example of a case where a firm can lear from something demonstrated to it by a foreign organisation and because of its accumulated technological capabilify the frtm succeeds in making it.

(3) The third example involved mboly anmwom oup used for taking the wholly communion in the church. The actual ptocess ptoceds as follows: The churches usually demonstate the kind of communion cups they want made to the MCEL3 who study them and then come up with the required cups. These cups are new in the country, as they have only been manufactured by foreign firms abroad. As usual, the firm underwent through the normal challenges but eventually was able to come up with the required ctips. Such challenges involve making the right size dies and then adopting the machinery in order to make such snall cups, which had not been manufactured before. The capability developed at this time enabled them to make more cups for other churches, which were even bigger than the ones made before. The wholly communion cups were a demonstration from abroad where this particular church had originated from.

(4) The fourth example involves requests from firm's customers. Based on items/products they have seen in the local market. The requests are that MCEL3 makes such products for these companies. Things often demonstated come from supermatkets and can include anything e.g. making an Aluminum soap dish from a plastic soap dish demonstrated. This is possible since MCEL3 has developed enough technological capability in-house in the firms fabticating unit.

(5) The fifth example involved UNCEF Cooking Set. This followed a successful tender, which they won for the supply of a cooking set for a relief operation. "The set was demonstrated to them, it included 4 bowls with a capacity of 1 litre each; two sufurias of 3 and 5 litues; coffee port 1.7 litres, frying pan with a detachable handle, 6 mug cups of 7 $\mathrm{cm}$ diameter. The firm was able to make the set and as a result they have been able to do the same for other international organisations like UNHCR, UNIDO and Red Cross.

(6) The sixth example involved collaboration between the firm, the government of Keryy and ILRI. This was done to improve the marketing and sale of milk. This came as a recommendation from a survey done and based on the feedback received, they decided to introduce a new milk can for the sale of milk different from the one used arlier on.

(7) The eighth example involved making dies for baking queen ataes and other established products. The customer come with the items and demonstrates them to the engineers in the firm. The engineers studied them and then try to investigate how they can introduce fabrications that would enable them make the required items. "This was possible as the firm had the capaciry to make very intricate shapes as a result of tacit and expericntial knowledge garnered by the frm engineers.

In sum, demonstration effect from foreign firms and organisations affected the following activities in the firm: Assisted in the development of new products or improvement of existing products to market needs. Assisted in the processing activities; taw material and quality control; upgrading machinery and equipment stretching to save energy; cost; rase productivity etc. Assisted in repair and maintenance of physical capitall, inventory control etc. strengthened the marketing department with new ideas and thowledge of existing local and foreign export markets. 
Contraty to the above cases, MCEL4 had not enjoyed any demonstration effects fiom fums based in Kenya. According to the general manager, MCEL4 whs the most advanced in the region and thus other firms imitated their prowers and way of doing things. They have akways been first in many areas. They are the first to license the new product technology Al-Zn in the segion. They were the first to introduce colour-coted sheets. From the country they were the first to penetrate the international export market in their line of products. They were the first to introduce the sophisticated Japanese CGL in the country. They were the first to be awarded ISO 9000 and $1 S O 14000$ in quality systems management and environmental management respectively, They have won management, financial and quality awards several times. In this case other firms hwe indeed had demonstration effect from MCEL4. These fims have introduced new steel rolling lines some have exen started processing colout-coated sheets. However, MCEL4 enjoys demonstration effects from $\mathrm{MNCs}$ in other countries e.g. BHP of Australia. It wants to constanty upgrade and invest in machinery and technology to match BHP of Australia. Similarly, they want to introduce flexible processing technologies to match Japanese firms. Excerpt "At low cost with speedy delivery and assured customer satisfaction through benchmarking with Japanese Rolling Mills". This represents international spillovers through demonstration effects.

\subsection{Perceived Govertment Role in the Spillover Process}

The analysis done so fat indicated that the government atracted FDI and created institutions all to promote industrialisation in Kenya. See our discussion in Chapter 3. However, it has emerged in this research that institutions remained inefficient and weak in petfomance. This was due to the constraints they faced including lack of support by the government. Their inefficiency added to the transactions costs of oporating in the country. This aspect reduces technological spillovers from occurring. Institutions need support from the government wntil they are sound in their operations. Without these there will be very little support to the local firms iri terms of finance, information and technical support etc. This demonstrated a lack of government attention and concern in scooping the benefits that atises from foreign presence in a host country. Take for example spillover accurrence through linkages formed. This study, Chapter 5 , indicated linkages to be one of the lowest mechanisms that generated spillowers. While in other countres this has been a main mode of spillover occurrence [Lall, 1980; Rasiah, (1995: 2004); Rodriguez-Claire, 1996; UNCTAD 2001; Smarzynska, 2003]. This is so partly due to government's failure to encourage formation of linkages and interactions among economic agents; furms, institutions, business associations etc.

On competition some of the locally owned firms felt that competition was not properly regulated and tended to harm incligenous fums and thus theit capability development. The firms argued that the government seemed to operate a blanket rule as if foreign and locally owned firms were equally endowed in terms of capacity and resources (c.g. rechnology and finance). Others felt that in some form of manufactures, which characterized by low value addition should be left to the locals. "These arguments were supported by claims from the general manager of FBL2 who reiterated that: "the gowernment needed to assist infant industries; by refwsing to license fortign companies to packeage commodivies that can be packaged by local inveshars and which add no pahe"." 
The prowision of the facilities eg. utihties and infrastructure remained below par. The frms clamed that despute their growth and expansion, they faced severe constraints: the cost of utilities to the firms $e . g$. powet remained extremely high. The infrastructure (toads, railway, ports and telephone) affected their efficiency negatively. The general manager of MCEL3 outlined these problems as follows:

There is scrious lack of capital in this country; lack of industrial development banks that provide credir at competirive rates; infrastructure remains inferior, cost of communication (inland, road and shipping frequencies); for instance transportacion of goods to Northern Keny, Moyale, is just impossible; cost of clearing at port is higher than within the land; telecommunication problem is unbearable. $56 \mathrm{~km}$ bandwidth gets divided and there is no viber optics in this place; regional cost of telephoning is extremely high; no cheap wacb access.

These factors make the local furms uncompetitive. They increase operation and transactions costs. That way they hinder spillovers occurrence. As a result, large export orders even in the immediate region ate left only to large economies like China and India. The high interest rates in Kenya make the cost of capital temain constantly high. All these factors were futther aggtavated by poot performance of the economy in the $1990 \mathrm{~s}$ that resulted in declined local matket due to low purchasing power and few projects undertaken. However, the firms have remained optimistic that the new political dispensation in the country in the wake of a new government was still likely to bring favourable policy changes to industrial development hence economic growth.

In sum, the government needs to decisively come up with pro-active industrial policies. This will be presented in Chapter 8. Firms and institutions need continuous and committed facilitation. Although the country has a fair level of human capital the firms need facilitation in technological learning and training. Here we mean training that is geared towards promotion of science and engineering and one tailored to the supply of industrial needs. This is possible particularly to the firms through training allowances. Firms also need facilitation to continuously acquire technology and machinery. This is innovation to the furms, which the government ought to consider and encourage in firms and industry. In doing this, it should make it a policy to give R\&D allowances and put in place supportive industrial R\&D institutions. With this kind of facilitation Kenyan products will be as competitive as those from adwanced developing countries such as China; Tawan; Korea; Japan etc. Export should be encouraged also through tax rivets etc. Competition should be critically scrutinized to avoid crowding out of the domestic investment. Such regulation would for instance take into consideration the effect of foreign firms having to penetrate the domestic firms" markets. "Tariffs or a careful selective vetting process should be considered to block foreign firms, which would compete negatively with efficient domestic firms. Successful examples of infant industry protection and suppott can be traced to the East Asian countries e.g. Tawan and Korea (Fransman, 1988; Amsden, 1989; Chang 1991).

\subsection{Summary and Conclusion}

In this chapter, we conducted eight detailed case studies from the perspective of locally owned firms to examine the extent to which foreign firms stimulated spillover occurrence. We used a similar analytical frmmework to that developed in Chapter 6 , itself based on approach developed in Chapter 2 and urilised in Chapter 5 . Accordingly, the chapter considered the following elements: human resource development and labour 
mobility, linkage effects, demonstration effects and competition efers. The daptert began by presenting a quick overview of background characteristics for each of the th case study frms. The findings obtained in this chapter supported the empirical andysts done in Chapter 5. Analysis of the eight case studies done showed that FDI the tho industries played a role in stimulating learning, capabiliry development, innowation and performance in locally owned firms. This confirmed spillover occurrence from foretgn firms to the locally owned firms in the two industries studied.

The choice and justification of the case study firms was mainly based on the aature of production technology, learning and innovation. Localy owned firms trelied on international sources for the acquisition of their production technology and machinery. This was also found to be the case with foreign firms studied in Chapter 6 . In a tew cases the locally owned firms had obtained their production technology from MNCs located in the country. Product technology was also often licensed from abroad (FBL3, FBL4 and MCEL4). Hence these firms did not do serious R\&D but only maintained technical departments and laboratories for quality control checks and to ensure smooth ruming of the process. It emerged that locally owned firms were able to learn and build capabinties based on the foreign production technology and products. Participation in production activities allowed human capital development in that locals were able to accumulate tacit and experiential knowledge from on-the-job training and leatning by doing. This would be expected since production technology obtained was sophisticated and new to the firms hence requiring training. Trainings commenced with plant lay-out and process installation. It would also include process operations, process adaptations and maintenance procedures etc. Training also involved product technology with locals learning how to make products including those produced under foreign license (e.g. FBI 2, FBL4 and MCEL4).

Examination of humat resource development showed that local firms offered taining in the firms. However, this was not comparable to the foreign firms training. This supported the argument that foreign firms offer more training than locally owned firms (Chen, 1983: Gerschenberg, 1987). Workers in foreign furms were able to acquire skills and experiential knowledge from better trainings offered. "This was supported by resources enjoyed by foreign firms hence enabling them to offer better training programmes and superior training facilities. Foreign furms are in a position to organise skill entichment programmes either in-house of extemblly. When locally owned firms just sent a few of its staff abroad for specialised training, foreign firms sent even more through exchange programme trainings or with the firms ${ }^{2}$ parent companies. Although locally owned firms obserwe some labour ethics by allowing formation of unions, transportation, better terms and conditions of service they still had a lot of things to learn or to match with foreign firms e.g. awarding high salary and wages.

Analysis done in this chapter indicated that labour mobility existed in the locally owned firms. There were many cases identiffed of professionals, engineers, and technically skilled workers who had left jobs with MNCs and taken up new appoinments with locally owned firms and vice versa. There were many cases observed of expatriates who had joined the local firms (e.g. MCEL2 and MCEL4). This is supported in the literatrute by studies that found labour mobility from foteign to domestic firms (Pack, 1973; Behrman and Wallender, 1976; Gerschenberg, 1987). There were also cases of staff leaving to run their own entrepreneurship implying their role in breeding domestic entrepreneurs. Investigations done in the firms with some of the staff who had joined from foreign firms confirmed the usefulness and applicability of the skills they had 
acquited while working with MCs (FBL1 and FBL2). This confinmed existence of knowledge spillovers through labour mobility. It also supported a broad and positive tole DDI played in the country humath capital development effort, which has a positwe bearing towards industrial development.

We examined linkages generated by these fitms with foreign fims and interactions existing with institutions and business associations. Both pecuniary and non-pecuniary linkages were discoveted. local firms maintained backward linkages with suppliers of raw thaterials, services (banking and financing institutions), machinery and equipment. Forward linkages were maintained with distributors, transport and communication. In each of these cases local firms were observed to have benefited technological spillowers. Pecuniary linkages were important to the firms im that the demand they created helped the local futm to grow and expand as a result of finance obtained. First, international linkages maintained with uechnology and machinery suppliers provided a form for interactions during machine repairs and maintenance. This was evidence of technological spillovers. It was noted that firms benefited training at every stage of plant setting ranging from initialisation to commissioning (FBL1, FBL2, FBL3 and MCEL4 offered good examples). In other cases intemational links with foreign firms offered technical support in making some products or adopting them to the local conditions and requirements. This was supported by the case of wine making firm (FBL4), soft drink firms (FBL2 and FBL3) and Iton rolling firm (MCEL4). These were noted to be possible due to the technological effort maintaned in firms.

Technological spillovers with regard to backward linkages emerged in a more or less the same mannex. There were cases of locally owned firms (FBL1) that obtained production lines; products; marketing and distribution network from MNCS in the country. All these amounted to technological spillovers, which the firm was able to scoop due to its high level of human capital and availability of finance. This enabled the firm to learn, accumulate production capability and become innovative. Inditect cases of spillover occurrence were also found - second levell linkage. This happened when spillovers occurred to a locally owned fitm through another locally owned firm. As a result, such firms had to introduce technological changes, learn from doing and build capabilities (FBL3, FBL4, MCEL2 and MCEL4). Backward linkages with spillovers were maintained in agro-industry as well (FBL1; FBLA and MCEL2).

With regand to forward linkages, the firms contended that due to the demand created by foreign firms they have been able to grow, expand and build technological capability as a result of leaming from the otders placed from these foreign firms. It also allowed them to obtain finance. Foreign firm offered strict conditions to the supplying frrms and maintained routine audit and certification. Most MNCs were $1 S O$ accredited while others followed World Class Performance (WCP) and thus they had to observe strict requirement with local suppliers. Local suppliers had to be or hac to acquire ISO certifed or at worst maintain KEBS quality certification. As noted also in Chapter 6 some of the MNCs encouraged llocally owned firms to become $1 S O$ certified and to improve their efficiency. To the local firms that implied obtaining the right machinery and equipment, offer regular training and maintain sound management practices. All these amounted to spillovers. Some locally owned firms benefited spillovers when they offered services like contract packaging to MNCs (FBF5) benefiting spillovers in quality control which amounted to building production capability. Indirect cases of spillover occurtence were also noted with forward linkages (MCEL1). All these were possible due to the technological capabilities accumulated over a long period of time in production. 
Local firms interacted with institutions such as $R \& D /$ academic institutions, financing institutions and government regulatory organisations and enforcement agencies they also interacted with business assaciations. Although these interactions result in technical support; financial support; sharing of skills and lknowledge; this was only to a linited extent as firms strongly felt that ought to have been better. Our findings in this chapter concurred with those of Chapter 3 that institutions in Kenya were weak and performed inefficiently partly due to neglect by the government. Their weak operation and poor coordination increased the transactions costs and tended to lower spillover occurrence. With regard to business and marketing associations, the situation was somehow better as the local firms interacted with foreign firms and enjoyed sharing knowledge and expettise in areas such as labour ethics, trade disputes, corporate govenance, policy lobbying technique, technology transfer, formation of linkage, strategic alliances and mergers and acquisitions, intellectual property tights etc.

On competition, locally owned firms were able to shrvive competitive pressure due to a number of reasons including spillover benefits from such subsidiaries. First one is that MNC subsidiaries provide technical assistance to their local suppliers and customers, train workers and managers who are later employed by locally owned turms. Second is that locally owned firms may move into the production networks and interaction netwotks of subsidiaries (FBL1 and FBL2). Third is that an oppornunity to catch up arises stimulated by the interactions they have with MNC subsidiaries. The fonal one is that some demonstration and competitive elements force firms to undertake changes; these could also be made open by certain kind of policies that ensues foreign investment (FBL1, FBL2, FBL4, MCEL2, MCEL3 and MCEL4). Competitive pressure exerted by subsidiaries forces locally owned farms to operate more efficiently and introduce new technologies eatliet than what would have otherwise been the case.

Locally owned fitms benefited tremendous demonstration effects from foreign firms. This was often possible due to the technological effort maintained in the studied firms. The findings in this chapter presented interesting cases where locally owned firms were able to imitate processes or products from foreign firms. Products imitated would sometimes come from abtoad (MCEL2 and MCEL3). This process enabled local firms to benefit a wider set of product and portfolio without having to do R\&D for product or process development. The most important thing to point out here is that, local firms would then advance in their learning curve and build more capability to innovate.

As a conclusion, we argue that FDI in Kenyan manufacturing played a crucial wole in industrial development through spillower accurrence to the locally owned firms. Spillovers of knowledge resulted in learning, accumulation of technological capability innovation, growth and enhanced performance. The case study findings in this chapter supports empirical analysis conducted in Chaprer 5 and 6 . 


\section{Chapter Eight}

\section{SUMMARY, CONCLUSIONS AND POLICY IMPLICATIONS}

\subsection{Introduction}

This chapter presents the summary, conclusions and policy implications of this study. The chapter is organised in six sections. Section 8.2 prowides a summary of the study"s purpose i.e. the nesearch problem set for this study is described. Section 8.3 presents a summary of the theoretical issues and conceptual tramework developed for the study. In section 8.4 , the summaries of the study's main empirical findings with regard to the econometric and case study analyses conducted, are presented. Section 8.5 presents the summary of the policy implications based on the research findings obtained while section 8.6 provides the recommendations for further and future research wotks.

\subsection{Research Problem and Objectives}

This thesis arose out of concerns to understand how FDI affects industrialisation process in Kenya with patticular emphasis on spillovers and rechnological capability. The broad objectives were outlined in Chapter 1. The thesis investigated whether technology, knowledge and skills transferred to the country from technically developed countries contributed to learning ard development of technological capabilities in locally owned firms which would in turn enable them to innovate. The analysis was done by examining the effect of technological spillovers from MNC affiliates to locally owned firms in the Kenyan manufacturing industry.

\subsection{Theoretical Considerations and Conceptual Framework Design}

Due to the weaknesses observed in spillover analysis, an alternative theoretical Gramework was presented in Chapter 2. In view of the wast developments in the endogenous and evolutionary literature, neoclassical production function approaches utilised in examining technological spillovers ate definitely flawed. Technological spillovers are to a large extent unnoticeable, as they do not leave a trail of smoke behind them, are uncertain and complex implying that an appropriate attempt to analyse them would beg for an equally complex and integrated systemic approach. Hence, a near understanding of technological spillovers can therefore be approached by assuming an endogenous, evolutionary and institutional approach, which views firms not as isolated, static and pure economic organisations, but tather as members of changing economic and social-economic-institutional networks. For instance, this would requite a deep understanding of the network dynamics and corroborative linkages that exist in the industry and/or economy wide systems. The role and importance of the local support system in the spillover process would have to be taken into consideration as well as social capital.

In this light, an alternative framework was suggested for this study which extracted some owerlapping elements of industrial organisation and incorporating them with the national 
system of innovation. Spillovers were conceptualised in tems of leatning and capability building. This follows the argument that in rechnically underdeveloped countries like Kenya, occurrence of spillovers was likely to place domestic fums on a learning function hence stimulating their capacty to build and accumulate capabilities which would in turn enable them introduce more technological changes and innowation.

\subsection{Summary of the Study's Findings}

In this section we present the summary of the study's findings starting with the findings obtained in context setting chapter.

\subsubsection{Empirical Results Obtained Based on the Context Setting Analysis}

The analysis done in Chapter 3 produced interesting findings. FDI was noted to be important for the emergence and continued development of manufacturing industry in Kenya. From the onset, Kenyan manufacturing was started by foreign firms mainly from Britain which established their operations mainly in agro-based industries. During the colonial days and before Second World War, the foreign firms only performed simple and very basic manufacturing activities characterised by low walue adition. Nevertheless, the country is believed to have enjoyed extensively from the early colonal manufacturing experience since in strict sense no modern manufacturing existed before. In pursuit for further development and expansion by FDI, the country benefited and continues to enjoy most of the infrastructure developed then. Most of the pottfolio investment such as railway, roads, airport, port harbour and public utility departments all instrumental in stimulating technology diffusion and market outlets for locally owned firms were made during this period. Similaty, most of the revenue earning primary sectors in the country wete developed during the same period (examples include coffee, sisal and tea estates). $A$ few public and private institutions were also established then.

The analysis done showed that after the Second World War, the British Government decided to allow more industrialisation in her colonies done under strict protection by use of tariffs and quota restrictions. After the Second World War the US started sending its FDI internationally. This created pressure indirecty to Britain as this would mean sending such EDI into its colontes and thus erosion of its market. Thus in addition to encouraging industrialisation in the colonies, the British Govenment also encouraged its firms to invest in its collonies. As a result of this drastic policy changes, the period 1945 . 1963 saw increased EDI inflow from Btitain into Kenyas manufacturing. The production was meant to substitute manufactuted products earlier imported - thus a kind of import substitution policy was being pursued.

At independence in 1963 , Kenga enacted industrial policies meant to promote its industrialisation which was still at its infancy. The country continued pursuing the import substitution policy started earlier. Different kinds of policies were enacted: First, some policies were enacted meant to encourage entry of indigenous entrepreneurs into manufacturing. Second, some policies were enacted meant to open up to more and diversified FDI. Specific policies were tallored to change the witnessed outflow of some FDI from the country due to the existing fever at independence that most firms would 
be nationalized under the Kenyanzation prograwnye ${ }^{\text {tys }}$. Due to friendly polices enacted, good conomic performance, raw materials and exisung market, many MNCs made their entry into manufacturing. There was increased foreign capital in manufacturing placing the country among the leading in the region ${ }^{10}$. It is believed too that in this period the Kenya's manutactuing benefited tremendous manufacturing expertence in the form of technological spillowers. Industrialisation proceeded steadily with high manufacturing growth rates. In addition to the industrial policies formulated, many institutions were established meant to offer systemic support and promote industrialisation through stimulation of industrial capability building. The institutions were supposed to provide firance, offet entrepreneurial training, support acquisition of technology and machinery and support in industrial R\&D etc. Similarly, interaction between FDI and these institutions would be important in spillover occurrence to the locally owned firms. At their setting the institutions played an important role in industrial development.

Due to the economic crises of late 1970 s and 1980s import substitution policy was dropped and outwardoriented policies adopted by mid $1980 \mathrm{~s}$ meant to re-orient industrial production in favour of exports. This was done together wirh a whole range of other policies contained in the SAPS as advocated for by the neo-liberal architects. There was improved performance but only for a short period due to the government's failure to show continued commitment in the liberalisation measures it was undertaking.

Further struciural teforms were therefore undertaken in 1993 to reverse the declining trend. This was without much success due to more problems as explaine din chapter 3 . During this period, $\mathbb{F D I}$ inflows continued to decline but maintaining high stock levels in manufacturing which contimued to generate high levels in employment, revenue generation, value added, export performance etc. There was howver increased effort to promote exports and stimulate FDI. This was through several new institutions established to attract FDI; to promote exports by formulating marketing strategies, export culture and identify export opportunities and finally to administered industrial property rights. FDI examined in the context of institutions such as EPZA and IPC showed that FDI dominated in performance on many fronts such as value added, exports, skilled employee and imports of machinery and equipment etc. This reinforced our argument of their useful role in industrialisation - industrial capability development. Although these institutions (including those established during the import substitution period) played an important role in industrialisation, their performance was severely constrained with multiple problems ranging from lack of adequate finance, lack of required skills, sometimes poor governance and weak systemic co-ordination. This instimtional failure was aggravated by reduced government support on the institutions.

Despite inconsistencies in policies pursued and other structural problems, the analysis and findings of Chapter 3 showed that FDI played an important role in Kenyas industrialisation process. Similarly, despite the constraints faced, institutions established played some facilitation role in this process. "The implication of this is that FDI contributed to industrial capability development through positive spillover occurrence in Kenya's manufacturing which needed to be ascertained concretely. The findings of this

\footnotetext{
24: As ourlined in Chaprer 2 and 3, Kenyutisation programme was intended to Africanse commerce and industy in the county sinec these were dominated by foreigners before and at Kenya"s independence in 1963.

ay Studics done showed that in 1967 . TDT in Kenya's manutacturing was 32.4 to while the arerage for the whole of $\Lambda$ frica was $18.8 \%$. Similarly, at the same ume, HDI was shown to have dominant control in value added and total manubcturing sale in henya with. $71 \%$ and $72 \%$ respectively.
} 
chapter, therefore, morivated out study to attempt a more rigotous empincal inwestigation by using econometric techniques and case studies to analyse technological spillovers.

\subsubsection{Empirical Results Obtained Using Data from Secondary Sources}

The empirical objectives outlined in Chapter 4 were examined using unpulblished firm level data collected from secondary sources. For the purpose of our analysis, an 8 year panel database for the period 1994-2001, was created comprising 175 foreign firms and 245 locally owned firms. The objectives considered in the chapter enabled us to generate a wider set of tesults for a comparative behaviour among firms and with other existing spillover studies based on productivity. This was important given the existing divergence in spillover analysis and conclusions as outlined in Chapter 3.

The compantive behaviour undertaken in the period (1999-2001) showed that foreign firms continued to enjoy higher shares than locally owned furms in wittually all the economic activities. Analysis done using some of the key indicators in manufacturing showed that foreign firms dominated in productivity (in terms of value added, labour productivity, raw material productivity, capital intensity and skill intensity). "T-test analysis done confirmed empirically that foreign firms were more productive than locally owned firms. Foreign firms also dominated in factors of production, processing capability and in human capital (taken in terms of skilled labour force). Similarly, foreign firms controlled in market performance as illustrated by the high shares observed in output sales and exports. On the basis of other indicators, foreign firms were noted to be older, bigger in size and utilised higher capacity than locally owned firms. Interestingly and on the contrary, the analysis showed that locally owned firms had a better performance than foreign firms on the basis of growth rates recorded. While foreign fitms recorded declining growth rates with virtually all their variables, domestic firms had positive growth rates in several variables that included; valued added (2.9\%), labour productivity $(2.2 \%)$, skilled labour $(2 \%)$ and employment $(1 \%)$. These findings were quite fascinating as they implied that the locally owned firms were gradually catching up with foreign firms.

Further comparative analysis done by manufacturing sector revealed that manufacturing sectors were different with regatd to foreign presence. Foreign firms were noted to be concentrated in only a few sectors. These sectors were identified as: food, beverages and tobacco; machine and engineering and chemical, petroleum and plastics industry. On the bases of the same variables, the accivities of foreign furms demonstrated a slewed distribution in that they were also concentrated in just a few sectors. Interestingly, these wete the same sectors with high foreign presence noted earlier. As in above, annual growth rates showed that while foreign firms tended to decline in real terms, locally owned firms tended to rise as supported by the positive growth mates computed in the period 1994-2001. This supported the gradual catching up phenomenon with foreign firms in the three sectars, Annual growth rates examined for a long time series data, 1963-2000, confirmed that the three sectors identified to have high foteign ptesence wrere the same sectors that continued to do well with regard to growth rates and performance shares. In this case there was some kind of correlation that could be drawn linking EDI and manufacturing performance. In essence this could be viewed as a process that translates directly and indirectly in industrial development. 
The aralysis of TDI effect on productivity was examed using total factor productivit. Forengn presence was considered at both frm 'foreign participation' and sector level. Foregn participan had the expected tesults which wete consistent and robust with and whthout time and industry specificities. These results implied that foreign equirg participation at the firm level influenced productivity positively - suggesting productwe benefits from foreign owners.

The findings obtained in the case of foreign presence at the sector level were quite interesting. Two sets of results emerged depending on the methodological approach adopted. Results estimated following 'early contributors' supported spillover occurrence while analysis based on "new developments' falled to support spillover occurrence. This showed that the existing divergence in the spillover literature could be viewed in the Kenyan context. Estimations done taking size and technology gap into consideration produced a similar kind of results. Given the advancement with the new developments approach we would be tempted to conclude in their favour that technological spillowers do not occur in Kenya's manufacturing. We decided not to stop at that point but rathet to probe further. It could be the case that sectors with negative effect or low affect due to foreign presence offsetted those with strong positive impact making the resultant effect neutral sometimes negative hence insignificant results. This was possible in Kenya's manufacturing since results based on compantive behaviour showed that foreign presence was not uniformly distributed. These tesults, therefore, begged for an alternative frameworts as discussed in Chapter 2. As noted earlier, this approach largely failed to demonstrate a dynamic mechanism or link through which spillowers impact productivity. Given the tacit nature of knowledge and technology, productivity may depend on technological capabilities and effort of locally owned firms and not entirely on FDI, hence underestimating the role of recipient firms. The btoader system of imovation plays an equally important role which must not be assumed. Thus results of Chapter 4 were very important in that they motivated our study to use an alternative framework, beyond productivity techniques, by taking sectors and sub sectors into consideration through in depth firm interriews supported by case studies illustrations. This was attempted in Chapter 5 conceptaalising spillovers in terms of technological learning and capability building.

\subsubsection{Empirical Results Obrained Using Data from Surrey Sources}

The analysis and findings of Chapter 4 inspired the next step of our study to attempt an alternative and a more rigorous approach in examining spillovers in Kenya's manufachuing. From the alternative framework oudined in Chapter 2, we developed an index, spillover: index, conceptualising spillovers in terms of leatring and capability building which resulted from technological changes. Preliminary descriprive analysis done in Chapter 5 on the basis of spillover occurtence mechanisms resulted in the following findings: Fint, a high propottion of locally owned firms faced very stiff competition compared to the foreign firms. Second, foreign firms had higher proportions of firms with both backward and fonward linkages compared to locally owned firms. Third, all fims were observed to have gained and/or lost some of their professionals and managers, engineers and scientists, and skilled and technically trained workers to other firms. Interestingly, locally owned firms were observed to be employing more of these professionals and skilled wotkers than they lost to the foreign firms and joint wentures. Another interesting finding was that a high proportion of workers from foreign firms left their jobs to start their own frms compared to that of the locally owned firms. The consequence of this was that foreign firms in Kenya's manufacturing were acting as 
breeding grounds for domestic entrepreneurs. Fondt, that demonstration effects also existed in the two industries. Both domestic and foneign fims had high levels of demonsuration effect but foreign firms had higher. This is expected given their thigh capacity in terms of financial resources and human capinal that can be translated into imitation and innovation. The preliminary descriprive analysis confirmed that spillovers mechanisms were present and active in the manufacturing.

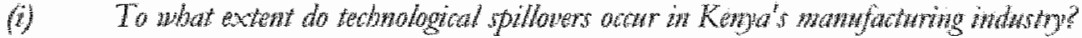

Using the spillower index developed, spillover occurtence from foreign firms as well as from locally owned fims was detemined; jointly and/or sepanately. First, the tesults of spillover derived from both foreign and locally owned firms jointly showed that both food and machine engineering industries combined had a spillover index of 3.30. This suggested an "avenge" technological spillover occurrence in Keny's manufacturing. The findings suppotted existence of knowledge spillovers in Kenya's manufacturing industry. Interestingly, more spillovers appeared to occur in machine engineering (3.36) than in food processing industry (3.25). The spillover index computed for the two industries from foreign firms was 3.48 and that from locally owned firms was 3.11. From the ordinal scale, these results indicated a telatively "bigh" spillover occurrence from foreign firms and "anerage" from locally owned firms. Compatison done by T-Test contimed statistically that the spillover indexes computed by foreign and locally owned furms were significantly different. "This confirmed our hypothesis that foreign firms generated more techmological spillovers than locally owned firms. The index computed for food processing was 3.45 with forcign firms and 3.05 with local firms, while that of machine engineering was 3.53 with foreign firms and 3.19 with locally owned furms. This implied that more spillovers from foreign firms occurred in machine engineering than in food processing.

To what oxtent does the presence of foreign fanzs stimulate techoological spillowers to loud manuf acturing enteprises?

Using the spillover index, we determined the extent to which foreign firms stimulated spillover occurrence to the locally owned firms. The results produced an average spillover index of 3.31 for the two industries - from both foreign and local firms. Food processing had 3.27 while machine engineering had 3.35. These indexes suggested awerage spillover occurrence into the two industries. However, the spillower index computed for locally owned firms in the two industries from foreign firms was 3.44. while that from locally owned firms was 3.19. By industry, food processing had an index of 3.40 while machine engineering industry had 3.46 with foreign fincs. Index computed from locally owned firms had and index of 3.14 for food processing and 3.23 for machine engineering industry. These results showed that locally owned firms in machine rengineering industry enjoyed more spillovers from foreign fims in comparison to locally owned firms in food processing industry. Moreover, the spillover indexes showed that foreign firms generated more spillowers in the wo industries in comparison to the locally owned firms. These findings were very interesting in that based on the alternative framework considered, they supported our hypothesis that knowledge spillowers occured in locally owned firms from FDI. The findings supported observations and arguments made in Chapter 2,3 and 4.

\section{(iii) What kind of lectwologital spilloners accur most?}

Analysis of the kind of technological spillovers occuring showed that knowledge spillovers occurred most in products and in process. The consequence of this is that there were a lot of technological changes and leaming taking place in products and 
procenses as a result of spillovers. This would be interpreted as high technological capability building in the two compared to the other technological changes considered. These two were followed by marketing strategy. Interestingly, management and organisation, and repairs and maintenance had the lowest levels of spillovers occurrence. Interegtingly allso, in all these kinds of technological changes, foreign firms generated higher spillovers compared to the locally owned firms further supporting our argument that spillover benefirs existed from FDI to food processing and machine engineering industries. It woxild be extremely difficult to generalise due to the sectoral differences in foteign presence noted.

(in) What are the nechanisms through which technological spillowers ocour?

Examination of spillovet mechanisms done showed that the thighest level of technological spillovers was generated by competition and demonstration effects. Staristical comparison by T-Test analysis showed that while there was no statistical difference due to competition and demonstration effects there was statistical and significant diffetence between them and both linkage and labour mobility. This implied that the first two mechanisms were more important mechanisms for spillover occurrence than the latter two in the Kenyan context. These findings were very relevant for enhancing industrial policies pertaining to spillowers. The competition results supported Schumpeterian argument of creative destruction while demonstration effects supported the East Asian imitation and reverse engineering models. Low levels of spillover occurrence by linkage and labour mobility indicated weak linkage systemic cohesion (with low knowledge flow), and labour mobility that generated low technological changes in the system. The results also indicated immature, inefficient and less supportive institutions and business associations in the manufacturing industry. These results motiwate policy interventions in future if the industry must benefit spillovers through linkage and labour mobility mechanisms.

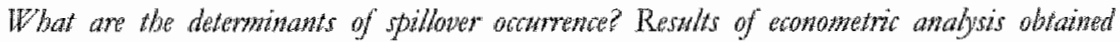
using binary and ondered logit technigues.

Determinants of spillover occurtence were examined using binary and ordered logit estimation techniques. The two techniques enabled consistency checks of the results obtained. Results from our analysis showed that foreign presence had a positive correlation with spillover index - implying that an increase in foreign presence increased spillover occurrence in firms. These findings supported our hypothesis that foreign presence generated positwe technological spillovers in Kenya's manufacturing industry.

Our analysis showed that virtually all of the spillover determinants had the expected signs, were statistically significant and made intuitive sense. Firm characteristics such as. firm size, firm age and age of the machinery had significant and positive influence on spillover occurrence. These results strongly stapported the alternative framework formulated and presented in Chapter: 2. These findings suggested that spillovers were more likely to occur in large firms than in the stmal]. firms; in old firms than in young firms and in frrms with old production machinery than with young machinery. As noted, thrge firms are endowed with the necessary resources to spread over technological changes incurred while age teflected experience accumulated over time. Interestingly, results obtained with age-squared produced a negative correlation that tended to imply a non-linear "inverted-U" spillover occurtence pattern. This meant that more spillovers to the middle aged firms than in the young and old firms. Another important finding obtained showed that Kenyan Asian firms enjoyed mote spillovets compared to nonAsian firms in Kenya. This was not surprisingly in that as outlined in Chapter 2 and 3 
frims owned by Asians in Kenya were more adwanced in terms of resources and sophistication than those owned by indigenous Africans. This placed them in a better position to absorb and ssimilate technological spillovers.

The rariables for infrastructure, institutional support and interactions produced the expected results. This supported our hypotheses that interactions with business, private and public institutions stimulated spillover occurtence. Similarly, absorptive capacity was important for spillover occurrence. This supported our hypothesis that skilled petsonnel are important for spillorer absorption and assimilation. The results of low technological gap were in line with our hypothesis that low technology gap influences on spillover accurrence in Kenyan manufacturing. This finding was also in accordance with the proponents of low technology gap - certain minimum threshold for spillover occurrence.

The results obtained with firm strategy were as expected. A firm with strong strategy to constantly modify and upgrade its processing technology was more likely to obtain high spillovers than one without such a strategy. This would be expected since the process of constant modification and upgrading improves a firm's absorptive capacity. Similarly, it emerged that a firm with a strong training strategy was more likely to have high spillover occurrence than one withour a strong training strategy. This supported our hypothesis that the more a firm undertakes technological training in the more the spillovers were likely to occur.

The results estimated with trade orientation were contrary to expectation. While the results estimated for imports were as expected those estimated for exports were contrary to expectation. The marginal effects estimated for exports implied that exports had a negative influence on spillover occurrence. This seemed to suggest that none exporting firms were introducing many technological changes with lots of things to learn. Results of imports suggested that participating in imports increased spillover occurrence in fims.

The results of labour market conditions were as expected. The variable wages representing labour market conditions had a negative influence on spillover occurrence. This was in line with spillower literatute where good labour market conditions such as payment of efficiency wages, fridge benefits and prudent human resource development practices translates into reducing the mobility of workers hence reducing spillower occurtence.

\subsubsection{Empirical Results Obtained from Case Study Analysis}

\section{(i) Case study Thusmations frow Foreign Firms}

Analysis of spillover occurrence was examined from the angle of foreign firms using ten detailed case studies selected on the basis of analysis done in Chapter 4 and 5 . The case studies were done in line with the analytical framework designed in Chapter 2.

Analysis of the case studies showed that local personnel in the firms considered acquited skills and accumulated experiential knowledge from trainings offered and through learning by doing. Due to their endowment in resources these firms had well organised training supported with good training facilities. On labout market conditions, the firms studied observed good labont ethics; allowed workers to have a union, high wages, transportation, better terms and conditions of service etc. In many cases, skills acquired and knowledge accumulated resulted in an upward intra-firm mobility, hierarchical, of 
the local staff. The analysis done in Chapter 6 presented cases where many locals were promioted to become senior managers and professionals after acquiring work experience.

The case sudies discovered existence of tremendous labour mobility from these firms to locally owned fums. Litetestingly, this mobility involved professionals, engineers, and fechnically skilled workets who gave up their employment to take up new appointments with locally owned firms. This was an important phenomenon in the development of the ICI in industry, (see Ernst et al 1998). Another interesting finding was that some left to start own firms which suggested that FDI played an active role in the industry as a breeding ground tor local entrepreneurs. From the case study firms, such entrepreneurs were able to function due to the skills they acquited while working in these firms. These findings showed that spllowers were occurring through labour mobility from foreign firms. These findings also indicated that FDI was playing an active and positive tole in the human capital development effort of the industry and thus the country.

The analysis showed that firms mainly relied on international sources for the supply of processing and product technology. The implication of this was that no serious process ar product R\&D was conducted in-house. Foreign firms are known to conduct little or no R\&D in host countries (Lall, (1979; 1980); Cantwel, 1995; OECD, 1998; Patel and Vega, 1999; Amsclen, Tschang and Goto, 2001). Nevertheless, all the firms maintained strong technical departments and quality control laboratories. The analysis showed that when ptoducts were locally developed, parent companies were usually involved as they provided technical support. The foreign production technology and participation in production activrites played a role in human capital development. It enabled local employees to accumulate tacit and experiential knowledge gathered from on-the-job training and learning by performing. "The processing machinery and technology obtained were often complex, implying that locals had to be trained to operate, maintain and repait them. Technological trainings often commenced with plant lay out and process installation including commissioning and would ental process operations, process adaptations and maintenance procedures etc. The same case happened with product technology where locals had learnt how to make products including the ones produced under foreign license. Hence, the interesting finding in this was that, through learning by using and by doing; enabled locals to learn from foteign process and product technology.

Analysis of linkages had interesting findings. Cases were identified where demand created by foreign firms through pecuniary linkages with locally owned firms helped the growth of local firms by providing them with capital for growth, investment and expansion. The effort to improve their orders helped them to improve on their capabilitics. Non pecuniary linkages included machine engineering linkages and technical assistance. Reliance on foreign suppliers of machinery and technology reduced local technical links to only maintenance, repairs and sale of machine engineering equipment. Many benefits were noted through these links. Forteign firms engaged local firms in intermediary activities sometimes positioning some of their staff in the local firms to supervise and oversee the processing activities. In such cases, local firms enjoyed spillovers in information sharing, trainings on quality control and production management.

Interactions with institutions and business associations resulted in skills and knowledge sharing and in some cases technical assistance. This was however limited due to the weaknesses of the institutions discussed in Chapter 3. For instance, the cost of finance with the industrial development banks was extremely high. Technology and innovation support was almost not there. In addition, the intrastructure remained poorly facilitated. 
This, it was noted had a negative implication for local firms in the spillover process. However, in some associations foreign firms were observed to have direct and active participation, e.g. KAM. In many cases the firms were active members of KAM with their chief executives holding board membership or chairnanship positions in sectoral commitrees charged with specific tasks. The chief executwes were often foreigners with enomous experience, including international exposure and thus their intenctions with other KAM often resulted in knowledge and expertise sharing in areas such as labour ethics, trade disputes, corporate governance, policy lobbying technique, technology transfer, formation of linkage, strategic alliances and mergers and acquisitions, intellectual property rights etc.

Foreign firms patricipated in the broader national human capacity development by offering fellowships to students in engineering and computing courses as well as professional courses like marketing and business management. Some foreign firms worked closely with government bodies such as Directorate of Indusitrial Training (DIT), Kenya Polytechnic and Mombasa Polytechnic in developing special training programmes. Foreign firms also allowed students from tertiary instioutions to do their industrial internships.

Competition between foreign firms and locally owned firms was stiff - mainly for market. Competition was exacerbated by the onset of liberalisation with increased import into the country. As noted from the foreign firms, the competition pressure forced locally owned firm to introduce technological changes in their operations. This resulted in learning and capability building. Similarly, locally owned. firms benefited demonstration effects from foreign firms. This happened as they copied and imitated production processes or products of foreign firms. From the foreign fums' point of view, local firms benefited ftom a wider set of product portfolio presented to them without having to conduct a prolonged search for products. On the basis of case study illustration, we conclude that foreign presence stimulated spillover occurrence to locally owned firms in Kenya's manufacturing.

\section{(ai) Case Strudy Whastrations from Locally Ouwed Finms}

The findings of our case study illustrations from locally owned firms supported the empirical analysis done in Chapter 5 and 6 . Analysis of the 8 case studies done showed that $\mathrm{HDI}$ in the two industries played a role in leaning, capability development, innovation and performance in locally owned firms. This confitmed spillover occurrence from foreign fims to the locally owned firms.

Although locally owned firms offered training, it was not comparable to the foreign firms training. As a result of resources, employees in foreign owned firms enjoyed better training programmes and superior training facilities. This included exchange programme with foreign firms' parent companies. Locally owned firms still had a lot to learn from foreign firms pertaining to labour market conditions. With regard to labour mobility, interesting cases were identified where professionals, engineers and technically skilled workers had joined locally owned firms from foreign firms. Expatriates from abroad were also observed (MCTL2 and MCTL4). Spillover occurrence as a result of labour mobility was confirmed. The skills and knowledge acquired while in MNCs were extremely useful and applicable in locally owned firms - many technological changes in process, product, orgamisation and marketing etc were introduced. 
Locally owned firms relied on intemational sources for their process and product technology. These firms did not conduct process or product R\&D but only maintained technical deparments and labotatories for quality control checks and to ensure smooth runing in the process. It was interesting to find out that local firms were able to leam and build capabilities based on process and product technology from abroad. The on-job raining and learring by doing enabled accumulation of tacit and expertential knowledge hence human capital development.

Spillowers wete noted with both pecuniary and non-pecuniary linkages discovered. Pecuniary linkages were impottant to the firms in that the demand they created helped the local firm to grow and expand as a result of finance obtained. International linkages with stppliers of production technollogy were characterized by trainings during plant initialisation or during interaction wherever major machine repairs and maintenance have to be undertaken. Technical support was also offered in making products or adopting them to the local serting (FBL4, FBL2, FBL3 and MCTL4).

Spillovers were also discovered in the context of backward linkages. This rook place when locally owned firms obtained production machinery, products, marketing and distribution netwotk from foreign firms in Kenya (FBL1). Due to the trainings involved, it amounted to acquisition of technological spillovers. High level of human capital and availability of finance enabled these firms to enjoy such spillover benefits. As a result, the firm learns, accumulates production capability and becomes innovative. Indirect cases of spillover occurrence were noted when spillovers occurred to locally connected firms. Foreign firms buying from locally owned firms created demand that enabled firms to grow, expand and bivild technological capability as a result of leaming from the orders placed by the foreign firms. The strict conditions offered to the supplying firms forced firms to learn and improve their skills. For example, MNCs encouraged locally owned fitms to achieve ISO certification and improve their efficiency. Indirect cases of spillover occurtrence were also noted with forward linkages.

Local firms' interactions with institutions and business associations did not result in any significant technical, financial, skills or knowledge gain. Institutions in Kenya were weak and performed inefficiently partly due to neglect by the government. As a result of poor support, poor coordination emerges; all of which increases transactions costs lowering spillower occurence. Interactions with and within business and marketing associations were a bit better as firms indicated to have shared knowledge and expertise in areas such as labour ethics, trade disputes, corporate govemance, policy lobbying technique, technology transfer, formation of linkage, strategic alliances and mergers and acquisitions, intellectual property rights etc.

Competition pressure forced locally owned firms to undertake technological changes and learn to innovate. They were also forced to operate more efficiently and introduce new technologies earlier than what would have otherwise been the case. Locally owned firms benefited tremendous demonstration effects from foreign firms through copying and imitation of processes, products etc from foreign firms. This is beneficial as it presents a wider set of process or product portfolio without having to do R\&D for process or process development. The process also involves leaming, trials and errors and in the process, accumulation of capability to innovate. On the basis of these findings, FDI in Kenya's manufacturing is noted to be playing an important role in industrial development through spillovers occurrence that results in leaming, accumulation of technological capability, innovation and enhanced performance. 


\subsubsection{Conclusion}

In light of the aboxe summary, several conclusions emerge Frot that, the results obtained in most spillover analyses are hrgely detemined by the theoretical and analytical methodology used. Thus, altemative methodologies must be aken into consideration before concrete conclusion can be drawn pertaining to the spillower process. Second, that FDI mainly from Britain pioneered in Kenya's manufacturing industry making the country enjoy an early experience from FDI, mainly Britush firms. Thw, that FDI in Kenya"s manufacturing was more dominant on the basis of key indicators of manufacturing performance. Howexer, locally owned firms performed better, tended to be catching up with foreign firms, as observed from the positive growth rates computed. Fownth, that conceptualising technological spillovers in terms of technological leaming and capability building, presence of FDI in manufacturing stimulates spillover occurrence in food processing and machine engineering industries. These results may not be generalised since FDI presence was not equally distributed in all manufacturing sectors and thus each sector need to be examined separately. Furthermore, the rechnological changes as a result of spillovers were different. The implication of these findings is that through spillower occurrence, HDI plays an important role in stimulating rechnological leaming and capability butlding. This appeared to be the case not only in the firms but also in the institutions. Fifb, that despite constraints facing institutions designed to support industrial promotion they played a facilitation role in the spillover occurrence process. As a conclusion; given the importance of technological leatning and capability in the innovation process, we can then argue that FDI directly and indirectly promotes innovation in Kenyas manufacturing industry. These findings were supported by the case study illustrations done in the perspective of foreign and locally owned firms. In sum, the analysis and findings of this study supports our clam that FDI plays an important role in Kenyats industrialisation process.

\subsection{Policy Implications of the Study}

This study has shown that FDI plays an important role in industrial development in the country. In light of this, the analysis done generates some important lessons with wide ramifications for government policy which can be outlined as follows:

\section{1) Poligy Comsistency}

The analysis done showed that manufacturing policies pursued were changed and/or reversed erratically (as was the case since the introduction of SAPS in mid 1980s). A combination of erratic policy changes, inefficient institutions and poor infrastructure makes operations and transaction costs extremely high. This interferes with the technological leaming and capability building process as it cannot thrive under circumstances presented by such an environment. It also makes investors (including FDI) shy away from investing locally. This emphasises the importance of having consistent and carefully formulated industrial policies based on wide consultations among all the stake holders. Cleat long term policies allow firms to formulate long term planning horizons to achieve long term goals. 
The analysis showed that linkages did not generate substantial spillowers implying that existing linkages were less in content in tetms of information, technology, hnowledge, skills etc. Botrowing experiences from other cotntries (e.g. Taiwan or Malaysia in East Asia), industrial linkages have played a vital tole in spurring spillover occurrence for industrial capability development. The government should thetefore come up with more definitve policies geared towards promotion of linkages. Due to the ovenwhelming task involved in this process, the government should create a national linkage promotion programme to deal with all issues related with linkages nationally and intemarionally. Such a progtamme can be referred to as Renga National Linkage Promotion Programwne (KNIPP)". The programme would then deal with issues such as promotion of linkage formation between and among firms, sectors and institutions. This could also include match making domestic firms with MNCs abroad etc. International hinkages would also have to be promoted where embassies and other foreign missions abroad could all be incorporated to assist in this programme. Through this progtamme, MNCs willing to forge linkages should be identified and given first priority. In addition to promoting linkage formation, the programme would also promote deepening the linkages formed in ierms of their content. As an example the linkages should be rich in information, technology, finance, knowledge flow etc.

\section{(3) Absorptive Capacity.}

From our study, absorptive capacity was noted to be an important factor for spillovers to accur. Absorptive capacity can be viewed in terms of human capital and technological capability of firms. First, human capital was very important for spillovers to occur i.e. a pool of well-trained personnel such as professional and managers, scientist and engineers was needed in the firms and institutions. Hence the government need to formulate policies, focused at human capital accumulation particularly in science, technology and engineering. This should be done at firm and national level. Establishment of a stable pool of human capital stock has added advantage "vicious cycle advantage" in that in the long run it would lead to a more entry of FDI seeking skilled labour. Second, in order for the firms to increase their ability to absorb and assimilate spillovers, they need to develop a strong culture of technology development. Policies should be focused at supporting firm learning and innowation in order to build technological capabilities. There should be increased effort in terms of policy to facilitate and encourage formal R\&D in firms. The industry lacked a strong guiding policy and one that encourages an $R \& D$ and innovation culture - only through a culture of vibtant R\&D and innowation that techoology and industrial development can be propelled and in the long-run economic growth. In sum, this would go a long way towards creating science, technology and innovation culture; whose consequences in detecting, absorbing and assimilating spillovers are positive not only to the firm but to the national system of innovation in the country.

\section{(4) Weak and Mising Institwtions}

It was noted that the role played by institutions in the spillover process would have been much higher were it not for their weaknesses in capacity to perform. This implied reduced role in science, technology and other supportive institutions in industrial capability development. Due to the weakened facilitation and coordination role by the institutions, the government needs to re-address its role and come up with policies which will ensure sound running and performance of these institutions. Interviews indicated that the supportive role of the government was declining. We therefore recommend that the government reconsiders its policy stand taking institutional cases, case by case. For 
instance, institutions offering finance for industral promotion must be supported by the government either by providing finance or acting as a guanto for the lown obeined by such domestic institutions from interntional financing osganisations ${ }^{\text {tath }}$. Also instivitions dealing with industrial R\&D should be empowered in tems of broad capacities i.e. human capital and finance to support such R\&D related activies. Through these efforts and much more, this is the only way to promote endogenous industral capabilites necessary for catching-up. No country can claim to have long-run growth without solid industrial capabilities. Finally, the government should provide coordination guidelines to encourage otderly and coordinated development of manufacturing industry, Coordination among institations (private, public, business assoctations etc) in manufacturing industry would remove operating bottlenecks, enhance efficiency and stimulate spillowers from FDI.

\section{(5) Poor Infustruture}

Poor infrastructure emerged to be one of the biggest problems facing furm operations in the country. This makes operation and transaction" cost extremely high. "The consequence is that it lowers interactions among firms and reduces willngness to invest or expand (this makes. FDI reduce or decline from investing). Thus poor infrastructure hinders technological spillovers from occurring. As an example, bad roads and high cost of telephone reduces interactions and thus shating of information, knowledge etc. The government should therefore provide basic infrastructure in earnest [examples include transport and telecommunication, and stable provision of basic utilities such as water and electricity power). Much has been said on this in the Kenyan context; hence the government should do something once and for all. The success story of East Asian countries shows us that a government that does not offer continuous support and effective industrial facilitation often fails its own entrepreneuts.

\section{(6) Interations with Institutions and Bustiness Assowiotions}

Formal and informal interactions with institutions and business associations were important factors in the spillover occurrence process. For instance, interactions created an atmosphere where local entrepreneurs shares manufacturing expetiences, matket information, skills and technological knowledge with foreign firms. The govemment should therefore encourage more of such interactions (formal and informal interactions). It should encourage and facilitate more and routine manufacturing exhibitions, trade fairs and agricultural shows. This should include international exhibitors who in this case could be rechnology, machinery and equipment suppliers or just ordinary manufacturing firms. It should encourage product, process and marketing promotions by foreign and local manufacturers. It should encourage firm and institutional visits. Joint activities such as learning and training should be encouraged. Encourage informal collaborations in activities which reach SMEs and the local communities, through community responsibility programmes, such would widen scope of spillover occurrence. These are just a few examples as cases of useful interactions are endless.

\section{(7) Comperition Policier}

Although the findings in our study showed that competition played an important role in the spillower process, it is also noted that high competition from foreign firms could

\footnotetext{
201 'The interest raves should be maintained at low levels favoumble for industrialists, Only then we can talk of industrial promotion.

201 Most firms noted cited examples whereby due to poor infrastructure that things moved from South Africa to Mombasa port faster than they did from Mombasa to Nairobi industral area Or betrer still from Japan to port of Mombasa pont than from Mombasa port to Namolbi industral arro.
} 
crowd out domestic inwesment. Hence an instirution (bureaucratic instiution) should be established to deal with comperition regulation in manufacturng. From the interviews, the existing competition regulatory body under the Ministry of Finance has been blamed as inefficient and weak in performance hence a new, semi-autonomous institutions "Kenya Competition Regulatory Body (KCRB)" should be established. It should have the capacity to deternine the prevaling competition levels and implement corrective measures in advance. It should assess FDI so that only MNCs with high potential of generating technological spillovers of capabilty development whout crowding out domestic firms are approved to invest in the country. It should have the capacity to examine the complementary capabilitus between foreign and domestic firms. The institution should be highly dynamic with continuous analysis of the invesment climate and technology foresight so that il can adjust its recommendations to the government from time to time. It should collaborate intensively with other institutions.

Examples of countries that benefited a good balance between FDI and competition levels can be invoked. Some NICs triggered endogenous capabiliny development process by opening up to FDI gradually and only letting mote FDI entry with increase in local fims' technological capability. This was in line with the infant industry protection theorem where competition is allowed strategically to exert pressure on the local firms to leam and accumulate technological capabilities. However, a strong bargaining position possessed by some MNCs (and multilateral organisations) is acknowledged but we strongly argue that government must be in a position to select and regulate is manufacturing industry by controlling monopoltes, offering incentives through tax imposition etc. Fot instance, only $\mathrm{FDI}$ that conforms to the country's industrial promotion agenda should be permited. As an example, when Korea was developing its manufacturing industry before 1970 s, its FDI policy was specifically concetned with project eligibility criteria, foreign ownership critertia and investment scale criteria. Foreign ownership and investment scale were tegulated by a ceiling level. On eligibility, projects which would distupt domestic demand and supply of raw materials and intermediate products were ruled out. Also ruled out were projects which would compete in foreign markets with domestic firms (Koo, 1984: p. 69).

\section{(8) Thade Orientation}

Our study showed that imports were important in the spillower pecess. Import of capital goods by NICs enabled them to deepen their technology base. The Kenya govemment should remove import barriers of capital goods, technology, machinery and equipment that could serve as sources of learning and capability development through imitation, replication and reverse engineeting. Also, although exports failed to cortelate spillover accurrence in Kenya, participation in exports should be encouraged as that would force domestic lirms to learn and increase their technological effort in order to compete effectively in the international global market.

\section{(9) Labour Market Conditzons}

Good labour matket conditions are important for industrial growth and development. Hence the government should promote them and in addition promote a culture of labour mobility.

\subsection{Recommendation for Further Research Works}

The study has several suggestions for further future reseatch work, which can be outlined as follows: First, although this study used a substantial amount of data set from secondaty sources; with more resources a longet time span and more firms than was 
used in this study can be considered. A large data set spaning a longer time series is expected to be more illuminating. Such was not avalable at the twre of this study and thus it would be appropriate to repeat the study in future.

Second, the survey focused on only two sectors in manufacturing. There is a need to undertake a more detailed study including more manufacturing sectors especially those with relatively high foreign presence. A case in point is chemical and phamacentical industry. Special economic zones such as export processing zone should be equally studied. In addition, future study should be extended to include more case studies as they were observed to be more revealing. Aggregare analysis did not reveal how spillovers translate to productivity treating the entire process as a black box. Such an approach is however expensive, time consuming, requiring many people and much effort and thus time factor and resources constraint limited us.

Thind, it would also be interesting to conduct simillar studies in other Sub Saharan countries applying the conceptual and analytical framework designed. Other developing and technically backward countries in other parts of the world can also be studied in order to draw comparisons. With the application of this analytical framework, international comparisons of the findings can be made.

Fowkth, given the tremendous shift observed in FDI ${ }^{2 m}$ e.g. the shift to service sector; the conceptual and analytical framework can be extended to these sectors for the examination of FDI and spillover occurrence. In Kenya for instance, service sectors with significant $\mathrm{FDI}$ can be traced to tourism and hotel sectors, finance and insurance sectors as well as in building and construction industry. The approach could also be extended to the agriculture especially the flourishing and successful case of horticulture sector in Kenya. Analysis of FDI and spillovers would shed more light into a wider economic standpoint in Kenya.

Fufib, since we focused on production capabilities and complementary capabilities (marketing, management and organisation capabilities); there is a need to broaden the study and include other kinds of technological capabilities such as investment and linkage capability. Again this is an enormous and daunting task.

Sixth, since this study did not examine technological spillover occurtence from the perspective of FDI origin, there is a need to conduct a study which enables spillover comparisons by MNC's origin. "This recommendation follows an argument and observation that spillovers from MNCs of different countries could be different. "That is MNCs from Europe would be different from America as would do from Asia. Even then, MNCs from the same continent say for instance MNCs from Germany and Britain could also have different spillover experiences. Further, a comparison between MNCs from developed countries and those from advanced developing countries could also be studied for comparisons.

202 UNCTAD (2004) 


\section{REFERENCES}

Abramovitz, M. A. (1986), "Catching Up, Forging Ahead, and Falling Behind", Jowrol of Ecomalatic Histary 66: $385-406$.

Abramowiz, M. A., Ed. (1994). The Origins of the Postarar Cath Up and Connengenate Boom. The Dywanics of Trade, Techology and Growtb, Aldershow Edward Elgar.

Aghion, P. and P. Howitt (1990). "A Model of Growth through Creative Destruction", Economica 60: 323-351.

Aitken, B. and A. E. Harrison (1992). "Does Proximity to Foteign Firms Induce Technology Spillowers?" Mimco, World Bank and International Monetary Fund.

Aithen, B., A. Harrison and R. E. Lipsey (1996). "Wages and Foreign Ownership: A Comparative Study of Mexico, Venezuela, and the Uniced States", Jom of Inalemationat Econaratios 40: $345-371$.

Aitken, B., G. H. Hanson and A. E. Harrison (1997). "Spillovers, Foreign Investment and Export Behaviour", Journal of Internationsal Economid 43: 103-132.

Aitken, B. J. and A. E. Harrison (1999). "Do Domestic Firms Benefit from Direct Foreigr Investment? Exidence from Venezuela", The Amserisan Ecomomic Rewion 89(3): 605-618.

Amin, S. (1973). Growth is not Development, Development Forum, Dakat.

Amin, S. (1976). Unequal Detwelopment. New York: Monthly Review Press.

Amin, S. (1977). Imperialism and Uneawal Development, New York, Harwester and Monthly Review Press.

Amsden, A. H. (1989). Sowth Korea awd Late Industrialisation. New York: Oxford University Press.

Amsden, A. H. (1994). "Why Isn't the whole World Experimenting with the East Asia Model to Develop? Review of the East Asian Miracle", W'ordd Depietopment 22(4): 627-634.

Amsden, A. H., T. Tschang and A. Goto (2001). Do Foreign Companies Conduct R\&D in Developing Countries? A New Approach to Analyzing the Level of R\&D, with an Analysis of Singapore ADB Tolizy, Asian Dewelopment Bank Institute.

Aoki, M. (2001). Tanawds a Comparatin Institutional Analysis, Cambridge: MIIT Press.

Arrow, K. J. (1962). Economic Welfare and Allocation of Resources for Inventive Activity, in The Rate and Dinctiow of Resowres for Inwentive Astivity. R. R. Nelson (Ed.) Princeton: Princeton University Press.

Arrow, K. J. (1962). "The Economic Implications of Leaming by Doing", Rewew of Exomomit Stndiey XiX.

Audretsch, D. and A. Zoltan (1991). Imnowation and Tedonotogieal Connge: An Intemationat Componrom. Ann Arbor: University of Michigan Press.

Audretsch, D. (2002). "The Dynamic Role of Small Firms: Evidence from US", Smalt Business Economics 1(3): 13-40. 
Bain, J. (1968). Indutrial Opanisation, New York; John Whey and Sons.

Baran, P. (1957). The Poldical Economy of Growth, New Yotk: Monthly Review Press.

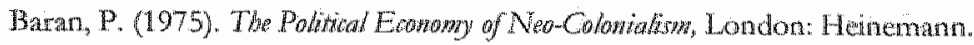

Barnes, J. and J. Lotentzen (2003). Learning Upgrading, and Innotation in the South African Automotive Industry. Paper presented at the International Workshop FDI-Assisted Development, Oslo 22-24 May 2003.

Batrios, S., H. Gorg and E. Strobl (2003). "Explaining Fitms' Fisport Bahariout: R\&d, Spillovers and the Destination Market", Oxford Bulletin of Emomomics $65(475496)$.

Barro, R. and J.-W. Lee (1993). "Tntemational Comparisons of Educational Aetainment", Jound of Montugy Econominto 32:361-394.

Barro, R. and J.-W. Lee (1994). Sources of Econonic Growth. Carnegie Rochester Conference on Public Policy.

Basant, R, and B. Fikkert (1996). "The Effects of R\&D, Foreign Technology Purchase and Technology Spillovers on Productivity in Indian Firms", "The Review of Eowanics and Statistics 78(187-199).

Behrman, J. and H. Wallender (1976). Transferring of Manufaturing Techmology mithin Multinational Enterphises, Cambridge, Massachusetts, Ballinger.

Belderbos, R. and G. Capannelli (2001). "Backward Vertical Linkages of Foreign Manufacturing Affliates: Evidence from Japan Multinationals", World Deptopment $29(1)$.

Bell, M., D. Scott-Kemmis and W. Satyarakwit (1982). Limited Leatning in infant industry: A Case Study, in The Economict of Nen Tetonology in Developing Coumtries. F. Stewart and I. James (Eds.) London \& Colorado: Frances Princer \& Westview Press.

Bell, M. (1984). Learning and the Accumulation of Industral Technological Capaciry in Developing Countries, in Todmologiod Capalozity in the Thwol World M. Fransman and $\mathrm{K}$. King (Eds.) London: Macmillan Press Jutd.

Bell, M. and K. Pavitr (19,2), Accumulating Technological Capability in Developing; Countries. Proceedings of the World Bank Annual Conference on Derclopment: Economics.

Bell, M. and K. Pavitt (1993). "Technological Accumulation and Indusurial Growth: Contrats between Deweloped and Developing Countries", Iwdustrial and Conporate Change 2: 157. 210.

Benhabib, 1. and B. Jowanovic (1991). "Externalitics and Growth Accounting", Amoricam Economic Remies 81(1): 82-113.

Benhabib, J. and M. M. Spiegel (1994). "The Role of Human Capital in Economic Development: Evidence from Aggregate Cross-Country Data", Jounaf of Momefary Ecowamios 34: 143-173.

Best, M. H. (1990). The New Competition: Institutions of Industrial Restridtuing, Massachusetts: Havard Univetsity Press. 


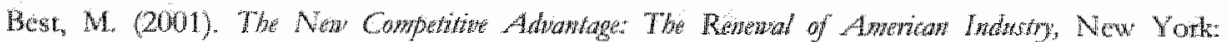
Oxford Unwersity press.

Bigeten, A. and P. Kimuyu (2002). Sitructure and Performance of Manufacturing in Kenga, in Shather on the Afram Econvomids. P. Collier and J. W. Gunning (Eds.) New York: Palgrave Publishers.

Blomstrom, M and H. Persson (1983). "Foreign Investment and Spillover Efficiency in an Underdeveloped Econony: Evidence from the Mexican Manufacturing Industry", Word Demlogsyen 11(6): 493-501.

Blomstrom, M. (1986). "Multinationals and Matken Structure in Mexico", World Depelophsent $14(4): 523-530$.

Blometrom, M. and M. Zejan (1991). "Why Do Multinational Firms Seek Out Joine Ventures?", Jownal of luternational Developwen 3(1): 53.63.

Flomstrom, M. A. Kokko and M. Zcjan (1992). "Host Country Compertion and Technology Transfer by Multinationals", NBBER working paper No. 4131.

Blomstrom, M., A. Kokko and M. Zejan (1994). "Host Country Competition, Labour Skills and Technology Transfer by Multinationals", Welwwintshaftholes Arthe (Band $130): 521-533$.

Blomstrom, M. and E. Wolf (1904). Mulunational Corparations and Producrivicy Convergence in Mexico, in Convergence of Prvduthing: Crors-Nationd Studier and Historical Evadente. W. Bamol, R. Nelson and E. Woll (Eds.) Oxford: Oxford University Press.

Blomstrom, M. and A. Kokko (1997). "How Foreign Inwestment Affects Host Countries." A Policy Research Working paper No. 1745. The World Bank International Economics Department, International Trade Division.

Blonstrom, M. and A. Kokko (1998). "Multinational Corporations and Spillovers", foumal of Econonnit Swoy 12: $247-78$.

Blomstrom, M. and 1H". Sjoholm (1999). "Technology Transer and Spillovers: Does Local

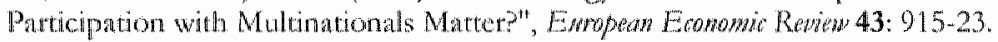

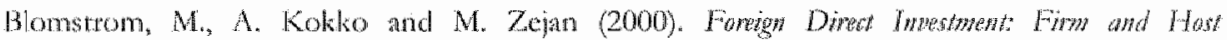
Commtry Strateghes, London and New Yotk: Macmillan Press Ltd and St. Martins Press, Inc.

Borensztein, F., J. D. Gregorio and J-W Lee (1995). "How Does Foreign Direct Investment Affect Economic Growth", NBER Working Paper No. 5057.

Brusco, S. and C. Sabel (1981). Artisan Production and Economic Growth, in The Dynamis of Labou Marke Signentation. F. Willkinson (Ed. London: Academic Press.

Brusco, S. (1982). "The Emilian Model: Productive Decentralisation and Social Integration", Cambrige Jound of Eronomise 6(2): 167-84.

Buckley, P. J. and M. Casson (1976). The Forture of the Mwtituational Entesprise London, Macmillan. 


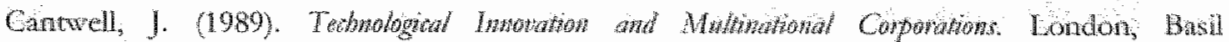
Blackwell.

Cantwell, J. (1995). "The Globalisation of Technology: What Remains of Product Cycle

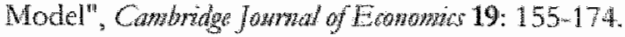

Cantwell, J, Ed. (1999). Foreign Diret Imwathest and Tedmical Change UK and USA: Edward Eilgar Publishing limited.

Cardoso, F. H. (1977). "The Consumption of Dependency "Theory in the United States", Lahin Anerican Research Rewien 12(3):7-24.

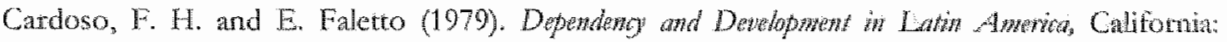
University of California.

Caves, R. (1974). "Multinational Firms, Competition and Productivity in Host-Country Markets", Economica 41(162): 176-93.

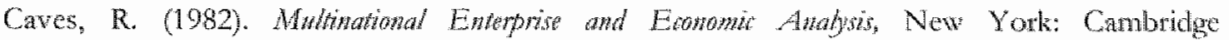
University Press.

Chabari, N. (1999). The Political Ecomomy of Export Processing Zomes: The Ratyan Case. Nairobi: University of Nairobi.

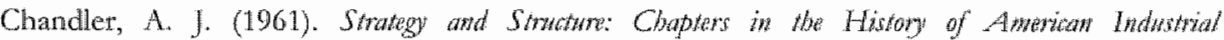
Exiterprise, Cambridge: MTT Press.

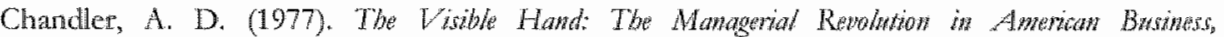
Cambridge, Massachusetts: Harward University Press.

Chang, H.-1. (1994). The Politial Erowomy of Industrial Poligy, Basingstoken Macmillan.

Chudnovsky, D. (1988). "The Diffusion and Production of Numerically Controlled Machine Tools with Special Reference to Argentina", WForld Detulopment 16(6): 723-732

Coe, D. T. and E. Helpman (1995). "International R\&D Spilloxers", Enoropean Euonomic Reway 39(5): 859-87.

Cohen, W. M. and D. A. Levinthal (1989). "Innovation and Learninge The Two Faces of R\&D", Economit Jouma/99(397): 569-596.

Cohen, W. M. and D. A. Levinthal (1990). "Absotptive Capacity: A new Perspective on

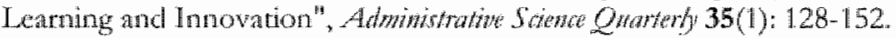

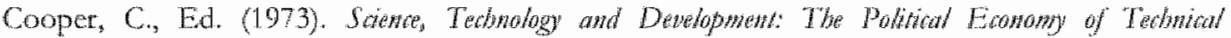
Adname in Underderetoped Cowntriss. London, Frank Cass.

Cooper, C. (1980). Policy Intervention for Technological Innowation in Developing Countrics, Washington, World Bank.

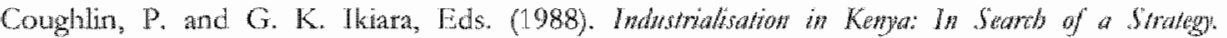
Nairobi \& London, Heincmann Kenya \& James Currey UK.

Coughlin, P. and G. K. Ikiara, Eds. (1991). Kengy's Indathitasation Ditemma, Nairobi, Kenya: Heinemann Kenya Limited. 
Criscudio, P. and R. Wandla (2002). "A Nowel Approach to National Technological Aceumulation and Absoptive Capacity; Aggregating Cohen and Levinthal", Working Paper No.15, Oslo TTK.

Criscuolo, P. (2004). R\&D Internationalisation and Knowledge Transfer: Impact on MNES and their Home Countries. Unpublished P.h.D. thesis MERT: Maastricht University.

Dahlman; C. and L. Westphal (1982). Technologicall Effort in Industrial Development: An

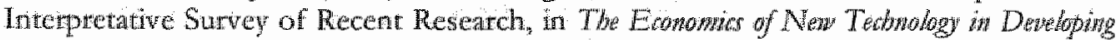
Cowntries. $\mathbb{E}$. Stewart and J. James. London (Eds.) Frances Pinter (Publishers), London Westriew Press, Boulder, Colorado.

Dahiman, C. J., B. Ross-Latson and I. E. Westphal (1987). "Managing Technological Development; Lessons from the Newly Industrialising Countries", Warld Dewelopment $15(6): 759-776$.

Dahlman, C. and R. Nelson (1995). Social Absorptive Capability, National Innovation Systems and Economic Development, in Sotial Capabitity and Lang Tirm Eanomit Growth. B. Koo and D. Perkins: 82-122 (Eds.) London, Macmillan.

Das, S. (1987). "Externalities and Technology Tramsfer through Multinational Corporacions. A Theoretical Analys is", Journal of Intornationad Ecomomics 22(1-2): 171-182.

David, P. A. (1992). Knowledge, Property, and the System Dynamics of Technological Change. Proceedings of the World Bank Annual Conference on Development Economics, The International Bank for Reconstruction and Development/World Bank.

Departments of Economics, Gothenburg and Nairobi University (1994). Limitations and Rewards in Kenya's Manufacturings Sector: A Study of Enterprise Development, Washington DC: World Bank.

Diankov, S. and B. Hoekman (1998). "Foreign Investment and Productivity Growth in Czech Enterprises", World Bank Economic Review: World Bank.

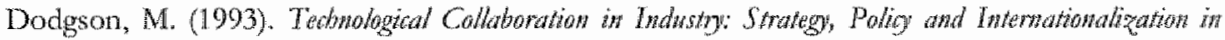
Imrovarion, London: Routledge.

Doner, R. (2001). Instirutions and the Tasks of Economic Upgrading. Paper Prepared for Delivery at the 2001 Annual Meeting of the American Political Science Association, San Francisco.

Dosi, G., C. Freenam, I.. Soete and G. Silversberg Eds. (1988). Tedmical Change and Economic Thoon, London: Pinter.

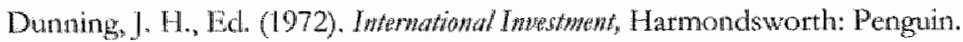

Dunning, J. H. (1973). "The Deteminanis of International Production", Oxford Economits Papers 25: $289-336$.

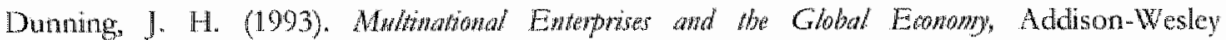
Publishing Company.

Dunning, J. H. (1994). "Multinational Enterprises and the Globalisation of Innowatory Capacity", Researd Manogenzent and Planning 23(1):67-88. 
Edquist, C. (1997). Systems of Innovation: Technologies, Instimutions and Omganizations, London, Science, Technology and the International Political Economy.

Eglin, R. (1978). The Oligopolistic Structure and Competitive Chamacteristics of Foreign

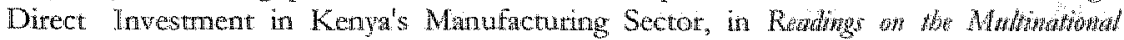
Camponation in Kevya. R. Kaplinshy (Ed, Naitobi: Heineman.

EPZA (2002). Information and a Guide for Prospective EPZ Investors, Nairobi, Kenya: EPZA.

Enst, D., L. Mytelka and T. Ganiatsos (1998). Technological Capabilines in the Context of

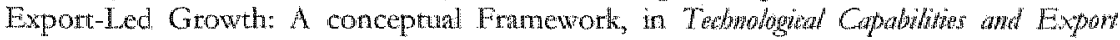
Sweess in Asia. D. Emst, T. Ganiatsos and L. Mytelka (Eds.) Lonclon: Routledge.

Ernst, D. (2000). "Inter-organisational Knowledge Outsourcing: What Permits Snall Taiwanese Firms to Compere in the Computer Induscry?", Asta Pation Jownat of Mantagemut 17(2): 223-55.

Findlay, R. (1978). "Relative Backwardness, Direct Foreign Investment, and the Transfer of Technology: A Simple Dynamic Model", Qnariery Joumal of Enowomits 12(1): $42-56$.

Fosfuri, A., M. Motta and T. Ronde (2001). "Foreign Direct Investment and Spillovers "Through Workers' Mobility", Jantwal of International Economicr 53: 205-222.

Frank, A. G. (1973). Dewelopment of Undeddepelopment. Poldical Economy of Deuelopment and Underdevelopment, New York: Random House.

Frank, A. G. (1978). Dependent Anwazsdation and Utudendewelopment, London: Macmillan.

Fransman, M. (1984). Technological Capability in the Third World: An Overview and Introduction, in Tedonologital Capability in the Third Word. M. Fransman and $K$. King (Eds.) London: The Macmillan Press Ltd.

Fransman, M. (1985). "International Competitiveness, Technical Change and the State: "The Machine Tool Industries in Taiwan and Japan", Horld Developmem 14(12): 1375-1396.

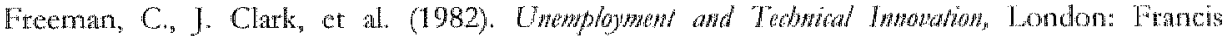
Pinter.

Freeman, C. (1987). The Case for Technological Determinism, in In/orwation Tedwhogy: Sorial Iswex. R. Finnegan, G. Salaman and K. "Thompson (Eds.) 3rd Impression. London: Hodder and Stoughton; etc

Freeman, C. (1991). "Nerworks of Innovators: A Synthesis of Research Issues." Reseand Polig 20: 499-51.4.

Freeman, C. (1995). "The National System of Innowation in Historical Perspective" , Cowmbrige Journal of Economic $19(1)$.

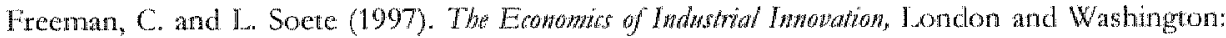
Pinter.

Furtado, C. (1973). The Structure of External Dependence, in Political Economy of Divelopment atd Underdeselopment. C. K. Wiber (Ed.) New York: Random House. 
Gachurw; G. (1998). Fiscal Policy and Economic Growth in Kenya An Econometric Approach. Unpublished master thesis, Economics Department. Universiry of Chastat, Legon.

Gachino, G. G. (2003). "Foreign Direct Imrestment, Export Performance and Capability Building: Evidence from Kenyan manufacturing Industry." Paper presented at the Intemational Workshop Transnational Compotations, Technological Capabilities and Competiveness: Evidence from Africa, Asia and Latin America, Institute for New Technologies, United Nations University, Maastrichr, 1920 May 2003.

Gachino G. and R. Rasiah (2003) "Labour Productivity, Exports and Skills Formation: Comparing Foreign and Local Firms in Kenyan Manufacturing." Paper presented at the Intemational Workshop FDI-Assisted Development, Oslo 22-24 May 2003.

Gerff, G. (1994). The Organisation of Buyer-Driven Global Commodity Chains: How U.S. Retailers Shape Overseas Production Networks, in Compnodity Chatns and Global Capifalissz. G. Gereffind M. Korzeniewicz (Eds.) Westport, Connecticut, London: Praeger.

Gerff, G. (2002). "Intenational Competitiveness in the Global Apparel Commodity Chain", International Journal of Business and Sociely $3(1): 1-23$.

Gerschenkron, A. (1962). Econtomic Barkswardness in Histarial Perspettite, Cambridge, Havard: University Ptess.

Gershenberg, I. (1987), "The Training and Spread of Marnagerial Know-How, A Comparative Analysis of Mulunational and Other Firms in Kenya", World Dewelopment 15(7): 931-939.

Glenday, G. and D. Ndii (2000). "Trade Liberalization and Customs Revenues: Does Trade Libetaization Lead to Lower Customs Revenues? The Case of Kenga", African Economic Policy Discussion Paper No. 44.

Glenday, G. and D. Ndii (2000). "Export Platforms in Kenya", Center for International Development, Harvard University, Working Paper No. 43.

Globerman, S. (1979). "Foreing Direct Investment and Spillover Efficiency Benefits in Canadian Manufacturing Industries", Canadian formal of Economics 12(1): 42-56.

Gomes-Cassetes, B. (1989). "Ownership Structures of Foreign Subsidiaries: Theory and

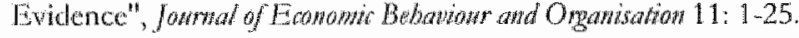

Gorg, H., E. Strolbl and F. Walsh (2002). "Why Do Foreign Fitms Pay More? "The Role of Onthe-fob Training", Discussion Paper 590, 12A Bonn..

Gorg, H. and D. Greenaway (2003). "Much Ado About Nothing? Do Domestic Firms Really Benetit from Foreign Direct Invesment?", World Bank Research Observer.

Green, W. H. (2002). Econometric Anatysis, London: Prentice-Hall linternational.

Greenaway, D., N. Sousa and K. Wakelin (2004). "Do Indigenous Firms Learn to Export from Multinationals", Ewopean fowm of Political Econony 19.

Griliches, Z. (1979). "Issues in Assessing the Contribution of Research and Development to Productivity Growth", The Bell Joumal of Eomoman 10(1): 92-116.

Griliches, 7 and F. Lichtenberg (1984). "Interindustry Technology Flows and Productiving Growth: A Re-examination", The Rewizy of Erowomics and Statistic lxvi(2): 324-329. 


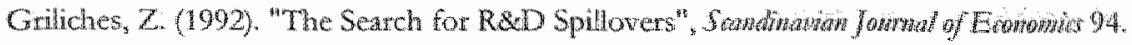

Grossman, G. M. and E. Helpman (1991). "Trade, Knowledge Sphlowers and Growt", Europecan Eanosmit Rentraw 35: 517-526.

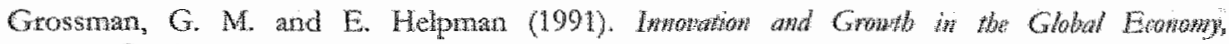
Cambridge MA: MJT Press.

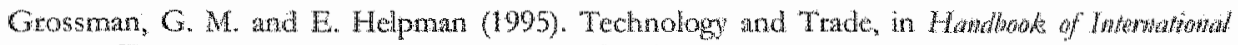
Eromomics. Gr. Grossman and K. Rogoff (Eds.) Elscvier Science.

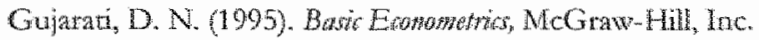

Haddad, M. and A. Farrison (1993y. "Ate There Spillovers from Direct Foreign Investment? Evidence from Panel Data for Mortoco", Jommal of Ditelopment Exwomica 42(1): 51 -74.

Harrison, A. (1996). Determinants and Effects of Ditect Foreign Investment in Cote

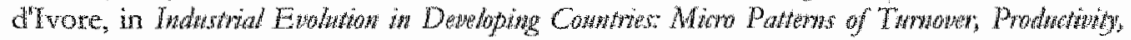
and Market Strutare. M. J. Roberts and J. R. Tyboue (Eds.) Washington: Oxford Universiny Press.

Helleiner, G. K. (1973). "Manufactuted Exports from Less-Developed Comtries and Multinational Firms", The Economato fosymal $83(329): 21-47$.

Hill, H. (1982). "Vertical Inter Fin Linkages in LDCs: A Note on the Philippines", Oxford Buhetim of Eronomics and Stonistio 44(261): 261-271.

Himbara, D. (1994). "The Failed Africanisation of Commerce and Industry in Kenya", Wrord Development 22(3): 469-482.

Himbata, D. (1994). Kenva Capitalists, the State, and Detwipament, Boulder, Collotado: Lynne Rienner Publishers.

Hirschman, A. O. (1958). The Strategy of Economic Development (New haven: Yale University Press).

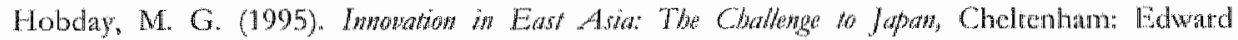
Elgar.

Hveem, H. (1975). The Extent and Type of Direct Foreign Investment in Africa, in Mathinatiower Fons in Afria. C. Widstrand. Uppsala (Ed): Scandinavian Institute of A frican Studies.

Hymer, S. (1960). The Intemational Operations of Nationat Fisngs: A Study of Dirat Fondign Inwestment, Massachusets, Published 1976 Cambridge, Massachuserts: MIT Press.

IDB (2002). Services, Scope, Policies and Operating Procedures. Nairobi, Kenya, Industrial Development Bank Limited (Kenya).

IDB (2002). Tariff Guide. Nairobi, Kenga, Industrial Development Bank Limited.

Ikiara, G. K. (1988). The Role of Governement Institutions in Kenya's Industrialisation, in Industriationtion in Kerga. P. Coughlin and G. K. Ikiarn (Eds.) Nairobi, London: Heinemann Kenya, James Cutrey. 
Ikiara, G. K. and W. Odhiambo (2001). A Revicw of the First Decade of Kenya's Export Processing Zones, 1990-2000, University of Wairobi.

IPC (2001). Kenya Invesment Guide: Promoting Irvestment in Kenya. Nairobi, Invesment Promotion Centre.

Jaffe, A. B. (1986). "Technological Opportunity and Spillowers of R\&D: Evidence from Firms" Patconts, Profits, and Market Value", The Amavican Econowi Review 76(5): 984-1001.

Jaffe, A. B. and M. Trajtenberg (1999). "International Knowledge Flows: Evidence from Patent Citations", Economics of Ingmovation axd Nen Tedbologies 8(1): 105-136.

Jenkins, R. (1990), "Comparing Foreign Subsidiaries and Local Firms in LDCs: Theoritical Issues and Empiricall Evidence", Jouryal of Detelopingent Stadies 26: 205-228.

Jotgensen, J. ). (1975). Multinational Corpotations and the Indigenization of the Kenyan Economy, in Muthinationat Fim in Africa. C. Widstrand (Eds.): Uppsala.

Jovanovic, B. (1982). "Selection and the Evolution of Industries" "Econometria 50(3): 649-70.

Kaldor, N. (1957). "A model of Ficonomic Growth", Economic Joumal 67: 591-624.

Kaplinsky, R. (1978). Technical Change and the Multinational Corporation: Some British Multinationals in Kenya, in Readings on the Muthmational Conponation in Kenyas. R. Kaplinsky (Ed.) Nairobi, Heinemann.

Kaplinsky, R, Fud. (1978). Readings on the Mtrlinational Conporations in Kenya, Nairobi: Heinemann.

Kaplinsky, R. (1984). "Indigenous Technical Change: What Can We Learn from Sugar Processing", World Dingelopsyent 12(4): 419-432.

Katz, J. M. (1969). Production Funtions, Fondgy Imseswont and Growth, Amsterdam: North Holland.

Katz, J. and E. Ablin (1979). "From Infant Industry to Technology Exports: The Argentine Experience in the International Sale of Industrial Plants and Engineering Works, Buenos Airen, IDB/ECIAN", Research Programme in Science and Technology, Working Paper No. 14.

Kara, J. M. (1985). Domestic Technological Innovarion and Dynamic Comparative Advantages: Further Reflection on a Comparative Case - Study, in International Technology Trangfor: $\mathbb{N}$. Rosenberg and C. Frischtak (Eds.) Now York: Praeger.

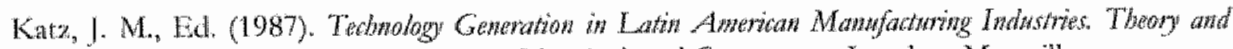
Case Studes Conterning its Nature, Magnitude and Consequtwhes, London: Macmillan.

Kayizai-Mugerwa, S. and P. Kimuyu (2002). Infrastructure and Fnterprise Performance, in Shroture and Perforysance of Mawafacturing in Kenya. A. Bigsten and P. Kimulyu (Eds.) New York: Palgrave Publishers.

Keller, W. (1990). "Absorption Capacity: On the Creation and Acquisition of Technology in Development", Jownal of Demeloponent Enowomics 49: 199-227.

Kenya Government, The Seventh National Development Plan (1994). Resource Mobilisation for Sustainable Development, Natrobi, Kenya: Government Publishers. 
Kenya Gowernment, Sessional Paper No.2 (1997(a)). Industrial Trunsfomntion to the Year 2020, Nairobi, Kenya: Government Publishers.

Kenya Gowemment, The $8^{\text {t }}$ National Development Plan (1997(b)). The gth National Development Plan 1997-2001, Nairobi, Kenya: Gowernment Publishers.

Kenya Economic Survey (Various Issues). Nairobi, Kenya, Government Publishers.

KIE 2003y. Kenya Indiustral Estates: Financing for Small Solle Industries since 1967, Nairobi Kenya: Kenya Industrial Estates.

Kim, L. and H. Lee (1987). "Patterns of Technological Change in a Rapidly Developing Country: A syathesis", Tednowation 6(4):261-276.

Kim, L. (1988). "Technological Transformation in Korea and its Implications for other

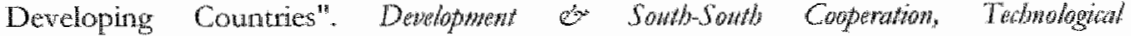
Transformation of the South IV( 7): 19-29.

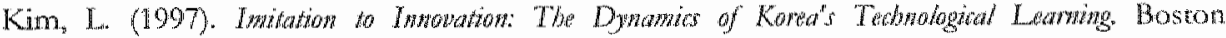
Massachusetts: Harvard Business School Press.

Kim, L. (1999). Leannug and Innowation in Econonic Dexelapment, Massachusetts, Chelteriham; Edward Elgar Publishing, Inc.

Kirmuyu, P. and Kayizzi-Mugerwa (1993). "Infrastructural Assymetrics in Kenya's Manufacuring Sector", Background Paper.

Kimuyu, P. (1999). Structure and Performance of the Manufacturing Sector in Kenya, in

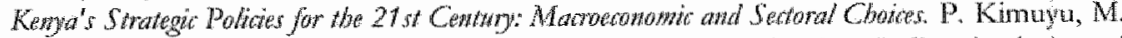
Wagacha and $O$. Abagi (Eds.) Nairobi, Kenya: Institute of Public Policy Aratysis and Reseatch (IPAR).

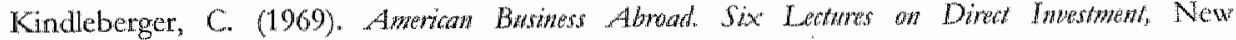
Haven and London: Yale Unwersity Press.

Kinoshita, Y. (2000). "R\&D and Technology Spillovers via FDI: Innowation and Absorptive Capacity", CEIRGE-EI, Mimeo.

KIPPRA (2001). Legal and Other Constraints on Access to Financial Services in Kenya, Kenya Institute of Public Policy Research and Analysis.

Kline, S. J. and N. Rosenberg (1989). An Overview of Innowation, in The Positive Sum Stuttgy: Harwessing Technology for Eoonomic Growth. R. Landan and N. Rosenberg (Eds.) Washington, DC: National Academy Press.

Koizumi, T. and K. J. Kopecky (1977). "Economic Growth, Capital Movements and the

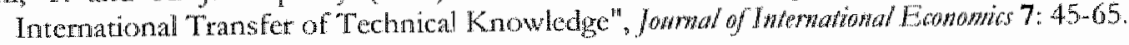

Kokko, A. (1994). "Technology, Market Characteristics, and Spillovers", Journat of Demetopyzent Eronomics 43(2): 279-293.

Kokko, A. and M. Blomstrom (1995). "Policies to Encourage Inflows of Technology through Foreign Multinationals", World Development 23(3): 459-468. 
Kokko, A, R. Tansini and M. Zejan (1990. "Jocal Technological Capabilicy and Producrity

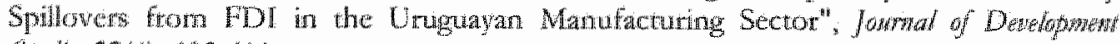
Sindiat $32(4): 602-611$.

Kokko. A. (1996). "Pitoductivity Spillovers from Competition between Lacal Firms and

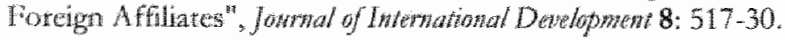

Kokko, A. M. Zejan and R. Tansin (2001). "Trade Regimes and Spillover Feffects of

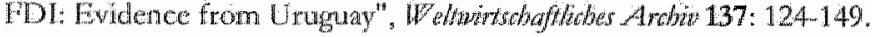

Kracmer, K. J. and J. Dedeick (2003). "The Information Technology Sector and International Competitiveness", Intematrowal Jourtyat of Business and Saciey 4(2): 111-34.

Krugman, P. (1979). "A Model of Tnnovation, Technology Transfer and the World Distribution of Income", Jaurnal of Polinical Econowy 87: 253-266.

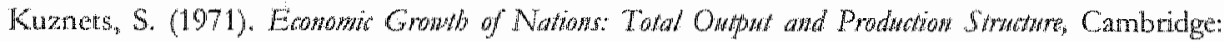
Harvard University Press, USA.

Jall, S. (1978). "Transuationals, Domestic Enterprises and Industrial Structure in LDCs: A Survey", Oxford Economic Papers 30:217-248.

Lall, \$. (1979). "Mutinationals and Marker Structure in an Open Developing Economy: The Case

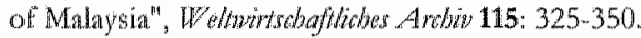

Lall, S. (1980). The Mwhnowowat Compomion, London and Basingstoke: The Macmillan Press Lid.

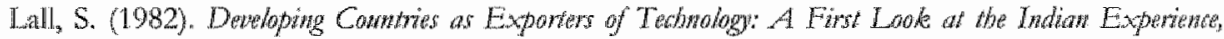
London: Macmillan Press.

Lall, S., Ed. (1985). Multinatiowalls, Tedonalogies and Expons: Selected Papers, London: The Macmillan Press Lid.

Lall, S. (1987). Lenwing Industriatise: The Anquisition of Tethological Capability by India, London: Macmillan Piess.

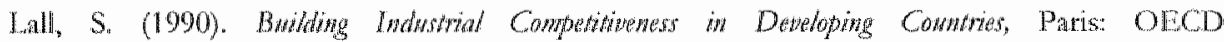
Development Centre.

I.all, 5. (1992), "Technological Capabilities and Industrialisation", W" orld Dew/opment 20(2): 165186.

Latl, S., G. B. Navaretti, S. Teitel and G. Wignaraja (1994). Tebonology and Enterprise Denelopment:

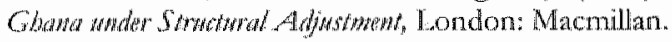

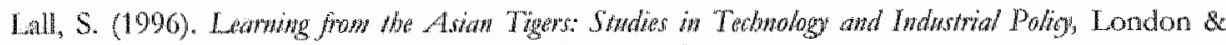
New York: Macmillan Press Ltd \& St. Martin's Inc,.

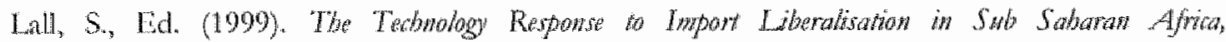
London: Macmillan.

Lall, S. (2001). Competitimewer, Tedwology awd Skills, London: Edward Elgar Publishing.

Lall, S., and C. Pierrobelli (2002). Failing to Compete: Technology Denelopment and Tedhrolngy Sysom in Afrom. Cheltenham, UK: Edward Elgar 


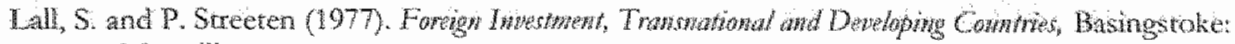
Matcrillan

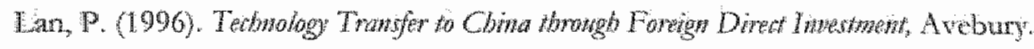

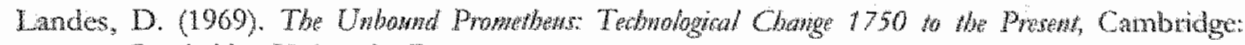
Cambridge Universiry Press.

Langdon, S. and M. Godfrey (1973). Partners in Underdevelopmene The Transnationalisation Thesis in a Kenyan Context. Paper Presented at MDS, Sussex.

Langdon, S. (1978). Multinational Corporations in the Political Economy of Kenya, in Reading on the Multinational Coptorations in Kenya. R. Kaplinsky (Ed.) London: Macrillan.

Langdion, S. (1981). Muthinational Copporations in the Politial Eoonomy of Kenya, London: Macmillan.

Langdon, S. (1984). Indigenous Technological Capability in Africa: The Case of Textiles and

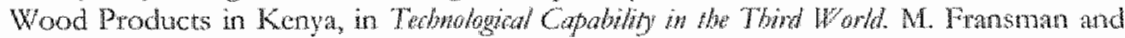
K. King. London (Eds.), The Macmitlan Press Lud.

Lankhuizen, M. (1996). "Catching up, Absorption Capability and the Organisation of Human Capital", MERIT Working Paper.

Lapan, H. and P. Bardhan (1973). "Localized Technical Ptogtess and Tronsfer of Technology and Economic Development", Joutrial of Economit Theory 6(6): 585-595.

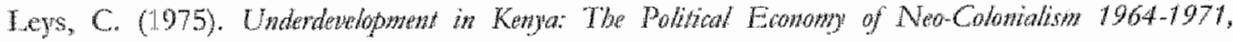
Nairobi: Heinemann.

Leys, C. (1996). The Rise and Fall of Denelopment Theom, Nairobi Kenya: East AFican Echeational Publishers.

I.in, Y. and R. Rasiah (2003). "Structure, Technical Change and Government Intervention: The Development of the Information Hardware Electronics Industry in Tawan", International Jowrwal of Business and Sorieg 4(2): 135-71.

Lipsey, R. and F. Sjoholm (2001), "Foreign Direct Investrment and Wages in Indoncsian Manufacturing", NBER Wotking Paper (8299).

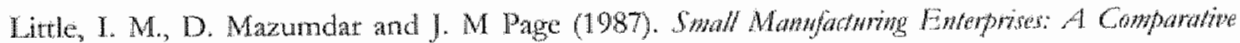
Anatysis of Istia and Other Econowiz, London: Oxford Uniwersity Press.

Litu, X., C. Wang and Y. Wei (2001). "Causal Links between loteign Direct Inwestment and Trade in China", China Eronamic Rewien 12(2-3): 190-202.

Logan, I. B. and M. Kidane (1993). "MM-World Bank Adjustment and Structural Transformation in Sub-Saharan Affica" "Economic Geogroply 69(1): 1-24.

Lucas, R. E. J. (1988). "On the Mcchanics of Economic Dewclopment", Jowrthat of Mondary Eronomics $22(1): 3-42$.

Lundvall, B. A. (1988). Innovation as an Interactive Proces: From User-Producer finteraction to the National System of Innovation, in Tedhital Change and Enowomie Theog. G. Dosi, C. Freeman, R. Nelson, G. Silverberg and L. Soete (Ecls.) London and New York: Pinter Publishers. 


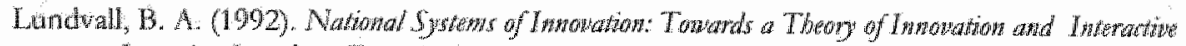
Larying London: Francis Pinter.

Ufundvall, B.-A. and S. Borras (1997). The Globalising Learning Economy: Implications for Innovation Policy, Report Based on Contributions from Seven Projects under the TSER Programme. DGXI, Commission of the European Union.

Lundvall, B. A. (2000). Promoting Innowation Systems as a Response to the Globalising Latning Economy, Aalborg Uniwetsiry.

Lundvall, K. and G. B. Battese (2000). "Firm Size, Age and Efficiency: Evidence from Kenyan Manufacturing Firms", The Jownd of Development Swadies 36(3): 146-163.

Maddala, G. S. (1983). Limited Dependent and Quathative Variables in Economedriv, Cambridge: Cambridge University Press.

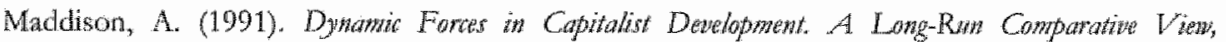
Oxford: Oxford University Press.

Mansficld, E. (1961). "Technical Change and the Rate of Imitation", Econometrita 29(4):741-766.

Mansfeld, E., D. Teece and A. Romeo (1979). "Overseas Research and Development by USBased Firms", Fonomita 46: 187-196.

Mansfield, $\mathbb{E}$ and A. Romeo (1980), "Technology "Transfer to Overseas Subsidiaties by U.S. Based Firms", Quateryy Jommal of Economics 95; 737-50.

Mansfield, E. (1985). "How Rapidly Does New Industrial Teclnnology Ieak Out", The Jowryal of Ind dustriat Economics 34.

Matshall, A. (1890). Principles of Economics. An Introductory Voluwe, London: Macmillan.

Maurseth, P. B. and B. Verspagen (2000). "Knowledge Spillovers in Europe. A Patent Citations Analysis." Seandinawian Journal of Economics 104(4): 531-545.

Mazundar, D. (1995). Wage Differences by Size of Enterprise in African Manufacturing Regional Programme on Enterprise Development Paper. Washington, Wond Bank.

Mazumdar, D. and A. Mazaheri (2003). The African Manufadtring Fitzm An Anabsis Based on Finn

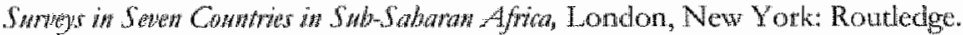

McAlecse, D. and D. McDonald (1978). "Employment Growth and Development of Linkages in Foreigm-Owned and Domestic Manufacturing Enterprises", Oxfort Bultetin of Ecowomita and Statisfics 40: 321-339.

Metcalie, S. (1989). Evolution and Economic Change. Techology and Economic Progress. A. Silberston (Ed.) Jondon: Macmillan.

Willer, R. $\mathbb{R}_{2}$, I. D. Glen, F. Z. Jaspersen and Y. Karmokolias (1996). "International Joine Ventures in Developing Countries: Happy Marriages? Statistics for 1970-95", IFC Discussion Paper Number 29.

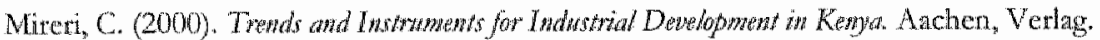


Mowery, D. C. and J. Oxley (1997). Inwand Teclanology Transfer and Competiveness: The Role

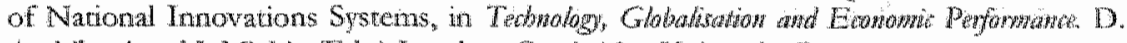
Archibugi and J. Michie (Eds.) London: Cambridge University Press.

Moram, H. M. E. M. Graham and M. Blomstrom Eds. (2005). Does Foneign Dintu Imwoment Prowote Dextopment? Washington, D.C. Institute for International Economics. Center for Global Development.

Munene, K. M. and S. Wandibba (1989). History and Govemwem, Nairobi, Kenya: Heinemann.

Mwamadzingo, M. and N. Ndung'u (1999). "Funancing of Science and Technology Instimutions in Kenya during the Periods of Structural Adjustment", ATPS Working Paper No. 13.

Mytelka, L. K. (1978). "Licensing and Technology Dependence in the Andean Group", World Development 6: 447-59.

Mytelka, L. K. (1985). Stimulating Effective Technology Transfer: The Case of Textiles in Africa, in International Tedknology Thansfer. N. Rosenberg and C. Fribchtak (Eds.) New York: Praeger.

Mytelka, L. K. (1989). "The Unfulfilled Promise of African Industrialisation", Afritan Sitries $32(3): 77-137$.

Mytelka, L. K. and T. Tesfachew (1998). The Role of Policy in Promoting Enterprise Learning During Early Industrialisation: Lessons for African Countries. Geneva, UNCTAD.

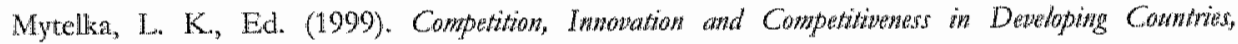
Paris: OECD.

Mytelka, L. K. (2000). "Local Systems of Innovation in a Globalised World Economy", Industry and Innoution $7(1): 15-32$.

Mytelka, L. K. (2004). The Dynamics of Catching Up: The Relevance of an Innovation System Approach in Africa, in Putting Afria First: The Moking of African Invowation Systems. M. Muchie, P. Gammeltoft and B. Lundvall (Eds.) Aalborg: Aalborg University Press

Mytelka, L. K. and E. Farinelli (2000). Local Clusters, Innovation Systems and Sustained Competitiveness, Paper presented at a Conference in Rio de Janeiro.

Mytelka, L. K. and H. Goertzen (2004). "Learning, Innovation and Cluster Growth: A Study of Two Inherited Organisations in the Niagara Peninsula Wine Cluster", UNU-INTECH Discussion Paper Series 1.5.

Nadvi, K. (1999). "Collective Efficiency and Collective Failure: The Response of Sialkot Surgical Instrument cluster to Global Quality Pressures", Workd Dexelopment 27(9).

Narula, R. (1996). Multinational Inwestment and Eonomie Strwtwr, London: Routledge.

Nelson, R. R. and E. Phelps (1966). "Investment in Humans, Technological Diffusion, and Economic Growth", Anterican Econanzic Reniow 56: $67-75$.

Nelson, R. R. and S. G. Winter (1982). An Eitwituonary Theory of Econonnic Change, Cambridge: Harvard University Press. 
Nelson, R. R. aind N. Rosenberg (1993). Technical Innovation and National Systems, in

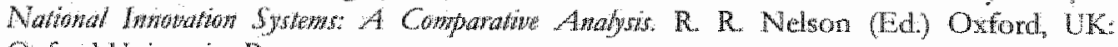
Oxford University Press.

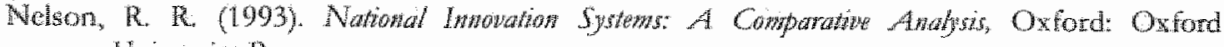
Undersity Press.

Nelson, R. R. and H. Pack (1997). "The Asian Mitacle and Modem Growth Theor", World Bank Working Papers:

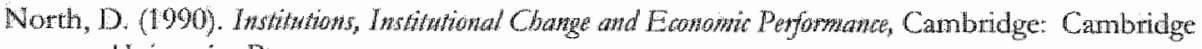
University Press.

Nyong'o, P. A. (1988). The Possibilities and Historical Limitations of Import Substitution Industrialisation in Kenya, in Indastratisatiom in Kenyas, in P. Coughlin and G. K. Mkiara (Eds.) Nairobi, London: Heinemann Kerya, James Currey London.

OECD (1998). The Intentationalization of Industral Red D Patterns and Trend, Paris, OECD.

Ofreneo, R. (2003). "TRIMS and the Automobile Industy in Philippines", Tectonology Polig Brief 2(1): $5-7$.

Pack, H. and K. Saggi (1997). "Inflows of Foreign Technology and Indigenous Technological Development", Review of Detelopment Economics 1(1):81-98.

Patcel, P. and P. Vega (1999). "Parterns of Internationalisation of Corporate Technology: Location vs. Home Country Advantages", Researb Policy 28: 145-155.

Patibandla, M. and B. Petersen (2002). "Role of Transnational Corporations in the Evolution of sing-Tech Induscry: The Case of India's Software Industry", Wordd Dewelopment 30(9): $1.561-1577$.

Pearson, D. S. (1969). Indwstrial Development in East Africa, London, United Kingdom: Oxford University Press.

Penrose, F. (1959). The Theov of the Gow th of the Fown, Oxford: Ox ford University Press.

Pietrobelli, C., (2000). The Role of International Technology Transfer in the Industralisation of Developing Conntries, in Tebnology Transfer. M. Elena and D. Schtocer (Eds.) Aldershot UK, Burlington USA: Ashgate Publishers.

Pictrobelli, C, (2001). National Systems in Africa: The nature and Deficiencies of Technological Effort in African Industry. A Background Paper for UNIDO World Industrial Development Report.

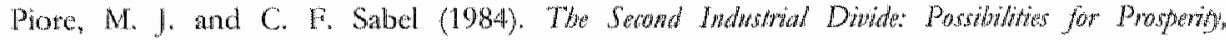
New Yorlk: Basic Books.

Polanyi, M. (1966). The Tad Dimeksion, New York: Doubleday.

Polanyi, M. (1973). Personal Knowledge: Towards a Post-Critical Philosopby, London: Routledge \& Kcgan Paul.

Posner, M. V. (1961). "Internacional Trade and Technological Progress", Oxfow Eromomic Papers 13(323-341). 


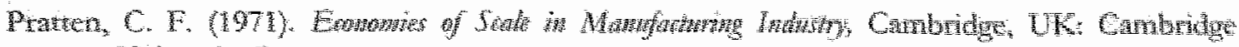
Univerary press.

Quadros, R. G. (2003). "TRMS, TNGs, Techolgy Polcy and the Brathen Automotile

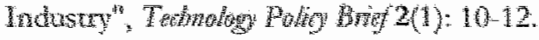

Ramachandran, V. and M. K. Shat (1998). "Frrm Pertomance and Foregn Owmerhio in Africa: Evidence from Zimbabwe, Ghara and Keny." Rural Progtmane to Enterprise Development RPED Paper No. 81.

Rasiah, R. (1988). "The Semiconductor Industry in Penang: Implications for New Interrational

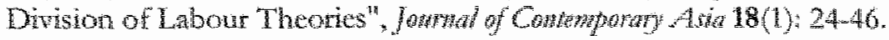

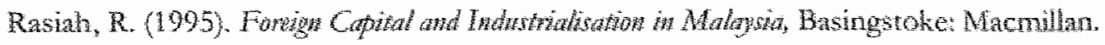

Rasiah, R. (2002\%. "TRTPS and Techological Capability Buiding in East and South Asia", Esmopian youmal of Dewelopment Reatard 14(1).

Rasiah, R. (2003). "Systemic Coordination and the Knowledge Economy" Human Cetpital Development in MNC-driven Electronics Clusters in Malaysian", TFanslational Copporations $1(3)$.

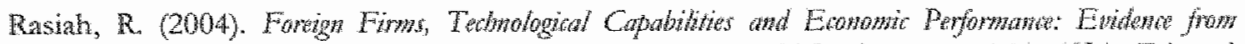
Africa, Asia aw Latim America, Chettenham, UK and Northampion, MA, USA: Edwat Elgar.

Rasiah, R. and Gachino, G. (2004). Productivity, Export and Technological Differences in Kenya, in Foreign Firms, Technologion/ Capabiaties and Econowic Performance. Enwdence from Afria, Asia and Latin Amerioa. R. Rastah (Ed) Cheltenham: Edward Elgar.

Rasiah, R and Gachino, G. (2005). Are Foreign Finms more Productive, and Export and Technology Intensive than Local Firms in Kenyan Manufacturing? Oxford Dentoptwent Sindier $33(2): 211-228$.

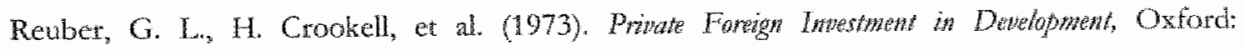
Clarendon Press.

Richardson, O. B. (1960). Information and Wwathent, Ox fond: Oxford Universiry Press.

Richardson, G. B. (1972). "The Otganisation of Jndustry", Economic Jowma/82: 883-96.

Rodrigucz-Clare, A. (1996). "Multinationals, Linkages, and Economic Development", Amerian Exomonic Rewien 86(4): 852-873.

Romer, P. M. (1986). "Increasing Returns and Long Run Growth", Joumal of Political Economy 1002-1037.

Romer, P. M. (1990). "Endogenous Technological Change", Jutumal of Politicol Ecowowy 98: S71102.

Romijn, H. (1999). Acquision of Tedbotogical Capability in Small Fims in Developing Commines. London: Macmillan Press.

Ronge, E. E. and H. O. Nyangito (2000). "A Review of Kenya's Current Industrialization Policy", KIPPRA, Discussion Papers No. 3. 
Rowentierg, N. (1982). Irotide the Black Bax, New York: Cambridge University Press.

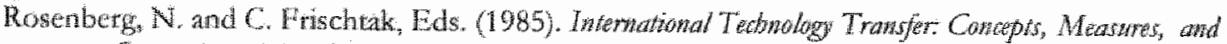
Compariouss, New York, Praeger Publishers.

Roscntein-Rodan, P. N. (1984). Natura Facit Saltum: Analysis of the dismequilibrim growth Process, in Proweers in Dentuphest. G. M. Meier and D. Seers (Eds.) New York: Oxford Uniwersity Press.

Rothwell, R. and M. Dodgson (1991), "External Linkages and Innovation in Small and Medium-Sized Firms", Rero Mancagenew 21(2): 125-137.

Sabel, C. (1989). Fexible Specialisation and the Re-ennergence of Regional Economies, in Renersing Industrial Dewhes?: Indhstrial Srrature and Poligy in Britain and Her Competitors. $\mathrm{P}$. Hirst and J. Zeitlin (Eds.) OxFord: Berg Publishers.

Saggi, K. (1999). Trade, Foreign Direct Investment, and Intemational Technology Transfer A Survey, A background Paper Prepared for the World Bank's Microfoundations of International Technology Diffusion.

Saxenian, A. L. (1991). "The Origins and Dynamics of Production Neworks in Silicon Valley", Reseand Poligy 20.

Scherer, F. M. (1973). "The Determinants of Inclustry Plant Sizes in Six Nations", Remien of Fonowiles and Statistrios 55(2): $135-175$.

Scherer, F. M. (1974). Economies of Scale and Industrial Concentration, in Indrstrial Concutration: The Nen Learwing. H. Goldschmid, H. M. Mann and J. F. Weston (Ids.) Boston: Litcle Brown.

Scherer, F. M. (1980). Industriat Manket Smoture and Economic Peryornume, Chicago: Rand McNally.

Schumpeter, J. A. (1934). The Theory of Ecomonati Dexplopment, Oxford: Oxford University Press.

Schumpter, J. A. (1952). Capitalism, Sackalism, and Democracy, London: Unwin.

Scitorsky, T. (1964). Paphers on Woffare and Growth, Allen \& Unwin.

Sengcrberger, W. and F. Pyke (1991). "Small Fims, Industrial Districts and Jucal Economic Regeneration", Labown" and Soriely 16(1): 1-24.

Siddharthan, N. S. (1992). "Transaction Costs, Technology Transfer, and In-house R\&D", Jownat of Ecomonic Bebatimur and Organiantion 18: 265-71.

Sjoholm, F. (1997). "Technology Gap, Competition and Spillovers from Direct Foteign Investment: Evidence from Established Data", Jommal of Detelopment Studies 36: 1 .

Snarynska, B, K. (2003). "Does Foreign Direce Investment Inctease the productivity of Domestic Firms? In Search of Spillovers through backward Linkages", William Davidson Working Paper No 548.

Stata (2003). Stata Versiom 8 Reference Momsat, Stata Press. 
Stewark, F. (1972). "Choice Technique in Deweloping Countries" Jowyat of Dewaphont Sindier, $9(1)$.

Stewart, F. (1979). Employment and Choice of Technique: Two Case Studies in Kenya, in Evats an Employnent in Kenya, D. Ghai and M. Godfrey (Eds.) Nairobi, Kenya Literanure Burcau.

Stoneman, P. (1983). The Enomomic Anabsis of Temological Change, Oxford: Oxford University Press.

Stoneman, P., Ed. (1995). Handbook of the Erononics of Inowation and Technological Change, London: Unwin University Books.

Summers, R. and A. Heston (1991). "The Penn World Table (Mark 5): An Fxpanded Ser of International Comparisons 1950-1988", Qwarterby Jound of Eionomio 106(327-368).

Sunkel, O. (1989). "Big Business and 'Dependencia': A Latin American Vicw", Formigur Afow $50(3)$.

Swainson, N. (1978). Company Formation in Kenya before 1945 with Particular Reference to the Role of Foreign Capital, in Readings on the Mulvinational Canpontion in Kenva. R. Kaplinsky (Ed.) Naitobi, Heinemann.

Swainson, N. (1980). The Detelopment of Capponate Capitahin in Kema, 1918-1977. London, Ibadan, Nairobi: Heinemann.

Teece, D. J. (1977). "Technology Transfer by Multinational Fitms: The Resource Cost of Transferring Technological Know-how," Erononic Jowmal 87: 242-261.

Tommaso, P. (1998). Multinational Enterprises and Tedbnologiad Spillowers: Harwood Academic ]?ublishers.

Tybout, J. R. (2000). "Manufacturing Firms in Developing Countrics: How Well Do they Do, and Whyt", Josmal of Exonomic Litcrature 28: 11-44.

UNCTAD (1997). World Inwestment Report: Transnational Corponations, Market Structure and Competition Policy. New York, Geneva, United Nations Conference on 'Trade and Development.

UNCTAD (1999). World Investment Report: Forcign Direct Investment and the Challenge of Development. New York, Geneva, United Nations Conference on Trade and Development.

UNCTAD (2001). World Investment Report: Promoting Linkages. New York, Geneva, United Nations Conference on Trade and Development.

UNDP (2005). Innowation: Applying Knowledge in Development, United Nations Development Programme.

Vaitsos, C. (1991). The State and Foreign Business Interests, in Kampars Indastrialization Dilenma, P. Coughlin and G. K. Ikwara (Eds.) Nairobi, Kenya: Heinemann Kenya U.imited.

Velde, D. W. and O. Morrissey (2001). "Foneign Ownership and Wages: Evidence from Fiwe African Countries", CREDIT Discussion Paper. 
Vernon, $\mathrm{R}$ (1960). "haternational Investment and Intemational Trade in the Product Cycle." Quartery youmal of Ecowomics 80: 190-207.

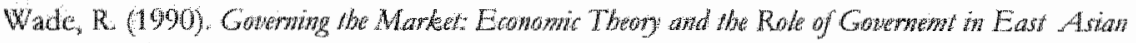
Indhstrialisation. Princeton: Princetion University Press.

Wang, J. and M. Blomstrom (1992). "Foreing Investment and Technology 'Transfer: A Simple Model", Earopean Eowowic Rewien 36: $137-155$.

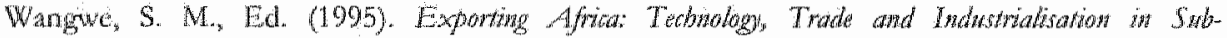
Satharas Afrim, UNU/INTECH Studies in New Technology and Development. London and New York: Routledge.

Wasow, B. and He Hill (1986). The Instrance Ludusty in Eronomic Denelopment, New York: New York University Press.

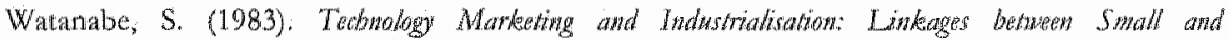
Large Enterpirises, New Delli: Macmillan.

Westphal, L. E, L. Kim and C. I. Dahlman (1985). Reflections on Korea's Acquisition of

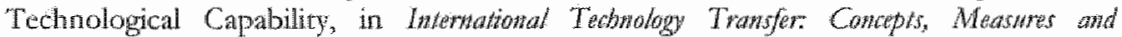
Camparisoms. N. Rosenberg and C. Firischtak (Fds.) New York: Pergamon Press

Westphal, L. E. (1990). "Industrial Policy in an Expont-Propelled Economy: Lessons from South Koren"s Experience", Jowrwal of Econonsic Pexpective 4(3): 41-59.

Westphal, I. E., K. Ktitayakirana, K. Petchsuwan, H. Sutabutr and Y. Yuthavong (1990). "The Development of Technological Capability in Manufacturing: A Mactoscopic Apptoach to Policy Research, in Scievice and Tedmology: Lessons far Development Pohig. R. E. Evenson and $G$. Ranis (Fds.) London, Intermediate Technology Publications.

White, H. (1980). "A Heteroscedasticity-consistent Covatiance Matrix Fistimator and a Direct Test for Heteroscedasticity", Eronometrica 48: 817-830.

Wignaraja, G. and G. Tkiara (1999). Adjustment, Technological Capabilities and Enterprise Dynamics in Kenya, in The Tectmological Response to Import Liberalisation in Sub Sahatan

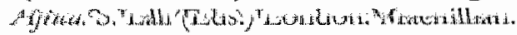

Wignaraja, G. (2001). "Firm Size, "Technological Capabilities and Market-Oriented Prolices in Mauritius", Working paper presented at UNU/INTECH.

Wialkinson, F. and J. I. You (1995). "Competition and Cooperation: "Towards an Understanding of the Industrial District", Revien of Polltical Ecomony 6: 259-78.

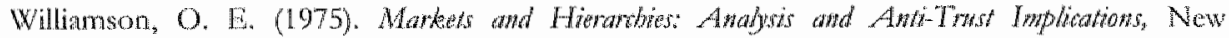
York: Free Press.

Williamson, O. E. (1979), "Transaction Cost Economics: The Governance of Contractual Relations", Jownal of Lan and Econowici 22: 233-62.

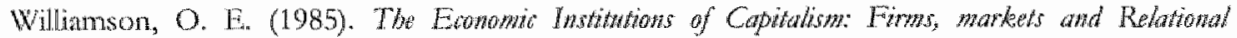
Contracting, New York: Finee Press.

Willoughby, B. W. (1990). Tebnotogy doite: A iritique of the Appropriate Mowentent International Technology Publications, 103-105 Southampton Row "London WC1B 4HH, UK. 
Wolfe D. A. 2000). Socha Capital and clustet Dexelopment in Ieaming Regions A paper Fresented to the XVII Word Congres of die Intematonal Political Science Association, Quebec City, Quebec.

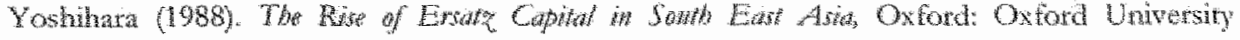
press.

Young A. (1928). "Increasing Retums and Economic Progress", Erowomi foum a 38(152): 52742

Young, A. (1994). "Lessons from the East Asian NICs: A Contarian View", Europtont Economaik Renaza 38: 964973 .

Zeirlin, J. E. (1989). "Local Industrial Straregies: Special issue", Eronowy and Swatg 18(4). 


\title{
The United Nations
} University

\section{INTECH}

Institute for New Technologies

\author{
FOREIGN DIRECT INVESTMENT, SPILLOVERS AND INNOVATION IN \\ THE KENYAN MANUFACTURING INDUSTRY
}

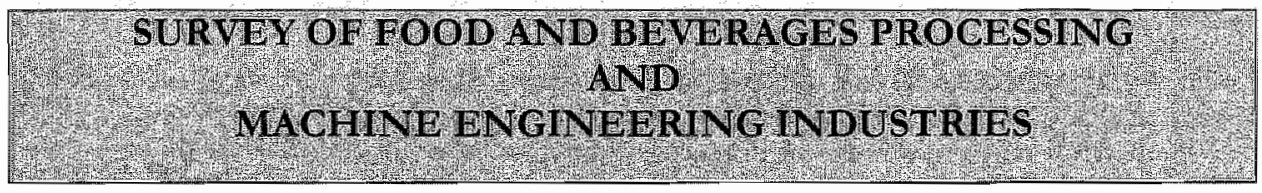

\section{Research Group:}

Geoffey G. Gachino United Nations University - INTECH/MERIT Prof. Dr. Rajah Rasialy United Nations University - INTECH/MERIT Prof. Dr. Lynn Mytelka United Nations University - INTECH/MERTT

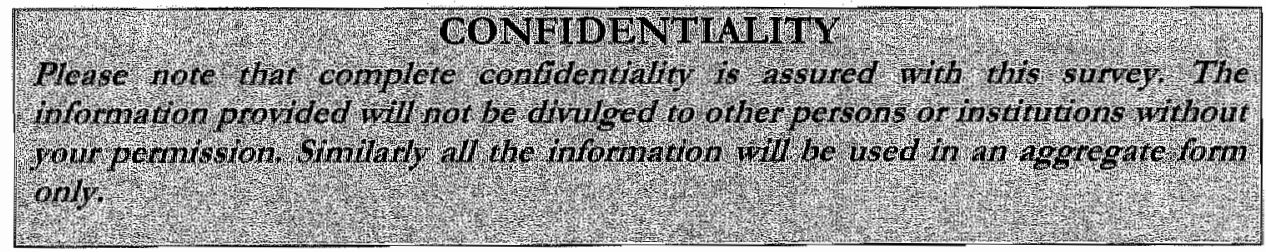


1.1 Name of the firm: Year of establishment:

1.2 What is the ownership structure of your firm
(a) 100 percent state owned
(b) 100 percent foreign owned
(c) 100 percent locally owned
(d) Joint Venture
$\rightarrow \quad$ Local equity foreign equity $0 \%$ $-10$

1.3 Does your company have any affliates overseas/abtoad? (a) Yes $\square$ (b) No

1.4 What was your firm's total fixed assets in 2002 ? KShs.

1.5 What is the nationality of firm owner(s)?
(a) Kenyan African
$\square$ (b) Kenyan Asinn
D (c) Asia/Middle East
(d) Europe
(e) U.S.A
1 (I) Others (sperify)

\subsection{BASTC MNORM ATION ON FIRM PERFORMANCF}

2.1 What was your firm's average capacity utilisation in 2002 ? $\%$

2.2 Please list the THREE main activities or products of your firm.

\begin{tabular}{|l|c|}
\hline \multicolumn{1}{|c|}{ Products } & Percentage \\
\hline (i) & \\
\hline (ii) & \\
\hline (iii) & \\
\hline
\end{tabular}

2.3 Does your firm export?

(a) No $\square$

(b) Yes $\square \rightarrow$ lif yes for how long? Years

$\rightarrow$ If yes what ate yout main export markets?

2.4 What is your firm"s estimated annual output, input and sales ( $\mathrm{a}$ altre in $K S$ bs.)?

\begin{tabular}{|l|l|}
\hline Output, Input, Sales and Exports & 2002 \\
\hline Gross outpur & \\
\hline Gross inputs & \\
\hline Total sales & \\
\hline Export sales & \\
\hline Sales to domestic exporting companies & \\
\hline
\end{tabular}

2.5 What was the value of your imported raw materials without including machinery and equipment in 2002 ? KShs. What was this value as percentage of the total raw materials consumed by your firm? $\%$. 
3.1 Please provide your firm's employment figures for 2002.

\begin{tabular}{|c|c|c|}
\hline $\begin{array}{l}\text { CATEGORY OF } \\
\text { EMPLOYMENT }\end{array}$ & KENYANS & NON - KENYANS \\
\hline Regular erroployees & Number of Employees & Number of Employees \\
\hline Wh Wmagral & & \\
\hline Tectrical & & \\
\hline Non-technical & & \\
\hline 21210 mormornal & & \\
\hline Technical & & \\
\hline skilled & & \\
\hline Semi-skilled & & \\
\hline Ohers (eg. clerical) & & \\
\hline TOTAI & & \\
\hline
\end{tabular}

3.2 Has your firm offered training of any kind to the workess in the last THREE years?
(a) No
(b) Yes.
$\square \rightarrow$ Estimated cosc as a percentage of payroll

3.3 Are your fitm workers unionised?

(a) Yes

(b) No

3.4 Is the owner of the firm also the manager? (a) Yes $\square$

(b) No

3.5 What is the educational level of the firm owner(s)? (Mwhiph ansurers cast be prowided).
(a) Uniwersity
[?
(b) High school
(c) Tech/Vocational
(d) others

3.6 Give the proportion of your staff with the following
(a) Universiry/College $\%$
(b) High School
(c) Tech/Vocational
(d) Lower/Elementary

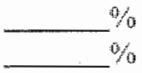

3.7 Has your company ever lost some of its workers to other competing firms in the past?
(a) No
(b) res

$\rightarrow \quad J_{a}$ general torms mbat alliber of workers wene

the?

Managers and professionals.

Engineers and technicians

Others (please specifiy)

3.8 If your answer to $Q 3.7$ above was yes, what kind of firms dicl they join (Multiple atiswers an be prowided?
(a) Forcign firms
(b) Joint rentures
(c) Local firms
(d) Stat their own firms

3.9 If you camot tell whether the firms in $\mathrm{Q} 3.8$ above are forting fitms, joint ventures or local firms, please provide their names, a maximum of FOUR names only.
(a)

(c)

(b)

(d) 
3.10 How sercere is lack of skilled workers (qualifed enguneets and technicians) ro your firm?
(a) Not severe
(b) Averagre
(c) Very severe

3.11 What is the policy of your frm tegarding employment of skilled qualitied wotkers: $c . \mathrm{g}$. scientists, engineers, technicians and other professionals (Phate cirte your ramb to 5 - fow WEAK polio to wey $5 T R O N G$ paliog? Multiple choices can be provided.

\begin{tabular}{|l|l|l|l|l|l|}
\hline \multicolumn{1}{|c|}{ Category of Employees } & \multicolumn{4}{c|}{ Ranking by } \\
\hline To employ graduates from poly-technique/ rocational institutions & 1 & 2 & 3 & 4 & 5 \\
\hline To employ fresh university gtaduates & 1 & 2 & 3 & 4 & 5 \\
\hline To employ experienced workers from other local fims & 1 & 2 & 3 & 4 & 5 \\
\hline To employ experienced workers from foreign firms in the country & 1 & 2 & 3 & 4 & 5 \\
\hline To employ experienced workers from ourside the country (abroad) & 1 & 2 & 3 & 4 & 5 \\
\hline Others (please penify) & 1 & 2 & 3 & 4 & 5 \\
\hline
\end{tabular}

3.12 If your firm has employed workers from other fums before what kind of workers were they?
(a) Manggers and professionals
(b) Skilled scientists and engineers
(c) Technicians, craftsmen artisans
(d) Others (please specify)

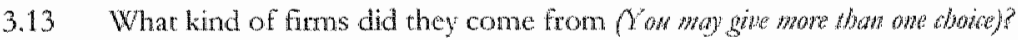
(a) Foreign tirms
(b) Joint ventures
(c) Local firms
D (d) others (specib)

3.14 If you cannot tell whether the firms in Q3.13 above are foreign firms, joint ventures or local firms, please provide their names, a maximum of FOUR names only.

(a)

(c) (b)

(d)

3.15 If your answet to $Q 3.13$ above is (a) or (b) or both of thenr. How would you tate the contributions of such wotkers to your firm in the following aspects (Please arde your rante.

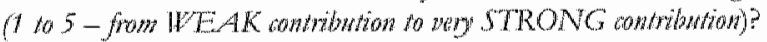

\begin{tabular}{|c|c|}
\hline Contribution to the Firm & $\begin{array}{l}\text { Ranking by } \\
\text { Contribution }\end{array}$ \\
\hline $\begin{array}{l}\text { Assisted in the development of new products or improvement of existing } \\
\text { products to market needs. }\end{array}$ & 012345 \\
\hline $\begin{array}{l}\text { Assisted in the processing activities, mw material and quality control, upgrading } \\
\text { machinery and equipment stretching to save energy, cost, twise productivity etc. }\end{array}$ & 012345 \\
\hline Assisted in repair and maintenance of physical capital, inventory control ctc. & $0 \| 2345$ \\
\hline $\begin{array}{l}\text { Strengthened our marketing department with new ideas, skills, and knowledge } \\
\text { of existing local and foreign markets for exporting. }\end{array}$ & 0112345 \\
\hline $\begin{array}{l}\text { Contributed to the organisational changes that brought in better management } \\
\text { and implementation of production \& routhe activities conancing fimm's } \\
\text { efficiency. }\end{array}$ & 012345 \\
\hline Others (pleatre strecif). & 012345 \\
\hline
\end{tabular}

3.16 Plase provide your firm's estimated total payroll in 2002

KShs. 
3.17 If your answer to 03.13 above is (c) or (d) or both of thent How would you rate the contributions of such workers to your firm in the following aspects (Plase cirde your rank

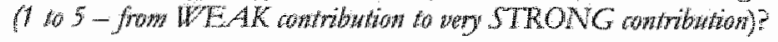

\begin{tabular}{|c|c|}
\hline Contribution to the Fin & $\begin{array}{l}\text { Ranking by } \\
\text { Contribution }\end{array}$ \\
\hline $\begin{array}{l}\text { Assisted in the dewelopment of aew products or improvement of existing } \\
\text { products to marker needs. }\end{array}$ & 012345 \\
\hline $\begin{array}{l}\text { Assisted in the processing activities, taw material and quality control, upgrading } \\
\text { machinery and equipment stretching to save energy, cost, raise productivity etc. }\end{array}$ & 012345 \\
\hline Assisted in tepair and maintenance of physical capital, inventory control etc. & 012345 \\
\hline $\begin{array}{l}\text { Strengthened out matketing deparment with new ideas, skills, and knowledge } \\
\text { of existing local and foreign markets for exporting. }\end{array}$ & 012345 \\
\hline $\begin{array}{l}\text { Contribited to the organisational changes that brought in better management } \\
\text { and imaplementation of production \& toutine activities enhancing firm's } \\
\text { efficiency. }\end{array}$ & 012345 \\
\hline Others (prease syedify). & 012345 \\
\hline
\end{tabular}

\section{PROCTSSING AND PRODUCT IECHNOLOGY}

4.1. Does your firm thave quality assurance certification?
(a) No
(b) Yes
Which one?

4.2 What quality control system(s) does your firm use? (You may dhoose more thath onte)
(a) Statistical quality control.
(b) Technical benchmarking
(c) Statistical process controll
(d) Others (sperify)

4.3 When did your firm last make and/or introduce new product(s)?
(a) $0-1$ year $\mathrm{D}$
(b) $1-2$ years $\mathrm{D}$
(c) $2-5$ years $\square$
(d) Over 5 years $\square$

4.4 What was the estimated cost of making and/or introducing this product(s) KShs.

4.5 Were the new products new to?
(a) Your firm $\square$
(b) Local market [
(c) Regional market [
(d) Global market []

4.6 Has your company undertaken any improvements on any of its already existing $\begin{array}{llll}\text { products in the last Five years? } & \text { (a) Yes } & \text { (] } & \text { (b) No }\end{array}$

4.7 What was the source of your ore production machinery?
(a) Locally fabricated
(b) Combination of local and foreign
(c) Tully loteign
i.
Main foreign country source

4.8 What is the estimated age of your cone production machinery? Years.

4.9 What is the estimated value of your ore production machinery? KShs.

4.10 When did you last make new investment in production equipment?
(a) 0.1 year
$\square \quad$ (b) $1-2$ years
(c) $2-5$ years
(d) Over 5 years

4.11 Do you have foreign technical partners? (a) Yes $\mathrm{O}$ (b) No 
4.12 Have you catricd out my modifications on your madinefy in the lagt PrVt: years?
(a) No $\square$
(b) Yes $\square \rightarrow$ how wonld you regsurd it?
(a) Major D
(b) Mino:

4.13 In doing modifications on your machinery did you get assistance from
(a) Local consullants?
(c) Foreign technical partmers?
(b) In house? 0
(d) Others?

\subsection{TNFASTRUCTURE AND BUSRNESS ENMTRONMUNT}

5.1 How would you rate prowision of the following in frastructure please vivte the

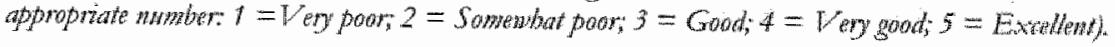

\begin{tabular}{|l|l|l|l|l|l|}
\hline Physicall Infrastructure & \multicolumn{5}{|l|}{ Ranking by Usefulness } \\
\hline Transport services (e.g. roads) & 1 & 2 & 3 & 4 & 5 \\
\hline Water supply & 1 & 2 & 3 & 4 & 5 \\
\hline Electricity/power supply & 1 & 2 & 3 & 4 & 5 \\
\hline Telecommunication network (c.s. telephonc) & 1 & 2 & 3 & 4 & 5 \\
\hline Public health facilities & 1 & 2 & 3 & 4 & 5 \\
\hline
\end{tabular}

5.2 What types of technical support have you received and from which government and privare agencies?

\begin{tabular}{|l|l|l|l|l|l|}
\hline $\begin{array}{l}\text { Type of Technical } \\
\text { Support }\end{array}$ & Government & $\begin{array}{l}\text { Business } \\
\text { Assoc. }\end{array}$ & $\begin{array}{l}\text { Private } \\
\text { Sources }\end{array}$ & NGOs & $\begin{array}{l}\text { Others } \\
\text { (Specify) }\end{array}$ \\
\hline Intormation & & & & & \\
\hline Standards \& Training & & & & & \\
\hline Quality control & & & & & \\
\hline R\&D services & & & & & \\
\hline Others (specify) & & & & \\
\hline
\end{tabular}

5.3 How do you tate the quality of the following institutions? Poor $\rightarrow$ Exwellent

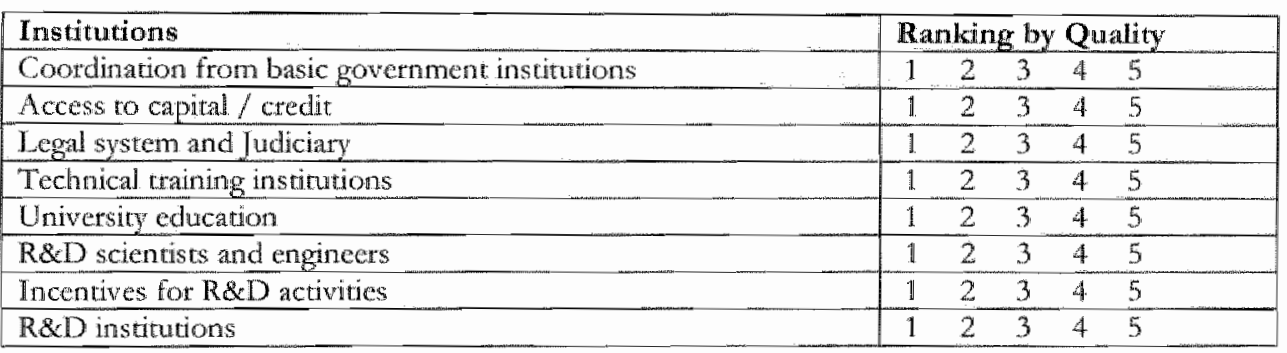

5.4 What was your firm's estimated cost of marketing including advertisoment in 2002 as a percentage of total firm sales?

5.5 Has your firm received any marketing support from either government, private or business associations on marketing in formation, intelligence or training?
(a) Yes
(b)
No 
5.6 On a scale of $1 \rightarrow 5(1=$ WEAKEST and $5=$ VERY STRONG), how would you rate export \& matketing support From?
(a) Gowemment
(b) Private
(c) Business associations
(d) Others (spexify and nank)

5.7 How has your company benefived from the services offered by the following business organisations: Poor $\rightarrow$ Exodlent

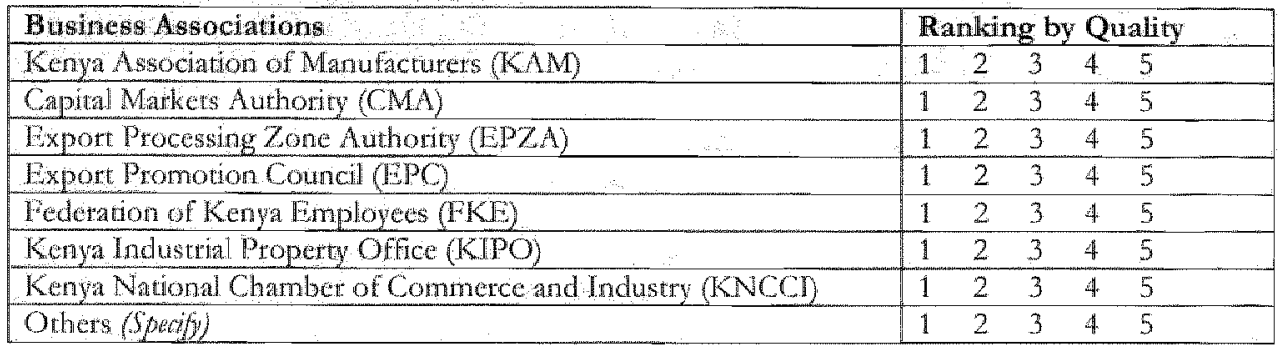

5.8 To what extent has your firm benefited from both formal and informal interactions with

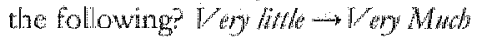

\begin{tabular}{|c|c|c|c|c|}
\hline Institutions \& Business Associations & \multicolumn{4}{|c|}{ Ranking by Usefulness } \\
\hline Machinery suppliers and consultants & 12 & 3 & 4 & 5 \\
\hline Other patricipants during local exhibitions \& trade fairs & 12 & 3 & 4 & 5 \\
\hline Government and private institutions & 12 & 3 & 4 & 5 \\
\hline Universidies and technical tonining institutions & 1 & 3 & 4 & 5 \\
\hline Industry and business association & 12 & 3 & 4 & 5 \\
\hline Investment and export promoters & 12 & 3 & 4 & 5 \\
\hline Raw material supplices, buyers and distributors & 12 & 3 & 4 & 5 \\
\hline Others (spendf) & 2 & 3 & 4 & 5 \\
\hline
\end{tabular}

\subsection{ACGESS TO CAPITAL AND RINANGE FOR NNOYATION}

6.1 Did you obtain any finances (c.g. loans) before?
(a) Yes
(b) $\mathrm{No}$

6.2 Do you maintain a relationship with your formal lenders?
(a) No
(b) Yes
If yes for how long (wis years)? Years.

6.3 If your answer to $\mathrm{Q} 6.1$ above was yes, what is your main source of finance ( $p$ lease indiate its \% ?

\begin{tabular}{|c|c|c|c|}
\hline Source of Finance & Capital $\%$ & Source of Finance & Capital $\%$ \\
\hline Private domestic banks & & Loan from friend \& relatives & \\
\hline Development bank & & Own money & \\
\hline Special government credir & & lo-house & \\
\hline Other sources (specitol & & Other sources (specify) & \\
\hline
\end{tabular}

6.4 How do you rate financial support as a constraint?
(a) Very severe
(b) Severe
(c) Not severe 
6.5 What are the main obstacles that generally linder you trom obtaining finance?
(a) Lack of collatemal
(b) High interest rates

(c) Others (specify)

6.6 For what types of investment have you required financial support in the last THREE years?
(a) New machinery
(d) Organisational change
(b) Expansion to new products
(e) Others (specify)
(c) Exports

6.7 If your furm undertakes research and development (R\&D) how much did you spend on R\&D in 2002 ( ou can protide figures in Keyga Sbillings)? KShs.

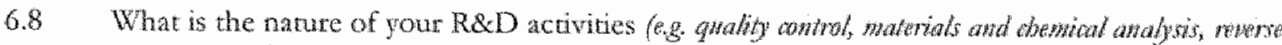

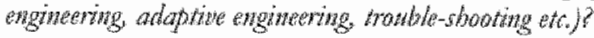

(a)

(b)

\subsection{INKAGE WTIH OTIER FIRMS AND INSTITUTIONS}

\section{Backward co-operation with suppliers of raw materials, services, machinery \& equipment etc..}

7.1 Does your company maintain relationship with its suppliers (e.g. suppliers of machinexy and equipment, naw materials and services erc.)?
(a) Yes
(b) No

7.2 If your answer to $\mathrm{Q} 7.1$ above is yes, who are yout main suppliers (Yow can thone thow than wate answery?
(a) Foreign firms
(b) Joint ventures
(c) Local firms
(d) others (specifid)

7.3 Please provide about FOUR names of your main suppliets?

(a)

(c) (b)

(d)

7.4. To what extent has the relationship between you and your supplicrs affected the following: (Ifyour answer so $Q 7.2$ above was (a) or (b) or both of them)? Please circle yout rank ( 1 to 5 - from WEAK effect to very STRONG effect).

\begin{tabular}{|c|c|}
\hline Suppliers Effect & $\begin{array}{l}\text { Ranking by } \\
\text { Importance }\end{array}$ \\
\hline $\begin{array}{l}\text { Improving your products, develop new products, copy/imitate their products } \\
\text { etc. }\end{array}$ & 012345 \\
\hline $\begin{array}{l}\text { Improve processing techniques, raw material \& quality control, upgrade our } \\
\text { machinery \& ecjupment streching to save energy, cost, raise productivity ctc. }\end{array}$ & 012345 \\
\hline Repair and maintenance of physical capital, inventory control etc. & 012345 \\
\hline $\begin{array}{l}\text { Tmprove and strengthen our marlketing department by new ideas, skills and } \\
\text { knowledge of existing local and foreign matkets for exporting. }\end{array}$ & 012345 \\
\hline $\begin{array}{l}\text { Undertake organisational changes for better management and implementation } \\
\text { of production \& other routine activities that enhance the firm's efficiency. }\end{array}$ & 012345 \\
\hline 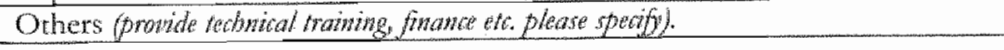 & 012345 \\
\hline
\end{tabular}


To what extcrt has the telationship between you and your suppliers affected the follswing (If your answer to 27.2 abowe was (c) or (d) ar both of themi? Plestse circle pour rank (1 to 5-from WEAK affect to very STRONG effect).

\begin{tabular}{|c|c|}
\hline Suppliers Effect & $\begin{array}{l}\text { Ranking by } \\
\text { limportance }\end{array}$ \\
\hline $\begin{array}{l}\text { Improving your products, dewelop new products, copy/imitate their products } \\
\text { etc. }\end{array}$ & 012345 \\
\hline $\begin{array}{l}\text { Improve processing technigues, raw material \& quality control, apgrade our } \\
\text { machinery \& equipment stretching to save energy, cost, raise productivity etc. }\end{array}$ & 012345 \\
\hline Reparr and maintenance of physical capicall, inventory control ctc. & 012345 \\
\hline $\begin{array}{l}\text { Improve and strengthen our markering department by new ideas, skills and } \\
\text { knowledge of existing local and foreign markets for exporting. }\end{array}$ & 012345 \\
\hline $\begin{array}{l}\text { Undertalke onganisational changes for better management and implementation } \\
\text { of production \& other toutine activities that enhance the firm's efficiency. }\end{array}$ & 012345 \\
\hline 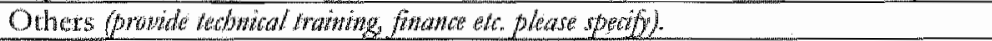 & 012345 \\
\hline
\end{tabular}

\section{Forwatd co-operation with buyers/distributors etc.}

7.6 Does your company develop and maintain relationship with its buyers/distributors?
(a) Yes
(b) No

7.7 If your answer to $Q 7.6$ is yes, who are your main buyers/distributors (You may woose more than oxic answizer)?
(a) Foreign firms
(b) Joint ventures
(c) Local firms
(d) Others (specifis)

7.8 What proportion of your buyers/distributors are directly involved in production activities (value added to the products bought)? $\%$

7.9 Please provide FOUR names of your main buyers/distributors?

(a)

(c) (b)

(d)

7.10 To what extent has the relationship between you and your buyers affected the following: (If your answer to $Q 7.7$ abowe mas (a) or (b) or both of ihem)? Please circle your mank (1 to 5- from WEAK effect to very STRONG effect).

\begin{tabular}{|c|c|}
\hline Buyers/Distributors Effect & $\begin{array}{l}\text { Ranking by } \\
\text { Importance }\end{array}$ \\
\hline $\begin{array}{l}\text { Improving your products, develop new products, copy/imitate their products } \\
\text { etc. }\end{array}$ & 012345 \\
\hline $\begin{array}{l}\text { Improwe processing techniques, raw material \& quality control, upgrade our } \\
\text { machinery \& eguipment stretching to save energy, cost, raise productivity etc. }\end{array}$ & 012345 \\
\hline Repait and maintenance of physical capital, inventory control etc. & 012345 \\
\hline $\begin{array}{l}\text { Improve and strengthen our marketing department by new ideas, skills and } \\
\text { knowledge of existing local and foreign markets for exporting. }\end{array}$ & 012345 \\
\hline $\begin{array}{l}\text { Undertake organisational changes for better management and implementation } \\
\text { of production \& other routine activities that enhance the firm's efficiency. }\end{array}$ & 012345 \\
\hline 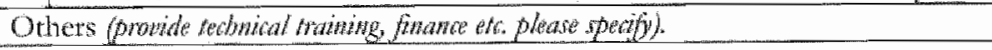 & 012345 \\
\hline
\end{tabular}


7.11 To what extent has whe relationship between you and you buyers affected the following

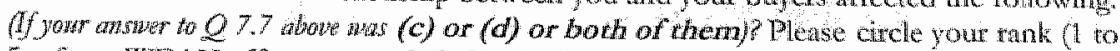
5 - from WEAK effect to very STRONG effect).

\begin{tabular}{|c|c|}
\hline Buyers/Distributors Effect & $\begin{array}{l}\text { Ranking by } \\
\text { Importance }\end{array}$ \\
\hline $\begin{array}{l}\text { Improving your products, develop new products, copy/imitate their products } \\
\text { etc. }\end{array}$ & 012345 \\
\hline $\begin{array}{l}\text { Improve processing techniques, raw material \& quality control, upgrade our } \\
\text { machinery \& equipment stretching to save energy, cost, raise productivity cre. }\end{array}$ & 012345 \\
\hline Repair and maintenance of physical capial, inventory control etc. & $0123: 45$ \\
\hline $\begin{array}{l}\text { Improve and strengthen our marketing department by new idcas, skills and } \\
\text { knowledge of existing local and foreign markers for exporting. }\end{array}$ & 012345 \\
\hline $\begin{array}{l}\text { Undertake organisational changes for better management and implementation } \\
\text { of production \& other routine activities that enhance the firm's efficiency. }\end{array}$ & 0112345 \\
\hline Others (pronide rechnical training finana etr. phease specify) & 012345 \\
\hline
\end{tabular}

\subsection{COMPETITION}

8.1 How would you rate the competion faced by your firm as a result of imports into the country by competing firms?
(a) None
(b) Moderate
(c) Stiff []
(d) Very stift

8.2 How would you rate the competition faced by your firm from competing firms domestically?
(a) None
(b) Moderate
(c) Stiff $\square$
(d) Very sciff

8.3 Who are your main competitors (You can chase mont than one ansuer)?
(a) Foreign firms
(c) Local firms
(b) Joint ventures
(d) others (sperify)

8.4 Please provide about FOUR names of your main competitors?

(a)

(c) (b)

(d)

8.5 How does your fim manage to contain such comperition pressures especially from foreign or joint venture firms (ff your amswer to $Q 8.3$ abowe was (a) ar (b) or both of thenx) Please circle your rank (1 to 5 - from WEAK effect to very STRONG offect).

\begin{tabular}{|c|c|}
\hline Competition Effect & $\begin{array}{l}\text { Ranking by } \\
\text { Importance }\end{array}$ \\
\hline $\begin{array}{l}\text { Improwing your products, devellop new products, copy/mitate their products } \\
\text { ctc. }\end{array}$ & 012345 \\
\hline $\begin{array}{l}\text { Improve processing techniques, raw material \& quality control, upgrade our } \\
\text { machinery \& equipment stretching to save energy, cost, raise producuvity etc. }\end{array}$ & 012345 \\
\hline Repair and maintenance of physical capical, inventory control cte. & 012345 \\
\hline $\begin{array}{l}\text { Improve and strengthen our marketing department by new ideas, skills and } \\
\text { knowledge of existing local and foreign markers for cxporting. }\end{array}$ & 012345 \\
\hline $\begin{array}{l}\text { Undertake organisational changes for better managenent and implementation } \\
\text { of production \& other routine activities that enhance the firm's efficiency. }\end{array}$ & 012345 \\
\hline Others (please specify). & 012345 \\
\hline
\end{tabular}


How does your fim manage to contain such competicion pressures especially from local

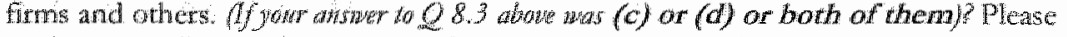
circle your rank (1 to 5 - from WEAK effect vo very STRONG effect).

\begin{tabular}{|c|c|}
\hline Competition Effect & $\begin{array}{l}\text { Ranking by } \\
\text { Importance }\end{array}$ \\
\hline $\begin{array}{l}\text { Improving your products, develop new products "copy/imitate their products } \\
\text { etc. }\end{array}$ & 012345 \\
\hline $\begin{array}{l}\text { Improwe processing techniques, raw material \& qualiry control, upgrade our } \\
\text { machinery \& equipment stretching to save energy, cost, aise productivity etc. }\end{array}$ & $0123 \# 5$ \\
\hline Repair and maintenance of physical capital, inventory control etc. & 012345 \\
\hline $\begin{array}{l}\text { Improwe and strengthen our marketing deparment by new ideas, skills and } \\
\text { knowledge of existing local and foreign markets for exporting. }\end{array}$ & 012345 \\
\hline $\begin{array}{l}\text { Undertake organisational changes for better management and implemencation } \\
\text { of peoduction \& other routine acrivites that enhance the firm's efficiency. }\end{array}$ & 012345 \\
\hline Others (platse sperify). & 012345 \\
\hline
\end{tabular}

8.7 On what aspect do you compete keenly? (What is your competitive strength?) (Rank the

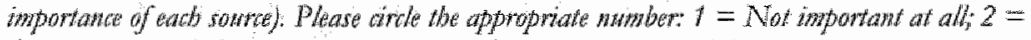

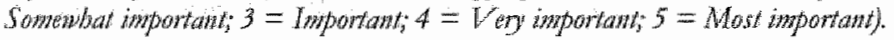

\begin{tabular}{|c|c|c|c|c|c|}
\hline Source of Competitive Strength & \multicolumn{5}{|c|}{$\begin{array}{l}\text { Ranking by } \\
\text { Irmportance }\end{array}$} \\
\hline Price (c.g. due to low overhead costs) & 1 & 2 & 3 & 4 & 5 \\
\hline Product experience (Qhality of our produrts) & 1 & 2 & 3 & 4 & 5 \\
\hline 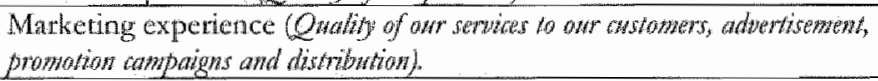 & 1 & 2 & 3 & 4 & 5 \\
\hline Reliability of services provided to our customers & 1 & 2 & 3 & 4 & 5 \\
\hline Volume capacity (Sale of our production) & 1 & 2 & 3 & 4 & 5 \\
\hline 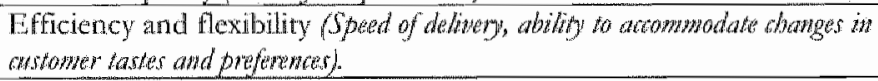 & 1 & 2 & 3 & 4 & 5 \\
\hline Others (Please specify) & 1 & 2 & 3 & 4 & 5 \\
\hline
\end{tabular}

8.8 What is the current strategy of the firm for instance to deal with competition and other problems/ factors that affect your firm? (Please ank the appropriafe numbers $1=$ Least likeby:

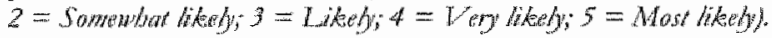

\begin{tabular}{|c|c|c|c|c|c|}
\hline Planned Strategy & \multicolumn{5}{|c|}{$\begin{array}{l}\text { Ranking by } \\
\text { Importance }\end{array}$} \\
\hline Diversify into other products & 1 & 2 & 3 & 4 & 5 \\
\hline Acquite new processing technoiques & 1 & 2 & 3 & 4 & 5 \\
\hline Underialse workens training & 1 & 2 & 3 & 4 & 5 \\
\hline Relocation to lower wage-cost countries & 1 & 2 & 3 & ith & 5 \\
\hline Improve market strategies (serve other markets) & 1 & 2 & 3 & 4 & 5 \\
\hline Improve organisation and management structure & 1 & 2 & 3 & 4 & 5 \\
\hline Form joint ventures & 1 & 2 & 3 & 4 & 5 \\
\hline Others (please sponit) & 1 & 2 & 3 & 4 & 5 \\
\hline
\end{tabular}




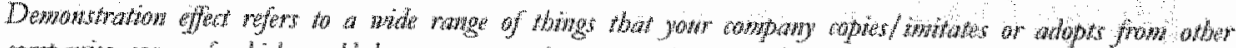

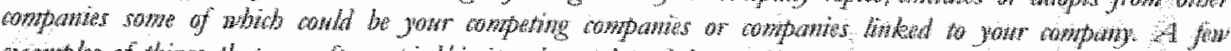

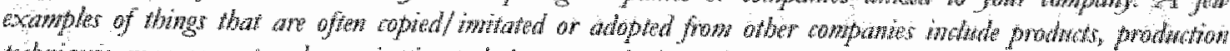

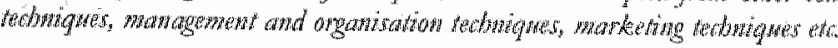

9.1 Has your company ever introduced or adopted nex producrs and new techniques

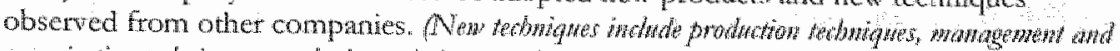

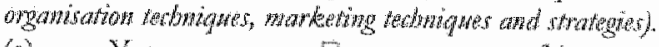
(a) Yes
(b)
No

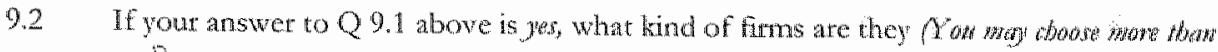
onele
(a) Competing fitms
(b) Ordinary firms
(c) Supplying firms to your company
(d) Processing firms that buy your products
(e) Firms that distribute your products

9.3 If your answer to $Q 9.1$ above is yes was your company able to make similar but own products?
(a) Yes
(b)
No
t.i.

9.4 If your answer to $Q 9.1$ above is yer, what kind of companies are they fon moy chose mow wan on answert)?
(a) Foreign firms
(b) Joint wentures
(c) Local firms
(d) others (spowib)

9.5 Please provide FOUR names of such companies?

(a)

(c)

9.6 How has demonstration effect especially from foreign and foint venture firms affected the following activities in your frm (19your amswer a $Q 9.4$ abow was (a) or (b) or both of them)? Please circle your rank: (1 to 5 - from WEAK effect to very STRONG effect).

\begin{tabular}{|c|c|}
\hline Demonstration Effect & $\begin{array}{l}\text { Ranking by } \\
\text { Importance }\end{array}$ \\
\hline $\begin{array}{l}\text { Improving your products, develop new products, copy/imitate their products } \\
\text { etc. }\end{array}$ & 12345 \\
\hline $\begin{array}{l}\text { Improve processing techniques, taw material \& quality control, upgradc out } \\
\text { machinery \& equipment stretching to save energy, cost, taise productivity ctc. }\end{array}$ & 12345 \\
\hline Repair and maintenance of physical capital, inventory control etc. & 12345 \\
\hline $\begin{array}{l}\text { Improwe and strengthen our marketing deparment by new ideas, skills and } \\
\text { knowledge of existing local and foreign markets for exporing. }\end{array}$ & 12345 \\
\hline $\begin{array}{l}\text { Undertake organisational changes for bette management and implementation } \\
\text { of production \& other routine activities that cohance the firm's efficicncy. }\end{array}$ & 12345 \\
\hline Others please tpecofol & 12345 \\
\hline
\end{tabular}


9.7 How has demonstration effect especially from local firms and others affected the following actuvities in your firm (ffyour answer $Q 9.4$ abowe awas (c) or (d) or both of them) Please circle your rank (1 to 5 - from WEAK effect to very STRONG effect).

\begin{tabular}{|c|c|}
\hline Demonstration $\mathbb{E} f f e c t$ & $\begin{array}{l}\text { Ranking by } \\
\text { Importance }\end{array}$ \\
\hline $\begin{array}{l}\text { Improwing your products, develop new products, copy/imitate their products } \\
\text { etc. }\end{array}$ & 12345 \\
\hline $\begin{array}{l}\text { Tmprowe processing technigues, raw material \& quality control, upgrade our } \\
\text { machinery \& equipment stretching to save energy, cost, raise productivity etc. }\end{array}$ & 12345 \\
\hline Repair and maintenance of physical capital, inventory control etc. & 12345 \\
\hline $\begin{array}{l}\text { Improwe and strengthen our marketing department by new ideas, skills and } \\
\text { knowledge of existing local and foreign matkets for exporting. }\end{array}$ & 12345 \\
\hline $\begin{array}{l}\text { Undertake organisational changes for better management and implementation } \\
\text { of production \& other routine activities that enhance the firm's efficiency. }\end{array}$ & 12345 \\
\hline Others (ptease specify! & 12345 \\
\hline
\end{tabular}

END IF YOU WANT A COPY OF THE OUTPUT OF THIS RESEARCH, PLEASE
PROVIDE US WITH YOUR CONTACT ADDRESS AND E-MAIL.

Thanking you in advance for your time and kind cooperation. 


\section{SAMENVATTING (SUMMARY IN DUTCH)}

De brede doelstelling wan deze studie is de rol van FDI in industriele ontwikkeling in Kenia te onderzoeken. Er werd gesteld dat de investering in de vorm van FDI de potentie heeft om ontwikkeling in een gastland te versnellen door een ondersteunende rol te spelen of door als a anwulling op lokale investetingen en innovatie te fungeren. In bepalde omstandigheden kan FDI dienen om de industrielle ontwikkelingsinspanning wan gastlanden en hun concurrentievermogen te verbeteren, door sommige wenselijke eigenschappen zoals beste praktijken in productie, nieuwe vaardigheden en opleidingen, leading-edge of nieuwe technologie, nieuwe bestuurs- en matketing know-how te brengen, en zodoende levering en kennisnetwerkvorming te vergemakkelijken.

Dergelijke netwerkvorming vergemakkelijkt de verspteiding van wardigheden en informatie in de economie en zou op die manier de bestaande ondernemersinspanningen door demonstratie-effecten kunnen katalyseren. Verder, FDI zou kunnen helpen lokale systemen van innovatie binnen ontwikkelingslanden te verstetken wannever de dochtermatschappijen van multinationale ondernemingen (MNO) de lokale O\&O instituten aanmoedigen om de commercialisatie van hun geaccumuleetd vemogen te verbeteren. Deze studie komt daarom voort uit de noodzaak om te begrijpen hoe FDI de industrialisering in Kenia beinvloedt, met bijzondere nadruk op de invloed wan MNO in het bevorderen van een dynamische menwerkende industrie, door het stimuleren van leerprocessen, de opbouw van wakmanschap en innowaties. De specifieke doelstellingen van deze studie werden geschetst als rolgt:

(1) De mate te onderzoeken waarin de aanwezigheid van MNO spillovers an lokate verwerkende ondernemingen in Kenia bevordert.

(2) De voorwarden te bepalen waarop de spillovers in Keniaanse verwerkende ondernemingen tot stand komen.

(3) Te onderzoeken hoe de spillovers van MNO technologische innovaties op het ondernemingsniveau in de Kentaanse verwerkende industrie beïnvloeden.

(4) Om sommige lessen en beleidsimplicaties voor een spillovers gedreven industriële ontwikkeling in Kenia te trekken.

De thesis wendde een empirische benadering an die in drie stadia werd ontworpen; geaggregeerde en bedrijfsniveauanalyses die officièle gegevens gebruiken, bedrijfsniveau analyse die onderzoek gebruikt en tenslotte casus-studie analyses die tot doel heeft het verschaffen wan diepere inzichten in de onderliggende kwesties. Drie literatuurstromingen werden gehanteetd: spillovers, cluster en nerwerkdynamica, en technologische innovaties. De gemaakte vergelijkende analyse met gebruik van officièle gegevens toonde aan dat de buitenlandse firma's in vrijwel alle economische activiteiten overheersten. Wat ook opviel was het feit dat buitenlandse firma's slechts in enkele sectoren geconcentreerd waren. De analyse heeft interessante bevindingen ann het licht gebracht: ze toonde an dat de plaatselijke firma's betere prestates hadden dan buitenlandse firma's op basis van waargenomen groeipercentages. T'erwijl buitenlandse firma's dalende groeipercentages vertonen met vrijwel al hun variabelen, de binnenlandse firmal"s hadden positieve groeipercentages in verscheidene vartabelen, hetgeen impliceert dat zij geleidelijk de buitenlandse firma's aan het inthalen waren. Om eer bredere reeks resultaten voor vergelijking te hebben, hebben wij besloten een productiviteitsanalyse uit te voeren. De bevindingen over de aanwezigheid wan buitenlandse op het sectorniveau zijn interessant. Twee reeksen resultaten werden verkregen, athankelijk wan de gevolgde methodologische aanpak. De geschatte resultaten op basis van "vroege bijdragers" 
bewestigen het bestuan wan spillowers terwil analyse die op "nieuwe ontwikkelimgen" gebaseed is geen spillowers effect toont. Dit toonde aan dat de bestaande divergentie in de spilloverliteratut ook in de Kenianse context watgenomen kon worden. Wii besloten om niet op dat punt op te houden mat verder te onderzoeken. Het zou het geval kunnen zijn dar secromen met een laag of negatief effect wan de aanwezigheid van butienlandse ondernemingen het positieve effect van sectoren die wel voordeel hebben van buitenlandse aanwezigheid teniet doen zodat het resulterende effect verwarloosbaar of zelfs negatief wotdt. Dit was mogelik in Kenia angezien de op gedragsvergelijking gebaseed resultaten antoonden dat de butenlandse aanwezigheid niet uniform was verdeeld. Dexe tesultaten vroegen daarom om een andere analytisch raamwerk dan de gebruikelike productiviteit technielen.

De analyse wan onderzoksgegevens verzameld uit 180 bedripven in de voeding en drankensector en de machine-industrie toonden an dat de aanwezigheid van buitenlandse bedtijwen spillovers naar lokale bedrijven stimulectde. Deze spillovers vinden plats rooval in producten en processen mar ook in marketingstrategie. Opvallend genoeg, management en organisatie alsook reparaties en onderhoud hadden de lagste niveaus van spillovers. Het onderzoek van spillovermechanismen toonde aan dat deze spillovers hoofdzakelijk door concurtentie en demonstratie-effecten werden veroorzakt. OP de derde plats kwam arbeidsmobiliteit gevolgd door onderlinge vertandirigen tussen bedrijven. De determinanten van spillowers wetden onderzocht met gebruikmaking van binaire en geordend logit schattingstechnieken. De resultaten van onze analyse toonden an dat de buitenlandse anwezigheid een positieve correlatie had met spilloverindex, hetgecn impliceent dat een uitbreiding wan buitenlandse aanwezigheid de kans op spillovers naar lokale firma's werhoogde. Deze bevindingen bevestigen onze hypothese dat de butenlandse aanwezigheid positieve technologische spillovers in de verwerkende industrie van Kenia produceerde.

Onze analyse toonde aan dat de vajwel elke van spilloverfactoren de verwachte tekens hadden, statistisch significant waren en ook intuitieve waren. Bedrijfskenmerken zoals grootte, leeftijd en de leefrijd wan de machines hadden significante en positieve invloed op spillowers. Deze bevindingen betekenen dat spillovers eerdet in grotere dan in kleine firma's plaatsvinden, eerder in oudere dan in jonge firma's, en eerder in firma's met oude producticmachines dan in die met jonge machines. Zoals opgemerkt, de grote bedrijuren beschikken over de noodzakelijke middelen om in re spelen op technologische vetanderingen, terwijl de leeftijd duidde op deaccumuleerde erwaring inde loop der tija.

Het kwadrat wan leeftijd lewerde een negatieve correlatie op, hetgeen op een niet-lineair, "otmgekectdu" patroon van spillovers duid, met meer spillovers bij firma's van gemiddelde leeftijd dan bij jonge en oude firma"s. De Keniaanse Aziatische bedrijven hadden meer spillovers in vergelijking met niet-Aziatische firma's in Keniaanse productie. Dit was geen verrassing arangezien de Aziatische firma's in Kenia over meer middelen en technologische verfijning beschiken dan die in handen van inheemse Afrikanen. Een dergelijk vootcleel platst Aziatische frma's in een betere positie om spillovers te absorberen en te assimileren. De variabelen woor infrastructure, de institutionele steun en de interactio produceerde de werwachte resulaten. Bijvootbeeld, het resultaar van interactie bevestigde onze hypothese dat interacties met zakelijke, privé en publicke instellingen spillovers bevorderen. Op dezelfde manier, kleinere technologische verschillen tussen Kenianse en buttenlandse bedrijven hadden invloed op de mogelijkheid wan spilloves narar lokale bedrijwen. Dit duidt op een minimale drempel van technologische ontwilkeling van bedrijyen on van spillovers te kunnen profiteren. 
De resultaten ower bedrijwenstrategie wruten ook als verwacht. Bedriven met sterke training strategieen hadden een grotere kans van spillovers rooddelen in vergeliking met bedrijwen zonder een dergetuke strategie. Op dezelfde manier, bedripren met sterke strategieen om procestechnologie constant te modemiseren hadden een grotere spillower kans dan firmats zonder dergelijke strategieen. Deze bevindingen bevestigen de stelling dat opleiding in bedrijen en constante aanpassing en verbetering van processen de algemene absorptiecapaciteit verhoogt. Met betrekking tot hardelsonientatie, onze bevindingen waren vertassend. Terwij de resultaten geschat met betrekking tot de invoer zoals verwacht waren, die voor de uitvoer waren strijdig met de verwachung. Deze resultaten zouden dan impliceren dat de uitwoeronientatie de spillovers negatief beïnloedt, in de zin dat niet-exporterend firma's meer spillovers antrokken dan exporterende firma's. Tot slot, de resultaten van arbeidsmarktomstandigheden waren zoals verwacht en in overeenstemming met de spilloverliteratuur: goede arbeidsmarktwoonwarden zoals betaling van efficiencylonen, de koelkast voordelen en voorzichtig human resource management beleid vertalen zich in verminderde mobiliteit wan arbeiders en zo verminderen de kans op spillovers. In overeenstemming met dit argument, de lonen, als surrogat voor arbeidsmarktwoonwarden hadden een negatieve invloed op de kans op spillowers.

De case studies bevestigden de spillovers en verlenen steunen ann onze stelling dat VDI in de Keniaanse fabrieken een essentiele rol heeft gespeeld in de industriële ontwiklkeling. Op basis van de gemaakte analyse en door spillovers te conceptualiseren als technologische leeprocessen en capaciteitopbouw, komen wij tot de conclusie dat de buitenlandse aanwezigheid spillovers heeft bevorderd in de wee bestudeerde industrieern. Nochtans kunnen deze resultaten niet veralgemeend worden voor de volledige verwerkende industrie, aangezien de buitenlandse annwezigheid niet gelijkmatig verdeeld is in alle sectoren. Voorts, de technologische veranderingen als resultaat van spillovers zijn verschillend per sectoren. Elke verwerkende sector vereist eigen en afzonderlijke behandeling. Niettemin, de implicatie van deze bevindingen is dat door spillovers, FDI een bellangrijke rol speelt in het bevorderen wan het leren, capaciteitsopbouw, hetgeen innovatie heeft bevorderd zowel direct als onrechtstreeks in de verwerkende industrie van Kenia.

Samenvattend, de analyse en de bevindingen van deze studie steunen onze stelling dat FDIl een belangrijke rol speet in industrialisering van Kenia. Het analytische kader dat we hier ontwikfelen stelit de bestaande benaderingen in spilloweranalyse in vrag. De bevindingen van deze studie produceren werscheidene lessen met belangrijke implicaties woor owetheidsbeleid. Onze analyse toonde an dat om industriele ontwiklkeling en capaciteirsopbouw te stimuleren door buitenlandse investeringen enspillovers verscheidene factoren moeten worden overwogen. Daarom pleit deze studie voor een uitvoetige reeks beleidsmatregelen.

De beleidsimplicaties die danuit voortwloeien kunnen daarom als volgt worden gescherst: Ten eerste, de overheid moet met consistentie te werk gaan in het formuleren wan industrieel beleid. Duidelijke, lange termijn beleidsformulering geven bedrijve cen kader waarin ze hun lange termijn doelstellingen kunnen formuleren, plannen en bereiken. Ten tweede, de overheid zou met meer duidelijk beleid op de proppen moeten komen ten behoeve van bevordering van onderlinge bedrijferbindingen. Wij adviseren dat een national programma in het leven wordt geroepen om bedrijvenvetbindingen te bevorderen en alle kwesties te behandelen dic zowel national als international verband 
houden met deze verbindingen. Ten derde, de overheid moet beleid formuleren om zin menselfke kapitaal accumulatie te verbeteren. Voor firma's om hun absorptiecapaciteit en spillovers assimilatie te hunen verhogen is een sterke cultuir van technologicontwikkelling vereist. Bijgevolg, het beleid zou zich moeten focussen op het ondersteunen van leeprocessen op bedrijfniveau, capaciteitsopbouw en innovatie. 080 op bedrifs-en industrieniveau zou moeten worden angemoedigd en vergemakkelikt. Ten vierde, wegens een zwakke faciliatie en coördinatierol die doot instellingen wordt gespeeld, de owerheid moet met beled op de proppen komen dat het cotrecte functioneren en prestaties van deze instellingen verzelert. Bijwoorbeeld, de instellingen die industrite $0 \& \mathrm{O}$ behandelen zouden verbeterd moeten worden in termen van het wutbreiding wan hun capaciteiten, met name doot meer menselijk kapitaal en finaniciele middelen om $0 \& O$ en daaraan gerelateerde activiteiten te steunen. Vijfde, de overheid zou voorzichtiger moeten zijn door operationele knelpunten in deze instellingen aan te pakken door middel van continuele coordinatie en efficiencystimulatie. Zesde, de slechte infrastructuur maakt operationele en de transactiekosten uiterst hoog en zo vermindert de bereidheid te investeren, de interactie onder firma's en belemment zo de kans op spillovers. De overheid zou daarom basisinfrastructurur maeten werstrekken.

Het succesverhaal van de zogeheten nieuwe industrielander (NICs) in Oost-Azië toont ons aan dat een overheid die geen ononderbroken steun of efficiënt industrieel faciliteit geeft, valk haar eigen ondernemers in de steek laat. Zevende, de formele en informele interacties tussen bedrijen, instellingen en bedrijfswetenigingen leiden tot een atmosfeer waarin de lokale ondernemers productie-ervaring, markt informatie, wardigheden en technologische kennis met buitenlandse furma"s delen. De overheid zou daarom meer van dergelijke interacties moeten aanmoedigen. Achtste, hoewel de concurrentie een belangrijke rol speelt in het spilloverproces, men moet nochtans oppassen dat de hoge concurrentie van MNO binnenlandse investering niet verdringt.

Wij adviseren het opzetten van een nienwe, semi-autonome, regulatorische (bureaucratische) instelling met de bevoegdheid om de optimale concurrentieniveaus te bepalen en correctieve matregelen op tijd ten uitvoer te leggen. Negende, onze studic toonde an dat de invoer belangrijk was in het spilloverproces. De overheid in Kenia zou de invoerhindernissen van investeringsgoederen, technologie, machines en materiaal die als bronnen dienen van het leerproces, of capaciteitsopbouw door imitatie, strategisch uit de weg moeten ruimen. De participatie in de uitroer zou moeten worden angemoedigd omdat deze pasticipatie binnenlandse firma's zou dwingen om hun technologische inspanning te verhogen om effectief te kunnen concurreren op de globale markt. Tot slor, de goede arbeidsmarktvoorwarden zijn belangrijk voor de industriële groei en ontwikkeling. Datom zou de overheid ze moeten bevorderen maar daamaast een cultuur van arbeidsmobiliteit bevorderen.

De studie heeft verscheidene suggesties voor verder toekomstig onderzoekswerk. Ten eerste, angerien het onderzoek zich op slechts twee sectoren concentreerde, is er ven behoefte om de studie te verbteden om andere sectoren met viij hoge buitenlandse annwezigheid ook te onderzoeken. Bowendien zonden de toekomstige studies meer case studies moeten omvatten aangezien zij duidelijk meex inzichten verschaffen. Een dergelijke benadering is nochtans duur, tijdrovend, en vereist veel arbeidsktachten en grote inspanningen. In deze studie, de tijd factor en de middelenbeperking beperkten ons werkbeneik. 
Ten tweede, het zou ook interessant zijn on het hier ontwikkelde analytische kader toepassen om gelijkardige studies in andere landenten zuiden van de Saharawoeswin uit te voeren. Op dezelfde manier kunnen ook andere ontwiklelingshaden in de rest van de wereld worden bestudeerd voor internationale vergelijkingen. Ten derde, gezten de enorme verschuiving die in FDI wordt waargenomen, bijwoorbeeld de verschuiving nar de dienstindustrie, de roepassing wan dit onderzoekskader lkan eveneens tor de dienstindustrie worden uitgebreid voor spilloweranalyse. De dienstsectoren met hoge buiteniandse aanwezigheid omvatten toerisme en hotelsector, financien en werzeketingssector evenals de bouw en bouwnijwetheid. Bovendien, de benadeting kan tot landbouw worden uitgebreid, vooral de bloeiende succeswolle tuinbouwsector in Kenia. Ten vierde, aangezien deze studie zich op productie en bijbehorende capaciteiten concentreerde, kan de studie worden verbreed om andere technologische capabiliteiten te omvatten zoals investering en verbindingsimogelijkheden. Tot slot, angezien deze studie geen analyse vanuit het spillover vanuit het perspectief van de ootsprong van FDI heef uitgevoerd, is er een behoefte om een studie uit te voeren die spilloversvergelijkingen door de oorsprong van MNO toelaat. Deze aanbeveling volgt een bestaand begrip dat het totstandkomen van spillovers wan MNO uit verschillende landen verschilt. Namelijk MNO van Europa zouden van Amerikaanse MNO verschillend zijn zoals MNO van Azü̈ ook anders zouden zijn. Zelfs voor MNO van het zelfde continent, bijvoorbeeld MNO van Duitsland en Groot-Brittannië, werschillende spilloverservatingen zijn mogelijk. De vergelijkingen tussen MNO van ontwikkelde landen en die van gevorderde ontwikkelingslanden zouden een interessante studie voot wergelijkende doeleindien ook kunnen wormen. 


\section{CURRICULUM VITAE}

Geoffey $G$ Gachino was born in Nyandarua on 1 June 1968. After his primary school. educatisn at Rutata Primaty School, Mr. Gachino joined Nyahururu High School for his ordinaty level education and Saint Patrick"s High School lten for his advanced level education. He obtained a Bachelor of Science degree (B.Sc. with honours) in Mathematics and Statistics from Kenyatta University in 1994. In 1995, he joined the Ministy of Planing and National Development (MP\&ND) as an Economist Statisticin/Planning Officer. In the Ministry Mr. Gachino worked at the Central Bureau of Statistics (CBS) and as involved with ptoviding economic planning analytical, statistical and demographic among other telated services.

Between 1996 and 1998 , he took a study leave to study a Master of Philosophy (M.Phil.) degree in economics from University of Ghana where he graduated with a distinction majoting in public finance, monetary studies and econometrics. His Mastets thesis was on public finance and was entited "Fiscal Policy and Economic Growth in Kenya: An Feonometric Approach". Feliowship awat to undertake the Masters programme was provided by African Economic Research Consortium (AERC). Upon completion of his programme, Mr. Gachino retumed to his job with the same Ministry in Kenya where he was granted another study leave after winning a fellowship to study Ph.D. at Unired Nations Univetsity in Maastricht, Netherlands. He joined the UNU.MERTT Ph.D. programme in September $199 \%$.

Mr. Gachino's research interests include Foreign Direct Investment (FDI), technology accumulation and capability building, globalisation, competitiveness and innowation. Mr. Gachino has participated and presented papers in several intemational conferences. He has published in tefereed journals, book chapters and working papers. 